\title{
Evaluation of Suitability of Selected Set of Coal Plant Sites for Repowering with Small Modular Reactors
}

March 2013

Prepared by

R. J. Belles

D. A. Copinger

G. T. Mays

O. A. Omitaomu

W. P. Poore

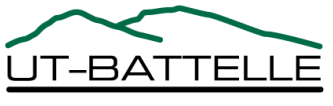




\title{
DOCUMENT AVAILABILITY
}

Reports produced after January 1, 1996, are generally available free via the US Department of Energy (DOE) Information Bridge.

Web site http://www.osti.gov/bridge

Reports produced before January 1, 1996, may be purchased by members of the public from the following source.

\author{
National Technical Information Service \\ 5285 Port Royal Road \\ Springfield, VA 22161 \\ Telephone 703-605-6000 (1-800-553-6847) \\ TDD 703-487-4639 \\ Fax 703-605-6900 \\ E-mail info@ntis.gov \\ Web site http://www.ntis.gov/support/ordernowabout.htm
}

Reports are available to DOE employees, DOE contractors, Energy Technology Data Exchange (ETDE) representatives, and International Nuclear Information System (INIS) representatives from the following source.

Office of Scientific and Technical Information

P.O. Box 62

Oak Ridge, TN 37831

Telephone 865-576-8401

Fax 865-576-5728

E-mail reports@osti.gov

Web site http://www.osti.gov/contact.html

\begin{abstract}
This report was prepared as an account of work sponsored by an agency of the United States Government. Neither the United States Government nor any agency thereof, nor any of their employees, makes any warranty, express or implied, or assumes any legal liability or responsibility for the accuracy, completeness, or usefulness of any information, apparatus, product, or process disclosed, or represents that its use would not infringe privately owned rights. Reference herein to any specific commercial product, process, or service by trade name, trademark, manufacturer, or otherwise, does not necessarily constitute or imply its endorsement, recommendation, or favoring by the United States Government or any agency thereof. The views and opinions of authors expressed herein do not necessarily state or reflect those of the United States Government or any agency thereof.
\end{abstract}


ORNL/TM-2013/109

Reactor and Nuclear Systems Division

Computational Sciences and Engineering Division

\title{
EVALUATION OF SUITABILITY OF SELECTED SET OF COAL PLANT SITES FOR REPOWERING WITH SMALL MODULAR REACTORS
}

\author{
R. J. Belles \\ D. A. Copinger \\ G. T. Mays \\ O. A. Omitaomu \\ W. P. Poore
}

Date Published: March 2013

Prepared for

US Department of Energy, Office of Nuclear Energy

Prepared by

OAK RIDGE NATIONAL LABORATORY

Oak Ridge, Tennessee 37831-6283

managed by

UT-BATTELLE, LLC

for the

US DEPARTMENT OF ENERGY

under contract DE-AC05-00OR22725 



\section{CONTENTS}

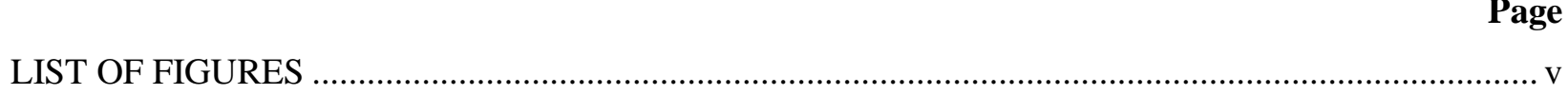

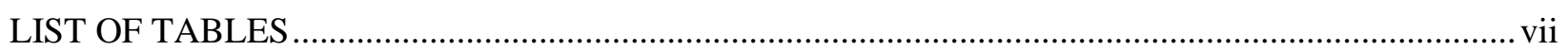

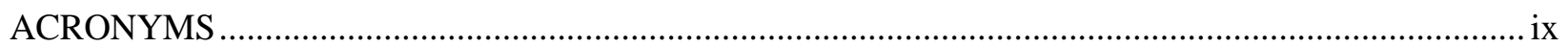

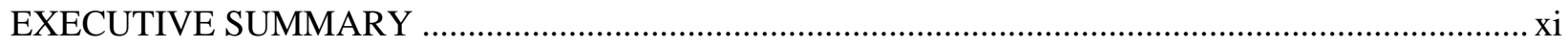

1. BACKGROUND, INTRODUCTION, AND METHODOLOGY …............................................ 1

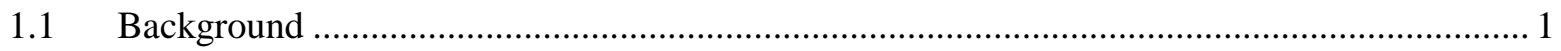

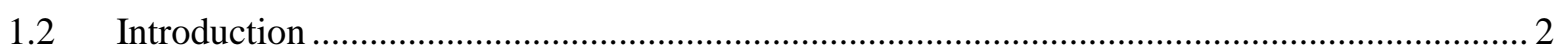

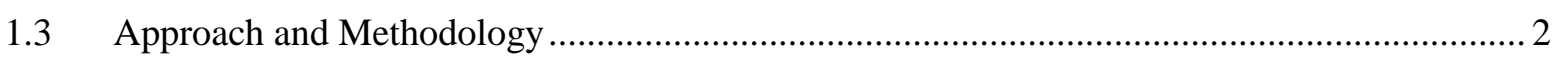

2. EVALUATION OF SELECTED COAL PLANT SITES …........................................................ 5

2.1 Review of Nominal SMR Site Selection and Evaluation Criteria ........................................ 5

2.2 Selection of Coal Plant Sample Set for Characterization ................................................... 6

2.3 Coal Station Evaluation Process......................................................................................... 10

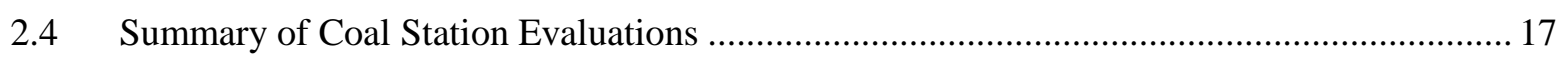

2.4.1 First Set of Coal Station Evaluations ................................................................... 17

2.4.2 Second Set of Coal Station Evaluations ............................................................... 18

2.4.3 Third Set of Coal Station Evaluations ..................................................................... 19

2.4.4 Fourth Set of Coal Station Evaluations ................................................................ 19

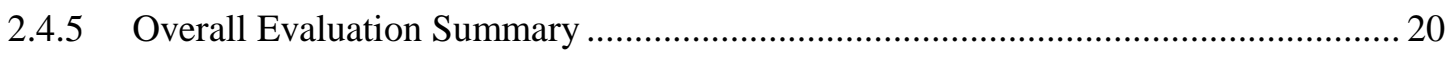

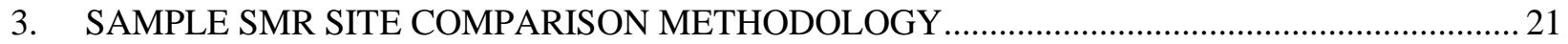

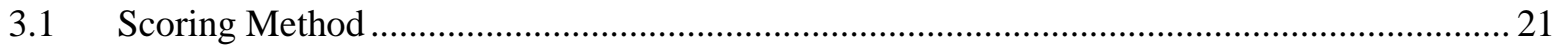

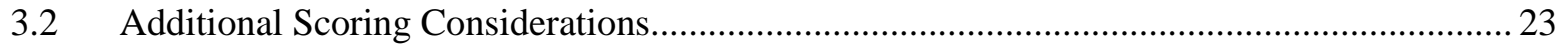

3.3 Scoring Method Application Results — Green Space ......................................................... 24

3.4 Scoring Method Application Results - Yellow Space ..................................................... 29

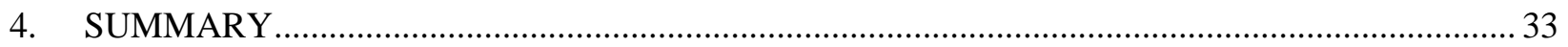

APPENDIX A-COAL PLANT EVALUATIONS OF MOST FAVORABLE SITES ......................... A-1

APPENDIX B - COAL PLANT EVALUATIONS OF SECOND-TIER SITES …............................. B-1

APPENDIX C—COAL PLANT EVALUATIONS OF THIRD-TIER SITES .................................... C-1

APPENDIX D —COAL PLANT EVALUATIONS OF FOURTH-TIER SITES ................................... D-1 



\section{LIST OF FIGURES}

Figure $\quad$ Page

ES-1 All US coal plant locations relative to SMR aggregate map. .........................................................ii

ES-2 Locations of coal stations selected for SMR characterization........................................................iii

ES-3 SMR base map with cumulative scoring comparison............................................................

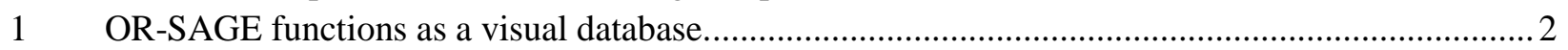

2 Nominal, bounding SMR composite map detailing siting challenges........................................... 6

3 All US coal plant locations relative to SMR aggregate map..................................................... 7

4 Locations of 34 coal stations selected for SMR characterization................................................. 9

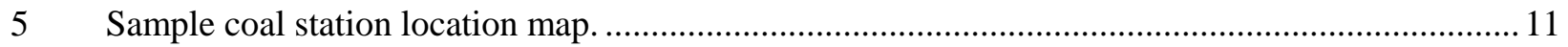

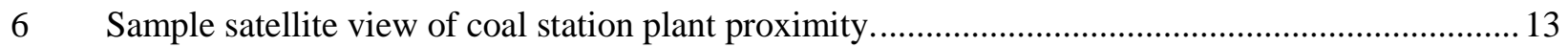

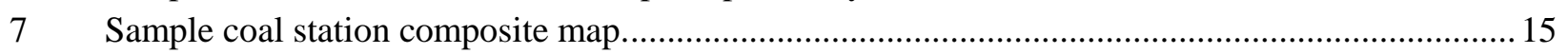

8 Sample individual siting criterion map (magenta aeras do not meet criterion)............................. 16

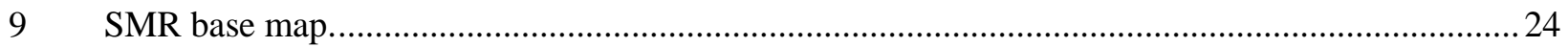

10 SMR base map with comparison by presence of a nuclear power plant. ........................................25

11 SMR base map with comparison by proximity to existing transmission lines................................26

12 SMR base map with comparison by available stream flow......................................................26

13 SMR base map with comparison by EPA nonattainment zones....................................................2

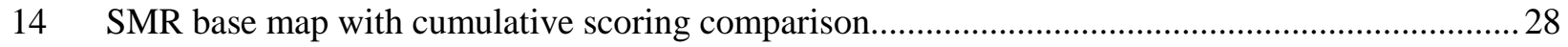

15 SMR base map with cumulative scoring comparison centered on Georgia. .................................29

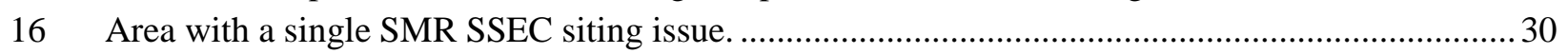

17 Cumulative scoring comparison of area with a single SMR SSEC siting issue ............................. 30

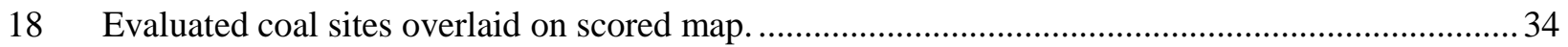

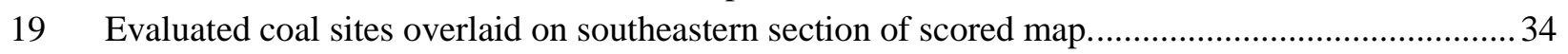





\section{LIST OF TABLES}

\section{Table}

Page

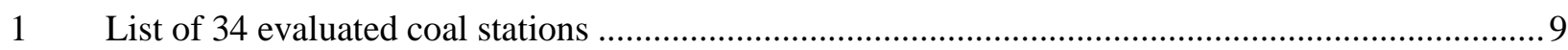

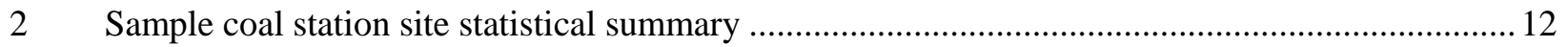

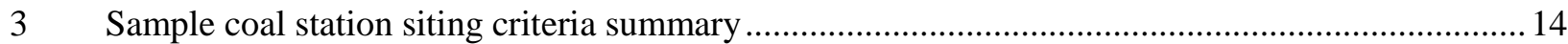

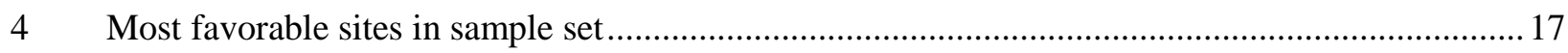

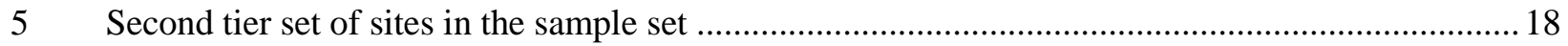

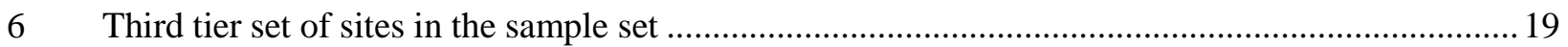

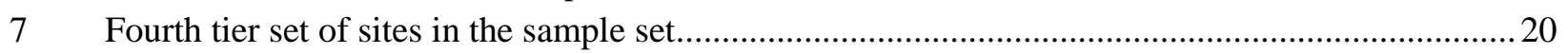





\section{ACRONYMS}

$\begin{array}{ll}\text { BREC } & \text { Big Rivers Electric Corporation } \\ \text { COL } & \text { Combined Operating License } \\ \text { DOE } & \text { US Department of Energy } \\ \text { EIA } & \text { DOE Energy Information Administration } \\ \text { EPA } & \text { US Environmental Protection Agency } \\ \text { EPRI } & \text { Electric Power Research Institute } \\ \text { ESP } & \text { early site permit } \\ \text { ETSZ } & \text { East Tennessee Seismic Zone } \\ \text { FENOC } & \text { FirstEnergy Nuclear Operating Company } \\ \text { GIS } & \text { geographic information systems } \\ \text { GMO } & \text { Greater Missouri Operations Company } \\ \text { GPM } & \text { gallons per minute } \\ \text { GW(e) } & \text { gigawatt electrical } \\ \text { HSIP } & \text { Homeland Security Infrastructure Protection } \\ \text { IPL } & \text { Interstate Power and Light } \\ \text { iPWR } & \text { integral pressurized-water reactor } \\ \text { KCP\&L } & \text { Kansas City Power and Light } \\ \text { LANL } & \text { Los Alamos National Laboratory } \\ \text { LWR } & \text { light-water reactor } \\ \text { MATS } & \text { Mercury and Air Toxics Standards } \\ \text { MW(e) } & \text { megawatt electrical } \\ \text { NE } & \text { (DOE) Office of Nuclear Energy } \\ \text { NMSZ } & \text { New Madrid Seismic Zone } \\ \text { NPPD } & \text { Nebraska Public Power District } \\ \text { NRC } & \text { US Nuclear Regulatory Commission } \\ \text { ORNL } & \text { Oak Ridge National Laboratory } \\ \text { OR-SAGE } & \text { Oak Ridge Siting Analysis for Power Generation Expansion } \\ \text { PPSM } & \text { people per square mile } \\ \text { PSNH } & \text { Public Service Company of New Hampshire } \\ \text { PWR } & \text { pressurized-water reactor } \\ \text { SCE\&G } & \text { South Carolina Electric \& Company } \\ \text { SCSZ } & \text { South Carolina Seismic Zone } \\ \text { SMEPA } & \text { South Mississippi Electric Power Association } \\ \text { SSEC } & \text { site selection and evaluation criteria } \\ \text { SMR } & \text { Small modular reactor } \\ \text { SRS } & \text { Savannah River Site } \\ \text { TDEC } & \text { USGS Survey } \\ \text { USGS } & \end{array}$





\section{EXECUTIVE SUMMARY}

\section{Background}

Beginning in late 2008, Oak Ridge National Laboratory (ORNL) responded to ongoing internal and external studies addressing key questions related to our national electrical energy supply. This effort has led to the development and refinement of Oak Ridge Siting Analysis for power Generation Expansion (OR-SAGE), a tool to support power plant siting evaluations. The objective in developing OR-SAGE was to use industry-accepted approaches and/or develop appropriate criteria for screening sites and employ an array of geographic information systems (GIS) data sources at ORNL to identify candidate areas for a power generation technology application. The basic premise requires the development of exclusionary, avoidance, and suitability criteria for evaluating sites for a given siting application such as siting small modular reactors (SMRs). For specific applications of the tool, it is necessary to develop site selection and evaluation criteria (SSEC) that encompass a number of key benchmarks that essentially form the site environmental characterization for that application. These SSEC might include population density, seismic activity, proximity to water sources, proximity to hazardous facilities, avoidance of protected lands and floodplains, susceptibility to landslide hazards, and others.

The OR-SAGE tool is essentially a dynamic visualization database. The SSEC are the fields of the database, and the GIS data for a given variable represent the values against which searches are performed. The evaluation process divides the contiguous United States into 100 by $100 \mathrm{~m}$ ( 1 hectare) squares (cells), applying successive SMR-appropriate SSEC to each cell. There are just under 700 million cells representing the contiguous United States. If a cell meets the requirements of each SMR criterion, the cell is included as a candidate to be integrated in the possible siting of an SMR. Some SSEC parameters preclude siting a facility because of an environmental, regulatory, or land-use constraint. Other SSEC assist in identifying less favorable areas, such as proximity to hazardous operations. All of the selected SSEC tend to recommend against sites; that is, they tend to identify areas in which there are challenges to using the site for the purpose of interest. In the first phase of this SMR site-screening study ${ }^{1}$ supporting the US Department of Energy Office of Nuclear Energy, the ORNL OR-SAGE siting tool was enhanced to focus on issues related specifically to the siting of SMRs.

This report summarizes the second phase of the approach that ORNL developed for screening a sample set of "small" coal stations for possible repowering with SMRs; the methodology employed, including spatial modeling; and initial results for these sample plants. The objective in conducting this type of siting evaluation is to demonstrate the capability to characterize specific sample coal plant sites to identify any particular issues associated with repowering existing coal stations with SMRs; it is not intended to be a definitive assessment per se as to the absolute suitability of any particular site.

According to the US Department of Energy/Energy Information Administration (DOE/EIA), the total existing generating capacity in the United States is $1,036 \mathrm{GW}(\mathrm{e}) .^{2}$ Of this, $318 \mathrm{GW}(\mathrm{e})(31 \%)$ was available from coal in 2010. The Environmental Protection Agency (EPA) finalized the Mercury and Air Toxics Standards (MATS) rule in December 2011. The MATS rule requires that maximum achievable control technology be applied to all power plants with capacities greater than $25 \mathrm{MW}(\mathrm{e})$ to control emissions of mercury and other toxics. The MATS standards are slated to take effect in 2015. As a result, many utilities are opting to retire older, smaller coal-fired power plants rather than install relatively expensive emissions control equipment. These older, small coal-fired plants may provide an opportunity

\footnotetext{
${ }^{1}$ R. J. Belles, G. T. Mays, O. A. Omitaomu, W. P. Poore, Updated Application of Spatial Data Modeling and Geographical Information Systems (GIS) for Identification of Potential Siting Options for Small Modular Reactors, ORNL/TM-2012/403, September 2012.

${ }^{2}$ US Department of Energy/Energy Information Administration (DOE/EIA), “Annual Energy Outlook 2012 with Projections to 2035,” DOE/EIA-0383(2012), Table 25, June 2012.
} 
to replace the demonstrated power need at existing grid locations with cleaner electrical power from SMRs.

\section{Sample Set Selection and Evaluation}

There are more than 2,000 individual coal-fired generators in the United States. These generators are located at more than 800 coal station sites, as shown in Fig. ES-1. The station nameplate generating capacity of each coal station site was evaluated for its potential to be replaced by an SMR. No attempt was made to analyze the possibility of augmenting power at a generating station by adding additional capacity to meet regional growing power demand and, thereby, converting a coal station into an energy park. Likewise, no attempt was made to analyze the possibility of only partially replacing the coal-fired generating capacity at a coal station with an SMR. Sample coal stations were simply identified and selected based on their cumulative station nameplate capacity, which in some cases included retired coalfired plants.

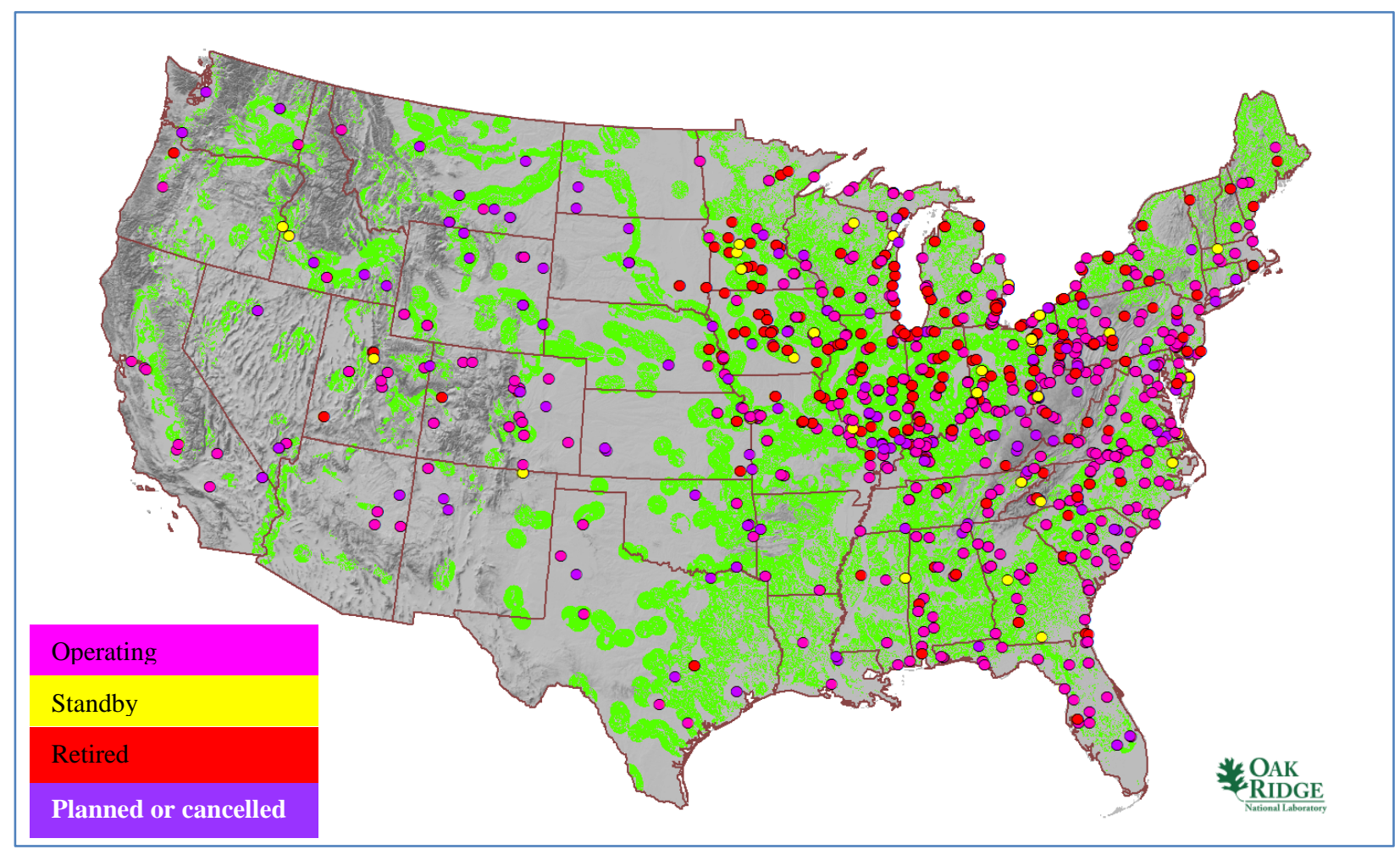

Fig. ES-1. All US coal plant locations relative to SMR aggregate map.

It was assumed that coal stations with a very small station nameplate capacity would not be likely candidates for SMR replacement. Unless the power forecast at a grid location with a very small coal-fired station was large, the excess power provided by even the smallest SMR designs would not likely warrant the expense of backfitting an SMR at that location. The low-end station capacity cutoff was selected at $50 \mathrm{MW}(\mathrm{e})$ based on engineering judgment. Similarly, it was assumed that a coal station with a very large station nameplate capacity would not be a likely candidate for an SMR replacement. Stations with nameplate capacities that exceed the largest modular SMR installations would actually be subject to a reduction in site nameplate capacity, which was considered undesirable for this analysis. The upper end station capacity cutoff was selected at $540 \mathrm{MW}(\mathrm{e})$ based on matching the largest modular SMR design configuration currently under consideration.

In addition to cumulative station nameplate capacity, the age of the existing coal-fired generators was contemplated. It was assumed that newer coal-fired plants would not be among the first coal plants to be 
considered for possible replacement by SMRs. Utilities are assumed to be more likely to invest in additional scrubbing equipment, if required for continued operation under revised EPA guidelines, for a newer plant with reasonable life expectancy to recoup additional capital costs. Therefore, stations with plants commissioned after 1980 were not considered as likely candidates for replacement by SMRs.

There were 148 coal station sites that met the criteria above. Characterizing all 148 coal stations relative to the potential for an SMR to be sited at the plant was deemed overly ambitious given the project scope, so some additional selection criteria were necessary. It was appropriate to spread the coal plants selected for additional characterization across most of the states represented in this assessment. In addition, many different utilities were represented by the 148 coal station sites in this assessment, including nonnuclear and nuclear utilities. To include at least one coal station from 25 different states and provide a distribution among nuclear and nonnuclear utilities, a 34-coal station sample set was selected as identified by yellow points in Fig. ES-2. A list of the sample set of coal stations is provided in the body of the report in Table 1. Overall, 31 utilities are represented, 12 nonnuclear and 19 nuclear.

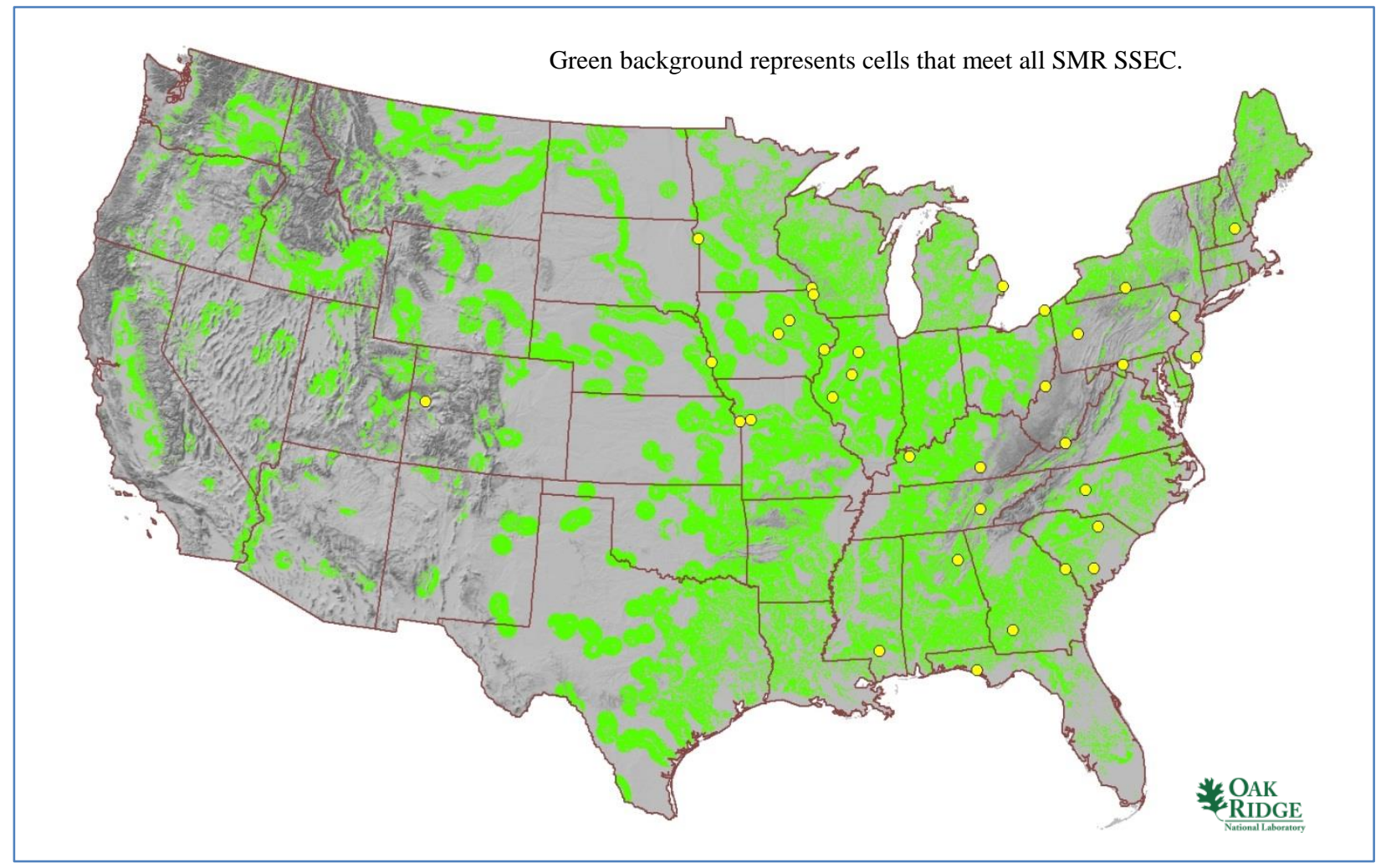

Fig. ES-2. Locations of coal stations selected for SMR characterization.

Each coal station in the sample set was evaluated. Detail about the utility that owns the coal station is provided and any partial or full siting issues are addressed. Extensive imagery detail is available for each site. Based on the analysis, the individual coal plant site is binned into one of four categories in increasing order of difficulty for SMR siting based on the review:

1. The site meets multiple conventional standards for consideration of siting an SMR at the coal station location. There are no current or near-term foreseeable SMR SSEC siting issues that should preclude this site from further SMR siting consideration. A total of 12 sites met this criterion.

2. The site meets multiple conventional standards in the near term for consideration of siting an SMR at the coal station location, but there may be longer-term issues that could potentially 
preclude this site from further SMR siting consideration. For example, a small population center is identified nearby that meets the current SMR SSEC for population density, but future growth near the coal station could present a siting challenge. A total of 6 sites met this criterion.

3. The site meets conventional standards pending verification of parameters or an engineered solution to an issue. For example, a coal station site meets all SMR SSEC with the exception of having a moderate to high potential for landslide hazard. The existing coal plant has been at that location without a landslide incident since it was commissioned on some date prior to 1980. In this case, since the potential for landslide hazards is a wide-area probabilistic calculation, additional site-specific geological survey could validate the acceptance of the site for further SMR siting consideration. A total of 8 sites met this criterion.

4. The site is not a likely candidate for consideration of siting an SMR. There are numerous SSEC criteria that are not met that could make it difficult for a utility to consider replacing the coal-fired power produced at an existing coal station with an SMR. A total of 8 sites met this criterion.

Overall, 26 - sum of sites for categories 1,2, and 3 above - of the 34 sample plant sites (77\%) meet multiple conventional standards for consideration of siting an SMR at one of the selected sample coal station sites. Given that half of the 34 sites selected initially (17) met all of the SMR SSEC at the selected values, a high percentage of the sample set was expected. Further investigation revealed that 9 of the 17 remaining sites in the 34-site sample set (53\%) also had good potential for siting an SMR. Combined, these 26 potential conversion sites represent $7.3 \mathrm{GW}(\mathrm{e})$ of coal-fired electrical generation that can possibly be repowered by SMR electrical generation. This is the equivalent of adding five $1.6 \mathrm{GW}(\mathrm{e})$ large nuclear power plants to the grid, which is $5 \%$ of the current reactor plant fleet. Results from the analyses of these 34 sites demonstrate that OR-SAGE provides useful insights for evaluating options and challenges related to repowering coal plant sites with SMRs.

\section{SMR Site Comparison Methodology}

Beyond designating areas as meeting all the siting criteria at a specific set of threshold values, it is desirable to have the capability to compare areas that meet all of the designated SMR SSEC. This allows further emphasis to be directed toward areas that may ultimately prove to be more desirable than others. For example, remote areas with low population density may have tremendous water resources to support many SMR units. This can artificially inflate the capacity evaluation for a region where added capacity is really not justified. A similar comparison between areas with a single SMR SSEC that is not met is also beneficial to better inform a decision about where to exert effort to engineer around a siting issue. To meet this need, a simple scoring method was developed to compare individual cells in a like category-no siting issue to no siting issue, and single issue to single issue. The initial scoring algorithm was intentionally kept simple by limiting the number of categories and scoring elements.

Four scoring categories are proposed to quantify desirable site attributes in the general areas of site expandability, economics and proximity to demand, acceptability, and engineering. Within these categories, eight elements are differentiated or scored by geographical suitability. The individual cell scores for all of the scoring elements for all of the cells that meet all of the designated SMR SSEC were added. The cells were then shaded in varying green hues based on the cumulative score.

Cell scores in the lower rank were shaded in a light green hue and assigned a "good" rating on a scale of good, better, or best. Cell scores in the middle tier were shaded in a medium green hue and assigned a "better" rating. Finally, cell scores in the top tier were shaded in a dark green hue and assigned a "best" rating. The point ranges were selected based on the best differentiation of the three green hues over the entire SMR base case map - those cells that meet all SMR SSEC. The results are shown in Fig. ES-3. 


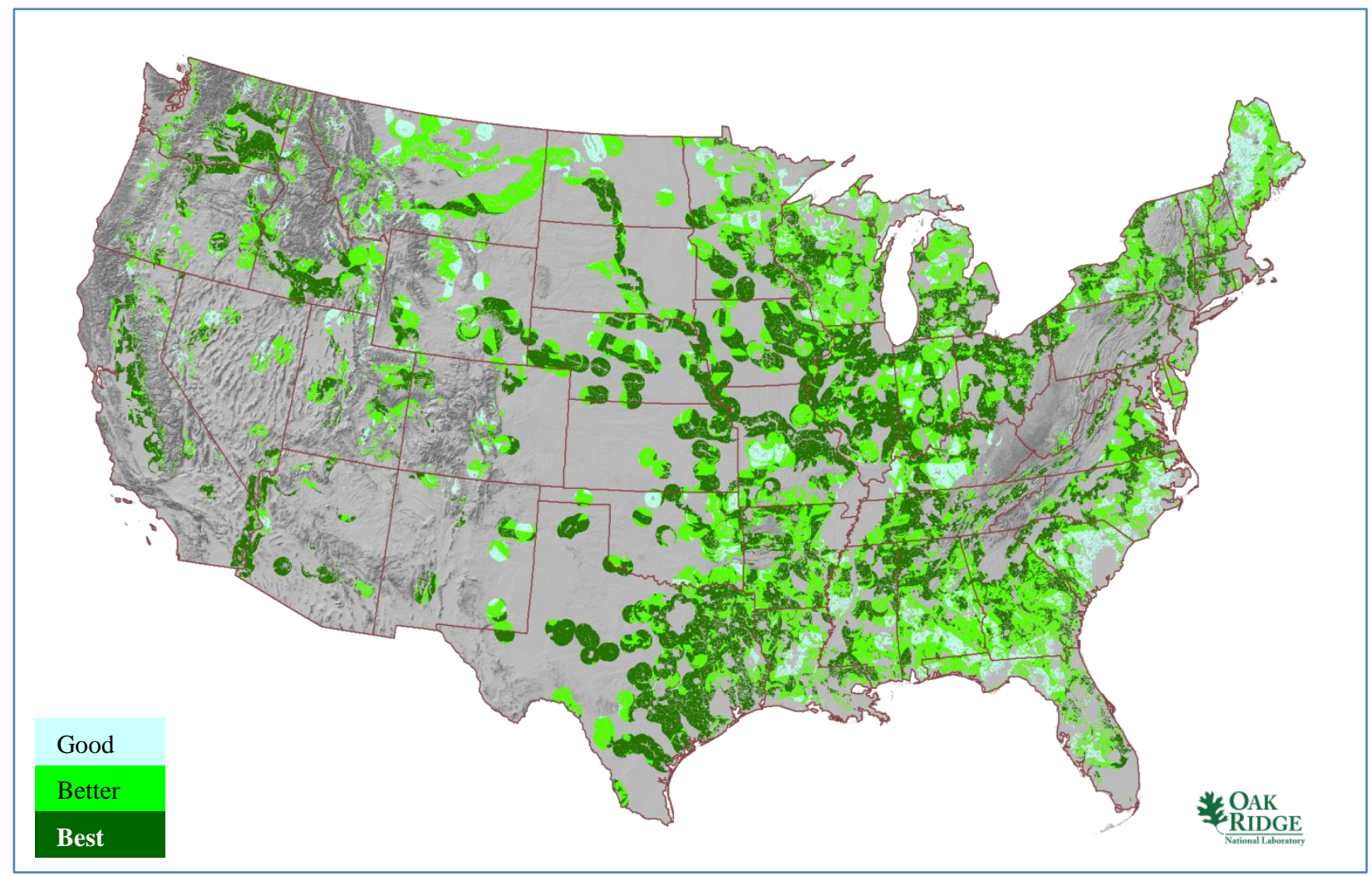

Fig. ES-3. SMR base map with cumulative scoring comparison.

Note that the darkest green area represents $21.6 \%$ of the contiguous United States. This includes land in close proximity to major cities such as Chicago, Nashville, Atlanta, Dallas, and Houston. Also, the medium green area represents $10.7 \%$ of the contiguous United States. This includes suitable land with tremendous water resources but less power demand, such as is seen in Montana. Land with an abundance of lakes and reservoirs is also scored in the medium green or better category. This includes large areas within Wisconsin, Alabama, and Georgia. Finally, the lightest green area represents just $1.1 \%$ of the contiguous United States.

A similar comparison was made for areas with a single SMR siting deficiency. This analysis is intended to assist in identifying areas where engineered solutions may best be applied to the single siting deficiency.

As shown in Fig. ES-3, a reasonable differentiation among areas that meet all the SMR SSEC is possible, although the initial scoring algorithm was intentionally kept simple by limiting the number of categories and scoring elements. Similar differentiation among areas that meet all but one SMR SSEC is also possible. A still higher degree of discrimination is possible using additional categories and elements such as those listed in Sect. 3.2 of the report. 



\section{BACKGROUND, INTRODUCTION, AND METHODOLOGY}

\subsection{Background}

The US Department of Energy (DOE) Office of Nuclear Energy (NE) has tasked Oak Ridge National Laboratory (ORNL) to support identification of candidate sites for deployment of new small modular reactor (SMR) power plants using a geographic information system (GIS) -based tool that ORNL has developed. ${ }^{3}$ The tool, Oak Ridge Siting Analysis for power Generation Expansion (OR-SAGE), is a flexible system being used to evaluate power plant siting options and considerations for a variety of power sources, as well as identify nuclear waste storage siting options. The objective in developing ORSAGE was to merge industry-accepted approaches for screening sites with the array of GIS data sources at ORNL to identify candidate areas for a particular application.

ORNL has employed the general concepts as presented in the 2002 Electric Power Research Institute (EPRI) Siting Guide ${ }^{4}$ methodology, developed to support Early Site Permit (ESP) applications, for the purpose of screening sites for nuclear power plants to develop exclusionary, avoidance, and suitability criteria. The ESP concepts were subsequently used to develop exclusionary, avoidance, and suitability criteria for screening sites for a variety of power plants. For a given application, it is necessary to develop site selection and evaluation criteria (SSEC) that encompass a number of key screening criteria that essentially form the site environmental characterization for that application. These SSEC might include population density, slope, seismic activity, proximity to cooling water sources, proximity to hazardous facilities, avoidance of protected lands and floodplains, susceptibility to landslide hazards, and others. OR-SAGE is a visual, relational database. The SSEC are the fields of the database, and the GIS data for a given variable represent the values against which searches are performed. The visual database concept is demonstrated in Fig. 1. The database partitions the contiguous United States, a total of 7.2E8 hectares ( $\sim 1.8$ billion acres), into 100 by $100 \mathrm{~m}$ ( 1 hectare or $\sim 2.5$ acre) cells. Therefore, the database is tracking just under 700 million individual land cells.

ORNL staff previously evaluated screening criteria for large and small nuclear power plants, advanced coal plants with carbon sequestration, wet and dry solar power technologies (excluding photovoltaic cells), and compressed air energy storage for EPRI. ${ }^{5}$ In initial evaluations, the principal differences between large and small nuclear power plants were cooling water demand and plant footprint. In the first phase of this SMR site-screening study supporting DOE-NE, the ORNL OR-SAGE siting tool was enhanced to focus on issues related specifically to the siting of SMRs.1 Applying SMR-centric screening criteria in OR-SAGE provides the ability to quickly analyze and characterize potential sites for SMR deployment. This report summarizes the characterization of a sample population of coal plants for potential SMR deployment to replace power provided by an aging coal plant fleet. Presumably, much of the necessary infrastructure needed to site an SMR at an existing coal station would be in place, making the SMR replacement option attractive.

\footnotetext{
${ }^{3}$ G. T. Mays, T. J. Harrison, and O. A. Omitaomu, Preliminary Report on Siting Evaluation Tool for Commercial Nuclear Power Plants Developed by Oak Ridge National Laboratory, LTR/DOE-NE/Siting-2010/002, November 2010.

${ }^{4}$ E. Rodwell (Project Manager), Siting Guide: Site Selection and Evaluation Criteria for An Early Site Permit Application, 1006878, Final Report, Electric Power Research Institute, March 2002.

${ }^{5}$ G. T. Mays, R. J. Belles, O. A. Omitaomu, et al., Application of Spatial Data Modeling and Geographical Information Systems (GIS) for Identification of Potential Siting Options for Various Electrical Generation Sources, ORNL/TM-2011/157/R1, May 2012.
} 


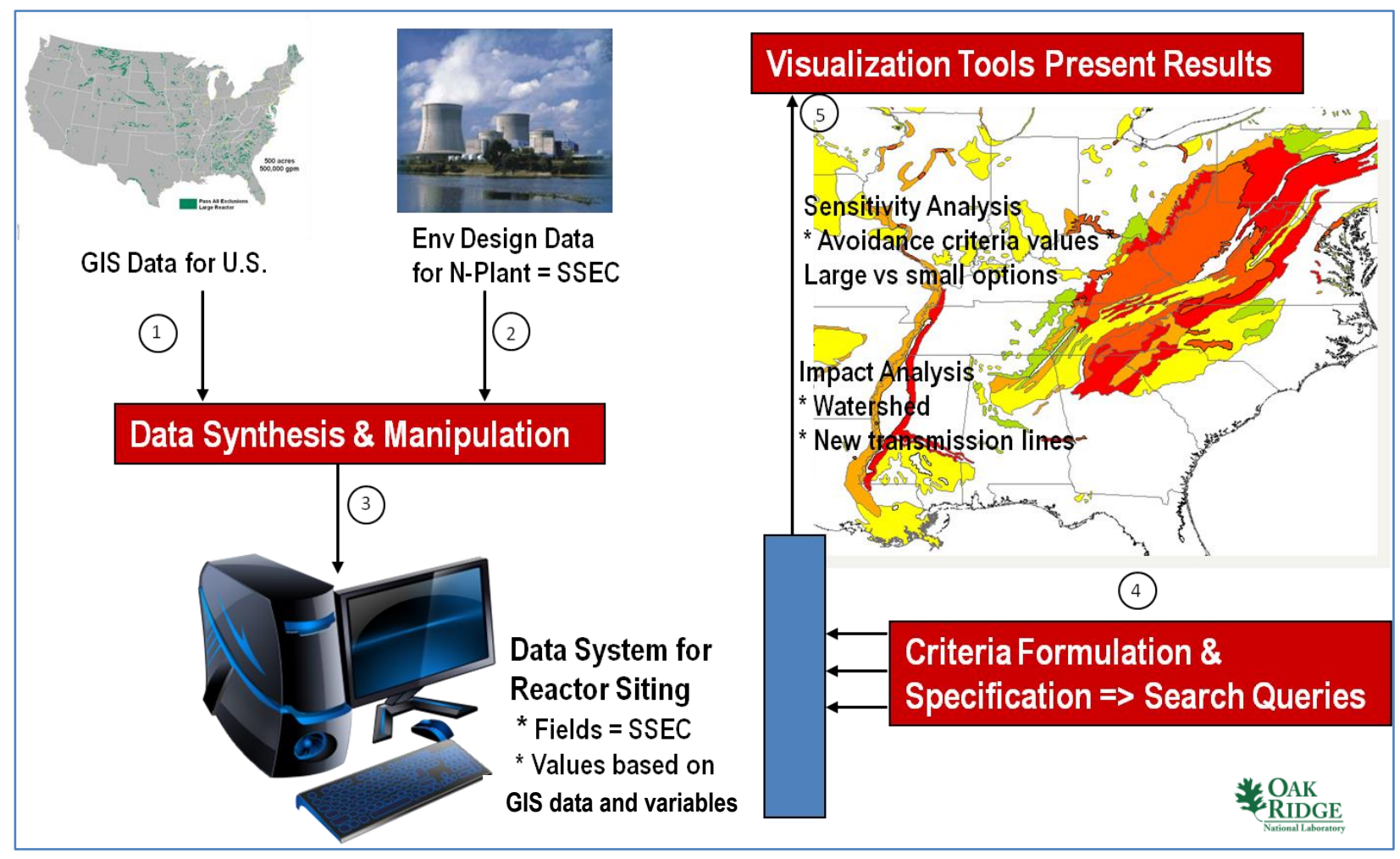

Fig. 1. OR-SAGE functions as a visual database.

\subsection{Introduction}

The objective of this SMR site-screening study is to support DOE-NE in enhancing and extending the capability of the ORNL OR-SAGE siting tool to focus on issues related specifically to the siting of SMRs. Applying SMR-centric screening criteria in OR-SAGE will provide the ability to quickly analyze and characterize potential SMR sites from a national deployment perspective as well as from a sitespecific vantage point.

This report summarizes the second phase of the approach that ORNL developed for screening a sample set of coal stations for possible repowering with an SMR, including the methodology employed, the spatial modeling, and the initial results for these sample plants. The objective in conducting this type of siting evaluation is to demonstrate the capability to characterize specific sample coal plant sites to identify any particular issues associated with repowering existing coal stations with SMRs; it is not intended to be a definitive assessment per se of the absolute suitability of any particular site.

\subsection{Approach and Methodology}

The key to the approach for this study was to use industry-accepted practices in screening sites and then to employ the proper array of data sources and identify candidate areas through the considerable computational capabilities of GIS technology available at ORNL, as documented in the first phase of this SMR site-screening study supporting DOE-NE.1

The focus of the ORNL electrical generation source siting study is on identifying candidate areas from which potential SMR sites might be selected, stopping short of performing any detailed site evaluations or comparisons. This approach is designed to quickly screen for and characterize candidate areas. This approach is a top-down look at SMR siting on a national and regional scale. Building on these 
fundamentals, a bottom-up look at some specific sites that may be ripe for SMR deployment is possible. To that end, a sample set of coal stations was selected and analyzed as outlined in Sect. 2 of this report.

In addition, it is desirable to have the capability to compare areas that meet all of the designated SMR SSEC, because some areas may actually prove to be more desirable than other areas. A similar comparison between areas with a single SMR SSEC that is not met may be desirable to better inform a decision about where to exert effort to engineer around a siting issue. Such a comparison or scoring of areas is outlined in Sect. 3 of this report. 



\section{EVALUATION OF SELECTED COAL PLANT SITES}

The initial phase of this project characterized all land in the contiguous United States regarding the potential for hosting a near-term SMR design. The initial analysis did not specifically consider proximity to load requirements brought about by the presence of significant population or industrial centers. In contrast, this phase of the analysis seeks to characterize land currently or recently occupied by a coal-fired power plant for possible deployment of an SMR. This assumes load requirements exist at such a location, and there may be a need to replace the power provided by an aging coal-fired power plant with cleaner power production from an SMR.

Near-term SMRs are based on light-water reactor (LWR) technology with compact design features that are expected to offer a host of safety, siting, construction, and economic benefits. These smaller plants are ideally suited for small electric grids and for locations that cannot support large reactors, thus providing utilities with the flexibility to scale power production as demand changes by adding modules or reactors in phases to deploy additional power. The near-term SMR designs are based on existing pressurized-water reactor (PWR) technology. They are characterized as "integral" PWRs (iPWRs) since these plants will have major equipment such as pumps, steam generators, and pressurizers all located within the pressure vessel in an integrated, compact design. Individual reactor units in these designs are typically in the 25 to $250 \mathrm{MW}(\mathrm{e})$ power range. Modular installations of iPWRs can range up to $540 \mathrm{MW}(\mathrm{e})$ based on proposed vendor configurations.

Though other longer-term advanced SMR designs - such as high-temperature gas reactors, liquid metal reactors, and molten-salt reactors - were not analyzed in the initial phase of the SMR study, the screening parameters selected for the near-term iPWR reactors are expected to also encompass these advanced SMRs, with the exception of cooling water.

\subsection{Review of Nominal SMR Site Selection and Evaluation Criteria}

A summary of the SSEC selected for SMR siting as documented in the first phase of this SMR sitescreening study is provided below. These parameters are tracked on a cell-by-cell basis for the entire contiguous United States. A more detailed discussion of each individual SSEC is available in the report1 on the first phase of this project.

- Land with a population density greater than 500 people per square mile (including a 10 mile buffer) is excluded

- Wetlands and open water are excluded

- Protected lands (e.g., national parks, historic areas, wildlife refuges) are excluded

- Land with moderate or high landslide hazard susceptibility is excluded

- Land that lies within a 100-year floodplain is excluded

- Land with a slope of greater than $18 \%\left(\sim 10^{\circ}\right)$ is excluded

- Land areas that are more than 20 miles from cooling water makeup sources with at least 65,000 gpm, based on a $540 \mathrm{MW}(\mathrm{e})$ modular iPWR installation, are excluded for nominal SMR plant applications

- Land too close to identified fault lines is excluded (the length of the fault line determines the standoff distance)

- Land located in proximity to hazardous facilities (airports and oil refineries) is avoided 
- Land with safe-shutdown earthquake peak ground acceleration ( $2 \%$ chance in a 50 year return period) greater than $0.5 \mathrm{~g}$ is excluded

Based on preliminary design information and expert judgment, it is assumed that an SMR iPWR base design package (single unit or multi-module) from each vendor can easily be accommodated on a 50-acre footprint. ${ }^{1}$ In general, more than 50 acres is available at a typical coal-fired power plant.

The OR-SAGE tool tracks the SSEC parameters for each 100 by $100 \mathrm{~m}$ cell. As a result, not only can the cells that are clear of all the SSEC layer exclusions be displayed visually, but also cells that are tripped by one, two, or three or more exclusions can be tracked and displayed. This is known as the "SMR composite map" (Fig. 2). This is a powerful aspect to the OR-SAGE tool, because it allows areas with a limited number of siting challenges to also be identified. Engineering solutions may be available for areas with limited siting challenges.

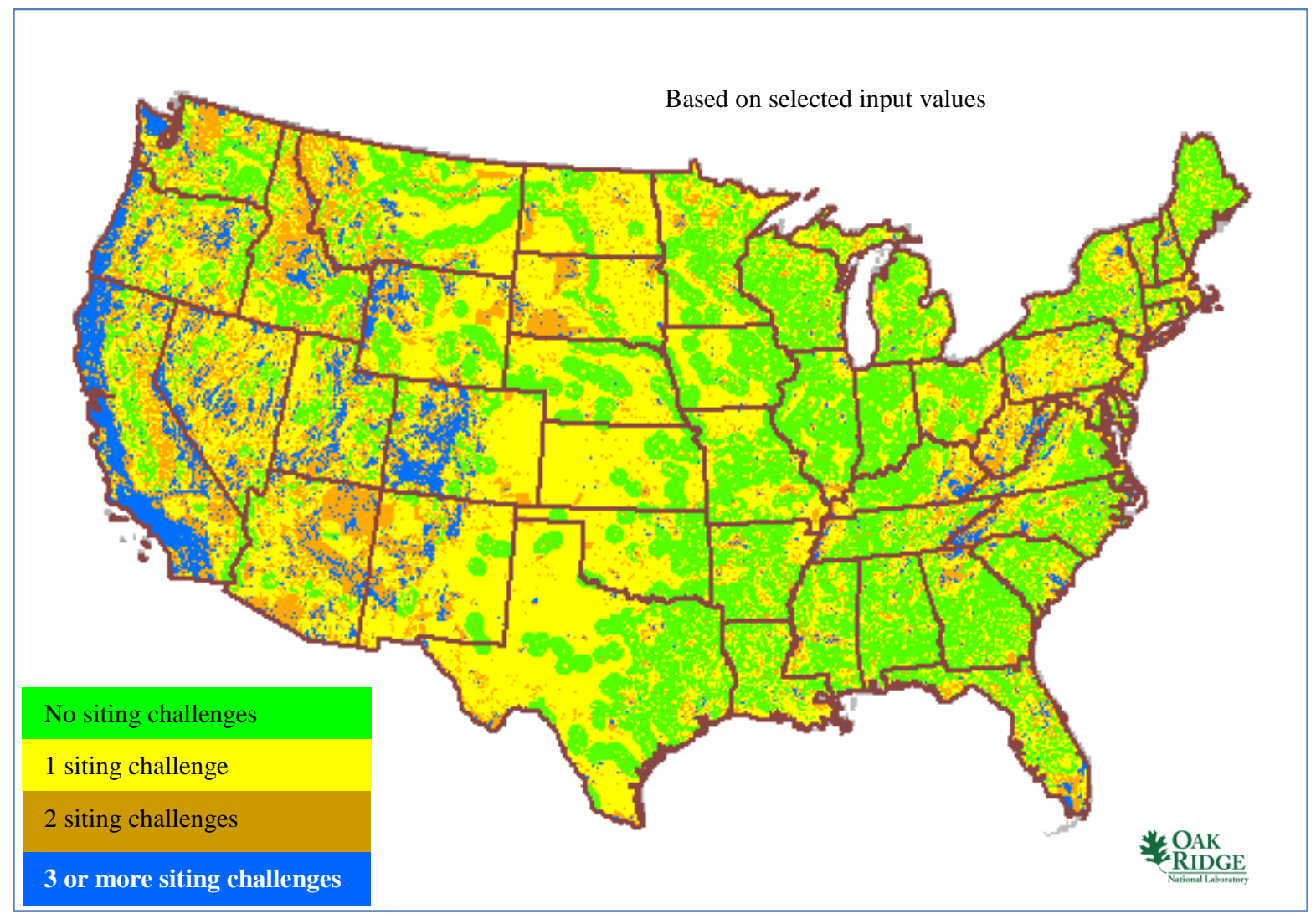

Fig. 2. Nominal, bounding SMR composite map detailing siting challenges.

\subsection{Selection of Coal Plant Sample Set for Characterization}

According to the 2012 Homeland Security Infrastructure Protection (HSIP) Gold Database, ${ }^{6}$ there are 2,146 individual planned, operating, standby, and retired coal-fired generators in the United States. These plants are located at 823 coal station sites, as shown in Fig. 3, and provide a nameplate capacity of 422 $\mathrm{GW}(\mathrm{e})^{7}$. The station nameplate generating capacity of each coal station site was evaluated for its potential

\footnotetext{
${ }^{6}$ National Geospatial-Intelligence Agency, Homeland Security Infrastructure Program-HSIP Gold 2012.

${ }^{7}$ This figure includes operating, standby, retired, and planned coal-fired plants. As of 2010, the available coal-fired capacity was $318 \mathrm{GW}(\mathrm{e})$ according to DOE/EIA.
} 
to be replaced by an SMR. No attempt was made to analyze the possibility of augmenting power at a generating station by adding additional capacity to meet regional growing power demand and thereby converting a coal station into an energy park. Likewise, no attempt was made to analyze the possibility of only partially replacing the coal-fired generating capacity at a coal station with an SMR. Sample coal stations were simply identified and selected based on their cumulative station nameplate capacity, which in some cases included retired coal-fired plants.

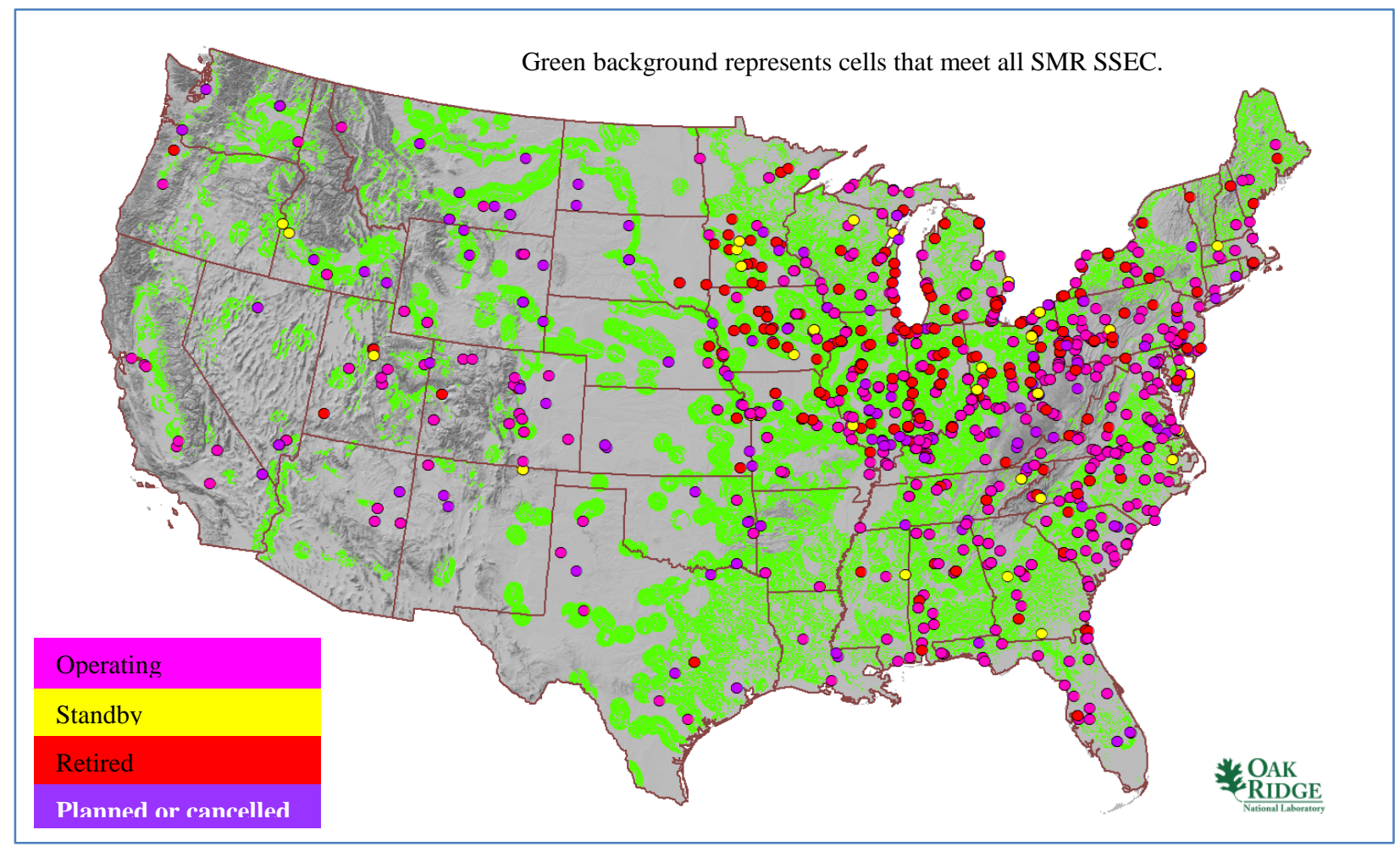

Fig. 3. All US coal plant locations relative to SMR aggregate map.

It was assumed that coal stations with very small station nameplate capacity would not be likely candidates for SMR replacement. Unless the power forecast at a grid location with a very small coal-fired station was large, the excess power provided by even the smallest SMR designs probably would not warrant the expense of backfitting an SMR at that location. The low-end station capacity cutoff was selected at $50 \mathrm{MW}(\mathrm{e})$ based on engineering judgment. Stations with total nameplate capacities as low as $40 \mathrm{MW}(\mathrm{e})$ were retained in case the sample selection pool became too small.

Similarly, it was assumed that coal stations with very large station nameplate capacity would not be likely candidates for SMR replacement. Stations with nameplate capacities that exceed the largest modular SMR installations would actually be subject to a reduction in site nameplate capacity, which was considered undesirable. The upper-end station capacity cutoff was selected at $540 \mathrm{MW}(\mathrm{e})$ based on matching the largest modular SMR configuration currently under consideration. Stations with total nameplate capacities as high as $600 \mathrm{MW}(\mathrm{e})$ were retained in case the sample selection pool became too small.

In addition to cumulative station nameplate capacity, the age of the existing coal-fired generators was contemplated. It was assumed that newer coal-fired plants would not be among the first coal plants to be considered for possible replacement by an SMR. Utilities are assumed to be more likely to invest in additional scrubbing equipment, if required for continued operation under revised Environmental Protection Agency (EPA) guidelines, for a newer plant with reasonable life expectancy to recoup additional capital costs. Therefore, stations with any individual coal-fired units commissioned after 1980 
were not considered as likely candidates for replacement by SMRs. A plant built in 1980 would be roughly 32 years old and would reasonably be expected to have at least an additional 8 years of operational use, assuming a traditional 40 -year life. Eight years is $20 \%$ of a 40 -year life, and engineering judgment suggested this was a conservative cutoff to recoup any additional equipment costs.

Based on these assumptions, 395 coal stations, or $48 \%$ of all coal stations, met the expanded sample requirements of station capacity between 40 and $600 \mathrm{MW}(\mathrm{e})$. Of these, 219 coal stations also met the sample requirements for plant age. Finally, 195 coal stations meet sample requirements of plant age and the more limiting station capacity between 50 and $540 \mathrm{MW}(\mathrm{e})$. The latter sample size is adequate for the purposes of this study. The median station capacity for this sample set of coal stations is $193 \mathrm{MW}(\mathrm{e})$ and the total capacity of the sample set is $44.2 \mathrm{GW}(\mathrm{e})$ or $10.5 \%$ of the total coal plant capacity. ${ }^{7}$

The sample set of 195 coal stations includes 22 stations that directly support an industrial site, such as a paper mill. These coal stations were not considered viable candidates for replacement with SMRs because of the expense and the lack of a rate base to fund such an endeavor. ${ }^{8}$ Likewise, an additional 25 coal stations are run by a small municipal utility. Similarly, these coal stations were not considered viable candidates for replacement with SMRs because of the expense and the relatively small rate base to fund such an endeavor. This left 148 "small" coal stations as the sample set for further characterization.

The 148 coal stations were then evaluated against the SMR composite map shown in Fig. 2. Only those stations that were located on land with no siting issues, a single siting issue, or within 5 miles of land that has no siting issues were considered for further evaluation. Essentially no station sites that had two or more siting issues were included for this initial round of characterization unless the site was within 5 miles of a 50-acre parcel of land with no siting issues. The latter consideration was made to maintain a broad spectrum of sites for analysis. While the coal station infrastructure would not necessarily be repowered and reused in such a case, there could be a secondary argument by a utility for maintaining current grid capacity at a given location. There were 94 coal station sites that met this criteria distributed as follows:

- 17 sites with no siting issues

- 45 sites with a single siting issue

- 32 sites with multiple siting issues, but within 5 miles of a location with no siting issues

Characterizing all 94 of the remaining coal stations relative to the potential for an SMR to be sited at the plant was deemed overly ambitious, given the project scope, so some additional selection criteria were necessary. All 94 coal station sites in the sample set reside in 25 states. It was appropriate to spread the coal plants selected for additional characterization across all the states represented in this assessment. All 17 coal station sites with no siting issues were included in the final sample set for characterization, because these plants would seem to be the obvious first candidates for an SMR under the given set of SMR SSEC assumptions. In addition, 43 different utilities were represented by the 94 coal station sites in this assessment, 24 nonnuclear utilities and 19 nuclear utilities. In order to include at least one coal station from each of the 25 states represented and provide a distribution among nuclear and nonnuclear utilities, 19 additional coal stations were selected for additional characterization for a total of 34 coal stations, as located in Fig. 4. A list of the coal stations is provided in Table 1. Overall, 31 utilities are represented, 12 nonnuclear and 19 nuclear utilities. The 34 coal stations selected for further characterization are distributed as follows when evaluated against the SMR composite map shown in Fig. 2:

- 17 sites with no siting issues

- 10 sites with a single siting issue

- 7 sites with multiple siting issues but within 5 miles of a location with no siting issues

\footnotetext{
${ }^{8}$ Some business models do explicitly consider single-user sites.
} 


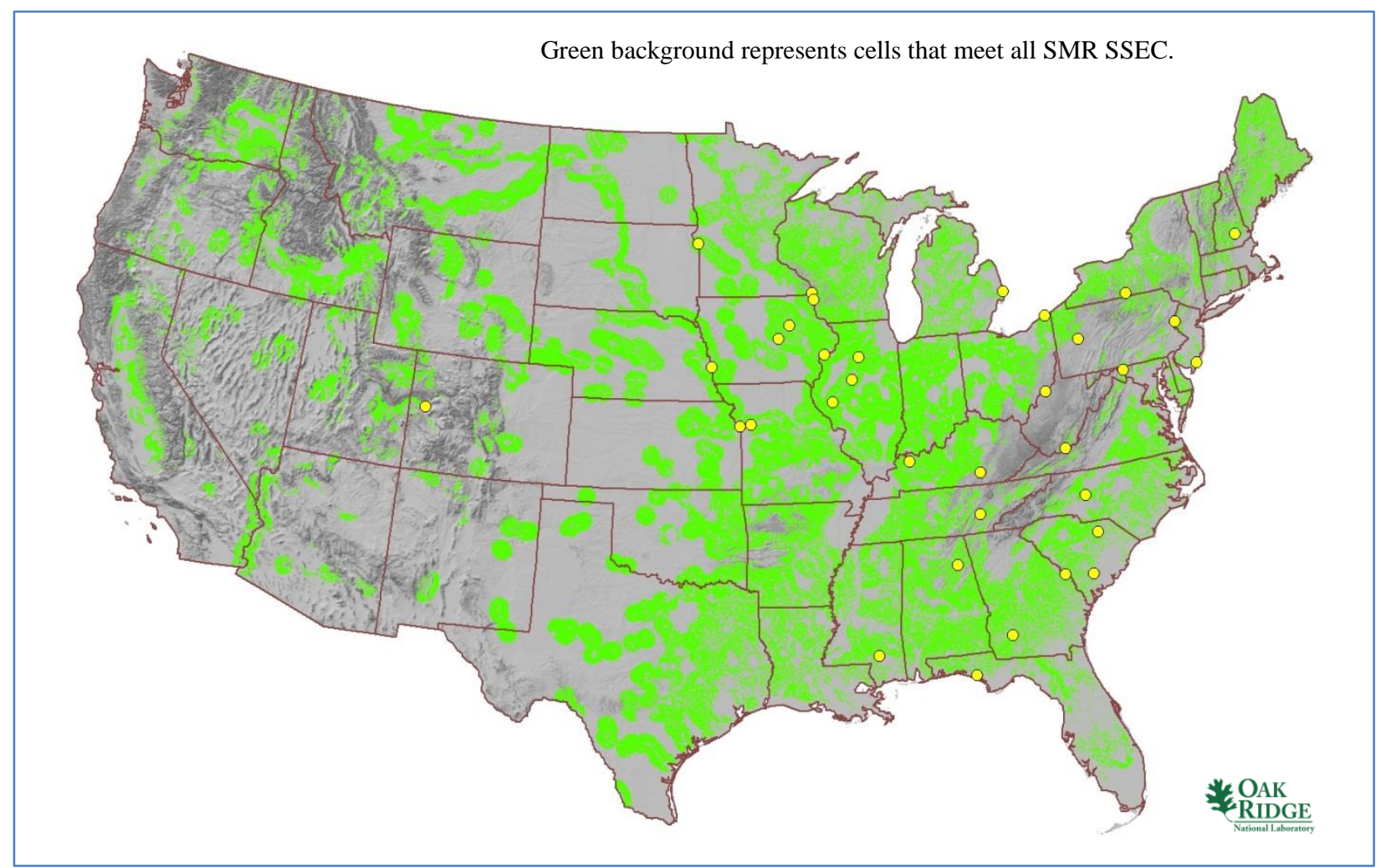

Fig. 4. Locations of 34 coal stations selected for SMR characterization.

Table 1. List of 34 evaluated coal stations

\begin{tabular}{|c|c|c|c|c|c|}
\hline Coal station & $\begin{array}{c}\text { Nameplate } \\
\text { capacity } \\
(\mathrm{MW}[\mathrm{e}])^{1}\end{array}$ & Utility & $\begin{array}{c}\text { Nuclear } \\
\text { utility }^{2}\end{array}$ & Initial GIS evaluation & State \\
\hline $\begin{array}{l}\text { AES Hickling Generation } \\
\text { Plant }\end{array}$ & 70 & AES Corporation & No & No siting issues & NY \\
\hline Armstrong Power Station & 326 & Allegheny Energy Supply & Yes & One siting issue & PA \\
\hline Ashtabula Power Plant & 440 & FirstEnergy & Yes & Multiple siting issues $^{3}$ & $\mathrm{OH}$ \\
\hline $\begin{array}{l}\text { B. L. England Generating } \\
\text { Station }\end{array}$ & 299 & R. C. Cape May & No & Multiple siting issues ${ }^{3}$ & NJ \\
\hline Big Stone Power Plant & 456 & Otter Tail Power Company & No & No siting issues & SD \\
\hline Buck Steam Station & 440 & Duke Energy & Yes & No siting issues & $\mathrm{NC}$ \\
\hline Cameo Station & 444 & $\begin{array}{l}\text { Public Service Company of } \\
\text { Colorado }\end{array}$ & Yes & One siting issue & $\mathrm{CO}$ \\
\hline Canadys Station & 490 & $\begin{array}{c}\text { South Carolina Electric \& } \\
\text { Gas Company }\end{array}$ & Yes & No siting issues & $\mathrm{SC}$ \\
\hline Cooper Power Station & 344 & $\begin{array}{c}\text { East Kentucky Power } \\
\text { Cooperative }\end{array}$ & No & One siting issue & KY \\
\hline Fair Station & 63 & $\begin{array}{c}\text { Central Iowa Power } \\
\text { Cooperative }\end{array}$ & No & No siting issues & IA \\
\hline $\begin{array}{l}\text { Gadsden Electric } \\
\text { Generating Plant }\end{array}$ & 138 & Alabama Power Company & Yes & One siting issue & AL \\
\hline Genoa Station & 346 & $\begin{array}{c}\text { Dairyland Power } \\
\text { Cooperative }\end{array}$ & Yes & No siting issues & WI \\
\hline Glen Lyn Plant & 406 & $\begin{array}{c}\text { Appalachian Power } \\
\text { Company }\end{array}$ & Yes & No siting issues & VA \\
\hline $\begin{array}{l}\text { H.B. Robinson Steam } \\
\text { Electric Plant }\end{array}$ & 207 & Duke Energy & Yes & No siting issues & $\mathrm{SC}$ \\
\hline
\end{tabular}


Table 1. List of evaluated coal stations (cont'd)

\begin{tabular}{|c|c|c|c|c|c|}
\hline Coal station & $\begin{array}{l}\text { Nameplate } \\
\text { capacity } \\
(\mathrm{MW}[\mathrm{e}])^{1}\end{array}$ & Utility & $\begin{array}{c}\text { Nuclear } \\
\text { utility }^{2}\end{array}$ & Initial GIS evaluation & State \\
\hline Hennepin Power Station & 306 & $\begin{array}{l}\text { Dynegy Midwest } \\
\text { Generation, Inc. }\end{array}$ & No & No siting issues & IL \\
\hline Kramer Power Plant & 137 & $\begin{array}{c}\text { Nebraska Public Power } \\
\text { District }\end{array}$ & Yes & Multiple siting issues $^{3}$ & $\mathrm{NE}$ \\
\hline $\begin{array}{l}\text { Lansing Generating } \\
\text { Station }\end{array}$ & 339 & Interstate Power and Light & No & No siting issues & IA \\
\hline $\begin{array}{l}\text { Lansing Smith Power } \\
\text { Station }\end{array}$ & 340 & Gulf Power & Yes & One siting issue & FL \\
\hline $\begin{array}{c}\text { Martins Creek Power } \\
\text { Plant }\end{array}$ & 312 & $\begin{array}{c}\text { PPL Martins Creek of } \\
\text { Pennsylvania }\end{array}$ & Yes & One siting issue & PA \\
\hline Marysville Power Plant & 306 & Detroit Edison & Yes & Multiple siting issues $^{3}$ & MI \\
\hline Maynard Power Station & 54 & Iowa Public Service & No & One siting issue & IA \\
\hline Meredosia Power Plant & 354 & Ameren Illinois & Yes & No siting issues & IL \\
\hline Merrimack Station & 459 & $\begin{array}{c}\text { Public Service Company of } \\
\text { New Hampshire }\end{array}$ & No & One siting issue & $\mathrm{NH}$ \\
\hline $\begin{array}{c}\text { Plant Mitchell Power } \\
\text { Station }\end{array}$ & 218 & Georgia Power Company & Yes & No siting issues & GA \\
\hline $\begin{array}{l}\text { R.D. Morrow Generating } \\
\text { Station }\end{array}$ & 400 & $\begin{array}{c}\text { South Mississippi Electric } \\
\text { Power Association }\end{array}$ & $\mathrm{Yes}^{4}$ & No siting issues & MS \\
\hline $\begin{array}{c}\text { Powerton Generating } \\
\text { Station } \\
\end{array}$ & 320 & Midwest Generation & Yes & Multiple siting issues ${ }^{3}$ & IL \\
\hline Quindaro Power Station & 239 & $\begin{array}{c}\text { Kansas City Board of Public } \\
\text { Utilities }\end{array}$ & No & One siting issue & $\mathrm{KS}$ \\
\hline $\begin{array}{l}\text { R. Paul Smith Power } \\
\text { Station }\end{array}$ & 160 & Allegheny Energy & Yes & Multiple siting issues ${ }^{3}$ & MD \\
\hline $\begin{array}{c}\text { Robert Reid Power } \\
\text { Station }\end{array}$ & 96 & $\begin{array}{l}\text { Big Rivers Electric } \\
\text { Corporation }\end{array}$ & No & No siting issues & KY \\
\hline Sibley Generating Station & 524 & $\begin{array}{c}\text { Kansas City Power and } \\
\text { Light }\end{array}$ & No & Multiple siting issues ${ }^{3}$ & $\mathrm{MO}$ \\
\hline $\begin{array}{c}\text { Sutherland Generating } \\
\text { Station }\end{array}$ & 157 & $\begin{array}{c}\text { Interstate Power and Light } \\
\text { Company }\end{array}$ & No & No siting issues & IA \\
\hline $\begin{array}{l}\text { Savannah River Site } \\
\text { Power Station }\end{array}$ & 78 & Federal Government & Yes & No siting issues & $\mathrm{SC}$ \\
\hline Watts Bar Fossil Plant & 240 & Tennessee Valley Authority & Yes & No siting issues & $\mathrm{TN}$ \\
\hline $\begin{array}{c}\text { Willow Island Power } \\
\text { Station }\end{array}$ & 213 & Monongahela Power & Yes & One siting issue & WV \\
\hline
\end{tabular}

1. Cumulative station nameplate capacity since initial unit was commissioned.

2. Utility may be an indirect nuclear utility via its parent company.

3. Sites have multiple siting issues but are within 5 miles of sites with no siting issues.

4. $10 \%$ owner of a nuclear power plant.

\subsection{Coal Station Evaluation Process}

A data package and analysis for each site in the sample set of 34 coal stations was prepared. These site summaries are available in Appendix A. Each station summary in Appendix A includes specific detail regarding the coal station location and a location map similar to the example shown in Fig. 5. In addition, a table of statistics similar to that shown in Table 2 supports a description of the site. Table 2 includes

- Population within $0.5,1,5$, and 10 miles, which allows a population density calculation 
- Distance to $400,800,1600$, and 3200 MW(e) grid capacity ${ }^{9}$

- Nearest cities with populations greater than $10,000,50,000,100,000$, and 500,000

- Distance to cooling water makeup source greater than 50,000, 100,000, 200,000, and 500,000 gpm stream flow

- Note that a $540 \mathrm{MW}(\mathrm{e})$ modular iPWR installation requires approximately 65,000 gpm stream flow, assuming no more than $10 \%$ of the available stream flow is used for power production

- Available cooling water makeup is based on current consumption. The cooling water already used by a given coal station may be sufficient for a replacement iPWR SMR

- Geotechnical information, including

○ Maximum earthquake acceleration (if greater than $0.3 \mathrm{~g}$ )

- Maximum slope

- Nearest fault line

○ Nearest hazardous site

- Accessibility by road, water, rail, and air

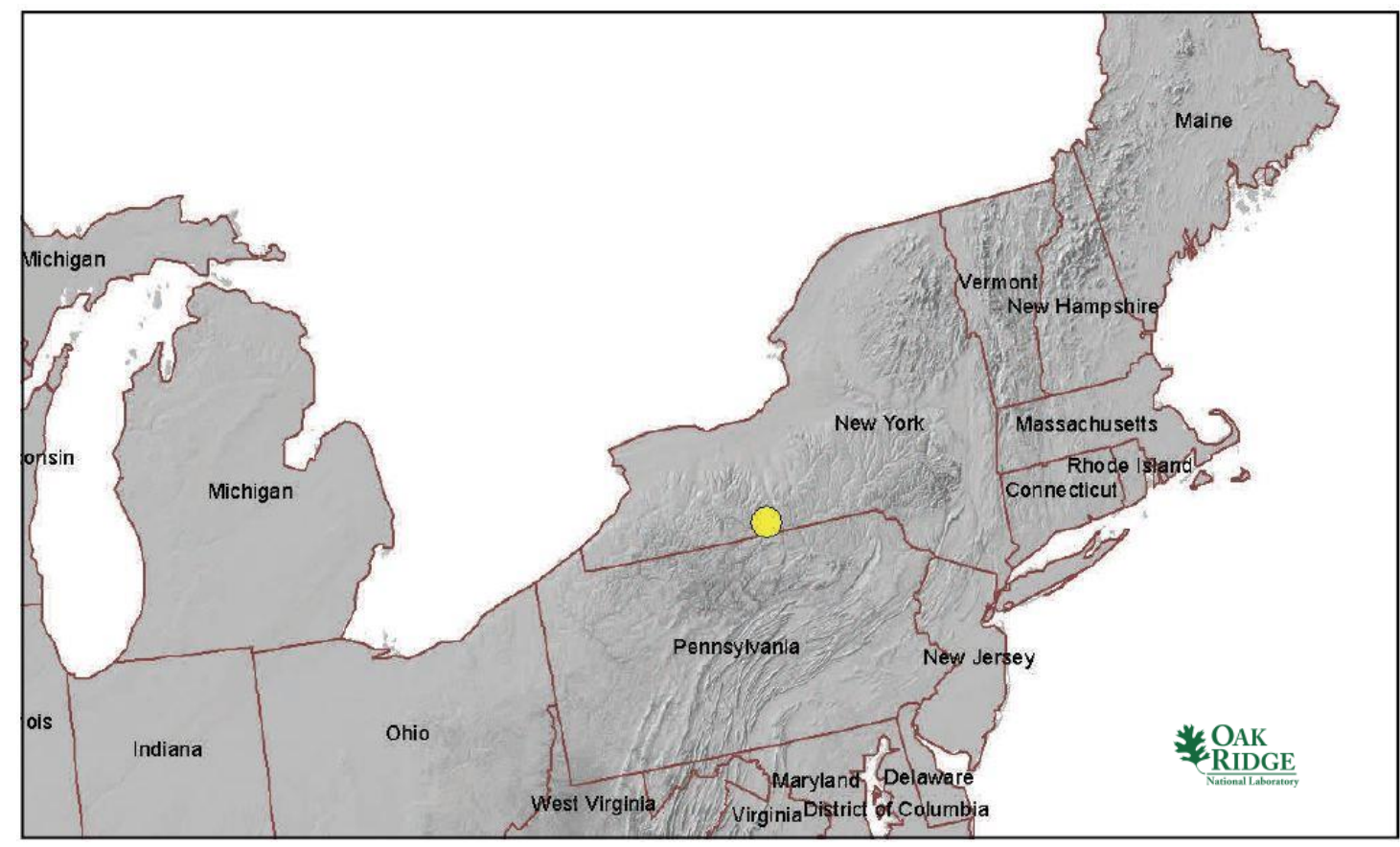

Fig. 5. Sample coal station location map.

\footnotetext{
${ }^{9}$ Grid capacity data are based on 2004 data.
} 
Table 2. Sample coal station site statistical summary

\begin{tabular}{|l|l|l|l|}
\hline $\begin{array}{l}\text { Population } \\
\text { Population Within }\end{array}$ & \multicolumn{2}{l|}{$\begin{array}{l}\text { Utility } \\
\text { Distance to Grid Capacity }\end{array}$} \\
\hline $0.5 \mathrm{mi}$ & $<500$ & $>400 \mathrm{MWe}$ & $\sim 10 \mathrm{mi}$ \\
\hline $1 \mathrm{mi}$ & $\sim 650$ & $>800 \mathrm{MWe}$ & $\sim 63 \mathrm{mi}$ \\
\hline $5 \mathrm{mi}$ & $\sim 46,300$ & $>1600 \mathrm{MWe}$ & $\sim 78 \mathrm{mi}$ \\
\hline $10 \mathrm{mi}$ & $>3200 \mathrm{MWe}$ & $\sim 129 \mathrm{mi}$ \\
\hline Nearest City with Population & Distance to Cooling Water \\
\hline \multicolumn{2}{|l|}{} & \multicolumn{2}{l|}{} \\
\hline$>10,000$ & Corning, NY & $>50,000$ gpm & $\sim 3.1$ mi (Chemung River) \\
\hline$>50,000$ & Irondequoit, NY & $>100,000$ gpm & $\sim 3.1$ mi (Chemung River) \\
\hline$>100,000$ & Rochester, NY & $>200,000$ gpm & $\sim 3.1$ mi (Chemung River) \\
\hline$>500,000$ & Philadelphia, PA & $>500,000$ gpm & $\sim 3.1$ mi (Chemung River) \\
\hline Geotechnical & \multicolumn{4}{|l|}{ Accessibility } \\
\hline Max Earthquake Acceleration & $<0.3 \mathrm{~g}$ & Distance to Major Roadway & $\sim 0.3$ mi (Interstate 86) \\
\hline Max Slope & $\sim 67 \%$ & Distance to Water Transport & $\sim 16$ mi (Seneca Canal) \\
\hline Nearest Fault Line & $\sim 1,190$ mi (Oklahoma) & Distance to Rail Transport & $\sim 0.2$ mi (NS) \\
\hline Nearest Hazard Site & $\sim 5$ mi (Airport- Corning Regional) & Distance to Airport & $\sim 5$ mi (Corning Regional) \\
\hline
\end{tabular}

In each coal station evaluation summary, a satellite aerial view of each coal station with overlaid concentric circles at 0.5 mile and 1 mile radii is provided. This provides a convenient look at the area topography, including major nearby roads, rivers, and population activity such as towns and subdivisions. A sample aerial image of a coal station is provided in Fig. 6.

Following the satellite view of the coal station, a screening criteria summary bar, or "dashboard" chart, for the 0.5 and 1.0 mile circles provides a quick look at what siting issues may exist for the site. The SMR SSEC that are not met within each of the 0.5 and 1.0 mile circles are indicated. If an SMR siting criterion box is green, there is no potential siting issue. Hatched purple and green indicates that only a portion of the area does not meet that criterion and is termed a "partial" siting issue for some part of one of the circles. A solid purple indicates that the particular SMR criterion is an issue for the entire site at either or both of the 0.5 and 1.0 mile radius circles. The SMR SSEC are listed; their respective values appear below the summary bar for reference. A sample coal station screening criteria dashboard is provided in Table 3.

Following the coal station screening criteria dashboard in each evaluation summary is a localized composite map based on the national composite map shown in Fig. 2. At the local level, individual 100 by $100 \mathrm{~m}$ cells can be identified. The cells are color-coded, as in Fig. 2, to quickly gain insight to compounded SMR siting criteria that are not met. A sample coal station composite map is shown in Fig. 7. A green square has no siting issues relative to the selected SMR SSEC values; a yellow square has a single siting issue; an orange square has two siting issues; and a blue square has three or more siting issues.

Following the coal station composite map, ten smaller individual siting criterion maps are provided to identify the locations where the selected individual parameter values may not be met within the 0.5 and 1.0 mile radius circles. Any areas shown in a magenta color do not meet the individual siting criterion at the value selected for SMR screening. A sample individual SSEC map is shown in Fig. 8. 


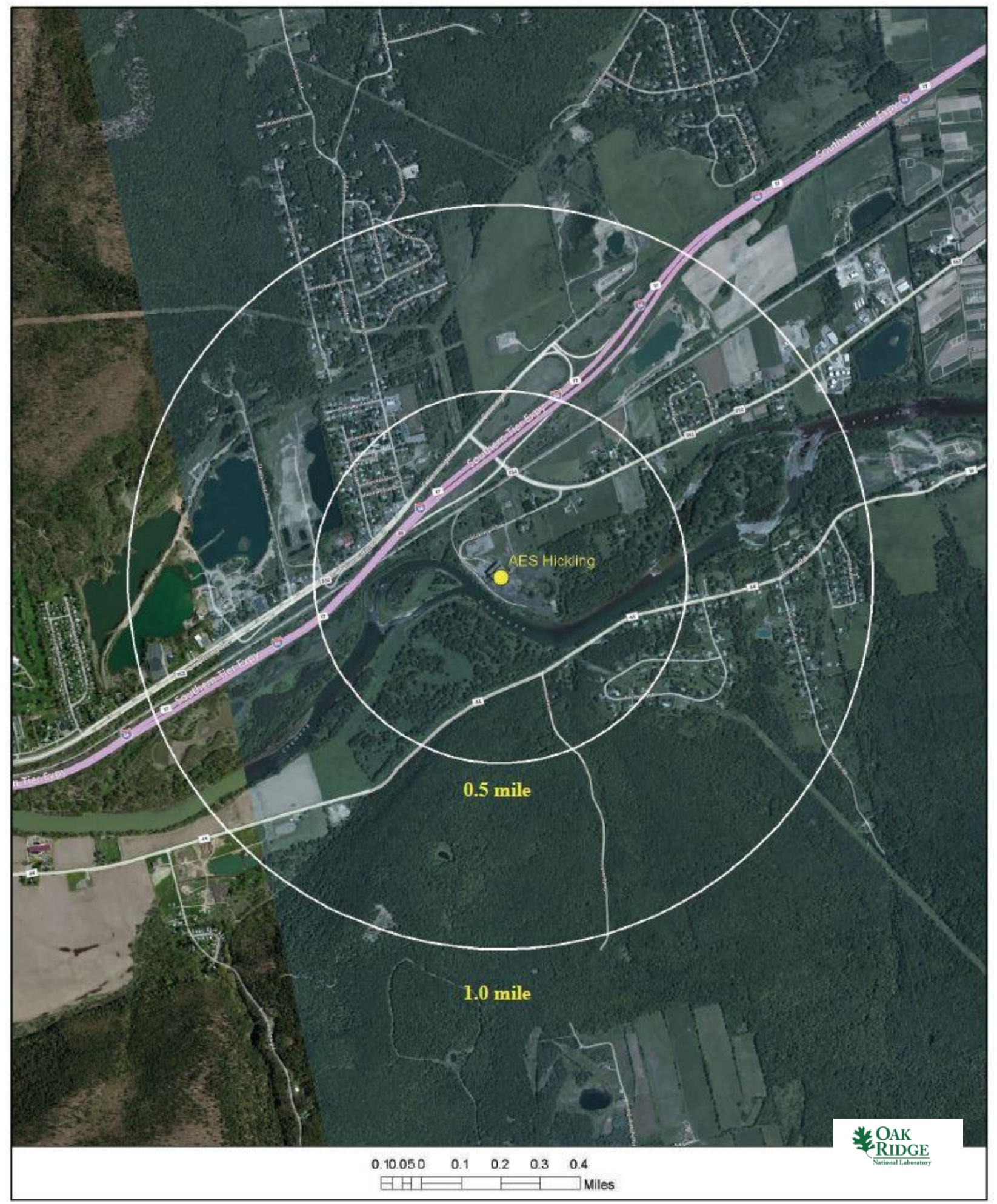

Fig. 6. Sample satellite view of coal station plant proximity. 
Table 3. Sample coal station siting criteria summary

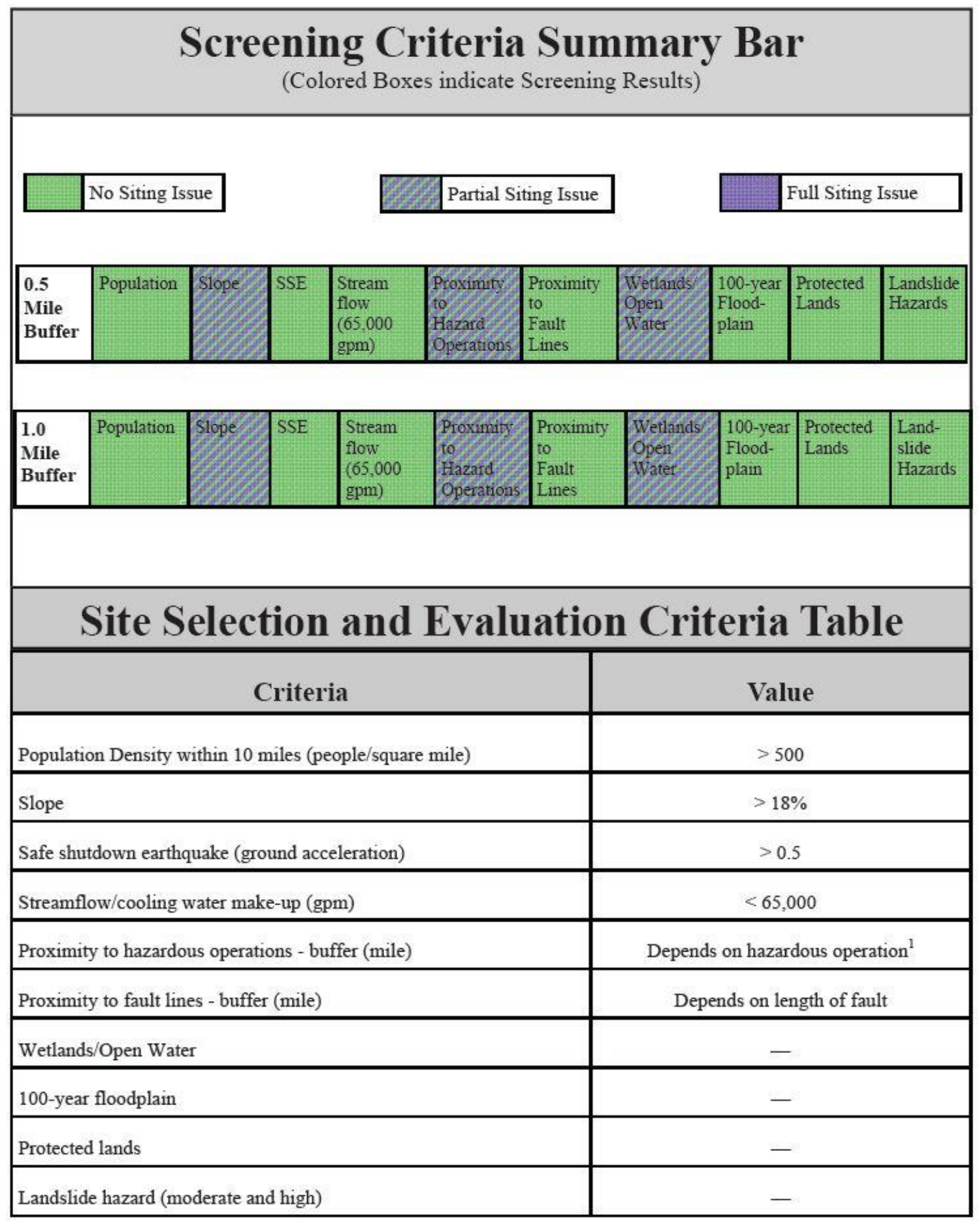




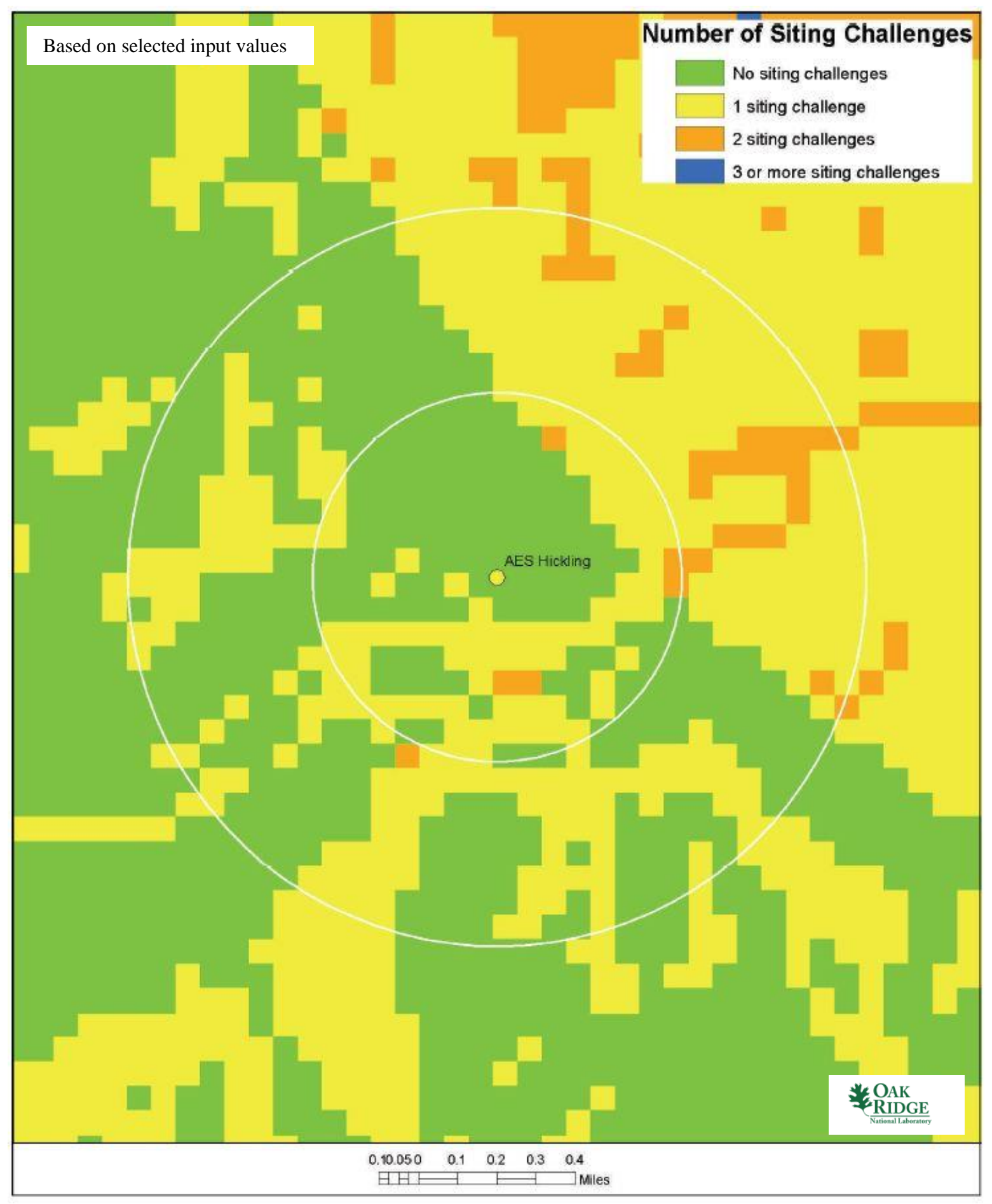

Fig. 7. Sample coal station composite map. 


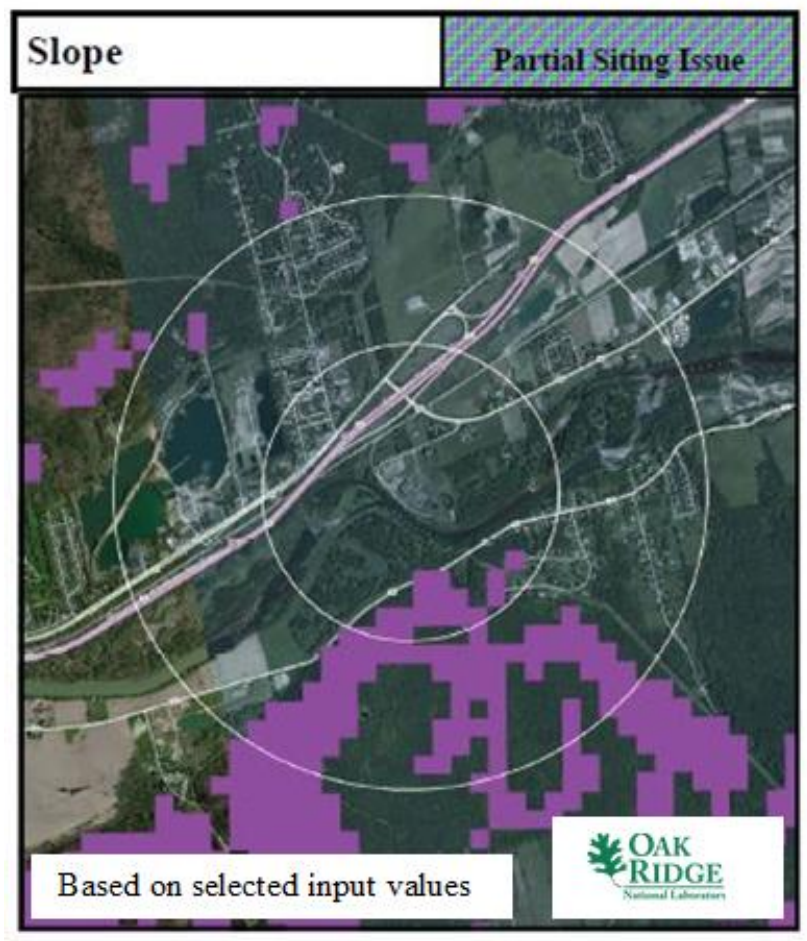

Fig. 8. Sample individual siting criterion map (magenta areas do not meet criterion).

Based on the detail provided in each coal station summary package, an evaluation of the coal station site is offered. Detail about the utility that owns the coal station is provided and any partial or full siting issues are addressed. Other imagery details are also explained. Based on the analysis, the individual site is binned into one of four categories in increasing order of difficulty based on the review:

1. The site meets multiple conventional standards for consideration of siting an SMR at the coal station location. There are no current or near-term foreseeable SMR SSEC siting issues that should preclude this site from further SMR siting consideration.

2. The site meets multiple conventional standards in the near term for consideration of siting an SMR at the coal station location, but there may be longer-term issues that could potentially preclude this site from further SMR siting consideration. For example, a small population center is identified nearby that meets the current SMR SSEC for population density, but future growth near the coal station could present a siting challenge.

3. The site meets conventional standards pending verification of parameters or an engineered solution to an issue. For example, a coal station site meets all SMR SSEC with the exception of having a moderate to high potential for landslide hazard. The existing coal plant has been at that location without a landslide incident since it was commissioned on some date prior to 1980. In this case, since the potential for landslide hazards is a wide-area probabilistic calculation, additional site-specific geological survey could validate the acceptance of the site for further SMR siting consideration. If a coal station site meets category 2 and 3 requirements, it is binned under category 3 , which represents the higher degree of effort to continue to favorably consider the site for SMR placement.

4. The site is not a likely candidate for consideration of siting an SMR. Numerous SSEC are not met that could make it difficult for a utility to consider replacing the coal-fired power produced at an existing coal station with an SMR. 


\subsection{Summary of Coal Station Evaluations}

Each coal station was evaluated visually using Google Earth to estimate available acreage, identify proximity to nearby towns, identify potential hazards, and identify other power generation resources, typically within 100 miles. Internet searches were conducted to identify more up-to-date plant status and other conditions that may limit the site for SMR placement. Numerous utilities opted to retire operating coal-fired facilities in 2012 or plan to do so in the near future rather than install updated emissions control equipment to meet revised EPA regulations that take effect in 2015. Also, a number of plants have had updated emissions controls installed or plan to install them before 2015. These plants are noted where information was available.

\subsubsection{First Set of Coal Station Evaluations}

The OR-SAGE tool identified 17 sites that initially met all of the SMR SSEC at the selected values. Of these 17 sites, further investigation indicated that 12 sites easily meet multiple conventional standards for consideration of siting an SMR at the coal station location. The specific evaluations of each site indicated that there were no current or near-term foreseeable SMR SSEC siting concerns that should preclude these sites from further SMR siting consideration. This is 35\% (12 of 34) of the sample set and 71\% (12 of 17) of the sites that were initially identified by OR-SAGE as meeting all the SMR SSEC (on green space in Fig. 4). The remaining five sites of the 17 sites that initially met all of the SMR SSEC at the selected value that were not binned into this category, were binned into categories 2 and 3 as discussed below. The sites binned into category 1 are listed in Table 4 and the individual plant evaluations are available in Appendix A.

Of these sites, eight are directly or indirectly owned and operated by a nuclear utility. Ten of the 25 states in the sample set are represented, including three sites in South Carolina. Two sites, H. B. Robinson and Watts Bar, already include large nuclear power plants. The Savannah River Site Power Plant is also included. These latter three sites would have the advantage of sharing logistical and security resources. Note that two sites listed in Table 4 are in states that currently restrict new nuclear construction, Illinois and Kentucky.

Table 4. Most favorable sites in sample set

\begin{tabular}{|c|c|c|c|}
\hline Coal Station & Utility & Nuclear Utility & State \\
\hline Big Stone Power Plant & Otter Tail Power Company & No & SD \\
\hline Buck Steam Station & Duke Energy & Yes & NC \\
\hline Canadys Station & $\begin{array}{c}\text { South Carolina Electric \& Gas } \\
\text { Company }\end{array}$ & Yes & SC \\
\hline Glen Lyn Plant & Appalachian Power Company & Yes & VA \\
\hline H.B. Robinson Steam Electric Plant & Duke Energy & Yes & SC \\
\hline Hennepin Power Station & Dynegy Midwest Generation, Inc. & No & IL \\
\hline Lansing Generating Station & Interstate Power and Light & No & IA \\
\hline Plant Mitchell Power Station & Georgia Power Company & Yes & GA \\
\hline R.D. Morrow Generating Station & South Mississippi Electric Power & Yes & MS \\
\hline Robert Reid Power Station & Association & No & KY \\
\hline Savannah River Site Power Station & Federal Government & Yes & SC \\
\hline Watts Bar Fossil Plant & Tennessee Valley Authority & Yes & TN \\
\hline
\end{tabular}

Half of the sites listed in Table 4 are cooled by once-through cooling from an adjacent river. Therefore, water resources and environmental temperature effects near these facilities would be positively impacted by replacing the existing coal-fired facilities with SMRs cooled by natural draft or mechanical draft cooling towers. Four of the sites listed in Table 4 are currently cooled by mechanical draft cooling towers, 
which could likely be used by an SMR as well, although supplemental cooling capability may be necessary, depending on the cooling capacity of the installed towers. The remaining two sites listed in Table 4 are cooled by once-through cooling from an onsite cooling pond or an adjacent lake established for that purpose. Presumably, an SMR at these two sites could be cooled in a similar manner.

Nine of the coal-fired stations listed in Table 4 are currently operating, and the remaining three have been retired. Two of the operating plants are scheduled to be retired in the near future, based on press releases by the associated utilities. Therefore, five of the sites listed in Table 4 are immediately available for SMR consideration if grid demand at the respective sites support continued power generation at that location.

\subsubsection{Second Set of Coal Station Evaluations}

Further investigation indicated that an additional six sites met multiple conventional standards for consideration of siting an SMR at the coal station location. However, these sites may be subject to longerterm issues, such as population growth, that could potentially preclude them from further SMR siting consideration. Four of these six sites initially met all of the SMR SSEC at the selected values. The six sites constitute $18 \%$ of the sample set, and four of the sites represent $24 \%$ of the sites that were initially identified by OR-SAGE as meeting all the SMR SSEC. These sites are listed in Table 5 and the individual plant evaluations are available in Appendix B.

Of these sites, only two are directly or indirectly owned and operated by a nuclear utility. Five of the 25 states in the sample set are represented, including 2 sites in Iowa. All six sites are noted to have the potential for population growth encroachment on the existing coal-fired sites before SMRs could be established at the locations. In addition, two site evaluations note the potential for traffic growth and control based on nearby major roadways. One site evaluation cites the future potential for increased exposure to flooding based on the site location on a peninsula on the Atlantic Ocean. Another site evaluation notes the potential for increased aircraft traffic at a local airport that is just 5.5 miles from the site. The distance from the site meets the SMR SSEC; however, the runway at this airport is in line with the site. Note that one site listed in Table 5 is in a state that currently restricts new nuclear construction, Illinois.

Table 5. Second tier set of sites in the sample set

\begin{tabular}{|c|c|c|c|}
\hline Coal station & Utility & Nuclear utility & State \\
\hline AES Hickling Generation Plant & AES Corporation & No & NY \\
\hline B. L. England Generating Station & R. C. Cape May & No & NJ \\
\hline Fair Station & Central Iowa Power Cooperative & No & IA \\
\hline Martins Creek Power Plant & PPL Martins Creek of Pennsylvania & Yes & PA \\
\hline Meredosia Power Plant & Ameren Illinois & Yes & IL \\
\hline Sutherland Generating Station & Interstate Power and Light Company & No & IA \\
\hline
\end{tabular}

Five of the six sites listed in Table 5 are cooled by once-through cooling from an adjacent river. Therefore, water resources and environmental temperature effects near these facilities would be positively impacted by replacing the existing coal-fired facilities with SMRs cooled by natural draft or mechanical draft cooling towers. The remaining site listed in Table 5 is currently cooled by mechanical draft cooling towers, which could likely be used by an SMR as well, although supplemental cooling capability may be necessary depending on the cooling capacity of the installed towers.

Four of the coal-fired stations listed in Table 5 are currently operating and the remaining two have been retired. One of the operating plants is scheduled to be retired in the near future, based on press releases by the associated utility. A $600 \mathrm{MW}$ (e) gas-fired plant has been proposed by the utility near the site that is pending closure. Therefore, only two of the sites listed in Table 5 may be immediately available for SMR consideration if grid demand at the respective sites supports continued power generation at those locations. 


\subsubsection{Third Set of Coal Station Evaluations}

After detailed investigation, an additional eight sites were deemed to meet multiple conventional standards for consideration of siting SMRs at the coal station locations pending verification of parameters or an engineered solution to an issue. For example, a site may meet all SMR SSEC with the exception of having a moderate to high potential for landslide hazard. In this case, since the potential for landslide hazards is a wide-area probabilistic calculation, additional site-specific geological survey could validate the acceptance of the site for further SMR siting consideration. One of these eight sites initially met all of the SMR SSEC at the selected values. The remaining seven sites were located on land with a single siting issue, or had multiple issues but were located within 5 miles of land that has no siting issues. The eight sites constitute $24 \%$ of the sample set. These sites are listed in Table 6 and the individual plant evaluations are available in Appendix C.

Of these sites, six are directly or indirectly owned and operated by a nuclear utility. Eight of the 25 states in the sample set are represented. Four of the sites meet multiple conventional standards for consideration of siting an SMR pending verification of geological data regarding the potential for landslides. An additional site has an open waters/wetlands issue and would require an evaluation regarding flooding. Another site is excluded by population, but land immediately adjacent to the site meets all SMR SSEC. Finally, the Genoa site initially met all of the SMR SSEC at the selected values. However, a dam immediately upstream should be evaluated for flooding potential at the site. The dam appears to be for navigational purposes and not flood control. Note that four sites listed in Table 6 are in states that currently restrict new nuclear construction-Illinois, Kentucky, West Virginia, and Wisconsin.

Table 6. Third tier set of sites in the sample set

\begin{tabular}{|c|c|c|c|}
\hline Coal station & Utility & Nuclear utility & State \\
\hline Armstrong Power Station & Allegheny Energy Supply & Yes & PA \\
\hline Cameo Station & Public Service Company of Colorado & Yes & CO \\
\hline Cooper Power Station & East Kentucky Power Cooperative & No & KY \\
\hline Genoa Station & Dairyland Power Cooperative & Yes & WI \\
\hline Lansing Smith Power Station & Gulf Power & Yes & FL \\
\hline Powerton Generating Station & Midwest Generation & Yes & IL \\
\hline Sibley Generating Station & Kansas City Power and Light & No & MO \\
\hline Willow Island Power Station & Monongahela Power & Yes & WV \\
\hline
\end{tabular}

Six of the eight sites listed in Table 6 are cooled by once-through cooling from an adjacent river. Therefore, water resources and environmental temperature effects near these facilities would be positively impacted by replacing the existing coal-fired facilities with an SMR cooled by natural draft or mechanical draft cooling towers. Another site listed in Table 6 is currently cooled by mechanical draft cooling towers, which could likely be used by an SMR as well, although supplemental cooling capability may be necessary depending on the cooling capacity of the installed towers. The remaining site listed in Table 6 is cooled by a large onsite cooling pond, which likely could easily accommodate the SMR cooling.

Six of the coal-fired stations listed in Table 6 are currently operating and the remaining two have been retired. One of the operating plants is scheduled to be retired in the near future, based on press releases by the associated utility. Therefore, three of the sites listed in Table 6 may be immediately available for SMR consideration if grid demand at the respective sites supports continued power generation at those locations.

\subsubsection{Fourth Set of Coal Station Evaluations}

After detailed investigation, the final eight sites were deemed not to be likely candidates for consideration of siting an SMR. There are numerous SSEC criteria not met at each of these sites that could make it 
difficult for a utility to realistically consider replacing the coal-fired power produced at an existing coal station with an SMR. None of these eight sites initially met all of the SMR SSEC at the selected values. Four sites were located on land with a single siting issue, and four were located on sites with multiple SMR SSEC issues but within 5 miles of land that has no SMR SSEC issues. The eight sites constitute $24 \%$ of the sample set. These sites are listed in Table 7 and the individual plant evaluations are available in Appendix D.

Of these sites, five are directly or indirectly owned and operated by a nuclear utility. Eight of the 25 states in the sample set are represented. All of the sites are excluded by high population density. In addition, two of the sites appear to have insufficient acreage to support an SMR, and several others have borderline acreage.

Table 7. Fourth tier set of sites in the sample set

\begin{tabular}{|c|c|c|c|}
\hline Coal station & Utility & Nuclear utility & State \\
\hline Ashtabula Power Plant & FirstEnergy & Yes & OH \\
\hline Gadsden Electric Generating Plant & Alabama Power Company & Yes & AL \\
\hline Kramer Power Plant & Nebraska Public Power District & Yes & NE \\
\hline Marysville Power Plant & Detroit Edison & Yes & MI \\
\hline Maynard Power Station & Iowa Public Service & No & IA \\
\hline Merrimack Station & $\begin{array}{c}\text { Public Service Company of New } \\
\text { Hampshire }\end{array}$ & No & NH \\
\hline Quindaro Power Station & Kansas City Board of Public Utilities & No & KS \\
\hline R. Paul Smith Power Station & Allegheny Energy & Yes & MD \\
\hline
\end{tabular}

Seven of the eight sites listed in Table 7 are cooled by once-through cooling from an adjacent river or lake. Therefore, water resources and environmental temperature effects near these facilities would be positively impacted by replacing the existing coal-fired facilities with SMRs cooled by natural draft or mechanical draft cooling towers. The remaining site listed in Table 7 is currently cooled by an onsite cooling pond.

Four of the coal-fired stations listed in Table 7 are currently operating and the remaining four have been retired. Two of the retired plants have been completely dismantled. One of the operating plants is scheduled to be retired in the near future, based on press releases by the associated utility.

\subsubsection{Overall Evaluation Summary}

Overall, 26 of the 34 sample plant sites (77\%) meet multiple conventional standards for consideration of siting an SMR at a coal station site. Given that half the sites initially selected met all of the SMR SSEC at the selected values, a high percentage of the sample set was expected. However, after further investigation, 9 of the 17 remaining sites in the sample set (53\%) also had good potential for siting an SMR. These 26 sites represent $7.3 \mathrm{GW}$ (e) of coal-fired electrical generation that can potentially be repowered by SMR electrical generation. This is the equivalent of adding five $1.6 \mathrm{GW}(\mathrm{e})$ large nuclear power plants to the grid, which is $5 \%$ of the current reactor plant fleet. Extrapolating these results to the 148 "small" coal station master sample set, a total of 86 coal-fired electrical generating stations could potentially be repowered with SMRs. At an average of 200 MW(e) per SMR site, this would represent 17.2 GW(e) of coal-fired electrical generation that can potentially be repowered by SMR electrical generation. This is the equivalent of adding eleven $1.6 \mathrm{GW}(\mathrm{e})$ large nuclear power plants to the grid. However, more specific site analyses would be required to confirm such a projection. 


\section{SAMPLE SMR SITE COMPARISON METHODOLOGY}

Beyond designating areas as meeting all the siting criteria at a specific set of threshold values, specifically the green space in the SMR composite map shown in Fig. 2, it is desirable to have the capability to compare areas that meet all of the designated SMR SSEC. This allows further emphasis to be directed toward areas that may ultimately prove to be more desirable than others. For example, remote areas with low population density may have tremendous water resources to support many SMR units. This can artificially inflate the capacity evaluation for a region where added capacity is really not justified. A similar comparison among areas with a single SMR SSEC that is not met is also beneficial to better inform a decision about where to exert effort to engineer around a siting issue. To meet this need, a simple scoring method was developed to compare individual cells in a like category — no siting issue to no siting issue, and single issue to single issue.

\subsection{Scoring Method}

Each of the approximately 700 million 100 by $100 \mathrm{~m}$ database cells is scored using multiple categories and elements. Green space cells as defined by the SMR composite map shown in Fig. 2 will be compared with other green space cells. Green space cells met all the SMR SSEC at selected values as outlined in the initial report ${ }^{1}$ on the siting methodology. Likewise, yellow space cells from the SMR composite map will be compared with other yellow space cells. Yellow space cells meet all but one of the SMR SSEC at selected SMR SSEC values.

Four scoring categories are proposed to quantify desirable site attributes in the general areas of site expandability, economics and proximity to demand, acceptability, and engineering. Within these categories, eight elements are differentiated or scored by geographical suitability. The proposed elements are listed below within the general plant attribute category.

\section{Expandability:}

More stream flow at a site implies that multiple SMR units could be supported at that location. Therefore, higher stream flow within 20 miles of a site is more desirable.

1. Cell stream flow $<65,000 \mathrm{gpm}$ $65000 \mathrm{gpm} \leq$ cell stream flow $<130,000 \mathrm{gpm}$

Cell stream flow $\geq 130,000$ gpm

0 points

1

2

\section{Economics and Proximity to Demand:}

If we assume that the construction cost of an SMR is $\$ 1 \mathrm{~B}$ and each mile of new transmission line costs $\$ 1 \mathrm{M},{ }^{10}$ then $1 \%$ of the SMR cost would be $\$ 10 \mathrm{M}$, or approximately 10 miles of transmission line construction. Keeping the fraction of the SMR capital cost low is considered desirable.

2. Cell $\geq 25$ miles from existing transmission lines ( $2.5 \%$ of cost)

10 miles $\leq$ existing transmission lines $<25$ miles

0 points

Cell $<10$ miles from existing transmission lines ( $1 \%$ of cost)

1

2

\section{Acceptability:}

If an area is within an EPA nonattainment zone for particulate matter and ozone, then a green power source would be more desirable or acceptable.

\footnotetext{
${ }^{10}$ American Electric Power Transmission Facts, www.aep.com/about/transmission/docs/transmission-facts.pdf.
} 
Population density near a proposed SMR facility is also an important acceptability factor for many reasons. First, evacuation planning is a key element in siting any nuclear facility. Second, while polls indicate that the US population generally backs the use of nuclear energy, ${ }^{11}$ many people often oppose the siting of such an energy source near their community. Therefore, lower population density is considered more favorable, although this tends to skew power plant siting away from the areas of highest power demand. Cells that meet all of the SSEC conditions, or green space cells, will never receive the minimum score by definition of the SMR SSEC for population. ${ }^{1}$

Finally, states with operating nuclear power plants or communities already served by a nuclear utility would likely be more amenable to the siting of a new nuclear power plant. This is based on the perceived community value placed on jobs and infrastructure improvements often associated with a nuclear utility.

Therefore, the following elements are included in the acceptability category.

3. Cell outside EPA nonattainment zone

Cell inside EPA nonattainment zone

0 points

1

4. Cell population density ( 10 miles) $\geq 500$ people per square mile (ppsm)

Cell population density (11-20 miles) $<500$ ppsm

Cell population density ( $>20$ miles $)<500$ ppsm

5. Cell within a state that does not have a nuclear power plant

Cell within a state with an existing nuclear power plant

Cell within a state AND utility service territory with an existing nuclear power plant
0 points

1

2

0 points

1

2

\section{Engineering:}

From an engineering perspective, certain conditions can greatly affect the plant design or the extent of site preparation work required to site an SMR. Cells within an area of moderate or high predicted landslide likelihood or consequence would require additional initial engineering work to verify that the selected site is stable. This element will differentiate only cells with an identified landslide SSEC issue, because cells that meet all of the SMR SSEC conditions - or green space cells - will receive the maximum score by definition.

Seismic activity near a proposed SMR facility is also an important engineering factor. The pipe snubber designs can be greatly affected by the site safe-shutdown earthquake analysis. Areas with lower seismic values would be more desirable. Cells that meet all of the SSEC conditions, or green space cells, will never receive the minimum score by definition of the SMR SSEC for seismic activity. ${ }^{1}$

Cells with lower slope values require less site preparation in terms of providing a level construction area. A lower slope value can often infer greater geologic stability as well. Lower slope values are considered more desirable. Cells that meet all of the SSEC conditions, or green space cells, will never receive the minimum score by definition of the SMR SSEC for slope. ${ }^{1}$

Therefore, the following elements are included in the engineering category.

6. Cell within area of high landslide probability Cell within area of moderate landslide probability Cell within area of low (or zero) landslide probability

0 points

1

2

0 points

7. Cell seismic $>0.5 \mathrm{~g}$

$0.3 \mathrm{~g}<$ cell seismic $\leq 0.5 \mathrm{~g}$

Cell seismic $\leq 0.3 \mathrm{~g}$
1

2

\footnotetext{
${ }^{11}$ World Nuclear News, “Gradual Growth in US Support for Nuclear,” September 24, 2012.
} 

8. Cell slope $>18 \%$
$12 \%<$ cell slope $\leq 18 \%$
0 points
Cell slope $\leq 12 \%$
1
2

For tracking purposes, the SMR SSEC categories not included in the scoring model were assigned scored of zero points. These binary criteria are of a go/no-go nature and assist in comparing "yellow" cells that fail to meet a single SMR SSEC. Green cells that meet all of the SSEC conditions are not affected by these criteria by virtue of the OR-SAGE process to screen these cells. These go/no-go criteria are

- wetlands/open waters

- protected lands

- flood plain

- fault lines

- hazardous facilities

There are 8 proposed scoring categories in this simple scoring model with a resulting maximum 100 by $100 \mathrm{~m}$ cell score of 15 . Based on the results of applying the sample scores, the cells that met all the SMR SSEC (green cells in Fig. 2) were compared with each other by binning these cells into good, better, or best location bins. Note that no matter what bin a green cell is categorized in, all the green cells meet all of the SMR siting criteria. Likewise, the cells that met all the SMR SSEC except one (yellow cells in Fig. 2) were compared with one another by binning these cells into low, medium, or high desirability bins. Note that no matter what bin a yellow cell is categorized in, all the yellow cells failed to meet one of the SMR siting criteria at the values specified. Therefore, there is no attempt to judge whether a yellow cell in the high category is somehow more favorable than a green cell in the good category.

\subsection{Additional Scoring Considerations}

The initial scoring algorithm was intentionally kept simple by limiting the number of scoring elements. Eventually, it might be useful to account for the factors that would totally negate a cell. Otherwise, a cell in the middle of a national park or in the middle of a lake will receive a score and possibly some modified shade of yellow (single-issue color from Fig. 2) above the "worst-case" shade of yellow. This is the situation for the current sample scoring methodology, which creates a need for additional explanation; whereas a final cell score of 0 would ensure that the cell in question will not receive any "improved" shading. A cell would receive a "0" multiplier for any of the following conditions, effectively trumping any other attributes:

- in wetlands or open waters

- in protected lands

- in flood plain

- in fault algorithm zone

- in airport or chemical plant zone

In addition, there are other scoring categories and elements that could be considered. The scoring example presented in this section was intentionally simple to demonstrate a site comparison methodology. Any GIS data-driven layer could be considered. Other categories and elements could include

- Proximity to demand - distance from existing substation

- Proximity to demand - areas with forecast population growth

- Expandability - 100 acre or 150 acre site availability

- Flooding - downstream distance from a dam

- Flooding - distance from stream, reservoir, lake, or shoreline

- Socioeconomics - relationship to snapshot of unemployment rate (generally available by county)

- Socioeconomics - relationship to snapshot of income level (generally available by county) 
- Socioeconomics - proximity to engineering-related educational opportunities

- Socioeconomics - states with current nuclear power restrictions

- Transportation - distance from major state or federal highway

- Transportation - distance from rail lines

- Transportation - distance from barge access

\subsection{Scoring Method Application Results-Green Space}

All map cells that meet all of the SMR SSEC at the select set of values as documented in the first phase of this SMR site-screening study1 are shown in green in Fig. 9. This is known as the SMR base map. Collectively, these are the cells that will be compared by the scoring process as good, better, and best.

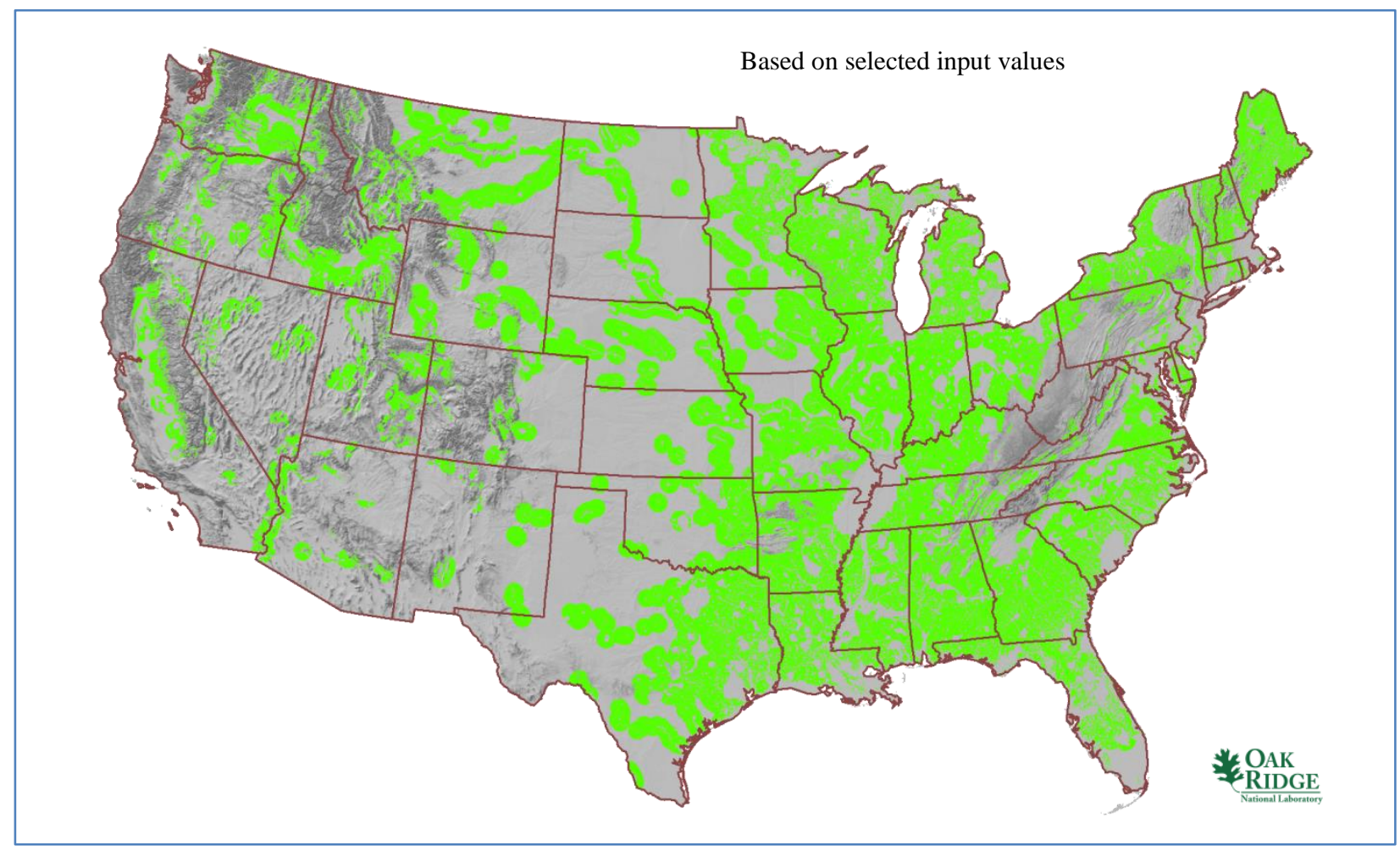

Fig. 9. SMR base map.

Each of the scoring elements is evaluated individually for each cell. The results for each cell are then summed to produce a final score for each individual cell. This process has the added benefit of providing an opportunity to visually evaluate each individual scoring element. Elements that have three possible bins are shaded in three different green hues: light green for zero points, medium green for 1 point, and dark green for 2 points. Binary elements are limited to zero or one point, so no cells with a binary score are visually represented in a dark green hue. Not all of the individual elements produce dramatic differences in cell hues across the map. However, there are a few interesting element results, such as states with operating nuclear power plants or communities already serviced by a nuclear utility, proximity to existing transmission lines, available stream flow, and EPA nonattainment zone.

States with operating nuclear power plants or communities already served by a nuclear utility are compared in Fig. 10. All three shades of green combined are the equivalent of the green space shown in Fig. 9. The lightest-green area depicts area within states that meet all SMR SSEC but in which no current nuclear power plant exists. This includes Maine, Indiana, Kentucky, Oklahoma, Montana, Idaho, and Colorado. The medium green and dark green areas differentiate between nuclear and nonnuclear utilities 
within states that host nuclear power plants. A similar two-color map could easily be produced and scored for states with legislation that prohibits new nuclear power plant construction.

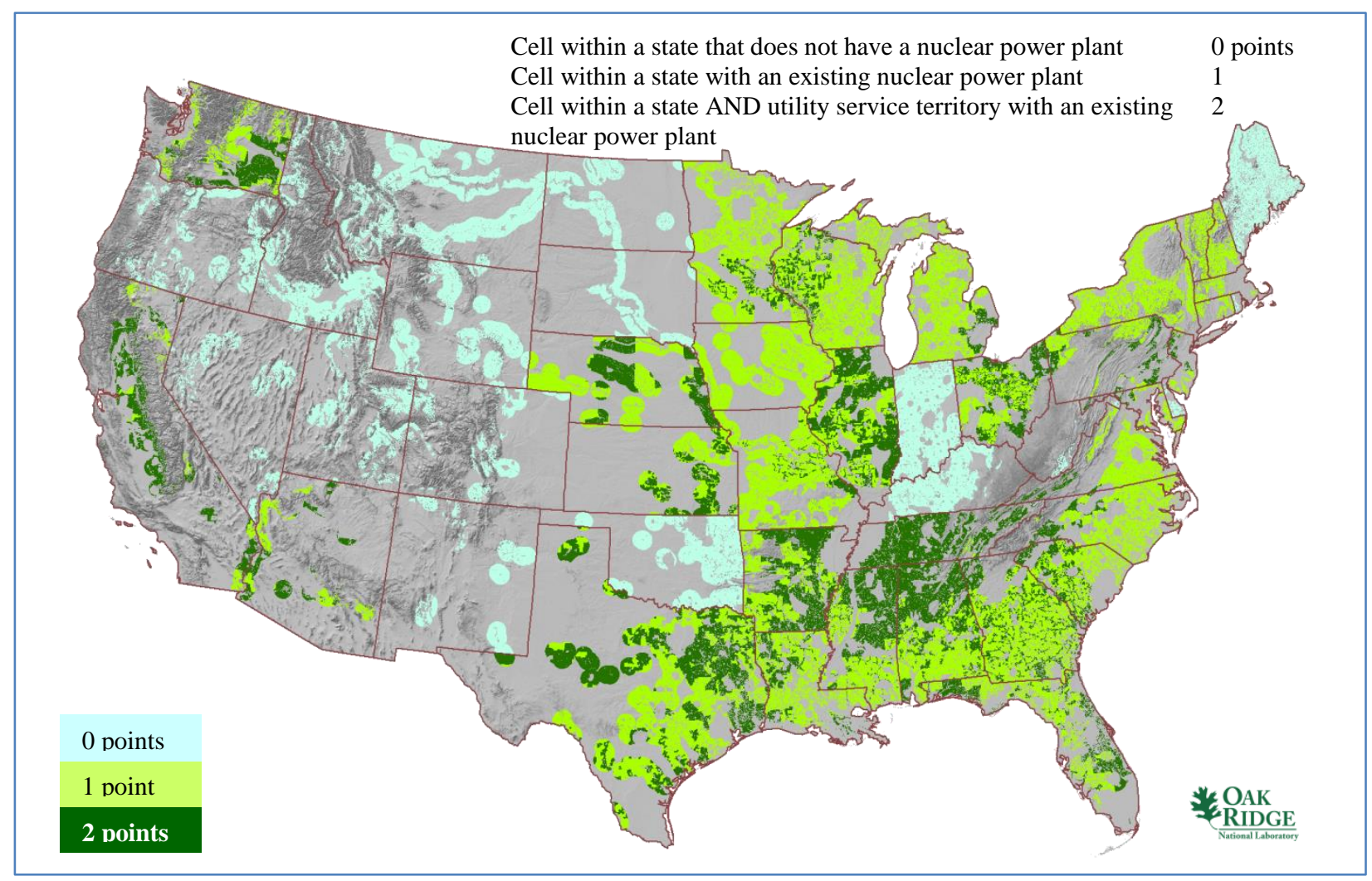

Fig. 10. SMR base map with comparison by presence of a nuclear power plant.

Proximity to existing power lines is compared on the SMR base map in Fig. 11. The transmission line data are taken from the Platt's power plant database. ${ }^{12}$ While existing transmission lines do not necessarily indicate additional available capacity, they do highlight existing transmission corridors. Areas in the lightest green hue would, in general, require longer transmission lines to be constructed as part of an SMR construction project. The map shows that in rural areas with good SMR site suitability coverage in states such as Montana, Mississippi, Alabama, and South Carolina, available transmission lines could be an issue. However, this scoring element by itself does not evaluate highly localized power needs that could be well served by an SMR installation close to the power demand.

The availability of the cooling water resource is representative of the potential for expanded power plant operations at a given site. A comparison of cooling water availability is provided in Fig. 12. The circular effect of the individual green shades reflects the 20-mile pumping distance allowed by this particular SMR SSEC. The cutoff for this SMR SSEC is actually set to at least 65,000 gpm stream flow under low flow conditions, so initially it would be expected that no green cells would take on a 0 -point value.

However, an allowance for cooling water is made for lakes and reservoirs that provide an average flow of 65,000 gpm. Therefore, the light green areas in Fig. 12 represent cooling from lakes and reservoirs. Such cooling would be the most prone to flux under drought or heavy use conditions. A complete explanation of the construction of the cooling water flow dataset is provided in a multiple-source electricity generation report prepared for EPRI. ${ }^{5}$

\footnotetext{
122012 Platt's Electrical Transmission Database.
} 


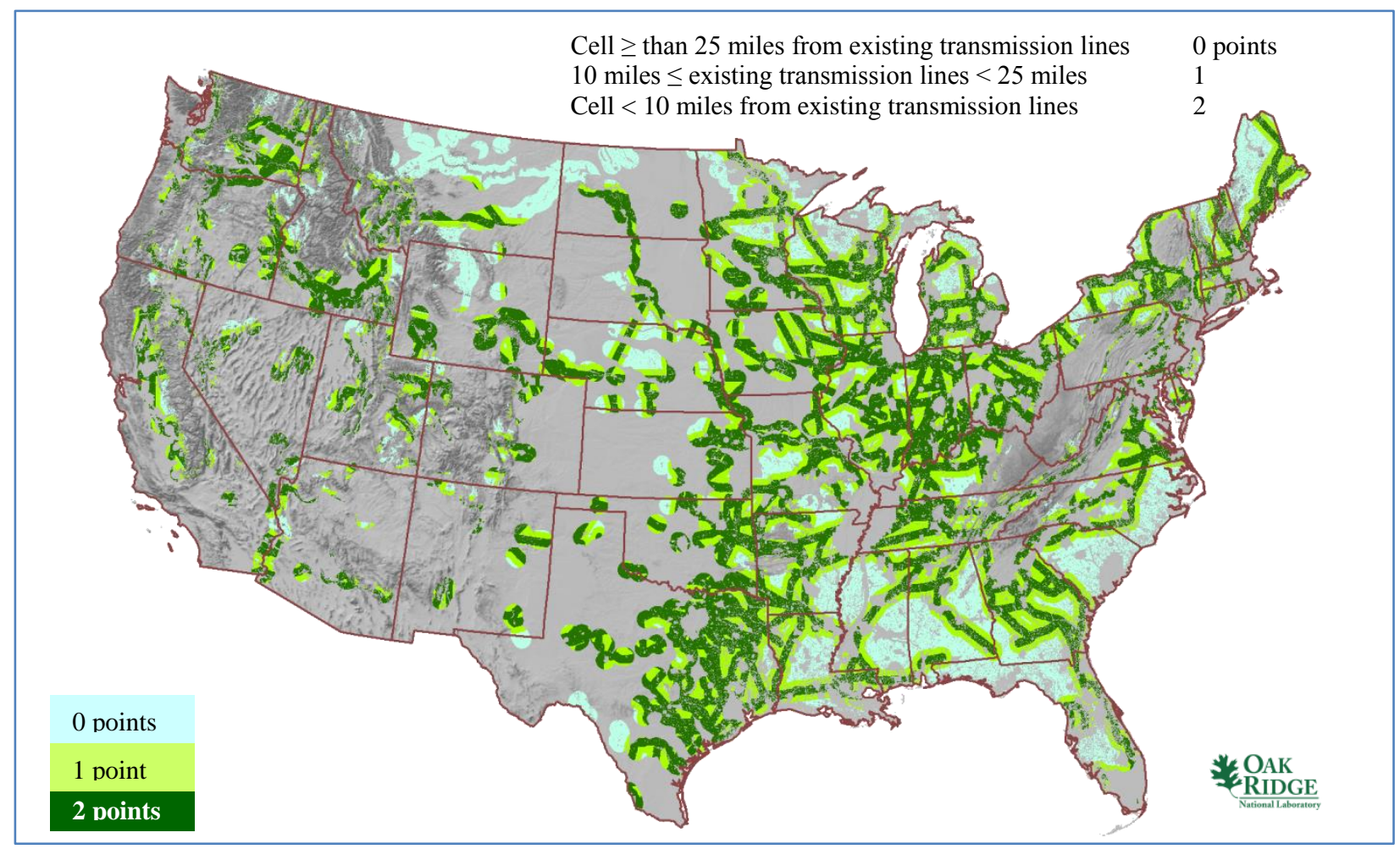

Fig. 11. SMR base map with comparison by proximity to existing transmission lines.

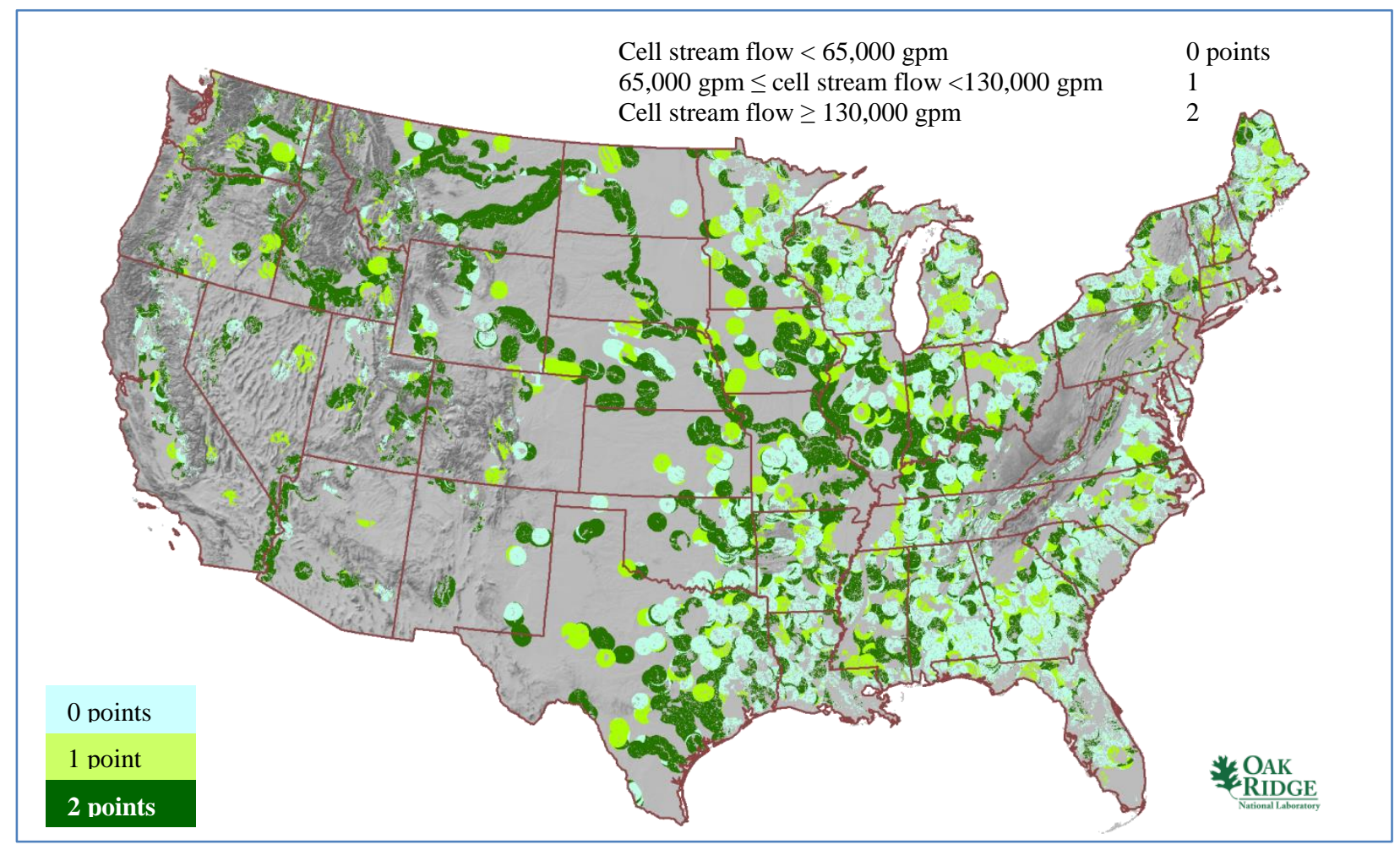

Fig. 12. SMR base map with comparison by available stream flow. 
SMR siting might be more preferential in areas that are within EPA nonattainment zones. The binary (two-color) comparison is shown in Fig. 13. Areas shown in the medium green color do not meet current EPA standards for ozone and particulate matter. This includes areas around many major cities and smogprone locations like the central California valley.

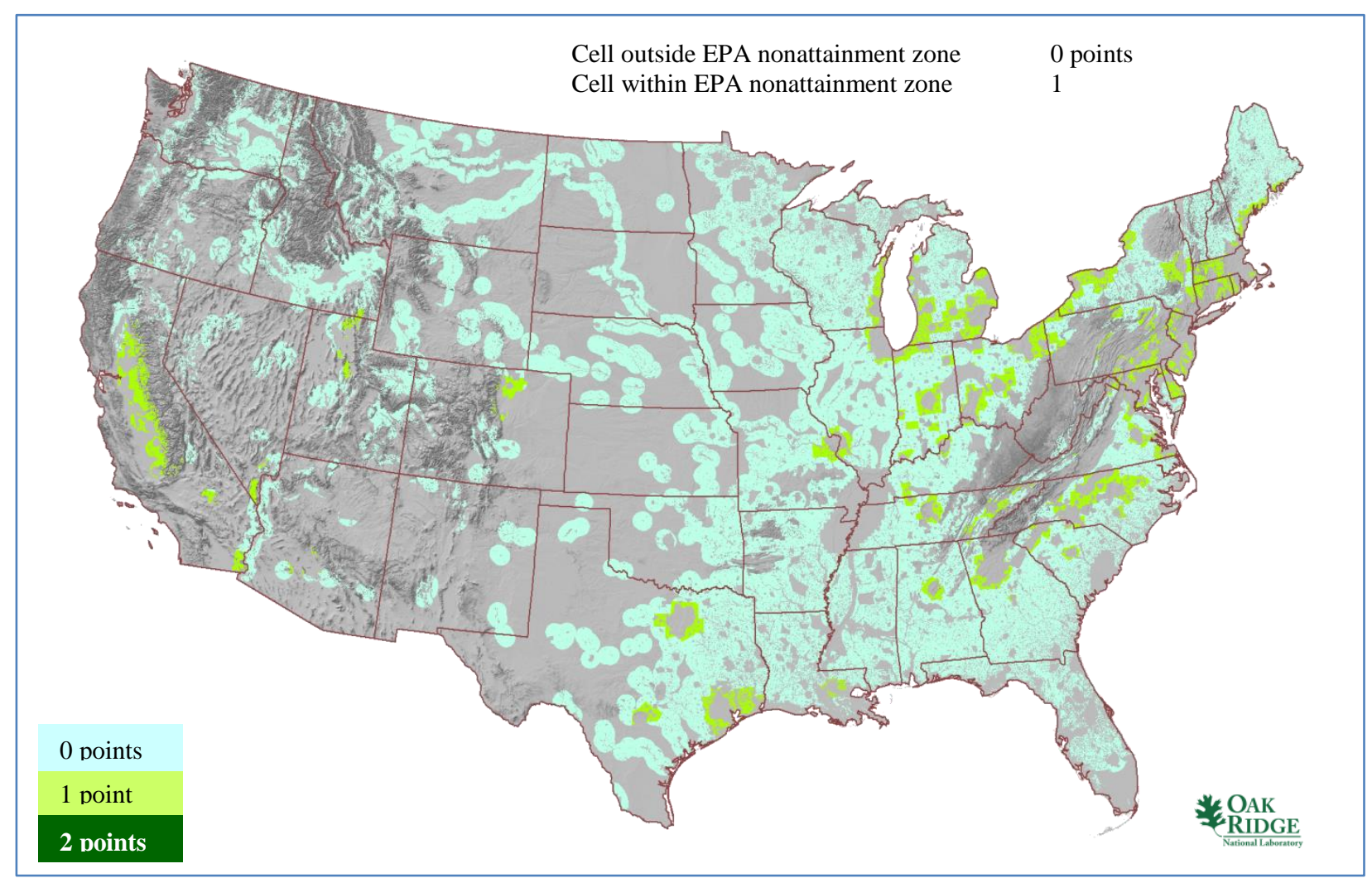

Fig. 13. SMR base map with comparison by EPA nonattainment zones.

The individual cell scores for all of the scoring elements for all of the green cells in Fig. 9 were added. The cells were then shaded similarly to the individual scoring element layers shown above, but based on the cumulative cell score. Green cell scores ranging from 4 to 9 points were shaded in a light green hue and assigned a "good" rating on a scale of good, better, or best. Green cell scores ranging from 10 to 11 points were shaded in a medium green hue and assigned a "better" rating. Finally, green cell scores ranging from 12 to 15 points were shaded in a dark green hue and assigned a "best" rating. The point ranges were selected based on the best differentiation of the three green hues over the entire map. The results are shown in Fig. 14.

Again, note that all three green hues meet all of the SMR siting criteria at the select set of values as documented in the first phase of this SMR site-screening study. ${ }^{1}$ The darkest green area represents $21.6 \%$ of the contiguous United States. This includes land in close proximity to major cities such as Chicago, Nashville, Atlanta, Dallas, and Houston. The medium green area represents $10.7 \%$ of the contiguous United States. This includes suitable land with tremendous water resources but less power demand, such as is seen in Montana. Land with an abundance of lakes and reservoirs also scored in the medium green or better category. This includes large areas within Wisconsin, Alabama, and Georgia. Finally, the lightest green area represents just $1.1 \%$ of the contiguous United States. Additional scoring elements could add greater differentiation. 


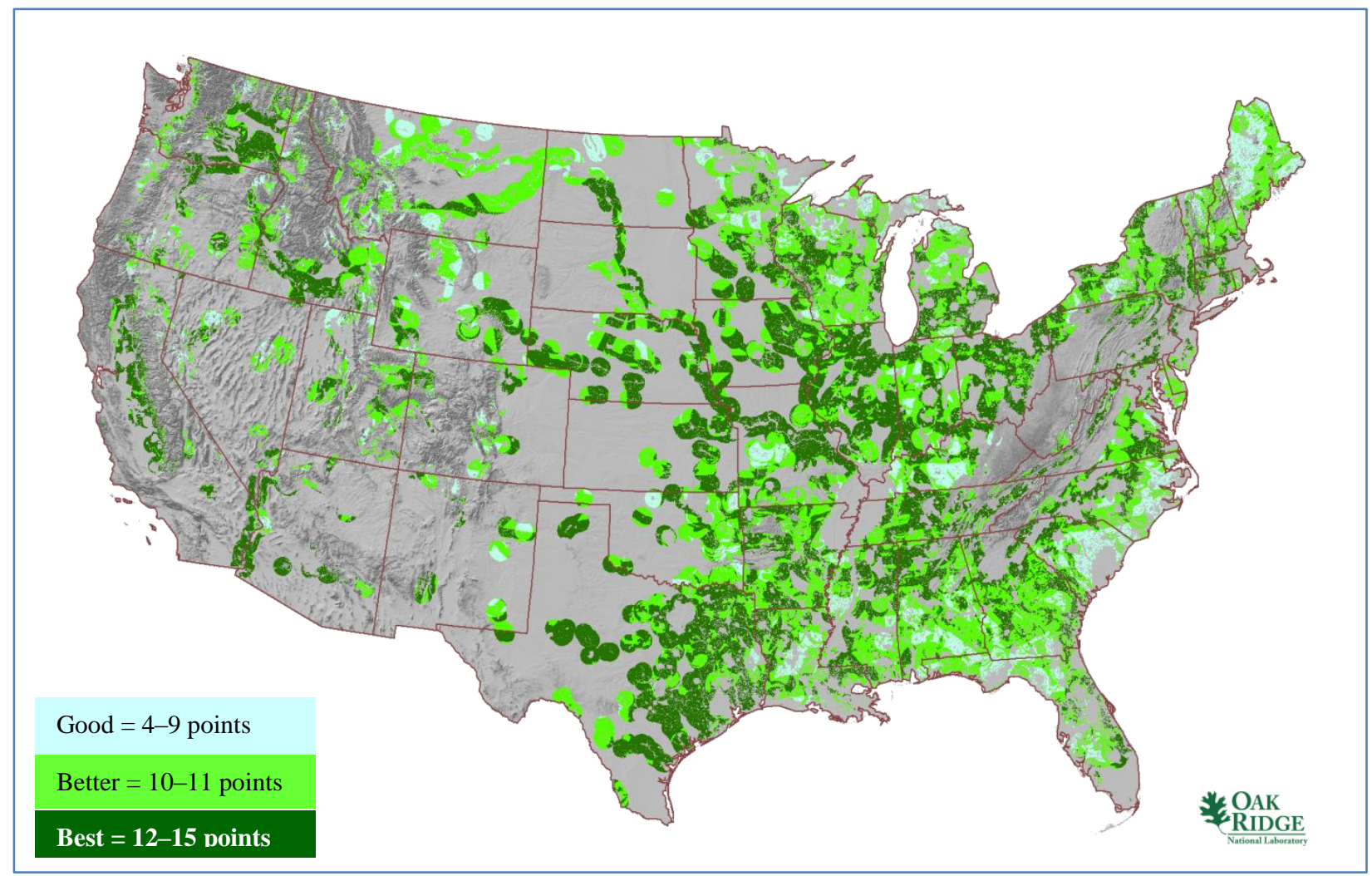

Fig. 14. SMR base map with cumulative scoring comparison.

Closer differentiation in the three color hues can be seen in the map detail of Georgia shown in Fig. 15. Most of Georgia meets all the SMR SSEC, as shown by the amassed shades of green on the map. The large exception is the Atlanta area and the sprawling suburban areas surrounding Atlanta. Significant dark green-colored cells surround Atlanta, indicating area with significant demands for power and land that meets all the SMR SSEC. Athens, Georgia, is east of Atlanta with a large area of dark green cells to the south of the city. Similarly, Savannah, Georgia, has a band of dark green cells just inland of the city. So although all the green hues meet all the SMR SSEC, the comparison methodology may help point to the best areas in which to search for a site to add power to the electrical grid using an SMR.

Therefore, the comparison methodology developed appears to be useful. Additional scoring elements could add even better differentiation. 


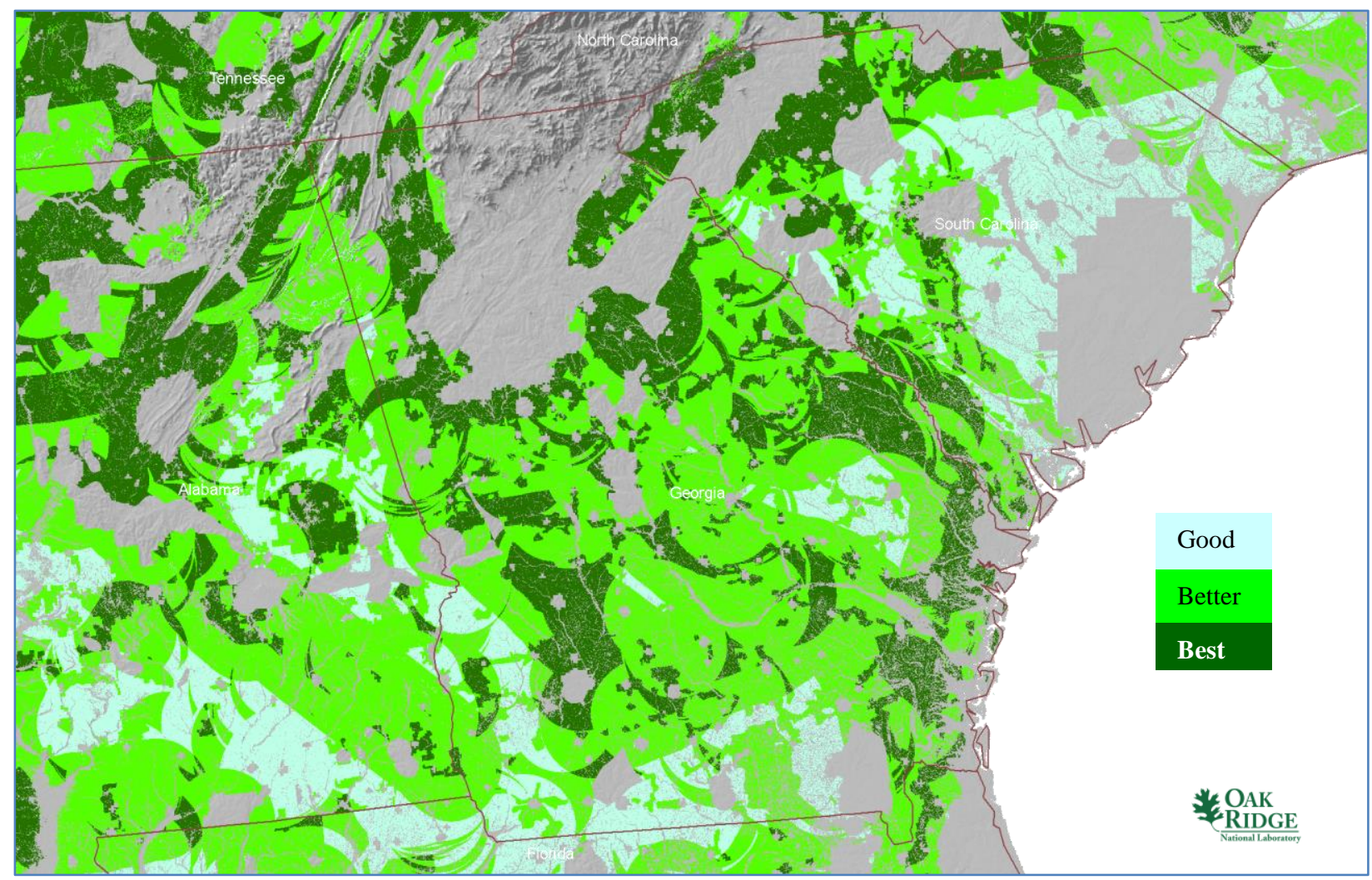

Fig. 15. SMR base map with cumulative scoring comparison centered on Georgia.

\subsection{Scoring Method Application Results_-Yellow Space}

Just over $41 \%$ of the contiguous United States failed to meet only one SMR SSEC at the select set of values documented in the first phase of this SMR site-screening study.1 This area is ripe for evaluation for areas where engineered solutions may best be applied to the single siting deficiency. Areas with a single SMR SSEC issue are shown in yellow in Fig. 2. The yellow area is extracted from Fig. 2 and shown separately in Fig. 16 below.

The same scoring process is applied to the yellow cells that was applied to the collective group of green cells shown in Fig. 9 (results for the green cells are shown in Fig. 14). In a similar fashion, the cells that met all the SMR SSEC except one were collectively compared with one another by binning these cells into low, medium, or high desirability bins. Note that no matter what bin a yellow cell is categorized in, all the yellow cells failed to meet one of the SMR siting criteria at the values specified. Therefore, there is no attempt to judge whether a yellow cell in the high category is somehow more favorable than a green cell in the good category. There is no overlap in area.

The individual cell scores for all of the scoring elements for all of the yellow cells in Fig. 16 were added. The cells were then shaded based on the cumulative cell score. Yellow cell scores ranging from 3 to 8 points were shaded in a light yellow hue and assigned a "low" rating on a scale of low, medium, and high. Yellow cell scores ranging from 9 to 10 points were shaded in an light orange hue and assigned a "medium" rating. Finally, yellow cell scores ranging from 11 to 15 points were shaded in a dark yellow hue and assigned a "high" rating. The point ranges were selected based on the best differentiation of the three yellow/orange hues over the entire map. The results are shown in Fig. 17. 


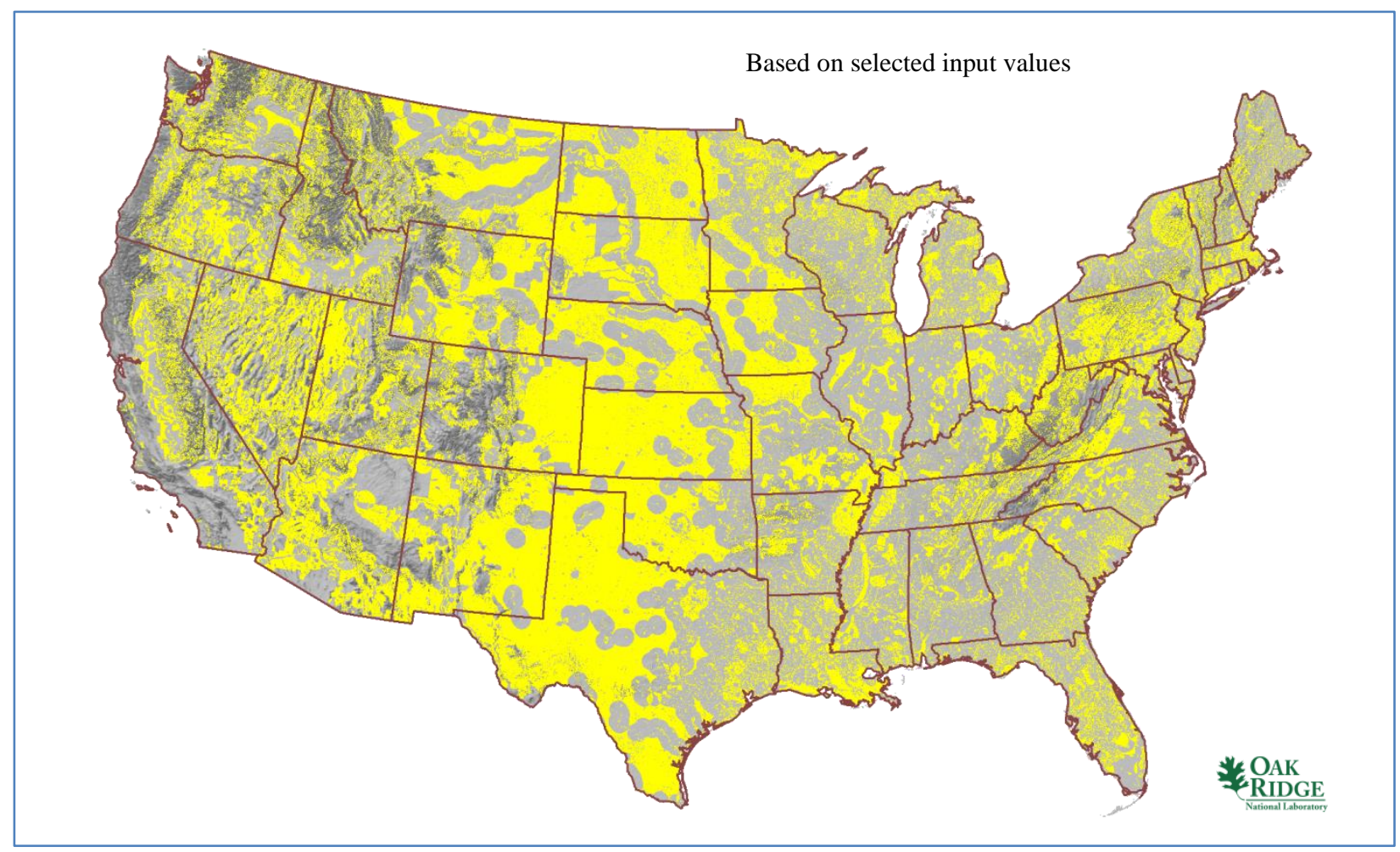

Fig. 16. Area with a single SMR SSEC siting issue.

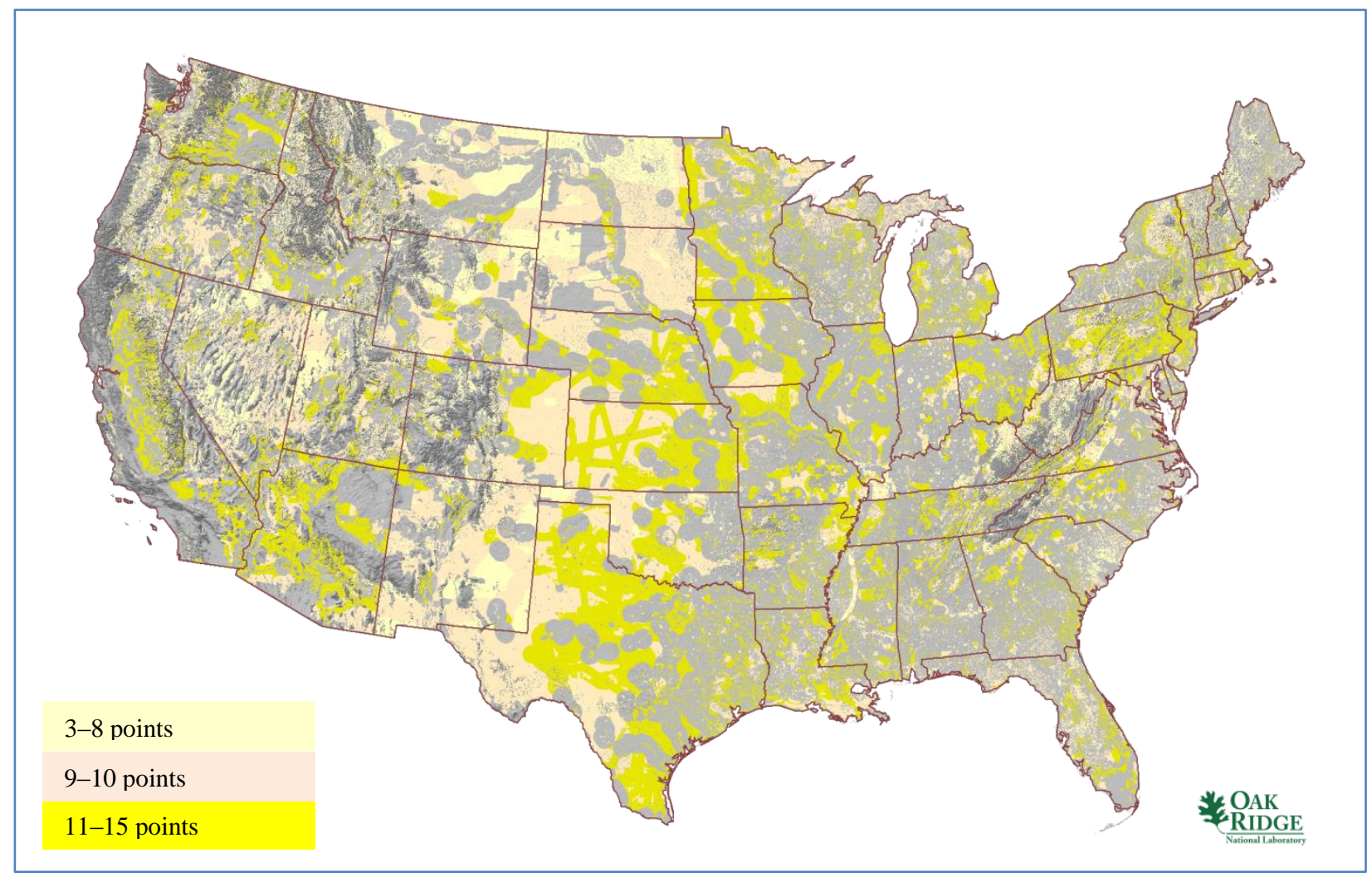

Fig. 17. Cumulative scoring comparison of area with a single SMR SSEC siting issue. 
The darkest yellow area represents $26 \%$ of the contiguous United States. This includes land along the western edge of significant green space in the central United States. The light orange area represents $14.1 \%$ of the contiguous United States. This includes considerable land to the east of the Rocky Mountains. Finally, just $1.1 \%$ of the contiguous United States is within the lightest yellow area. The cumulative score and coloration of the yellow cells does not provide an indication of the single SMR SSEC that was not met. This requires an analysis of the individual SMR SSEC. Much of the central section of the country is limited for SMR siting based on insufficient cooling water flow. If SMR designs that do not require cooling water were considered, much of this area would move to the "green" category and be compared with the previous green cells.

Consequently, the comparison methodology developed is useful for evaluating the areas with a single siting concern as well. Again, additional scoring elements could add even better differentiation. 



\section{SUMMARY}

Results from the analyses of these 34 sites demonstrate that OR-SAGE provides useful insights for evaluating options and challenges related to repowering coal plant sites with SMRs. Overall, 77\% (26 of 34 ) of the 34 sample plant sites meet multiple conventional standards for consideration of siting an SMR at one of the selected sample coal station sites. Conservatively extrapolating these results to the 148 "small" coal station master sample set, a total of 86 coal-fired electrical generating stations (58\%) could be predicted to have a favorable evaluation for repowering the station with an SMR. This should be evaluated further in greater detail. In addition, larger-capacity coal plant sites could be evaluated for the addition of SMRs as partial plant replacements or as plant expansions using the same evaluation process applied to the 34-plant "small station" sample set.

Los Alamos National Laboratory is building a national dataset of geological features including water table, bedrock, and unconsolidated sediment thickness and characteristics. The initial data gathering has focused on the Southeast. ${ }^{13}$ As this geological dataset is completed, national or regional evaluation criteria should be rolled into the SMR SSEC to allow further evolution of the SMR siting results.

The cell comparison methodology was developed independently of the evaluation of the 34 sample coal station site evaluations. Scoring is actually done on a cell-by-cell (100 by $100 \mathrm{~m})$ basis and is not specifically intended to rate sites that are typically larger than the approximately 2.5 acres represented by each cell. Although the scored cells that make up a site under evaluation could theoretically be added, the sample coal plants sites evaluated for this report are of varying acreage. However, although the evaluated coal plant sites are not a 2.5 acre pinpoint on the map, an overlay of the evaluated sites onto a cumulative scoring map can be informative, as shown in Fig. 18.

Yellow circles on Fig. 18 indicate the locations of the evaluated sites, although at a national scale it is difficult to make distinctions in much detail. A section of the cumulative scoring map centered on Georgia provides better differentiation between scored cells, as shown in Fig. 19. Six evaluated coal plant sites indicated by yellow circles are visible in Fig. 19. The site in northeastern Alabama is on land that did not meet all the SMR SSEC, and it was evaluated as not a likely candidate for consideration of siting an SMR. The remaining five sites were all evaluated as meeting multiple conventional standards for consideration of siting an SMR at a coal station location. Three of these sites are on dark green cells representative of land that is scored as the best of the areas that meet all SMR SSEC. One site is on medium green land that is scored as better, and one site is on light green land that is scored as good. All shades of green meet all SMR SSEC.

The initial scoring algorithm was intentionally kept simple by limiting the number of categories and scoring elements. As shown in Fig. 18, and supplemented in Fig. 19, reasonable differentiation among areas that meet all the SMR SSEC is possible. Similar differentiation among areas that meet all but one SMR SSEC is also possible. An expanded use of the scoring methodology providing a higher degree of discrimination should be evaluated using additional categories and elements from those listed in Sect. 3.2 or others. The results of such an expanded scoring system with better discrimination could possibly be used to recommend a small set of the most favorable coal-fired plant sites to be repowered with generation from SMRs.

\footnotetext{
${ }^{13}$ F. Perry, R. Middleton, R. Kelley, “Report on Subsurface Siting Factors for Small Modular Reactors,” LA-UR-13-21943, Los Alamos National Laboratory, March 2013.
} 


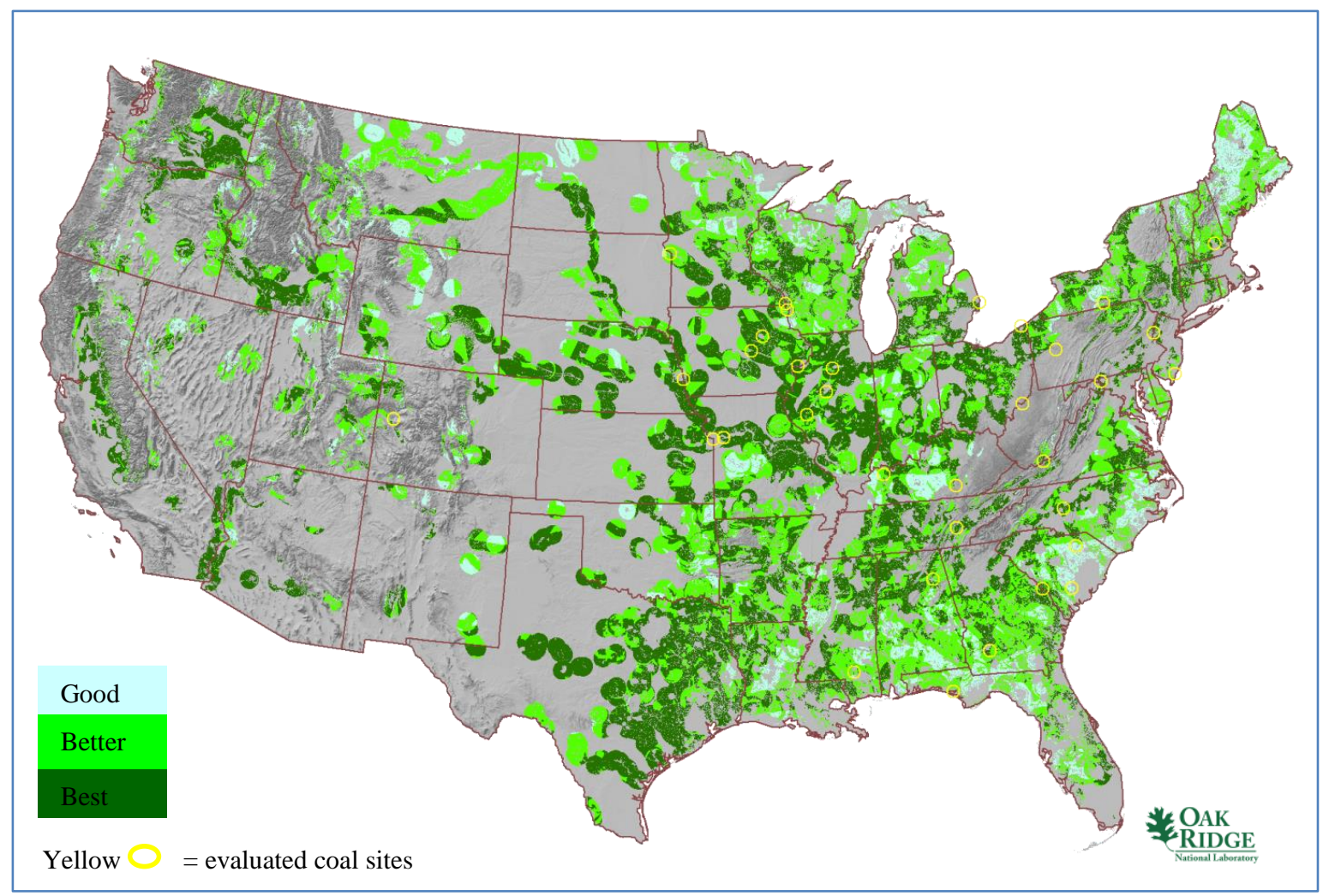

Fig. 18. Evaluated coal sites overlaid on scored map.

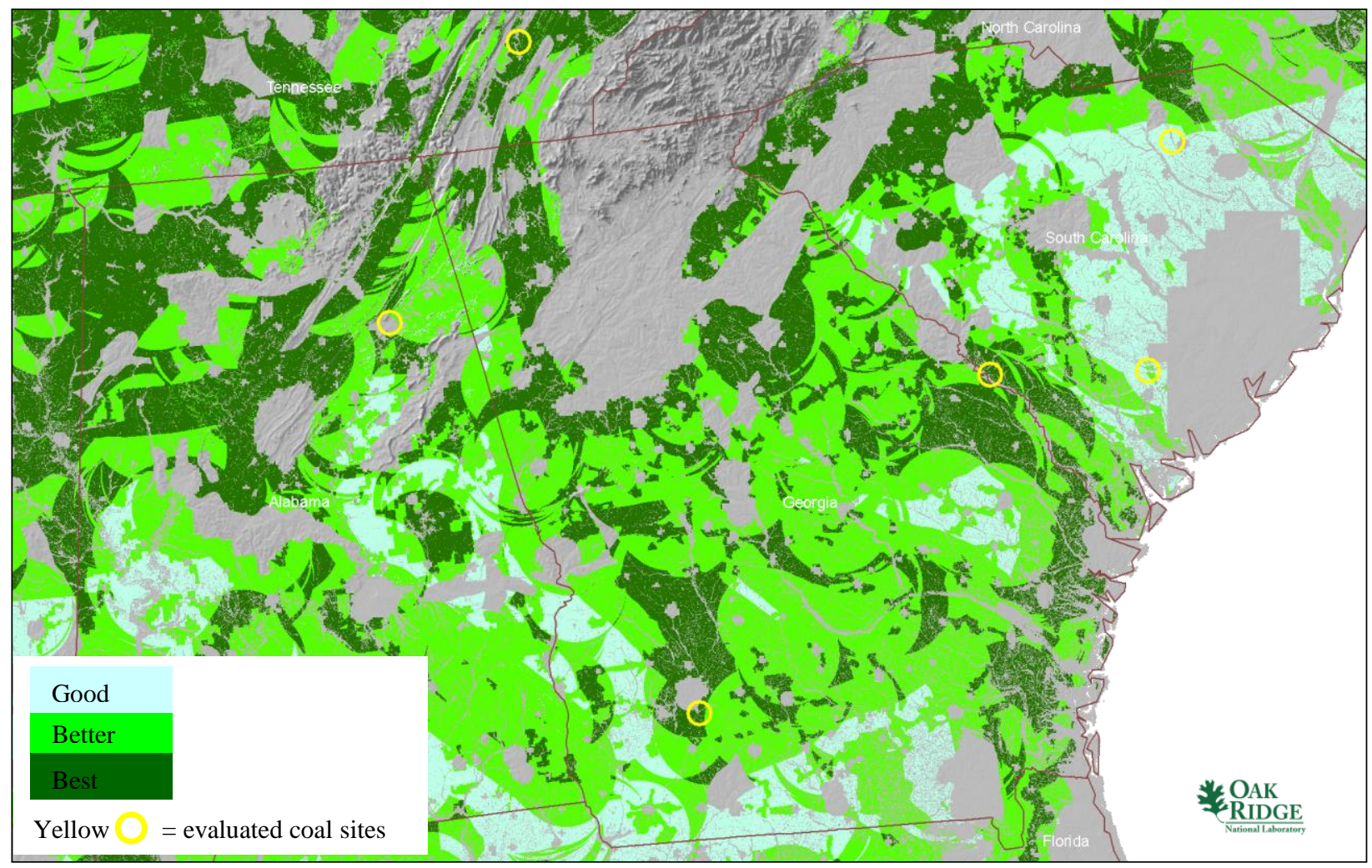

Fig. 19. Evaluated coal sites overlaid on southeastern section of scored map. 


\section{APPENDIX A—COAL PLANT EVALUATIONS OF MOST FAVORABLE SITES}

The site meets multiple conventional standards for consideration of siting an SMR at the coal station location. There are no current or near-term foreseeable SMR SSEC siting issues that should preclude this site from further SMR siting consideration.

Coal stations evaluated in this category are

- Big Stone Power Plant

- Buck Steam Station

- Canadys Station

- Glen Lyn Plant

- H.B. Robinson Steam Electric Plant

- Hennepin Power Station

- Lansing Generating Station

- Plant Mitchell Power Station

- R.D. Morrow Generating Station

- Robert Reid Power Station

- Savannah River Site Power Station

- Watts Bar Fossil Plant 



\section{APPENDIX A —COAL PLANT EVALUATIONS OF MOST FAVORABLE SITES}

\section{A.1 BIG STONE POWER PLANT}

\section{A.1.1 Location Detail}

As shown in Fig. A.20, the Big Stone Power Plant is located in northeastern South Dakota just west of the border with Minnesota. More specifically, the plant is located on the shores of Big Stone Lake, in Grant County, South Dakota. Highway 12 is within 2 miles southwest of the plant. Interstate 29 is available 24 miles west of the plant. Rail access is available onsite within 0.1 miles of the plant; barge access is not available. The closest towns are Big Stone City, South Dakota, which is 2.5 miles southeast of the plant, and Ortonville, Minnesota, which is 3.25 miles east of the plant just across the lake. Big Stone City has a population of fewer than 500 people and Ortonville has a population of approximately 1,916 people. The county seat, Milbank, South Dakota, is less than 9 miles southwest of the plant. The nearest city with a population in excess of 10,000 people is Watertown, South Dakota, which is approximately 42 miles to the southwest of the Big Stone Power Plant.

- Plant: Big Stone Power Plant

- Utility: Otter Tail Power Company

- Coordinates: lat. $45.30463^{\circ} \mathrm{N}$, long. $96.51123^{\circ} \mathrm{W}$

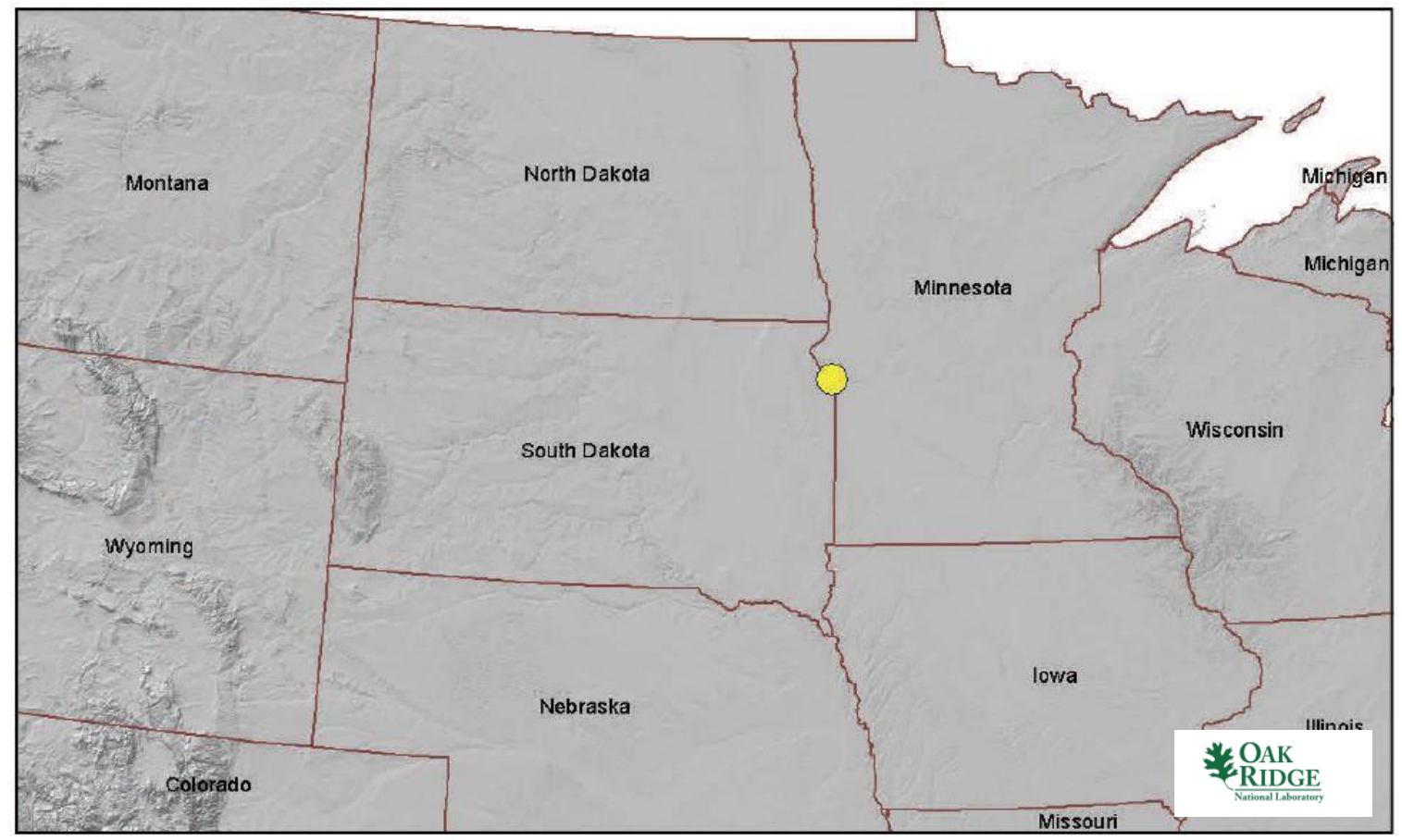

Fig. A.20. Big Stone Power Plant location map.

\section{A.1.2 Site Description and Status}

The Big Stone Power Plant is a single-unit coal station operated by Otter Tail Power Company, a subsidiary of the Otter Tail Corporation. Big Stone Power Plant generates about $456 \mathrm{MW}(\mathrm{e})$. Cooling is provided by an onsite cooling water pond. Big Stone Power Plant began commercial operation in 1975. The Otter Tail Corporation intends to install pollution control equipment to meet stricter EPA standards and continue coal-fired operation at the Big Stone Plant site. 
The plant is situated on roughly 1,500 acres approximately 130 miles west of the $600 \mathrm{MW}(\mathrm{e})$ Monticello nuclear facility. The plant is 71 miles south of the $129 \mathrm{MW}(\mathrm{e})$ coal-fired Hoot Lake Plant and 72 miles west of the 22 MW(e) coal-fired Willmar plant. The 493 MW(e) Big Bend Dam hydroelectric project is about 170 miles southwest of the Big Stone Power Plant. Numerous wind energy projects exist or are planned for Eastern South Dakota.

As noted in Table A.1, the nearest major fault line based on USGS data is 407 miles west in Montana. The maximum safe-shutdown earthquake for the site is less than $0.3 \mathrm{~g}$ peak ground acceleration. More than 500,000 gpm of cooling water makeup is available from the Minnesota River about 3 miles away.

The permanent population within 1 mile of the plant is fewer than 500 people, yielding a population density of fewer than 160 people per square mile. The permanent population within 10 miles of the plant is approximately 24,500 people, yielding a population density of about 78 people per square mile.

According to the US EPA Environmental Justice website, there are 3,147 occupied housing units within 10 miles of the plant site based on 2000 US Census data. Further, over $77 \%$ of area adults over age 25 have a high school diploma or higher education. The median annual income for the area is between $\$ 25 \mathrm{~K}$ and $\$ 50 \mathrm{~K}$.

Table A.1. Big Stone Power Plant site statistics

\begin{tabular}{|l|l|l|l|}
\hline $\begin{array}{l}\text { Population } \\
\text { Population Within }\end{array}$ & \multicolumn{2}{l|}{$\begin{array}{l}\text { Utility } \\
\text { Distance to Grid Capacity }\end{array}$} \\
\hline $0.5 \mathrm{mi}$ & $<500$ & $>400 \mathrm{MWe}$ & $\sim 37 \mathrm{mi}$ \\
\hline $1 \mathrm{mi}$ & $\sim 500$ & $>800 \mathrm{MWe}$ & $\sim 121 \mathrm{mi}$ \\
\hline $5 \mathrm{mi}$ & $\sim 9,400$ & $>1600 \mathrm{MWe}$ & $\sim 156 \mathrm{mi}$ \\
\hline $10 \mathrm{mi}$ & $\sim 24,500$ & $>3200 \mathrm{MWe}$ & $\sim 445 \mathrm{mi}$ \\
\hline Nearest City with Population & Distance to Cooling Water \\
\hline$>10,000$ & Watertown, SD & $>50,000$ gpm & $\sim 3.0$ mi (Minnesota River) \\
\hline$>50,000$ & Fargo, ND & $>100,000$ gpm & $\sim 3.0 \mathrm{mi}$ (Minnesota River) \\
\hline$>100,000$ & Sioux Falls, SD & $>200,000$ gpm & $\sim 3.0$ mi (Minnesota River) \\
\hline$>500,000$ & Milwaukee, WI & $>500,000$ gpm & $\sim 3.0$ mi (Minnesota River) \\
\hline Geotechnical & & Accessilbility & \\
\hline Max Earthquake Acceleration & $<0.3 \mathrm{~g}$ & Distance to Major Roadway & $\sim 1.8 \mathrm{mi}$ (US 12) \\
\hline Max Slope & $\sim 10 \%$ & Distance to Water Transport & $\sim 117$ mi (Mississippi River) \\
\hline Nearest Fault Line & $\sim 407 \mathrm{mi}$ (Montana) & Distance to Rail Transport & $\sim 0.1 \mathrm{mi}$ (PVTX) \\
\hline Nearest Hazard Site & $\sim 106$ mi (Airport- & Distance to Airport & $\sim 106$ mi (Hector Int'1) \\
\hline
\end{tabular}




\section{A.1.3 Aerial Imagery}

The aerial imagery in Fig. A.21 indicates that there are no interstate runs within 1.0 mile of the Big Stone Power Plant site.

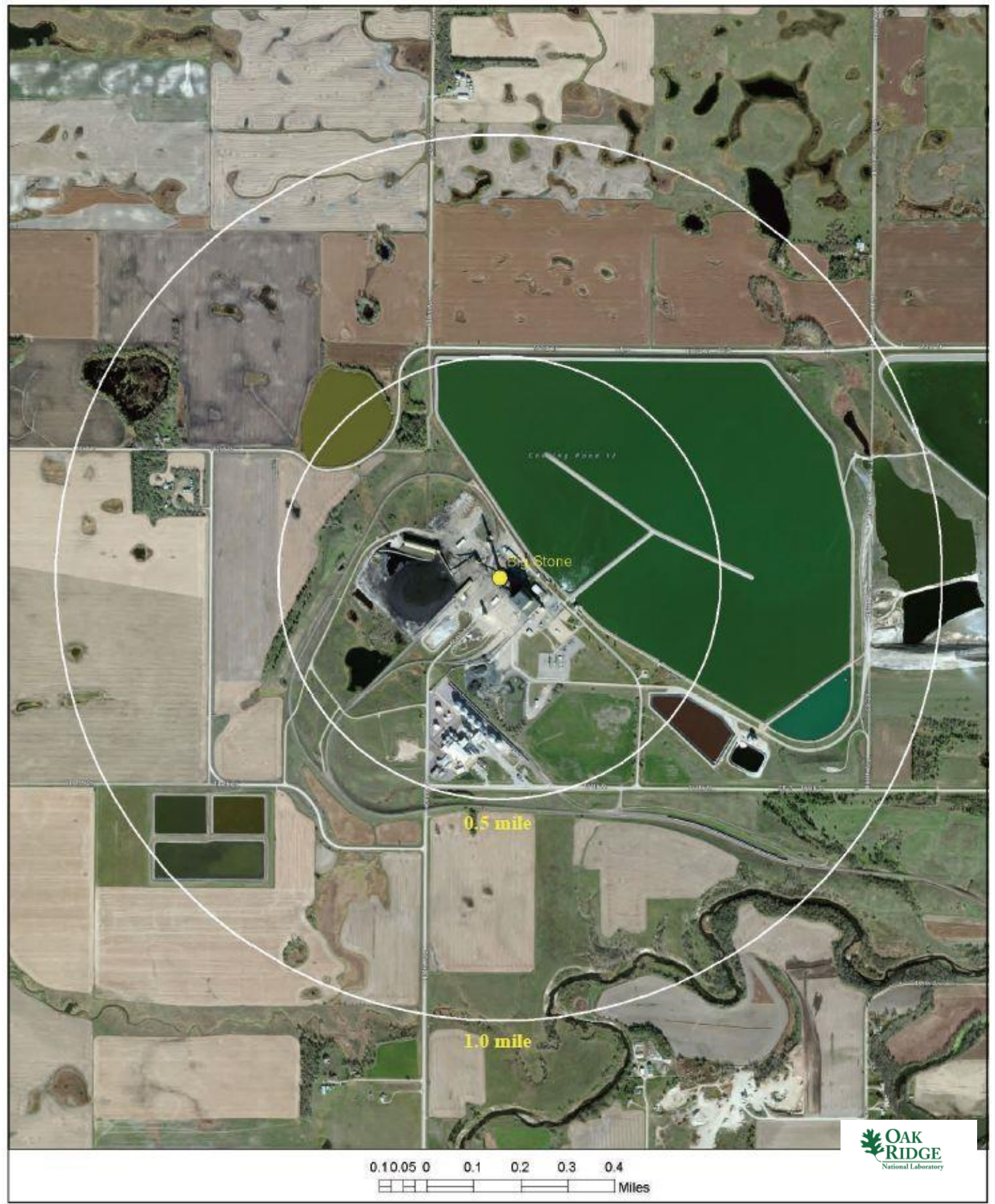

Fig. A.21. Satellite view of Big Stone Power Plant proximity. 


\section{A.1.4 Screening Criteria Overview}

Table A.2. Big Stone Power Plant siting criteria summary

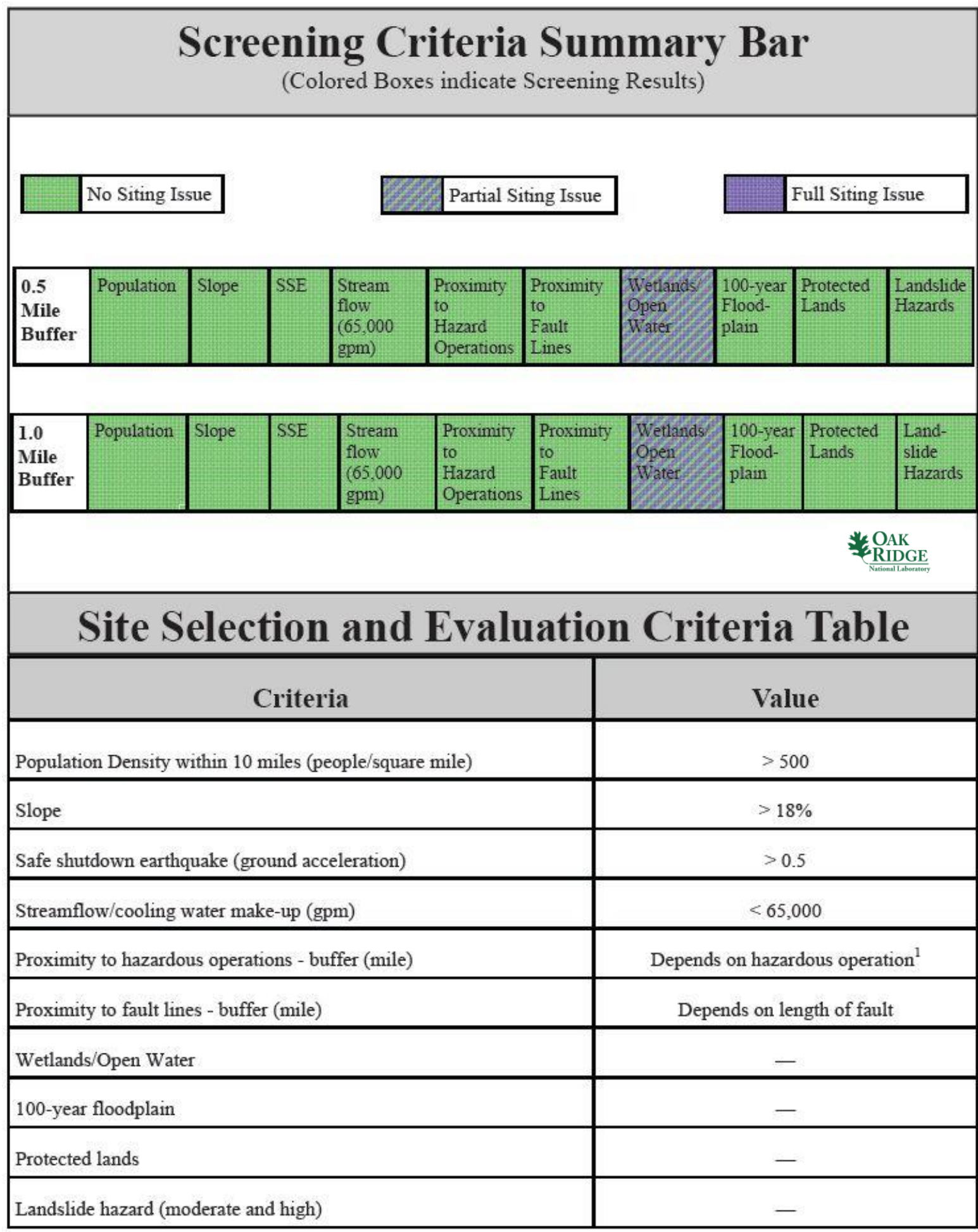

${ }^{1}$ Hazardous facilities (airports -5 miles and oil refineries -1 mile) 


\section{A.1.5 Composite Map and Individual Siting Issue Maps}

A composite map of SMR siting challenges to the Big Stone Power Plant is shown in Fig. A.22. The physical plant structures are located on land with one siting issue. Following this map are maps of the individual SMR siting criteria based on selected input values.

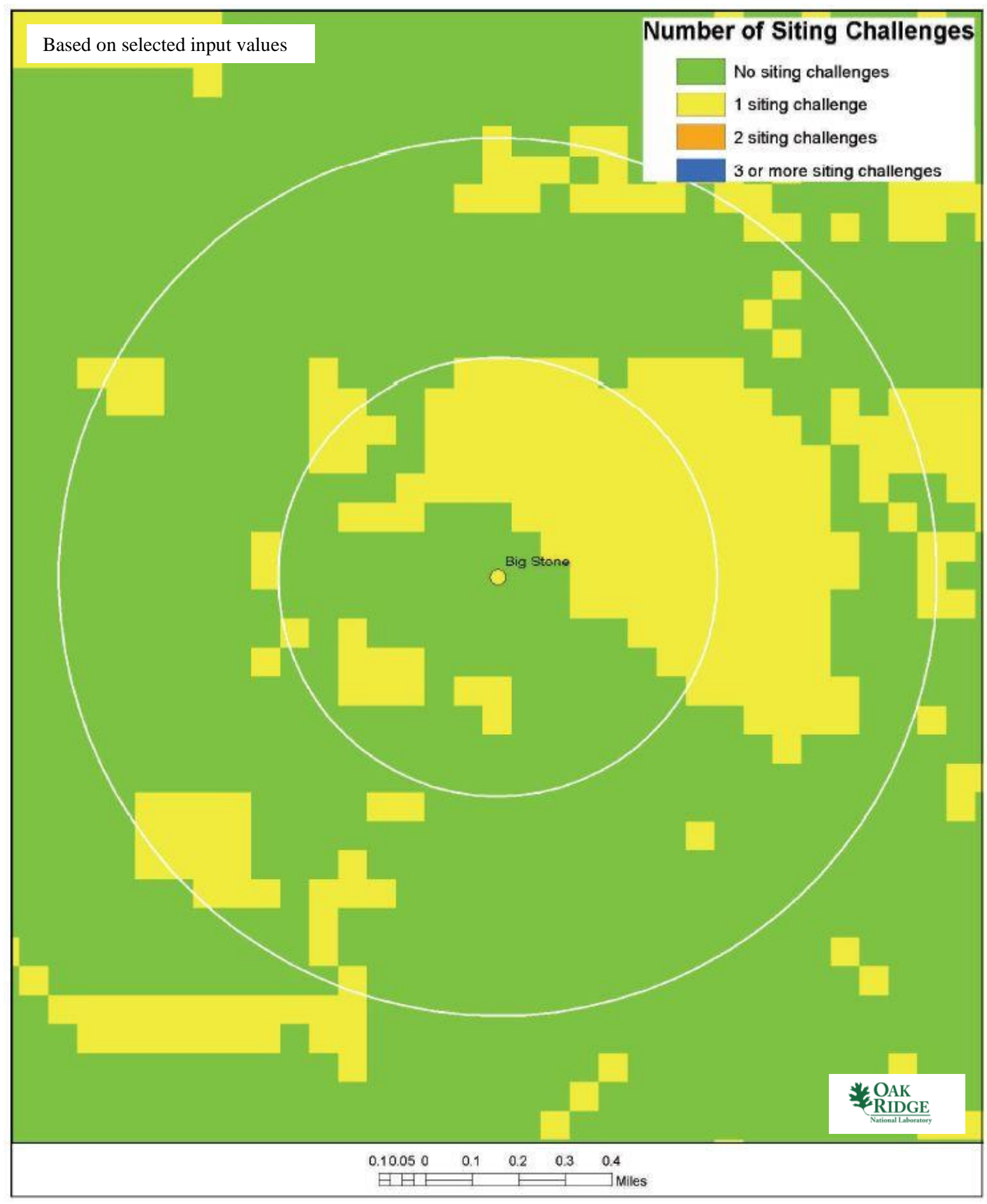

Fig. A.22. Big Stone Power Plant composite map. 

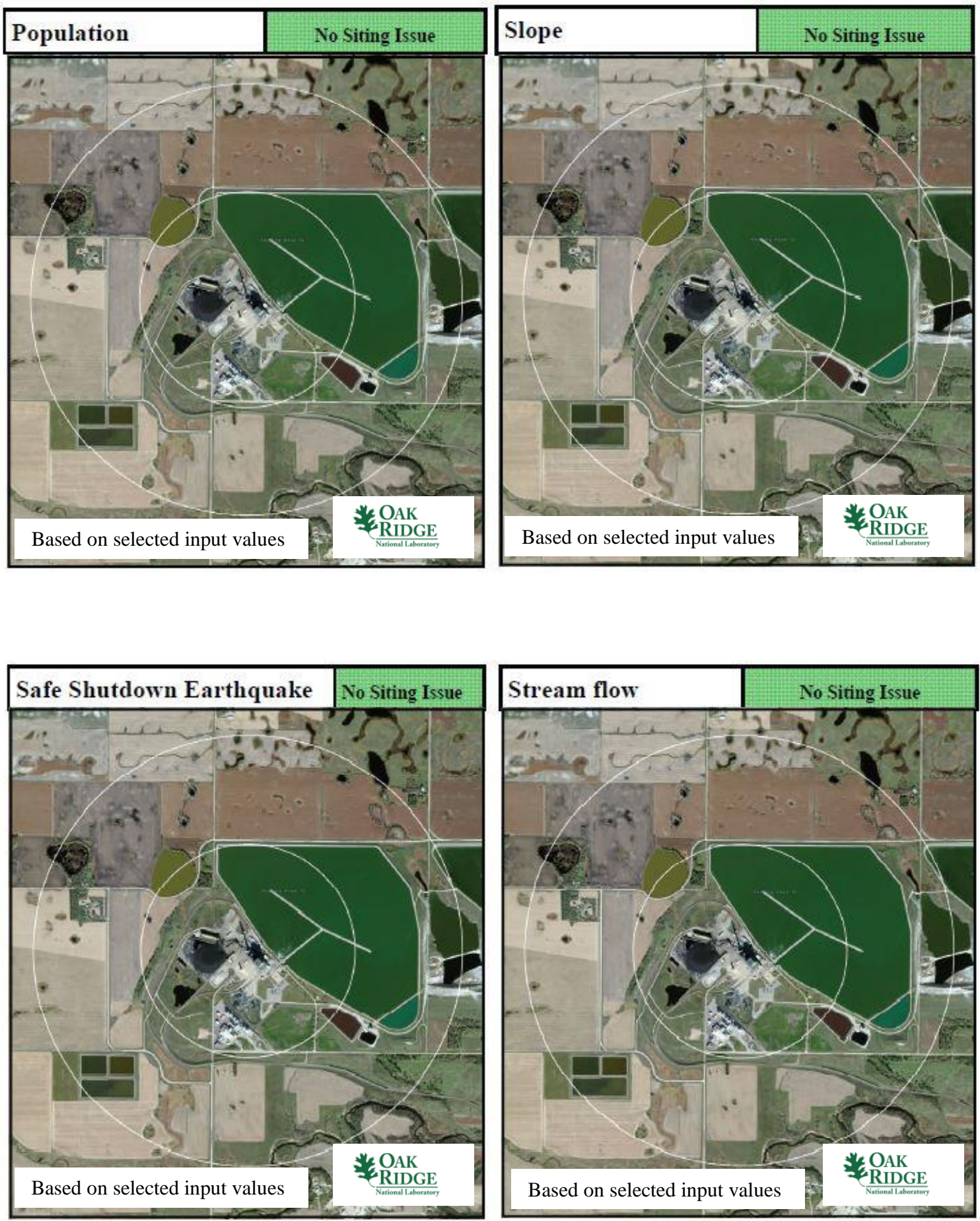

Big Stone Power Plant 

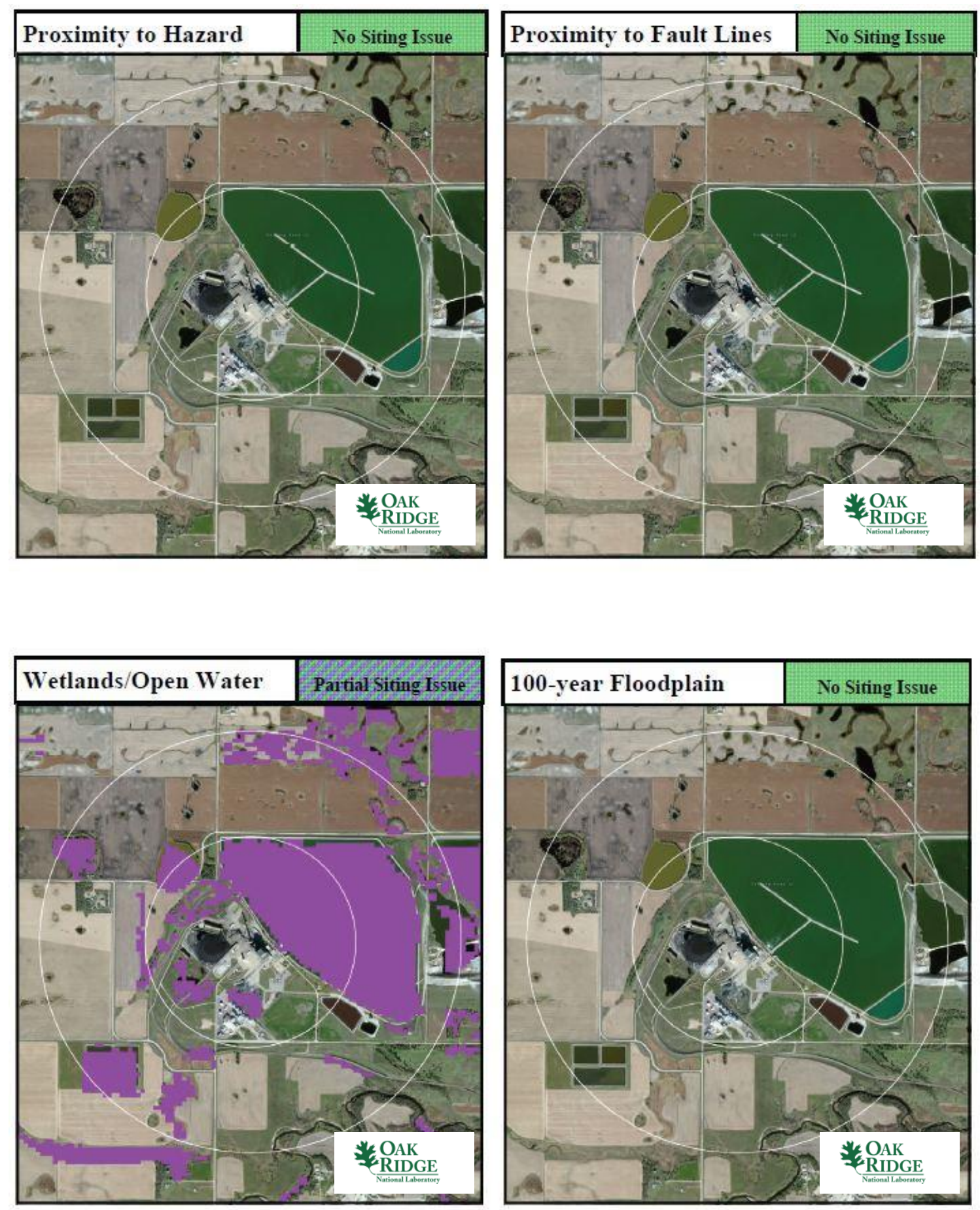

Big Stone Power Plant 

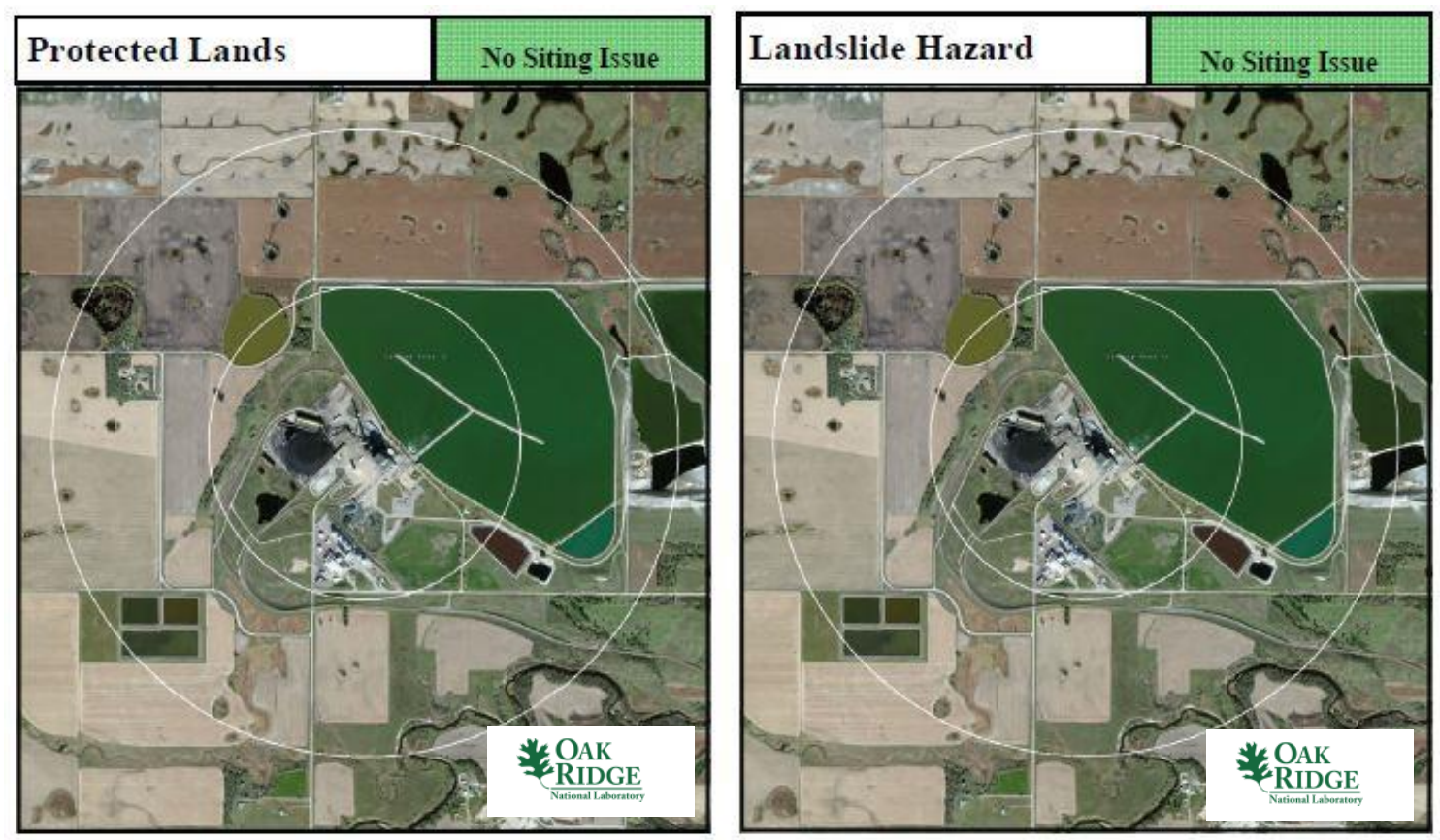

Big Stone Power Plant

\section{A.1.6 Site Evaluation}

Otter Tail Power Company does not operate or own a share of any nuclear power plants in the United States. Therefore, the utility would need to be mentored through the licensing process to build and operate an SMR. Additionally, there are numerous other electric power generation facilities within 100 miles of the Big Stone Power Plant to subsidize area power requirements. The site contains sufficient acreage to support siting an SMR.

From an environmental justice perspective, the community collectively appears to have achieved a reasonable level of education with median income levels typical of much of the United States. Therefore, siting an SMR at this location would not seem to be disenfranchising a less-educated or poverty-stricken community. Furthermore, the education level of the Big Stone Power Plant community would seem to support the higher-technology job opportunities provided by an SMR.

As shown in Sects. A.0 and A.0, the Big Stone Power Plant site has a partial SMR site screening issue with wetlands/open waters. The wetlands/open waters issue is due strictly to the facility cooling pond and what is likely an ash pond further east of the site. There appears to be no threat to the plant site from these ponds. Given that the rated thermal output of the existing coal plant matches well with various iPWR designs, the existence of a separate cooling pond is actually a benefit. The remaining SMR site screening criteria are met site-wide for the values established in the updated SMR siting report.1

Therefore, when future load demands indicate the need for expanded generation capacity in this region or environmental concerns dictate removing the Big Stone Power Plant from the grid, the utility could make the case for siting an SMR at this location. The site appears reasonably isolated, and it meets NRC RG 4.7 recommendations for population density without additional consideration for relaxed SMR population siting requirements based on reduced source term. The Big Stone Power Plant site meets multiple conventional standards for consideration of siting an SMR at the coal station location. There are no current or near-term foreseeable SMR SSEC siting issues that should preclude this site from further SMR siting consideration. 


\section{A.2 Buck Steam Station}

\section{A.2.1 Location Detail}

As shown in Fig. A.23, the Buck Steam Station is located in the middle of North Carolina, off Dukeville Road, in Rowan County. Interstate 85 is accessible less than 1 mile to the west. Rail access is available within 0.4 miles and barge access is available 92 miles to the southeast via the Cape Fear River. The closest town is Spencer, North Carolina, with a population of approximately 3,400 people. Spencer is approximately 6 miles southwest of the Buck Steam Station. The nearest city with a population in excess of 10,000 people is Salisbury, North Carolina, approximately 6.4 miles to the southwest of the Buck Steam Station.

- Plant: Buck Steam Station

- Utility: Duke Energy

- Coordinates: lat. $35.71348^{\circ} \mathrm{N}$, long. $80.37664^{\circ} \mathrm{W}$

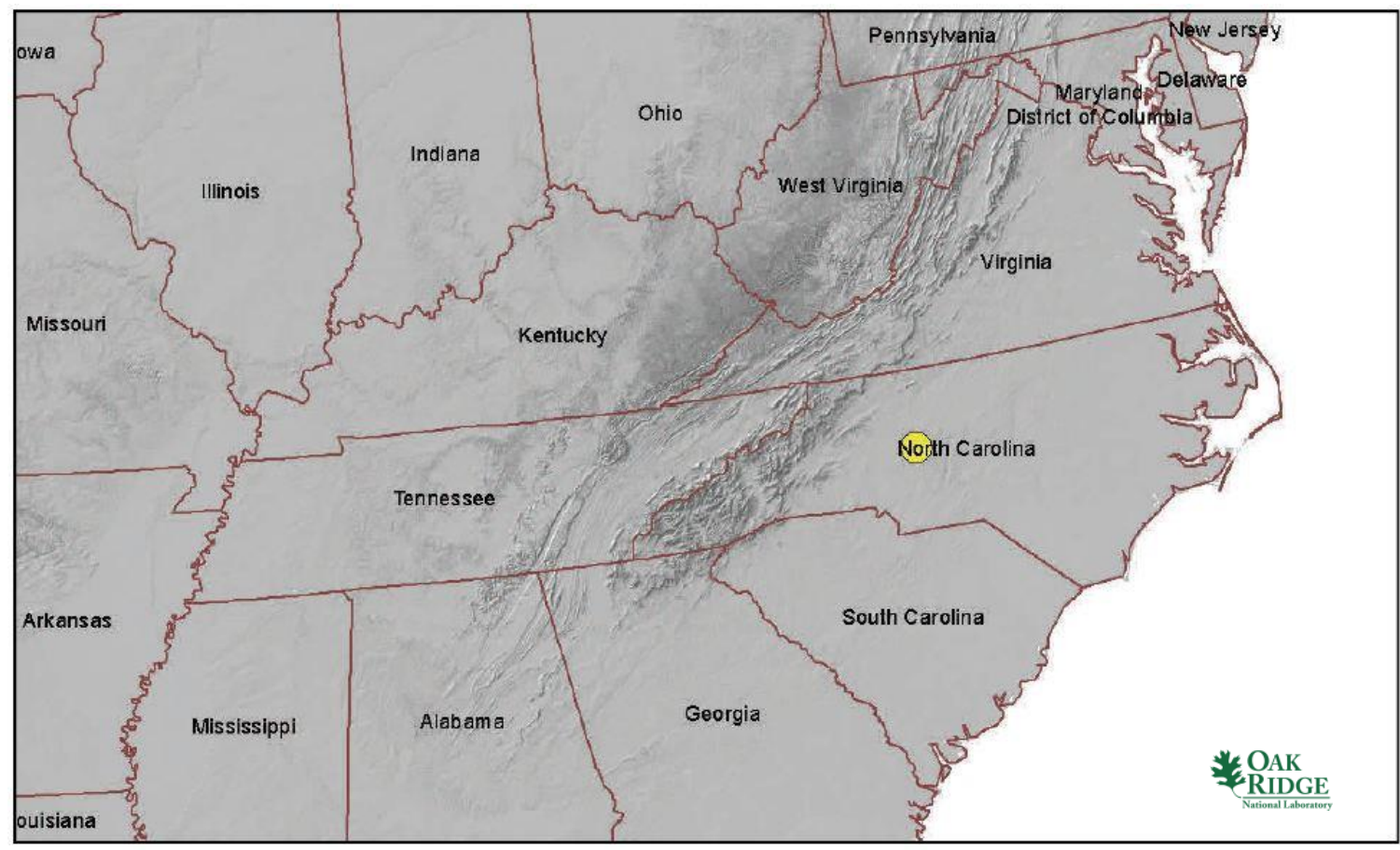

Fig. A.23. Buck Steam Station location map.

\section{A.2.2 Site Description and Status}

The Buck Steam Station is a 6-unit coal station along with a natural-gas fired combined cycle plant. Units 1 and 2 were retired in 1981. Units 3 and 4 were retired in mid-2011. Units 5 and 6, both commissioned in 1953, are operating at $125 \mathrm{MW}(\mathrm{e})$ each for a current station coal capacity of $250 \mathrm{MW}(\mathrm{e})$. These units are cooled by mechanical draft cooling. At its peak, the coal plants at the Buck Steam Station generated 440 MW(e). The first unit at the Buck Steam Station started in commercial operation in October 1926. The natural gas facility, rated at $620 \mathrm{MW}$ (e), began operation in late 2011. In addition, three gas-fired combustion turbines have been operated at the site but were shut down in 2012. The site is a key power generation location for Duke Energy.

The plant is situated on roughly 240 acres on the Yadkin River approximately 38 miles northeast of the 2,200 MW(e) McGuire nuclear facility and 80 miles west of the 900 MW(e) Shearon Harris nuclear 
facility. The Buck Steam Station is 34 miles north of the coal-fired 1,996 MW(e) Marshall Steam Station and 43 miles south of the coal-fired 2,160 MW(e) Belews Creek Steam Station. In addition, the 350 MW(e) Cowans Ford Dam hydroelectric project is 38 miles to the southeast.

As noted in Table A.8, the nearest major fault line based on USGS data is 957 miles west in Oklahoma. The maximum safe-shutdown earthquake for the site is below $0.3 \mathrm{~g}$ peak ground acceleration. More than $500,000 \mathrm{gpm}$ of cooling water makeup is available from the adjacent Yadkin River.

The permanent population within 1 mile of the plant is approximately 1,100 people, yielding a population density of about 350 people per square mile. The permanent population within 10 miles of the plant is approximately 202,000 people, yielding a population density of approximately 643 people per square mile. According to the US EPA Environmental Justice website, there are 37,592 occupied housing units within 10 miles of the plant site based on 2000 US Census data. Further, approximately $73 \%$ of area adults over age 25 have a high school diploma or higher education. The median annual income for the area is between $\$ 25 \mathrm{~K}$ and $\$ 50 \mathrm{~K}$.

Table A.8. Buck Steam Station site statistics

\begin{tabular}{|l|l|l|l|}
\hline $\begin{array}{l}\text { Population } \\
\text { Population Within }\end{array}$ & \multicolumn{2}{l|}{$\begin{array}{l}\text { Utility } \\
\text { Distance to Grid Capacity }\end{array}$} \\
\hline $0.5 \mathrm{mi}$ & $<500$ & $>400 \mathrm{MWe}$ & $\sim 21 \mathrm{mi}$ \\
\hline $1 \mathrm{mi}$ & $\sim 1,100$ & $>800 \mathrm{MWe}$ & $\sim 11 \mathrm{mi}$ \\
\hline $5 \mathrm{mi}$ & $\sim 35,000$ & $>1600 \mathrm{MWe}$ & $\sim 32 \mathrm{mi}$ \\
\hline $10 \mathrm{mi}$ & $\sim 202,000$ & $>3200 \mathrm{MWe}$ & $\sim 68 \mathrm{mi}$ \\
\hline Nearest City with Population & Distance to Cooling Water \\
\hline \multicolumn{1}{|l|}{} & \multicolumn{2}{l|}{} \\
\hline$>10,000$ & Salisbury, NC & $>50,000$ gpm & $\sim 0.1$ mi (Yadkin River) \\
\hline$>100,000$ & Concord, NC & $>100,000$ gpm & $\sim 0.1$ mi (Yadkin River) \\
\hline$>500,000$ & Winston-Salem, NC & $>200,000$ gpm & $\sim 0.1$ mi (Yadkin River) \\
\hline Geotechnical & Charlotte, NC & $>500,000$ gpm & $\sim 0.1$ mi (Yadkin River) \\
\hline Max Earthquake Acceleration & $<0.3 \mathrm{~g}$ & Acces sibility & \\
\hline Max Slope & $\sim 18 \%$ & Distance to Major Roadway & $\sim 0.9$ mi (Interstate 85 ) \\
\hline Nearest Fault Line & $\sim 957$ mi (Oklahoma) & Distance to Rail Transport & $\sim 0.4$ mi (NS) \\
\hline Nearest Hazard Site & $\sim 34$ mi (Airport- \\
\hline
\end{tabular}




\section{A.2.3 Aerial Imagery}

The aerial imagery in Fig. A.24 indicates that Interstate 85 runs approximately 1.0 mile west of the Buck Steam Station site.

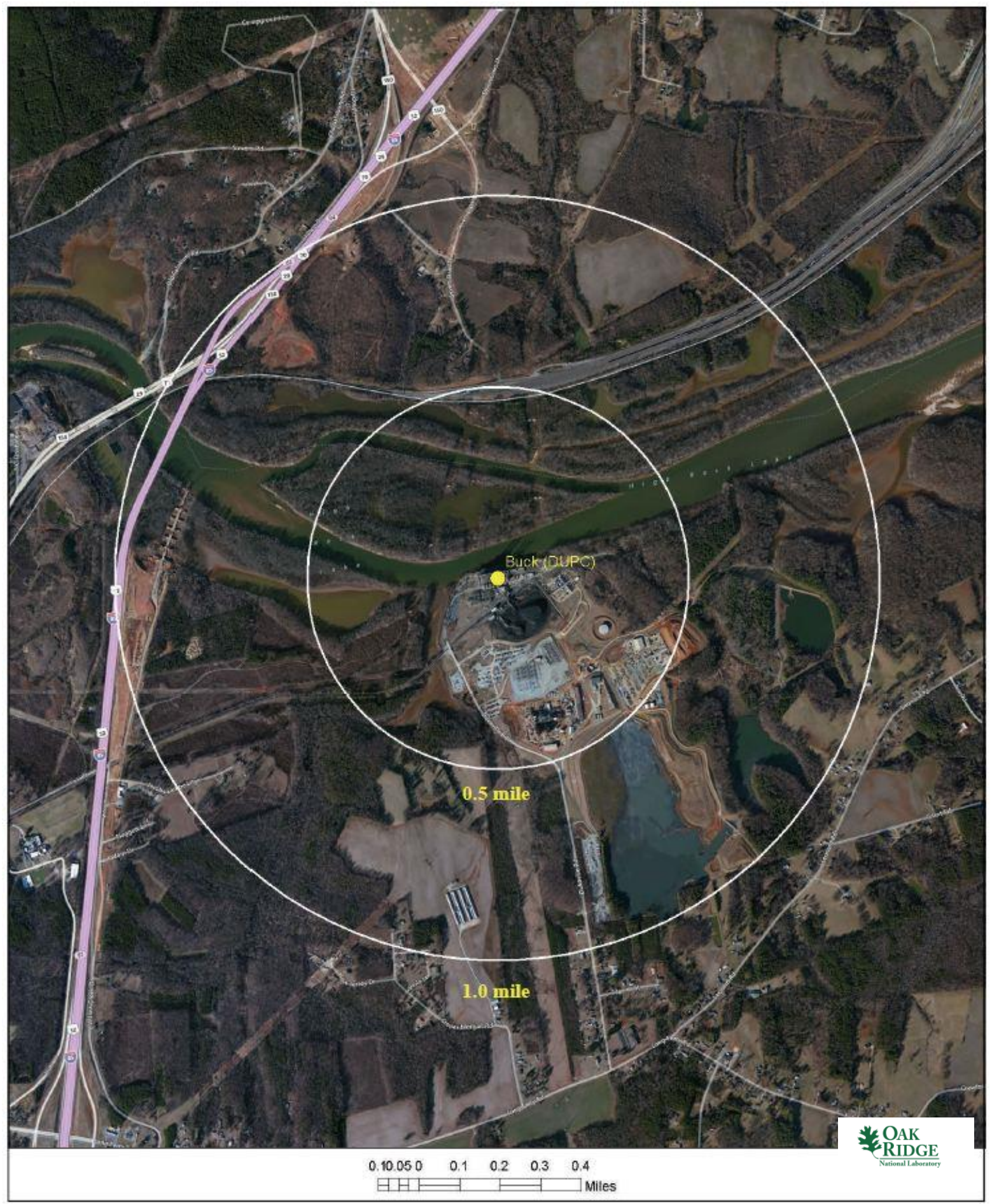

Fig. A.24. Satellite view of Buck Steam Station proximity. 


\section{A.2.4 Screening Criteria Overview}

Table A.9. Buck Steam Station siting criteria summary

\begin{tabular}{|c|c|c|c|c|c|c|c|c|c|c|}
\hline \multicolumn{11}{|c|}{ Screening Criteria Summary Bar } \\
\hline & \multicolumn{2}{|c|}{ No Siting Issue } & \multicolumn{2}{|c|}{\begin{tabular}{|l|l|} 
& Partial Siting Issue \\
\end{tabular}} & \multicolumn{2}{|c|}{ Partial Siting Issue } & \multicolumn{4}{|c|}{ Full Siting Issue } \\
\hline \begin{tabular}{|l|}
0.5 \\
Mile \\
Buffer
\end{tabular} & Population & Slope & SSE & $\begin{array}{l}\text { Stream } \\
\text { flow } \\
(65,000 \\
\text { gpm) }\end{array}$ & $\begin{array}{l}\text { Proximity } \\
\text { to } \\
\text { Hazard } \\
\text { Operations }\end{array}$ & $\begin{array}{l}\text { Proximity } \\
\text { to } \\
\text { Fault } \\
\text { Lines }\end{array}$ & \begin{tabular}{|l|} 
Wetlands \\
Wpen \\
\end{tabular} & $\begin{array}{l}\text { 100-year } \\
\text { Flood- } \\
\text { plain }\end{array}$ & $\begin{array}{l}\text { Protected } \\
\text { Lands }\end{array}$ & $\begin{array}{l}\text { Landslide } \\
\text { Hazards }\end{array}$ \\
\hline \begin{tabular}{|l|}
1.0 \\
Mile \\
Buffer
\end{tabular} & Population & Slope & SSE & $\begin{array}{l}\text { Stream } \\
\text { flow } \\
(65,000 \\
\mathrm{gpm})\end{array}$ & $\begin{array}{l}\text { Proximity } \\
\text { to } \\
\text { Hazard } \\
\text { Operations }\end{array}$ & \begin{tabular}{|l} 
Proximity \\
to \\
Fault \\
Lines
\end{tabular} & $\begin{array}{l}\text { Wetlands } \\
\text { Open } \\
\text { Water }\end{array}$ & $\begin{array}{l}100 \text {-year } \\
\text { Flood- } \\
\text { plain }\end{array}$ & $\begin{array}{l}\text { Protected } \\
\text { Lands }\end{array}$ & \begin{tabular}{|l|} 
Land- \\
slide \\
Hazards
\end{tabular} \\
\hline & & & & & & & & & & $\begin{array}{l}\text { AK } \\
\text { IDGE }\end{array}$ \\
\hline \multicolumn{11}{|c|}{ Site Selection and Evaluation Criteria Table } \\
\hline \multicolumn{7}{|c|}{ Criteria } & \multicolumn{4}{|c|}{ Value } \\
\hline \multicolumn{7}{|c|}{ Population Density within 10 miles (people/square mile) } & \multicolumn{4}{|c|}{$>500$} \\
\hline \multicolumn{7}{|l|}{ Slope } & \multicolumn{4}{|c|}{$>18 \%$} \\
\hline \multicolumn{7}{|c|}{ Safe shutdown earthquake (ground acceleration) } & \multicolumn{4}{|c|}{$>0.5$} \\
\hline \multicolumn{7}{|c|}{ Streamflow/cooling water make-up (gpm) } & \multicolumn{4}{|c|}{$<65,000$} \\
\hline \multicolumn{7}{|c|}{ Proximity to hazardous operations - buffer (mile) } & \multicolumn{4}{|c|}{ Depends on hazardous operation ${ }^{1}$} \\
\hline \multicolumn{7}{|c|}{ Proximity to fault lines - buffer (mile) } & \multicolumn{4}{|c|}{ Depends on length of fault } \\
\hline \multicolumn{7}{|c|}{ Wetlands/Open Water } & \multicolumn{4}{|c|}{-} \\
\hline \multicolumn{7}{|c|}{ 100-year floodplain } & \multicolumn{4}{|c|}{-} \\
\hline \multicolumn{7}{|c|}{ Protected lands } & \multicolumn{4}{|c|}{-} \\
\hline \multicolumn{7}{|c|}{ Landslide hazard (moderate and high) } & \multicolumn{4}{|c|}{-} \\
\hline
\end{tabular}

${ }^{1}$ Hazardous facilities (airports- -5 miles and oil refineries- -1 mile) 


\section{A.2.5 Composite Map and Individual Siting Issue Maps}

A composite map of SMR siting challenges to the Buck Steam Station is shown in Fig. A.25. The physical plant structures are located on land with no siting issues. Following this map are maps of the individual SMR siting criteria based on selected input values.

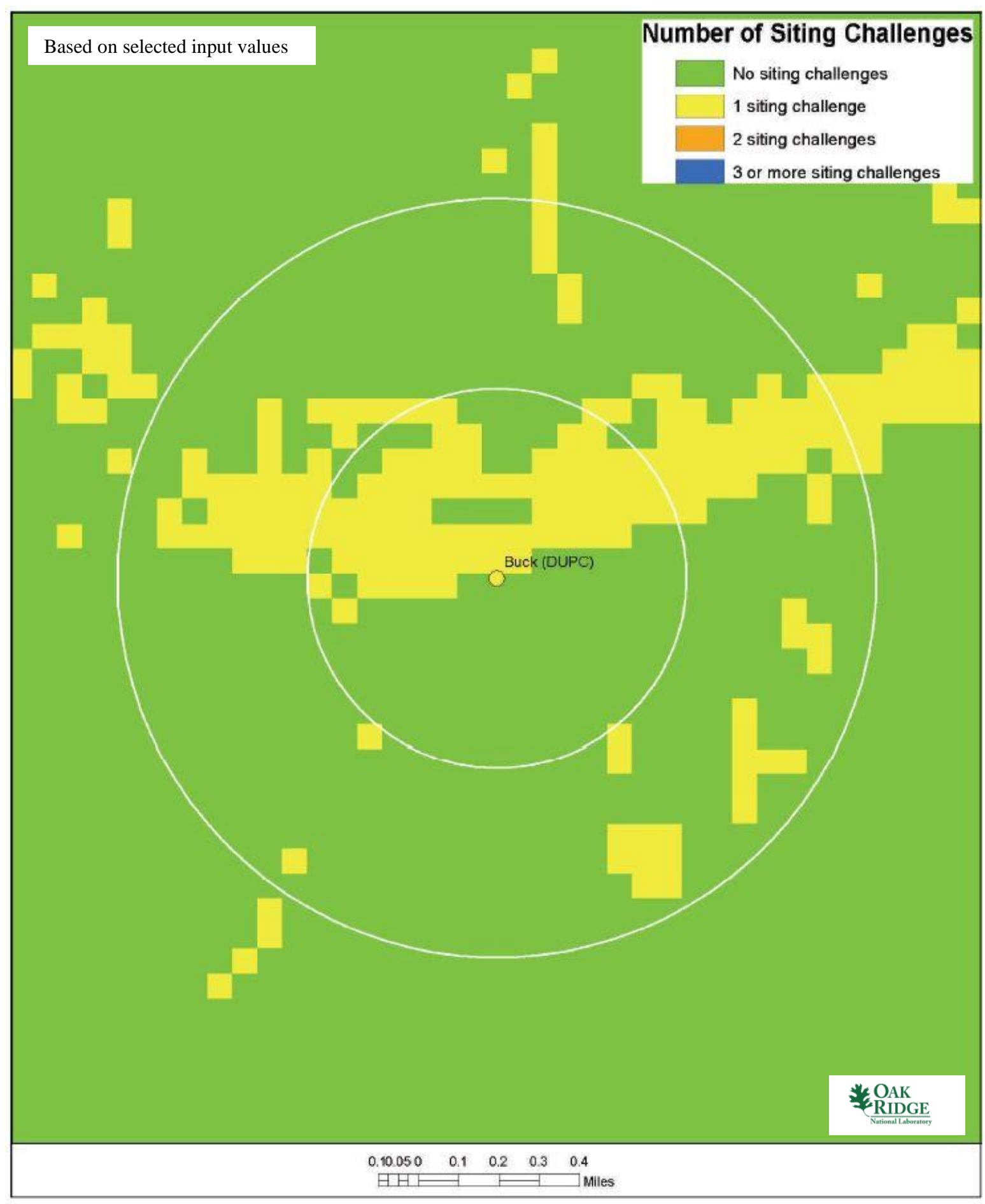

Fig. A.25. Buck Steam Station composite map. 

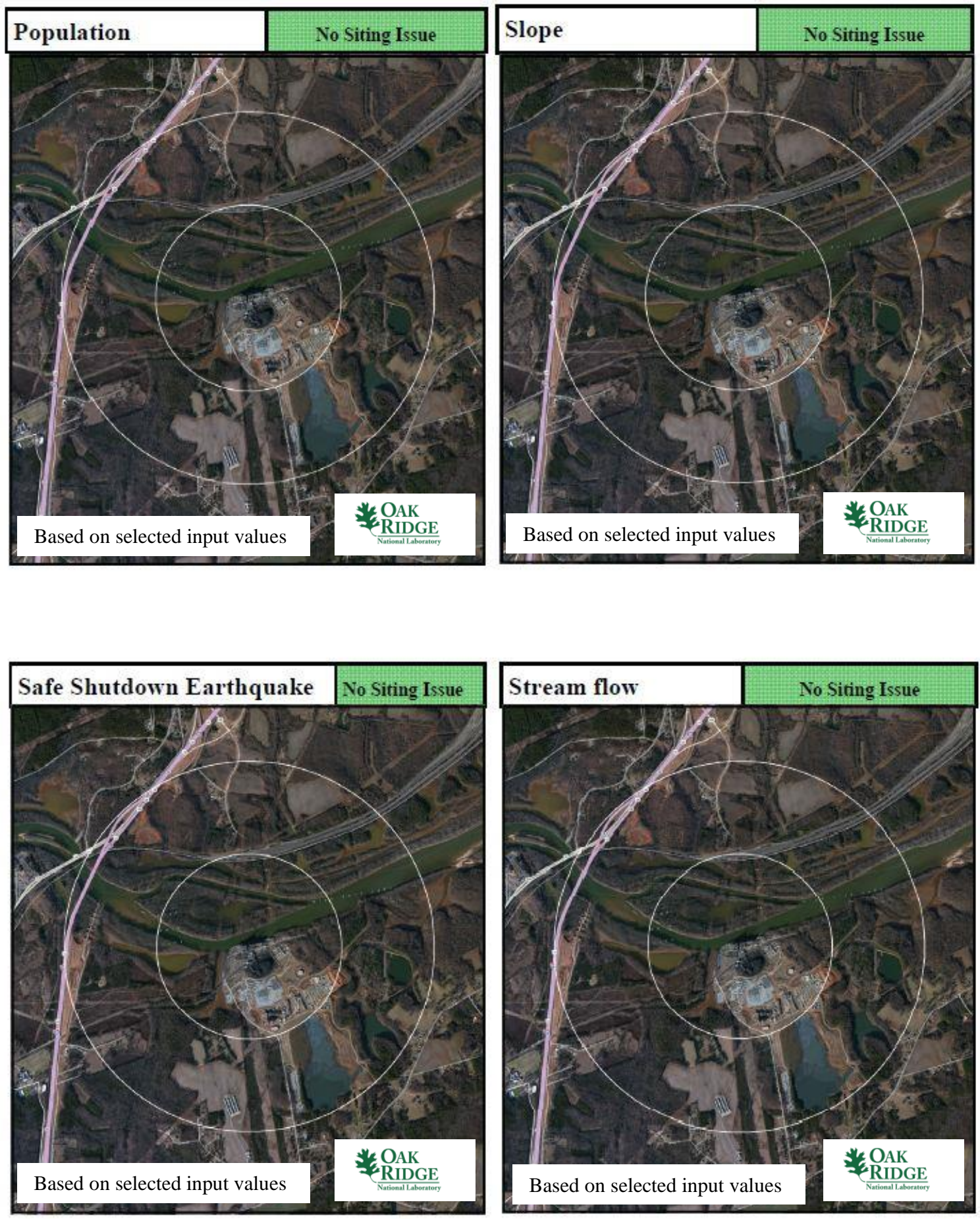

Buck Steam Station 

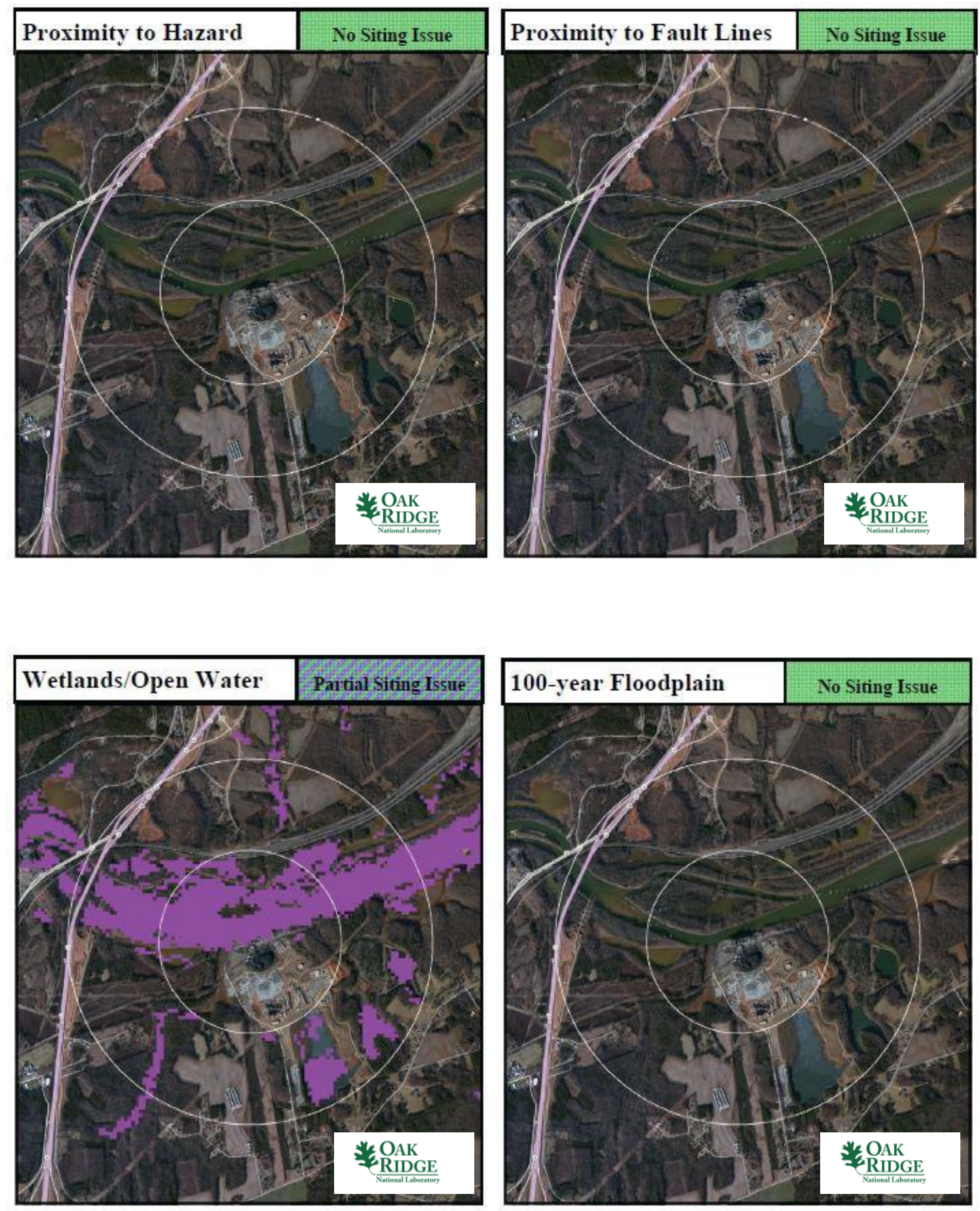

Buck Steam Station 

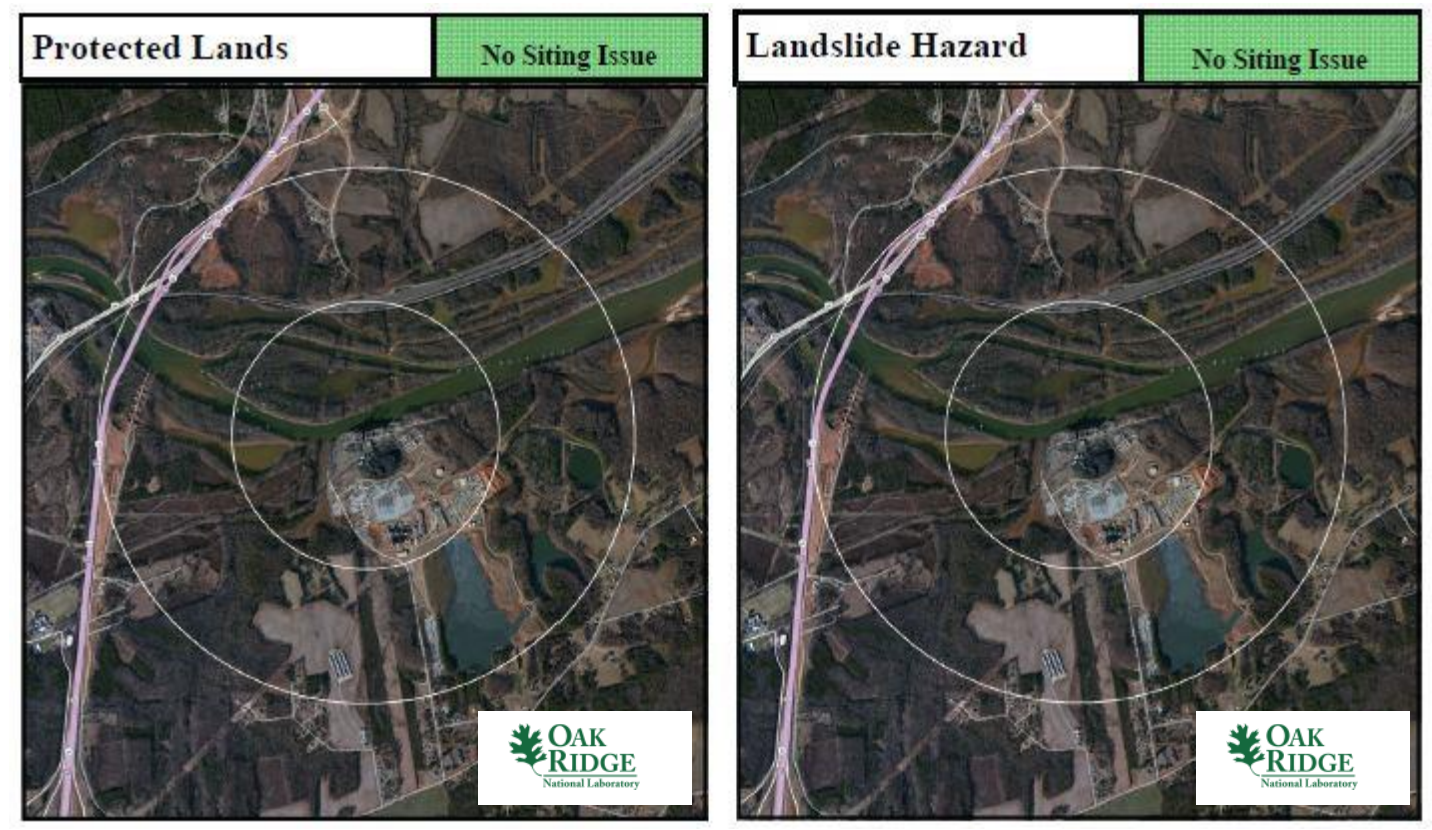

\section{A.2.6 Site Evaluation}

Buck Steam Station

Duke Energy Carolinas, LLC, operates seven nuclear power plants in both North and South Carolina. The Oconee Nuclear Station (three units) is located 30 miles west of Greenville, South Carolina. Catawba Nuclear Station (two units) and the McGuire Nuclear Station (two units) are located 18 miles south and 17 miles north, respectively, of Charlotte, North Carolina. Also, Duke Energy has applied for a Combined Operating License (COL) for two nuclear plants in Cherokee County, South Carolina, approximately 40 miles southwest of Charlotte, North Carolina. Therefore, Duke Energy has the licensing experience to operate an SMR at this site. The site contains sufficient acreage to support siting an SMR.

From an environmental justice perspective, the community collectively appears to have achieved a reasonable level of education with median income levels typical of much of the United States. Therefore, siting an SMR at this location would not seem to be disenfranchising a less-educated or poverty-stricken community. Furthermore, the education level of the Buck Steam Station community would seem to support the higher-technology job opportunities provided by an SMR. Duke Energy has operated power plants at this site since 1926.

As shown in Sects. A.0 and A.0, the Buck Steam Station site has a partial SMR site screening issue with wetlands/open waters. The wetlands/open waters issue affects area to the north of the plant site, including the Yadkin River, which appears to be the only threat to the plant site. The site is not in a floodplain. The remaining SMR site screening criteria are met site-wide for the values established in the updated SMR siting report. 1

Interstate 85 runs within 1 mile of the site, which could make it marginally difficult for a nuclear licensee to control land access to areas very near the plant location. In addition, the US EPA in September 2009 deemed the three ash basins onsite as having "significant hazard potential." This could be an added cost factor in site preparation for an SMR.

The site appears reasonably isolated and it meets current NRC RG 4.7 recommendations for population density with additional consideration for relaxed SMR population siting requirements based on reduced source term. The Buck Steam Station site meets multiple conventional standards for consideration of siting an SMR at the coal station location. There are no current or near-term foreseeable SMR SSEC siting issues that should preclude this site from further SMR siting consideration. 


\section{A.3 Canadys Station}

\section{A.3.1 Location Detail}

As shown in Fig. A.26, Canadys Station is located in southeastern South Carolina, off Augusta Highway (South Carolina State Highway 61) in Colleton County, South Carolina. Interstate 95 is accessible less than 2 miles to the west. Rail access is available within 0.1 miles and barge access is not available. The plant is sited near the intersection of State Highways 61 and 15. The closest town is Walterboro, South Carolina, with a population of approximately 5,398 people. Walterboro is approximately 10.3 miles south of Canadys Station. The nearest city with a population in excess of 10,000 people is Summerville, South Carolina, approximately 26 miles to the east of Canadys Station.

- Plant: Canadys Station

- Utility: South Carolina Electric \& Gas Company (SGE\&G)

- Coordinates: lat. $33.06501^{\circ} \mathrm{N}$, long. $80.62341^{\circ} \mathrm{W}$

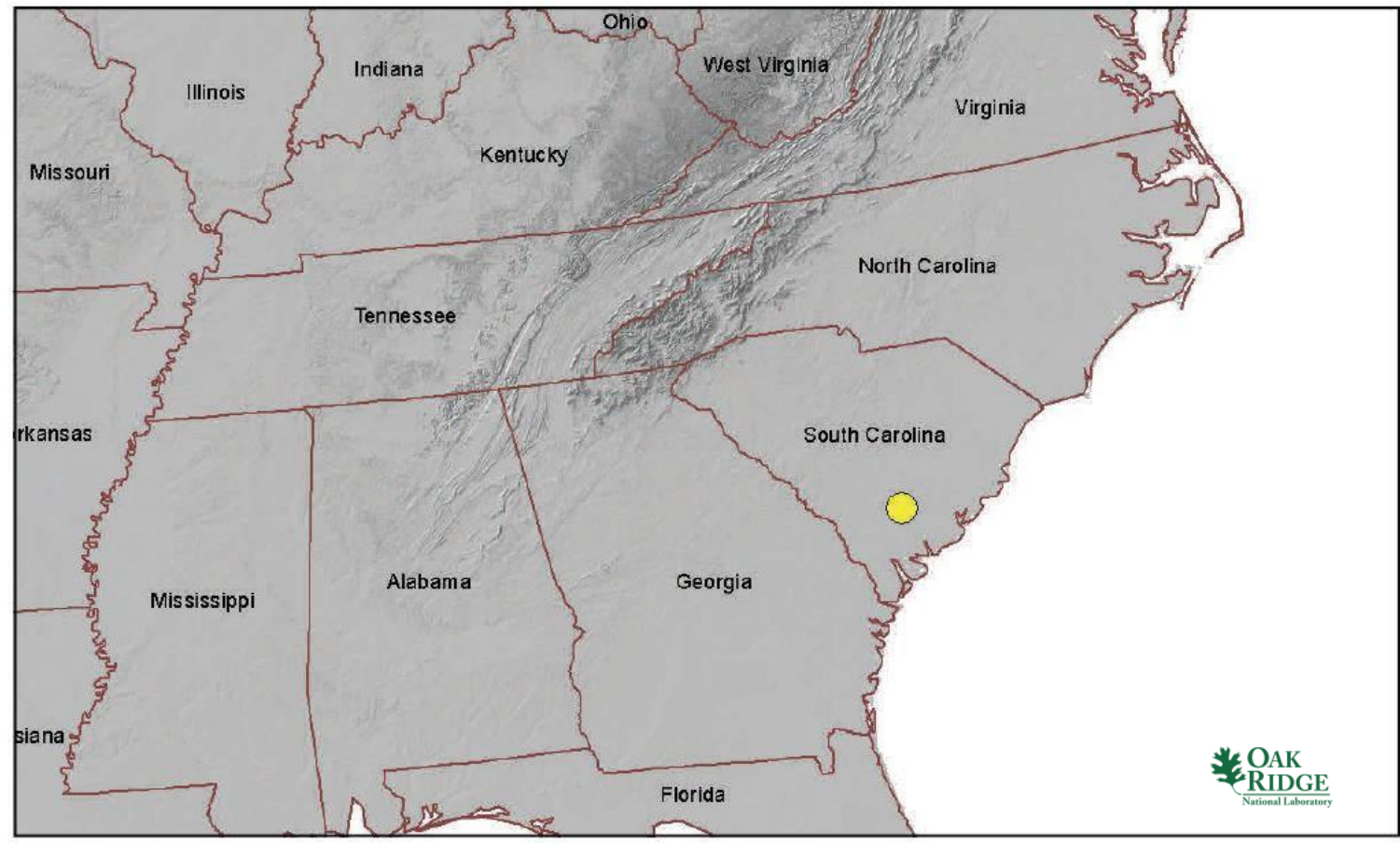

Fig. A.26. Canadys Station location map.

\section{A.3.2 Site Description and Status}

Canadys Station is a 3-unit coal station operated by SCE\&G, a subsidiary of the SCANA Corporation. Unit 1, commissioned in 1962, is rated at $136 \mathrm{MW}(\mathrm{e})$; Unit 2, commissioned in 1964, is rated at 136 MW(e); and Unit 3, commissioned in 1967, is rated at 218 MW(e), for a total site capacity of 490 MW(e). The plant is cooled by mechanical draft cooling towers. SCE\&G has indicated that it will phase out operation at the Canadys Station power plant over the next 5 years. Unit 1 was scheduled to shut down in December 2012. Units 2 and 3 will convert to natural gas by 2015 to meet EPA requirements that go into effect at that time. However, Units 2 and 3 are planned for permanent shutdown by 2017. Part of this decision is associated with the SCANA Corporation ongoing nuclear construction project at Summer Nuclear Power Plant that is scheduled for completion around that timeframe. Canadys Station employs 85 people and contributes $\$ 2.3 \mathrm{M}$ in property taxes annually to the local government. 
The plant is situated on roughly 100 acres on the Edisto River approximately 66 miles east of the 2,450 MW(e) Vogtle nuclear facility, 93 miles southeast of the 1,000 MW(e) Summer nuclear facility, and 96 miles south of the $724 \mathrm{MW}(\mathrm{e}) \mathrm{H}$. B. Robinson nuclear facility. The plant is 32 miles southeast of the $430 \mathrm{MW}(\mathrm{e})$ coal-fired Cope Station and 36 miles southwest of the 2,390 MW(e) coal-fired Cross Generating Station. The 207 MW(e) Saluda Dam hydroelectric project is 75 miles northeast of Canadys Station.

As noted in Table A.10, the nearest major fault line based on USGS data is 965 miles west in Oklahoma. The maximum safe-shutdown earthquake for the site is approximately $0.49 \mathrm{~g}$ peak ground acceleration. More than 500,000 gpm of cooling water makeup is available from the adjacent Edisto River.

The permanent population within 1 mile of the plant is fewer than 500 people, yielding a population density of fewer than 160 people per square mile. The permanent population within 10 miles of the plant is approximately 47,000 people, yielding a population density of about 150 people per square mile.

According to the US EPA Environmental Justice website, there are 5,505 occupied housing units within 10 miles of the plant site based on 2000 US Census data. Further, approximately $67 \%$ of area adults over age 25 have a high school diploma or higher education. The median annual income for the area is between $\$ 25 \mathrm{~K}$ and $\$ 50 \mathrm{~K}$.

Table A.10. Canadys Station site statistics

\begin{tabular}{|c|c|c|c|}
\hline \multicolumn{2}{|l|}{$\begin{array}{l}\text { Population } \\
\text { Population Within }\end{array}$} & \multicolumn{2}{|l|}{$\begin{array}{l}\text { Utility } \\
\text { Distance to Grid Capacity }\end{array}$} \\
\hline$\overline{0.5 \mathrm{mi}}$ & $<500$ & $>400 \mathrm{MWe}$ & $\sim 0.2 \mathrm{mi}$ \\
\hline $1 \mathrm{mi}$ & $<500$ & $>800 \mathrm{MWe}$ & $\sim 34 \mathrm{mi}$ \\
\hline $5 \mathrm{mi}$ & $\sim 6,100$ & $>1600 \mathrm{MWe}$ & $\sim 49 \mathrm{mi}$ \\
\hline $10 \mathrm{mi}$ & $\sim 47,000$ & $>3200 \mathrm{MWe}$ & $\sim 240 \mathrm{mi}$ \\
\hline \multicolumn{2}{|c|}{ Nearest City with Population } & \multicolumn{2}{|c|}{ Distance to Cooling Water } \\
\hline$>10,000$ & Summerville, SC & $>50,000 \mathrm{gpm}$ & $\sim 0.1 \mathrm{mi}$ (Edisto River) \\
\hline$>50,000$ & North Charleston, SC & $>100,000 \mathrm{gpm}$ & $\sim 0.1 \mathrm{mi}$ (Edisto River) \\
\hline$>100,000$ & Charleston, SC & $>200,000 \mathrm{gpm}$ & $\sim 0.1 \mathrm{mi}$ (Edisto River) \\
\hline$>500,000$ & Charlotte, $\mathrm{NC}$ & $>500,000 \mathrm{gpm}$ & $\sim 0.1 \mathrm{mi}$ (Edisto River) \\
\hline \multicolumn{2}{|l|}{ Geotechnical } & \multicolumn{2}{|l|}{ Accessibility } \\
\hline Max Earthquake Acceleration & $\sim 0.49 \mathrm{~g}$ & Distance to Major Roadway & $\sim 2 \mathrm{mi}$ (Interstate 95 ) \\
\hline Max Slope & $\sim 3 \%$ & Distance to Water Transport & $\sim \sim 22 \mathrm{mi}$ (South Edisto River) \\
\hline Nearest Fault Line & $\sim 965 \mathrm{mi}$ (Oklahoma) & Distance to Rail Transport & $\sim 0.1 \mathrm{mi}((\mathrm{HB})$ \\
\hline Nearest Hazard Site & $\begin{array}{l}\sim 34 \mathrm{mi} \text { (Airport- } \\
\quad \text { Charleston AFB Int' } 1 \text { ) }\end{array}$ & Distance to Airport & $\sim 34$ mi (Charleston Int'l) \\
\hline
\end{tabular}




\section{A.3.3 Aerial Imagery}

The aerial imagery in Fig. A.27 indicates that State Highways 61 and 15 run within 0.5 miles of the Canadys Station site.

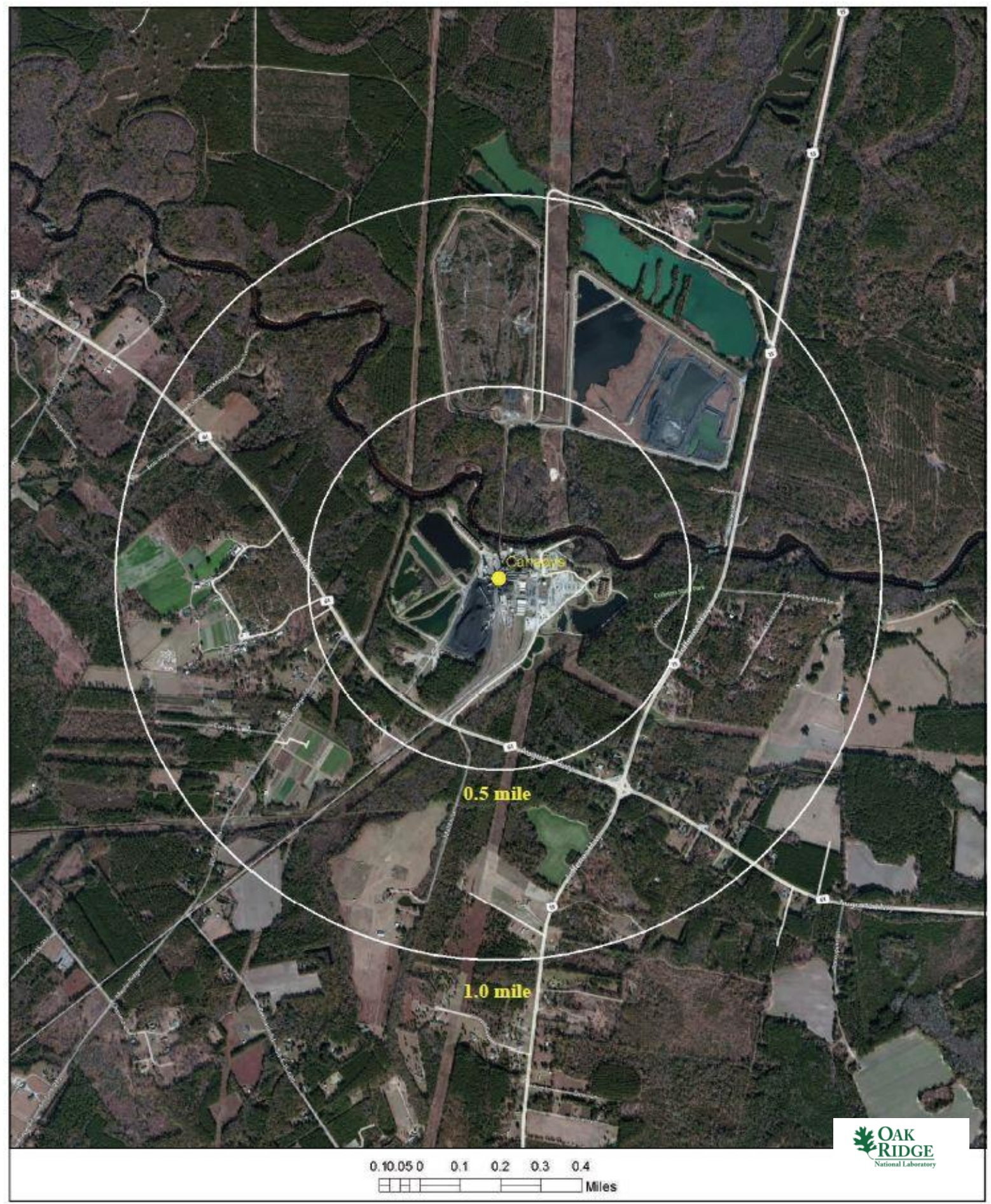

Fig. A.27. Satellite view of Canadys Station proximity. 


\section{A.3.4 Screening Criteria Overview}

Table A.11. Canadys Station siting criteria summary

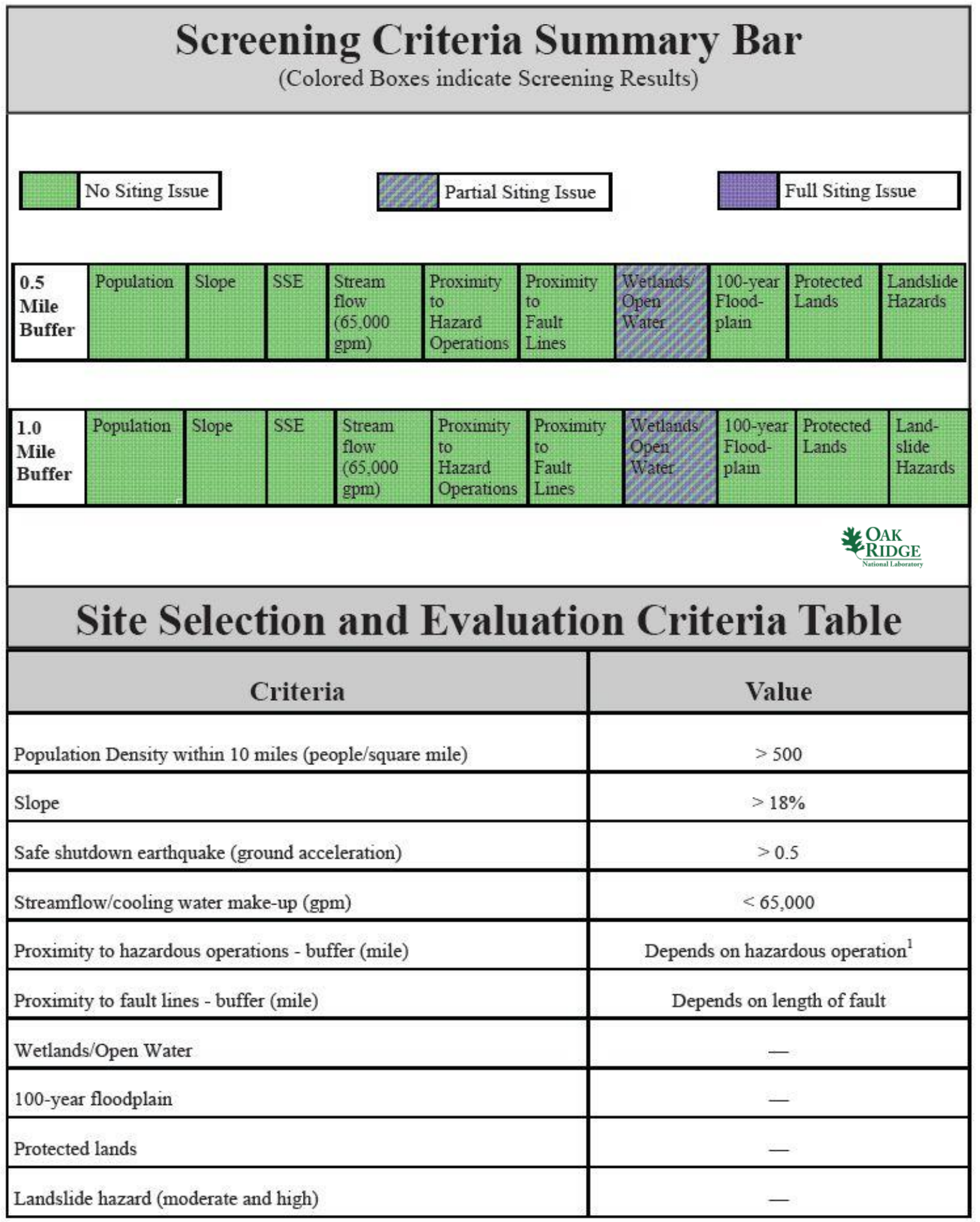

${ }^{1}$ Hazardous facilities (airports- 5 miles and oil refineries- -1 mile) 


\section{A.3.5 Composite Map and Individual Siting Issue Maps}

A composite map of SMR siting challenges to Canadys Station is shown in Fig. A.28. The physical plant structures are located on land with no siting issues. Following this map are maps of the individual SMR siting criteria based on selected input values.

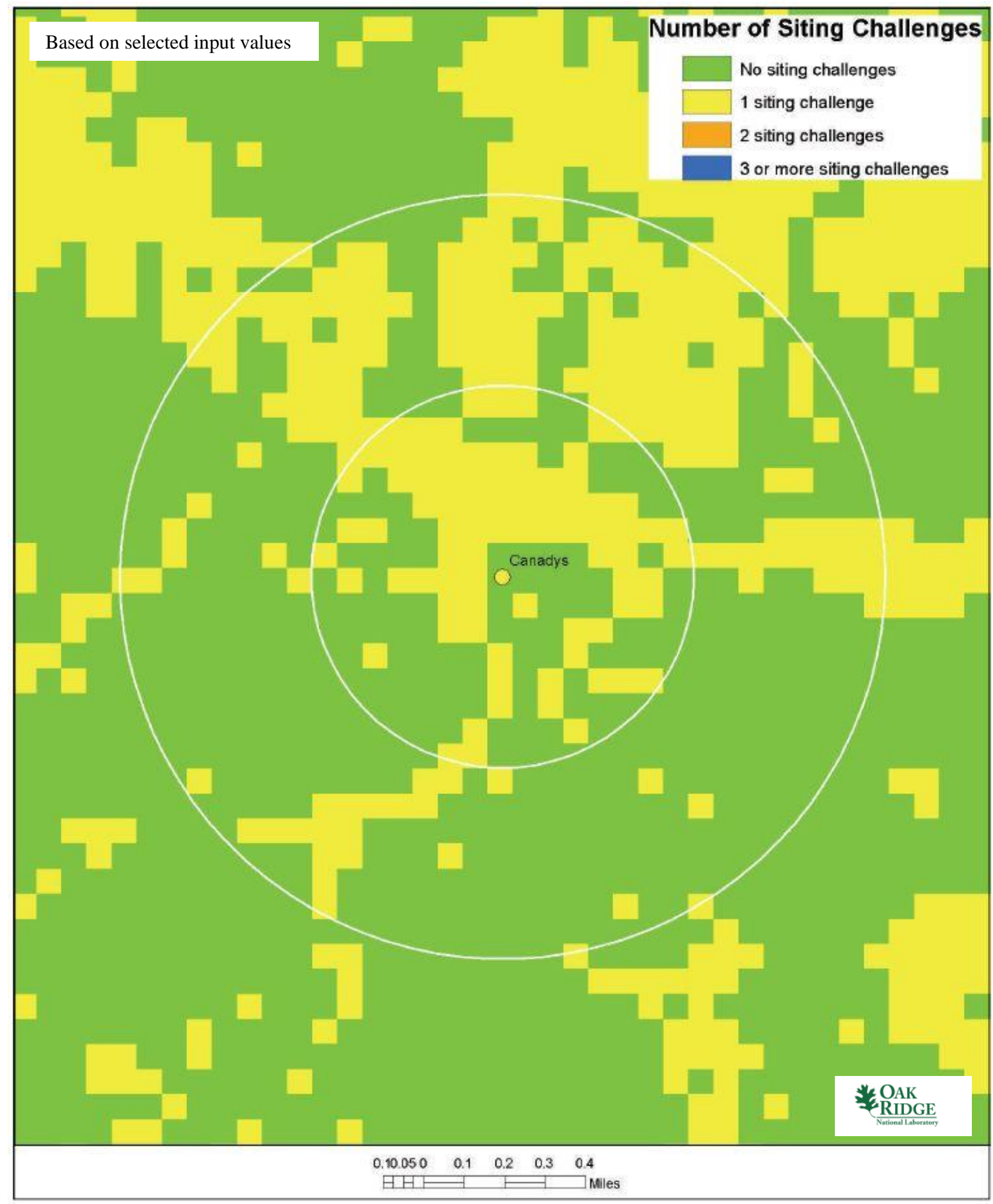

Fig. A.28. Canadys Station composite map. 

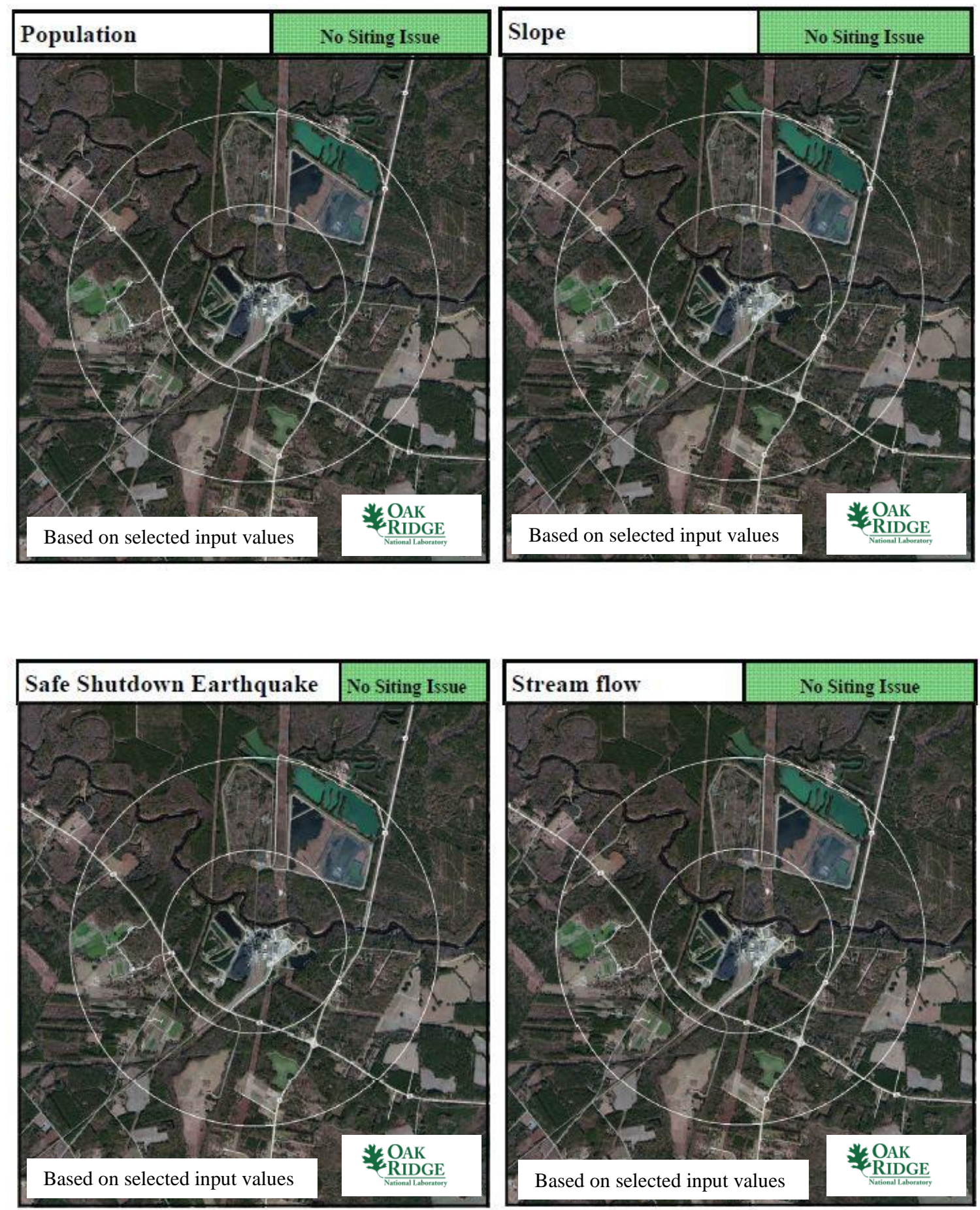

Canadys Station 

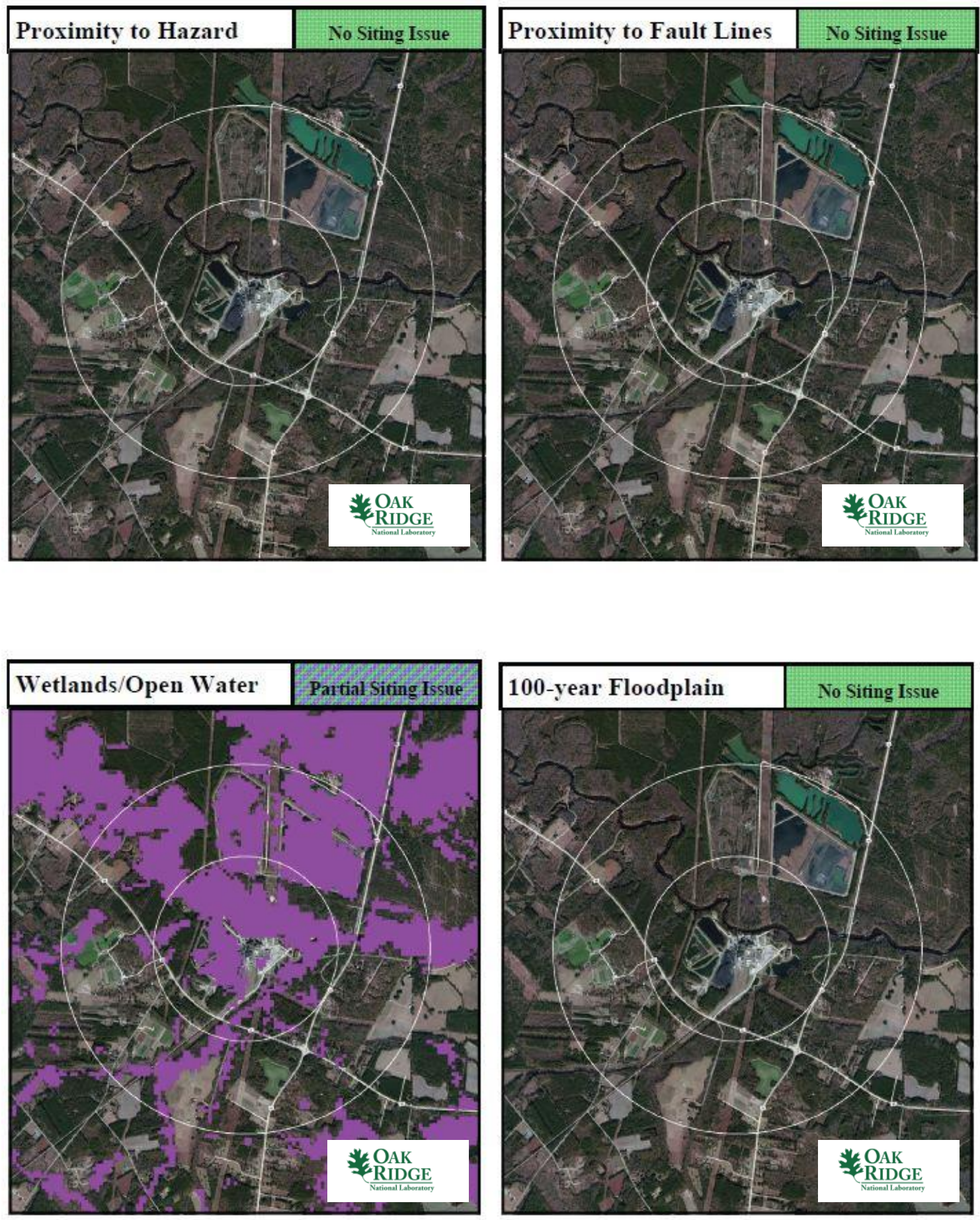

Canadys Station 

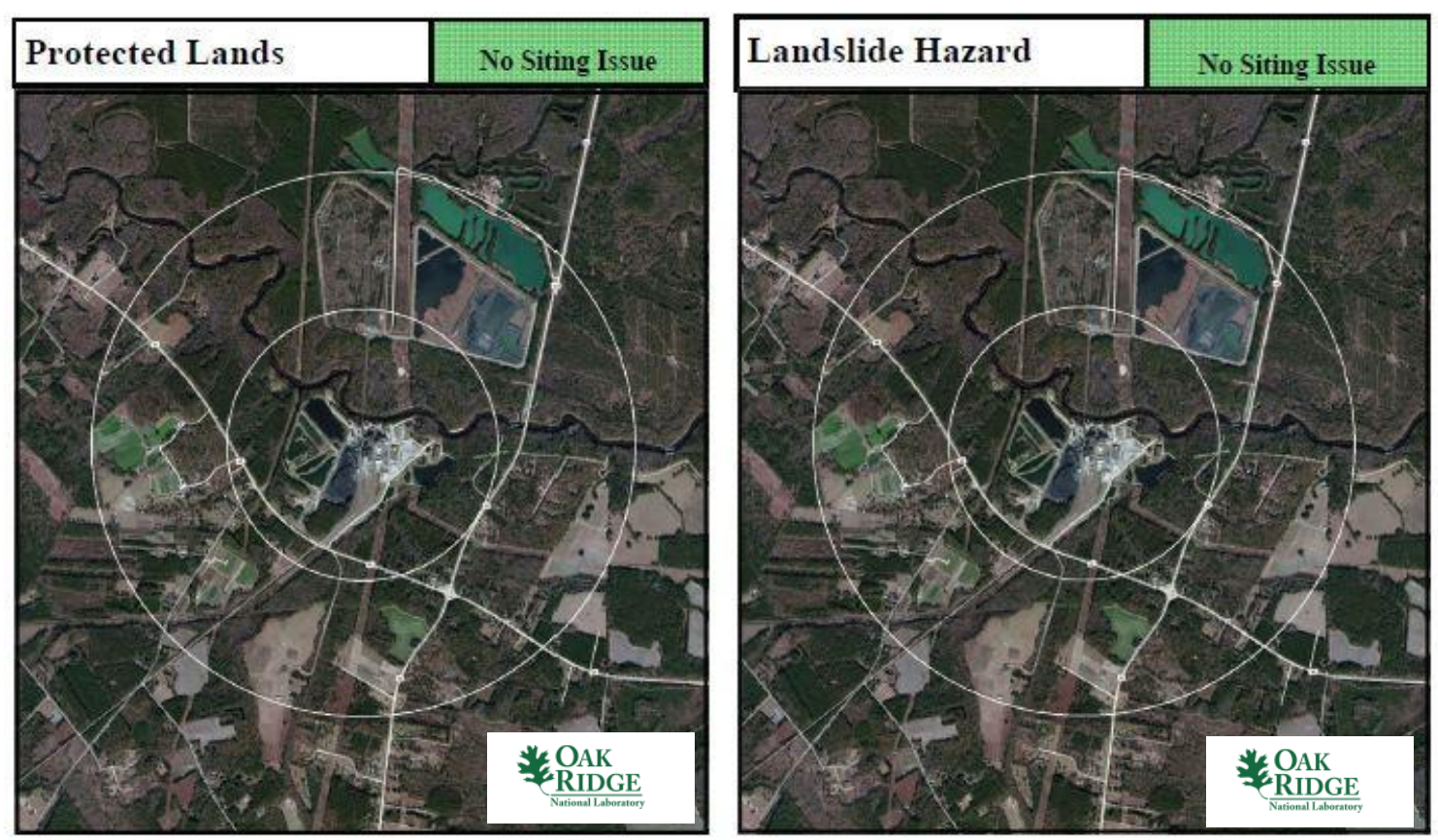

Canadys Station

\section{A.3.6 Site Evaluation}

South Carolina Electric \& Gas Company operates the Virgil C. Summer Nuclear Station, Unit 1, located about 26 miles northwest of Columbia, South Carolina. Also, SCE\&G has applied for a COL for two nuclear plants at the same location. Therefore, SCE\&G has the licensing experience to operate an SMR at this site. The site contains sufficient acreage to support siting an SMR.

From an environmental justice perspective, the community collectively appears to have achieved a reasonable level of education with median income levels typical of much of the United States. Therefore, siting an SMR at this location would not seem to be disenfranchising a less-educated or poverty-stricken community. Furthermore, the education level of the Canadys Station community would seem to support the higher-technology job opportunities provided by an SMR.

As shown in Sects. A.0 and A.0, the Canadys Station site has a partial SMR site screening issue with wetlands/open waters. The wetlands/open waters issue affects all areas surrounding the plant site, including the Edisto River. This could be a problematic issue for siting an SMR at this location in light of the recent industry focus on flooding. The remaining SMR site screening criteria are met site-wide for the values established in the updated SMR siting report.1

Interstate 95 runs within 2 miles of the site; therefore, it could be a marginal factor for a nuclear licensee to control land access to areas very near the plant location. There is one bridge across the Edisto River and a large ash pond (95 acres active and 80 acres inactive) just north of the plant. The US EPA, in December 2011, deemed the active ash pond facility to be considered "poor for continued safe and reliable operation." This could be an added cost factor in site preparation for an SMR.

The site appears reasonably isolated and it meets current NRC RG 4.7 recommendations for population density without additional consideration for relaxed SMR population siting requirements based on reduced source term. The Canadys Station site meets multiple conventional standards for consideration of siting an SMR at the coal station location. There are no current or near-term foreseeable SMR SSEC siting issues that should preclude this site from further SMR siting consideration. 


\section{A.4 Glen Lyn Plant}

\section{A.4.1 Location Detail}

As shown in Fig. A.29, the Glen Lyn Plant is located in Virginia just south of the West Virginia border. More specifically, the plant is located off Apco Road, in Giles County, Virginia. Highway 460 is 0.2 miles from the plant. Interstate 77 is accessible approximately 9 miles to the west and Interstate 81 is accessible approximately 22 miles to the south. Rail access is available onsite. Barge access is not available to the site. The plant is located in Glen Lyn, Virginia, with a population of approximately 150 people. Rich Creek, Virginia, with a population 774 people, is approximately 2.5 miles northeast of the Glen Lyn Plant. The nearest city with a population in excess of 10,000 people is Radford, Virginia, approximately 23 miles to the southeast of the Glen Lyn Plant.

- Plant: Glen Lyn Plant

- Utility: Appalachian Power Company

- Coordinates: lat. $37.36943^{\circ} \mathrm{N}$, long. $80.86304^{\circ} \mathrm{W}$

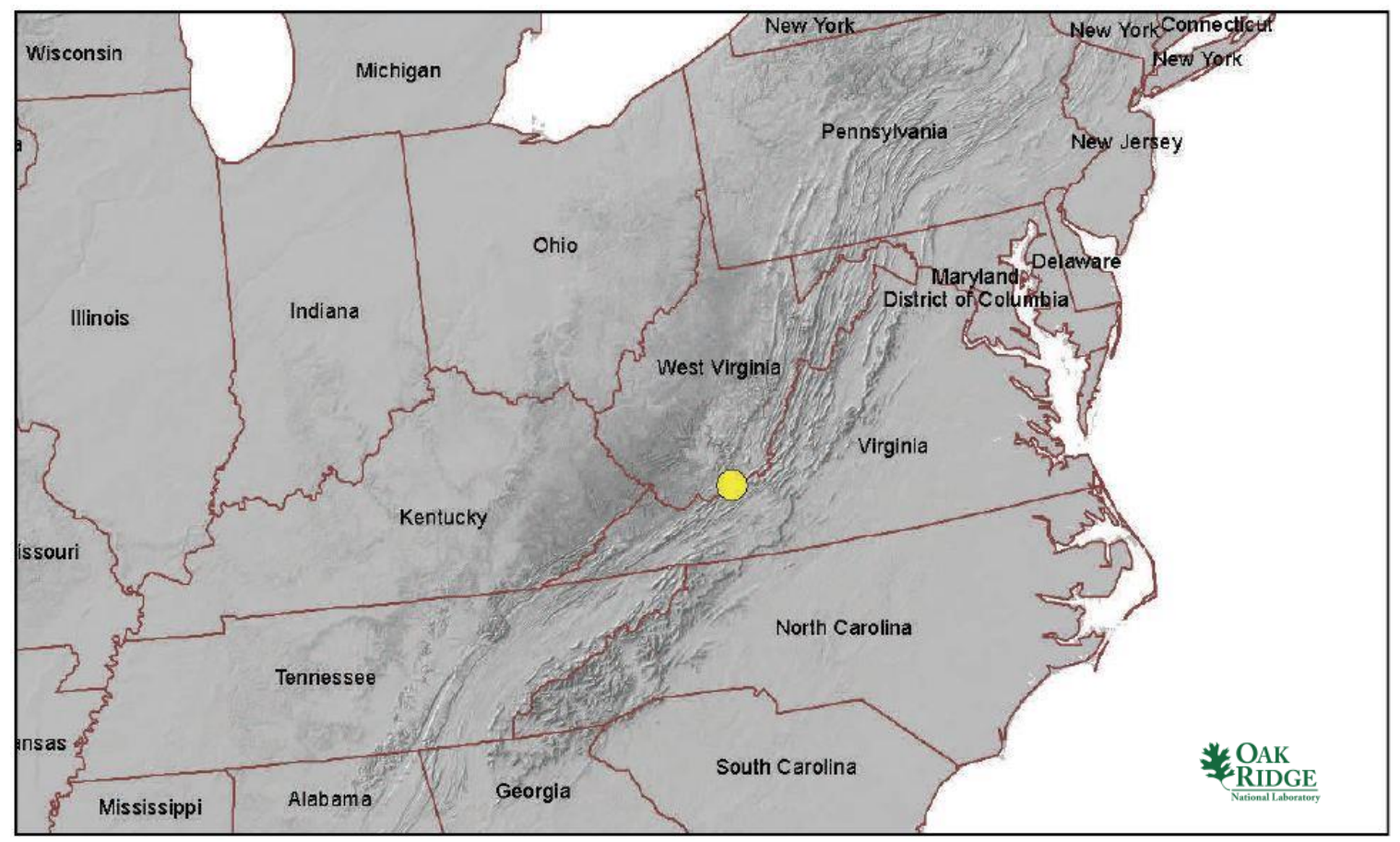

Fig. A.29. Glen Lyn Plant location map.

\section{A.4.2 Site Description and Status}

The Glen Lyn Plant is operated by Appalachian Power Company, a subsidiary of American Electric Power. The two-unit coal station is planned for shutdown sometime between December 2014 and June 2016 because of the high cost of implementing new EPA Mercury and Air Toxics Standards (MATS). One of the fossil units, commissioned in 1944, is rated at $100 \mathrm{MW}(\mathrm{e})$, and the second unit, commissioned in 1957, is rated at 237.5 MW(e) for a total site capacity of 337.5 MW(e). The two units are used as peaking units. The plants are cooled by once-through cooling from the New River. The plant was already slated to close in 2018 before the need to meet the revised EPA requirements. The Glen Lyn Plant employs 44 people and contributes $\$ 800 \mathrm{~K}$ in property taxes annually to the local government. 
The plant is situated on roughly 40 acres on the New River approximately 135 miles north of the 2,200 MW(e) McGuire nuclear facility and approximately 175 miles southwest of the 1,863 MW(e) North Anna nuclear facility. The plant is 80 miles northeast of the $714 \mathrm{MW}(\mathrm{e})$ coal-fired Clinch River Plant, 88 miles northwest of the $276 \mathrm{MW}$ (e) coal-fired Dan River plant, and 90 miles west of the $71 \mathrm{MW}(\mathrm{e})$ coal-fired Altavista plant. A 2,100 MW(e) pumped hydroelectric project is 82 miles northeast of the Glen Lyn Plant. In addition, the $560 \mathrm{MW}(\mathrm{e})$ Smith Mountain Dam hydroelectric project is 76 miles to the east.

As noted in Table A.12, the nearest major fault line based on USGS data is 935 miles west in Oklahoma. The maximum safe-shutdown earthquake for the site is below $0.3 \mathrm{~g}$ peak ground acceleration. More than $500,000 \mathrm{gpm}$ of cooling water makeup is available from the adjacent New River.

The permanent population within 1 mile of the plant is approximately 1,200 people, yielding a population density of roughly 380 people per square mile. The permanent population within 10 miles of the plant is approximately 54,000 people, yielding a population density of fewer than 175 people per square mile. According to the US EPA Environmental Justice website, there are 8,387 occupied housing units within 10 miles of the plant site based on 2000 US Census data. Further, over $70 \%$ of area adults over age 25 have a high school diploma or higher education. The median annual income for the area is between $\$ 25 \mathrm{~K}$ and $\$ 50 \mathrm{~K}$.

Table A.12. Glen Lyn Plant site statistics

\begin{tabular}{|c|c|c|c|}
\hline \multicolumn{2}{|l|}{$\begin{array}{l}\text { Population } \\
\text { Population Within }\end{array}$} & \multicolumn{2}{|l|}{$\begin{array}{l}\text { Utility } \\
\text { Distance to Grid Capacity }\end{array}$} \\
\hline $0.5 \mathrm{mi}$ & $<500$ & $>400 \mathrm{MWe}$ & $\sim 62 \mathrm{mi}$ \\
\hline $1 \mathrm{mi}$ & $\sim 1,200$ & $>800 \mathrm{MWe}$ & $\sim 19 \mathrm{mi}$ \\
\hline $5 \mathrm{mi}$ & $\sim 17,500$ & $>1600 \mathrm{MWe}$ & $\sim 21 \mathrm{mi}$ \\
\hline $10 \mathrm{mi}$ & $\sim 54,000$ & $>3200 \mathrm{MWe}$ & $\sim 32 \mathrm{mi}$ \\
\hline \multicolumn{2}{|c|}{ Nearest City with Population } & \multicolumn{2}{|c|}{ Distance to Cooling Water } \\
\hline$>10,000$ & Radford, VA & $>50,000 \mathrm{gpm}$ & $\sim 0.2 \mathrm{mi}$ (New River) \\
\hline$>50,000$ & Roanoke, VA & $>100,000 \mathrm{gpm}$ & $\sim 0.2 \mathrm{mi}$ (New River) \\
\hline$>100,000$ & Winston-Salem, NC & $>200,000 \mathrm{gpm}$ & $\sim 0.2 \mathrm{mi}$ (New River) \\
\hline$>500,000$ & Charlotte, $\mathrm{NC}$ & $>500,000 \mathrm{gpm}$ & $\sim 0.2 \mathrm{mi}$ (New River) \\
\hline \multicolumn{2}{|l|}{ Geotechnical } & \multicolumn{2}{|l|}{ Accessibility } \\
\hline Max Earthquake Acceleration & $<0.3 \mathrm{~g}$ & Distance to Major Roadway & $\sim 0.2 \mathrm{mi}(\mathrm{US} 460)$ \\
\hline Max Slope & $\sim 54 \%$ & Distance to Water Transport & $\sim 38.0 \mathrm{mi}$ (Big Sandy River) \\
\hline Nearest Fault Line & $\sim 935 \mathrm{mi}$ (Oklahoma) & Distance to Rail Transport & $\sim 0.1 \mathrm{mi}(\mathrm{NS})$ \\
\hline Nearest Hazard Site & $\begin{array}{l}\sim 46 \text { mi (Airport- } \\
\text { Roanoke Regional) }\end{array}$ & Distance to Airport & $\begin{array}{l}\sim 46.0 \text { mi (Roanoke Region- } \\
\text { al) }\end{array}$ \\
\hline
\end{tabular}




\section{A.4.3 Aerial Imagery}

The aerial imagery in Fig. A.30 shows Highway 460 passing next to the plant site. Portions of the town of Glen Lyn are on both sides of the river. The open area to the west on the river is also owned by the utility.

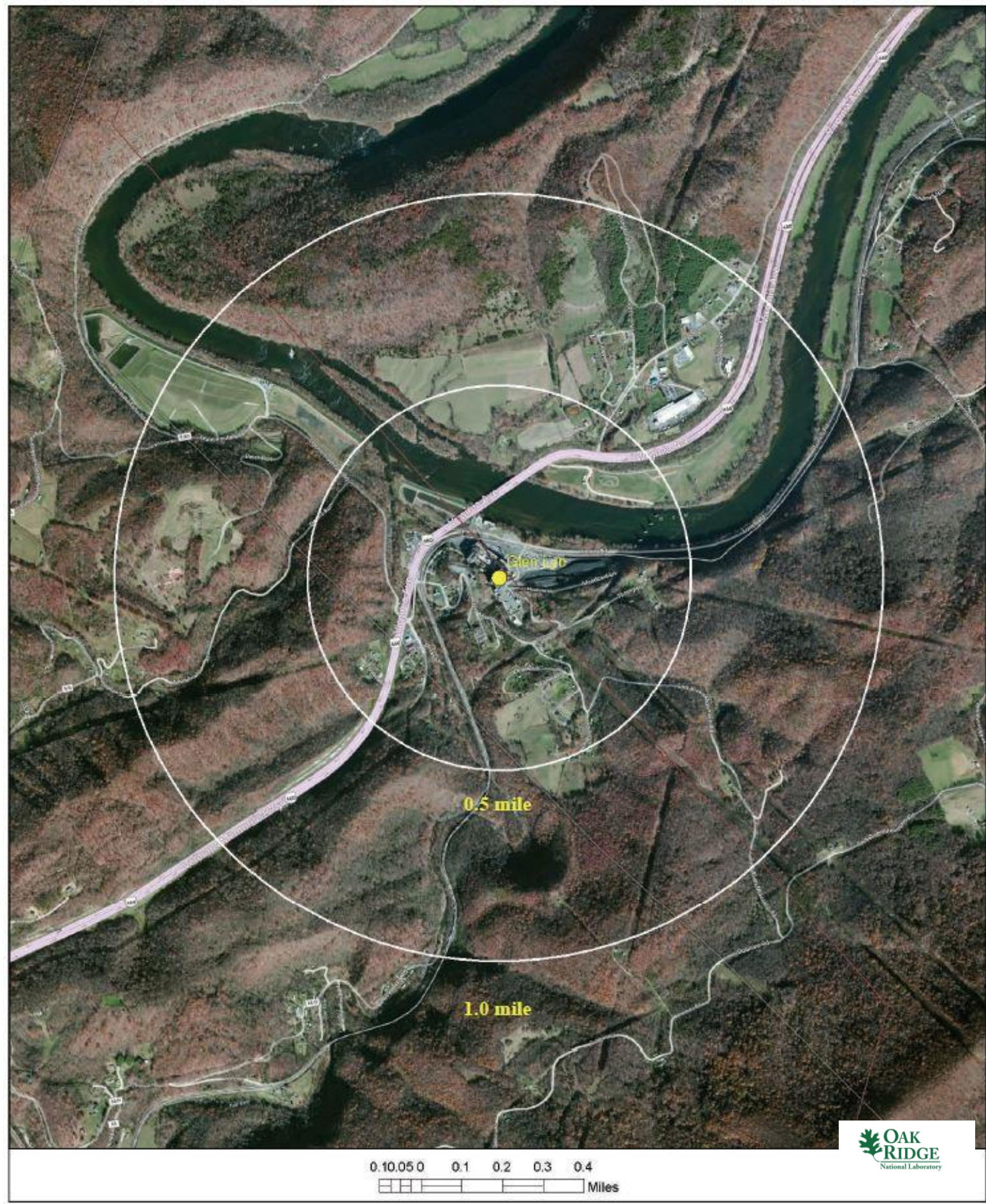

Fig. A.30. Satellite view of Glen Lyn Plant proximity. 


\section{A.4.4 Screening Criteria Overview}

Table A.13. Glen Lyn Plant siting criteria summary

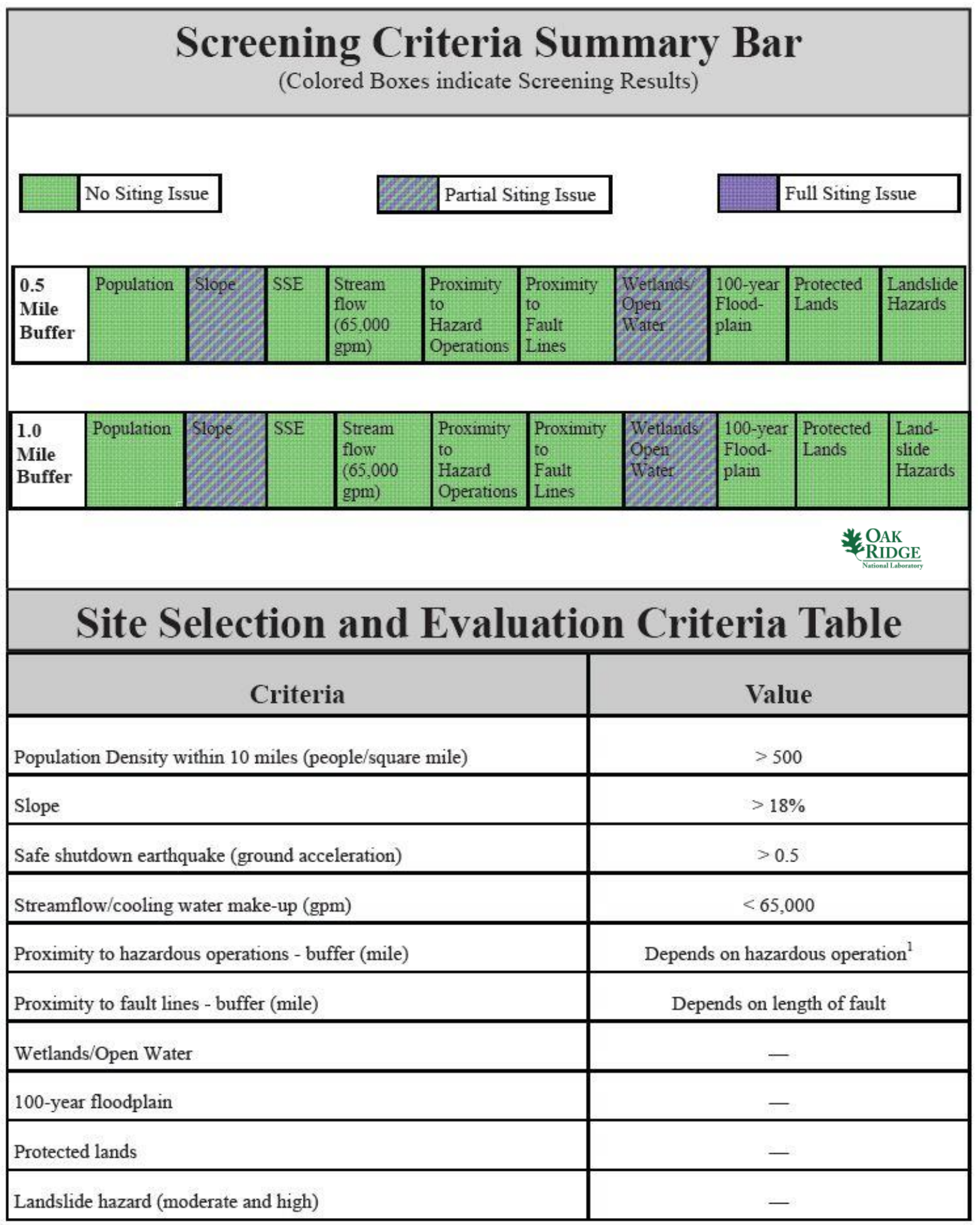

${ }^{1}$ Hazardous facilities (airports- 5 miles and oil refineries- -1 mile) 


\section{A.4.5 Composite Map and Individual Siting Issue Maps}

A composite map of SMR siting challenges to the Glen Lyn Plant is shown in Fig. A.31. The physical plant structures are located on land with no siting issues. Following this map are maps of the individual SMR siting criteria based on selected input values.

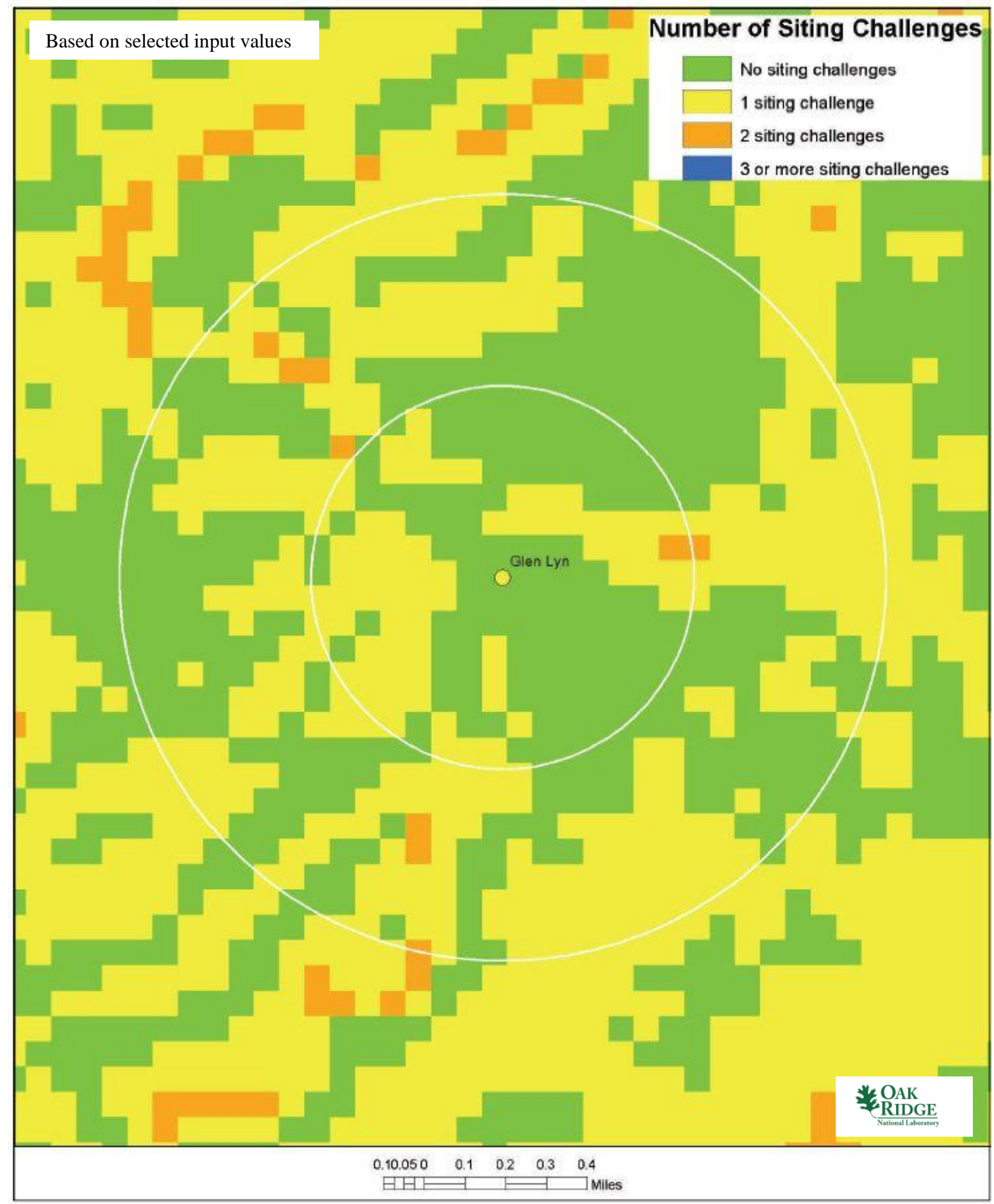

Fig. A.31. Glen Lyn Plant composite map. 

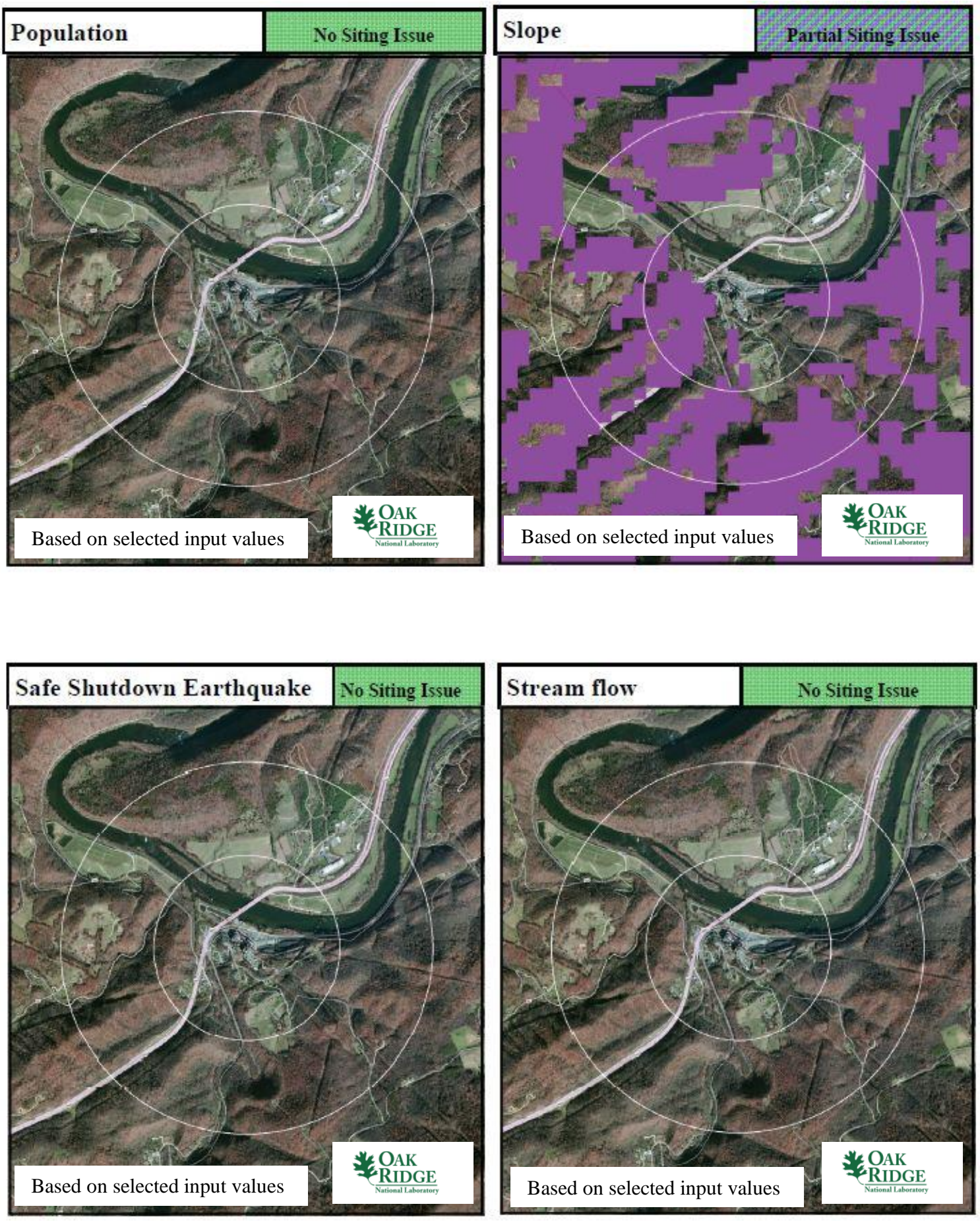

Glen Lyn Plant 

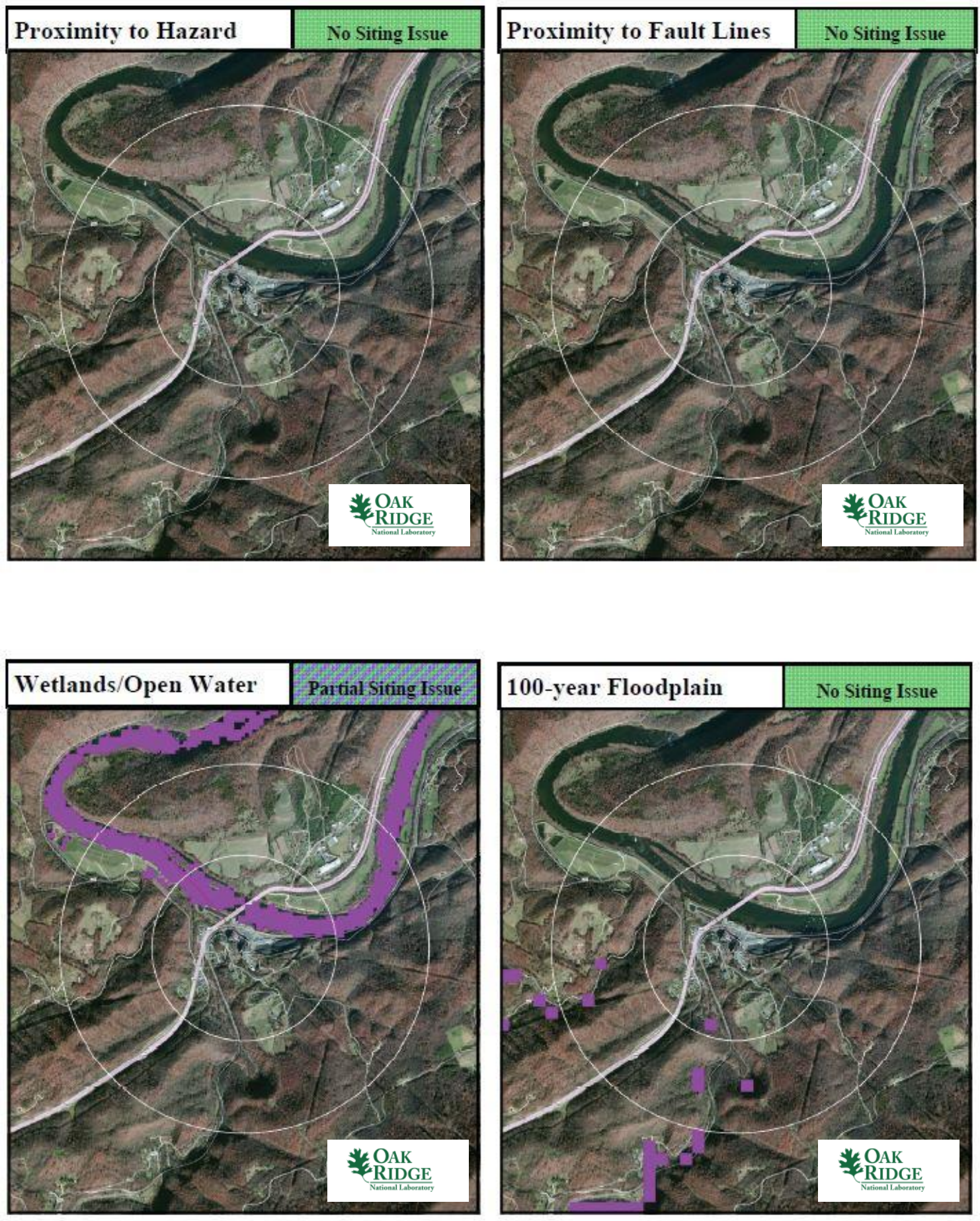

Glen Lyn Plant 

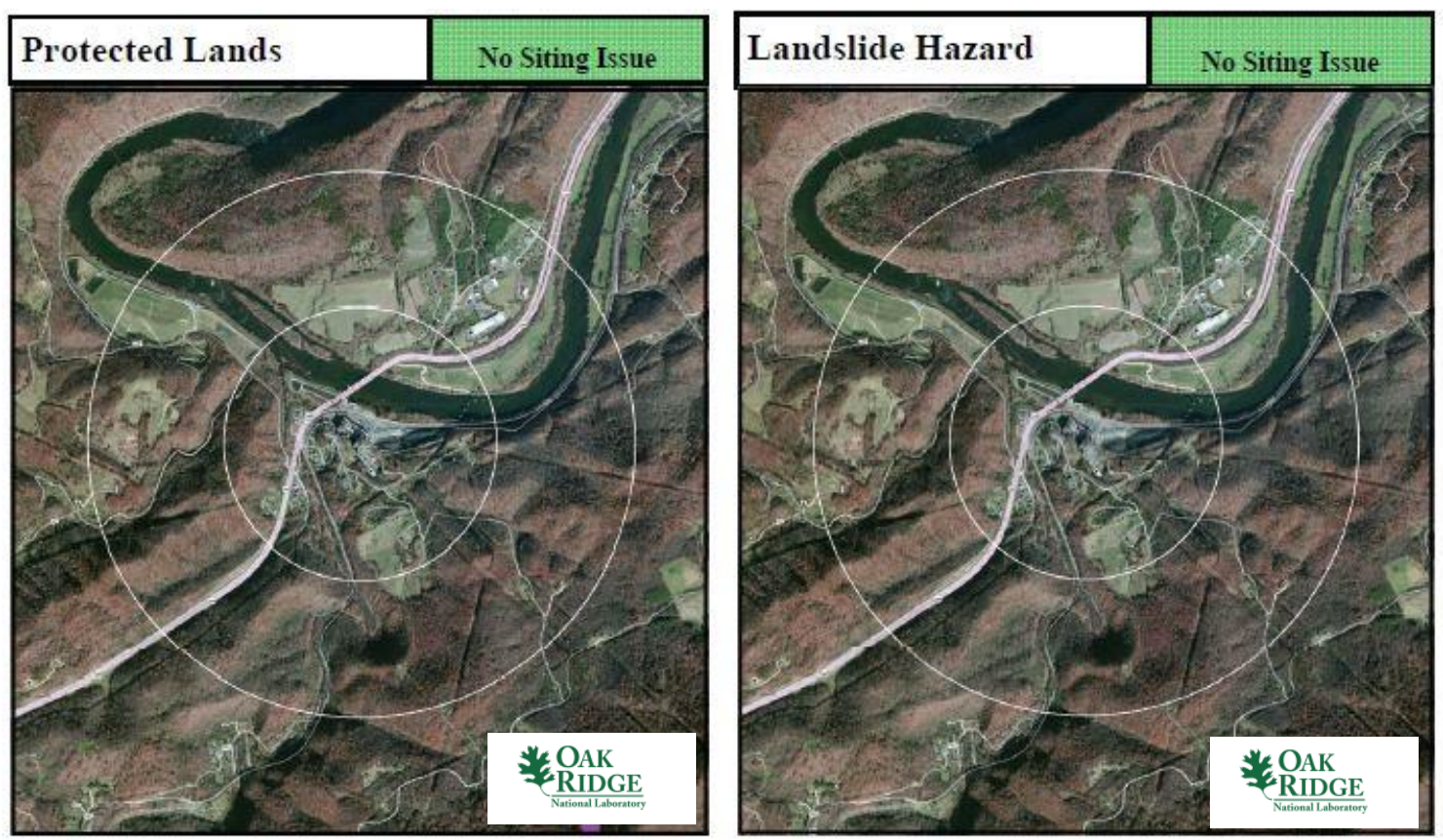

Glen Lyn Plant

\section{A.4.6 Site Evaluation}

American Electric Power does not operate or own a share of any nuclear power plants in the United States. Therefore, the utility would need to be mentored through the licensing process to build and operate an SMR. Additionally, there are numerous other electric power generation facilities within 100 miles of the Glen Lyn Plant to subsidize area power requirements. The site contains sufficient acreage to support siting an SMR.

From an environmental justice perspective, the community collectively appears to have achieved a reasonable level of education with median income levels typical of much of the United States. Therefore, siting an SMR at this location would not seem to be disenfranchising a less-educated or poverty-stricken community. Furthermore, the education level of the Glen Lyn Plant community would seem to support the higher-technology job opportunities provided by an SMR. The mayor of the community noted in a newspaper article that the incorporated 150-person town will probably cease to exist without the tax payments from the power plant.

As shown in Sects. A.0 and A.0, the Glen Lyn Plant site has partial SMR site screening issues with slope and wetlands/open waters. The slope issue is related to land away from the New River and does not directly affect land associated with the site. The wetlands/open waters issue reflects the adjacent New River and the associated 100-year floodplain and does not indicate any expected flooding potential at this location. Further visual inspection of the aerial imagery indicates that none of these should directly impact the siting of an SMR at this location. The remaining SMR site screening criteria are met site-wide for the values established in the updated SMR siting report.1

Highway 460 runs immediately adjacent to the Glen Lyn Plant site; that could make it difficult for a nuclear licensee to control land access to areas very near the plant location. The land within the arc of the highway is limited in size by the town and sloping hills. However, there is more level land available to the northeast of the site on the river. This utility-owned land may be better suited for any future SMR at this location. 
Therefore, when future load demands indicate the need for expanded generation capacity in this region, the utility could make the case for siting an SMR at this location. Because some occupied housing is located very near to this site, the utility would need to work closely with local leaders and civic groups to make the case for siting an SMR at this location. The site meets NRC RG 4.7 recommendations for population density without additional consideration for relaxed SMR population siting requirements based on reduced source term. The Glen Lyn Plant site meets multiple conventional standards for consideration of siting an SMR at the coal station location. 
A-36 


\section{A.5 H.B. Robinson Steam Plant}

\section{A.5.1 Location Detail}

As shown in Fig. A.32, the H.B. Robinson Steam Electric Plant is located in South Carolina, off South Carolina Highway 151 in Darlington County. Rail access is available onsite within 0.1 miles and barge access is available within 35 miles from the Wateree River. The closest town is Hartsville, South Carolina, with a population of approximately 7,764 people. The nearest city with a population in excess of 10,000 people is Florence, South Carolina, approximately 26 miles to the southeast of the H.B. Robinson Steam Electric Plant.

- Plant: H.B. Robinson Steam Electric Plant

- Utility: Duke Energy

- Coordinates: lat. $34.40318^{\circ} \mathrm{N}$, long. $80.15693^{\circ} \mathrm{W}$

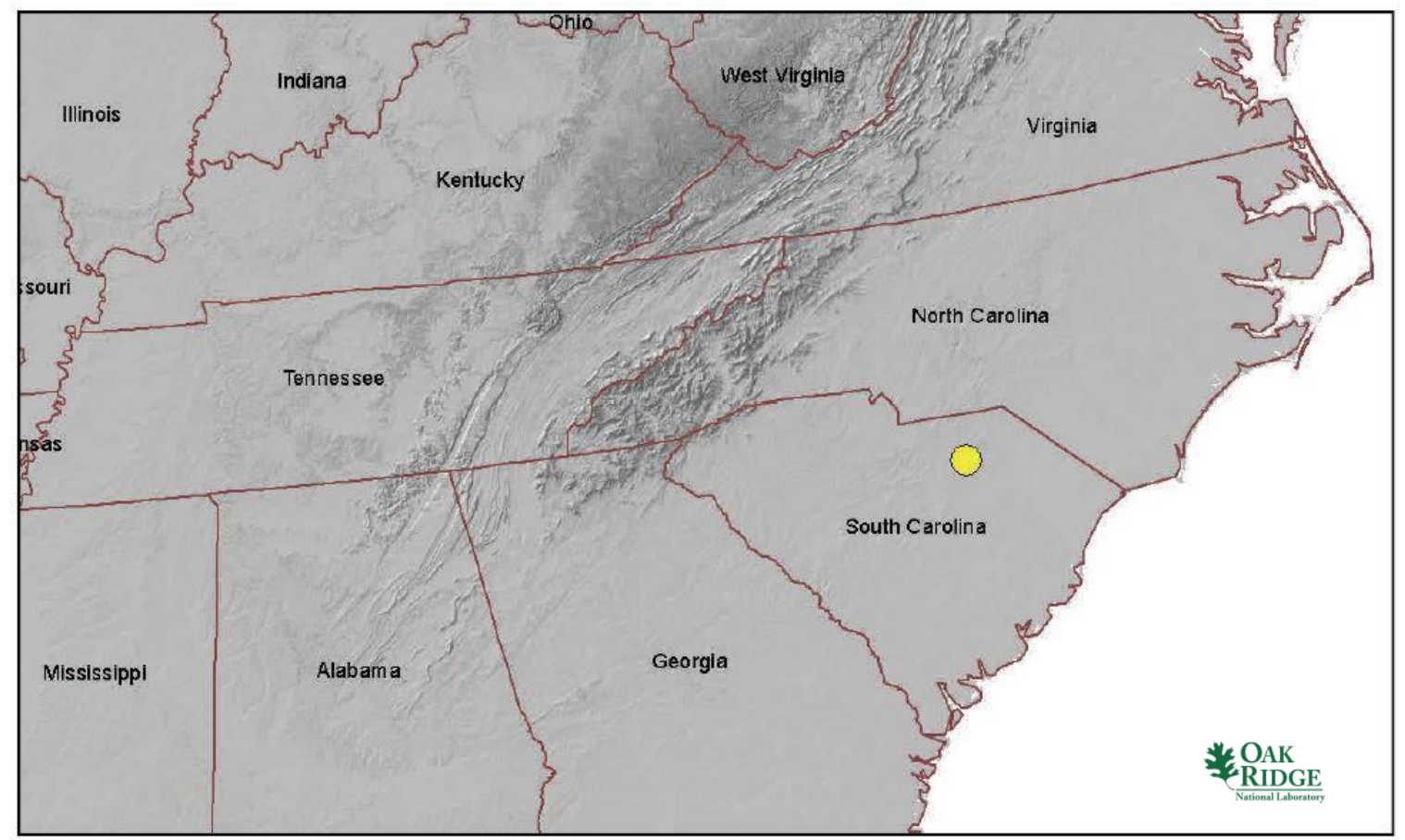

Fig. A.32. H.B. Robinson Steam Plant location map.

\section{A.5.2 Site Description and Status}

The H.B. Robinson Steam Electric Plant is a single-unit coal station along with a natural-gas fired combined cycle plant and nuclear power plant. The coal unit, commissioned in 1960, has a nameplate rating of $207 \mathrm{MW}(\mathrm{e})$. The site $15 \mathrm{MW}(\mathrm{e})$ natural gas facility began operation in 1968 and the $724 \mathrm{MW}(\mathrm{e})$ nuclear power plant began commercial operation in 1971. The coal unit ceased operation in October 2012. The operating units are cooled via once-through cooling from the adjacent lake Robinson.

The 600-acre H.B. Robinson site is 73 miles southeast of the 1,155 MW(e) coal-fired G. G. Allen Plant in North Carolina. The 207 MW(e) Saluda Dam hydroelectric project is about 65 miles southwest of the H.B. Robinson plant, and the 511 MW(e) Fairfield Pumped Storage project is about 67 miles west of the plant. 
As noted in Table A.14, the nearest major fault line based on USGS data is 976 miles west in Oklahoma. The maximum safe-shutdown earthquake for the site is below $0.3 \mathrm{~g}$ peak ground acceleration. More than $500,000 \mathrm{gpm}$ of cooling water makeup is available within 20 miles from the Great Pee Dee River.

However, more than 2000,000 gpm of cooling water makeup is available within 7 miles from the Lynches River, and more than 100,000 gpm of cooling water makeup is available within 0.3 miles from Black Creek. These latter sources are more than adequate for siting an SMR. Furthermore, Lake Robinson is immediately adjacent to the site.

The permanent population within 1 mile of the plant is approximately 800 people, yielding a population density of about 255 people per square mile. The permanent population within 10 miles of the plant is approximately 71,000 people, yielding a population density of approximately 223 people per square mile. According to the US EPA Environmental Justice website, there are 12,738 occupied housing units within 10 miles of the plant site based on 2000 US Census data. Further, over $70 \%$ of area adults over age 25 have a high school diploma or higher education. The median annual income for the area is between $\$ 25 \mathrm{~K}$ and $\$ 50 \mathrm{~K}$.

Table A.14. H.B. Robinson Steam Plant site statistics

\begin{tabular}{|c|c|c|c|}
\hline \multicolumn{2}{|l|}{$\begin{array}{l}\text { Population } \\
\text { Population Within }\end{array}$} & \multicolumn{2}{|l|}{$\begin{array}{l}\text { Utility } \\
\text { Distance to Grid Capacity }\end{array}$} \\
\hline $0.5 \mathrm{mi}$ & $<500$ & $>400 \mathrm{MWe}$ & $\sim 0.1 \mathrm{mi}$ \\
\hline $1 \mathrm{mi}$ & $\sim 800$ & $>800 \mathrm{MWe}$ & $\sim 32 \mathrm{mi}$ \\
\hline $5 \mathrm{mi}$ & $\sim 24,000$ & $>1600 \mathrm{MWe}$ & $\sim 36 \mathrm{mi}$ \\
\hline $10 \mathrm{mi}$ & $\sim 71,000$ & $>3200 \mathrm{MWe}$ & $\sim 150 \mathrm{mi}$ \\
\hline \multicolumn{2}{|c|}{ Nearest City with Population } & \multicolumn{2}{|c|}{ Distance to Cooling Water } \\
\hline$>10,000$ & Florence, $\mathrm{SC}$ & $>50,000 \mathrm{gpm}$ & $\sim 0.3 \mathrm{mi}$ (Black Creek) \\
\hline$>50,000$ & Rock Hill, SC & $>100,000 \mathrm{gpm}$ & $\sim 0.3 \mathrm{mi}$ (Black Creek) \\
\hline$>100,000$ & Columbia, SC & $>200,000 \mathrm{gpm}$ & $\sim 6.6$ mi (Lynches River) \\
\hline$>500,000$ & Charlotte, $\mathrm{NC}$ & $>500,000 \mathrm{gpm}$ & $\begin{array}{c}\sim 19 \mathrm{mi} \text { (Great Pee Dee } \\
\text { River) }\end{array}$ \\
\hline \multicolumn{2}{|l|}{ Geotechnical } & \multicolumn{2}{|l|}{ Accessibility } \\
\hline Max Earthquake Acceleration & $<0.3 \mathrm{~g}$ & Distance to Major Roadway & $\sim 0.6 \mathrm{mi}(\mathrm{SR} 151)$ \\
\hline Max Slope & $\sim 6 \%$ & Distance to Water Transport & $\sim 35 \mathrm{mi}$ (Wateree River) \\
\hline Nearest Fault Line & $\sim 976 \mathrm{mi}$ (Oklahoma) & Distance to Rail Transport & $\sim 0.1 \mathrm{mi}(\mathrm{CSXT})$ \\
\hline Nearest Hazard Site & $\begin{array}{l}\sim 27 \mathrm{mi} \text { ( Airport- } \\
\text { Florence Regional) }\end{array}$ & Distance to Airport & $\sim 27 \mathrm{mi}$ (Florence Regional) \\
\hline
\end{tabular}




\section{A.5.3 Aerial Imagery}

The aerial imagery in Fig. A.33 indicates the H.B. Steam Electric Plant. Housing is visible within a 1 mile radius of the plant site. The Robinson nuclear power plant containment structure is also visible in the middle of the image.

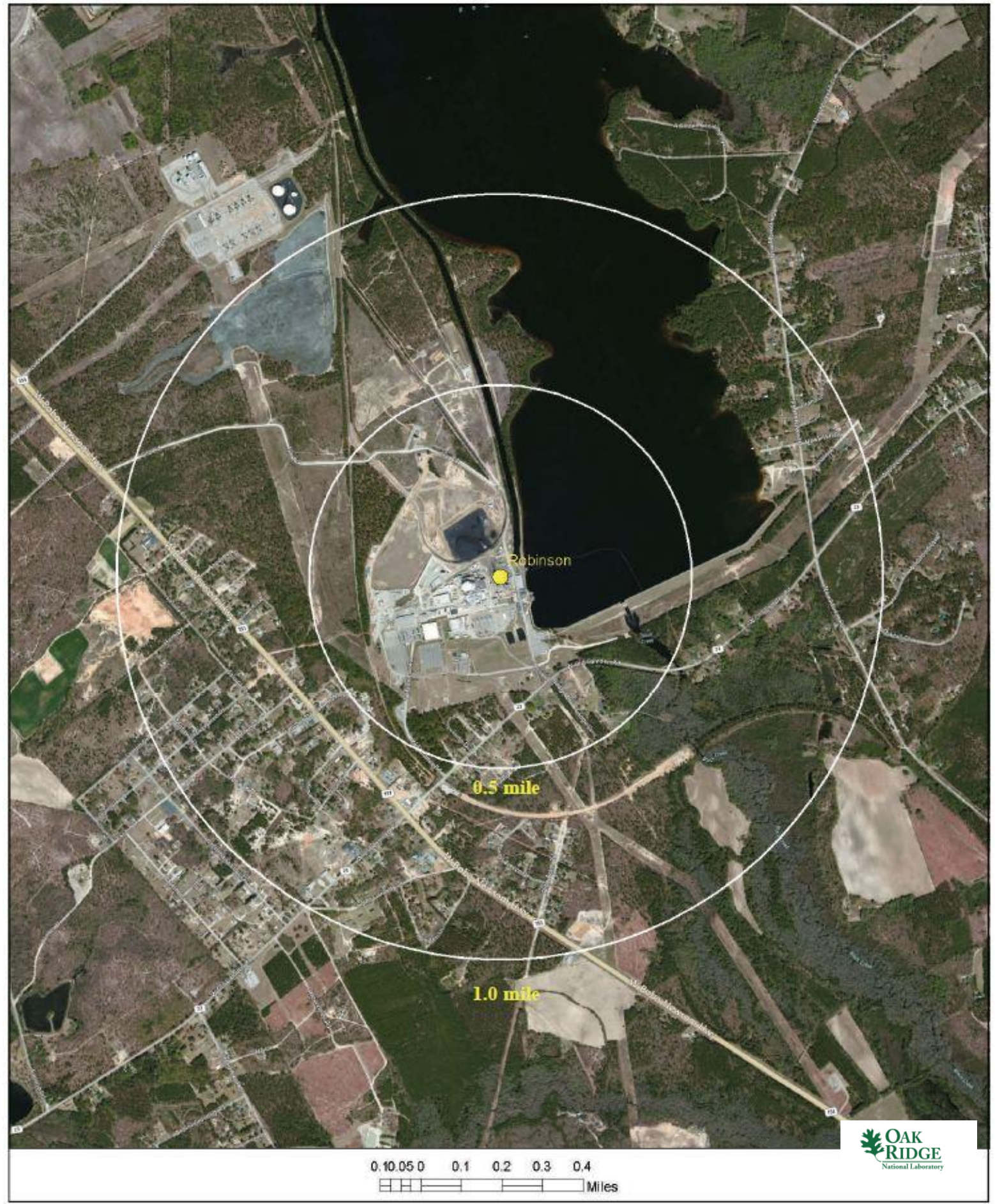

Fig. A.33. Satellite view of H.B. Robinson Steam Plant proximity. 


\section{A.5.4 Screening Criteria Overview}

Table A.15. H.B. Robinson Steam Plant siting criteria summary

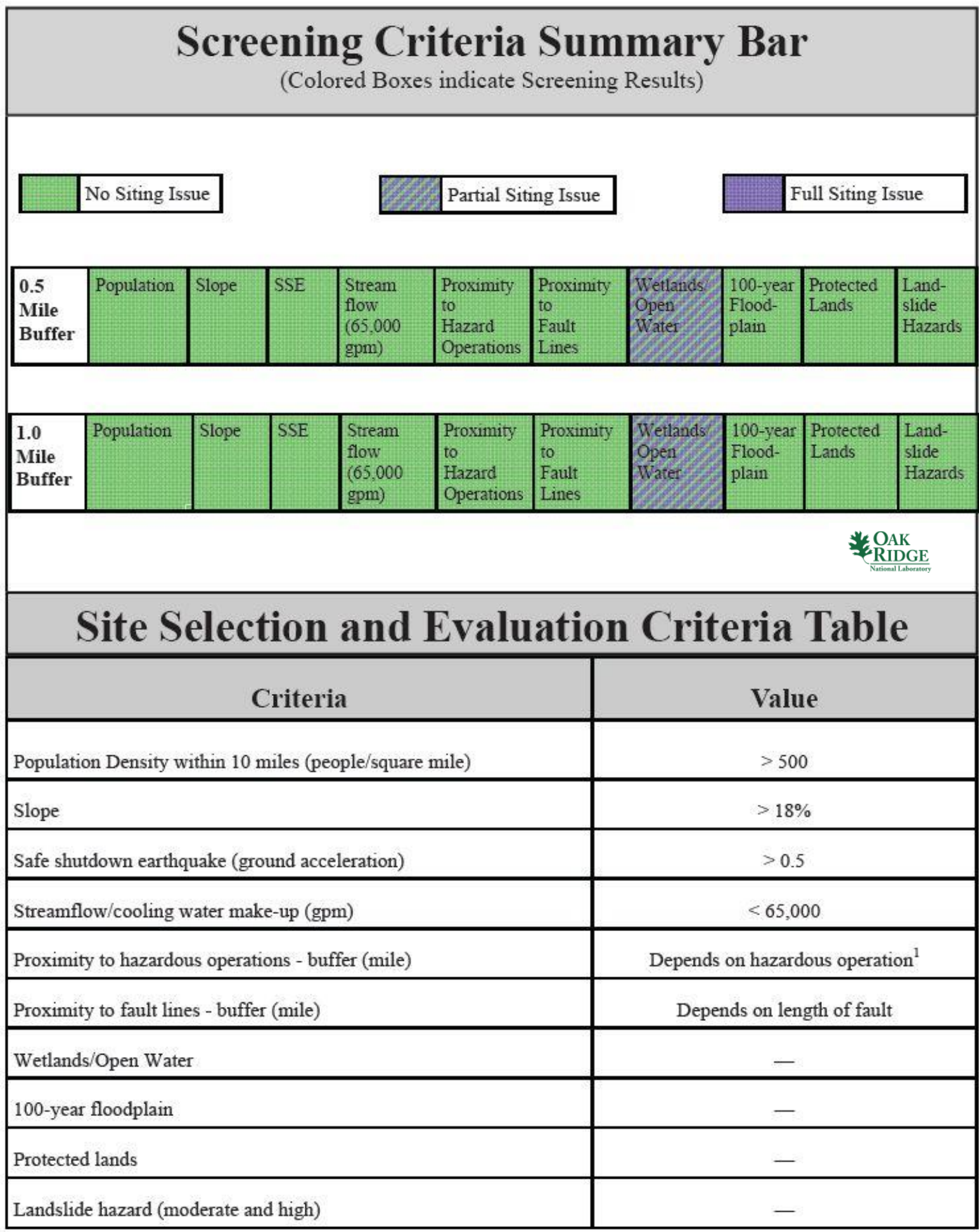

${ }^{1}$ Hazardous facilities (airports- 5 miles and oil refineries- -1 mile) 


\section{A.5.5 Composite Map and Individual Siting Issue Maps}

A composite map of SMR siting challenges to the H.B. Steam Electric Plant is shown in Fig. A.34. The physical plant structures are located on land that meets all specified SMR siting parameters. Following this map are maps of the individual SMR siting criteria based on selected input values.

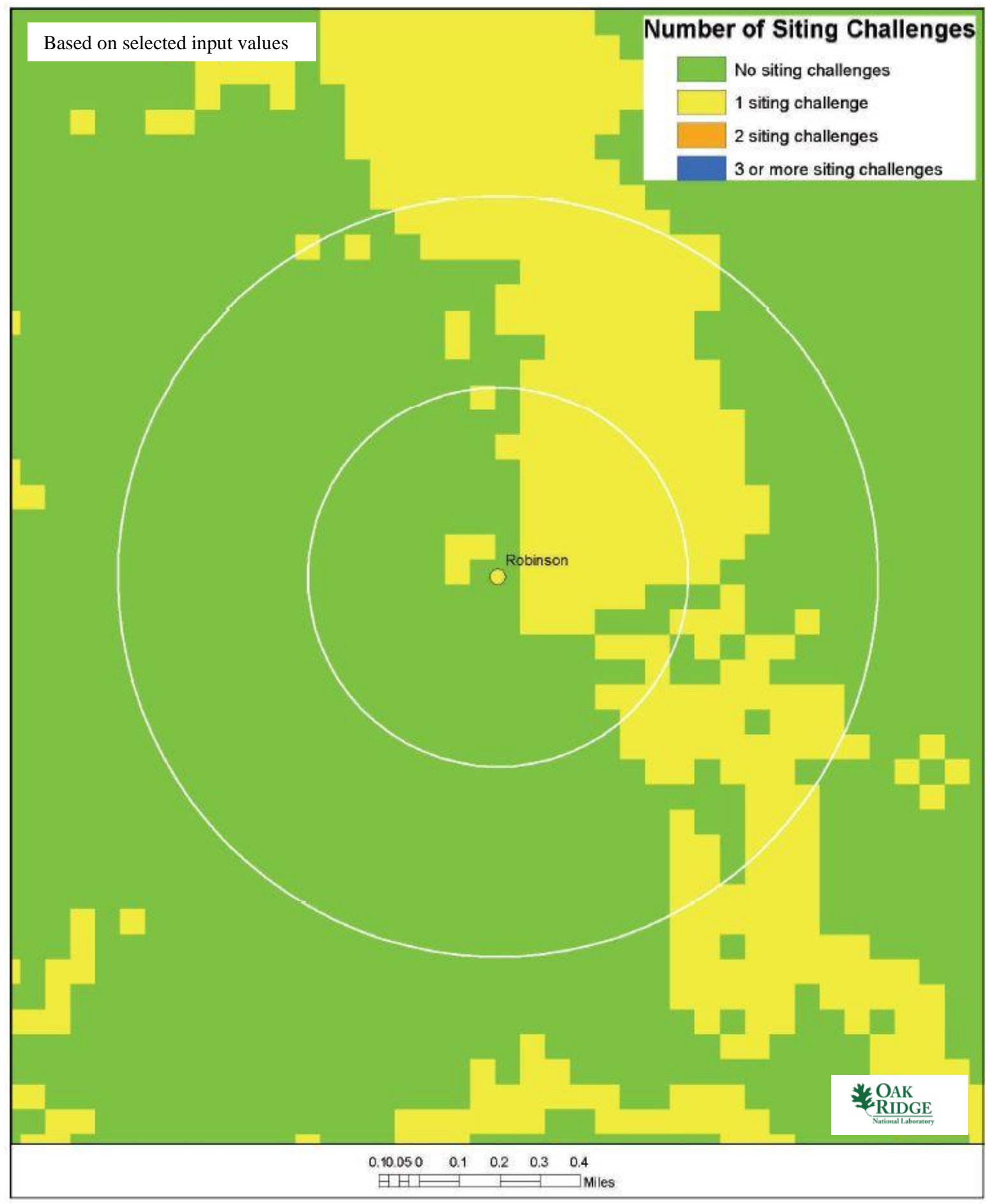

Fig. A.34. H.B. Robinson Steam Plant composite map. 

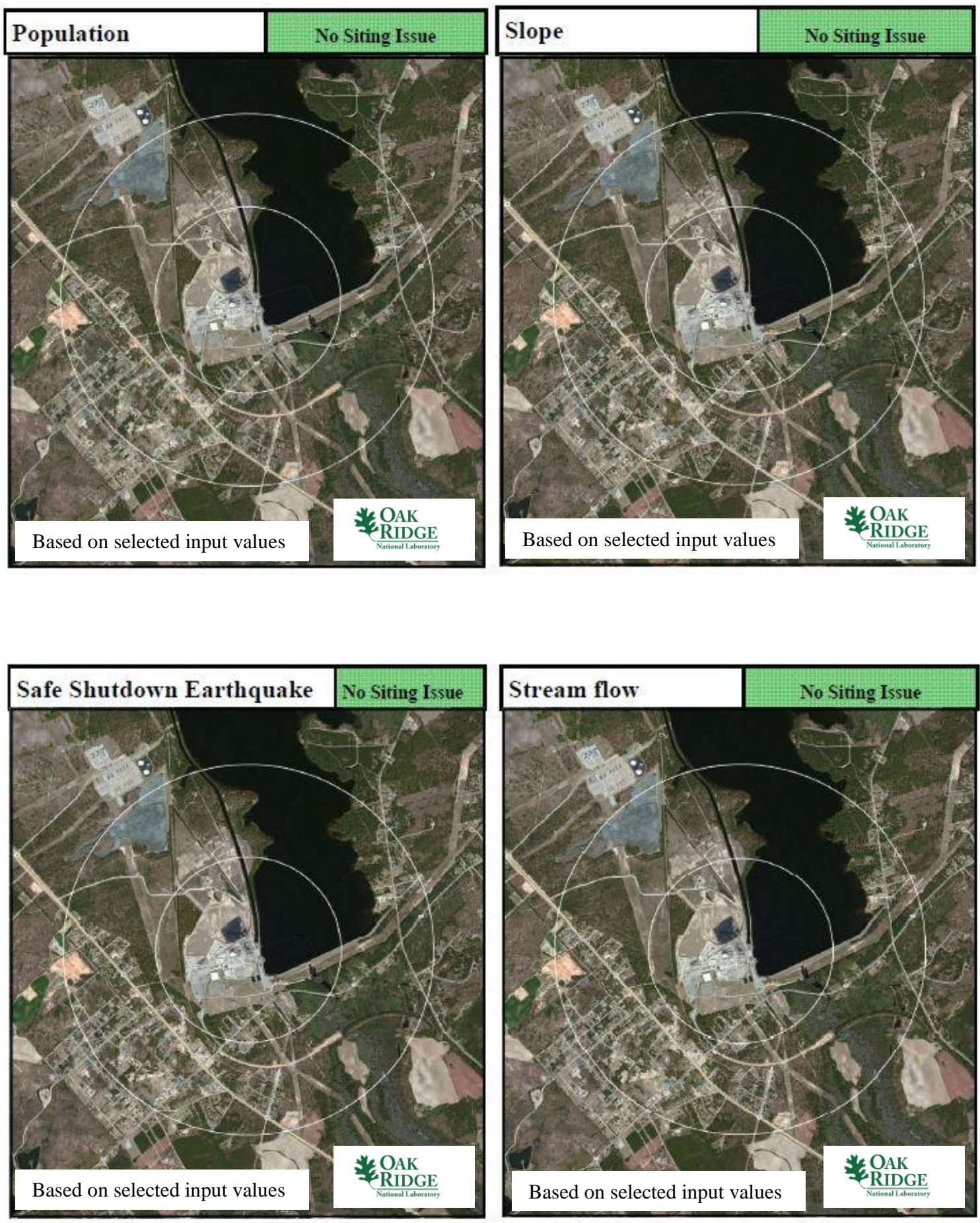

H.B. Robinson Steam Plant 

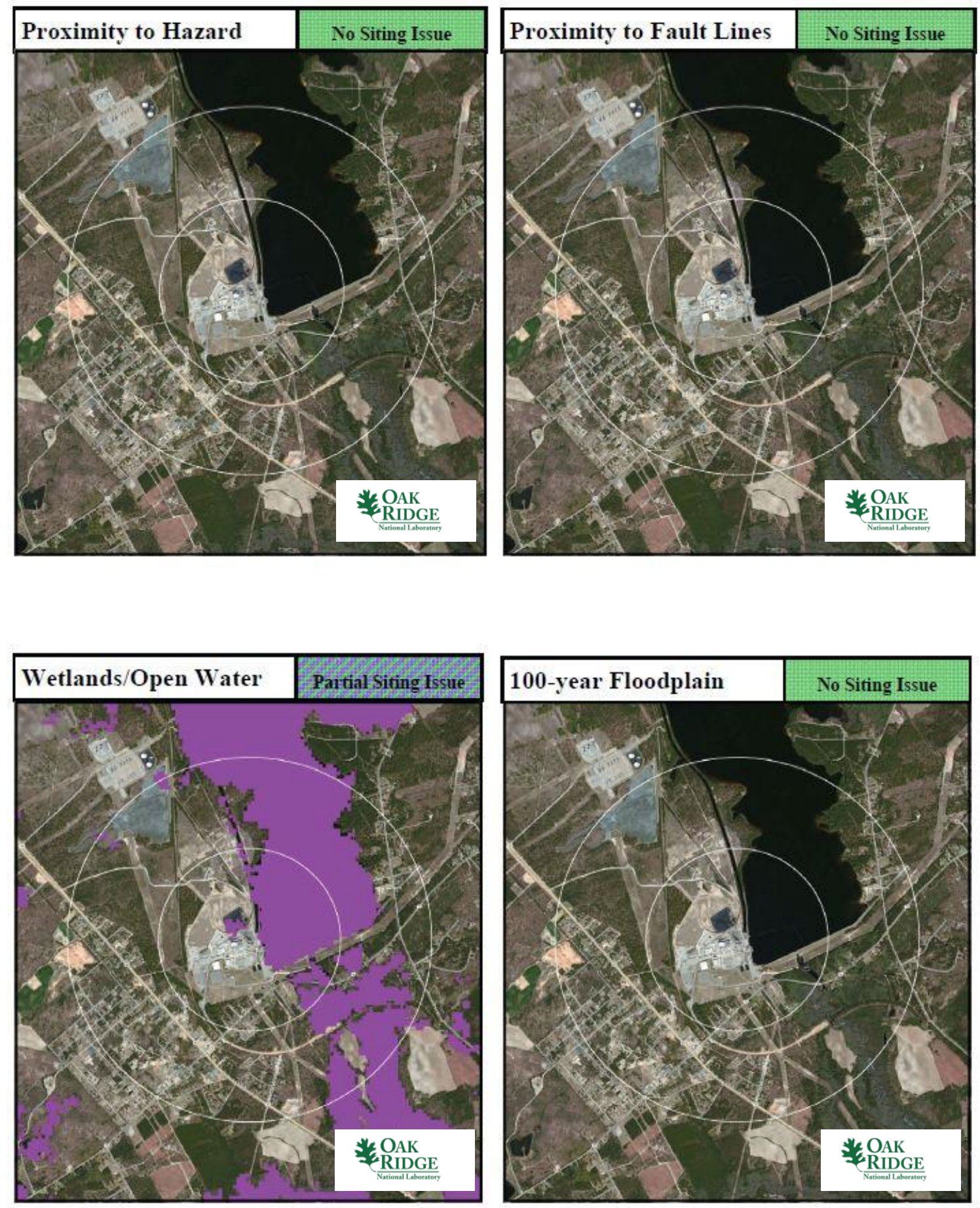

H.B. Robinson Steam Plant 

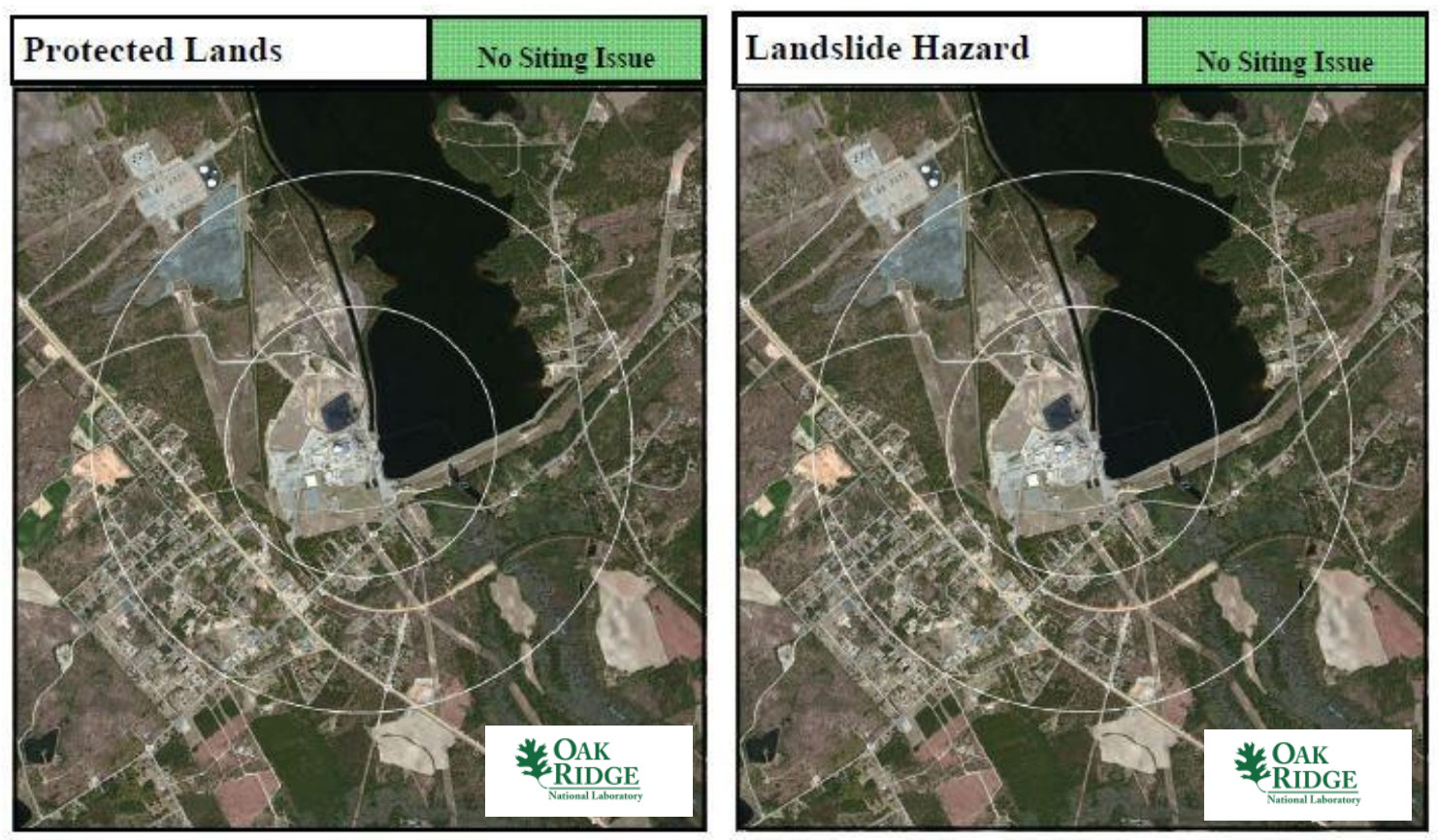

H.B. Robinson Steam Plant

\section{A.5.6 Site Evaluation}

Duke Energy merged with Progress Energy in July 2012. The resultant corporation, Duke Energy, owns and operates 12 nuclear power plants in North Carolina, South Carolina, and Florida. Also, Duke Energy has applied for a COL for six nuclear plants in Florida, South Carolina, and North Carolina. Therefore, Duke Energy has the licensing experience to operate an SMR at this site. The site contains sufficient acreage to support siting an SMR. In addition, co-locating an SMR with an existing nuclear plant would have the added benefit of sharing logistical and security resources.

From an environmental justice perspective, the community collectively appears to have achieved a reasonable level of education with median income levels typical of much of the United States. Therefore, siting an SMR at this location would not seem to be disenfranchising a less-educated or poverty-stricken community. Furthermore, the education level of H.B. Robinson Steam Electric Plant community would seem to support the higher-technology job opportunities provided by an SMR.

As shown in Sects. A.0 and A.0, the H.B. Robinson Steam Electric Plant has a partial SMR site screening issue with wetlands/open waters. The wetlands/open waters issue exists because the H.B. Robinson Steam Electric Plant is located on the shore of Lake H.B. Robinson. The lake was created by Progress Energy with the construction of Lake Robinson Dam on Black Creek in 1960. Further visual inspection of the aerial imagery indicates that this issue should not directly impact the siting of an SMR at this location. The remaining SMR site screening criteria are met site-wide for the values established in the updated SMR siting report.1

The US EPA conducted a coal combustion residuals impoundment assessment of the H.B. Robinson Steam Electric Plant in February 2011. The US EPA found the ash pond dike embankment and spillway to be structurally sound.

The retired H.B. Robinson Steam Electric Plant coal plant is located next to an operating nuclear power plant. If future energy demand requires additional generation capacity at this grid location, an SMR would make this site a multi-faceted energy park. The site meets current NRC RG 4.7 recommendations for population density without additional consideration for relaxed SMR population siting requirements 
based on reduced source term. The H.B. Robinson Steam Electric Plant site meets multiple conventional standards for consideration of siting an SMR at the coal station location. 
A-46 


\section{A.6 Hennepin Power Station}

\section{A.6.1 Location Detail}

As shown in Fig. A.35, the Hennepin Power Station is located in northern Illinois. More specifically, the plant is located along the Illinois River off County Road 800 E in Putnam County, Illinois. Highway 71 and Interstate 180 are accessible approximately 3 miles to the south. Rail access is available onsite within 0.1 miles and barge access is available within 0.1 miles from the adjacent Illinois River. The closest town is Hennepin, Illinois, with a population of approximately 758 people. The nearest city with a population in excess of 10,000 people is Ottawa, Illinois, approximately 24.7 miles to the northeast of the Hennepin Power Station.

- Plant: Hennepin Power Station

- Utility: Dynegy Midwest Generation, Inc.

- Coordinates: lat. $41.30337^{\circ} \mathrm{N}$, long. $89.31552^{\circ} \mathrm{W}$

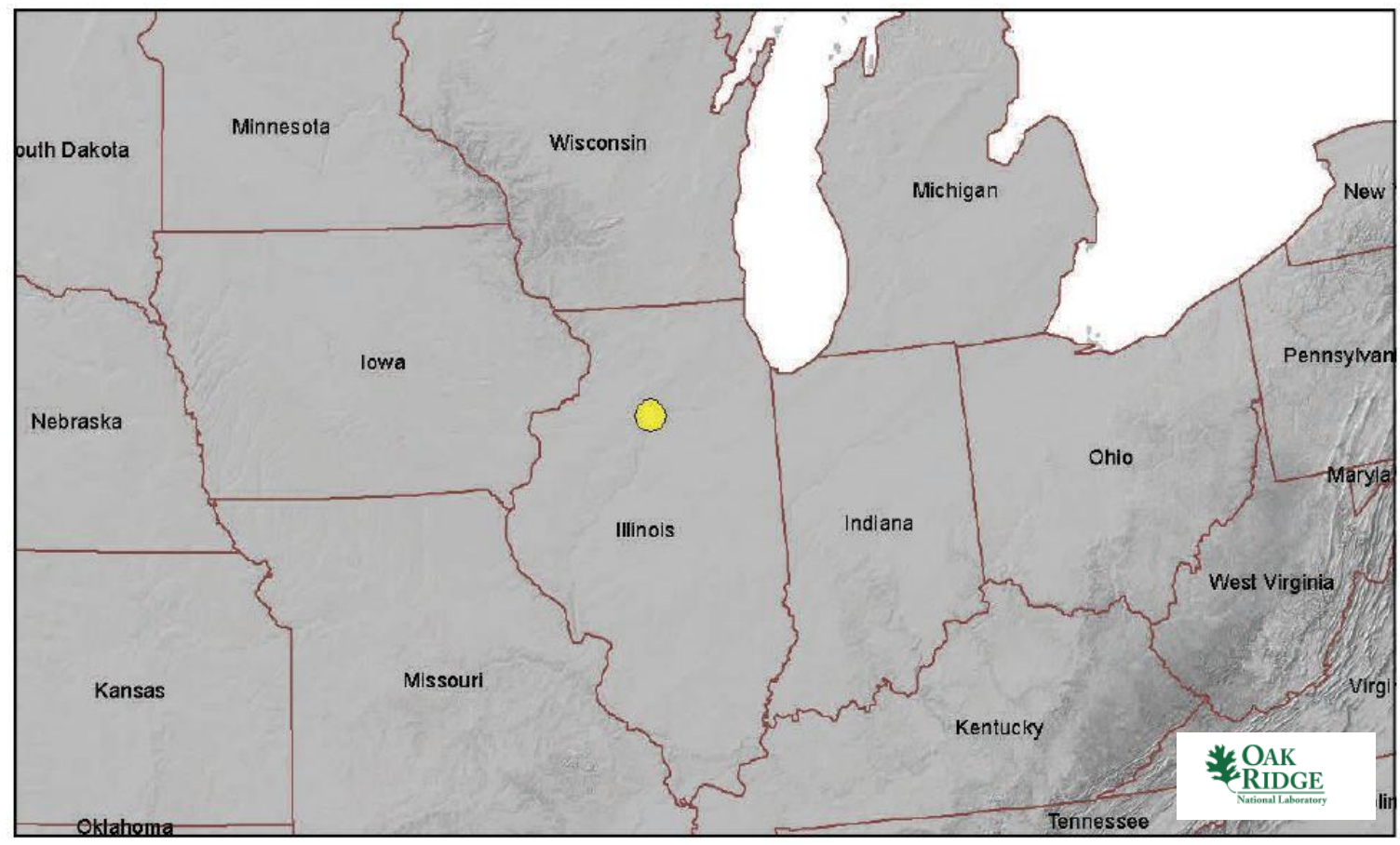

Fig. A.35. Hennepin Power Station location map.

\section{A.6.2 Site Description and Status}

The Hennepin Power Station is a two-unit coal station owned and operated by Dynegy Midwest Generation, Inc., a subsidiary of Dynegy, Inc. One of the fossil units, commissioned in 1953, is rated at $75 \mathrm{MW}(\mathrm{e})$ and the second unit, commissioned in 1959, is rated at $231 \mathrm{MW}(\mathrm{e})$ for a total site capacity of $306 \mathrm{MW}(\mathrm{e})$. These units are operated as base load units. The units are cooled by once-through cooling from the adjacent Illinois River.

The Hennepin plant is situated on roughly 500 acres on the Illinois River approximately 52 miles south of the 2,336 MW(e) Byron nuclear facility and 33 miles west of the 2,288 MW(e) LaSalle nuclear facility. The $488 \mathrm{MW}$ (e) coal-fired Havana plant also operated by Dynegy is approximately 81 miles southwest of the Hennepin plant. The 1,320 MW(e) coal-fired Juliet 29 plant operated by Edison International is 
56 miles east of the Hennepin site. A 1,256 MW(e) gas-fired plant operated by Dynegy is 62 miles east of the Hennepin site.

As noted in Table A.16, the nearest major fault line based on USGS data is 560 miles southwest in Kansas. The maximum safe-shutdown earthquake for the site is below $0.3 \mathrm{~g}$ peak ground acceleration. More than 500,000 gpm of cooling water makeup is available from the adjacent Illinois River.

The permanent population within 1 mile of the plant is approximately 700 people, yielding a population density of about 223 people per square mile. The permanent population within 10 miles of the plant is approximately 76,000 people, yielding a population density of about 242 people per square mile.

According to the US EPA Environmental Justice website, there are 11,664 occupied housing units within 10 miles of the plant site based on 2000 US Census data. Further, more than $80 \%$ of area adults over age 25 have a high school diploma or higher education. The median annual income for the area is between $\$ 25 \mathrm{~K}$ and $\$ 50 \mathrm{~K}$.

Table A.16. Hennepin Power Station site statistics

\begin{tabular}{|c|c|c|c|}
\hline \multicolumn{2}{|l|}{$\begin{array}{l}\text { Population } \\
\text { Population Within }\end{array}$} & \multicolumn{2}{|l|}{$\begin{array}{l}\text { Utility } \\
\text { Distance to Grid Capacity }\end{array}$} \\
\hline $0.5 \mathrm{mi}$ & $<500$ & $>400 \mathrm{MWe}$ & $\sim 0.5 \mathrm{mi}$ \\
\hline $1 \mathrm{mi}$ & $\sim 700$ & $>800 \mathrm{MWe}$ & $\sim 0.5 \mathrm{mi}$ \\
\hline $5 \mathrm{mi}$ & $\sim 14,500$ & $>1600 \mathrm{MWe}$ & $\sim 2.8 \mathrm{mi}$ \\
\hline $10 \mathrm{mi}$ & $\sim 76,000$ & $>3200 \mathrm{MWe}$ & $\sim 0.9 \mathrm{mi}$ \\
\hline \multicolumn{2}{|c|}{ Nearest City with Population } & \multicolumn{2}{|c|}{ Distance to Cooling Water } \\
\hline$>10,000$ & Ottawa, IL & $>50,000 \mathrm{gpm}$ & $\sim 0.1 \mathrm{mi}$ (Illinois River) \\
\hline$>50,000$ & Bloomington, IL & $>100,000 \mathrm{gpm}$ & $\sim 0.1 \mathrm{mi}$ (Illinois River) \\
\hline$>100,000$ & Peoria, IL & $>200,000 \mathrm{gpm}$ & $\sim 0.1 \mathrm{mi}$ (Illinois River) \\
\hline$>500,000$ & Chicago, IL & $>500,000 \mathrm{gpm}$ & $\sim 0.1 \mathrm{mi}$ (Illinois River) \\
\hline \multicolumn{2}{|l|}{ Geotechnical } & \multicolumn{2}{|l|}{ Accessibility } \\
\hline Max Earthquake Acceleration & $<0.3 \mathrm{~g}$ & Distance to Major Roadway & $\sim 3.0 \mathrm{mi}(\mathrm{SR} 71)$ \\
\hline Max Slope & $\sim 8 \%$ & Distance to Water Transport & $\sim 0.1 \mathrm{mi}$ (Illinois River) \\
\hline Nearest Fault Line & $\sim 560 \mathrm{mi}$ (Kansas) & Distance to Rail Transport & $\sim 0.1 \mathrm{mi}(\mathrm{NS})$ \\
\hline Nearest Hazard Site & $\begin{array}{l}45 \text { mi (Airport- } \\
\text { Greater Peoria Regional) }\end{array}$ & Distance to Airport & $\begin{array}{l}\sim 45 \mathrm{mi} \text { (Greater Peoria } \mathrm{Re}- \\
\text { gional) }\end{array}$ \\
\hline
\end{tabular}




\section{A.6.3 Aerial Imagery}

The aerial imagery in Fig. A.36 indicates the Hennepin Power Station. No housing is visible within a 1 mile radius of the plant site.

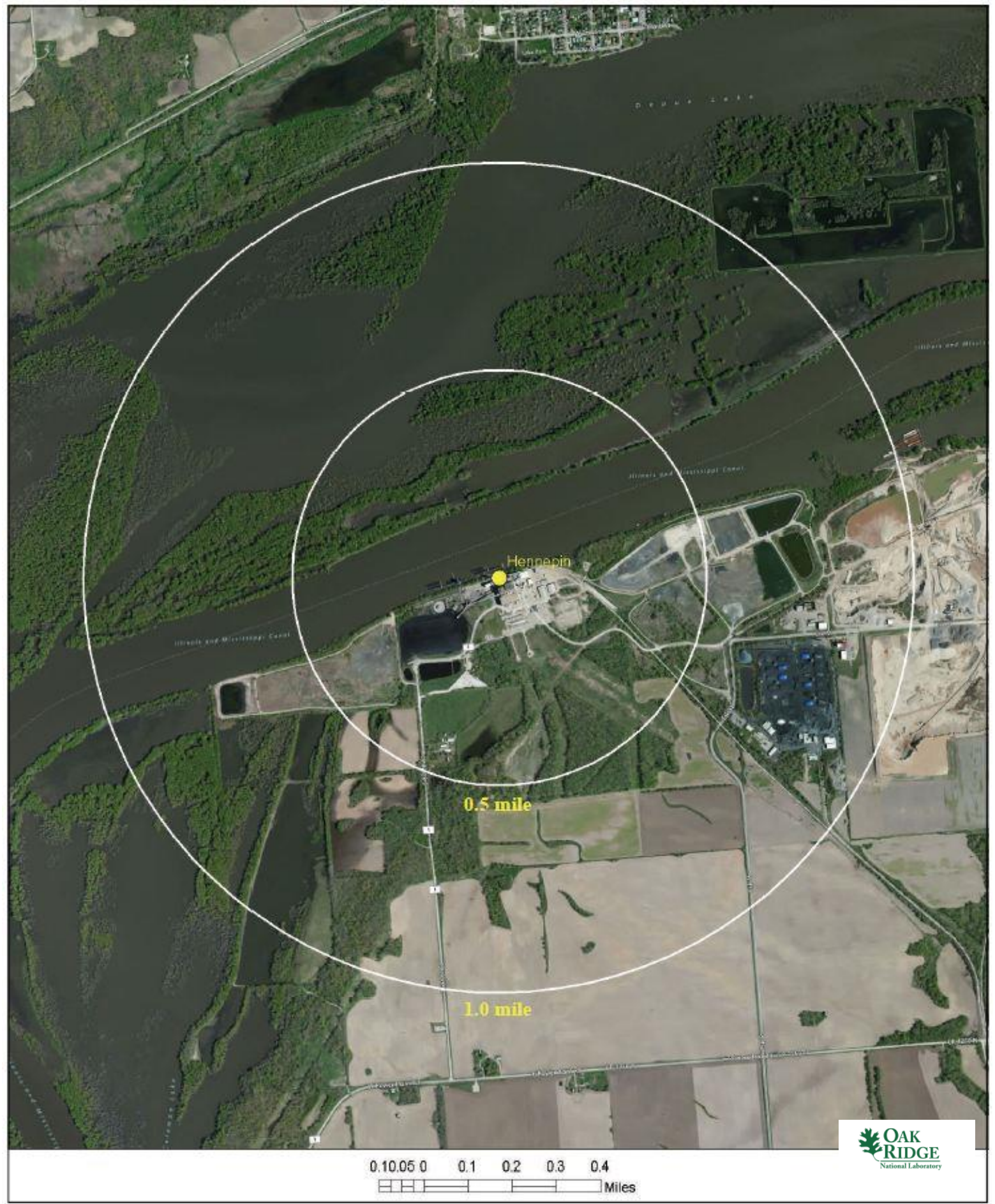

Fig. A.36. Satellite view of Hennepin Power Station proximity. 


\section{A.6.4 Screening Criteria Overview}

Table A.17. Hennepin Power Station siting criteria summary

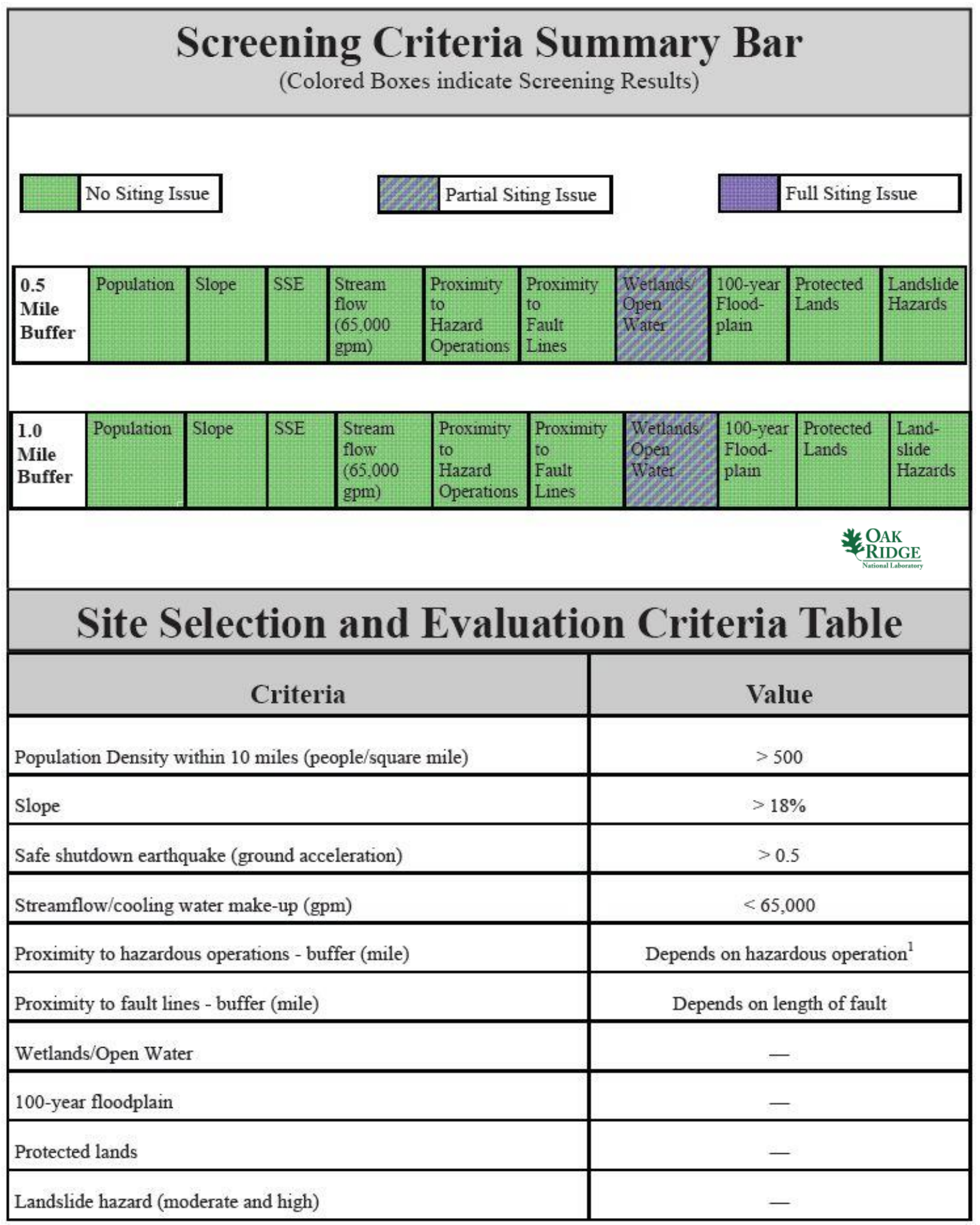

${ }^{1}$ Hazardous facilities (airports- 5 miles and oil refineries- -1 mile) 


\section{A.6.5 Composite Map and Individual Siting Issue Maps}

A composite map of SMR siting challenges to the Hennepin Power Station is shown in Fig. A.37. The physical plant structures are just south of the indicated central point, located on land that meets all the selected SMR siting criteria. Following this map are maps of the individual SMR siting criteria based on selected input values.

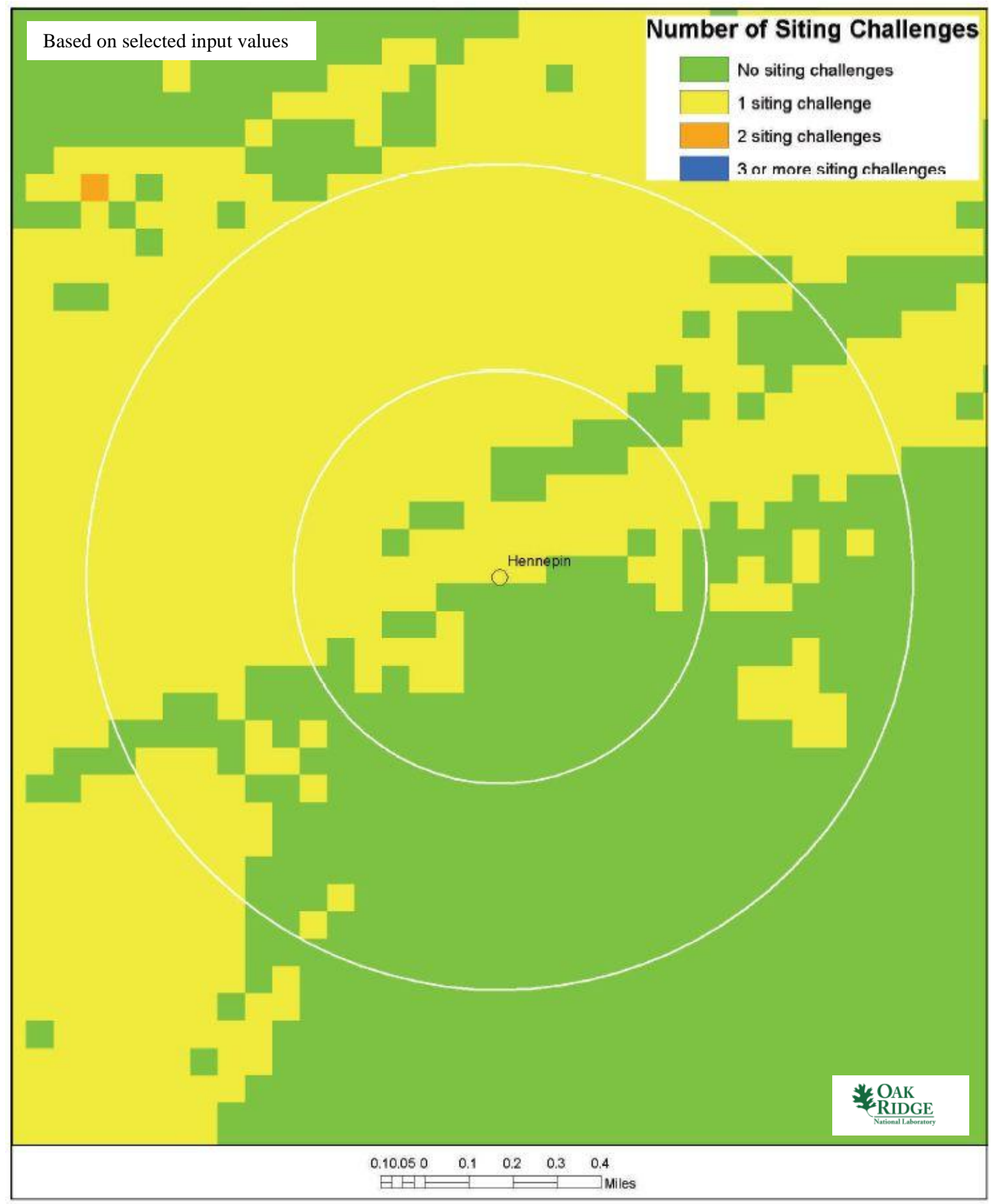

Fig. A.37. Hennepin Power Station composite map. 

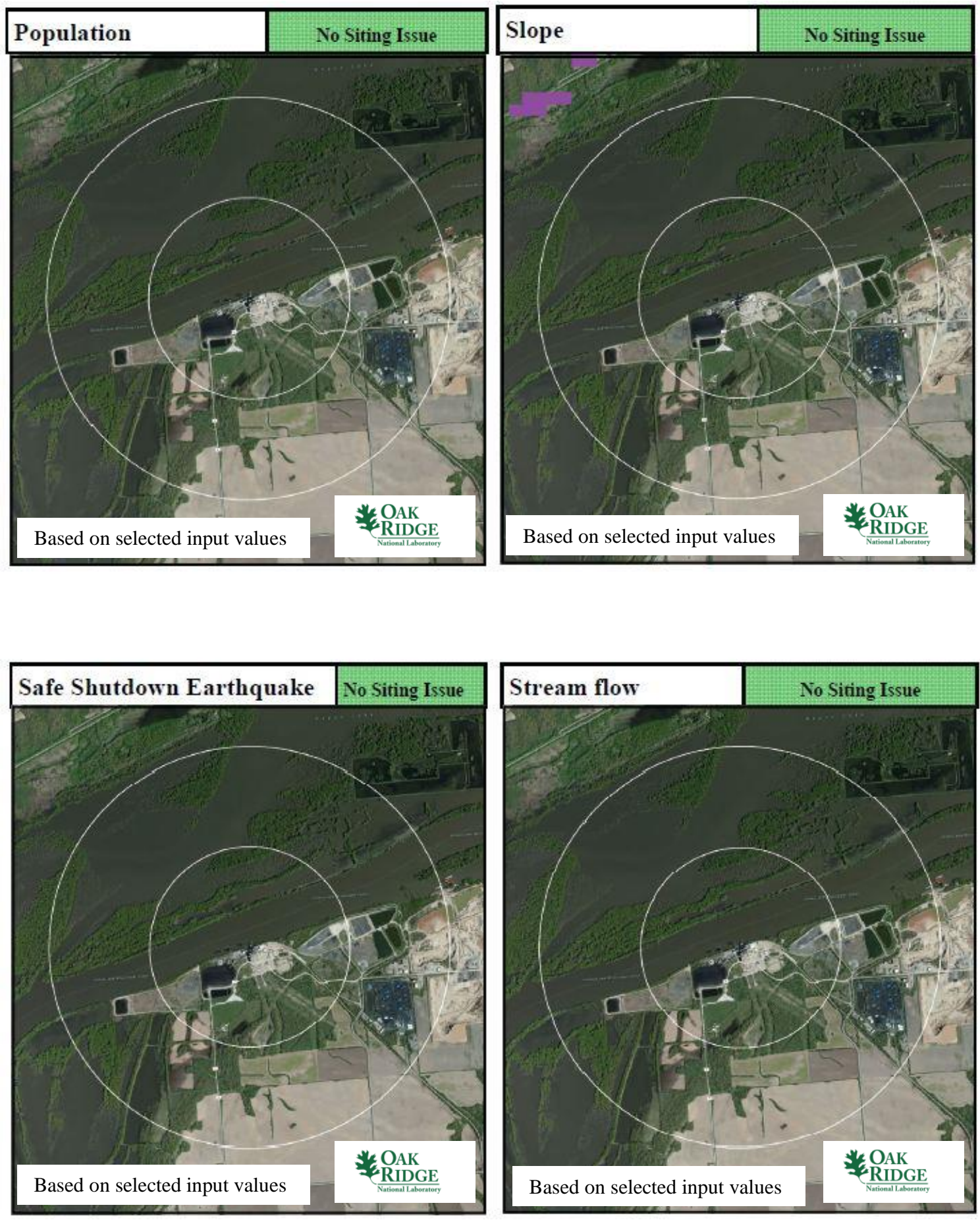

Hennepin Power Station 

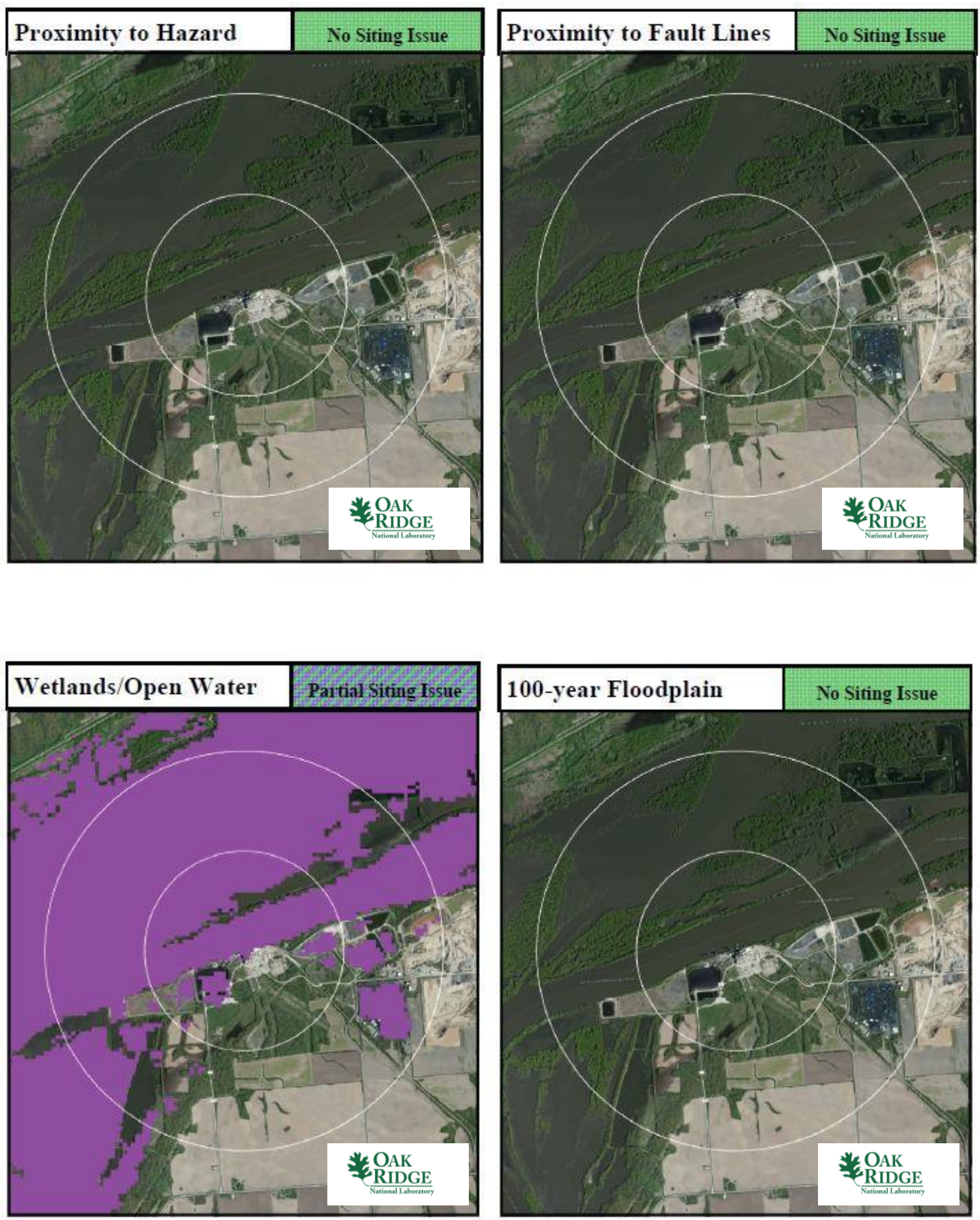

Hennepin Power Station 

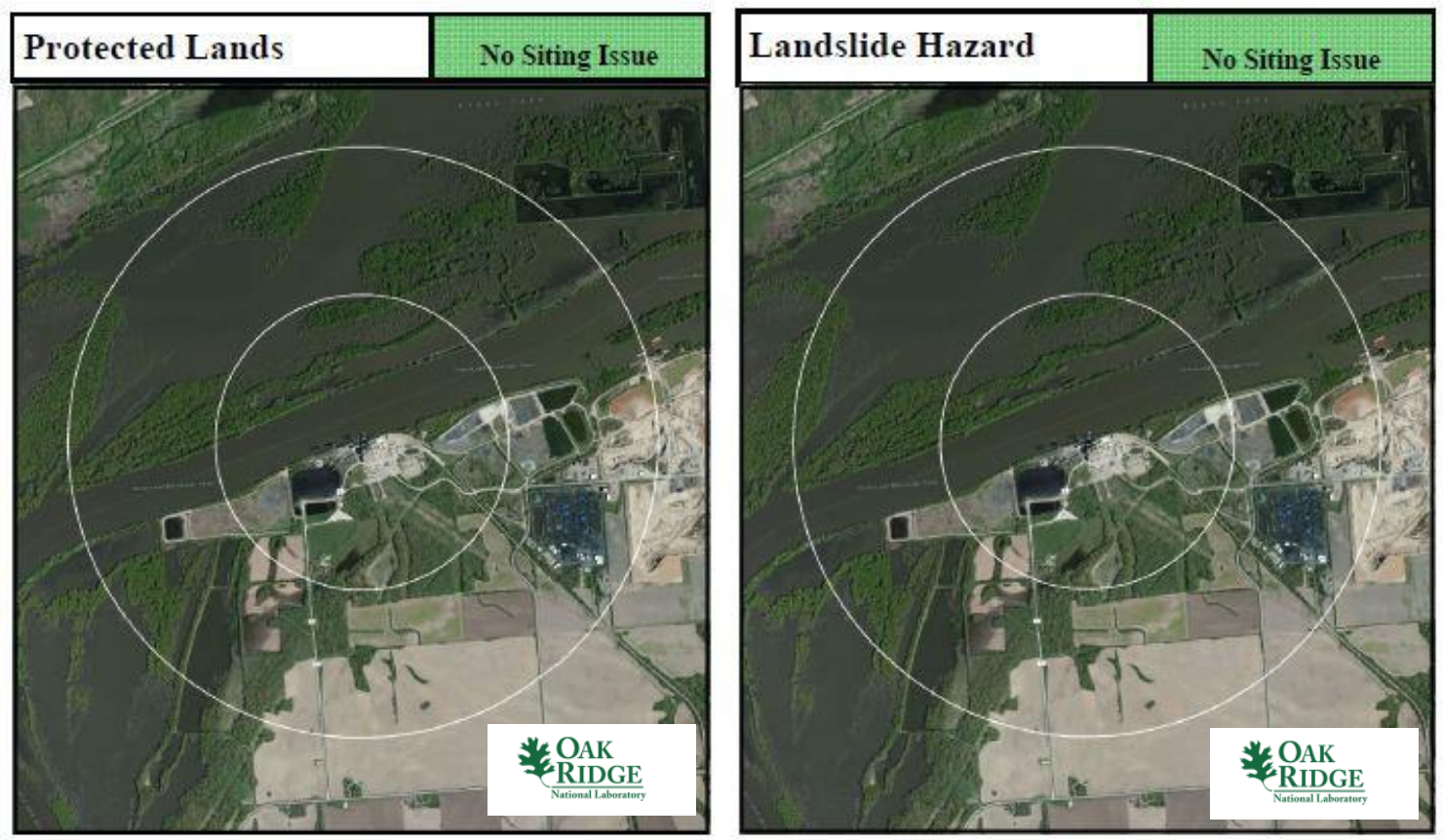

Hennepin Power Station

\section{A.6.6 Site Evaluation}

Dynegy does not operate or own a share of any nuclear power plants in the United States. Therefore, the utility would need to be mentored through the licensing process to build and operate an SMR.

Additionally, there are numerous other electric power generation facilities within 100 miles of the Hennepin Power Station to subsidize area power requirements. The site contains sufficient acreage to support siting an SMR.

From an environmental justice perspective, the community collectively appears to have achieved a reasonable level of education with median income levels typical of much of the United States. Therefore, siting an SMR at this location would not seem to be disenfranchising a less-educated or poverty-stricken community. Furthermore, the education level of the Hennepin Power Station community would seem to support the higher-technology job opportunities provided by an SMR.

As shown in Sects. 0 and A.0, the Hennepin Power Station site has a partial SMR site screening issue with wetlands/open waters. The wetlands/open waters issue reflects the adjacent Illinois River. Further visual inspection of the aerial imagery indicates that this issue should not directly impact the siting of an SMR at this location. The remaining SMR site screening criteria are met site-wide for the values established in the updated SMR siting report.1

The site meets current NRC RG 4.7 recommendations for population density without additional consideration for relaxed SMR population siting requirements based on reduced source term. The Hennepin Power Station site meets multiple conventional standards for consideration of siting an SMR at the coal station location. 


\section{A.7 Lansing Power Station}

\section{A.7.1 Location Detail}

As shown in Fig. A.38, the Lansing Generating Station is located in northeastern Iowa across the Mississippi River from Wisconsin. More specifically, the plant is located off County Highway X52 on Power Plant Drive in Allamakee County, Iowa. A heavy-haul highway is available 2.4 miles to the northeast on Wisconsin Highway 35, also known as Great River Road. Interstate 90 is 34 miles to the north. The Blackhawk Bridge that joins Iowa and Wisconsin at Lansing, Iowa, is approximately 3 miles upstream from the Lansing Generating Station. Rail access is available onsite within 0.1 miles and barge access is available within 0.2 miles on the Mississippi River. The plant is located about 3 miles southeast of Lansing, Iowa, with a population of approximately 1,000 people. The nearest city with a population in excess of 10,000 people is Onalsaka, Wisconsin, approximately 39.6 miles to the northwest of the Lansing Generating Station.

- Plant: Lansing Generating Station

- Utility: Alliant Energy Corporation

- Coordinates: lat. $43.33590^{\circ} \mathrm{N}$, long. $91.16687^{\circ} \mathrm{W}$

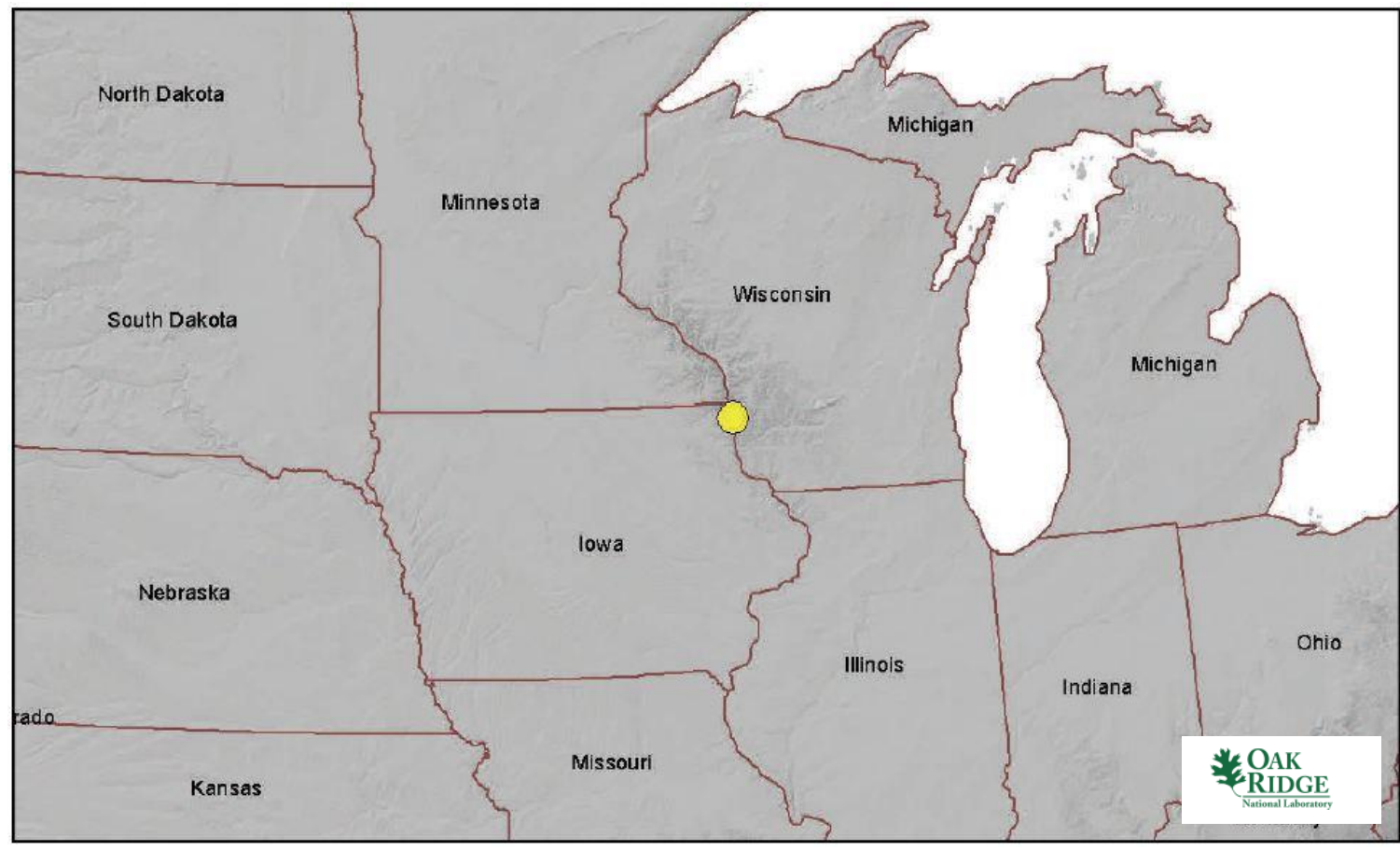

Fig. A.38. Lansing Power Station location map.

\section{A.7.2 Site Description and Status}

The Lansing Generating Station is operated by the Interstate Power and Light (IPL) Company of Iowa, a subsidiary of the Alliant Energy Corporation. The Lansing Generating Station is a four-unit coal-fired plant. Units 1-3, rated at $64 \mathrm{MW}(\mathrm{e})$ total and commissioned between 1948 and 1957, are slated to be shut down in the near future. The $275 \mathrm{MW}$ (e) Unit 4, commissioned in 1977, is currently offline while being back-fitted with scrubbing equipment. Unit 4 is expected to return to service in 2015. All the units are cooled by once-through cooling from the adjacent Mississippi River. 
The plant is situated on roughly 150 acres on the Mississippi River about 16 miles downstream from the shutdown and defueled La Crosse Boiling Water Reactor, located at the 346 MW(e) coal-fired Genoa Power Station. Lansing Generating Station is approximately 90 miles north of the 615 MW(e) Duane Arnold nuclear facility.

As noted in Table A.18, the nearest major fault line based on USGS data is about 585 miles southwest in Kansas. The maximum safe-shutdown earthquake for the site is below $0.3 \mathrm{~g}$ peak ground acceleration. More than 500,000 gpm of cooling water makeup is available from the adjacent Mississippi River.

The permanent population within 1 mile of the plant is approximately fewer than 500 people, yielding a population density of fewer than 160 people per square mile. The permanent population within 10 miles of the plant is approximately 12,500 people, yielding a population density of slightly fewer than 40 people per square mile.

According to the US EPA Environmental Justice website, there are 1,979 occupied housing units within 10 miles of the plant site based on 2000 US Census data. Further, more than $80 \%$ of area adults over age 25 have a high school diploma or higher education. The median annual income for the area is between $\$ 25 \mathrm{~K}$ and $\$ 50 \mathrm{~K}$.

Table A.18. Lansing Power Station site statistics

\begin{tabular}{|c|c|c|c|}
\hline \multicolumn{2}{|l|}{$\begin{array}{l}\text { Population } \\
\text { Population Within }\end{array}$} & \multicolumn{2}{|l|}{$\begin{array}{l}\text { Utility } \\
\text { Distance to Grid Capacity }\end{array}$} \\
\hline $0.5 \mathrm{mi}$ & $<500$ & $>400 \mathrm{MWe}$ & $\sim 60 \mathrm{mi}$ \\
\hline $1 \mathrm{mi}$ & $<500$ & $>800 \mathrm{MWe}$ & $\sim 58 \mathrm{mi}$ \\
\hline $5 \mathrm{mi}$ & $\sim 4,600$ & $>1600 \mathrm{MWe}$ & $\sim 169 \mathrm{mi}$ \\
\hline $10 \mathrm{mi}$ & $\sim 12,500$ & $>3200 \mathrm{MWe}$ & $\sim 167 \mathrm{mi}$ \\
\hline \multicolumn{2}{|c|}{ Nearest City with Population } & \multicolumn{2}{|c|}{ Distance to Cooling Water } \\
\hline$>10,000$ & Onalaska, WI & $>50,000 \mathrm{gpm}$ & $\sim 0.2 \mathrm{mi}$ (Mississippi River) \\
\hline$>50,000$ & La Crosse, WI & $>100,000 \mathrm{gpm}$ & $\sim 0.2 \mathrm{mi}$ (Mississippi River) \\
\hline$>100,000$ & Cedar Rapids, IA & $>200,000 \mathrm{gpm}$ & $\sim 0.2 \mathrm{mi}$ (Mississippi River) \\
\hline$>500,000$ & Milwaukee, WI & $>500,000 \mathrm{gpm}$ & $\sim 0.2 \mathrm{mi}$ (Mississippi River) \\
\hline \multicolumn{2}{|l|}{ Geotechnical } & \multicolumn{2}{|l|}{ Accessibility } \\
\hline Max Earthquake Acceleration & $<0.3 \mathrm{~g}$ & Distance to Major Roadway & $\sim 2.4 \mathrm{mi}(\mathrm{SR} 35)$ \\
\hline Max Slope & $\sim 66 \%$ & Distance to Water Transport & $\sim 0.2 \mathrm{mi}$ (Mississippi River) \\
\hline Nearest Fault Line & $\sim 585 \mathrm{mi}$ (Kansas) & Distance to Rail Transport & $\sim 0.1 \mathrm{mi}(\mathrm{ICE})$ \\
\hline Nearest Hazard Site & $\begin{array}{l}\sim 36 \mathrm{mi} \text { (Airport - } \\
\text { La Crosse Municipal) }\end{array}$ & Distance to Airport & $\begin{array}{r}\sim 36.0 \mathrm{mi} \text { (La Crosse } \\
\text { Municipal) }\end{array}$ \\
\hline
\end{tabular}




\section{A.7.3 Aerial Imagery}

The aerial imagery in Fig. A.39 indicates the site of the Lansing Generating Station. The plant site appears to be reasonably isolated.

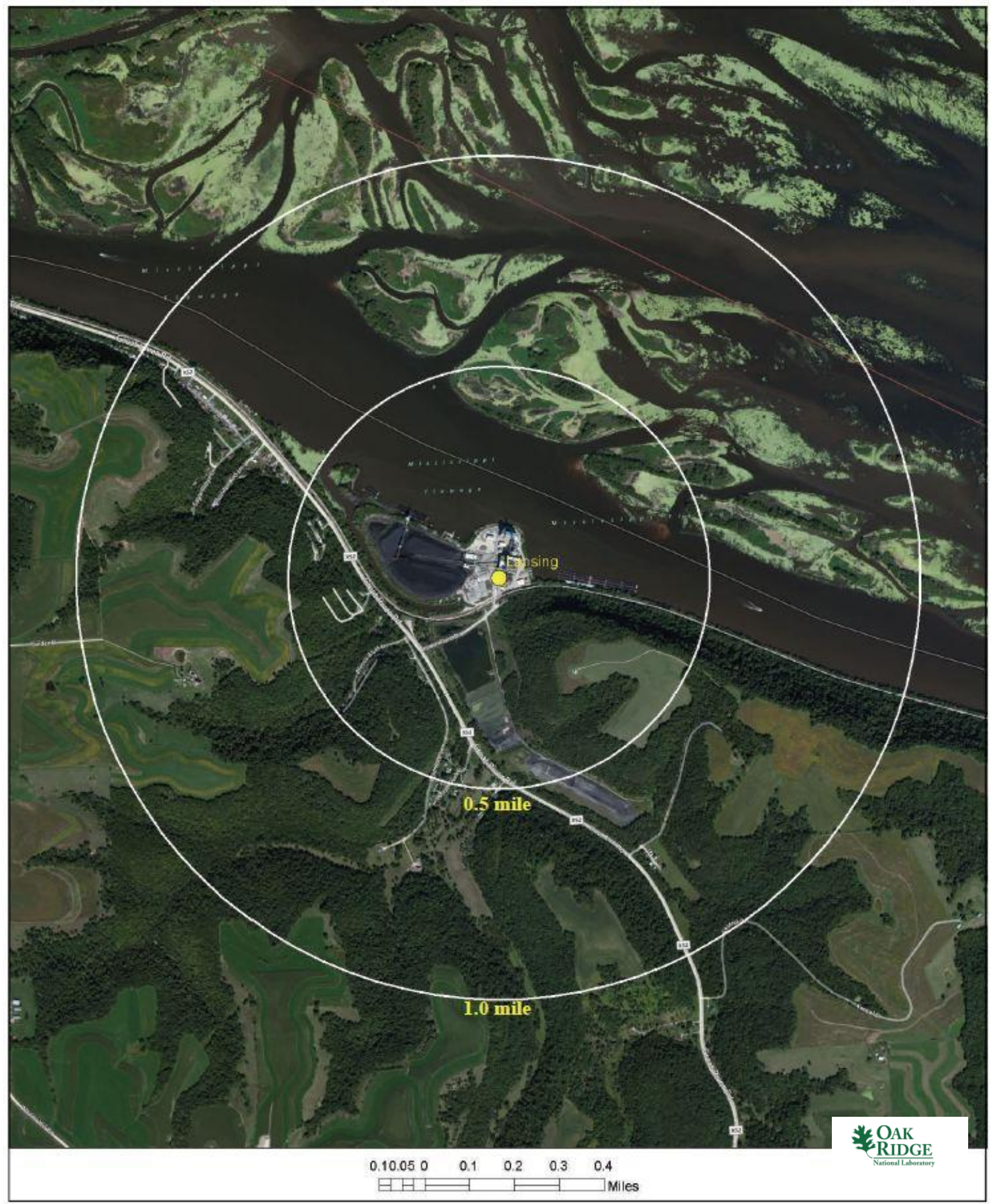

Fig. A.39. Satellite view of Lansing Power Station proximity. 


\section{A.7.4 Screening Criteria Overview}

Table A.19. Lansing Power Station Siting criteria summary

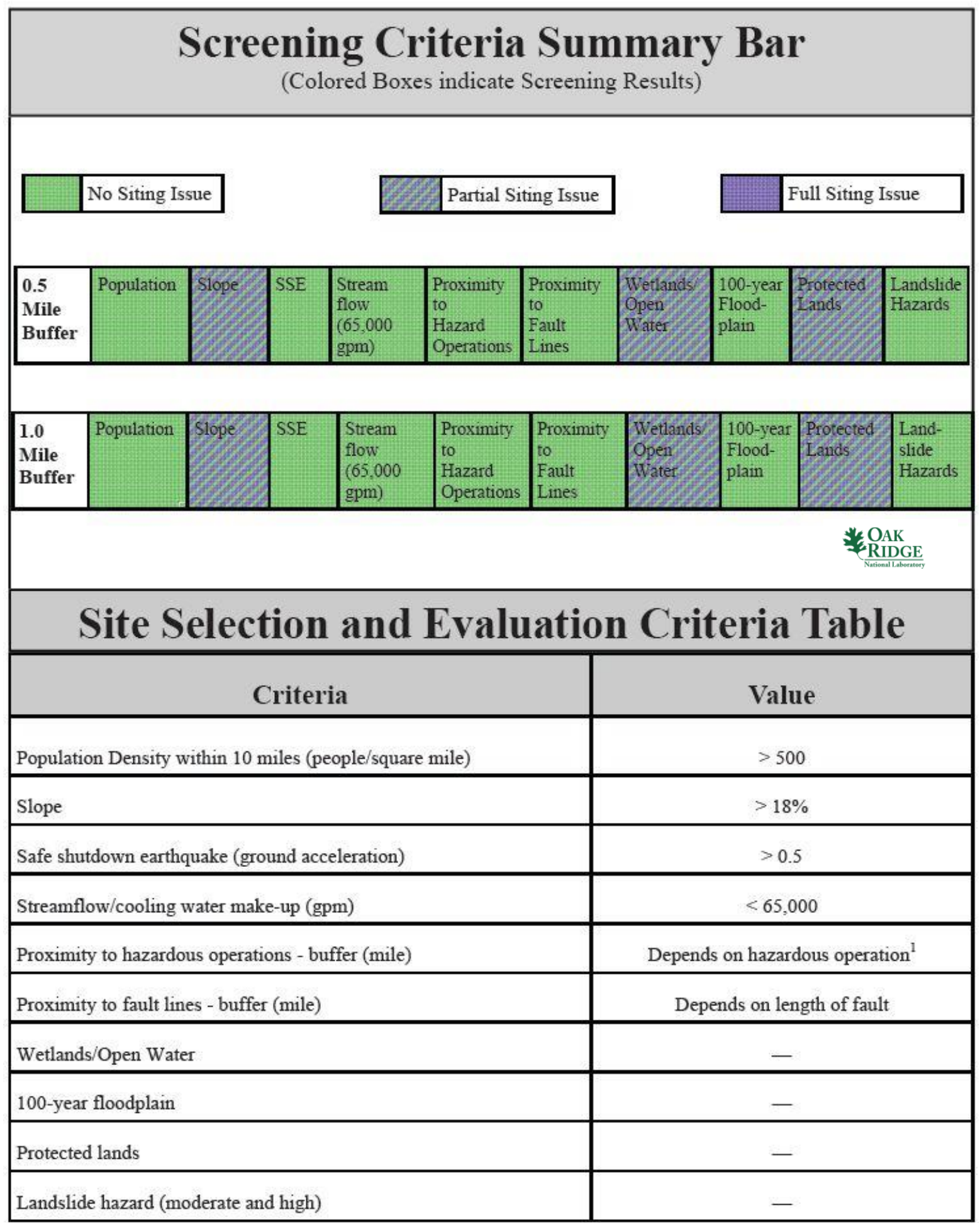

${ }^{1}$ Hazardous facilities (airports- 5 miles and oil refineries-1 mile). 


\section{A.7.5 Composite Map and Individual Siting Issue Maps}

A composite map of SMR siting challenges to the Lansing Generating Station is shown in Fig. A.40. The physical plant structures are located on land that meets all the selected SMR siting criteria. Following this map are maps of the individual SMR siting criteria based on selected input values.

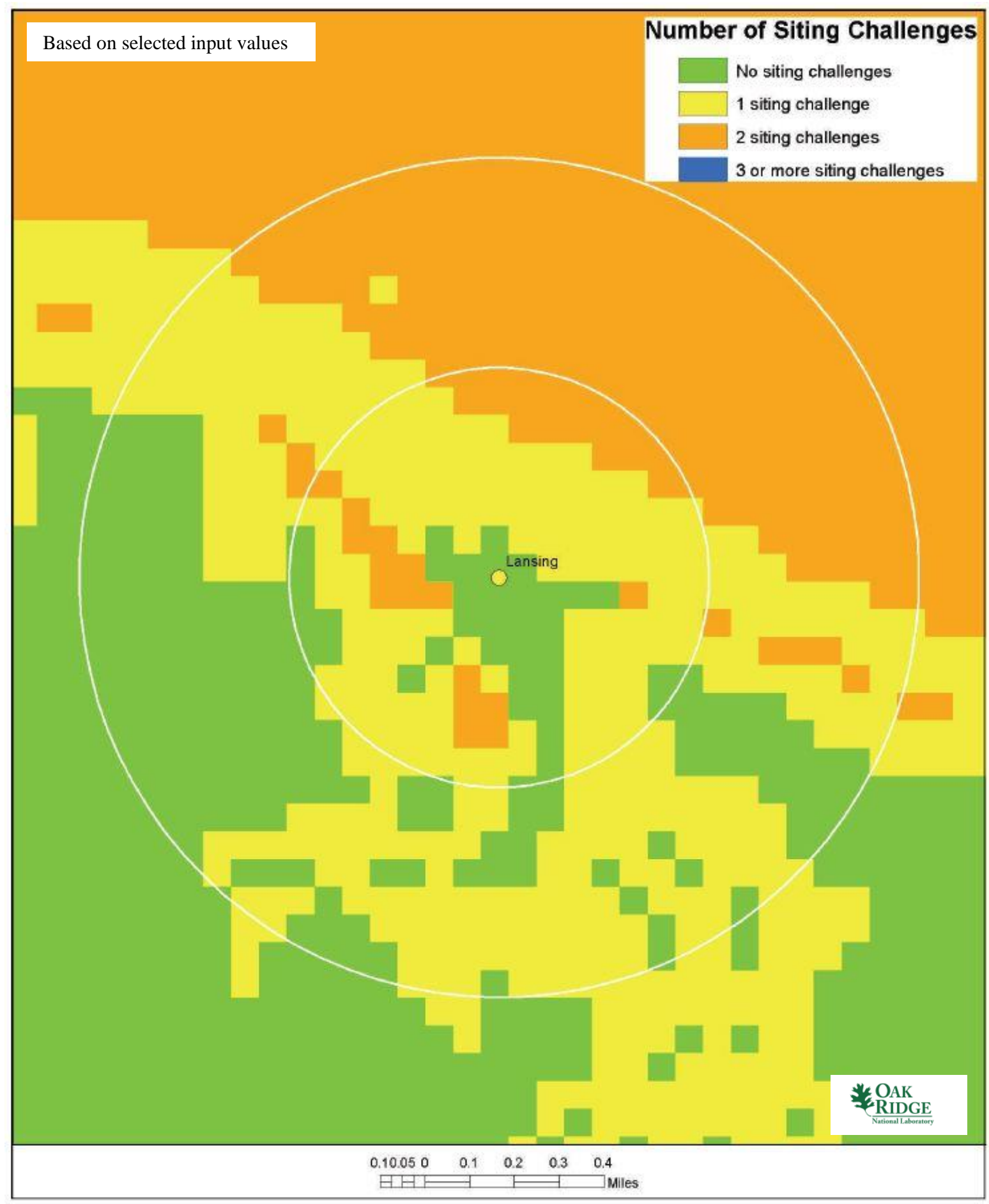

Fig. A.40. Lansing Power Station composite map. 

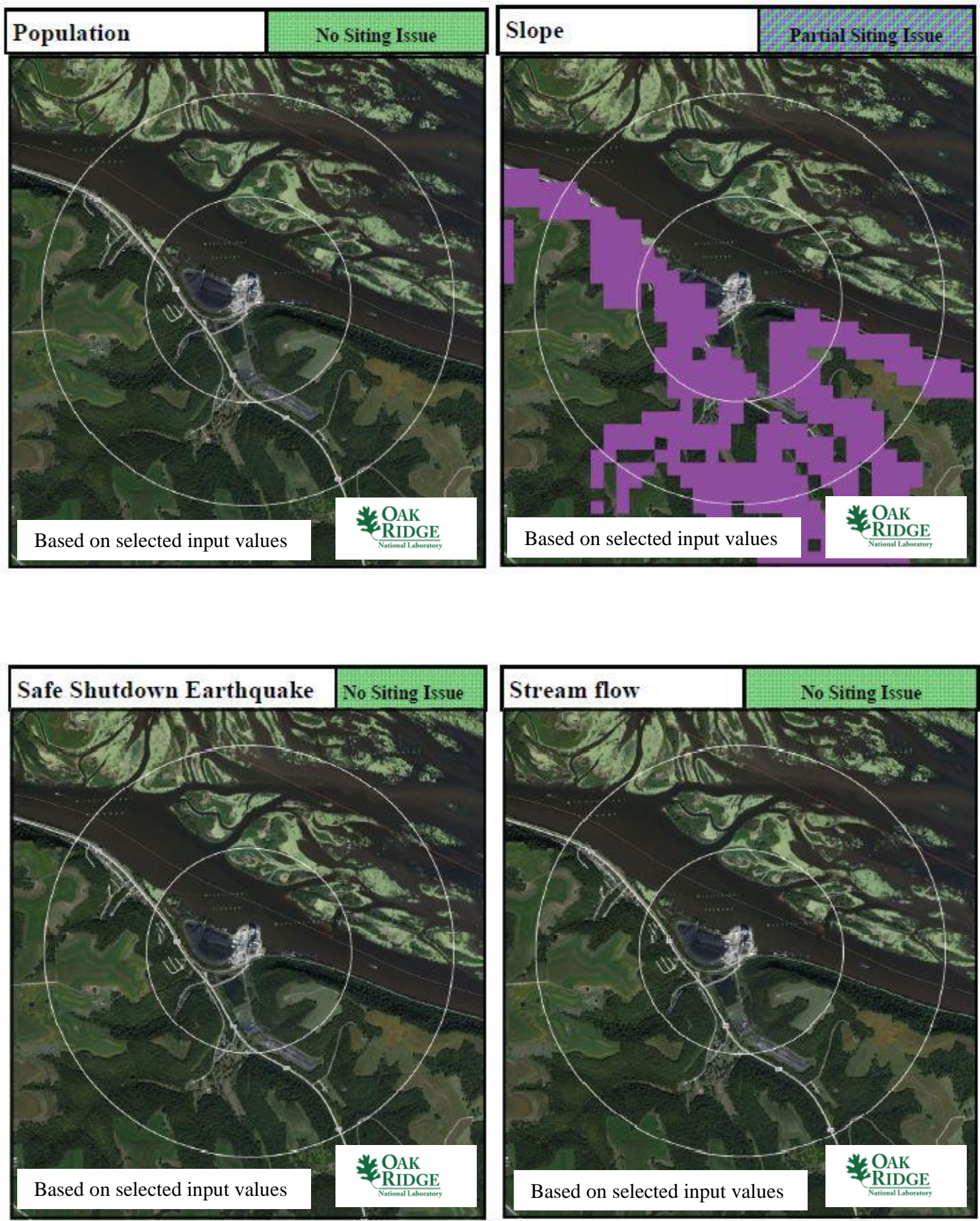

Lansing Power Station 

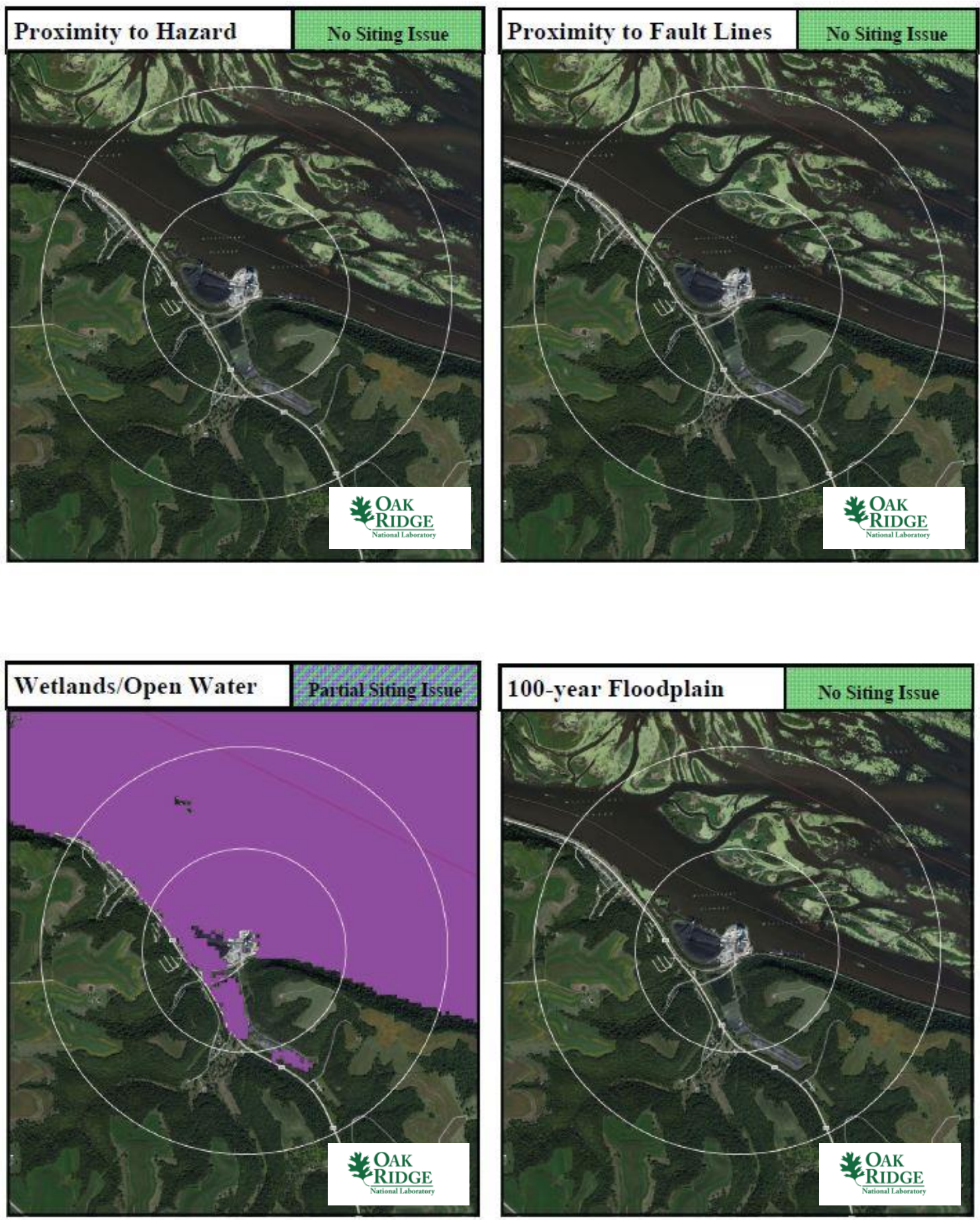

Lansing Power Station 

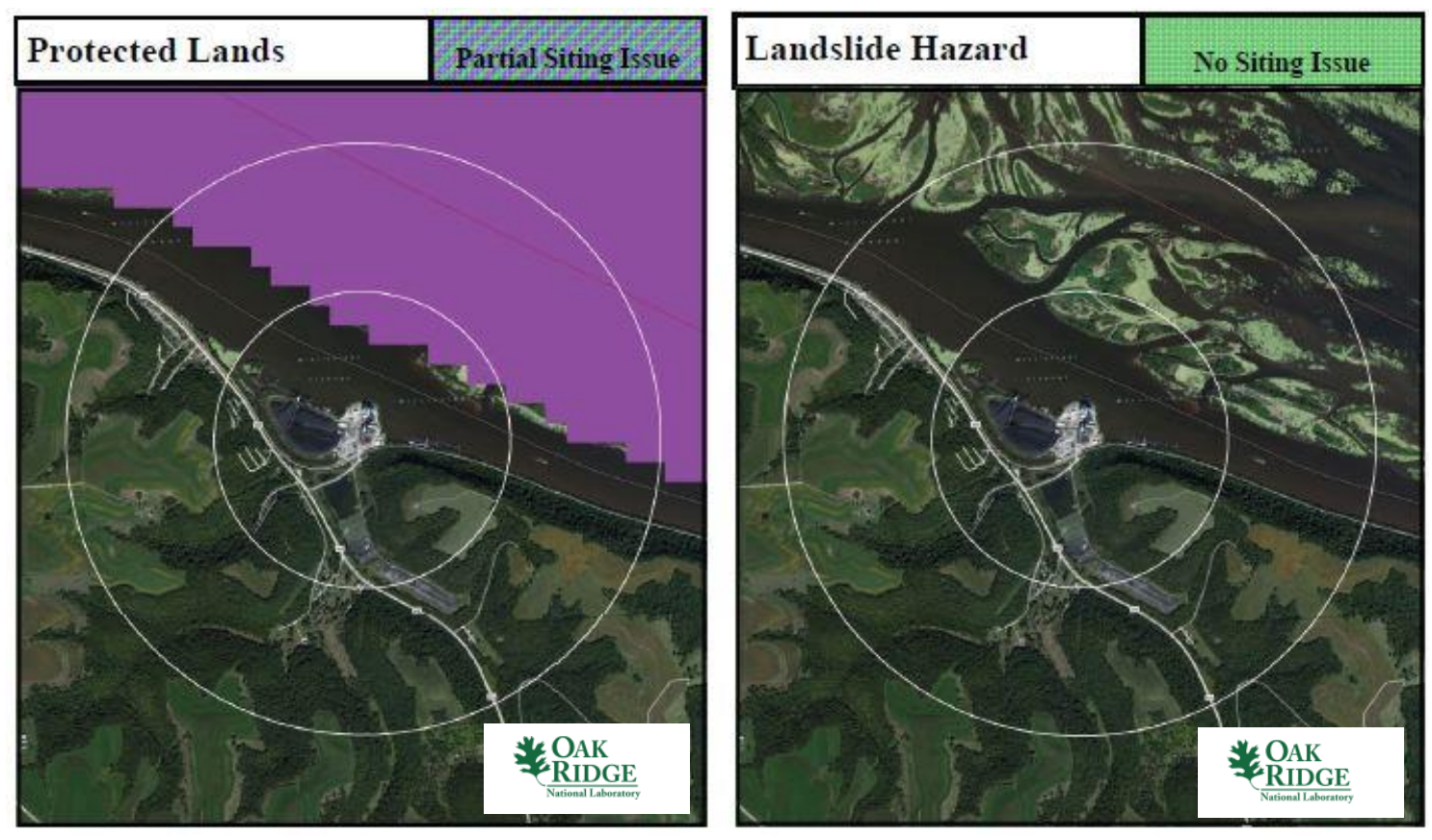

Lansing Power Station

\section{A.7.6 Site Evaluation}

Interstate Power and Light Company does not operate or own a share of any nuclear power plant in the United States. However, its parent company, Alliant Energy Corporation, announced in August 2012 that it was entering into a Purchase Power Agreement with NextEra Energy Duane Arnold, LLC, which owns and operates the Duane Arnold Energy Center nuclear power plant in Iowa. Therefore, Alliant Energy Corporation and by extension IPL may have a mentoring connection for any licensing process to build and operate an SMR. The site contains sufficient acreage to support siting an SMR, although continued operation of the coal-fired power plant could be problematic in terms of available space.

From an environmental justice perspective, the community collectively appears to have achieved a reasonable level of education with median income levels typical of much of the United States. Therefore, siting an SMR at this location would not seem to be disenfranchising a less-educated or poverty-stricken community. Furthermore, the education level of the Lansing Generating Station community would seem to support the higher-technology job opportunities provided by an SMR.

As shown in Sects. A.0 and A.0, the Lansing Generating Station site has partial SMR site screening issues with wetlands/open waters, protected lands, and slope. The slope issue is related to land on the western side of the plant site. However, the plant structures are on land that meets the slope criteria. Similarly, the wetlands/open waters and protected lands issues affect the area east of the plant site and reflect the adjacent Mississippi River. The remaining SMR site screening criteria are met site-wide for the values established in the updated SMR siting report.1

The site meets current NRC RG 4.7 recommendations for population density without additional consideration for relaxed SMR population siting requirements based on reduced source term. The Lansing Generating Station site meets multiple conventional standards for consideration of siting an SMR at the coal station location. 


\section{A.8 Plant Mitchell Power Station}

\section{A.8.1 Location Detail}

As shown in Fig. A.41, the Plant Mitchell Power Station is located in southwestern Georgia on the Flint River about 80 miles east of the Alabama border. More specifically, the plant is located off the Dixie Highway (Old Georgia Highway 3), in Dougherty County, Georgia. US Highway 19 (The Liberty Expressway or Georgia Highway 3) is accessible approximately 0.9 miles to the east and Interstate 75 is accessible 33 miles to the east. Rail access is available onsite within 0.3 miles and barge access is available from the adjacent Flint River within 0.2 miles of the plant. The plant is located about 10 miles southeast of Albany, Georgia, with a population of approximately 77,595 people.

- Plant: Plant Mitchell Power Station

- Utility: Georgia Power (Southern Company)

- Coordinates: lat. $31.44464^{\circ} \mathrm{N}$, long. $84.134^{\circ} \mathrm{W}$

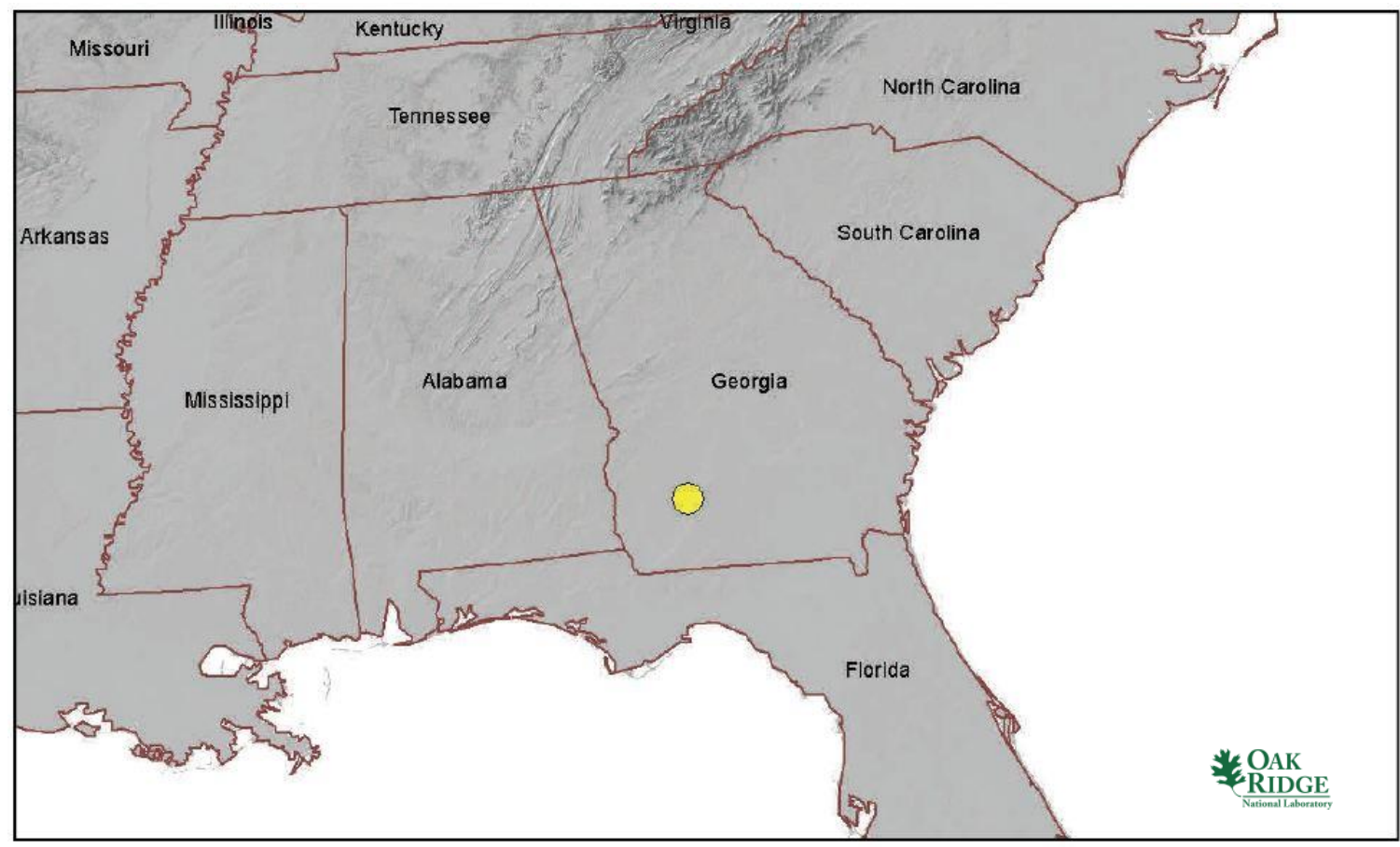

Fig. A.41. Plant Mitchell Power Station location map.

\section{A.8.2 Site Description and Status}

The Plant Mitchell Power Station is owned and operated by the Georgia Power Company, a subsidiary of Southern Company. Plant Mitchell Power Station consists of two shutdown coal-fired units and one operating coal-fired unit. Units 1-2, each rated at 27.5 MW(e), were commissioned in 1948 and 1949. Both units were retired in 2002. Unit 3, commissioned in 1964, is rated at $163 \mathrm{MW}(\mathrm{e})$. The utility has considered converting Unit 3 to biomass. The site also has three gas turbine units, each rated at 42 MW(e). The current Plant Mitchell Power Station capacity is 288.6 MW(e). The operating units are cooled by once-through cooling from the adjacent Flint River.

The plant site is located on roughly 100 acres on the Flint River approximately 60 miles east of the 1,709 MW(e) Joseph M. Farley Nuclear Plant. Plant Mitchell Power Station is approximately 30 miles southwest of the coal-fired $12.5 \mathrm{MW}(\mathrm{e})$ Crist plant. 
As noted in Table A.20, the nearest major fault line based on USGS data is about 806 miles west in Oklahoma. The maximum safe-shutdown earthquake for the site is below $0.3 \mathrm{~g}$ peak ground acceleration. More than 500,000 gpm of cooling water makeup is available from the adjacent Flint River.

The permanent population within 1 mile of the plant is fewer than 500 people, yielding a population density of fewer than 160 people per square mile. The permanent population within 10 miles of the plant is approximately 132,000 people, yielding a population density of about 420 people per square mile.

According to the US EPA Environmental Justice website, there are 5,461 occupied housing units within 10 miles of the plant site based on 2000 US Census data. Further, more than $80 \%$ of area adults over age 25 have a high school diploma or higher education. The median annual income for the area is between $\$ 25 \mathrm{~K}$ and $\$ 50 \mathrm{~K}$.

Table A.20. Plant Mitchell Power Station site statistics

\begin{tabular}{|l|l|l|l|}
\hline $\begin{array}{l}\text { Population } \\
\text { Population Within }\end{array}$ & \multicolumn{2}{l|}{$\begin{array}{l}\text { Utility } \\
\text { Distance to Grid Capacity }\end{array}$} \\
\hline $0.5 \mathrm{mi}$ & $<500$ & $>400 \mathrm{MWe}$ & $\sim 0.1 \mathrm{mi}$ \\
\hline $1 \mathrm{mi}$ & $<500$ & $>800 \mathrm{MWe}$ & $\sim 80 \mathrm{mi}$ \\
\hline $5 \mathrm{mi}$ & $\sim 18,000$ & $>1600 \mathrm{MWe}$ & $\sim 6 \mathrm{mi}$ \\
\hline $10 \mathrm{mi}$ & $\sim 132,000$ & $>3200 \mathrm{MWe}$ & $\sim 134 \mathrm{mi}$ \\
\hline Nearest City with Population & Distance to Cooling Water \\
\hline & & \multicolumn{2}{l|}{} \\
\hline$>10,000$ & Moultrie, GA & $>50,000 \mathrm{gpm}$ & $\sim 0.2 \mathrm{mi}$ (Flint River) \\
\hline$>50,000$ & Albany, GA & $>100,000$ gpm & $\sim 0.2 \mathrm{mi}$ (Flint River) \\
\hline$>100,000$ & Tallahassee, FL & $>200,000$ gpm & $\sim 0.2 \mathrm{mi}$ (Flint River) \\
\hline$>500,000$ & Jacksonville, FL & $>500,000$ gpm & $\sim 0.2 \mathrm{mi}$ (Flint River) \\
\hline Geotechnical & & Accessibility & \\
\hline Max Earthquake Acceleration & $<0.3 \mathrm{~g}$ & Distance to Major Roadway & $\sim 0.9$ mi (US 19) \\
\hline Max Slope & $\sim 6 \%$ & Distance to Water Transport & $\sim 0.2$ mi (Flint River) \\
\hline Nearest Fault Line & $\sim 806$ mi (Oklahoma) & Distance to Rail Transport & $\sim 0.3$ mi (GFRR) \\
\hline Nearest Hazard Site & $\sim 7$ mi (Airport- & Distance to Airport & $\sim 7$ mi (Southwest Georgia \\
\hline
\end{tabular}




\section{A.8.3 Aerial Imagery}

The aerial imagery in Fig. A.42 indicates that Highway 19 runs approximately 1.0 mile from the Plant Mitchell Power Station site. The area appears to be reasonably isolated.

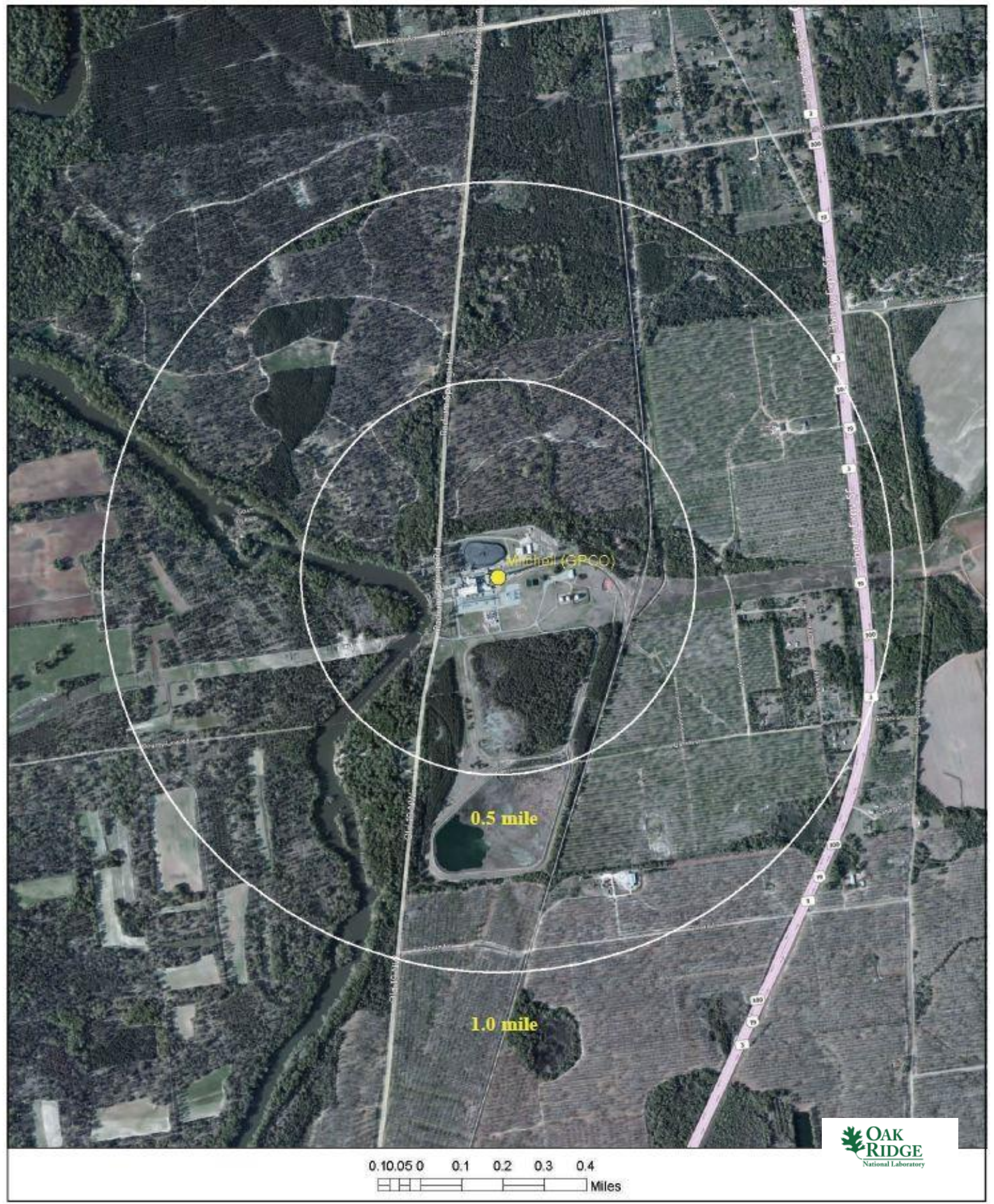

Fig. A.42. Satellite view of Plant Mitchell Power Station proximity. 


\section{A.8.4 Screening Criteria Overview}

Table A.21. Plant Mitchell Power Station siting criteria summary

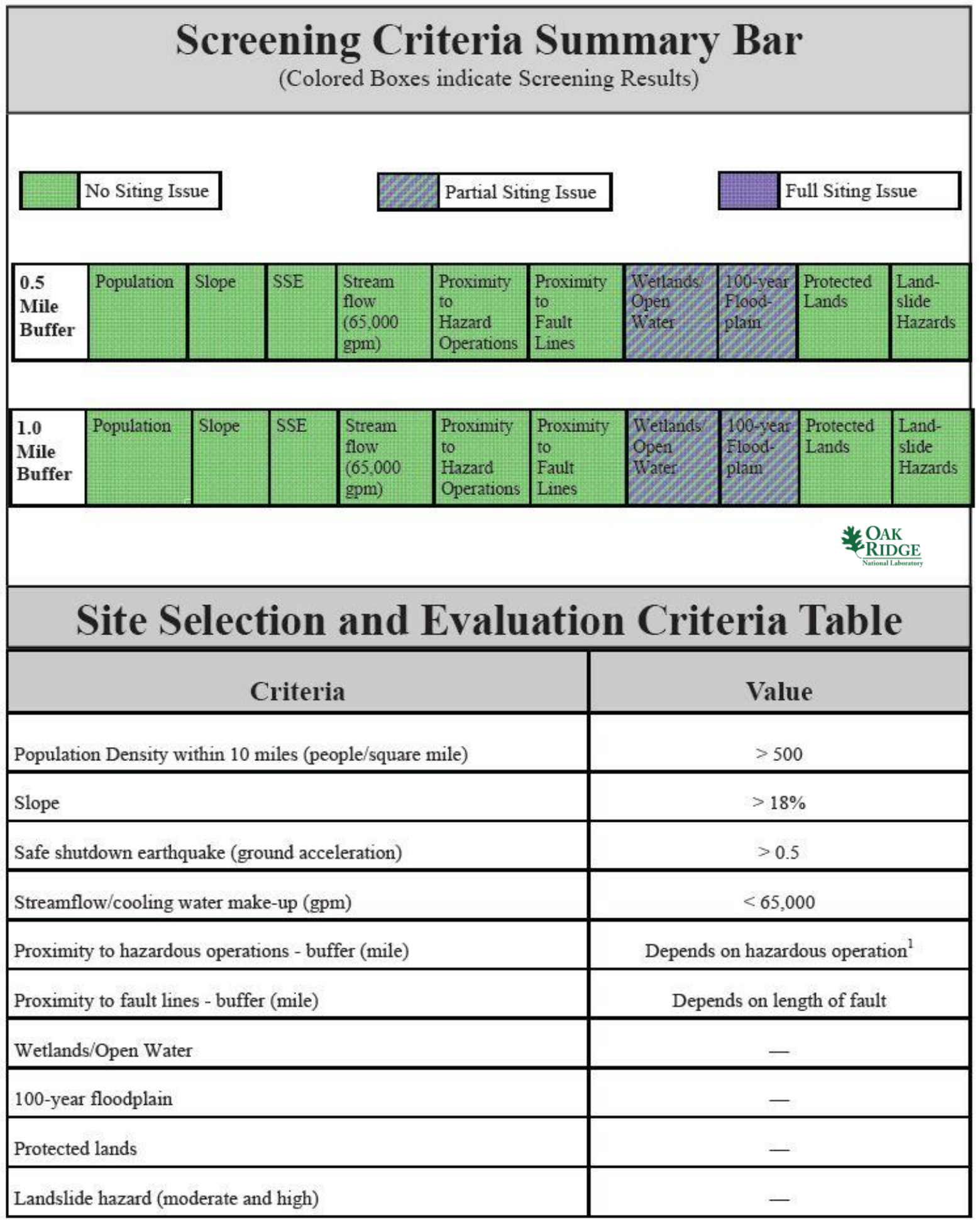

${ }^{1}$ Hazardous facilities (airports- 5 miles and oil refineries- 1 mile) 


\section{A.8.5 Composite Map and Individual Siting Issue Maps}

A composite map of SMR siting challenges to the Plant Mitchell Power Station is shown in Fig. A.43. The physical plant structures are located on land with no siting challenges. Following this map are maps of the individual SMR siting criteria based on selected input values.

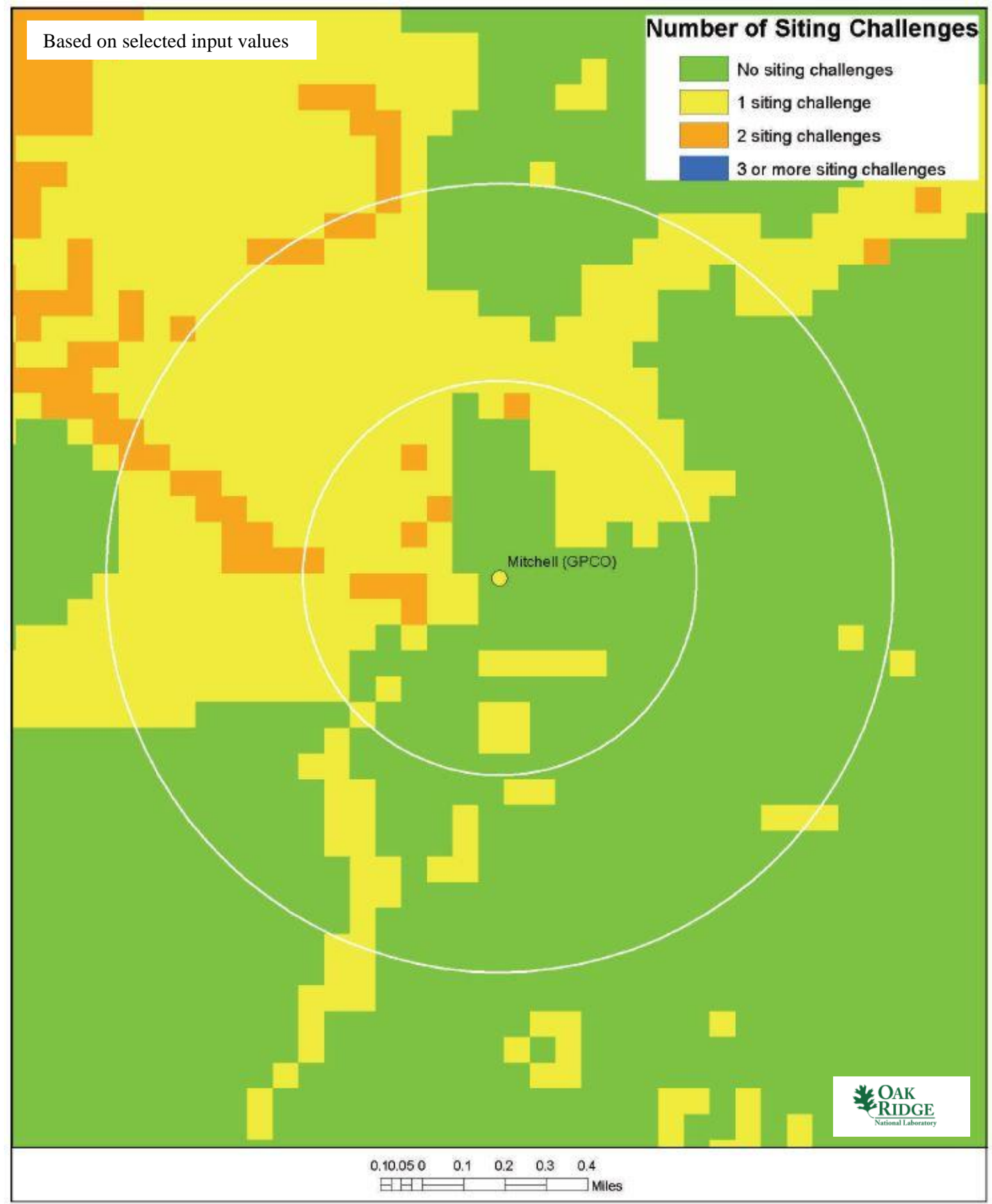

Fig. A.43. Plant Mitchell Power Station composite map. 

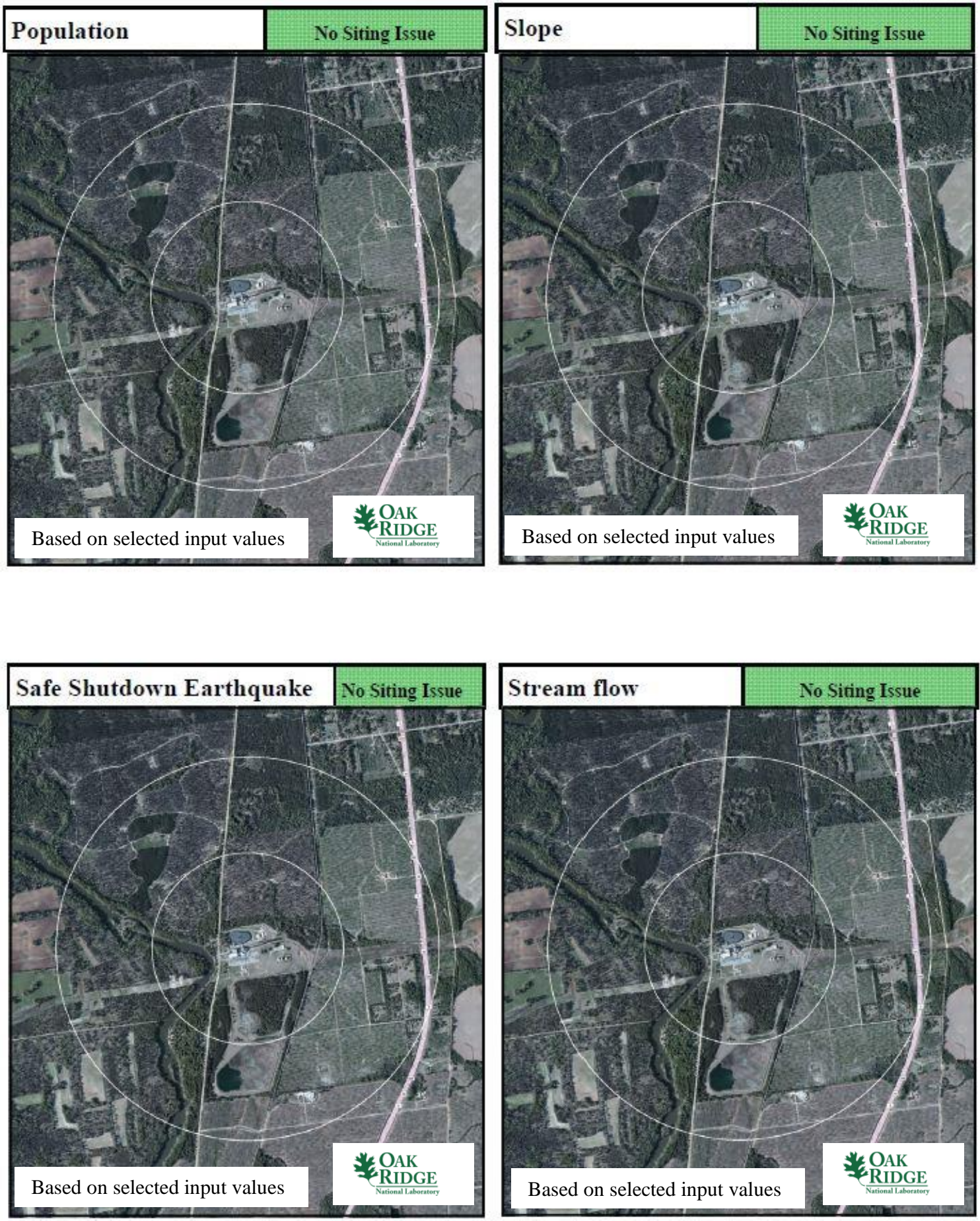

Plant Mitchell Power Station 

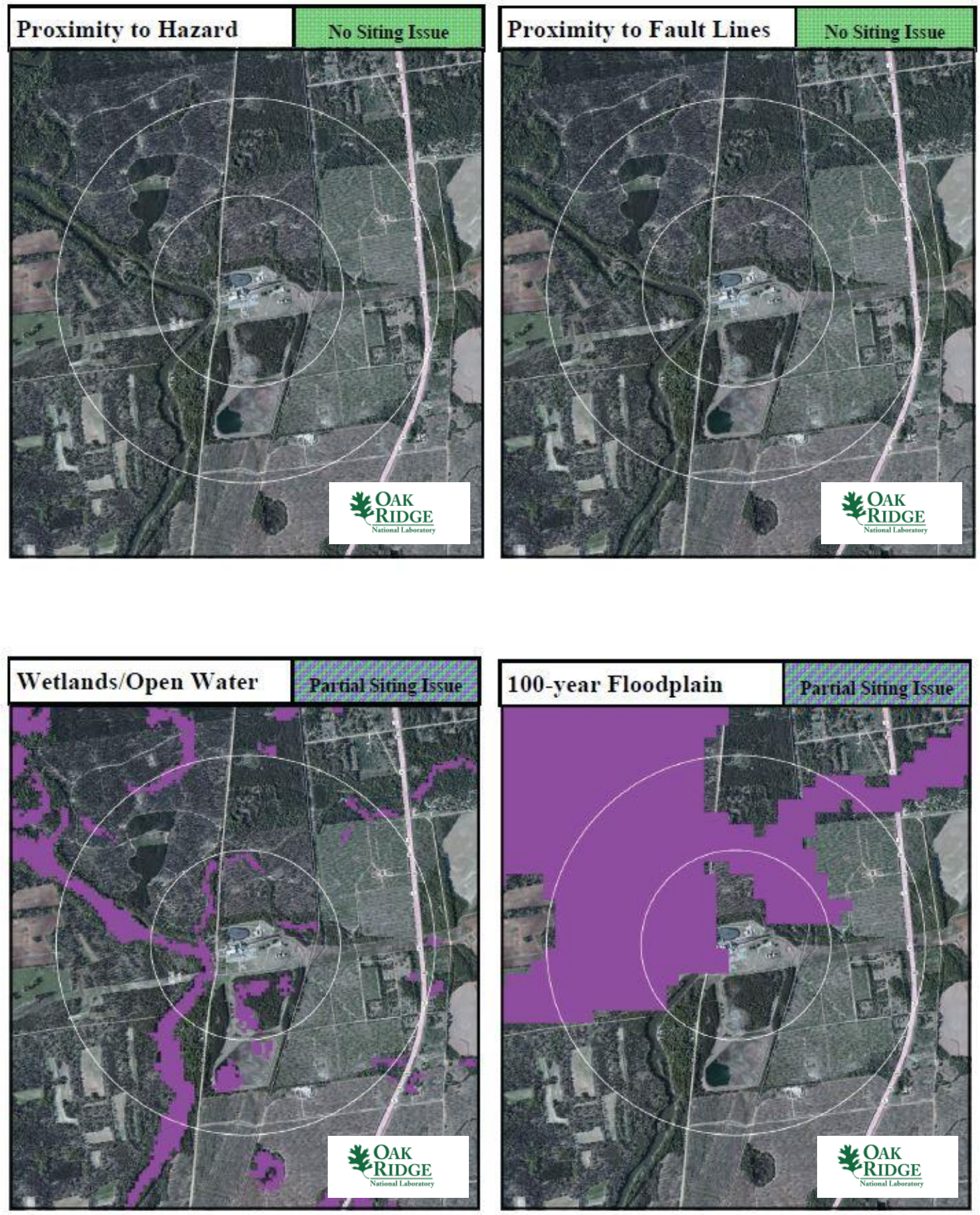

Plant Mitchell Power Station 

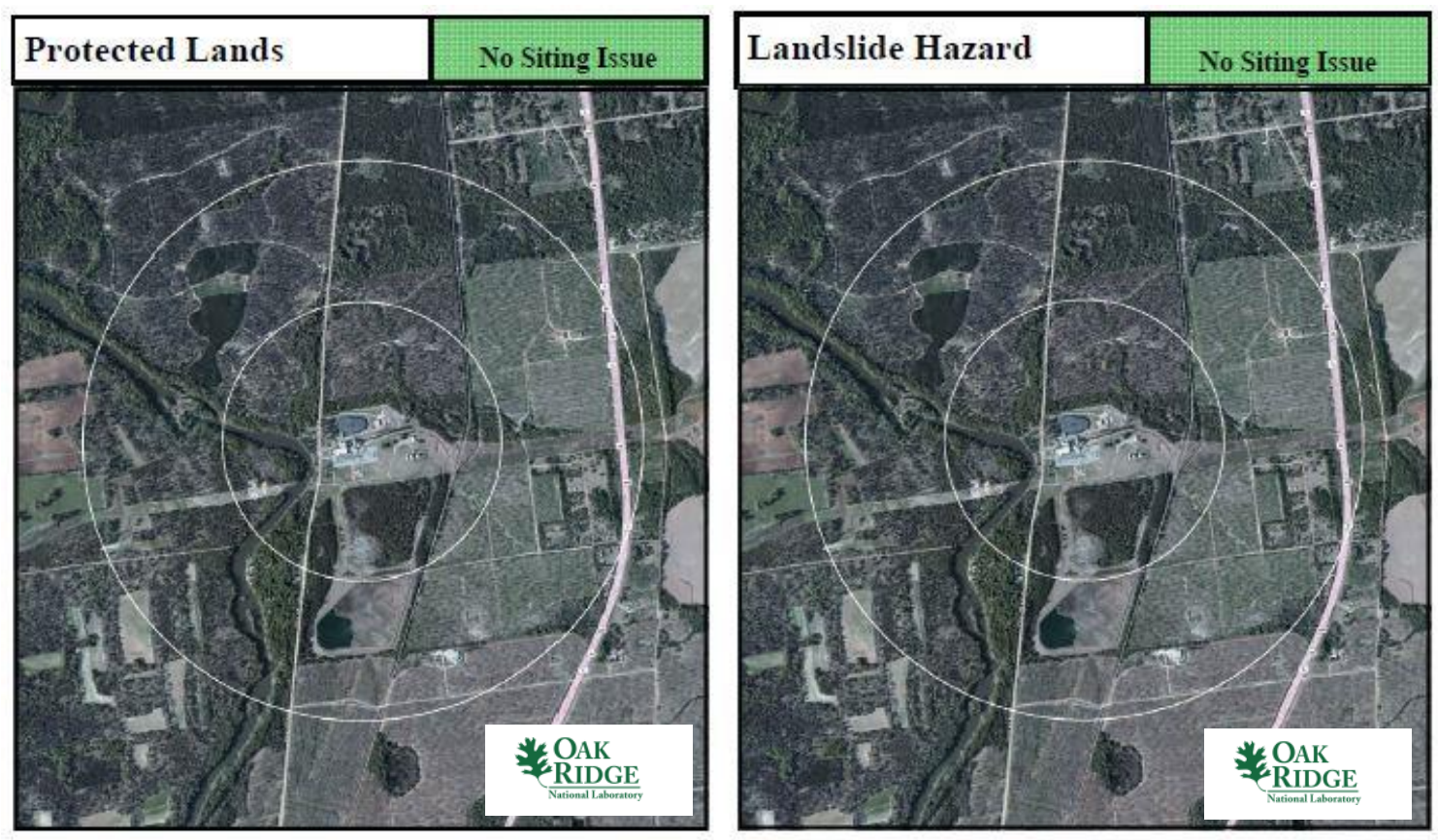

Plant Mitchell Power Station

\section{A.8.6 Site Evaluation}

Georgia Power does not operate any nuclear power plants in the United States. However, its parent company, Southern Company, does operate six nuclear power facilities, four in Georgia and two in Alabama. Southern Company has also applied for a COL for two nuclear plants at the Vogtle Plant site in Georgia. Therefore, Southern Company has the licensing experience to operate an SMR at this site. The site contains sufficient acreage to support siting an SMR.

From an environmental justice perspective, the community collectively appears to have achieved a reasonable level of education with median income levels typical of much of the United States. Therefore, siting an SMR at this location would not seem to be disenfranchising a less-educated or poverty-stricken community. Furthermore, the education level of the Plant Mitchell Power Station community would seem to support the higher-technology job opportunities provided by an SMR.

As shown in Sects. A.0 and A.0, the Plant Mitchell Power Station site has partial SMR site screening issues with wetlands/open waters and 100-year floodplain. The wetlands/open waters and the 100-year floodplain issues affect areas on the west and northwest sides of the plant site and are due most likely to the adjacent Flint River. The utility-owned land is not affected. The remaining SMR site screening criteria are met site-wide for the values established in the updated SMR siting report.1

Highway 19 runs within 1 mile of the site; that could be a consideration for a nuclear licensee to control land access to areas very near the plant location.

The site meets current NRC RG 4.7 recommendations for population density without additional consideration for relaxed SMR population siting requirements based on reduced source term. The Plant Mitchell Power Station site meets multiple conventional standards for consideration of siting an SMR at the coal station location. There are no current or near-term foreseeable SMR SSEC siting issues that should preclude this site from further SMR siting consideration. 


\section{A.9 R.D. Morrow Generating Station}

\section{A.9.1 Location Detail}

As shown in Fig. A.44, the R.D. Morrow Generating Station is located in south-central Mississippi about 25 miles northeast from the boot of the Louisiana border. More specifically, the plant is west of Mississippi Highway 11, in Lamar County, Mississippi. Interstate 59 is accessible approximately 3.3 miles to the east. Rail access is available onsite within 0.1 miles and barge access is available about 36 miles west on the West Pearl River. The plant is located about 5.8 miles north and slightly east of Purvis, Mississippi, with a population of approximately 2,164 people. The nearest city with a population in excess of 10,000 people is Hattiesburg, Mississippi, approximately 9.6 miles to the northwest of the R.D. Morrow Generating Station.

- Plant: R.D. Morrow Generating Station

- Utility: South Mississippi Electric Power Association

- Coordinates: lat. $31.21785^{\circ} \mathrm{N}$, long. $89.39414^{\circ} \mathrm{W}$

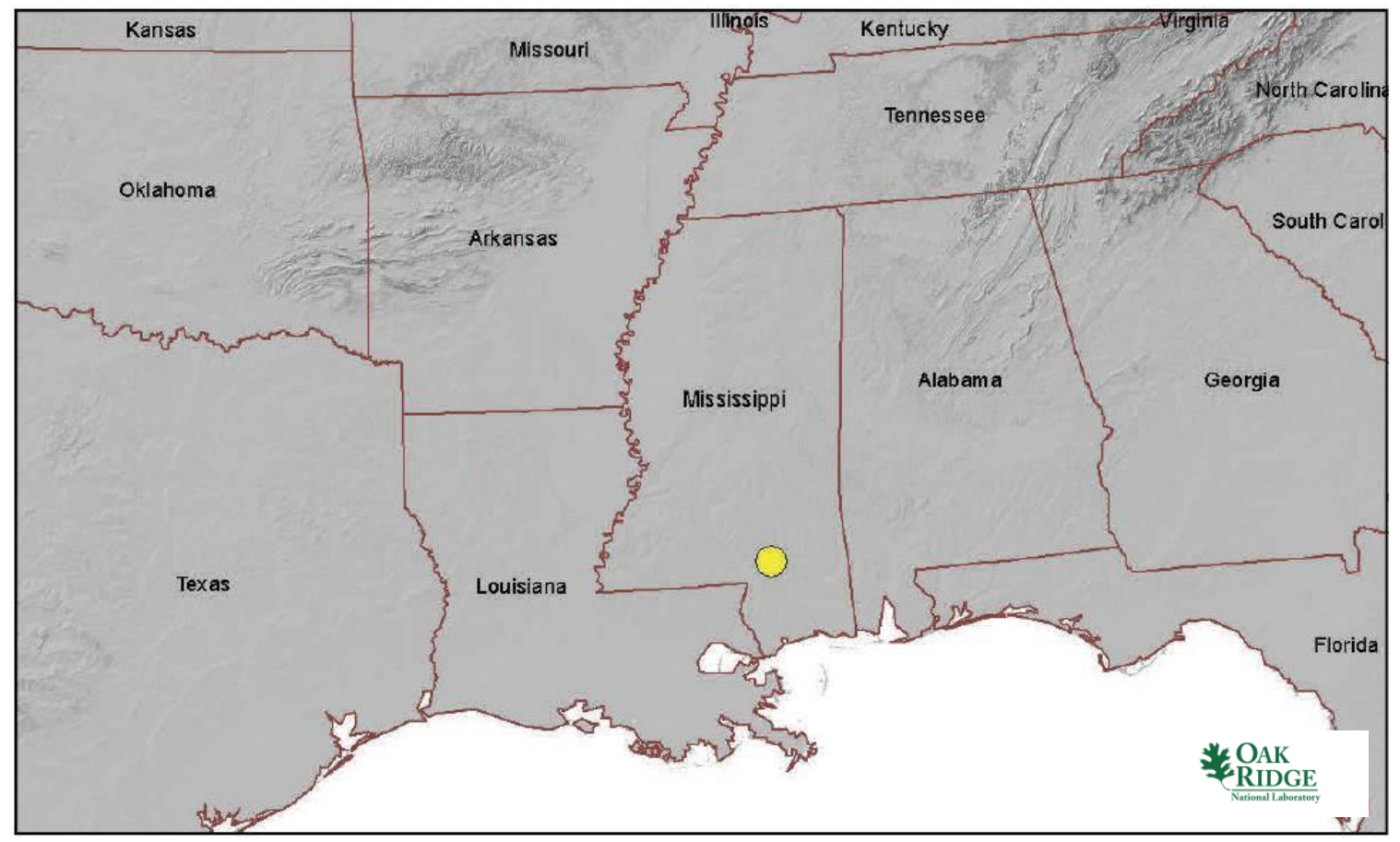

Fig. A.44. R.D. Morrow Generating Station location map.

\section{A.9.2 Site Description and Status}

The R.D. Morrow Generating Station is operated by the South Mississippi Electric Power Association (SMEPA), which is a consortium of 11 separate power associations. The R.D. Morrow Generating Station consists of two coal-fired units, rated at $200 \mathrm{MW}(\mathrm{e})$ each. Both units were commissioned in 1978. The emissions controls were upgraded in 2010 . The units are cooled by mechanical draft cooling towers. The site includes roughly 650 acres.

South Mississippi Power Association acquired a 10\% undivided interest in the 1,071 MW(e) Grand Gulf Nuclear Station located in Port Gibson, Mississippi, approximately 110 miles to the northwest of the R.D. Morrow Generating Station. The site is 58 miles north of the coal-fired 750 MW(e) Jack Watson plant and 68 miles northwest of the coal-fired 1,000 MW(e) Victor Daniel plant. 
As noted in Table A.22, the nearest major fault line based on USGS data is about 540 miles northwest in Oklahoma. The maximum safe-shutdown earthquake for the site is below $0.3 \mathrm{~g}$ peak ground acceleration. More than 500,000 gpm of cooling water makeup is available from the Leaf River approximately 9.5 miles to the north of the plant site.

The permanent population within 1 mile of the plant is approximately 1,200 people, yielding a population density of approximately 382 people per square mile. The permanent population within 10 miles of the plant is approximately 180,000 people, yielding an average population density of about 573 people per square mile.

According to the US EPA Environmental Justice website, there are 24,593 occupied housing units within 10 miles of the plant site based on 2000 US Census data. Further, more than $80 \%$ of area adults over age 25 have a high school diploma or higher education. The median annual income for the area is between $\$ 25 \mathrm{~K}$ and $\$ 50 \mathrm{~K}$.

Table A.22. R.D. Morrow Generating Station site statistics

\begin{tabular}{|c|c|c|c|}
\hline \multicolumn{2}{|l|}{$\begin{array}{l}\text { Population } \\
\text { Population Within }\end{array}$} & \multicolumn{2}{|l|}{$\begin{array}{l}\text { Utility } \\
\text { Distance to Grid Capacity }\end{array}$} \\
\hline $0.5 \mathrm{mi}$ & $<500$ & $>400 \mathrm{MWe}$ & $\sim 4 \mathrm{mi}$ \\
\hline $1 \mathrm{mi}$ & $\sim 1,200$ & $>800 \mathrm{MWe}$ & $\sim 38 \mathrm{mi}$ \\
\hline $5 \mathrm{mi}$ & $\sim 32,000$ & $>1600 \mathrm{MWe}$ & $\sim 88 \mathrm{mi}$ \\
\hline $10 \mathrm{mi}$ & $\sim 180,000$ & $>3200 \mathrm{MWe}$ & $\sim 282 \mathrm{mi}$ \\
\hline \multicolumn{2}{|c|}{ Nearest City with Population } & \multicolumn{2}{|c|}{ Distance to Cooling Water } \\
\hline$>10,000$ & Hattiesburg, MS & $>50,000 \mathrm{gpm}$ & $\sim 9.5 \mathrm{mi}$ (Leaf River) \\
\hline$>50,000$ & Gulfport, MS & $>100,000 \mathrm{gpm}$ & $\sim 9.5 \mathrm{mi}$ (Leaf River) \\
\hline$>100,000$ & Jackson, MS & $>200,000 \mathrm{gpm}$ & $\sim 9.5 \mathrm{mi}$ (Leaf River) \\
\hline$>500,000$ & Memphis, TN & $>500,000 \mathrm{gpm}$ & $\sim 9.5 \mathrm{mi}$ (Leaf River) \\
\hline \multicolumn{2}{|l|}{ Geotechnical } & \multicolumn{2}{|l|}{ Accessibility } \\
\hline Max Earthquake Acceleration & $<0.3 \mathrm{~g}$ & Distance to Major Roadway & $\sim 3.3 \mathrm{mi}$ (Interstate 59 ) \\
\hline Max Slope & $\sim 7 \%$ & Distance to Water Transport & $\sim 36 \mathrm{mi}$ (West Pearl River) \\
\hline Nearest Fault Line & $\sim 540 \mathrm{mi}$ (Oklahoma) & Distance to Rail Transport & $\sim 0.1 \mathrm{mi}(\mathrm{NS})$ \\
\hline Nearest Hazard Site & $\begin{array}{l}13 \mathrm{mi} \text { (Refinery- } \\
\text { Hunt Southland Refining } \mathrm{Co} \text { ) }\end{array}$ & Distance to Airport & $\begin{array}{c}\sim 57 \text { mi (Gulfport-Biloxi } \\
\text { Int'1) } \\
\end{array}$ \\
\hline
\end{tabular}




\section{A.9.3 Aerial Imagery}

The aerial imagery in Fig. A.45 indicates that the R.D. Morrow Generating Station site appears to be relatively isolated.

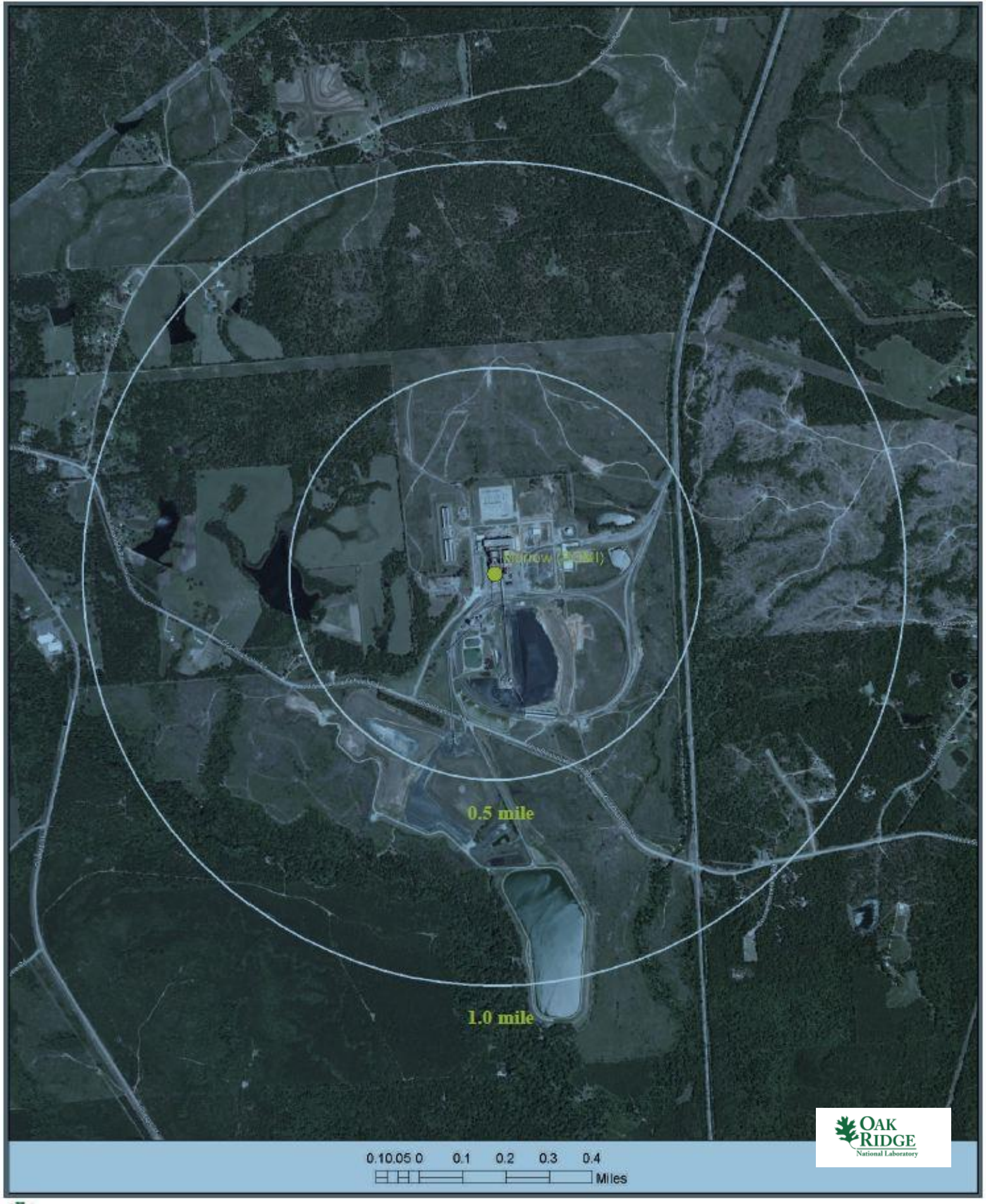

Fig. A.45. Satellite view of R.D. Morrow Generating Station proximity. 


\section{A.9.4 Screening Criteria Overview}

Table A.23. R.D. Morrow Generating Station siting criteria summary

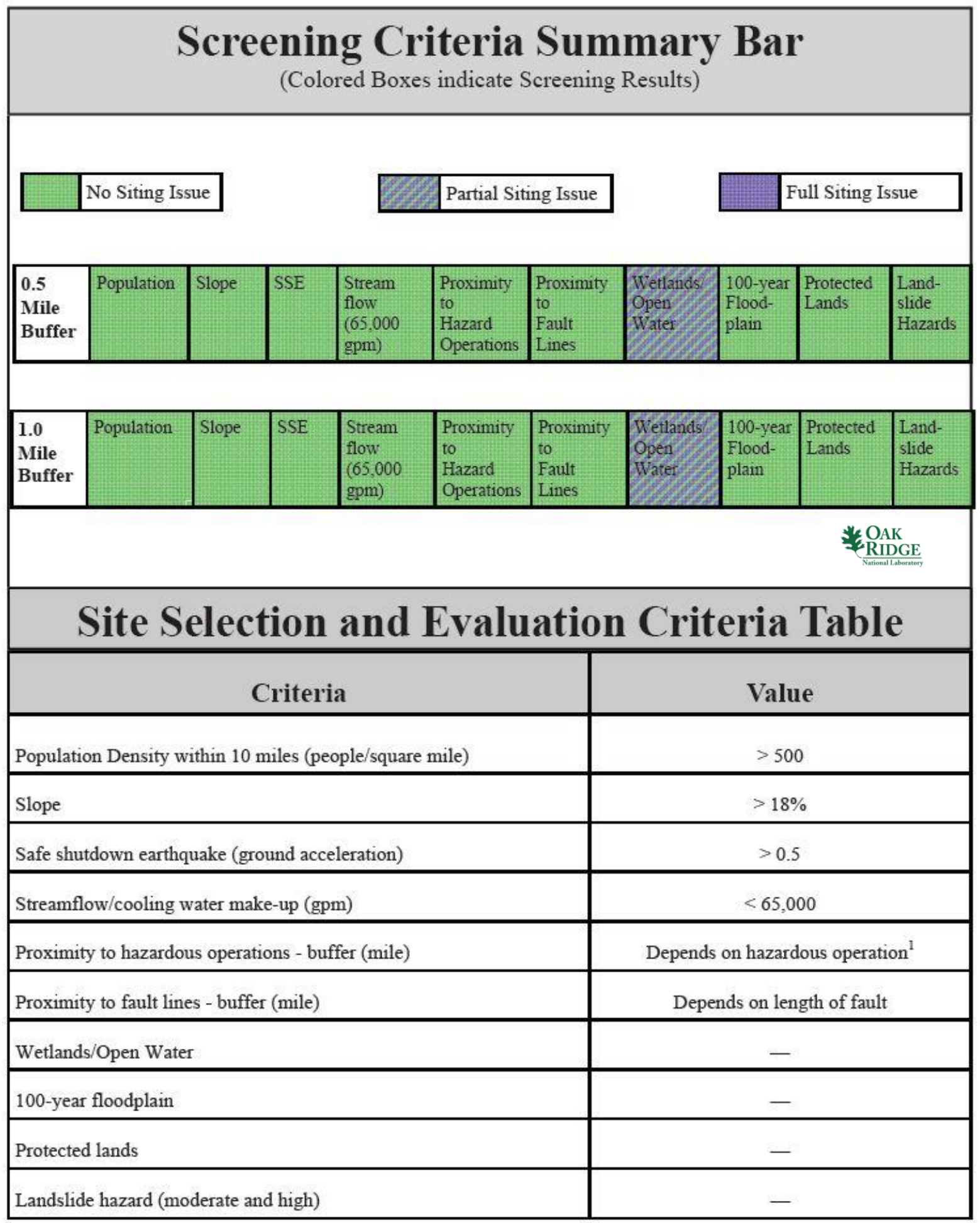

${ }^{1}$ Hazardous facilities (airports- 5 miles and oil refineries- -1 mile) 


\section{A.9.5 Composite Map and Individual Siting Issue Maps}

A composite map of SMR siting challenges to the R.D. Morrow Generating Station is shown in Fig. A.46. The physical plant structures are located on land with no siting challenges. Following this map are maps of the individual SMR siting criteria based on selected input values.

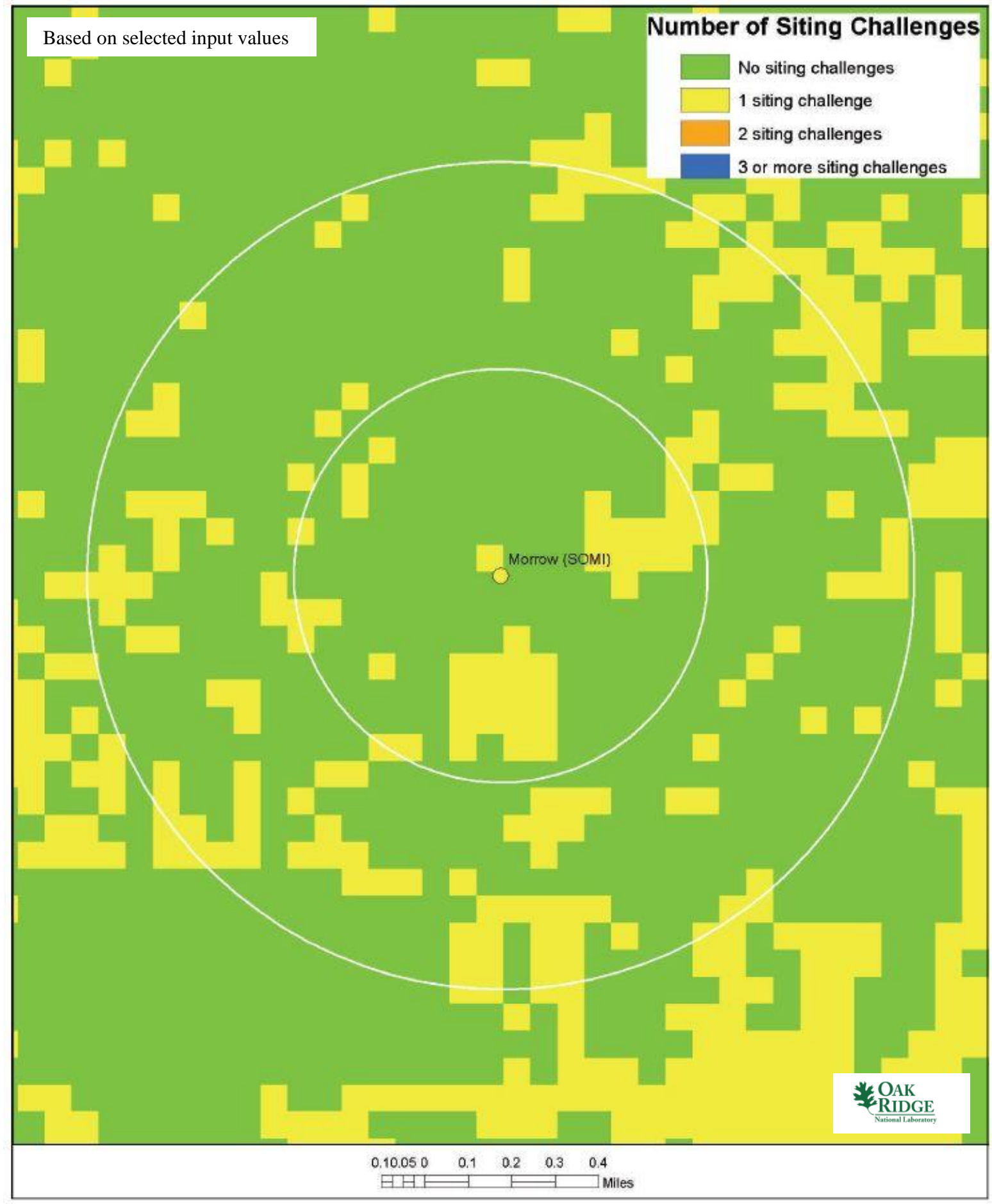

Fig. A.46. R.D. Morrow Generating Station composite map. 

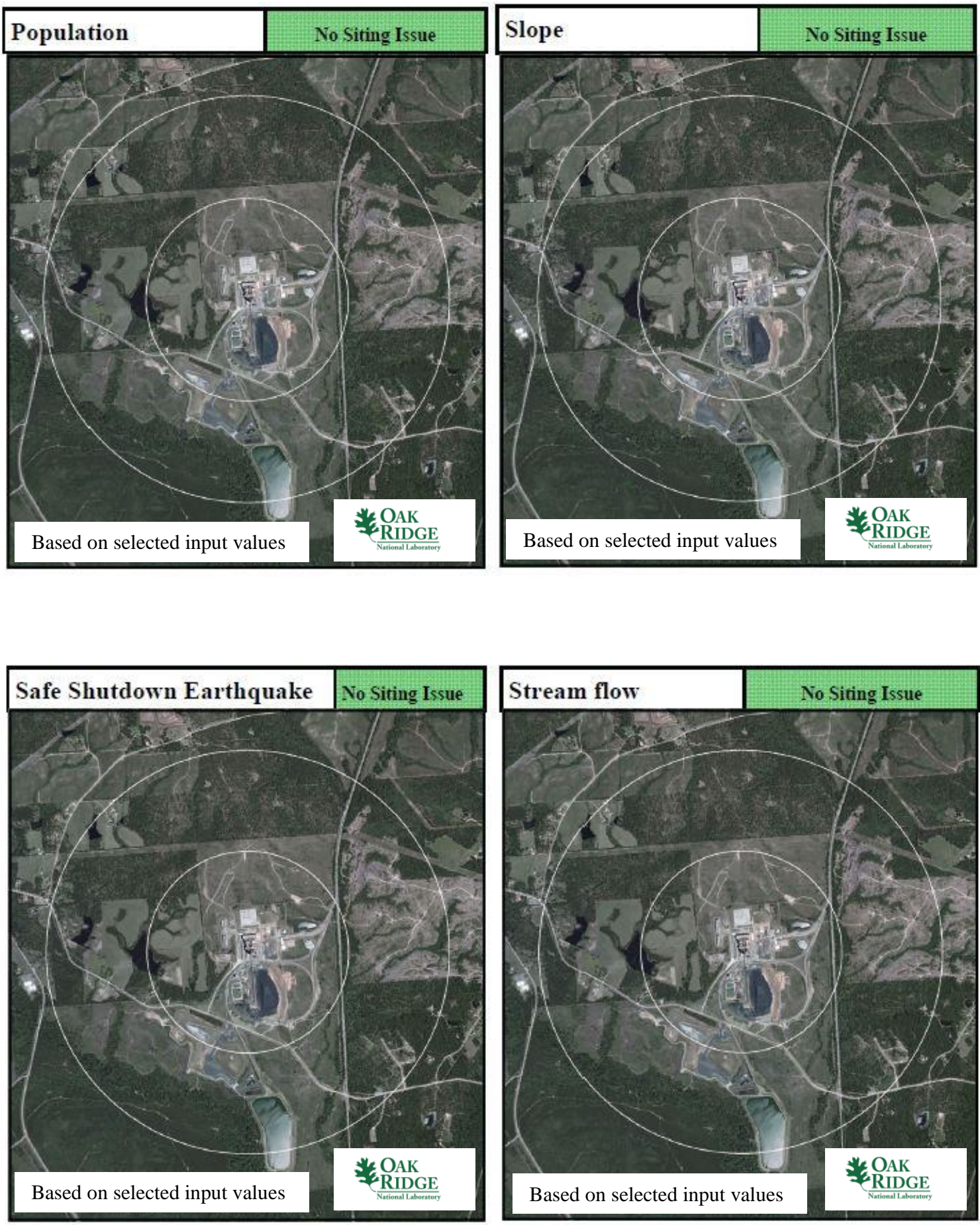

R.D. Morrow Generating Station 

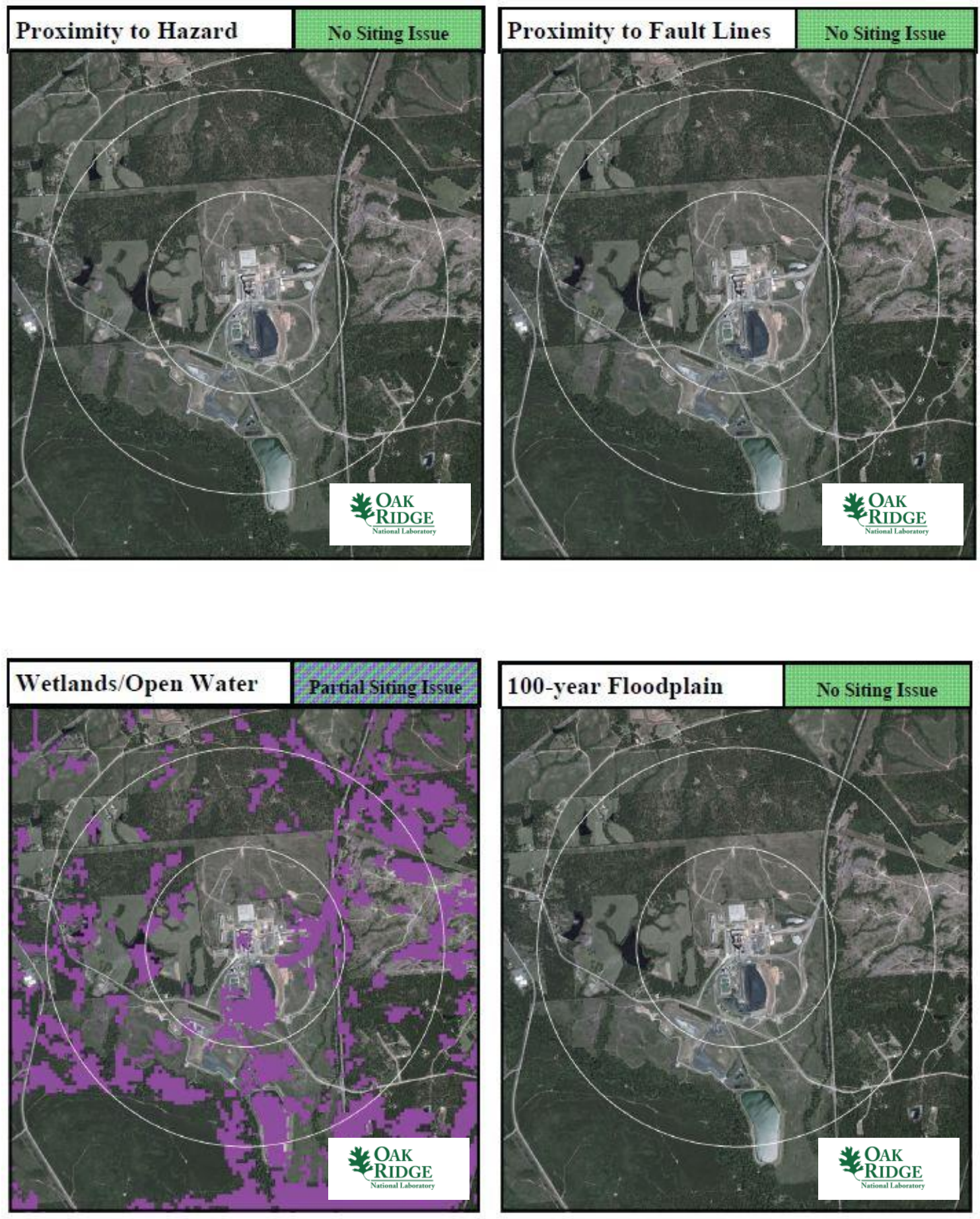

R.D. Morrow Generating Station 

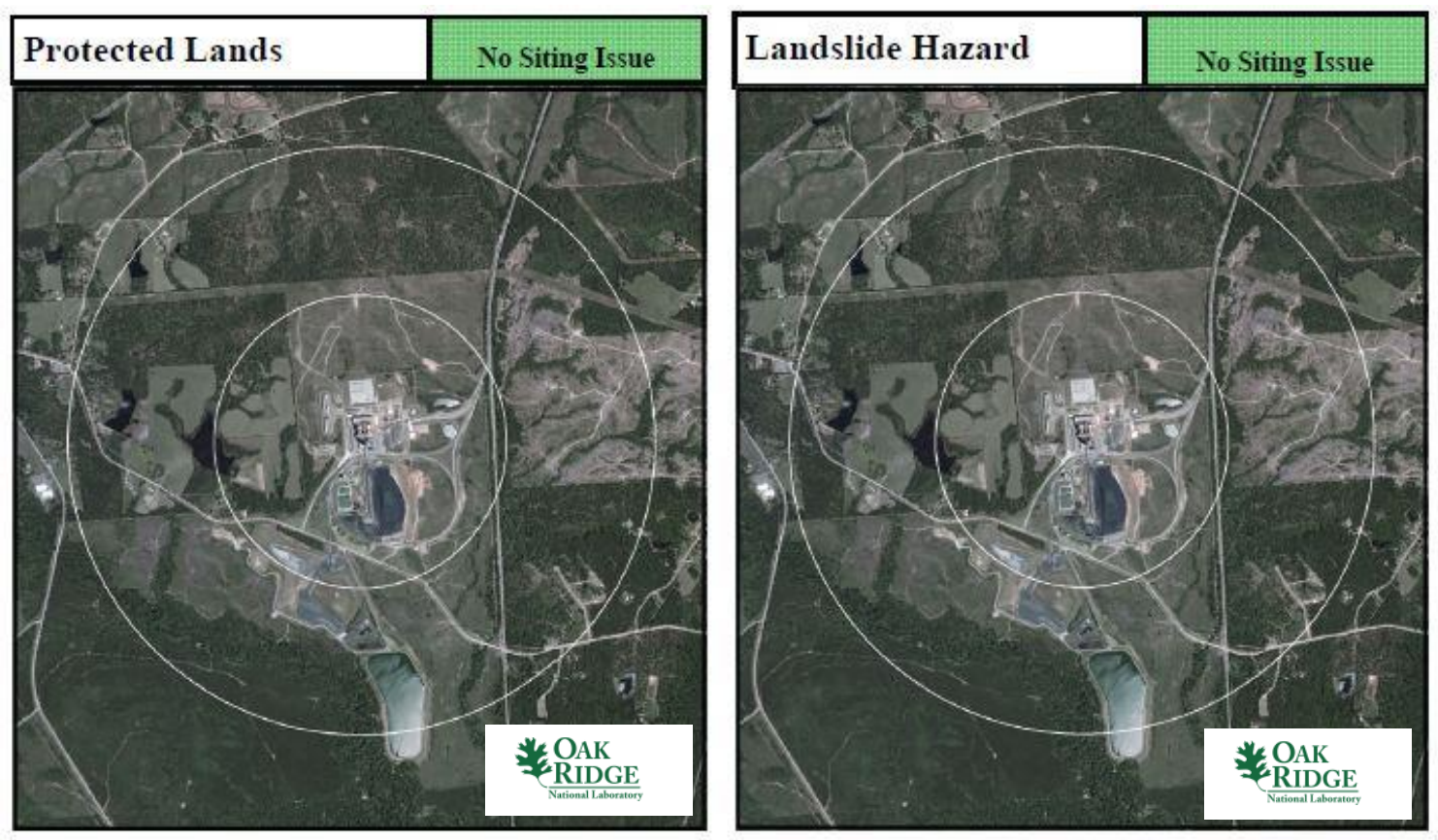

R.D. Morrow Generating Station

\section{A.9.6 Site Evaluation}

Other than the $10 \%$ interest in the Grand Gulf Nuclear Station, SMEPA does not own or operate any nuclear power plants in the United States. Therefore, SMEPA may need to be mentored through the licensing process to build and operate an SMR at this location. The site contains sufficient acreage to support siting an SMR.

From an environmental justice perspective, the community collectively appears to have achieved a reasonable level of education with median income levels typical of much of the United States. Therefore, siting an SMR at this location would not seem to be disenfranchising a less-educated or poverty-stricken community. Furthermore, the education level of the R.D. Morrow Generating Station community would seem to support the higher-technology job opportunities provided by an SMR.

As shown in Sects. A.0 and A.0, the R.D. Morrow Generating Station site has partial SMR site screening issue with wetlands/open waters. The wetlands/open waters issue reflects the various ponds and ash pits on the site. The plant has forced draft cooling and there does not appear to be any flooding issue. The remaining SMR site screening criteria are met site-wide for the values established in the updated SMR siting report.1

There is a large tank farm about 2 miles south of the plant site operated by Hess Oil. This could be a consideration in the decision to site an SMR at this location.

The site meets current NRC RG 4.7 recommendations for population density with additional consideration for relaxed SMR population siting requirements based on reduced source term. The R.D. Morrow Generating Station site meets multiple conventional standards for consideration of siting an SMR at the coal station location. There are no current or near-term foreseeable SMR SSEC siting issues that should preclude this site from further SMR siting consideration. 


\section{A.10 Robert Reid Power Station}

\section{A.10.1 Location Detail}

As shown in Fig. A.47, the Robert A. Reid Power Station is located in western Kentucky on the Green River, a tributary of the Ohio River, about 14 miles south of the Indiana border and about 35 miles east of the Illinois border. More specifically, the plant is located off Kentucky Highway 2097, also known as Quinn's Landing Road, in Henderson County, Kentucky. Part of the plant is also in Webster County, Kentucky. Interstate 69 is accessible approximately 0.4 miles to the west. Rail access is available within 2.0 miles and barge access is available from the adjacent Green River. The plant is located about 3 miles southeast of Robards, Kentucky, with a population of approximately 515 people. The nearest city with a population in excess of 10,000 people is Henderson, Kentucky, approximately 14 miles to the northwest of the Robert A. Reid Power Station.

- Plant: Robert Reid Power Station

- Utility: Big Rivers Electric Corporation

- Coordinates: lat. $37.64492^{\circ} \mathrm{N}$, long. $87.50327^{\circ} \mathrm{W}$

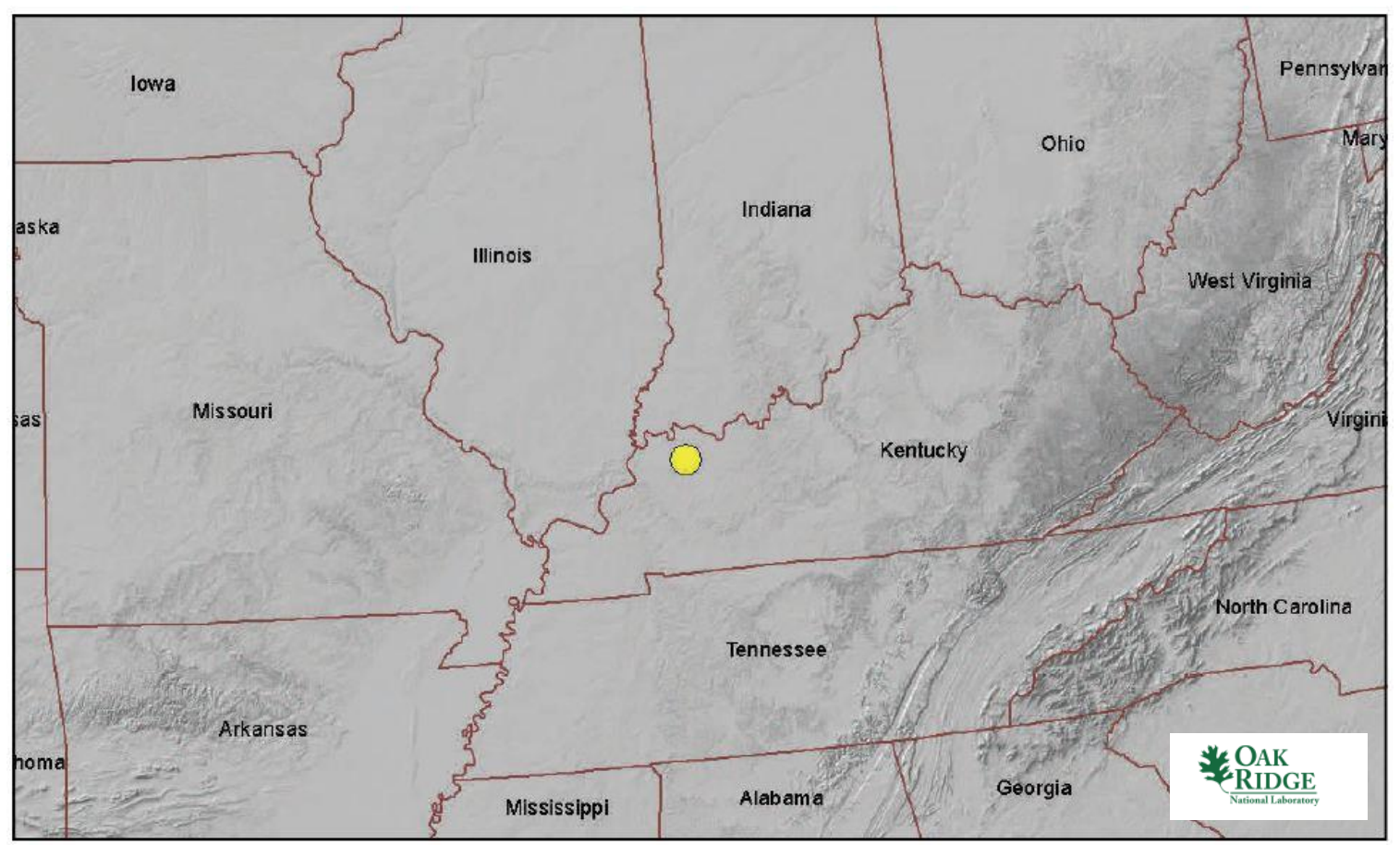

Fig. A.47. Robert Reid Power Station location map.

\section{A.10.2 Site Description and Status}

The Robert A. Reid Power Station is owned and operated by the Big Rivers Electric Corporation (BREC). BREC is a member's cooperative composed of three members: The Jackson Purchase Energy Corporation, The Kenergy Corporation, and The Meade County Rural Electric Cooperative Corporation. The Robert A. Reid Power Station is located on a site situated on the West Bank of the Green River that BREC calls The Sebree Station. The Sebree Station has three generating components: (1) the Robert A. Reid Generating Station, (2) the Robert D. Green Generating Station, and (3) Henderson Station 2. The Sebree complex generates more than $900 \mathrm{MW}(\mathrm{e})$. The Robert A. Reid Power Station is a single-unit $96 \mathrm{MW}(\mathrm{e})$ coal-fired plant, commissioned in 1966. Cooling is provided by mechanical draft cooling 
towers. The Robert D. Green Generating Station is a two-unit 492 MW(e) coal-fired plant. The Henderson Station 2 is a two-unit 337 MW(e) coal-fired plant.

The plant is located on roughly 280 acres. There are no nuclear power plants within 200 miles. Numerous coal-fired facilities are available nearby, including the 440 MW(e) Wilson Station, operated by BREC, 27 miles to the southeast. The 130 MW(e) Barkley Dam hydroelectric facility and the 175 MW(e) Kentucky Dam hydroelectric facility are approximately 60 miles to the southwest of the site.

As noted in Table A.24, the nearest major fault line based on USGS data is about 600 miles southwest in Oklahoma. The maximum safe-shutdown earthquake for the site is approximately $0.3 \mathrm{~g}$ peak ground acceleration. More than 500,000 gpm of cooling water makeup is available from the adjacent Green River.

The permanent population within 1 mile of the plant is approximately 1,000 people, yielding a population density of approximately 318 people per square mile. The permanent population within 10 miles of the plant is approximately 41,000 people, yielding a population density of about 130 people per square mile.

According to the US EPA Environmental Justice website, there are 4,540 occupied housing units within 10 miles of the plant site based on 2000 US Census data. Further, more than $75 \%$ of area adults over age 25 have a high school diploma or higher education. The median annual income for the area is between $\$ 25 \mathrm{~K}$ and $\$ 50 \mathrm{~K}$.

Table A.24. Robert Reid Power Station site statistics

\begin{tabular}{|c|c|c|c|}
\hline \multicolumn{2}{|l|}{$\begin{array}{l}\text { Population } \\
\text { Population Within }\end{array}$} & \multicolumn{2}{|l|}{$\begin{array}{l}\text { Utility } \\
\text { Distance to Grid Capacity }\end{array}$} \\
\hline $0.5 \mathrm{mi}$ & $<500$ & $>400 \mathrm{MWe}$ & $\sim 0.1 \mathrm{mi}$ \\
\hline $1 \mathrm{mi}$ & $\sim 1,000$ & $>800 \mathrm{MWe}$ & $\sim 50 \mathrm{mi}$ \\
\hline $5 \mathrm{mi}$ & $\sim 11,000$ & $>1600 \mathrm{MWe}$ & $\sim 31 \mathrm{mi}$ \\
\hline $10 \mathrm{mi}$ & $\sim 41,000$ & $>3200 \mathrm{MWe}$ & $\sim 245 \mathrm{mi}$ \\
\hline \multicolumn{2}{|c|}{ Nearest City with Population } & \multicolumn{2}{|c|}{ Distance to Cooling Water } \\
\hline$>10,000$ & Henderson, KY & $>50,000 \mathrm{gpm}$ & $\sim 0.3 \mathrm{mi}$ (Green River) \\
\hline$>50,000$ & Owensboro, KY & $>100,000 \mathrm{gpm}$ & $\sim 0.3 \mathrm{mi}$ (Green River) \\
\hline$>100,000$ & Evansville, IN & $>200,000 \mathrm{gpm}$ & $\sim 0.3 \mathrm{mi}$ (Green River) \\
\hline$>500,000$ & Nashville, TN & $>500,000 \mathrm{gpm}$ & $\sim 0.3 \mathrm{mi}$ (Green River) \\
\hline \multicolumn{2}{|l|}{ Geotechnical } & \multicolumn{2}{|l|}{ Accessibility } \\
\hline Max Earthquake Acceleration & $\sim 0.3 \mathrm{~g}$ & Distance to Major Roadway & $\sim 0.4$ mi (Pennyrile Pky) \\
\hline Max Slope & $\sim 9 \%$ & Distance to Water Transport & $\sim 0.3 \mathrm{mi}$ (Green River) \\
\hline Nearest Fault Line & $\sim 600 \mathrm{mi}$ (Oklahoma) & Distance to Rail Transport & $\sim 2 \mathrm{mi}(\mathrm{CSXT})$ \\
\hline Nearest Hazard Site & $\begin{array}{l}25 \text { mi (Airport- } \\
\text { Evansville Regional) }\end{array}$ & Distance to Airport & $\begin{array}{r}\sim 25 \text { mi (Evansville } \\
\text { Regional) }\end{array}$ \\
\hline
\end{tabular}




\section{A.10.3 Aerial Imagery}

The aerial imagery in Fig. A.48 indicates just the industrial complex that makes up Sebree Station. Interstate 69 runs within 0.5 miles of the site.

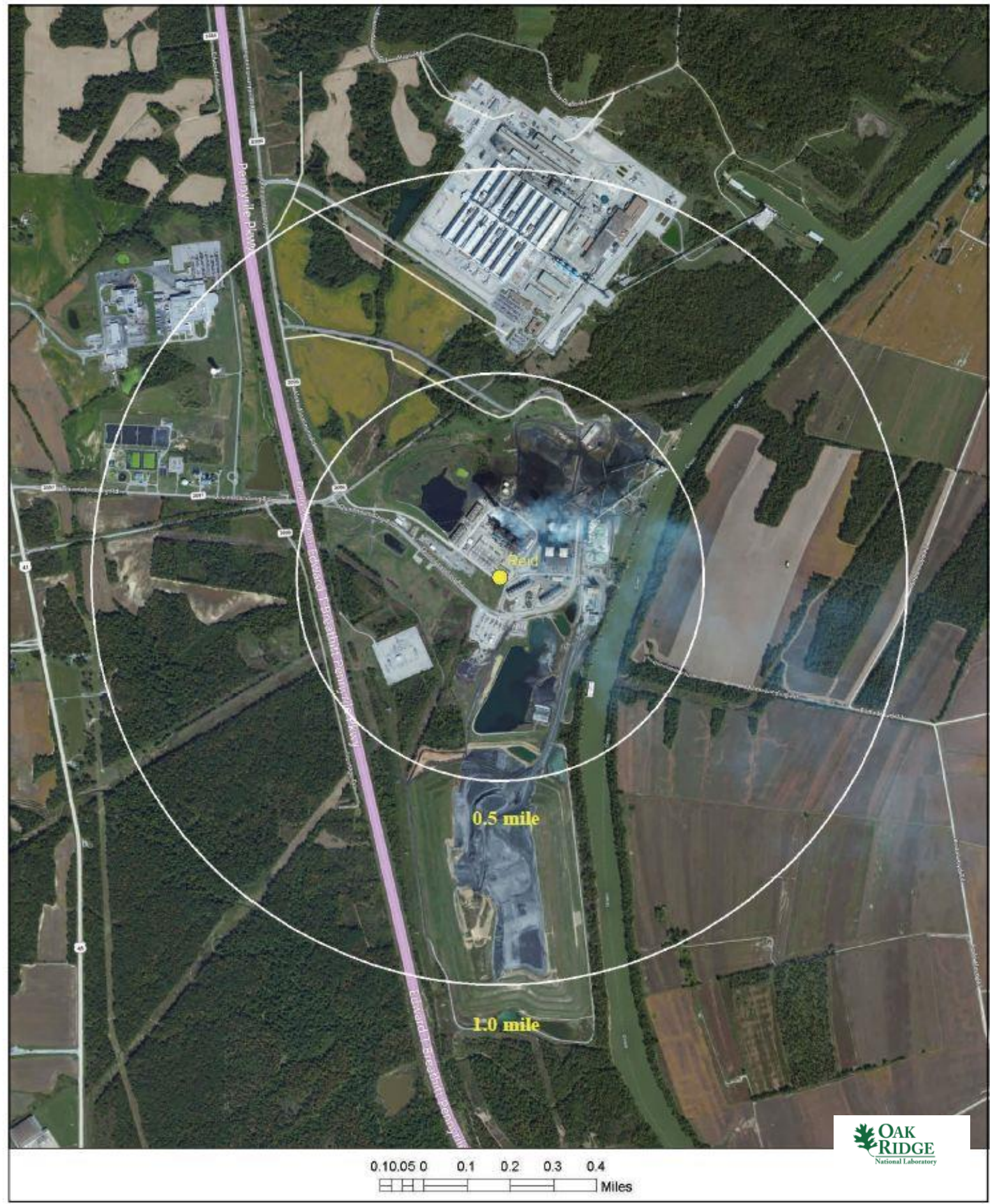

Fig. A.48. Satellite view of Robert Reid Power Station proximity. 


\section{A.10.4 Screening Criteria Overview}

Table A.25. Robert Reid Power Station siting criteria summary

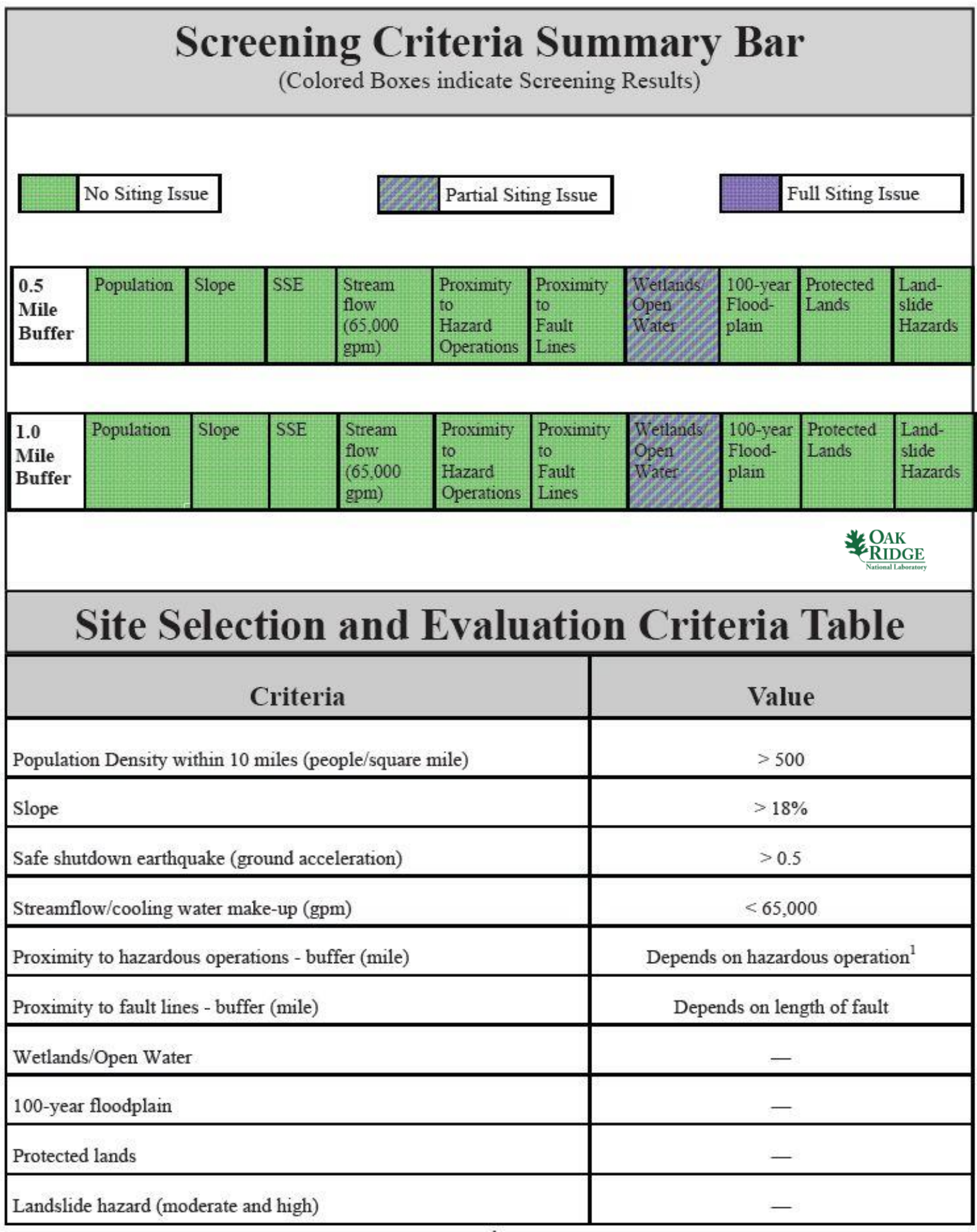

${ }^{1}$ Hazardous facilities (airports- 5 miles and oil refineries- -1 mile) 


\section{A.10.5 Composite Map and Individual Siting Issue Maps}

A composite map of SMR siting challenges to the Robert A. Reid Power Station is shown in Fig. A.49. The physical plant structures are located on land with no siting challenges. Following this map are maps of the individual SMR siting criteria based on selected input values.

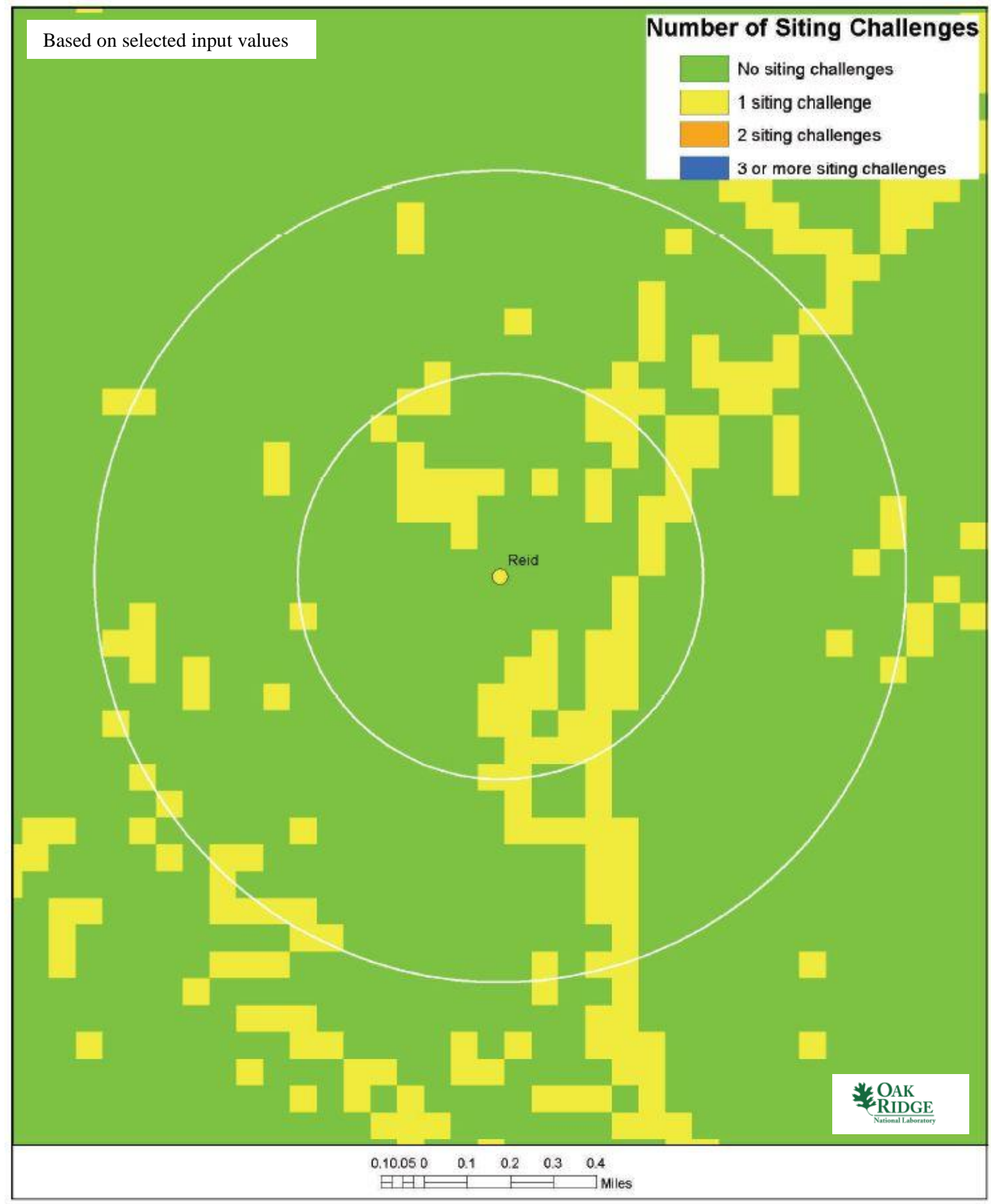

Fig. A.49. Robert Reid Power Station composite map. 

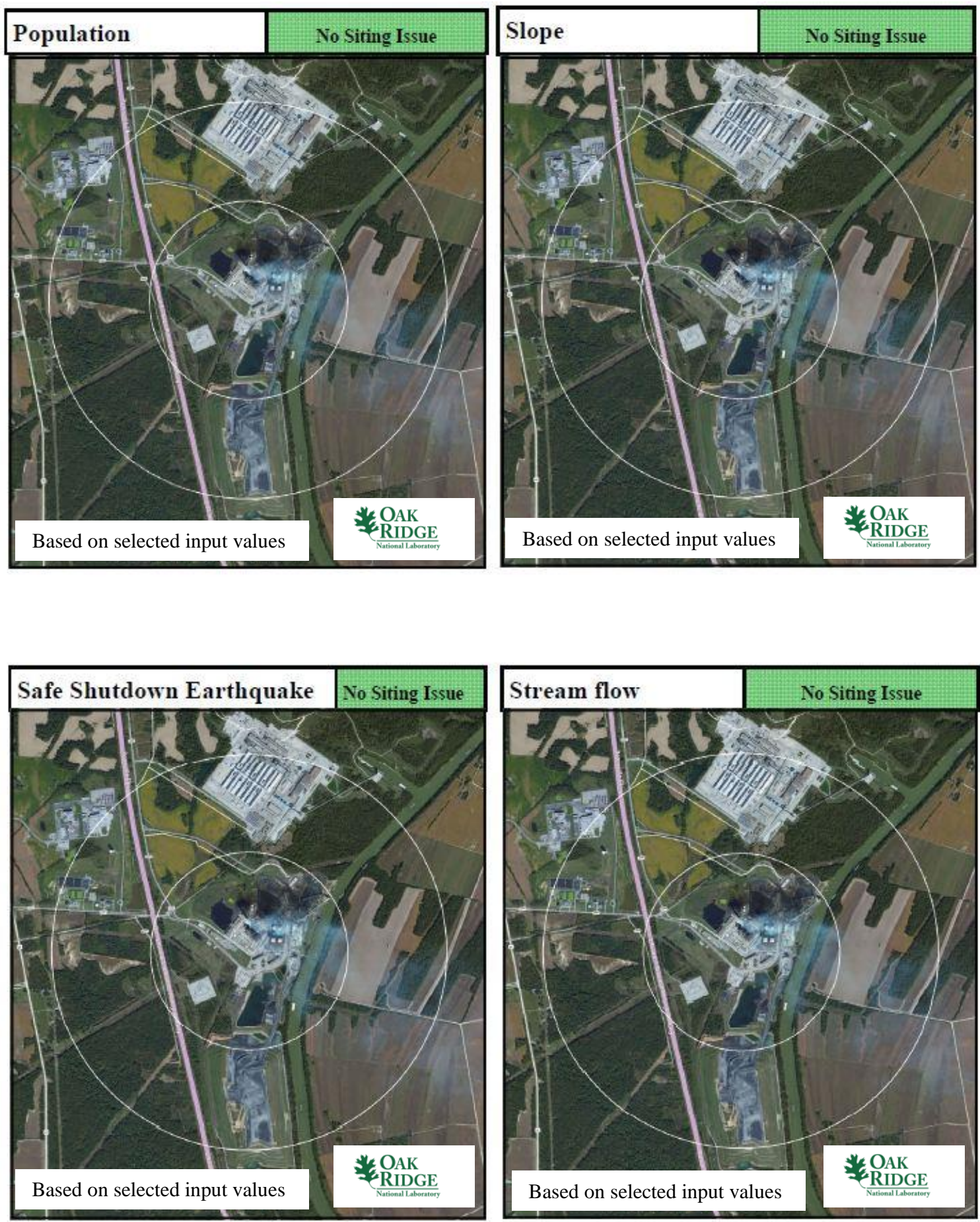

Robert Reid Power Station 

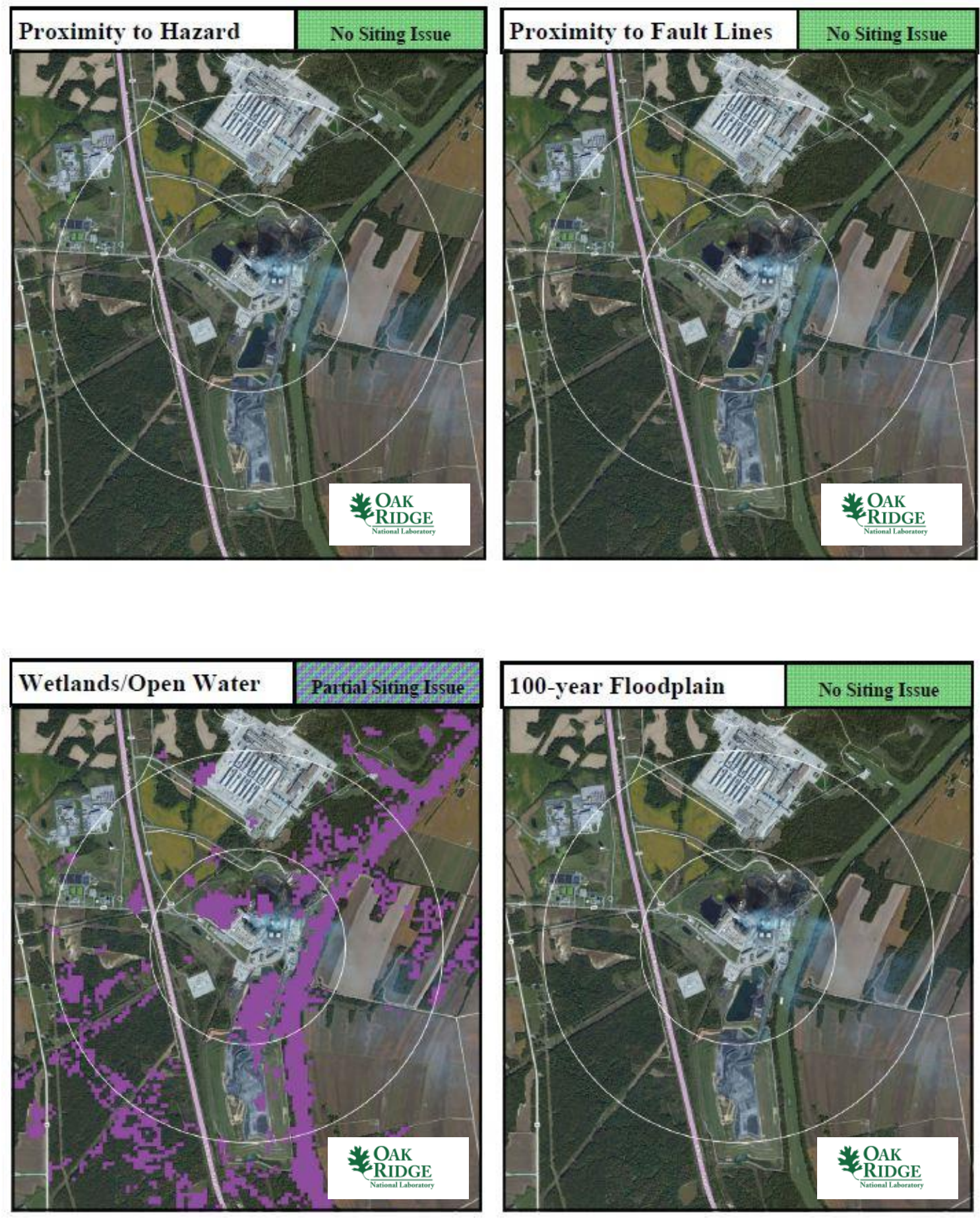

Robert Reid Power Station 

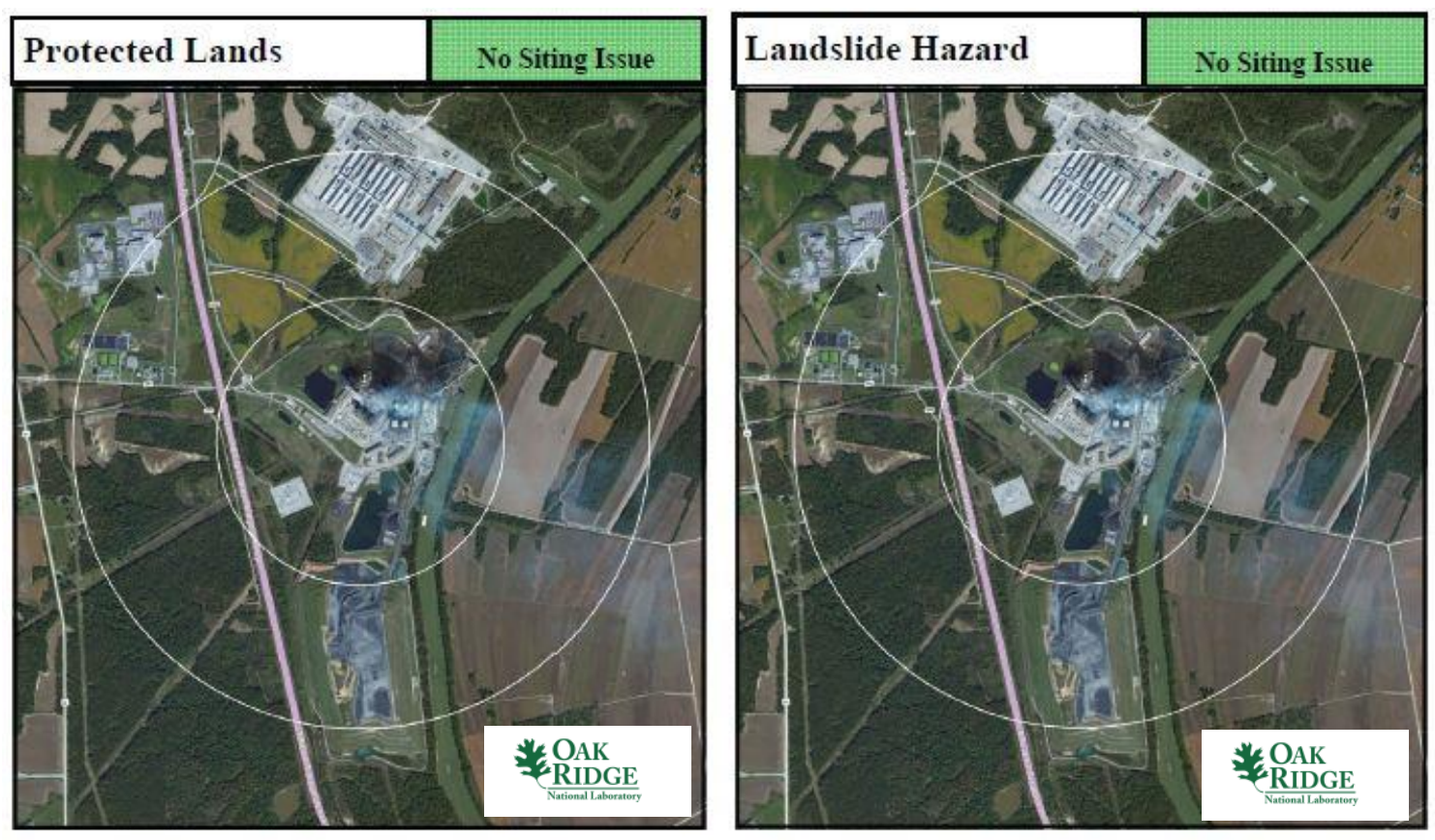

Robert Reid Power Station

\section{A.10.6 Site Evaluation}

BREC does not own or operate any nuclear power plants in the United States. Therefore, BREC would need to be mentored through the licensing process to build and operate an SMR at this site. The site contains sufficient acreage to support siting an SMR.

From an environmental justice perspective, the community collectively appears to have achieved a reasonable level of education with median income levels typical of much of the United States. Therefore, siting an SMR at this location would not seem to be disenfranchising a less-educated or poverty-stricken community. Furthermore, the education level of the Robert A. Reid Power Station community would seem to support the higher-technology job opportunities provided by an SMR.

As shown in Sects. A.0 and 0, the Robert A. Reid Power Station site has a partial SMR site screening issue with wetlands/open waters. This screening issue reflects the adjacent Green River. The remaining SMR site screening criteria are met site-wide for the values established in the updated SMR siting report.1

Interstate 69 runs near the site; that could make it difficult for a nuclear licensee to control land access to areas very near the plant location.

The site meets current NRC RG 4.7 recommendations for population density without additional consideration for relaxed SMR population siting requirements based on reduced source term. This site should be classified as acceptable with reservations. The Robert A. Reid Power Station site meets multiple conventional standards for consideration of siting an SMR at the coal station location. There are no current or near-term foreseeable SMR SSEC siting issues that should preclude this site from further SMR siting consideration. 


\section{A.11 Savannah River Site Power Station}

\section{A.11.1 Location Detail}

As shown in Fig. A.50, the Savannah River Site (SRS) Power Station is located in South Carolina on the border with Georgia defined by the Savannah River. More specifically, the plant is located in Barnwell County, South Carolina. Highway 278 is accessible approximately 12 miles to the north and Interstate 20 is accessible approximately 20 miles to the north. Rail access is available within 0.8 miles and barge access is available within 1mile via the Savannah River. The plant is located about 18 miles northeast of Waynesboro, Georgia, with a population of approximately 5,800 people. The nearest city with a population in excess of 10,000 people is North Augusta, South Carolina, approximately 24 miles to the northeast of the Savannah River Site Power Station.

- Plant: Savannah River Site Power Station

- Utility: Federal Government

- Coordinates: lat. $33.20270^{\circ} \mathrm{N}$, long. $81.73866^{\circ} \mathrm{W}$

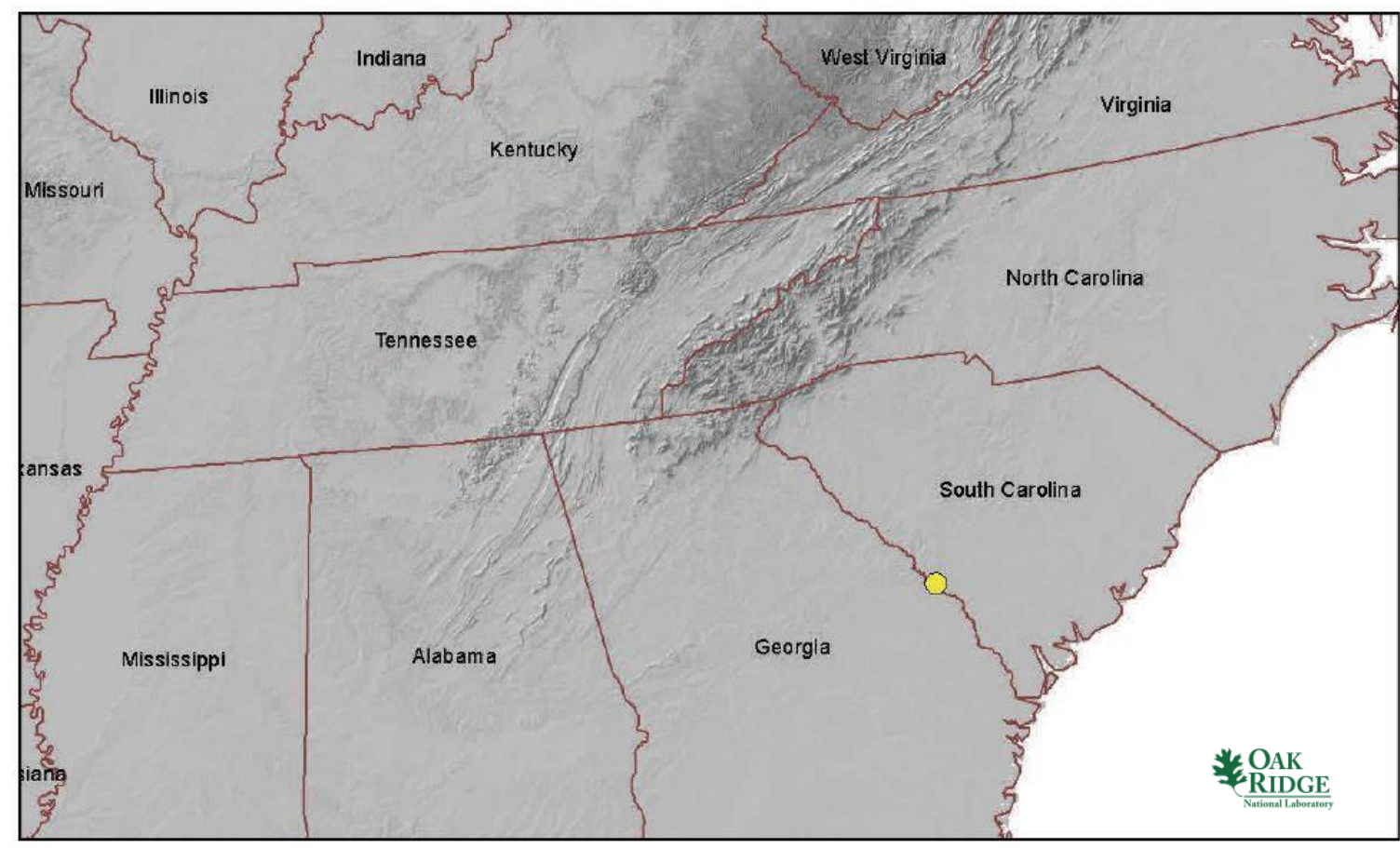

Fig. A.50. Savannah River Site Power Station location map.

\section{A.11.2 Site Description and Status}

The SRS Power Station is operated by the federal government. The $78 \mathrm{MW}(\mathrm{e})$ power plant consists of seven oil- or coal-fired units. The plant is cooled by once-through cooling from the Savannah River. All the units were commissioned in 1952. Three of the units are rated at 9.4 MW(e) and the remaining four units are rated at 12.5 MW(e). All the units were retired in December 2011 and replaced by a biomass plant that burns wood chips.

Over 600 acres, mostly brownfield, are available at the former SRS Power Station. The site is approximately 5 miles north of the 2,430 MW(e) nuclear Vogtle Electric Generating Station in Georgia. The plant is 18 miles southeast of the $650 \mathrm{MW}(\mathrm{e})$ gas and coal-fired Urquhart Station and 42 miles 
southwest of the 417 MW(e) coal-fired Cope Station. The 380 MW(e) Thurmond Dam hydroelectric project is 40 miles northwest of the SRS power station.

As noted in Table A.26, the nearest major fault line based on USGS data is about 900 miles west in Oklahoma. The maximum safe-shutdown earthquake for the site is below $0.3 \mathrm{~g}$ peak ground acceleration. More than 500,000 gpm of cooling water makeup is available from the nearby Savannah River.

The permanent population within 1 mile of the plant is fewer than 500 people, yielding a population density of fewer than 160 people per square mile. The permanent population within 10 miles of the plant is approximately 42,000 people, yielding a population density of about 135 people per square mile.

Table A.26. Savannah River Site Power Station site statistics

\begin{tabular}{|c|c|c|c|}
\hline \multicolumn{2}{|l|}{$\begin{array}{l}\text { Population } \\
\text { Population Within }\end{array}$} & \multicolumn{2}{|l|}{$\begin{array}{l}\text { Utility } \\
\text { Distance to Grid Capacity }\end{array}$} \\
\hline $0.5 \mathrm{mi}$ & $<500$ & $>400 \mathrm{MWe}$ & $\sim 1 \mathrm{mi}$ \\
\hline $1 \mathrm{mi}$ & $<500$ & $>800 \mathrm{MWe}$ & $\sim 65 \mathrm{mi}$ \\
\hline $5 \mathrm{mi}$ & $\sim 9,000$ & $>1600 \mathrm{MWe}$ & $\sim 4 \mathrm{mi}$ \\
\hline $10 \mathrm{mi}$ & $\sim 42,000$ & $>3200 \mathrm{MWe}$ & $\sim 179 \mathrm{mi}$ \\
\hline \multicolumn{2}{|c|}{ Nearest City with Population } & \multicolumn{2}{|c|}{ Distance to Cooling Water } \\
\hline$>10,000$ & North Augusta, SC & $>50,000 \mathrm{gpm}$ & $\sim 1.0$ mi (Savannah River) \\
\hline$>50,000$ & North Charleston, SC & $>100,000 \mathrm{gpm}$ & $\sim 1.0 \mathrm{mi}$ (Savannah River) \\
\hline$>100,000$ & Augusta, GA & $>200,000 \mathrm{gpm}$ & $\sim 1.0$ mi (Savannah River) \\
\hline$>500,000$ & Charlotte, NC & $>500,000 \mathrm{gpm}$ & $\sim 1.0$ mi (Savannah River) \\
\hline \multicolumn{2}{|l|}{ Geotechnical } & \multicolumn{2}{|l|}{ Accessibility } \\
\hline Max Earthquake Acceleration & $<0.3 \mathrm{~g}$ & Distance to Major Roadway & $\sim 12.4 \mathrm{mi}$ (US 278) \\
\hline Max Slope & $\sim 7 \%$ & Distance to Water Transport & $\sim 1.0$ mi (Savannah River) \\
\hline Nearest Fault Line & $\sim 903 \mathrm{mi}$ (Oklahoma) & Distance to Rail Transport & $\sim 0.8 \mathrm{mi}(\mathrm{CSXT})$ \\
\hline Nearest Hazard Site & $\begin{array}{c}17 \text { mi (Airport- } \\
\text { Augusta Regional) }\end{array}$ & Distance to Airport & $\begin{array}{l}\sim 17 \text { mi (Augusta Regional at } \\
\text { Bush Field) }\end{array}$ \\
\hline
\end{tabular}




\section{A.11.3 Aerial Imagery}

The aerial imagery in Fig. A.51 shows that the SRS Power Station is relatively isolated within the DOE site.

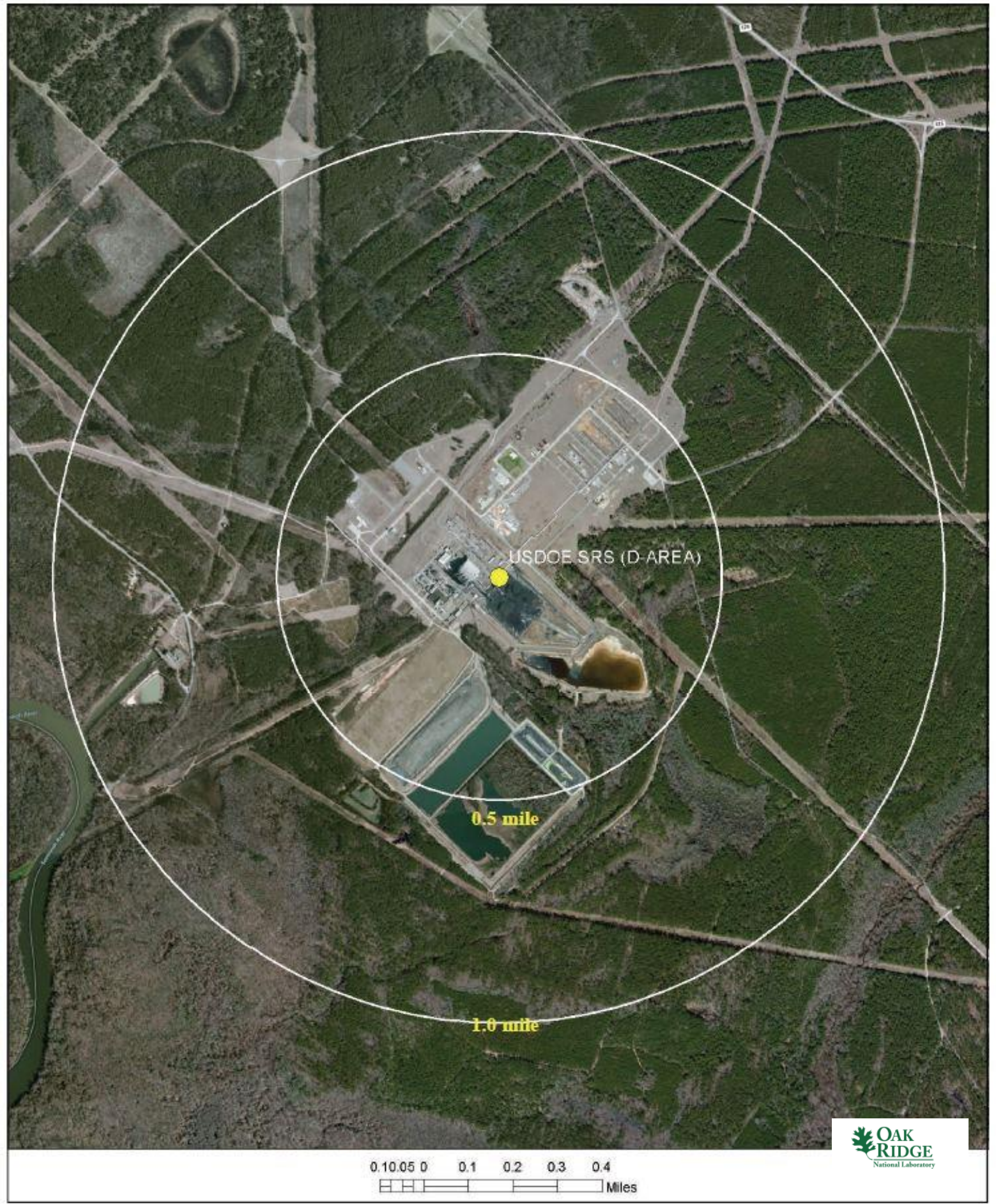

Fig. A.51. Satellite view of Savannah River Site Power Station proximity. 


\section{A.11.4 Screening Criteria Overview}

Table A.27. Savannah River Site Power Station siting criteria summary

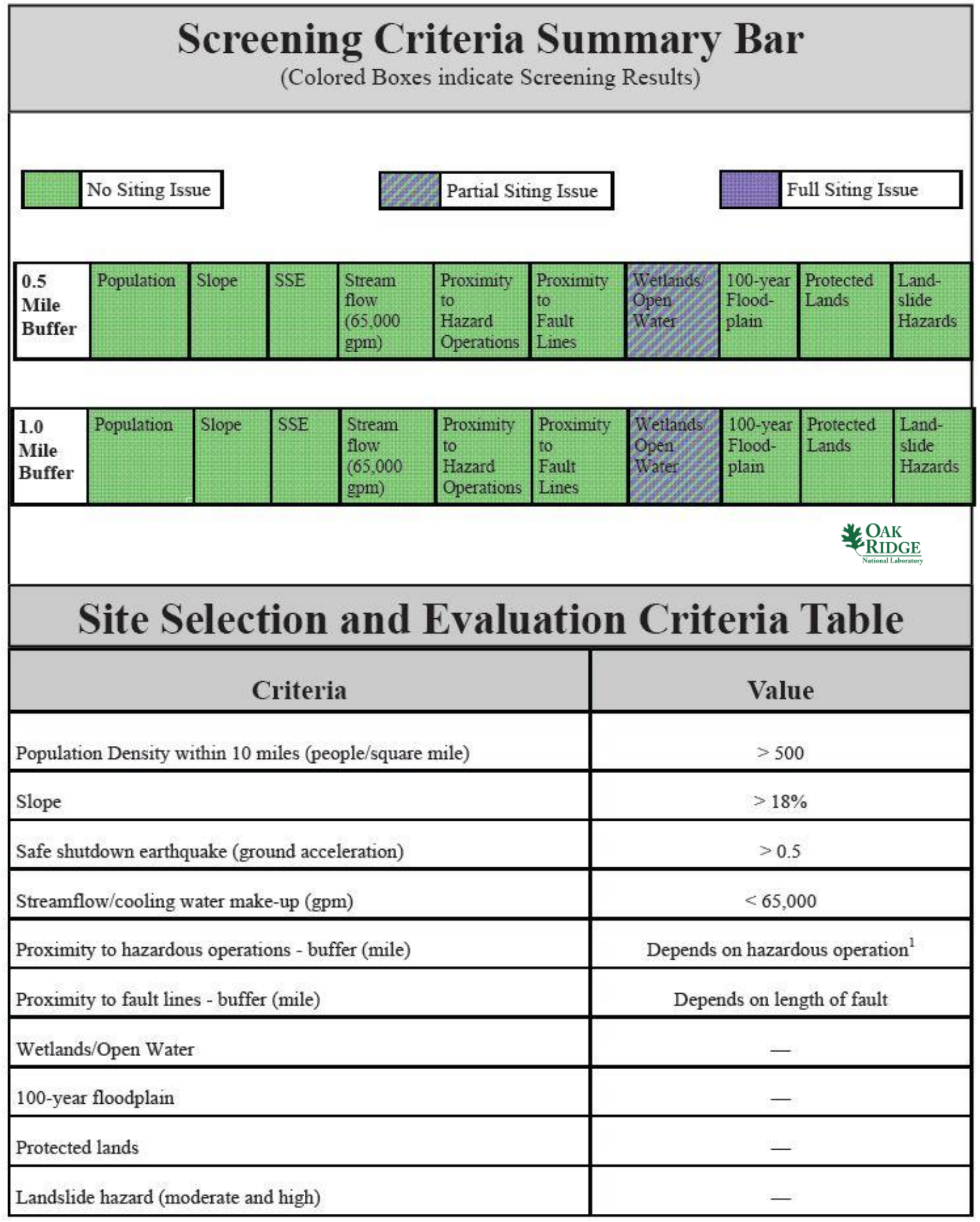

${ }^{1}$ Hazardous facilities (airports- 5 miles and oil refineries- -1 mile) 


\section{A.11.5 Composite Map and Individual Siting Issue Maps}

A composite map of SMR siting challenges to the SRS Power Station is shown in Fig. A.52. The physical plant structures are located on land that meets the SMR SSEC at the selected values. Following this map are maps of the individual SMR siting criteria based on selected input values.

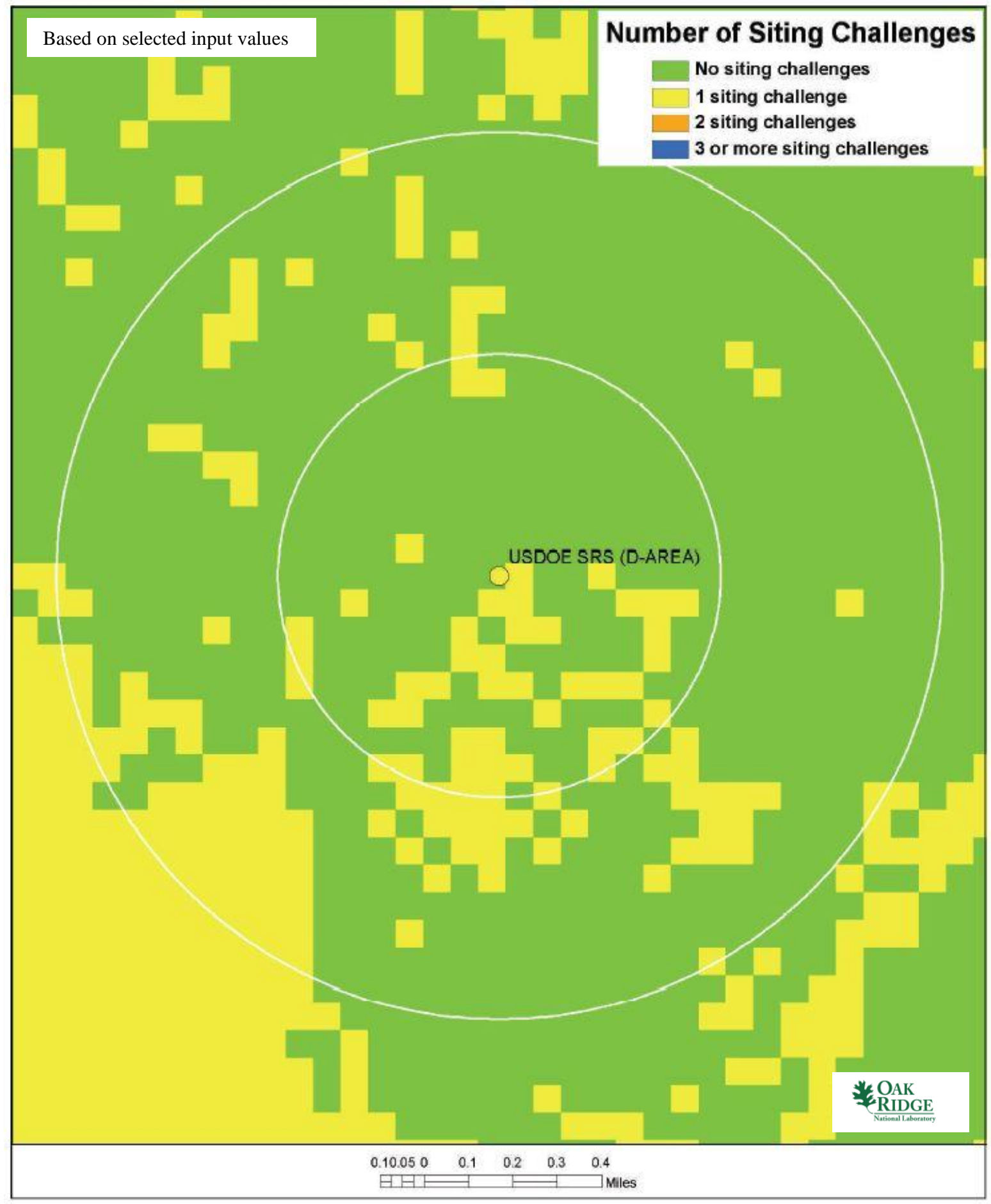

Fig. A.52. Savannah River Site Power Station composite map. 

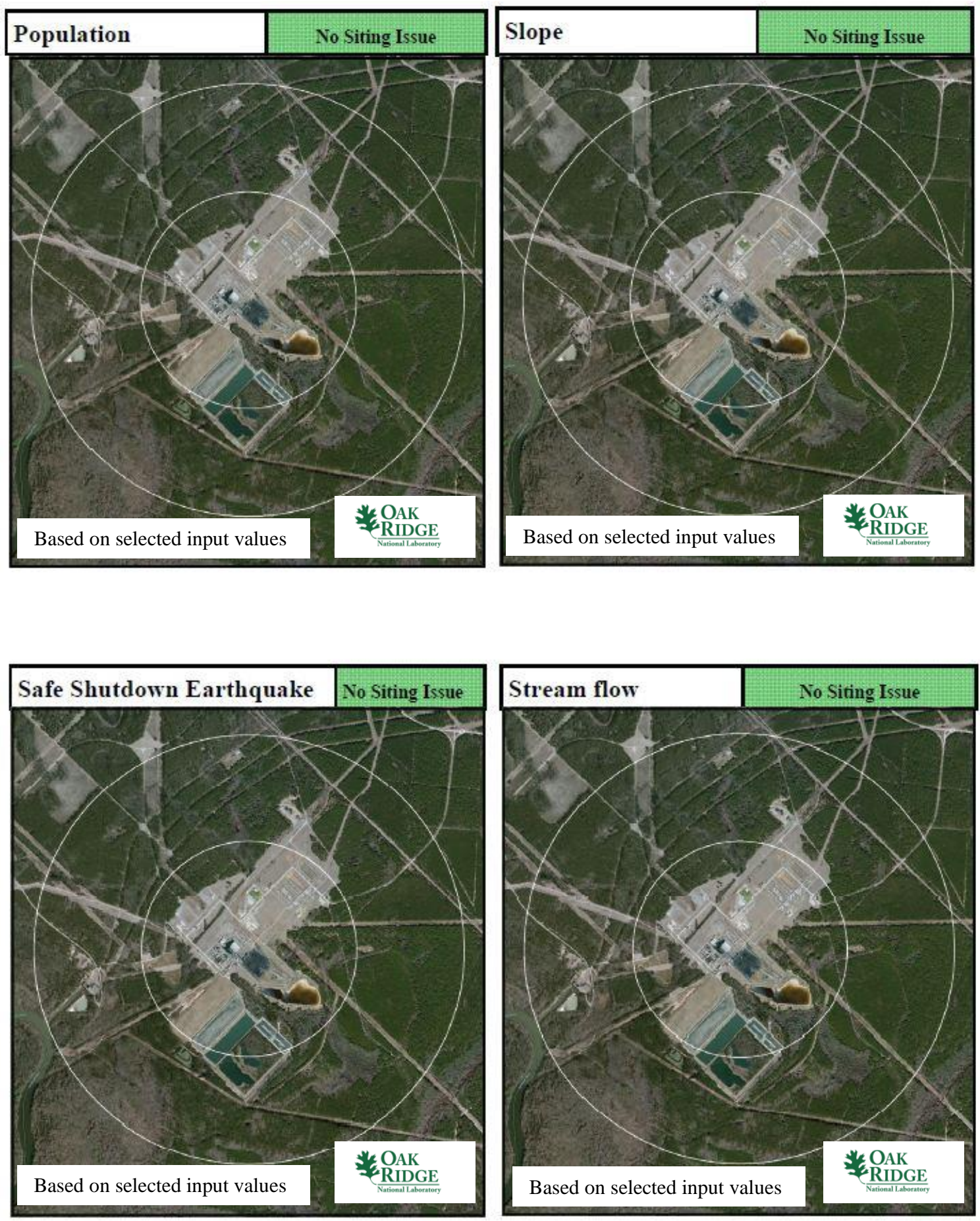

Savannah River Site Power Station 

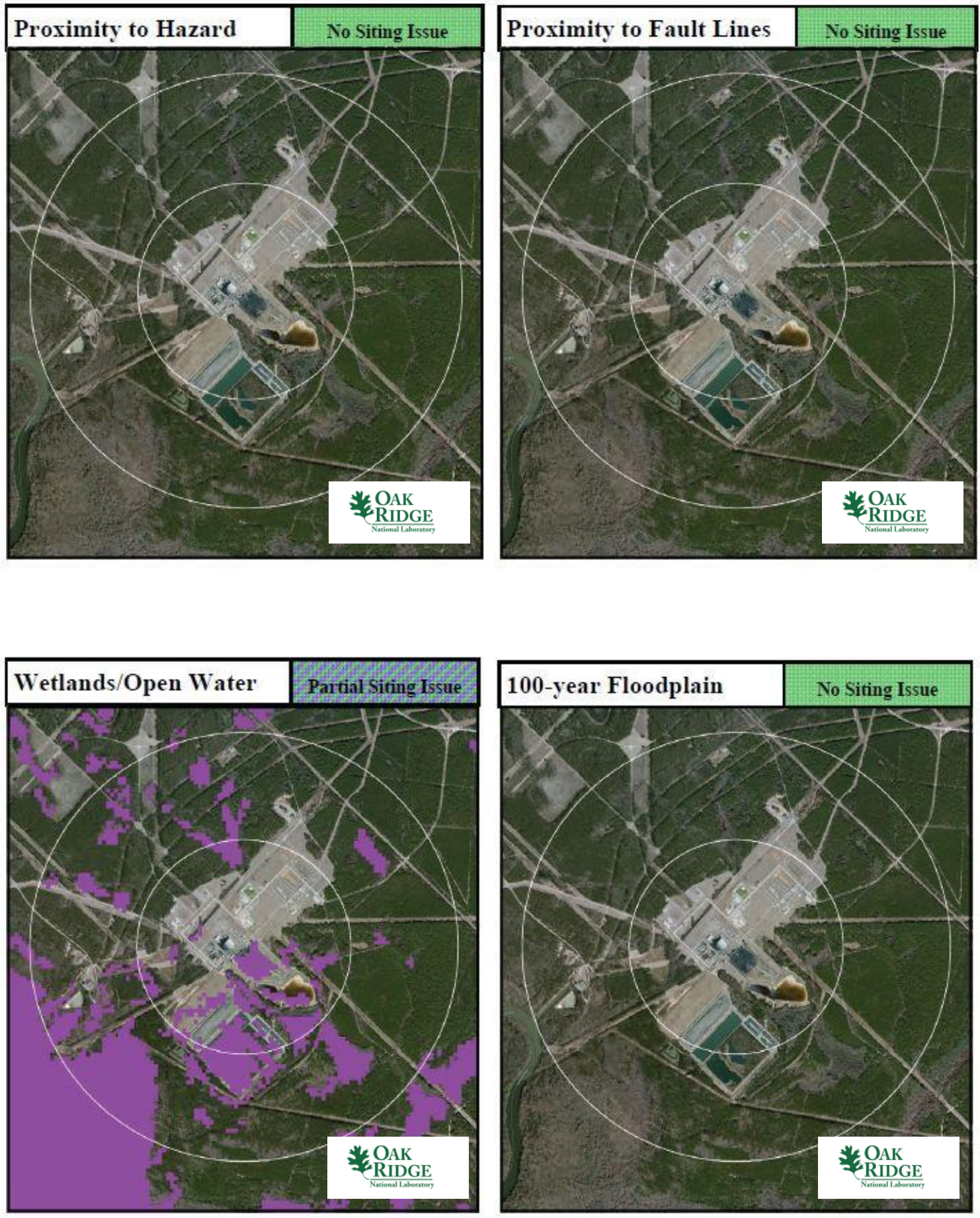

Savannah River Site Power Station 

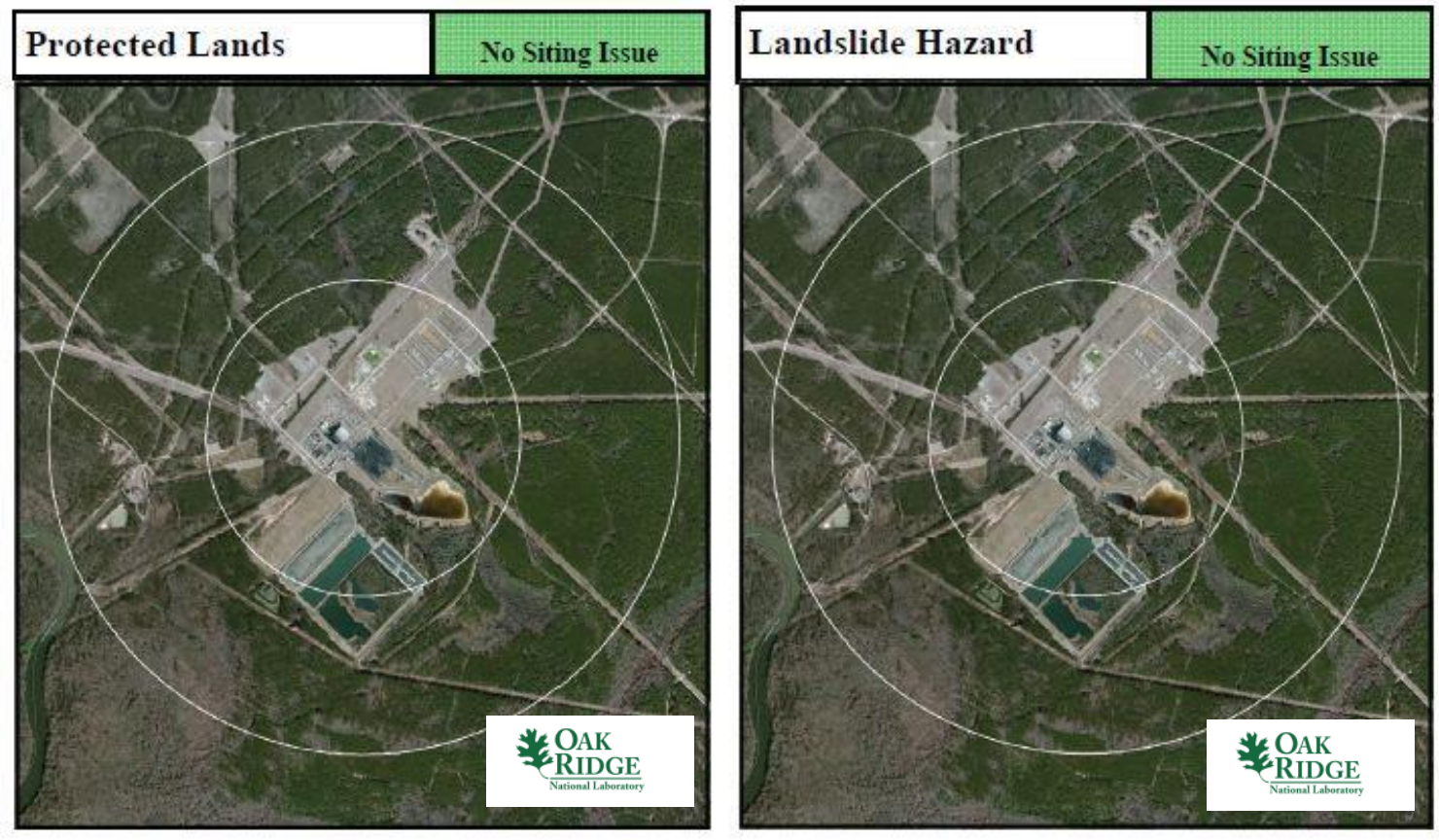

Savannah River Site Power Station

\section{A.11.6 Site Evaluation}

The federal government operates research reactors and has operated other special-purpose reactors at national laboratory sites. Furthermore, DOE has interfaced with the NRC on pre-licensing discussions related to the Next Generation Nuclear Plant. Therefore, DOE should have the licensing experience to license and operate an SMR at this site. In addition, locating an SMR at an existing DOE laboratory site would have the added benefit of sharing logistical and security resources. The site contains sufficient acreage to support siting an SMR.

As shown in Sects. A.0 and A.0, the SRS Power Station site has a partial SMR site screening issue with wetlands/open waters. The wetlands/open waters concern is related to the nearby Savannah River and does not impact the immediate site. The remaining SMR site screening criteria are met site-wide for the values established in the updated SMR siting report.1

When future load demands indicate the need for expanded generation capacity in this region or for the SRS facility, the SRS Power Station site would be a good candidate location. The site meets current NRC RG 4.7 recommendations for population density without additional consideration for relaxed SMR population siting requirements based on reduced source term. The SRS Power Station site meets multiple conventional standards for consideration of siting an SMR at the coal station location. 


\section{A.12 Watts Bar Fossil Plant}

\section{A.12.1 Location Detail}

As shown in Fig. A.53, the Watts Bar Fossil Plant is located in east central Tennessee between Knoxville and Chattanooga, less than a mile off State Road 68, Watts Bar Highway, in Rhea County. Interstate 75 is accessible 11.5 miles to the east. Rail access is available within 0.4 miles and barge access is available within 0.3 miles. The closest town is Spring City, Tennessee, with a population of approximately 2000 people. Spring City is approximately 6 miles northwest of the Watts Bar Fossil Plant. The nearest city with a population in excess of 10,000 people is Athens, Tennessee, approximately 16 miles to the southeast of the Watts Bar Fossil Plant.

- Plant: Watts Bar Fossil Plant

- Utility: TVA

- Coordinates: lat. $35.6107^{\circ} \mathrm{N}$, long. $84.7816^{\circ} \mathrm{W}$

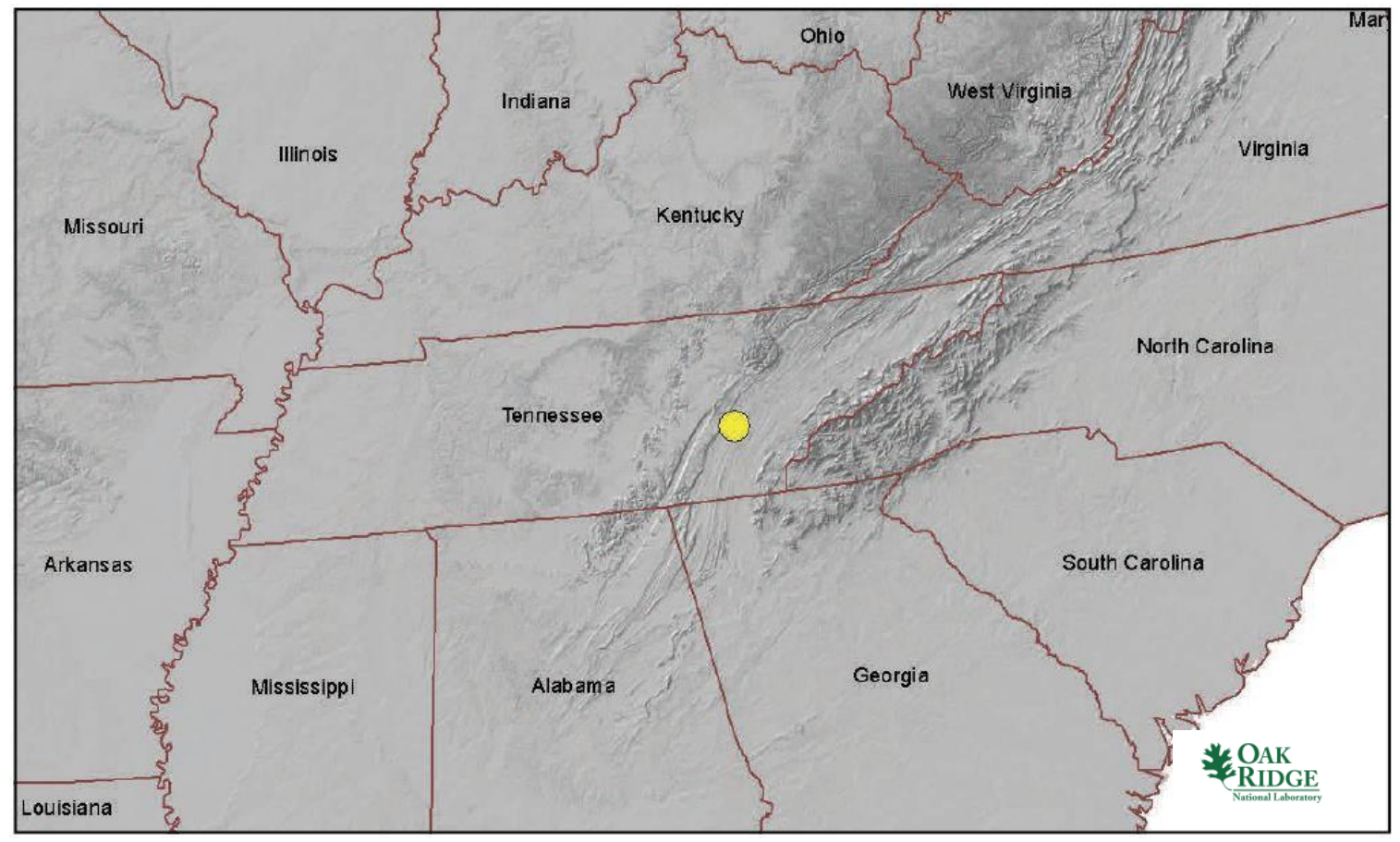

Fig. A.53. Watts Bar Fossil Plant location map.

\section{A.12.2 Site Description and Status}

The Watts Bar Fossil Plant is a four-unit coal station with all units currently retired. The Watts Bar Fossil Plant is located approximately 0.7 miles northeast of the 1,100 MW(e) Watts Bar nuclear facility (Unit 1) and 0.7 miles south of the $167 \mathrm{MW}(\mathrm{e})$ Watts Bar Hydroelectric Plant associated with the Watts Bar lock and dam. Each of the four fossil units was rated at $60 \mathrm{MW}(\mathrm{e})$ for a total site capacity of $240 \mathrm{MW}(\mathrm{e})$. The coal-fired units were cooled by once-through cooling from the adjacent Tennessee River, although the existing nuclear facility is cooled by natural draft cooling towers. The units were among the first coalpowered facilities built by the Tennessee Valley Authority (TVA) and were commissioned between 1942 and 1945. All of the units were decommissioned at the end of 1982. Dismantling of the Watts Bar Fossil Plant was completed in 2011, but the land remains in TVA possession and available for energy generation. 
An analysis ${ }^{14}$ conducted in 2009 by Stantec, a planning, engineering, and environmental sciences company, for TVA noted the following regarding the site geology:

"The Watts Bar Fossil Plant is located in east-central Tennessee along the west bank of the Tennessee River, just south (downstream) of the Watts Bar Lock and Dam. The plant is situated near the western edge of the Valley and Ridge Physiographic province near the base of the Cumberland Plateau. Numerous faults, trending northeast to southwest as characteristic of the Valley and Ridge Province, are depicted on the geologic mapping and the plant is positioned just south of the Chattanooga Fault. The geologic mapping shows the plant to be underlain by Cambrian age limestone and shale bedrock of the Conasauga Group and Rome Formation.

Seismic events affecting eastern Tennessee, and thus the plant site, primarily emanate from three zones of earthquake activity-the New Madrid Seismic Zone (NMSZ), Southern Appalachia Seismic Zone (SASZ), and the South Carolina Seismic Zone (SCSZ). The most active zone of the SASZ, the East Tennessee Seismic Zone (ETSZ), extends from northwestern Georgia through East Tennessee and is situated in close proximity to the plant. However, most earthquakes emanating from this zone are relatively low in magnitude, with the largest known event in the ETSZ registering a magnitude of 4.6, suggesting a moderate risk of damage from a seismic event. In contrast, if a large earthquake were to occur within the NMSZ to the west, damage to East Tennessee would be possible. The "Geologic Hazards Map of Tennessee-Environmental Geology Series No. 5" developed and published by the Tennessee Department of Environment and Conservation (TDEC), Division of Geology and compiled by Robert Miller (1978) shows the plant to be located in Seismic Risk Zone 2."

As noted in Table A.28, the nearest major fault line based on USGS data is 730 miles west in Oklahoma. The maximum safe-shutdown earthquake for the site is below $0.3 \mathrm{~g}$ peak ground acceleration. More than $500,000 \mathrm{gpm}$ of cooling water makeup is available from the adjacent Tennessee River.

The permanent population within 1 mile of the plant is fewer than 500 people, yielding a population density of fewer than 160 people per square mile. The permanent population within 10 miles of the plant is approximately 45,000 people, yielding a population density of approximately 145 people per square mile. According to the US EPA Environmental Justice website, there are 7,257 occupied housing units within 10 miles of the plant site based on 2010 US Census data. Further, over $65 \%$ of area adults over age 25 have a high school diploma or higher education. The median annual income for the area is between $\$ 25 \mathrm{~K}$ and $\$ 50 \mathrm{~K}$, although just over $20 \%$ of the area population has an annual income less than $\$ 15 \mathrm{~K}$.

\footnotetext{
${ }^{14}$ Stantec, "TVA Disposal Facility Assessment Phase 1 Plant Summary Watts Bar Fossil Plant (WBF)," http://www.tn.gov/environment/kingston/pdf/tva/StantecWattsBarAnalysisI.pdf, June 2009.
} 
Table A.28. Watts Bar Fossil Plant site statistics

\begin{tabular}{|c|c|c|c|}
\hline \multicolumn{2}{|l|}{$\begin{array}{l}\text { Population } \\
\text { Population Within }\end{array}$} & \multicolumn{2}{|l|}{$\begin{array}{l}\text { Utility } \\
\text { Distance to Grid Capacity }\end{array}$} \\
\hline $0.5 \mathrm{mi}$ & $<500$ & $>400 \mathrm{MWe}$ & $\sim 31 \mathrm{mi}$ \\
\hline $1 \mathrm{mi}$ & $<500$ & $>800 \mathrm{MWe}$ & $\sim 0.2 \mathrm{mi}$ \\
\hline $5 \mathrm{mi}$ & $\sim 8,500$ & $>1600 \mathrm{MWe}$ & $\sim 0.4 \mathrm{mi}$ \\
\hline $10 \mathrm{mi}$ & $\sim 45,000$ & $>3200 \mathrm{MWe}$ & $\sim 144 \mathrm{mi}$ \\
\hline \multicolumn{2}{|c|}{ Nearest City with Population } & \multicolumn{2}{|c|}{ Distance to Cooling Water } \\
\hline$>10,000$ & Athens, TN & $>50,000 \mathrm{gpm}$ & $\sim 0.3 \mathrm{mi}$ (Tennessee River) \\
\hline$>50,000$ & Murfreesboro, TN & $>100,000 \mathrm{gpm}$ & $\sim 0.3 \mathrm{mi}$ (Tennessee River) \\
\hline$>100,000$ & Chattanooga, TN & $>200,000 \mathrm{gpm}$ & $\sim 0.3 \mathrm{mi}$ (Tennessee River) \\
\hline$>500,000$ & Nashville, TN & $>500,000 \mathrm{gpm}$ & $\sim 0.3 \mathrm{mi}$ (Tennessee River) \\
\hline \multicolumn{2}{|l|}{ Geotechnical } & \multicolumn{2}{|l|}{ Accessibility } \\
\hline Max Earthquake Acceleration & $<0.3 \mathrm{~g}$ & Distance to Major Roadway & $\sim 0.6 \mathrm{mi}(\mathrm{SR} 68)$ \\
\hline Max Slope & $\sim 26 \%$ & Distance to Water Transport & $\sim 0.3 \mathrm{mi}$ (Tennessee River) \\
\hline Nearest Fault Line & $\sim 730 \mathrm{mi}$ (Oklahoma) & Distance to Rail Transport & $\sim 0.4 \operatorname{mi}($ TVAX $)$ \\
\hline Nearest Hazard Site & $\begin{array}{l}\sim 43.7 \mathrm{mi} \text { (Airport- } \\
\text { Lovell Field) }\end{array}$ & Distance to Airport & $\sim 43.7 \mathrm{mi}$ (Lovell Field) \\
\hline
\end{tabular}




\section{A.12.3 Aerial Imagery}

The aerial imagery in Fig. A.54 indicates that State Road runs approximately 0.75 miles northwest of the Watts Bar Fossil Plant site. Only the adjacent nuclear plant and hydro plant are visible within 1 mile of the site.

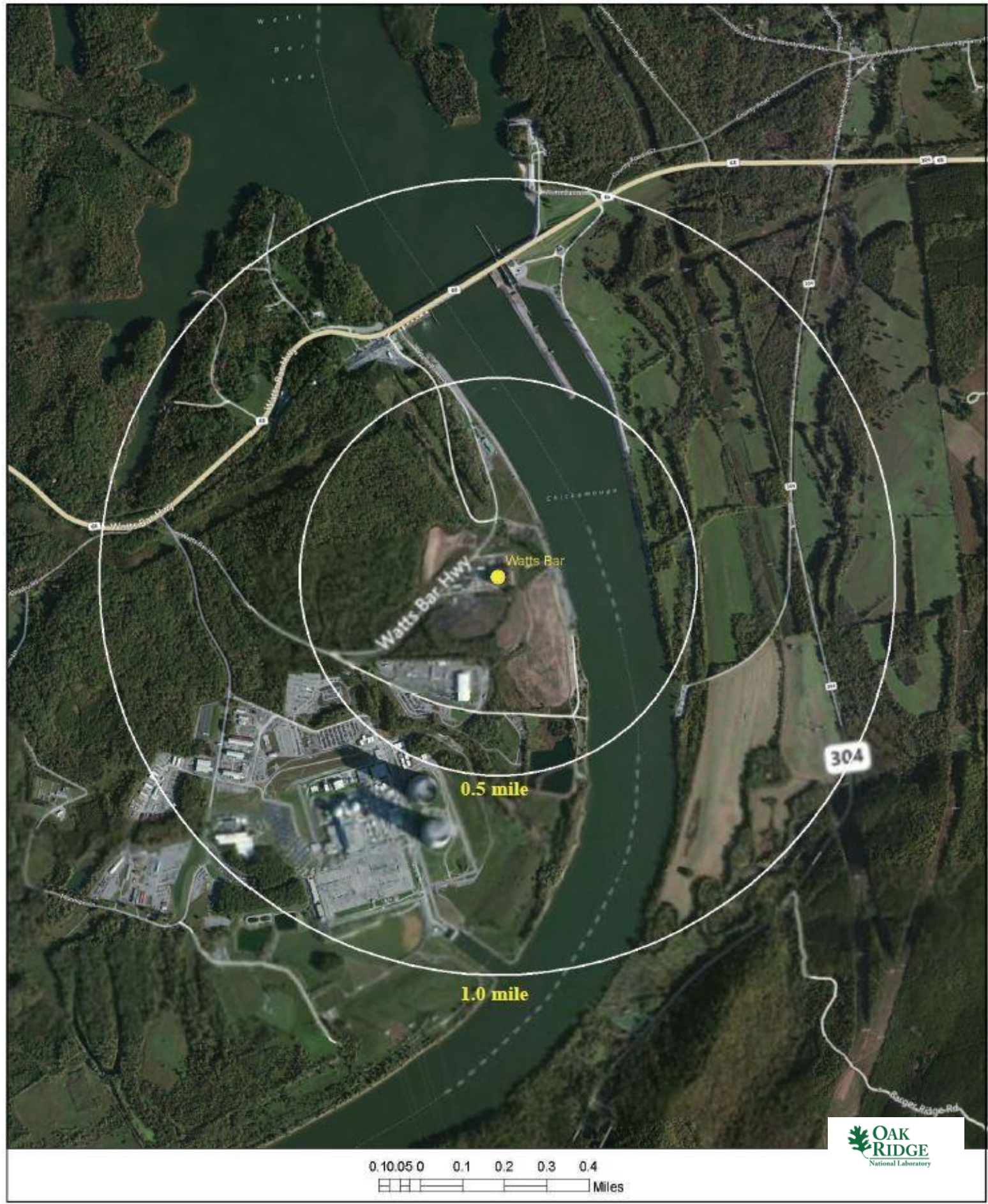

Fig. A.54. Satellite view of Watts Bar Fossil Plant proximity. 


\section{A.12.4 Screening Criteria Overview}

Table A.29. Watts Bar Fossil Plant siting criteria summary

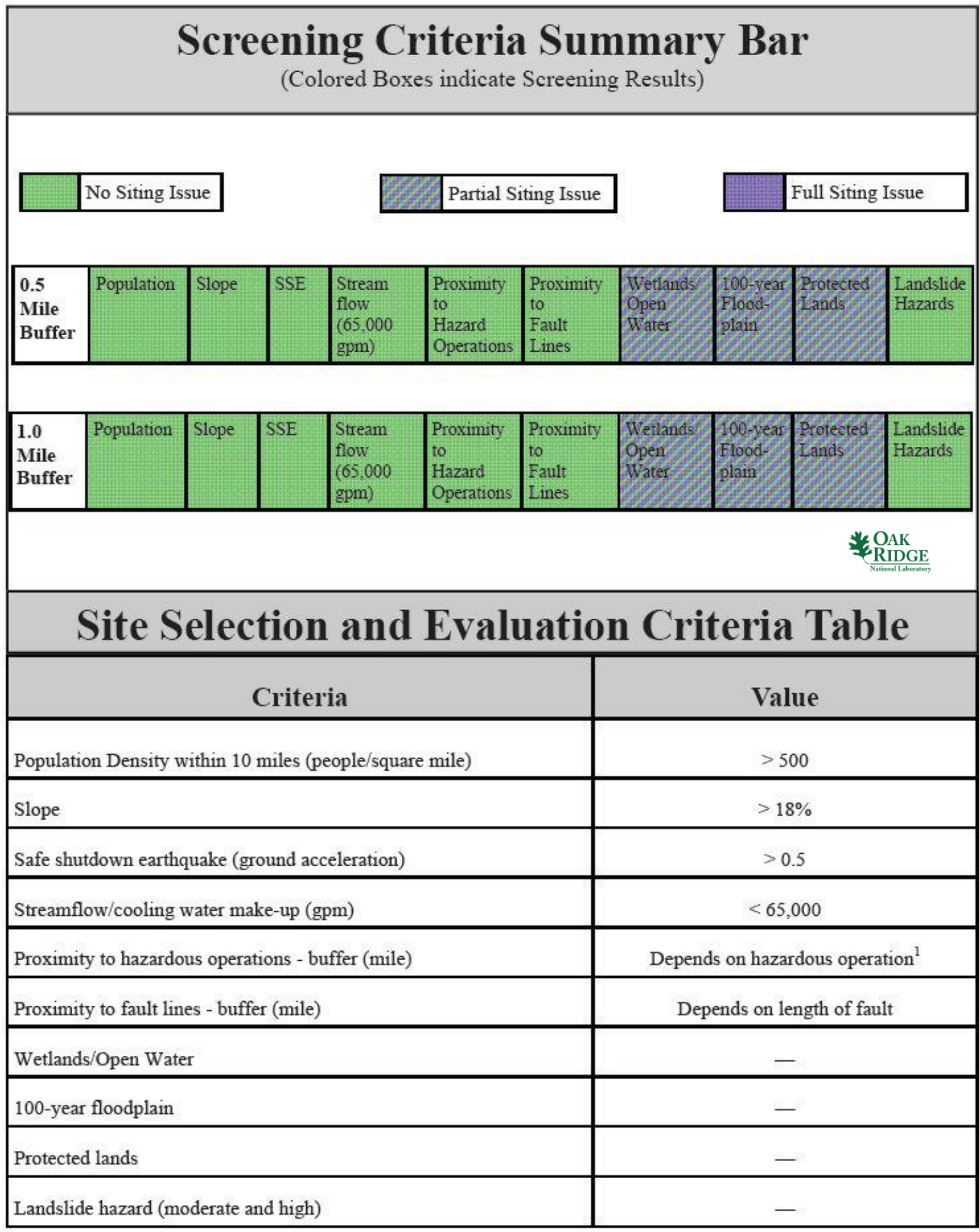

${ }^{1}$ Hazardous facilities (airports- 5 miles and oil refineries- -1 mile) 


\section{A.12.5 Composite Map and Individual Siting Issue Maps}

A composite map of SMR siting challenges to the Watts Bar Fossil Plant is shown in Fig. A.55. The physical plant structures are located on land with no siting issues. Following this map are maps of the individual SMR siting criteria based on selected input values.

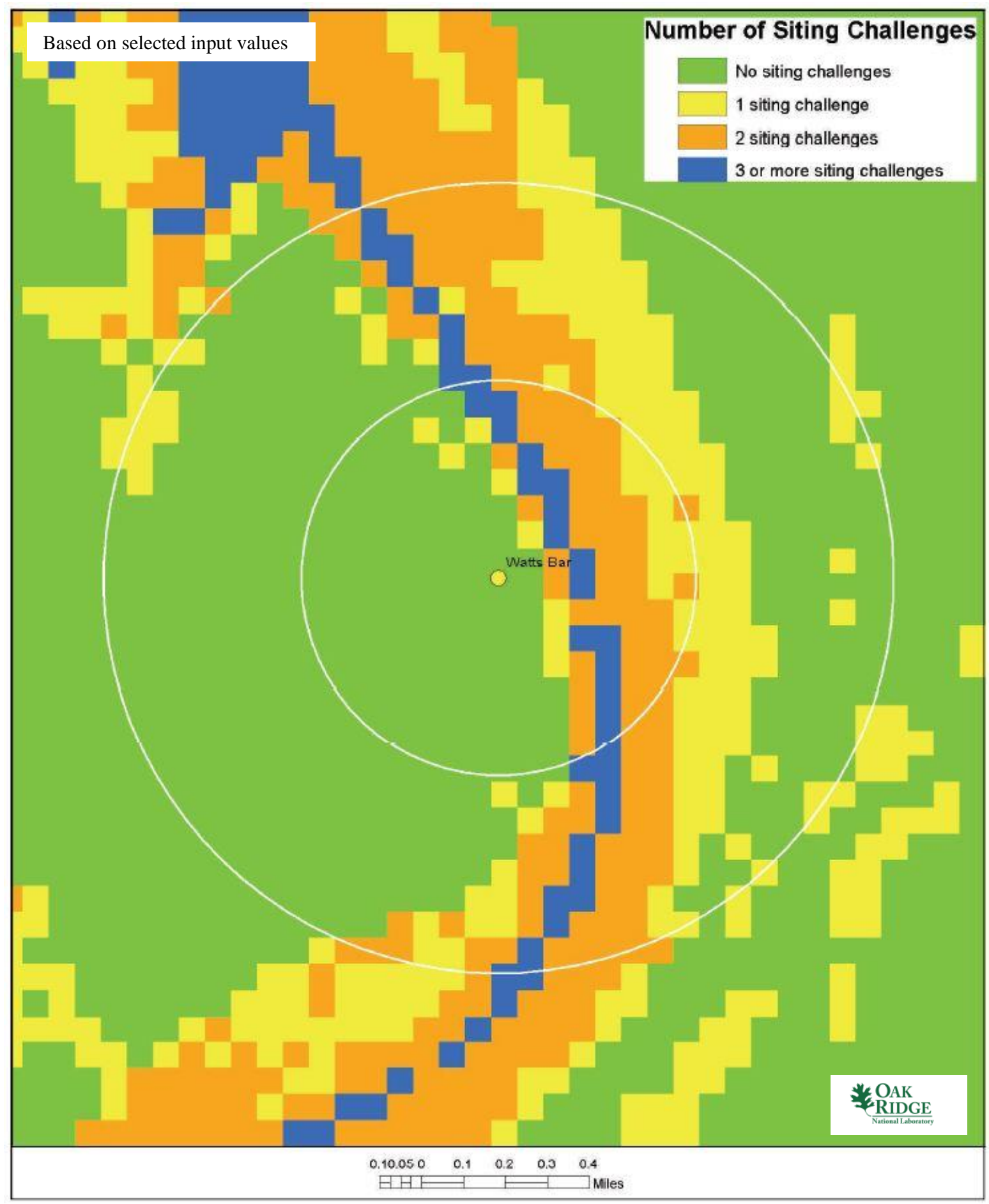

Fig. A.55. Watts Bar Fossil Plant composite map. 

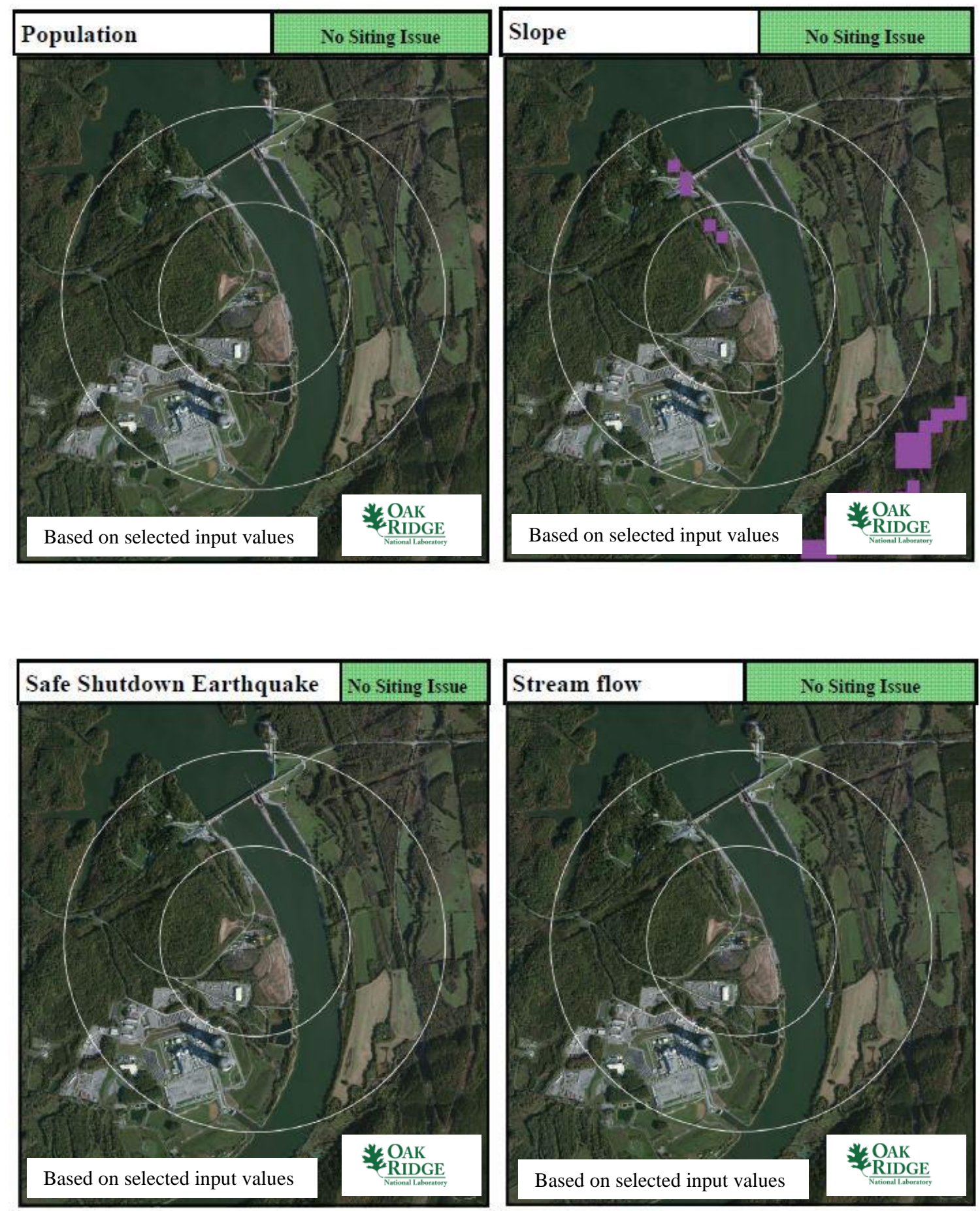

Watts Bar Fossil Plant 

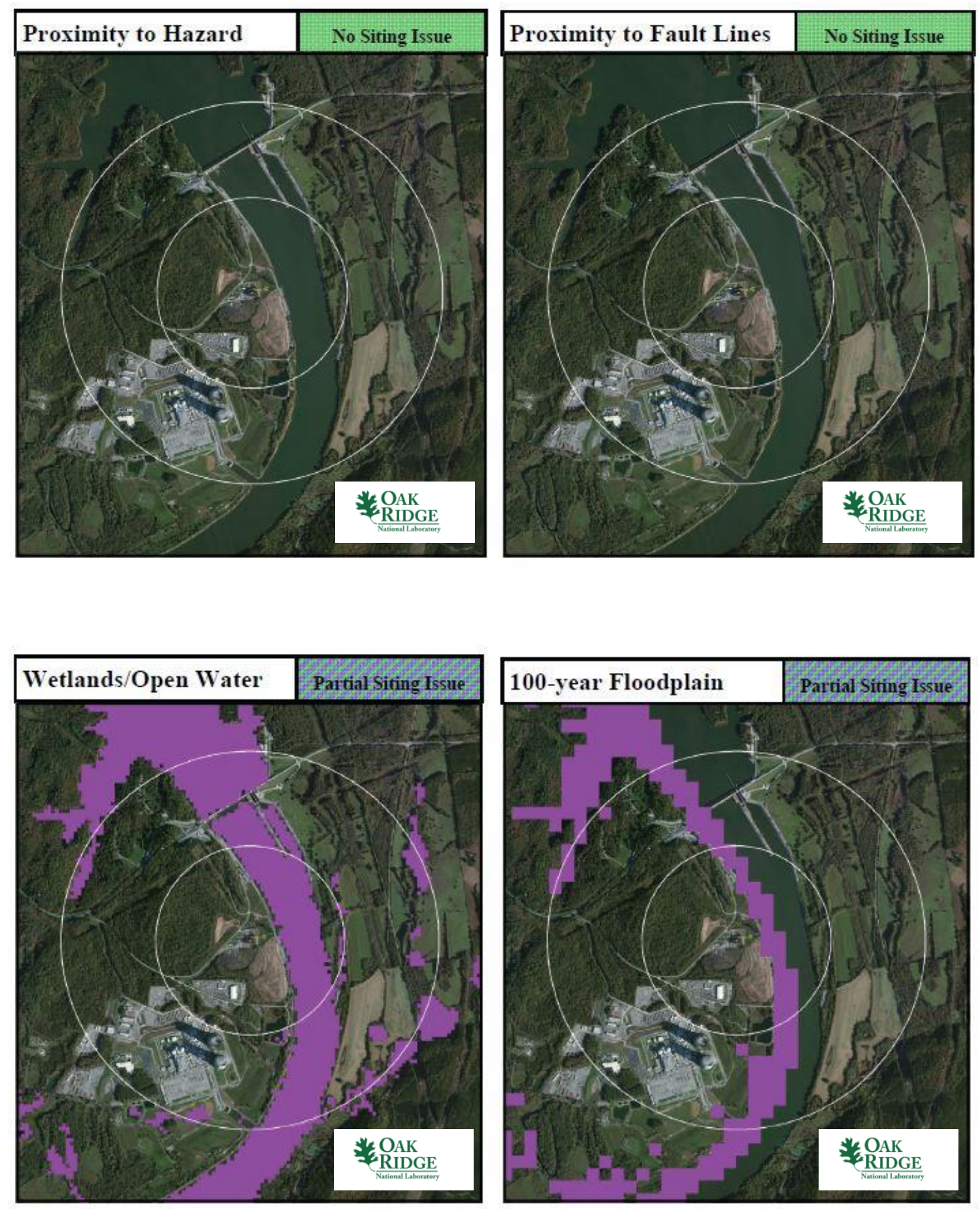

Watts Bar Fossil Plant 

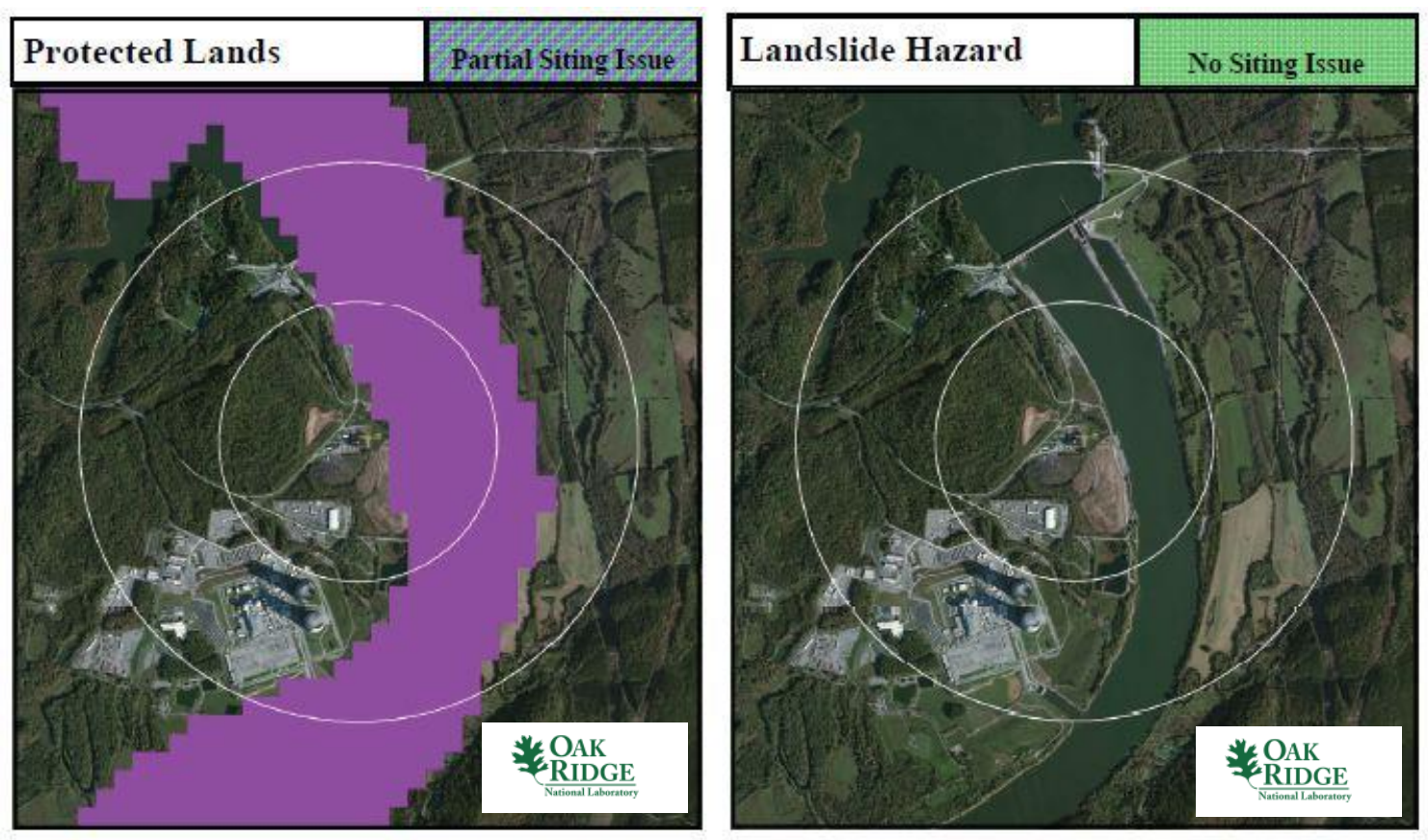

Watts Bar Fossil Plant

\section{A.12.6 Site Evaluation}

TVA operates several nuclear power plants, including the adjacent Watts Bar Nuclear Plant. Therefore, the utility has the licensing experience to operate an SMR. In addition, co-locating an SMR with an existing nuclear plant would have the added benefit of sharing logistical and security resources. The site contains sufficient acreage to support siting an SMR.

From an environmental justice perspective, the community collectively appears to have achieved a reasonable level of education with median income levels typical of much of the United States. Given that there is an existing nuclear power plant located in this community, siting an SMR at this location would not seem to be further marginalizing the community.

As shown in Sects. A.0 and A.0, the Watts Bar Fossil Plant site has partial SMR site screening issues with wetlands/open waters, 100-year floodplain, and protected lands. All three of these issues are related to the Tennessee River adjacent to the site. A visual inspection of the aerial imagery indicates that none of these issues should impact the siting of an SMR at this location. The remaining SMR site screening criteria are met site-wide for the values established in the updated SMR siting report.1

The Watts Bar Fossil Plant is 120 miles from Nashville, 55 miles from Knoxville, and 50 miles from Chattanooga. All these metropolitan areas are forecast to grow in the next 25 years. Therefore, as electrical demand increases with population growth, the Watts Bar Fossil Plant site may be acceptable for future consideration for SMR siting. The site meets current NRC RG 4.7 recommendations for population density without additional consideration for relaxed SMR population siting requirements based on reduced source term. The Watts Bar Fossil Plant site meets multiple conventional standards for consideration of siting an SMR at the coal station location. 



\section{APPENDIX B-COAL PLANT EVALUATIONS OF SECOND-TIER SITES}

The site meets multiple conventional standards in the near term for consideration of siting an SMR at the coal station location, but there may be longer-term issues that could potentially preclude this site from further SMR siting consideration. For example, a small population center is identified nearby that meets the current SMR SSEC for population density, but future growth near the coal station could present a siting challenge.

Coal stations evaluated in this category are

- AES Hickling Generation Plant

- B. L. England Generating Station

- Fair Station

- Martins Creek Power Plant

- Meredosia Power Plant

- Sutherland Generating Station 



\section{APPENDIX B—COAL PLANT EVALUATIONS OF SECOND-TIER SITES}

\section{B.1 AES HICKLING GENERATION PLANT}

\section{B.1.1 Location Detail}

As shown in Fig. B.56, the AES Hickling Generation Plant is located in western New York just north of the Pennsylvania border. More specifically, the plant is located off Hickling Road, in Steuben County, New York. Interstate 86 is accessible less than 1 mile to the north. Rail access is available within 0.2 miles and barge access is available within 16 miles via the Seneca Canal. The closest town is Big Flats, New York, with a population of approximately 7,700 people. Big Flats is approximately 2.5 miles east of the AES Hickling Generation Plant. The nearest city with a population in excess of 10,000 people is Corning, New York, approximately 4 miles to the west of the AES Hickling Generation Plant.

- Plant: AES Hickling Generation Plant

- Utility: AES Corporation

- Coordinates: lat. $42.1223^{\circ} \mathrm{N}$, long. $76.9823^{\circ} \mathrm{W}$

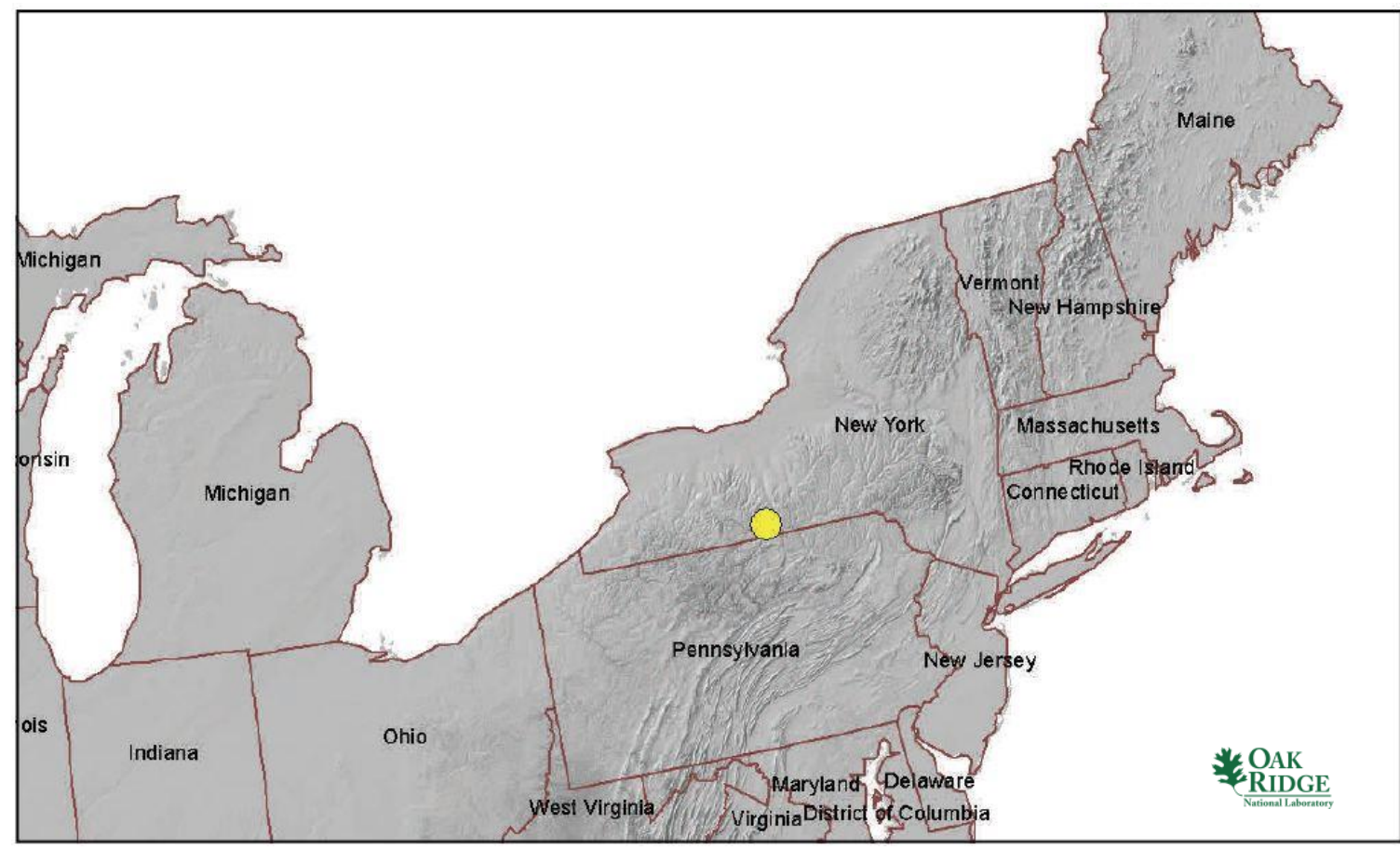

Fig. B.56. AES Hickling Generation Plant location map.

\section{B.1.2 Site Description and Status}

The AES Hickling Generation Plant is a two-unit coal station with both units currently in cold standby. The AES Hickling Generation Plant last operated in 2000. A significant amount of plant process equipment has been removed for salvage. The condenser tubing has been removed and pipe openings have been sealed. Most boiler piping below the turbine deck elevation has been removed. ${ }^{15}$ One of the

\footnotetext{
${ }^{15}$ New York Department of Environmental Conservation, Environmental Notice Bulletin, July 15, 2009.
} 
fossil units was rated at $30 \mathrm{MW}(\mathrm{e})$ and the second unit was rated at $40 \mathrm{MW}(\mathrm{e})$ for a total site capacity of $70 \mathrm{MW}(\mathrm{e})$. The plant was cooled by once-through cooling from the adjacent Chemung River.

The plant is located on the Chemung River approximately 81 miles southeast of the 610 MW(e) Ginna nuclear facility, 100 miles south of the 838 MW(e) Fitzpatrick and 1760 MW(e) Nine Mile Point nuclear facilities, and 83 miles northwest of the 2700 MW(e) Susquehanna nuclear facility in Pennsylvania. The AES Hickling Generation Plant is 37 miles southwest of the operational 322.5 MW(e) AES Cayuga Coal Plant and 38 miles south of the shuttered 192.5 MW(e) AES Greenidge Coal Plant. There are four significant hydroelectric facilities in New York; the closest is the shuttered Scoby facility 91 miles northwest of the AES Hickling Generation Plant.

As noted in Table B.30, the nearest major fault line based on USGS data is 1,190 miles west in Oklahoma. The maximum safe-shutdown earthquake for the site is below $0.3 \mathrm{~g}$ peak ground acceleration. More than 500,000 gpm of cooling water makeup is available from the adjacent Chemung River.

The permanent population within 1 mile of the plant is approximately 650 people, yielding a population density of fewer than 210 people per square mile. The permanent population within 10 miles of the plant is approximately 206,000 people, yielding a population density of approximately 660 people per square mile. According to the US EPA Environmental Justice website, there are 37,513 occupied housing units within 10 miles of the plant site based on 2000 US Census data. Further, over $80 \%$ of area adults over age 25 have a high school diploma or higher education. The median annual income for the area is between $\$ 25 \mathrm{~K}$ and $\$ 50 \mathrm{~K}$.

Table B.30. AES Hickling Generation Plant site statistics

\begin{tabular}{|c|c|c|c|}
\hline \multicolumn{2}{|l|}{$\begin{array}{l}\text { Population } \\
\text { Population Within }\end{array}$} & \multicolumn{2}{|l|}{$\begin{array}{l}\text { Utility } \\
\text { Distance to Grid Capacity }\end{array}$} \\
\hline $0.5 \mathrm{mi}$ & $<500$ & $>400 \mathrm{MWe}$ & $\sim 10 \mathrm{mi}$ \\
\hline $1 \mathrm{mi}$ & $\sim 650$ & $>800 \mathrm{MWe}$ & $\sim 63 \mathrm{mi}$ \\
\hline $5 \mathrm{mi}$ & $\sim 46,300$ & $>1600 \mathrm{MWe}$ & $\sim 78 \mathrm{mi}$ \\
\hline $10 \mathrm{mi}$ & $\sim 206,100$ & $>3200 \mathrm{MWe}$ & $\sim 129 \mathrm{mi}$ \\
\hline \multicolumn{2}{|c|}{ Nearest City with Population } & \multicolumn{2}{|c|}{ Distance to Cooling Water } \\
\hline$>10,000$ & Corning, NY & $>50,000 \mathrm{gpm}$ & $\sim 3.1 \mathrm{mi}$ (Chemung River) \\
\hline$>50,000$ & Irondequoit, NY & $>100,000 \mathrm{gpm}$ & $\sim 3.1 \mathrm{mi}$ (Chemung River) \\
\hline$>100,000$ & Rochester, NY & $>200,000 \mathrm{gpm}$ & $\sim 3.1 \mathrm{mi}$ (Chemung River) \\
\hline$>500,000$ & Philadelphia, PA & $>500.000 \mathrm{gpm}$ & $\sim 3.1 \mathrm{mi}$ (Chemung River) \\
\hline \multicolumn{2}{|l|}{ Geotechnical } & \multicolumn{2}{|l|}{ Accessibility } \\
\hline Max Earthquake Acceleration & $<0.3 \mathrm{~g}$ & Distance to Major Roadway & $\sim 0.3 \mathrm{mi}$ (Interstate 86 ) \\
\hline Max Slope & $\sim 67 \%$ & Distance to Water Transport & $\sim 16$ mi (Seneca Canal) \\
\hline Nearest Fault Line & $\sim 1,190$ mi (Oklahoma) & Distance to Rail Transport & $\sim 0.2 \mathrm{mi}(\mathrm{NS})$ \\
\hline Nearest Hazard Site & $\begin{array}{l}\sim 5 \mathrm{mi} \text { (Airport- } \\
\quad \text { Corning Regional) }\end{array}$ & Distance to Airport & $\sim 5 \mathrm{mi}$ (Corning Regional) \\
\hline
\end{tabular}




\section{B.1.3 Aerial Imagery}

The aerial imagery in Fig. B.57 indicates that Interstate 86 runs within 0.5 miles of the AES Hickling Generation Plant site. Also visible are several subdivisions within 1.0 mile of the site.

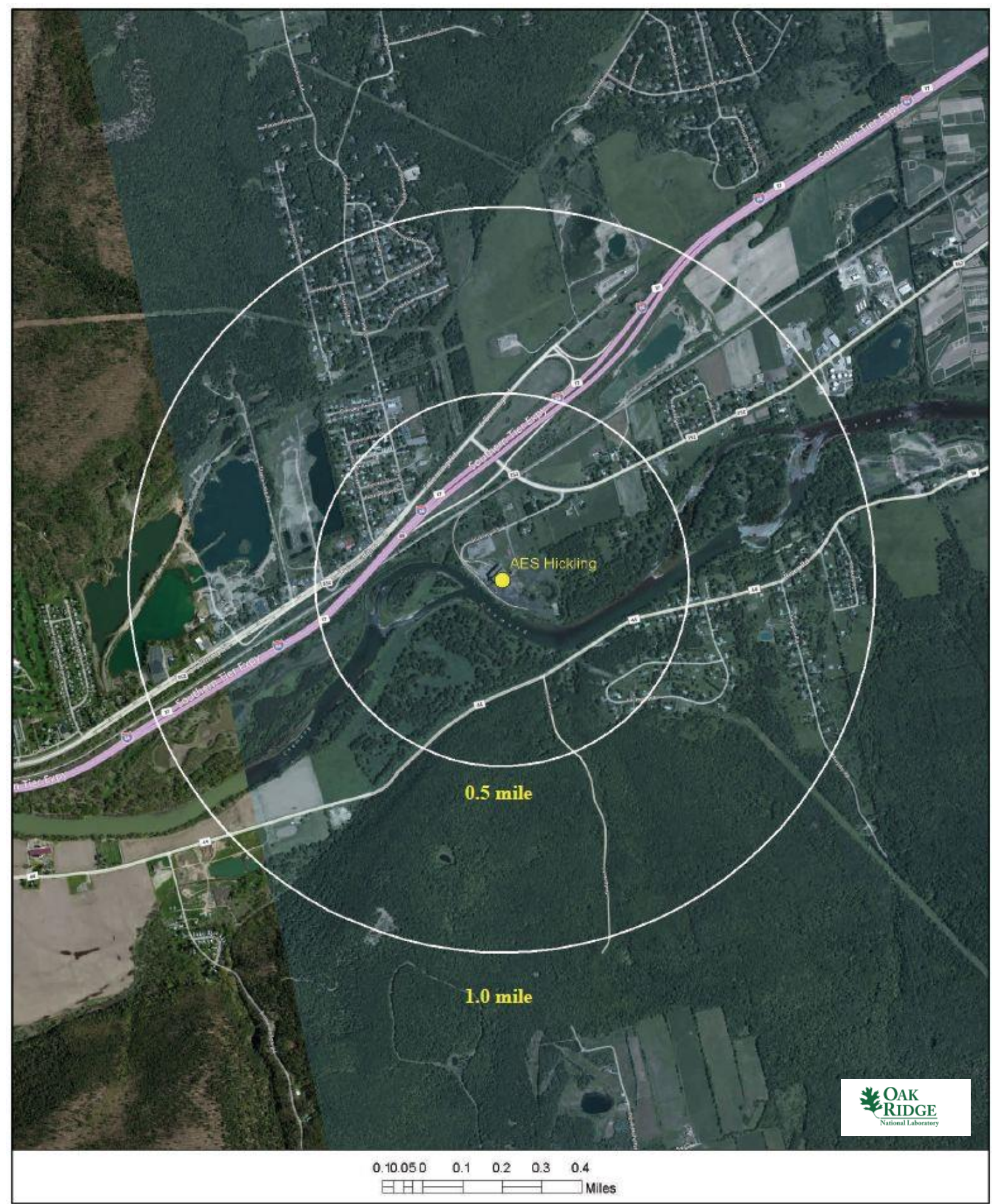

Fig. B.57. Satellite view of AES Hickling Generation plant proximity. 


\section{B.1.4 Screening Criteria Overview}

Table B.31. AES Hickling Generation Plant siting criteria summary

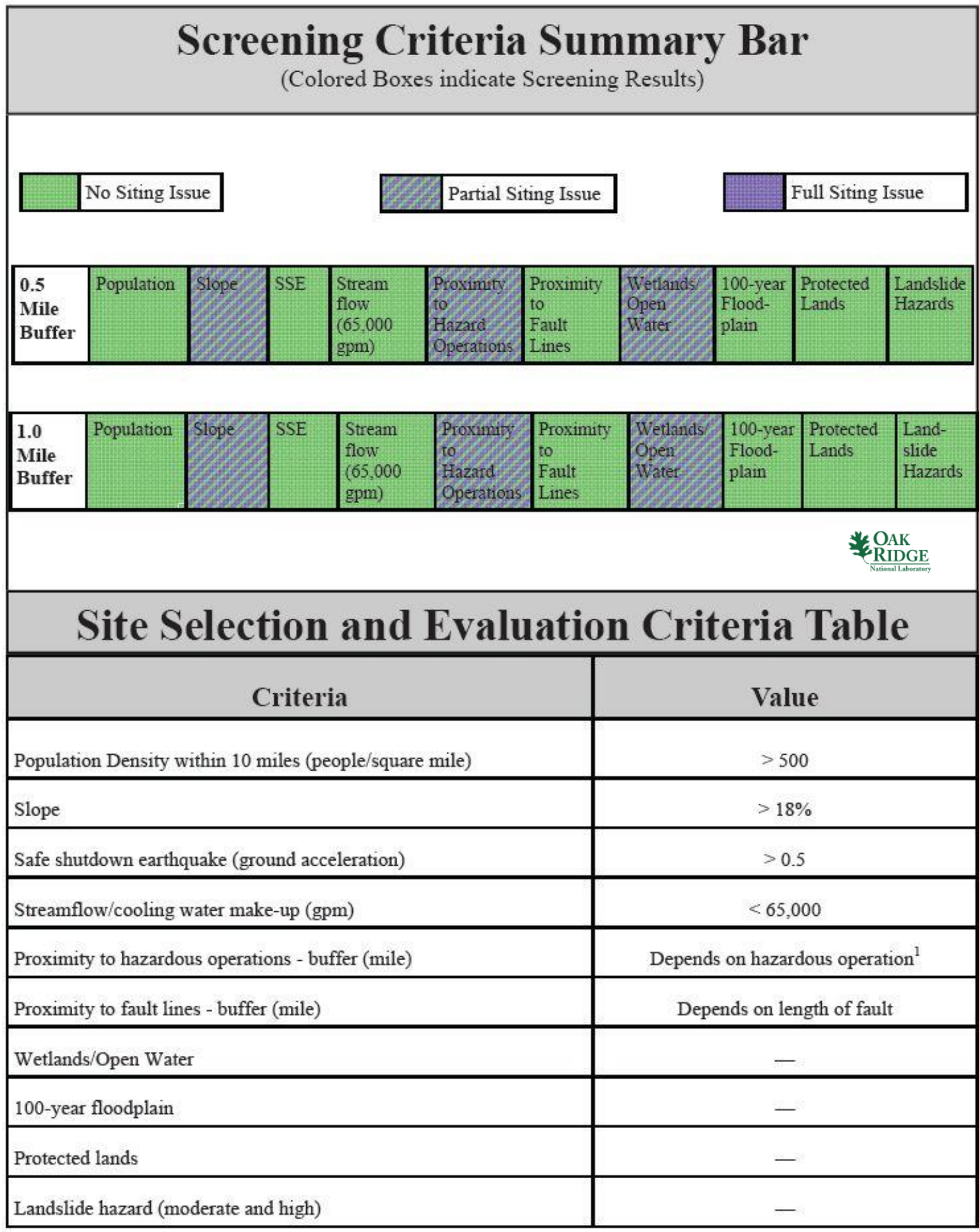

${ }^{1}$ Hazardous facilities (airports-5 miles and oil refineries-1 mile) 


\section{B.1.5 Composite Map and Individual Siting Issue Maps}

A composite map of SMR siting challenges to the AES Hickling Generation Plant is shown in Fig. B.58. The physical plant structures are located on land with no siting issues. Following this map are maps of the individual SMR siting criteria based on selected input values.

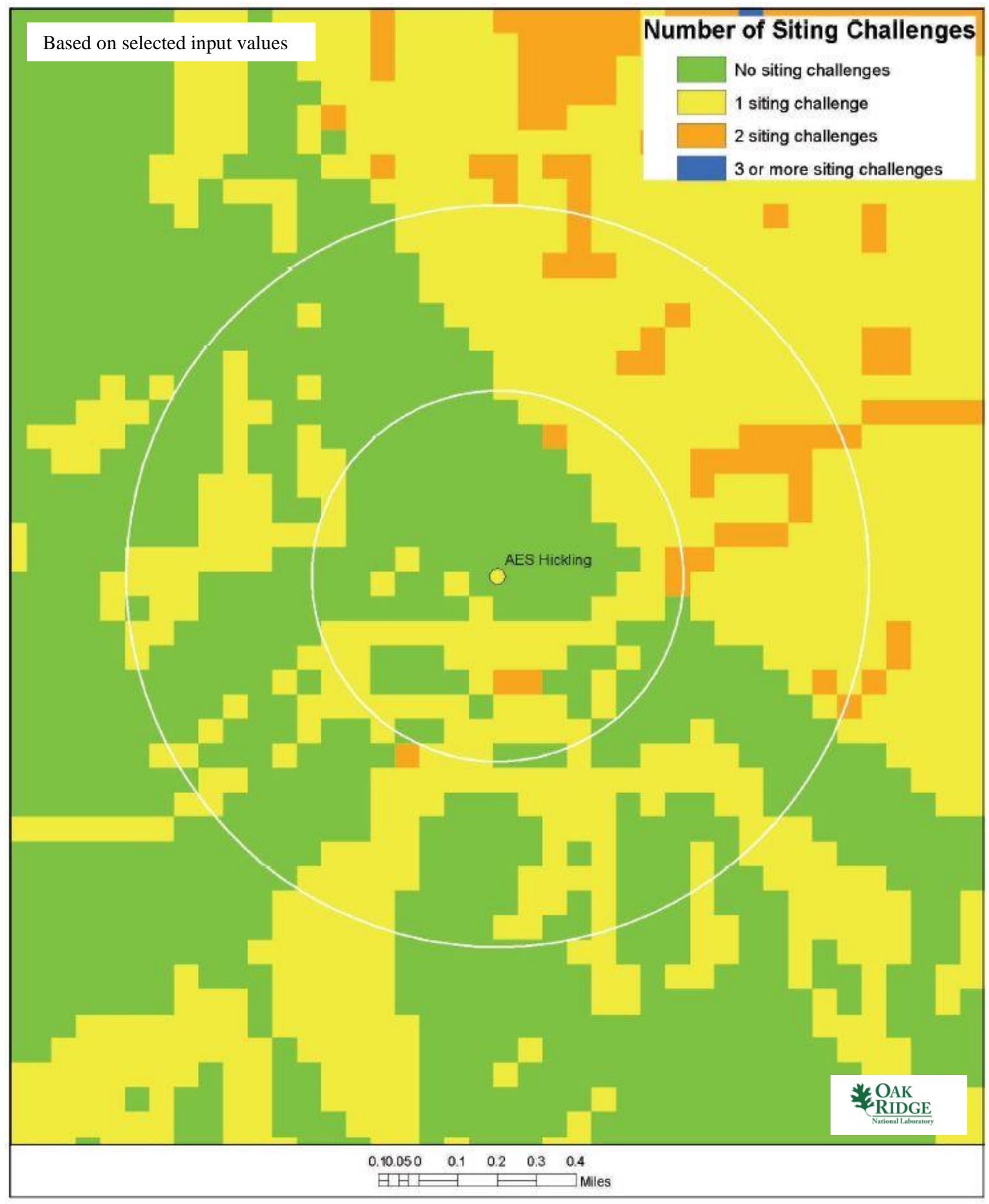

Fig. B.58. AES Hickling Generation Plant composite map. 

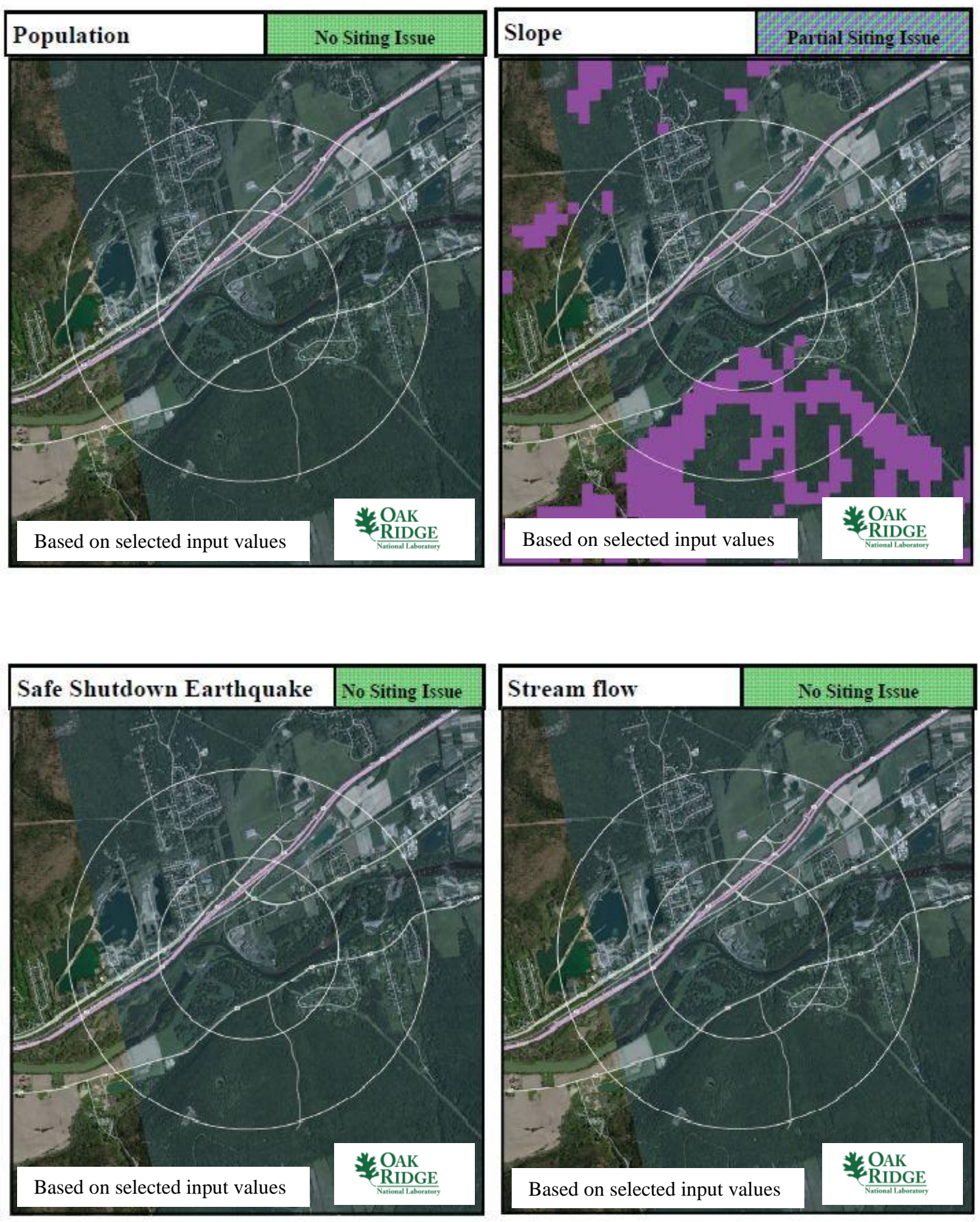

AES Hickling Generation Plant 

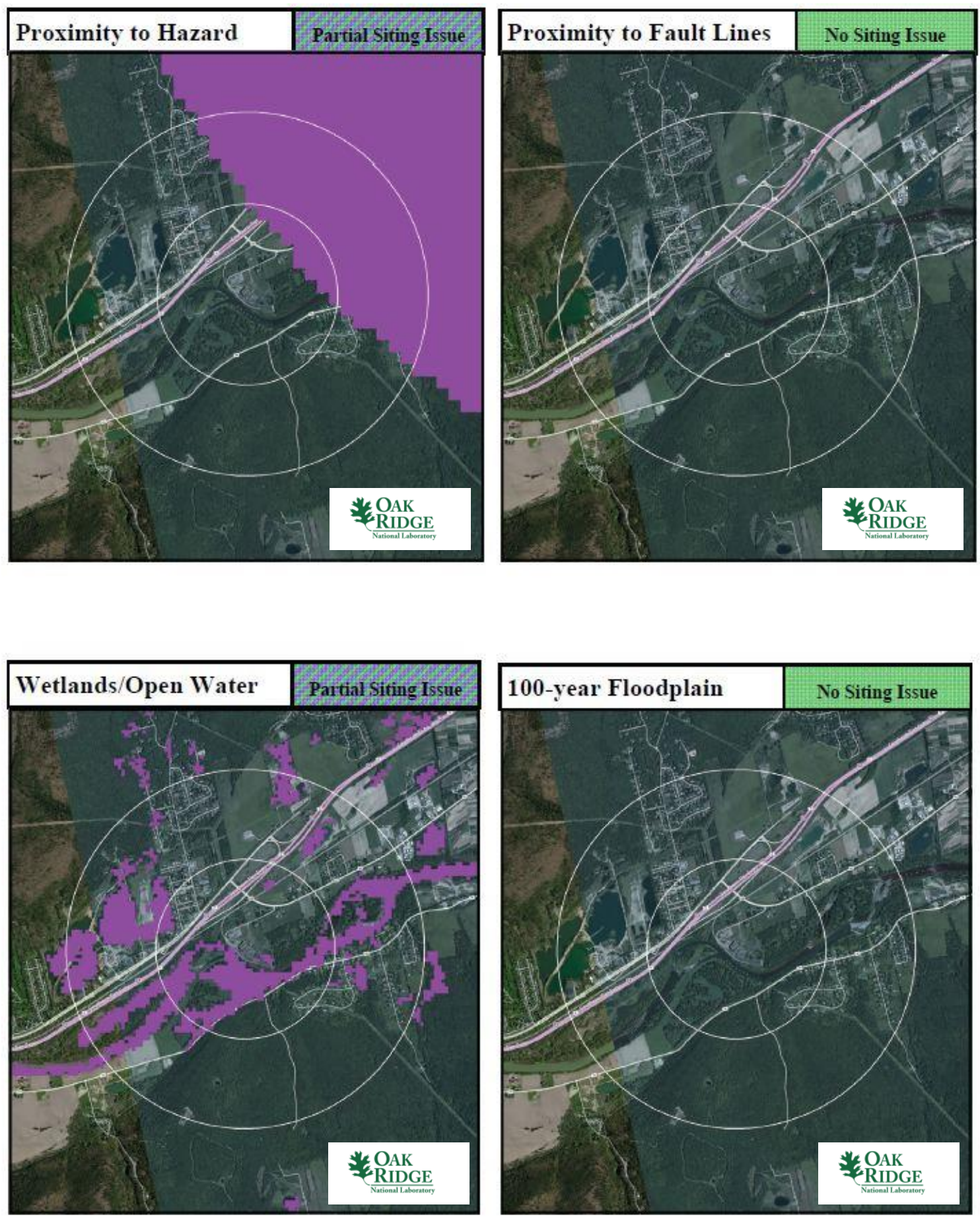

AES Hickling Generation Plant 

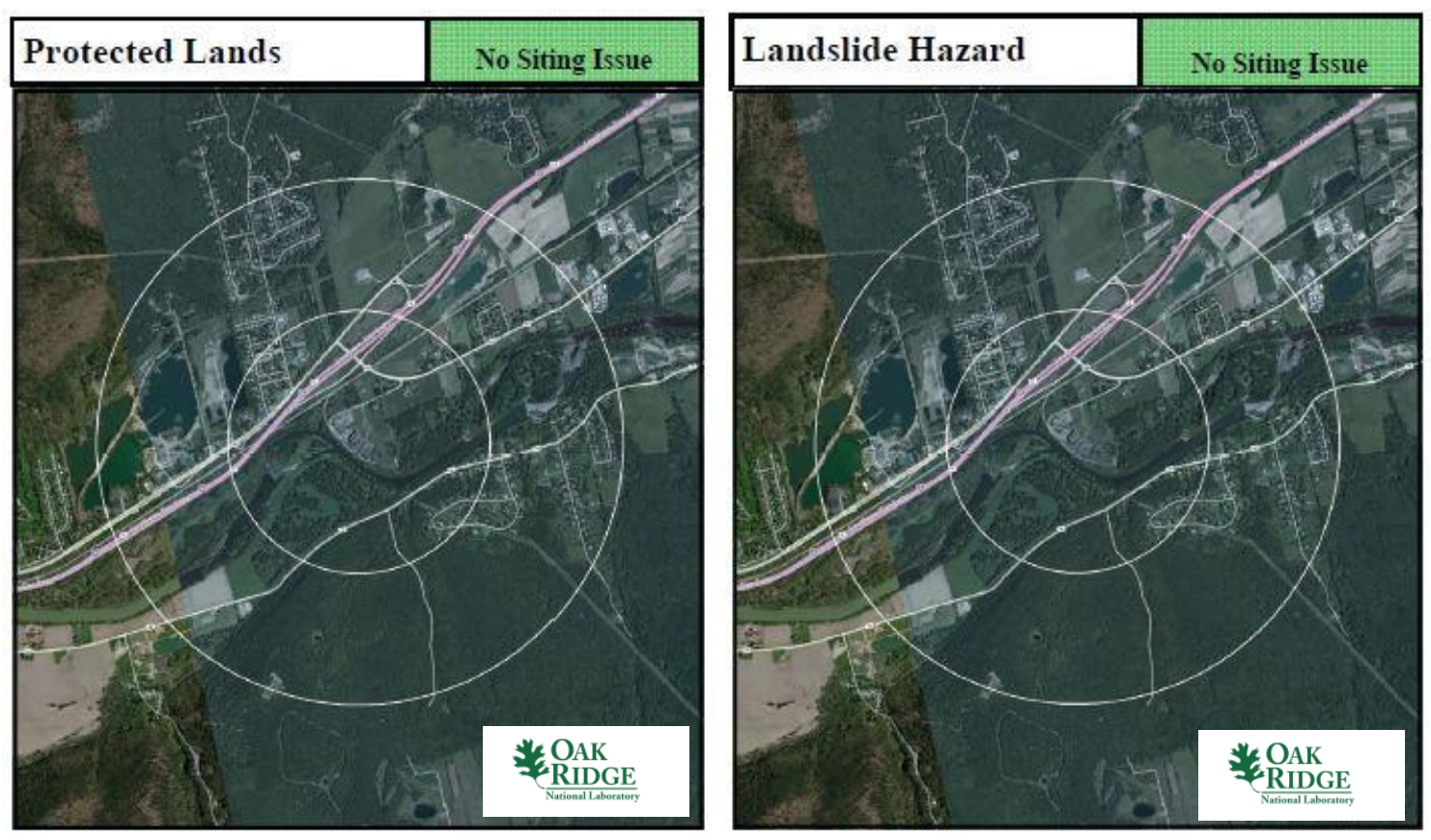

AES Hickling Generation Plant

\section{B.1.6 Site Evaluation}

AES Corporation does not operate or own a share of any nuclear power plants in the United States. Therefore, the utility would need to be mentored through the licensing process to build and operate an SMR. Additionally, there are numerous other electric power generation facilities within 100 miles of the AES Hickling Generation Plant to subsidize area power requirements. Furthermore, the AES Corporation previously made the decision to no longer use the coal generation equipment at this site to meet area electrical load demands.

From an environmental justice perspective, the community collectively appears to have achieved a reasonable level of education with median income levels typical of much of the United States. Therefore, siting an SMR at this location would not seem to be disenfranchising a less-educated or poverty-stricken community. Furthermore, the education level of the AES Hickling Generation Plant community would seem to support the higher-technology job opportunities provided by an SMR.

As shown in Sects. B0 and B.0, the AES Hickling Generation Plant site has partial SMR site screening issues with wetlands/open waters, slope, and hazardous facilities. The slope issue is related to land to the south of the site on the opposite side of the Chemung River from the coal plant. Likewise, the wetlands/open waters issue affects area to the south of the plant site, including the Chemung River. Finally, a proximity-to-hazards issue exists to the northeast of the site, cutting just inside the half-mile plant radius. This issue stems from the buffer zone associated with a small airport located in Big Flats. The runway at this airport is in line with the Hickling site. However, given that near-term SMR designs are expected to be underground, further visual inspection of the aerial imagery indicates that none of these three issues should directly impact the siting of an SMR at this location. The remaining SMR site screening criteria are met site-wide for the values established in the updated SMR siting report.1

Though population figures are not problematic within a 1 mile radius of the plant, several subdivision streets are visually apparent in an aerial view of the site between the 0.5 mile radius circle and the 1 mile radius circle. This could be a contentious issue should AES decide to submit a COL application for an SMR at this site to meet any growing need for electrical capacity at this grid location. In addition, 
Interstate 86 runs immediately adjacent to the site, which would make it difficult for a nuclear licensee to control land access to areas very near the plant location.

When future load demands indicate the need for expanded generation capacity in this region, the utility would need to work closely with local leaders and civic groups to make the case for siting an SMR at this location. The site slightly exceeds current NRC RG 4.7 recommendations for population density without additional consideration for relaxed SMR population siting requirements based on reduced source term. This AES Hickling Generation Plant site meets multiple conventional standards in the near term for consideration of siting an SMR at the coal station location, but there may be longer-term issues that could potentially preclude this site from further SMR siting consideration. The longer-term considerations include population growth, traffic control, and increased airport traffic. 
B-12 


\section{B.2 B. L. England Generating Station}

\section{B.2.1 Location Detail}

As shown in Fig. B.59, the B. L. England Generating Station is located in southeastern New Jersey near the Atlantic Ocean. More specifically, the plant is located off North Shore Road near the Garden State Parkway, in Cape May County, New Jersey. The New Jersey Turnpike is accessible approximately 40 miles to the east. Rail access is available within 0.2 miles at the site and barge access is also available within 0.2 miles via the Tuckahoe River. The closest town is Somers Point, New Jersey, with a population of approximately 10,795 people. Somers Point is approximately 3 miles northeast of the B. L. England Generating Station. The station is also known as Beesley's Point Generating Station.

- Plant: B. L. England Generating Station

- Utility: R. C. Cape May

- Coordinates: lat. $39.29060^{\circ} \mathrm{N}$, long. $74.63354^{\circ} \mathrm{W}$

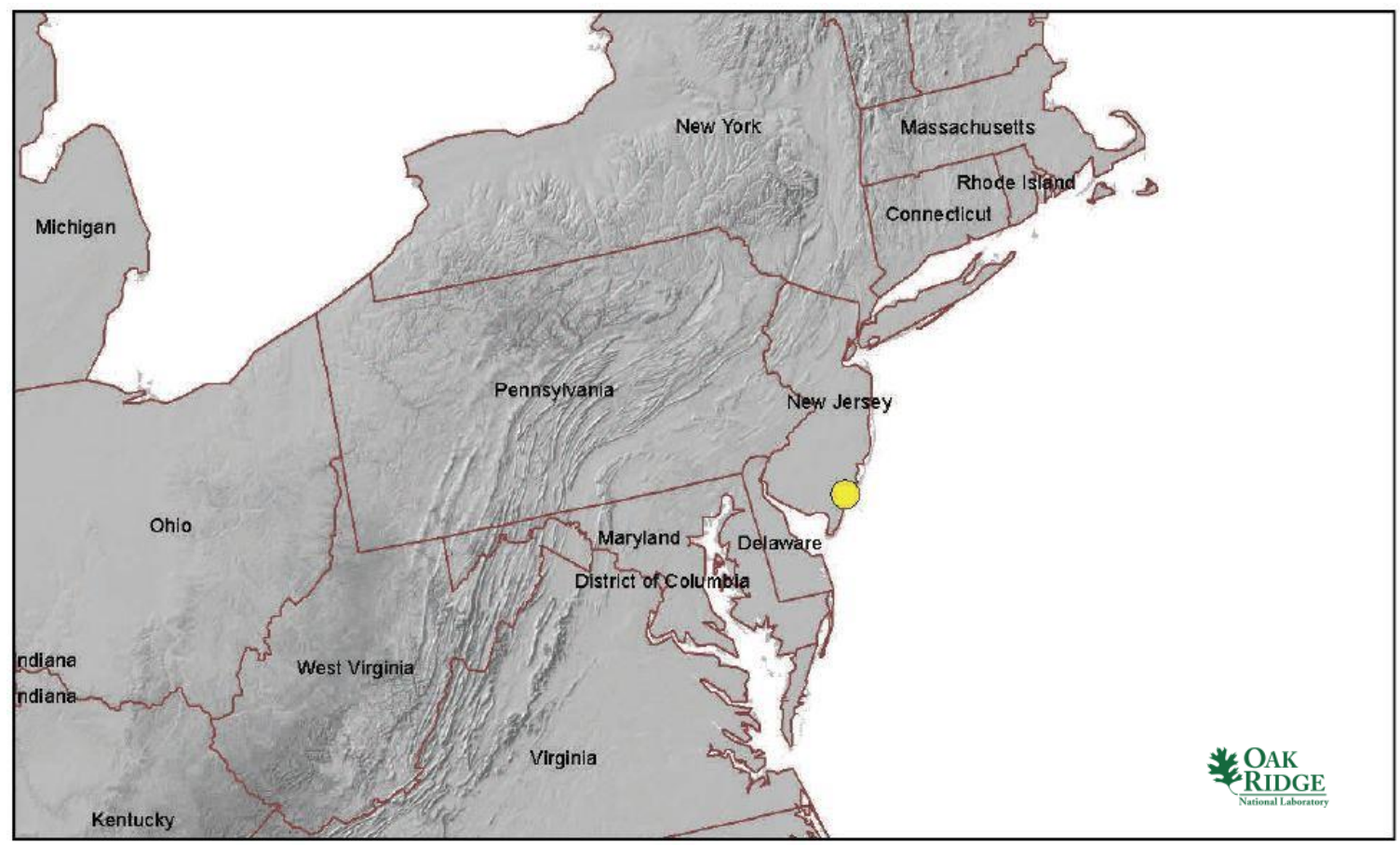

Fig. B.59. B. L. England Generating Station location map.

\section{B.2.2 Site Description and Status}

The B. L. England Generating Station is operated by R. C. Cape May, a subsidiary of the Rockland Corporation. The B. L. England Generating Station is a two-unit coal station with both units currently operational. The coal-fired units are cooled by once-through cooling from the adjacent Great Egg Harbor Bay. One of the coal-fired units, commissioned in 1962, is rated at $136 \mathrm{MW}(\mathrm{e})$ and the second unit, commissioned in 1964, is rated at $163 \mathrm{MW}(\mathrm{e})$ for a total coal-fired capacity of $299 \mathrm{MW}(\mathrm{e})$. In addition, there is an oil-fired unit at the site that provides approximately $150 \mathrm{MW}(\mathrm{e})$. The oil-fired unit is cooled by a natural draft cooling tower.

The older coal-fired unit is to be shut down by late 2013. The second coal-fired unit and the oil-fired unit are planned for conversion to natural gas with availability expected in 2016. A 22-mile natural gas line 
will be constructed to support the conversion. The investment is expected to give the plants a renewed 40year life and provide a continuation of an annual $\$ 6 \mathrm{M}$ in energy receipts tax to the local government. ${ }^{16}$

The plant is located on roughly 110 acres on the Great Egg Harbor Bay where the Tuckahoe River and Great Egg Harbor River flow into the Atlantic Ocean, approximately 42 miles south of the 645 MW(e) Oyster Creek nuclear facility and 50 miles east of the 1219 MW(e) Hope Creek and 2,357 MW(e) Salem nuclear facilities. The B. L. England Generating Station is 62 miles south of the operational 653 MW(e) Mercer Coal Plant.

As noted in Table B.32, the nearest major fault line based on USGS data is 1,263 miles west in Oklahoma. The maximum safe-shutdown earthquake for the site is below $0.3 \mathrm{~g}$ peak ground acceleration. More than 100,000 gpm of cooling water makeup is available upstream from the bay from the Great Egg Harbor River. Saltwater and brackish water cooling are available from the ocean and the bay, respectively.

The permanent population within 1 mile of the plant is fewer than 500 people, yielding a population density of fewer than 160 people per square mile. The permanent population within 10 miles of the plant is approximately 260,000 people, yielding a population density of approximately 830 people per square mile. According to the US EPA Environmental Justice website, there are 48,942 occupied housing units within 10 miles of the plant site based on 2000 US Census data. Further, over $80 \%$ of area adults over age 25 have a high school diploma or higher education. The median annual income for the area is between $\$ 25 \mathrm{~K}$ and $\$ 50 \mathrm{~K}$.

Table B.32. B. L. England Generating Station site statistics

\begin{tabular}{|l|l|l|l|}
\hline $\begin{array}{l}\text { Population } \\
\text { Population Within }\end{array}$ & \multicolumn{2}{l|}{$\begin{array}{l}\text { Utility } \\
\text { Distance to Grid Capacity }\end{array}$} \\
\hline $0.5 \mathrm{mi}$ & $<500$ & $>400 \mathrm{MWe}$ & $\sim 10 \mathrm{mi}$ \\
\hline $1 \mathrm{mi}$ & $\sim 2,500$ & $>800 \mathrm{MWe}$ & $\sim 40 \mathrm{mi}$ \\
\hline $5 \mathrm{mi}$ & $\sim 72,500$ & $>1600 \mathrm{MWe}$ & $\sim 34 \mathrm{mi}$ \\
\hline $10 \mathrm{mi}$ & $\sim 260,000$ & $>3200 \mathrm{MWe}$ & $\sim 313 \mathrm{mi}$ \\
\hline Nearest City with Population & Distance to Cooling Water \\
\hline \multicolumn{1}{|l|}{} & \multicolumn{2}{l|}{} \\
\hline$>10,000$ & Somers Point, NJ & $>50,000 \mathrm{gpm}$ & $\sim 11.3 \mathrm{mi}$ (Gt. Egg Harbor) \\
\hline$>50,000$ & Vineland, NJ & $>100,000 \mathrm{gpm}$ & $\sim 11.3 \mathrm{mi}$ (Gt. Egg Harbor) \\
\hline$>100,000$ & Edison, NJ & $>200,000$ gpm & $\sim 46.2 \mathrm{mi}$ (Delaware River) \\
\hline$>500,000$ & Philadelphia, PA & $>500,000$ gpm & $\sim 46.2 \mathrm{mi}$ (Delaware River) \\
\hline Geotechnical & \multicolumn{2}{|l|}{ Accessibility } \\
\hline Max Earthquake Acceleration & $<0.3 \mathrm{~g}$ & Distance to Major Roadway & $\sim 03 \mathrm{mi}$ (US 9) \\
\hline Max Slope & $\sim 2 \%$ & Distance to Water Transport & $\sim 0.2 \mathrm{mi}$ (Tuckahoe River) \\
\hline Nearest Fault Line & $\sim 1,263$ mi (Oklahoma) & Distance to Rail Transport & $\sim 0.2 \mathrm{mi}$ (CSAO) \\
\hline Nearest Hazard Site & $\sim 11$ mi (Airport- & Distance to Airport & $\sim 11$ mi (Atlantic City Int'l) \\
\hline
\end{tabular}

${ }^{16}$ C. Higgins, “\$200M in Improvements Planned for B. L. England Power Plant,” Upper Township Gazette, May 25, 2012. 


\section{B.2.3 Aerial Imagery}

The aerial imagery in Fig. B.60 indicates that the Garden State Parkway runs 0.5 miles of the B. L. England Generating Station site. Also visible is a housing subdivision within 1.0 mile of the site on the unincorporated Beesley's Point.

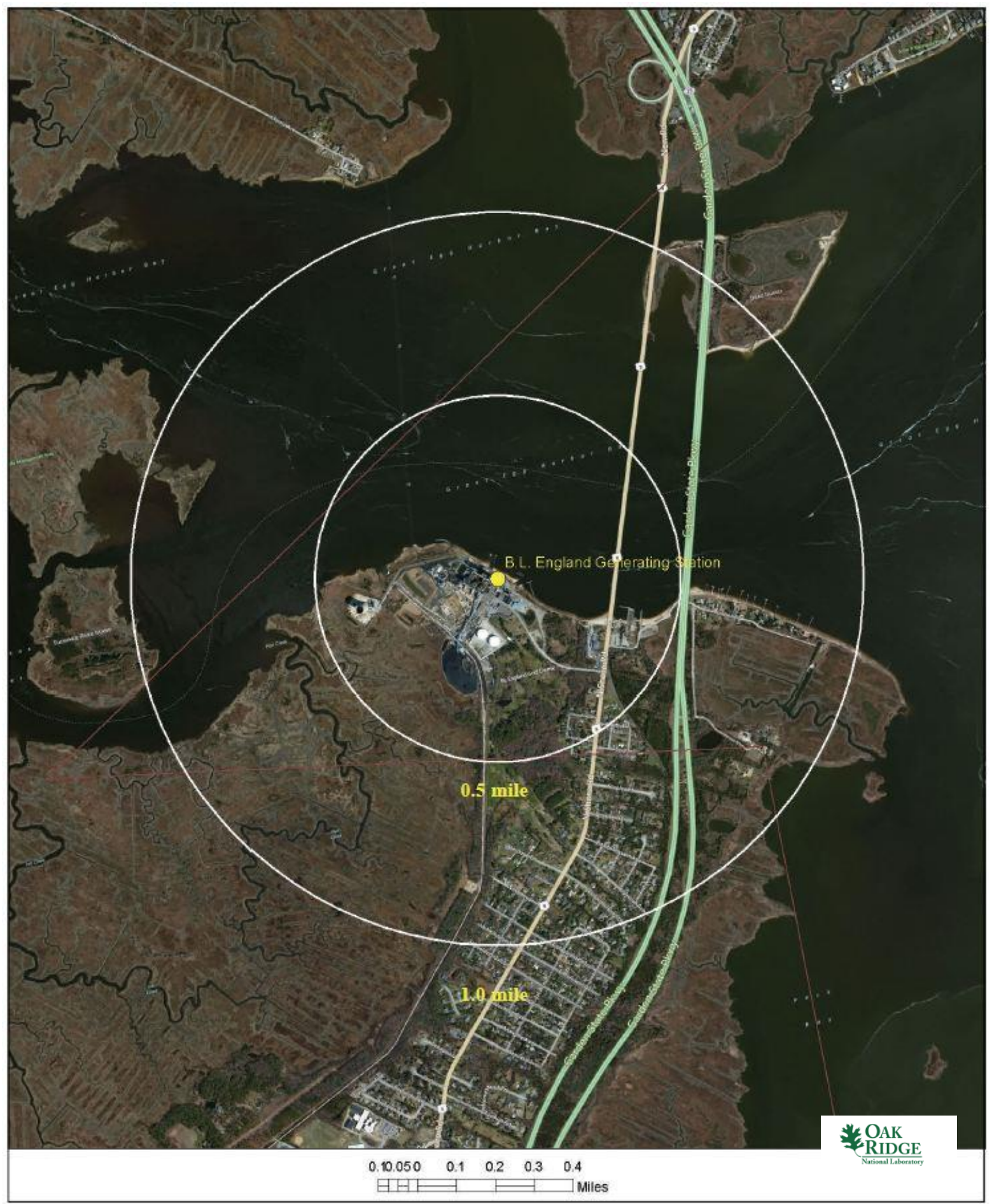

Fig. B.60. Satellite view of B. L. England Generating Station proximity. 


\section{B.2.4 Screening Criteria Overview}

Table B.33. B. L. England Generating Station siting criteria summary

\begin{tabular}{|c|c|c|c|c|c|c|c|c|c|c|}
\hline \multicolumn{11}{|c|}{$\underset{\text { (Colored Boxes indicate Screening Results) }}{\text { Screening Criteria Summary Bar }}$} \\
\hline & \multicolumn{2}{|c|}{ No Siting Issue } & \multicolumn{2}{|c|}{\begin{tabular}{|l|l|} 
& Partial Siting Issue \\
\end{tabular}} & \multicolumn{2}{|c|}{ Partial Siting Issue } & \multicolumn{4}{|c|}{ Full Siting Issue } \\
\hline $\begin{array}{l}0.5 \\
\text { Mile } \\
\text { Buffer }\end{array}$ & Population & Slope & SSE & $\begin{array}{l}\text { Stream } \\
\text { flow } \\
(65,000 \\
\text { gpm) }\end{array}$ & \begin{tabular}{l|} 
Proxinity \\
to \\
Hazard \\
Operations
\end{tabular} & $\begin{array}{l}\text { Proximity } \\
\text { to } \\
\text { Fault } \\
\text { Lines } \\
\end{array}$ & $\begin{array}{l}\text { Wetiands: } \\
\text { Open } \\
\text { Water }\end{array}$ & \begin{tabular}{l|} 
100-year \\
Flood- \\
plain
\end{tabular} & $\begin{array}{l}\text { Protected } \\
\text { Lands }\end{array}$ & $\begin{array}{l}\text { Landslide } \\
\text { Hazards }\end{array}$ \\
\hline $\begin{array}{l}1.0 \\
\text { Mile } \\
\text { Buffer }\end{array}$ & Population & Slope & SSE & $\begin{array}{l}\text { Stream } \\
\text { flow } \\
(65,000 \\
\text { gpm }) \\
\end{array}$ & $\begin{array}{l}\text { Proximity } \\
\text { to } \\
\text { Hazard } \\
\text { Operations }\end{array}$ & $\begin{array}{l}\text { Proximit } \\
\text { to } \\
\text { Fault } \\
\text { Lines } \\
\end{array}$ & $\begin{array}{l}\text { Wetlands } \\
\text { Open } \\
\text { Water }\end{array}$ & $\begin{array}{l}100 \text {-year } \\
\text { Flood- } \\
\text { plain }\end{array}$ & $\begin{array}{l}\text { Protected } \\
\text { Lands }\end{array}$ & $\begin{array}{l}\text { Land- } \\
\text { slide } \\
\text { Hazards }\end{array}$ \\
\hline \multicolumn{11}{|c|}{ OAK } \\
\hline \multicolumn{11}{|c|}{ Site Selection and Evaluation Criteria Table } \\
\hline \multicolumn{7}{|c|}{ Criteria } & \multicolumn{4}{|c|}{ Value } \\
\hline \multicolumn{7}{|c|}{ Population Density within 10 miles (people/square mile) } & \multicolumn{4}{|c|}{$>500$} \\
\hline \multicolumn{7}{|l|}{ Slope } & \multicolumn{4}{|c|}{$>18 \%$} \\
\hline \multicolumn{7}{|c|}{ Safe shutdown earthquake (ground acceleration) } & \multicolumn{4}{|c|}{$>0.5$} \\
\hline \multicolumn{7}{|c|}{ Streamflow/cooling water make-up (gpm) } & \multicolumn{4}{|c|}{$<65,000$} \\
\hline \multicolumn{7}{|c|}{ Proximity to hazardous operations - buffer (mile) } & \multicolumn{4}{|c|}{ Depends on hazardous operation ${ }^{1}$} \\
\hline \multicolumn{7}{|c|}{ Proximity to fault lines - buffer (mile) } & \multicolumn{4}{|c|}{ Depends on length of fault } \\
\hline \multicolumn{7}{|c|}{ Wetlands/Open Water } & \multicolumn{4}{|c|}{ - } \\
\hline \multicolumn{7}{|c|}{ 100-year floodplain } & \multicolumn{4}{|c|}{-} \\
\hline \multicolumn{7}{|c|}{ Protected lands } & \multicolumn{4}{|c|}{ - } \\
\hline \multicolumn{7}{|c|}{ Landslide hazard (moderate and high) } & \multicolumn{4}{|c|}{ - } \\
\hline
\end{tabular}

${ }^{1}$ Hazardous facilities (airports- 5 miles and oil refineries- -1 mile) 


\section{B.2.5 Composite Map and Individual Siting Issue Maps}

A composite map of SMR siting challenges to the B. L. England Generating Station is shown in Fig. B.61. The map indicates some "edge" effects in the GIS process, which causes some of the map area to lack a color overlay. The physical plant structures are located on land with no siting issues. Following this map are maps of the individual SMR siting criteria based on selected input values.

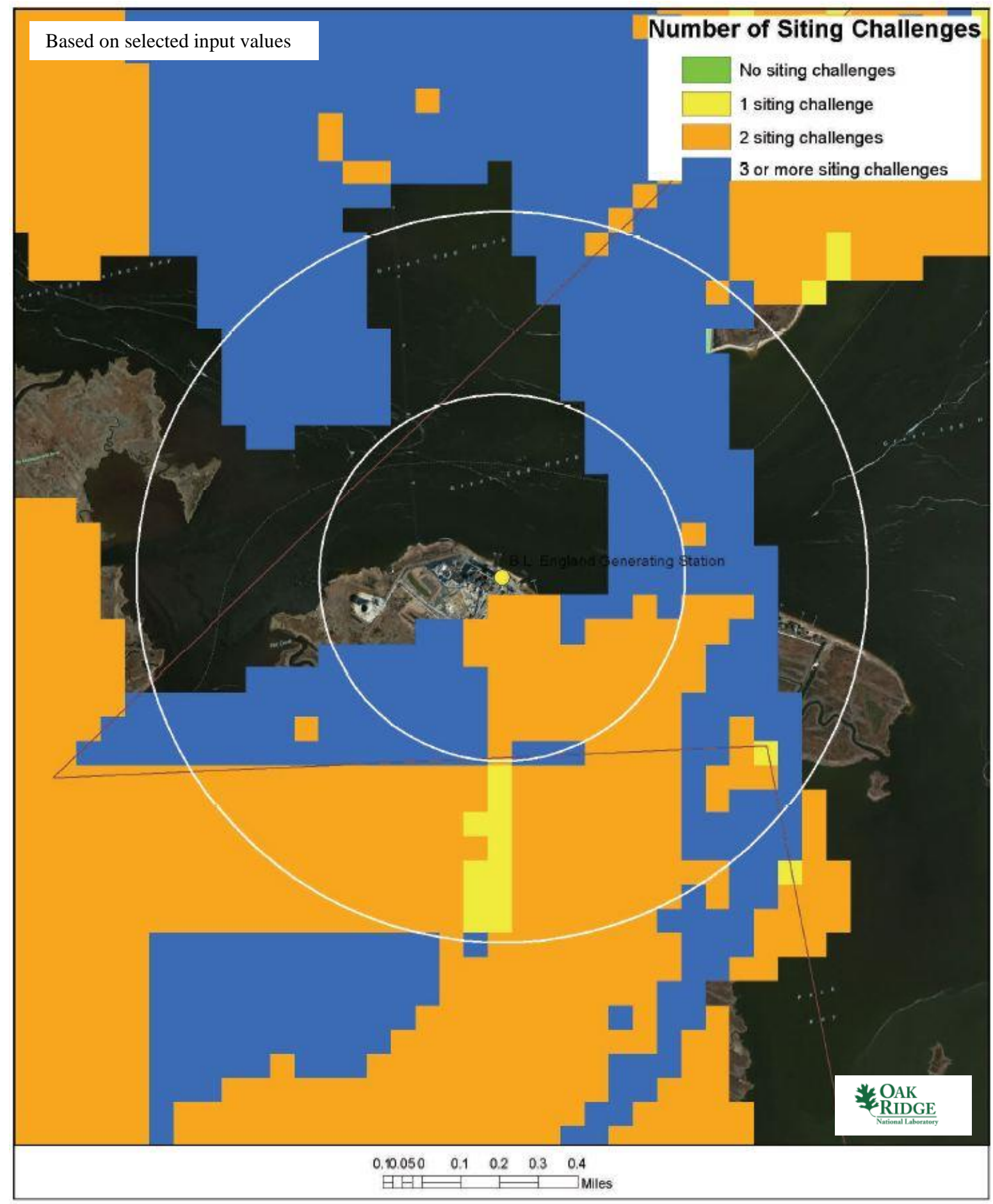

Fig. B.61. B. L. England Generating Station composite map. 

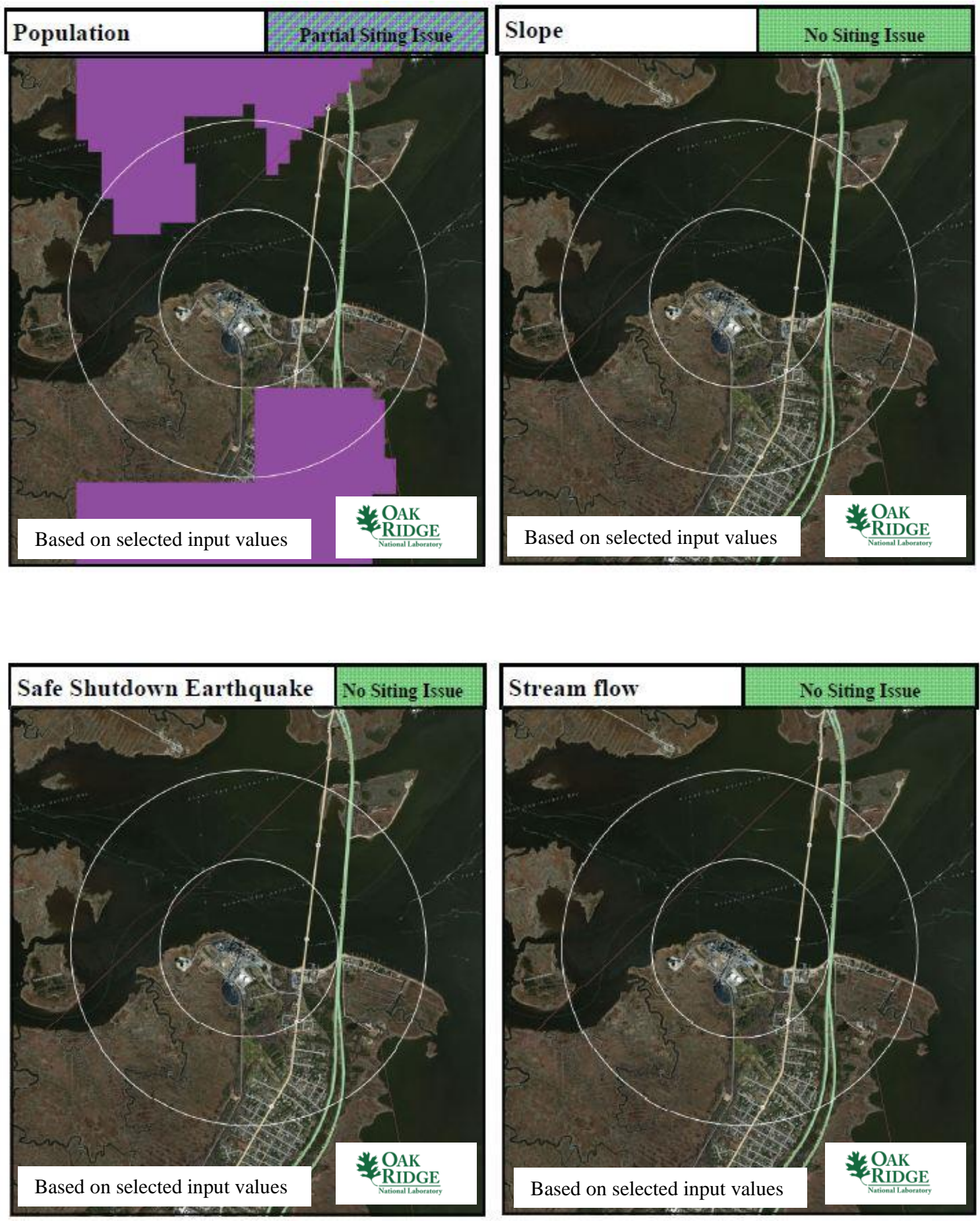

B. L. England Generating Station 

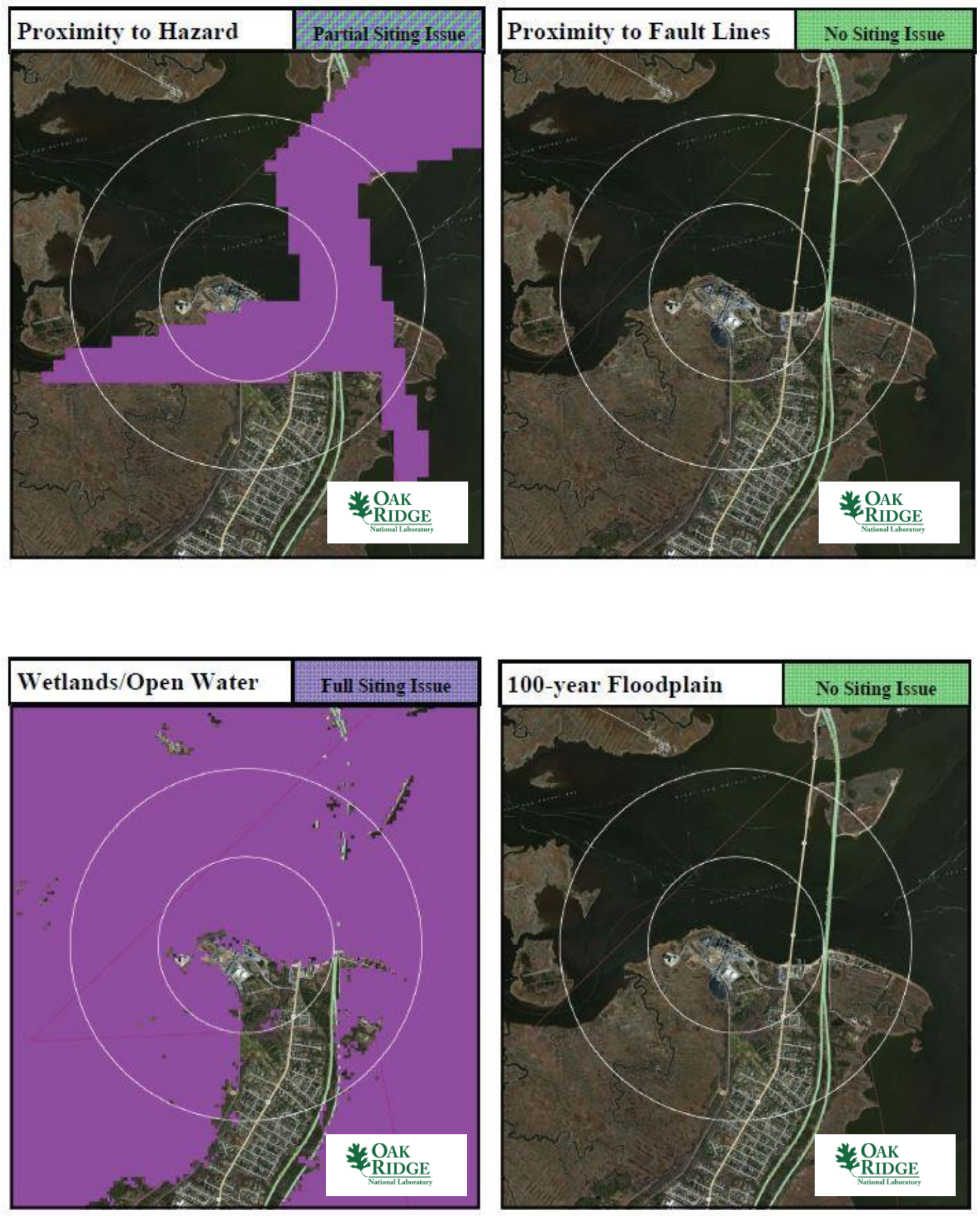

B. L. England Generating Station 

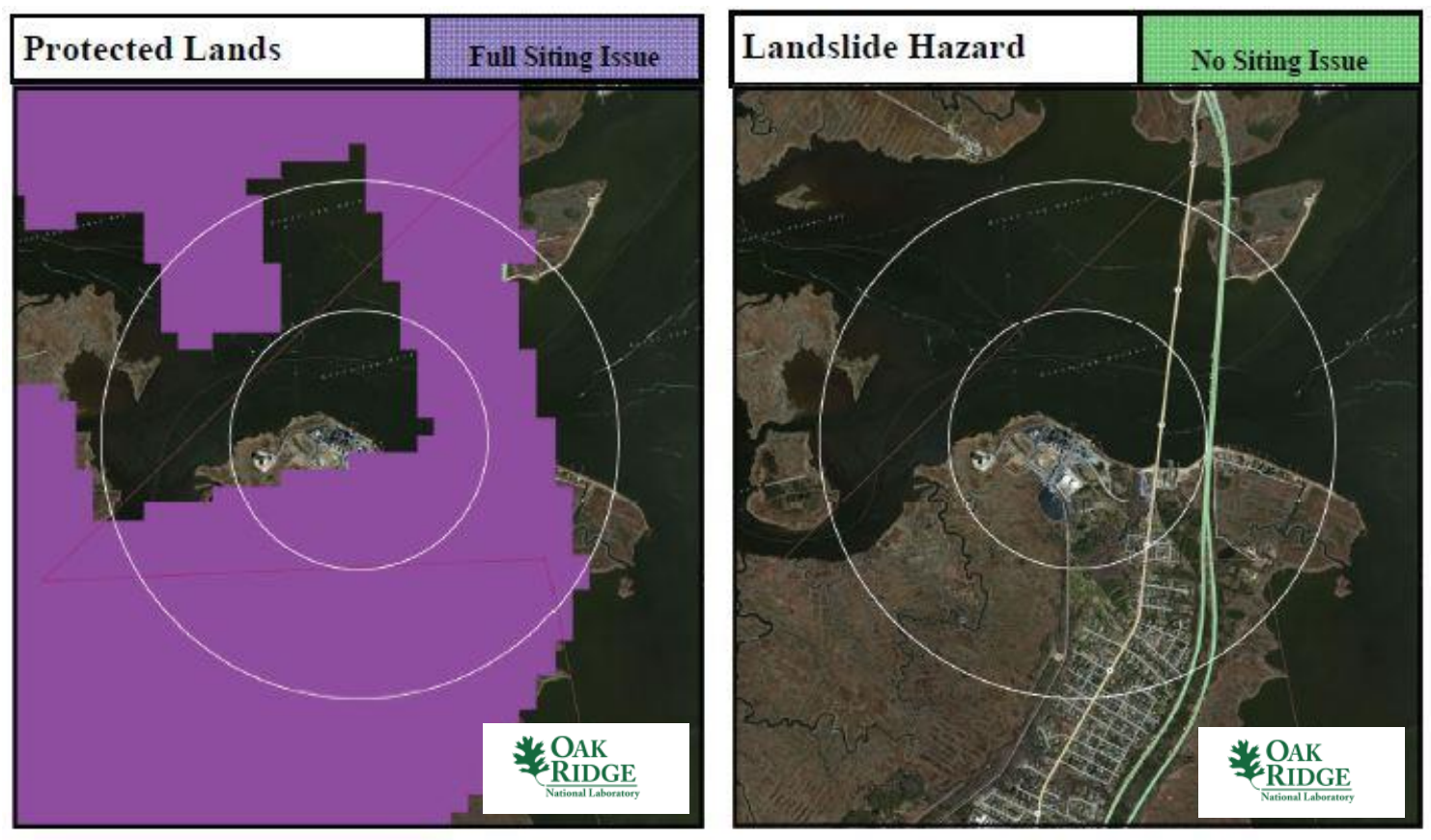

B. L. England Generating Station

\section{B.2.6 Site Evaluation}

The Rockland Corporation does not operate or own a share of any nuclear power plants in the United States. Therefore, the utility would need to be mentored through the licensing process to build and operate an SMR. Additionally, there are numerous other electric power generation facilities within 100 miles of the B. L. England Generating Station to subsidize area power requirements. Furthermore, the Rockland Corporation previously made the decision to convert some of the power generation equipment at this site to natural gas-fired units to meet area electrical load demands. The site contains sufficient acreage to support siting an SMR.

From an environmental justice perspective, the community collectively appears to have achieved a reasonable level of education with median income levels typical of much of the United States. Therefore, siting an SMR at this location would not seem to be disenfranchising a less-educated or poverty-stricken community. Furthermore, the education level of the B. L. England Generating Station community would seem to support the higher-technology job opportunities provided by an SMR.

As shown in Sects. B.0 and B.0, the B. L. England Generating Station site has a widespread issue with wetlands/open waters and protected lands. The plant structures are on elevated land surrounded on three sides by wetlands and open waters. This could be an issue under extreme flooding conditions such as the recent Hurricane Sandy weather event that struck this area. The protected lands are actually slightly further east than depicted in the individual siting criteria map. This map area reflects a land peninsula bordering a significant bay area and the ocean at the eastern edge of the United States. The GIS mapping techniques can develop "edge" effects or anomalies in such areas.

The B. L. England Generating Station site has partial SMR site screening issues with population and hazardous facilities. The center of the town of Somers Point is within 3 miles of the plant, with town edges within 1 mile of the site, and several unincorporated subdivisions are south of the plant within the 1 mile radius circle. Furthermore, Ocean City is just east of the site. The proximity-to-hazards issue is also due to a GIS mapping "edge" effect. There is no hazardous facility at this location. The remaining 
SMR site screening criteria are met site-wide for the values established in the updated SMR siting report.1

Though population figures are not problematic within a 1 mile radius of the plant, the local population rises substantially outside of this zone. This could be a contentious issue should the Rockland Corporation decide to submit a COL application for an SMR at this site to meet any growing need for electrical capacity at this grid location. In addition, the Garden State Parkway runs immediately adjacent to the site, which would make it difficult for a nuclear licensee to control land access to areas very near the plant location. Therefore, when future load demands indicate the need for expanded generation capacity in this region, the utility would need to work closely with local leaders and civic groups to make the case for siting an SMR at this location. The site exceeds current NRC RG 4.7 recommendations for population density without additional consideration for relaxed SMR population siting requirements based on reduced source term. The site is also surrounded on three sides by wetlands and open water. The B. L. England Generating Station site meets multiple conventional standards in the near term for consideration of siting an SMR at the coal station location, but there may be longer-term issues that could potentially preclude this site from further SMR siting consideration. The longer-term considerations include population growth, traffic control, and possible flooding under extreme weather conditions. 
B-22 


\section{B.3 Fair Station}

\section{B.3.1 Location Detail}

As shown in Fig. B.62, Fair Station is located in southeastern Iowa just west of the Illinois border. More specifically, the plant is located off Iowa Highway 22, in Muscatine County, Iowa. US Highway 61 is accessible 3 miles to the north and Interstate 280 is accessible roughly 9 miles to the east. Rail access is available onsite within 0.1 miles, and barge access is available within 0.2 miles via the Mississippi River. The closest town is Montpelier, Iowa, with a population of approximately 850 people. Montpelier is approximately 1 mile east of Fair Station. The nearest city with a population in excess of 10,000 people is Muscatine, Iowa, approximately 12 miles to the west of Fair Station.

- Plant: Fair Station

- Utility: Central Iowa Power Cooperative

- Coordinates: lat. $41.45740^{\circ} \mathrm{N}$, long. $90.82266^{\circ} \mathrm{W}$

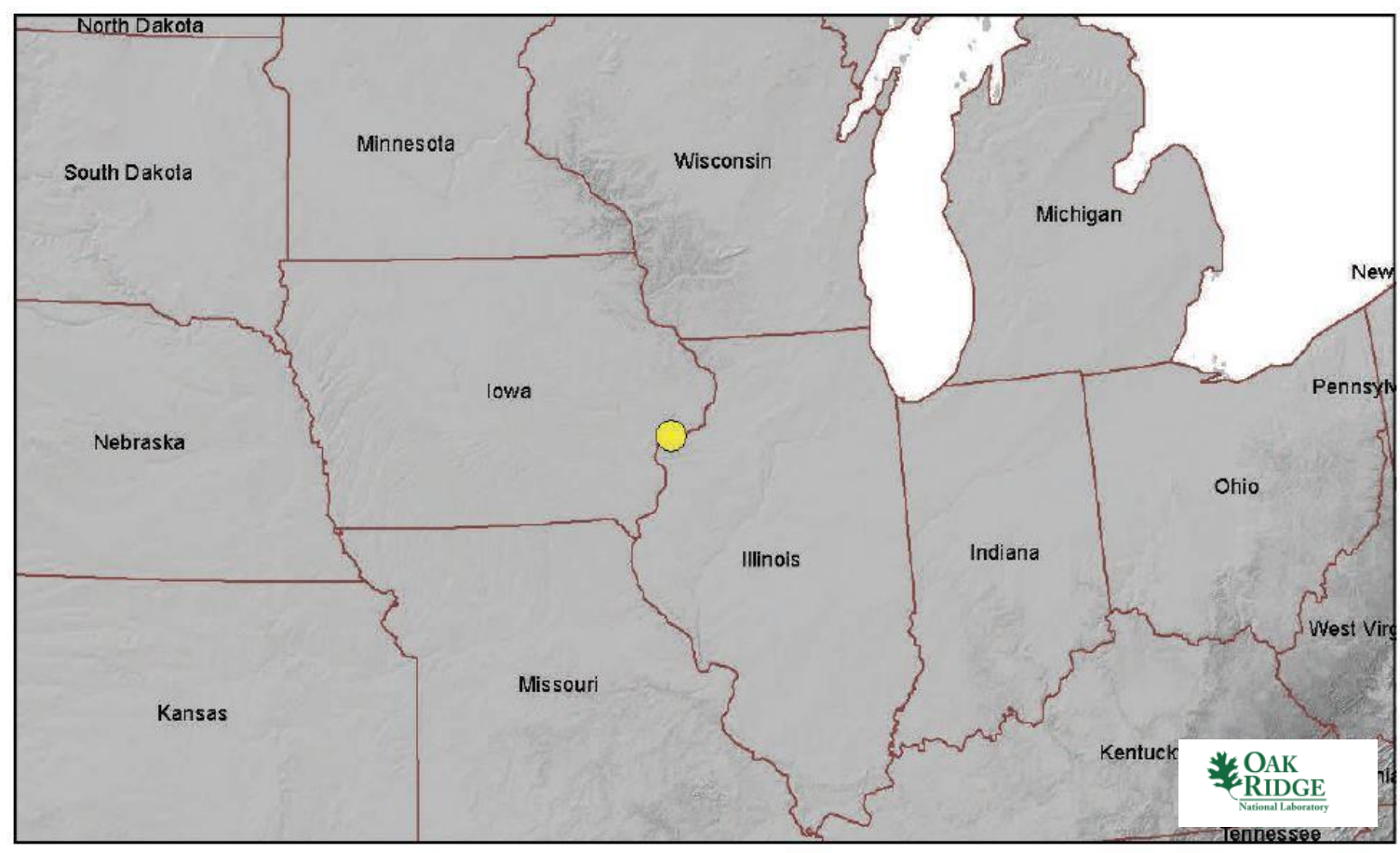

Fig. B.62. Fair Station location map.

\section{B.3.2 Site Description and Status}

Fair Station is a two-unit coal station with both units currently operating as base load plants. Fair Station is wholly owned and operated by the Central Iowa Power Cooperative. Unit 1, commissioned in 1960, is rated at $25 \mathrm{MW}(\mathrm{e})$ and Unit 2, commissioned in 1967, is rated at $37.5 \mathrm{MW}(\mathrm{e})$. The total site capacity is 62.5 MW(e). The units are cooled by once-through cooling from the adjacent Mississippi River. Both units have some emissions controls in place. Unit 1 has an electrostatic precipitator (ESP) and Unit 2 has 
an ESP with flue gas conditioner and low-NOX burners. The Central Iowa Power Cooperative is considering shutting down Fair Station by the end of 2013, but no firm decision has been reached. ${ }^{17}$

The plant is situated on approximately 60 acres on the Mississippi River approximately 32 miles southwest of the 1,737 MW(e) Quad Cities nuclear facility and 66 miles southeast of the $615 \mathrm{MW}(\mathrm{e})$ Duane Arnold nuclear facility. Fair Station is 13 miles upstream of the operational 294 MW(e) Muscatine Coal Plant and 20 miles downstream of the operational 141 MW(e) Riverside Coal Plant. In addition, the 135 MW(e) Keokuk Dam hydroelectric plant is 80 miles downstream of Fair Station, and the 30 MW(e) Story County Wind Farm is 133 miles to the west.

As noted in Table B.34, the nearest major fault line based on USGS data is 534 miles southwest in Kansas. The maximum safe-shutdown earthquake for the site is below $0.3 \mathrm{~g}$ peak ground acceleration. More than 500,000 gpm of cooling water makeup is available from the adjacent Mississippi River.

The permanent population within 1 mile of the plant is fewer than 500 people, yielding a population density of fewer than 160 people per square mile. The permanent population within 10 miles of the plant is approximately 117,000 people, yielding a population density of fewer than 375 people per square mile. According to the US EPA Environmental Justice website, there are 7,612 occupied housing units within 10 miles of the plant site based on 2000 US Census data. Further, over $80 \%$ of area adults over age 25 have a high school diploma or higher education. Just under $50 \%$ of the population makes more than $\$ 50 \mathrm{~K}$.

Table B.34. Fair Station site statistics

\begin{tabular}{|c|c|c|c|}
\hline \multicolumn{2}{|l|}{$\begin{array}{l}\text { Population } \\
\text { Population Within }\end{array}$} & \multicolumn{2}{|l|}{$\begin{array}{l}\text { Utility } \\
\text { Distance to Grid Capacity }\end{array}$} \\
\hline $0.5 \mathrm{mi}$ & $<500$ & $>400 \mathrm{MWe}$ & $\sim 8 \mathrm{mi}$ \\
\hline $1 \mathrm{mi}$ & $\sim 800$ & $>800 \mathrm{MWe}$ & $\sim 2 \mathrm{mi}$ \\
\hline $5 \mathrm{mi}$ & $\sim 25,000$ & $>1600 \mathrm{MWe}$ & $\sim 218 \mathrm{mi}$ \\
\hline $10 \mathrm{mi}$ & $\sim 117,000$ & $>3200 \mathrm{MWe}$ & $\sim 114 \mathrm{mi}$ \\
\hline \multicolumn{2}{|c|}{ Nearest City with Population } & \multicolumn{2}{|c|}{ Distance to Cooling Water } \\
\hline$>10,000$ & Muscatine, IA & $>50,000 \mathrm{gpm}$ & $\sim 0.2 \mathrm{mi}$ (Mississippi River) \\
\hline$>50,000$ & Iowa City, IA & $>100,000 \mathrm{gpm}$ & $\sim 0.2 \mathrm{mi}$ (Mississippi River) \\
\hline$>100,000$ & Davenport, IA & $>200,000 \mathrm{gpm}$ & $\sim 0.2 \mathrm{mi}$ (Mississippi River) \\
\hline$>500,000$ & Chicago, IL & $>500,000 \mathrm{gpm}$ & $\sim 0.2 \mathrm{mi}$ (Mississippi River) \\
\hline \multicolumn{2}{|l|}{ Geotechnical } & \multicolumn{2}{|l|}{ Accessibility } \\
\hline Max Earthquake Acceleration & $<0.3 \mathrm{~g}$ & Distance to Major Roadway & $\sim 1.4 \mathrm{mi}(\mathrm{SR} 92)$ \\
\hline Max Slope & $\sim 13 \%$ & Distance to Water Transport & $\sim 0.2 \mathrm{mi}$ (Mississippi River) \\
\hline Nearest Fault Line & $\sim 534$ mi (Kansas) & Distance to Rail Transport & $\sim 0.1 \mathrm{mi}(\mathrm{ICE})$ \\
\hline Nearest Hazard Site & $\begin{array}{r}15 \text { mi (Airport- } \\
\text { Quad City Int' } ' \text { ) }\end{array}$ & Distance to Airport & $\sim 15$ mi Quad City Int'l) \\
\hline
\end{tabular}

\footnotetext{
${ }^{17}$ Integrated Resource Plan
} 


\section{B.3.3 Aerial Imagery}

The aerial imagery in Fig. B.63 shows the small town of Montpelier within 1.0 mile of the site to the east. Also visible is a subdivision within 1.0 mile of the site to the west.

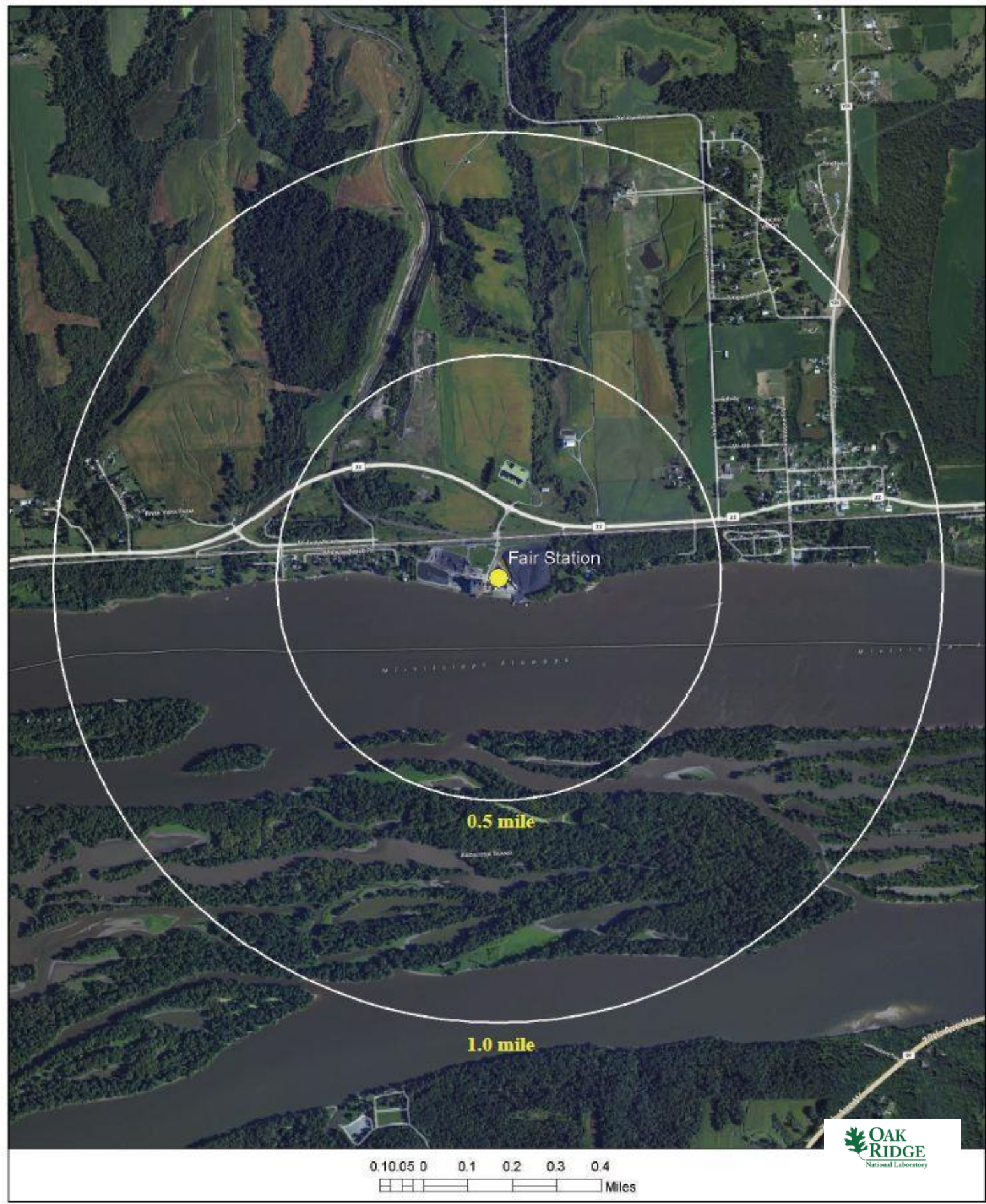

Fig. B.63. Satellite view of Fair Station proximity. 


\section{B.3.4 Screening Criteria Overview}

Table B.35. Fair Station siting criteria summary

\begin{tabular}{|c|c|c|c|c|c|c|c|c|c|c|}
\hline & & Ser & (Co & $\lg C$ & $\begin{array}{l}\text { iteria } \\
\text { s indicate }\end{array}$ & $\underset{\text { Screenin }}{\text { Sun }}$ & $\underset{\text { g Results) }}{\operatorname{nmary}}$ & Bal & & \\
\hline & No Siting Is & & & & Partial Sit & ting Issue & & & Full Siting I & Issue \\
\hline \begin{tabular}{|l|}
0.5 \\
Mile \\
Buffer
\end{tabular} & Population & Slope & SSE & $\begin{array}{l}\text { Stream } \\
\text { flow } \\
(65,000 \\
g \mathrm{gm}) \\
\end{array}$ & \begin{tabular}{l|} 
Proximity \\
to \\
Hazard \\
Operations
\end{tabular} & $\begin{array}{l}\text { Proximity } \\
\text { to } \\
\text { Fault } \\
\text { Lines }\end{array}$ & \begin{tabular}{|l|} 
Wetlands \\
Open \\
Water
\end{tabular} & \begin{tabular}{l|}
100 -year \\
Flood- \\
plain
\end{tabular} & $\begin{array}{l}\text { Protected } \\
\text { Lands }\end{array}$ & $\begin{array}{l}\text { Landslide } \\
\text { Hazards }\end{array}$ \\
\hline $\begin{array}{l}1.0 \\
\text { Mile } \\
\text { Buffer }\end{array}$ & Population & Slope & SSE & $\begin{array}{l}\text { Stream } \\
\text { flow } \\
(65,000 \\
\text { gpm })\end{array}$ & $\begin{array}{l}\text { Proximity } \\
\text { to } \\
\text { Hazard } \\
\text { Operations }\end{array}$ & $\begin{array}{l}\text { Proximity } \\
\text { to } \\
\text { Fault } \\
\text { Lines }\end{array}$ & $\begin{array}{l}\text { Wetlands } \\
\text { Oper } \\
\text { Water }\end{array}$ & $\begin{array}{l}\text { 100-year } \\
\text { Flood- } \\
\text { plain }\end{array}$ & $\begin{array}{l}\begin{array}{l}\text { Protected } \\
\text { Lands }\end{array} \\
\end{array}$ & $\begin{array}{l}\text { Land- } \\
\text { slide } \\
\text { Hazards }\end{array}$ \\
\hline & & & & & & & & & & $\begin{array}{l}\text { AK } \\
\text { IDGE }\end{array}$ \\
\hline & Site S & e & & and & valu & n & 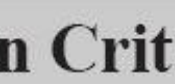 & ia & Tak & \\
\hline & & & rite & & & & & Valt & & \\
\hline Populati & on Density w & ithin 1 & iles ( & ople/squas & mile) & & & $>50$ & & \\
\hline Slope & & & & & & & & $>18^{\circ}$ & & \\
\hline Safe shu & tdown earthq & uake ( & and $\mathrm{ac}$ & eleration) & & & & $>0$. & & \\
\hline Streamf & ow/cooling $\mathrm{v}$ & vater $\mathrm{m}$ & e-up ( & & & & & $<65,0$ & & \\
\hline Proximi & y to hazardo & is oper & ons - $t$ & ffer (mile) & & & Depends & s on hazarc & dous operati & ion $^{1}$ \\
\hline Proximi & $y$ to fault lin & es - buf & (mile & & & & Depe & ends on len & gth of fault & \\
\hline Wetland & s/Open Wate & & & & & & & - & & \\
\hline 100-yea & floodplain & & & & & & & - & & \\
\hline Protecte & lands & & & & & & & - & & \\
\hline Landslic & e hazard (mo & derate & d high & & & & & - & & \\
\hline
\end{tabular}

${ }^{1}$ Hazardous facilities (airports- 5 miles and oil refineries- -1 mile) 


\section{B.3.5 Composite Map and Individual Siting Issue Maps}

A composite map of SMR siting challenges to Fair Station is shown in Fig. B.64. The physical plant structures are located on land with no siting issues. Following this map are maps of the individual SMR siting criteria based on selected input values.

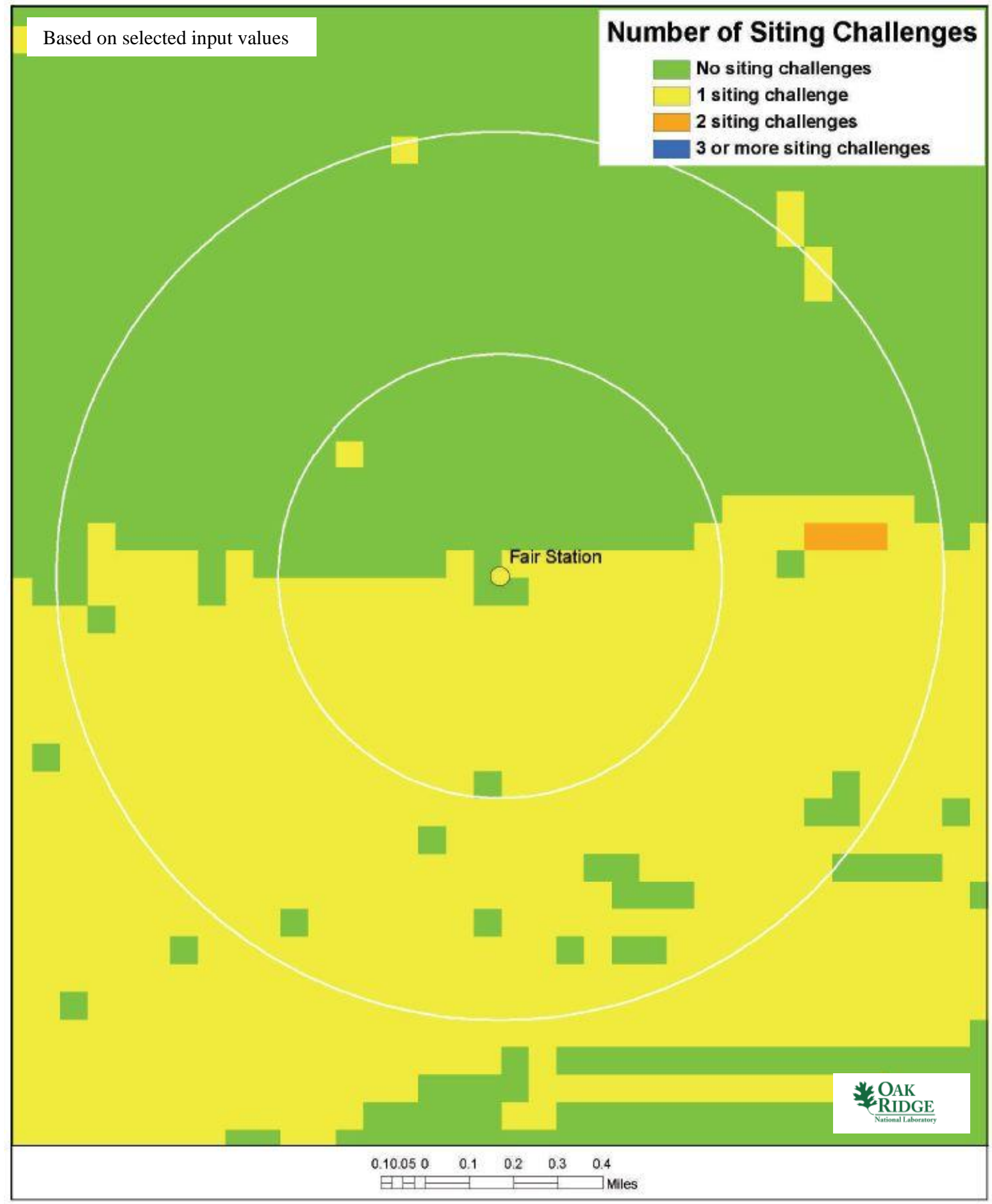

Fig. B.64. Fair Station composite map. 

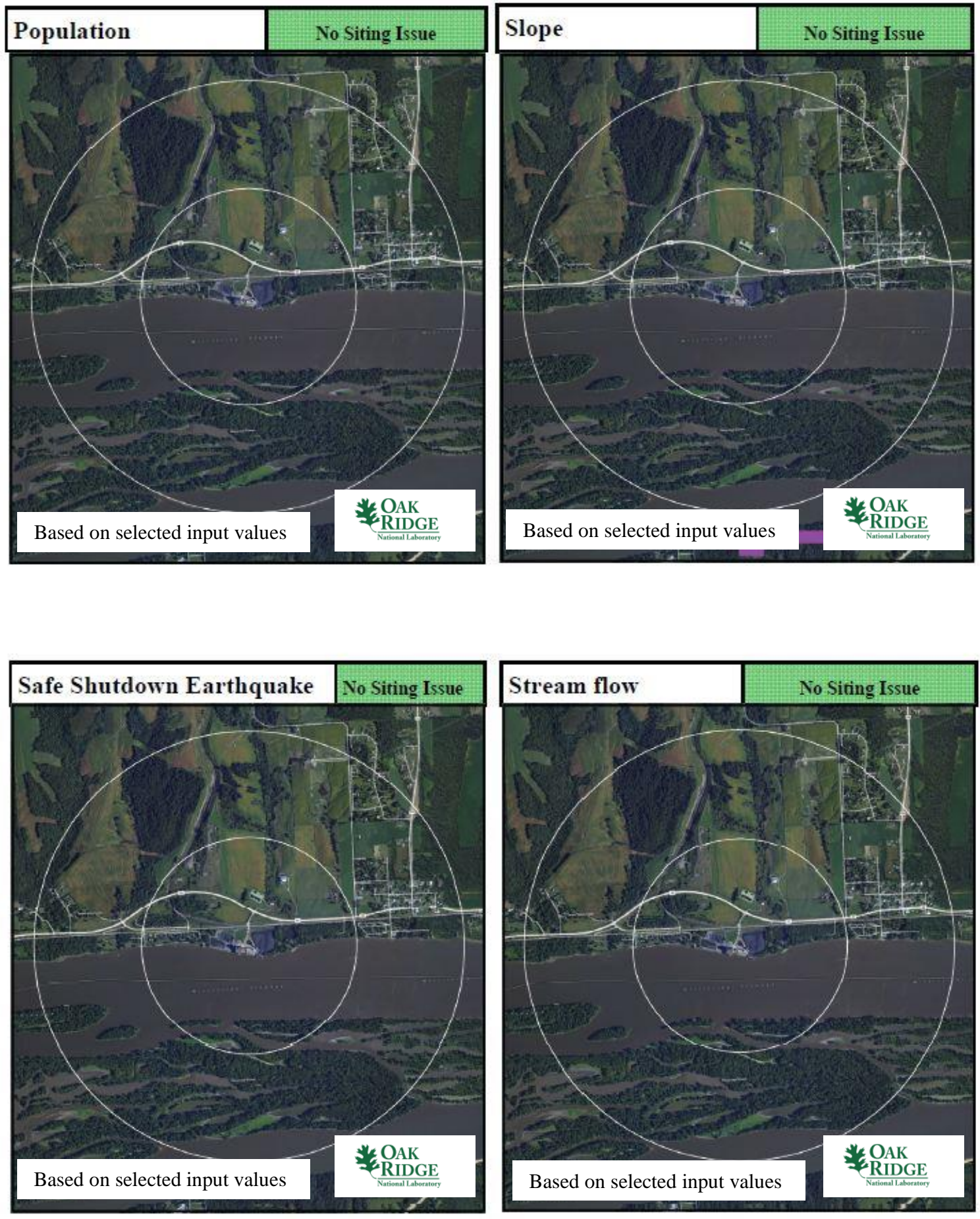

Fair Station 

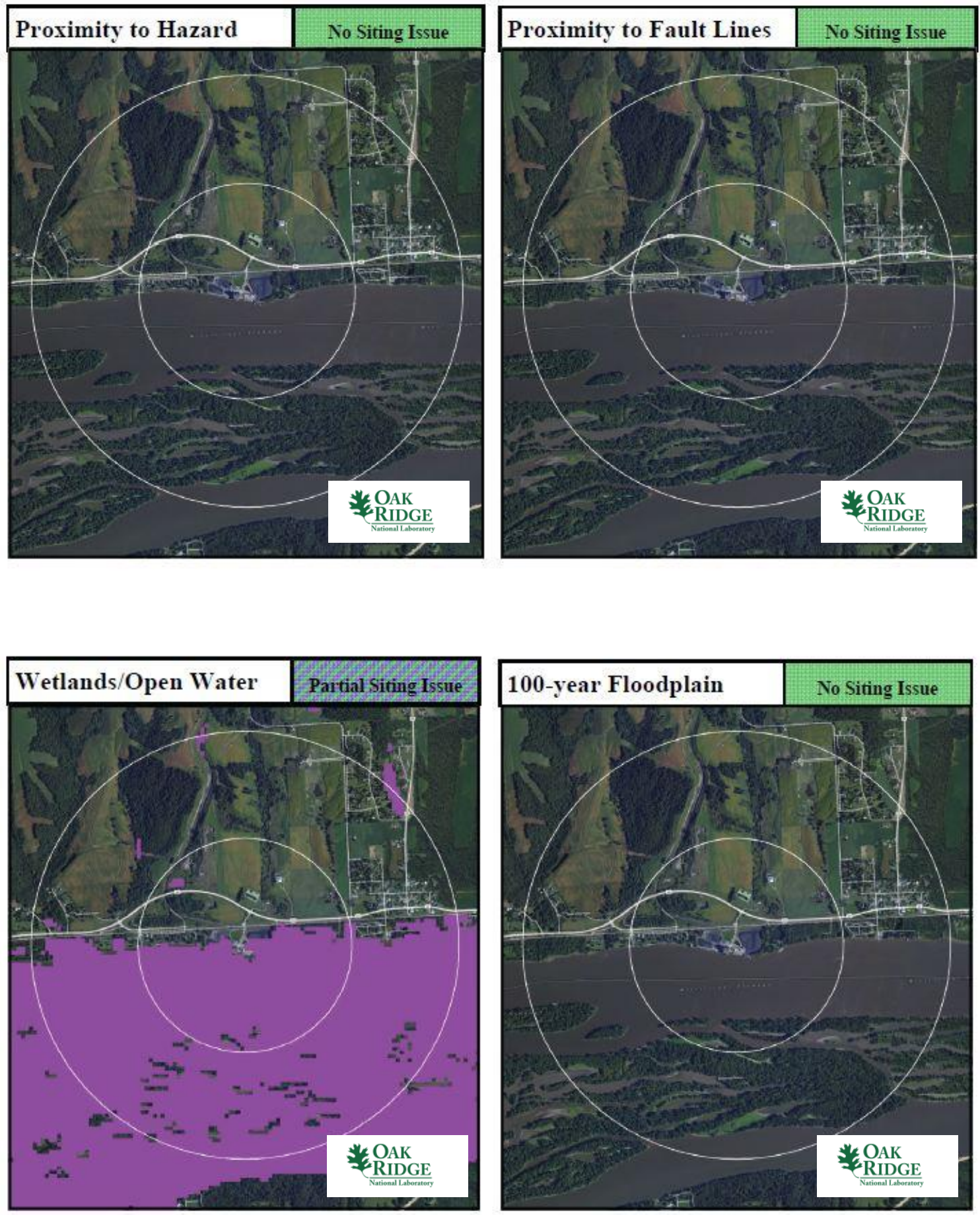

Fair Station 

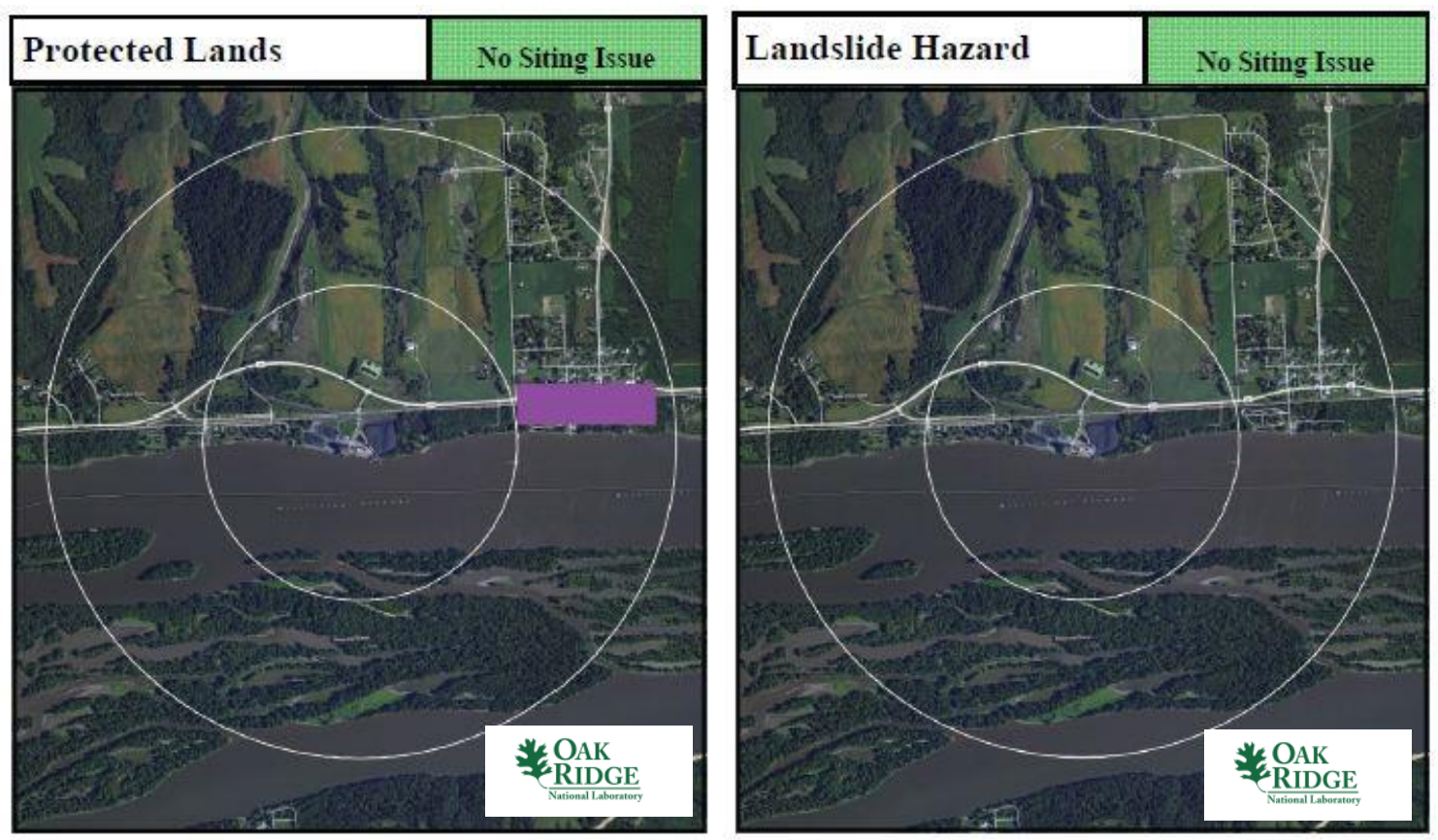

Fair Station

\section{B.3.5 Site Evaluation}

The Central Iowa Power Cooperative owns a 20\% share of the Duane Arnold nuclear plant operated by NextEra Energy. Therefore, the utility could be mentored by NextEra Energy through the licensing process to build and operate an SMR at Fair Station. As noted previously, there are numerous other electric power generation facilities within 100 miles of Fair Station to subsidize area power requirements. Central Iowa Power Cooperative has not yet decided whether to upgrade the plants for continued operation or mothball the plants. For planning purposes, the Central Iowa Power Cooperative intends to shut the units down by the end of 2013.

From an environmental justice perspective, the community collectively appears to have achieved a reasonable level of education with median income levels typical of much of the United States. Therefore, siting an SMR at this location would not seem to be disenfranchising a less-educated or poverty-stricken community. Furthermore, the education level of the Fair Station community would seem to support the higher-technology job opportunities provided by an SMR.

As shown in Sects. B.0 and B.0, the Fair Station site has a partial SMR site screening issue with wetlands/open waters. The wetlands/open waters issue affects area to the south of the plant site, including the Mississippi River. Further visual inspection of the aerial imagery indicates that neither of these issues should directly impact the siting of an SMR at this location. The remaining SMR site screening criteria are met site-wide for the values established in the updated SMR siting report.1

Though population figures are not problematic within a 1 mile radius of the plant, one subdivision area and the small town of Montpelier are visually apparent in an aerial view of the site between the 0.5 mile radius circle and the 1 mile radius circle. This could be a contentious issue should the Central Iowa Power Cooperative decide to submit a COL application for an SMR at this site to meet any growing need for electrical capacity at this grid location.

When future load demands indicate the need for expanded generation capacity in this region, the utility would need to work closely with local leaders and civic groups to make the case for siting an SMR at this 
location. The site meets current NRC RG 4.7 recommendations for population density without additional consideration for relaxed SMR population siting requirements based on reduced source term. The Fair Station site meets multiple conventional standards in the near term for consideration of siting an SMR at the coal station location, but there may be longer-term issues that could potentially preclude this site from further SMR siting consideration. The longer-term consideration includes population growth in the proximity of the town of Montpelier. 
B-32 


\section{B.4 Martins Creek Power Plant}

\section{B.4.1 Location Detail}

As shown in Fig. B.65, the Martins Creek Power Plant is located in eastern Pennsylvania across the Delaware River from New Jersey. More specifically, the plant is located off Depue Ferry Road in Lower Mount Bethel Township, Northampton County, Pennsylvania. Pennsylvania Highway 611 is accessible approximately 2.5 miles to the west and Interstate 78 is approximately 8 miles to the south. Rail access is available onsite within 0.1 miles and barge access is available within 0.1 miles on the adjacent Delaware River. The plant is located about 4.3 miles northeast of Martins Creek, Pennsylvania, with a population of approximately 2631 people. The nearest city with a population in excess of 10,000 people is Phillipsburg, New Jersey, approximately 8.7 miles to the southwest of the Martins Creek Power Plant.

- Plant: Martins Creek Power Plant

- Utility: PPL Martins Creek of Pennsylvania

- Coordinates: lat. $40.79582^{\circ} \mathrm{N}$, long. $75.10623^{\circ} \mathrm{W}$

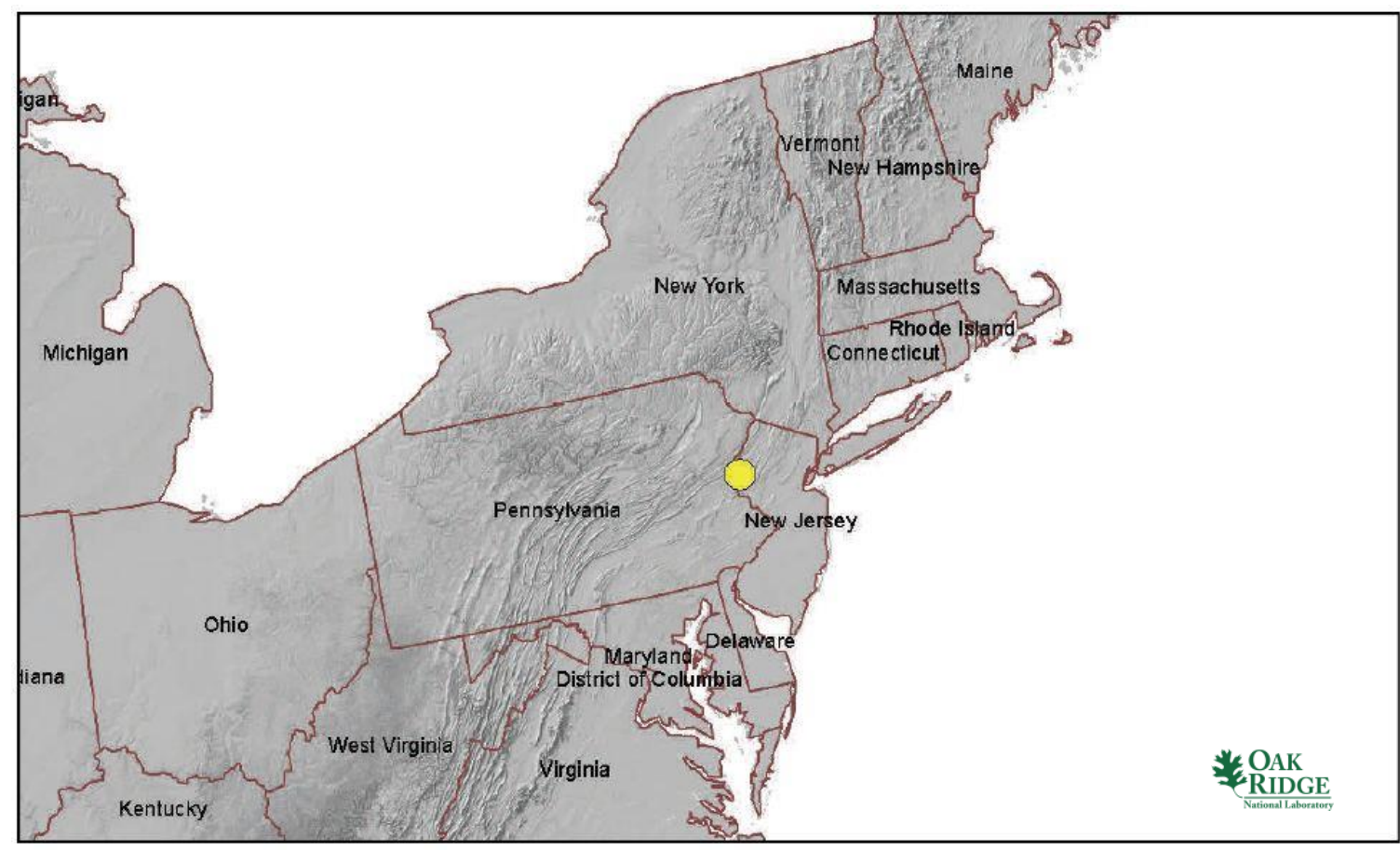

Fig. B.65. Martins Creek Power Plant location map.

\section{B.4.2 Site Description and Status}

The Martins Creek Power Plant is operated by the PPL Martins Creek of Pennsylvania, a subsidiary of the PPL Corporation. The Martins Creek Power Plant consists of two retired coal-fired units and two natural gas or oil-fired units. Unit 1, commissioned in 1954, was rated at $156 \mathrm{MW}(\mathrm{e})$. Likewise, Unit 2, commissioned in 1956, was rated at $156 \mathrm{MW}(\mathrm{e})$. Both coal-fired units were permanently shut down in 2007. The gas/oil-fired units 3 and 4 are both rated at 845 MW(e) and came online in 1974 and 1976, respectively. The shutdown coal-fired units have been removed, leaving a brownfield site. The coal-fired plants were cooled by once-through cooling from the adjacent Delaware River. The gas/oil-fired units are cooled by natural draft cooling towers. 
The plant is situated on roughly 750 acres on the Delaware River 61 miles southeast of the 2,700 MW(e) PPL Susquehanna nuclear power plant and 47 miles northeast of the 2,268 MW(e) Limerick nuclear facility. The Martins Creek Power Plant is 8 miles south of the 427 MW(e) coal-fired Portland plant. In addition, numerous hydroelectric plants are sited approximately 90 miles to the southeast.

As noted in Table B.36, the nearest major fault line based on USGS data is about 1,254 miles southwest in Oklahoma. The maximum safe-shutdown earthquake for the site is below $0.3 \mathrm{~g}$ peak ground acceleration. More than 500,000 gpm of cooling water makeup is available from the adjacent Delaware River.

The permanent population within 1 mile of the plant is approximately 1,700 people, yielding a population density of approximately 541 people per square mile. The permanent population within 10 miles of the plant is approximately 292,000 people, yielding a population density of slightly fewer than 930 people per square mile.

According to the US EPA Environmental Justice website, there are 48,502 occupied housing units within 10 miles of the plant site based on 2000 US Census data. Further, approximately $80 \%$ of area adults over age 25 have a high school diploma or higher education. The median annual income for the area is between $\$ 25 \mathrm{~K}$ and $\$ 50 \mathrm{~K}$.

Table B.36. Martins Creek Power Plant site statistics

\begin{tabular}{|c|c|c|c|}
\hline \multicolumn{2}{|l|}{$\begin{array}{l}\text { Population } \\
\text { Population Within }\end{array}$} & \multicolumn{2}{|l|}{$\begin{array}{l}\text { Utility } \\
\text { Distance to Grid Capacity }\end{array}$} \\
\hline $0.5 \mathrm{mi}$ & $<500$ & $>400 \mathrm{MWe}$ & $\sim 0.2 \mathrm{mi}$ \\
\hline $1 \mathrm{mi}$ & $\sim 1,700$ & $>800 \mathrm{MWe}$ & $\sim 17.8 \mathrm{mi}$ \\
\hline $5 \mathrm{mi}$ & $\sim 47,000$ & $>1600 \mathrm{MWe}$ & $\sim 21.0 \mathrm{mi}$ \\
\hline $10 \mathrm{mi}$ & $\sim 292,000$ & $>3200 \mathrm{MWe}$ & $\sim 234.0 \mathrm{mi}$ \\
\hline \multicolumn{2}{|c|}{ Nearest City with Population } & \multicolumn{2}{|c|}{ Distance to Cooling Water } \\
\hline$>10,000$ & Phillipsburg, NJ & $>50,000 \mathrm{gpm}$ & $\sim 0.1 \mathrm{mi}$ (Delaware River) \\
\hline$>50,000$ & Bethlehem, PA & $>100,000 \mathrm{gpm}$ & $\sim 0.1 \mathrm{mi}$ (Delaware River) \\
\hline$>100,000$ & Allentown, PA & $>200,000 \mathrm{gpm}$ & $\sim 0.1 \mathrm{mi}$ (Delaware River) \\
\hline$>500,000$ & Philadelphia, PA & $>500,000 \mathrm{gpm}$ & $\sim 0.1 \mathrm{mi}$ (Delaware River) \\
\hline \multicolumn{2}{|l|}{ Geotechnical } & \multicolumn{2}{|l|}{ Accessibility } \\
\hline Max Earthquake Acceleration & $<0.3 \mathrm{~g}$ & Distance to Major Roadway & $\sim 2.5 \mathrm{mi}(\mathrm{SR} 611)$ \\
\hline Max Slope & $\sim 11 \%$ & Distance to Water Transport & $\sim 0.1 \mathrm{mi}$ (Delaware River) \\
\hline Nearest Fault Line & $\sim 1254 \mathrm{mi}$ (Oklahoma) & Distance to Rail Transport & $\sim 0,1 \mathrm{mi}(\mathrm{NS})$ \\
\hline Nearest Hazard Site & $\begin{array}{l}\sim 19 \text { mi (Airport- } \\
\text { Lehigh Valley Int'l) }\end{array}$ & Distance to Airport & $\begin{array}{r}\sim 19.0 \text { mi (Lehigh Valley } \\
\text { Int' } 1 \text { ) }\end{array}$ \\
\hline
\end{tabular}




\section{B.4.3 Aerial Imagery}

The aerial imagery in Fig. B.66 indicates the site of the Martins Creek Steam Electric Station. No housing is visible within a 1 mile radius of the plant site.

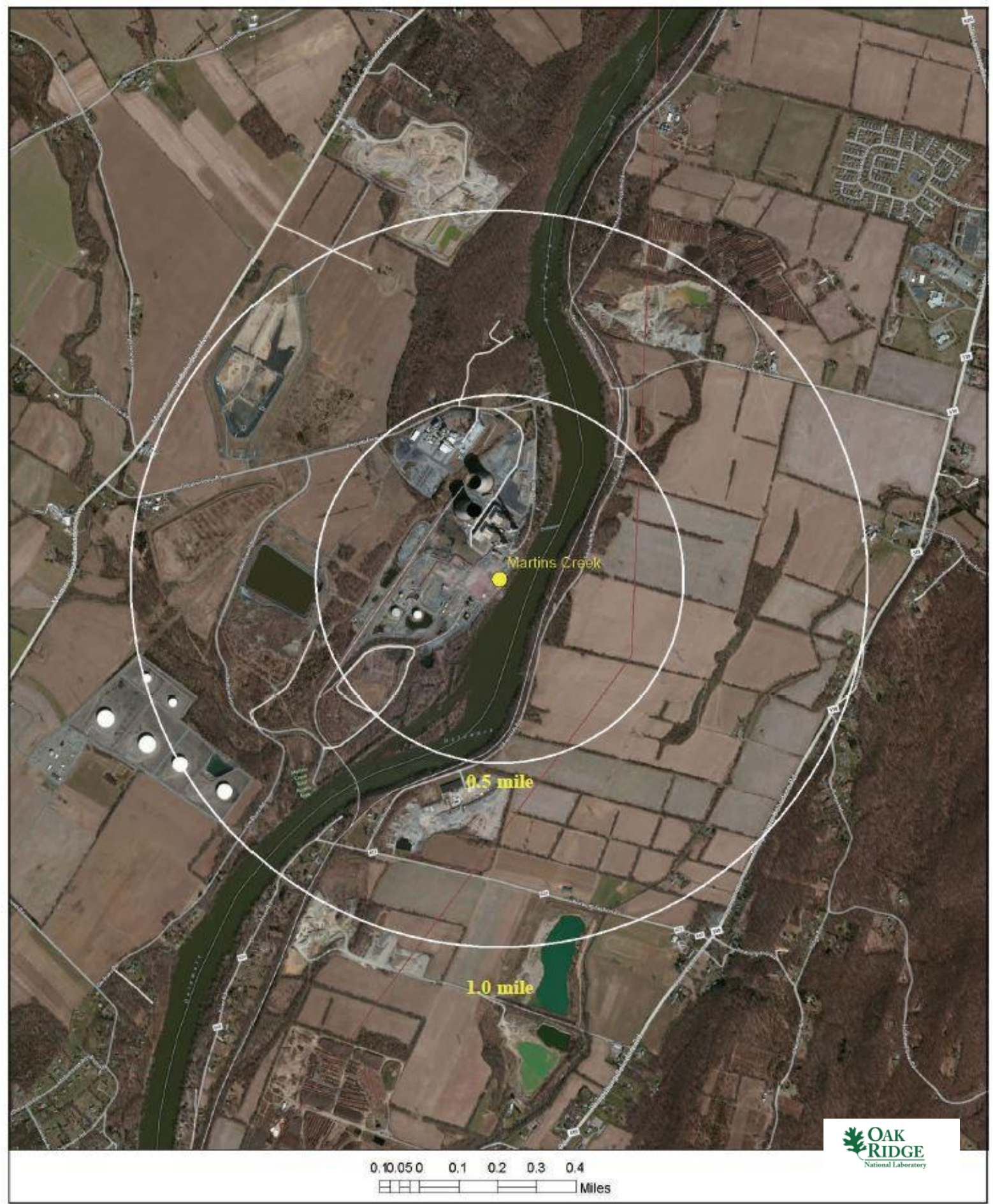

Fig. B.66. Satellite view of Martins Creek Power Plant proximity 


\section{B.4.4 Screening Criteria Overview}

Table B.37. Martins Creek Power Plant siting criteria summary

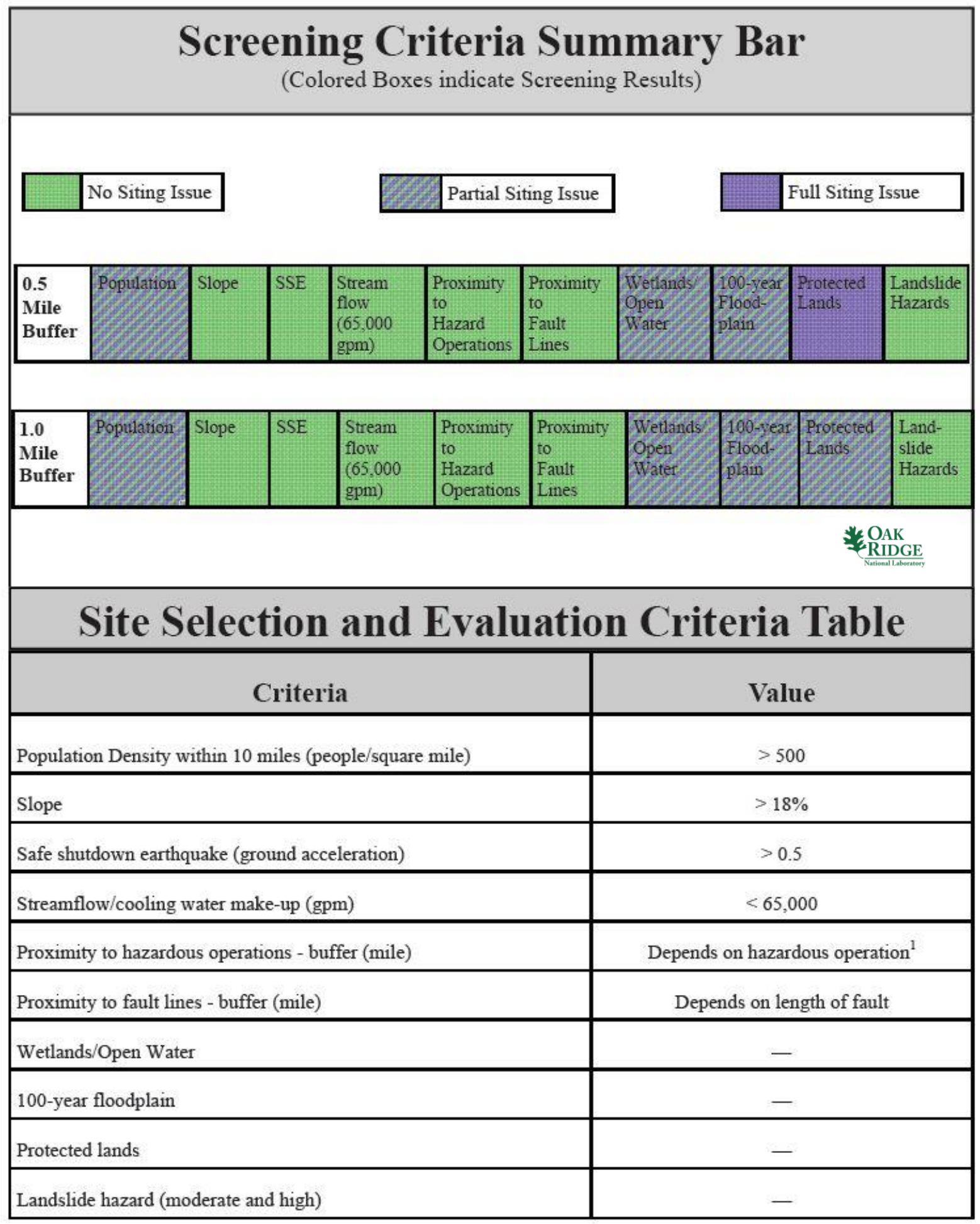

${ }^{1}$ Hazardous facilities (airports-5 miles and oil refineries-1 mile) 


\section{B.4.5 Composite Map and Individual Siting Issue Maps}

A composite map of SMR siting challenges to the Martins Creek Steam Electric Station is shown in Fig. B.67. The physical plant structures are located on land with a single siting challenge. Following this map are maps of the individual SMR siting criteria based on selected input values.

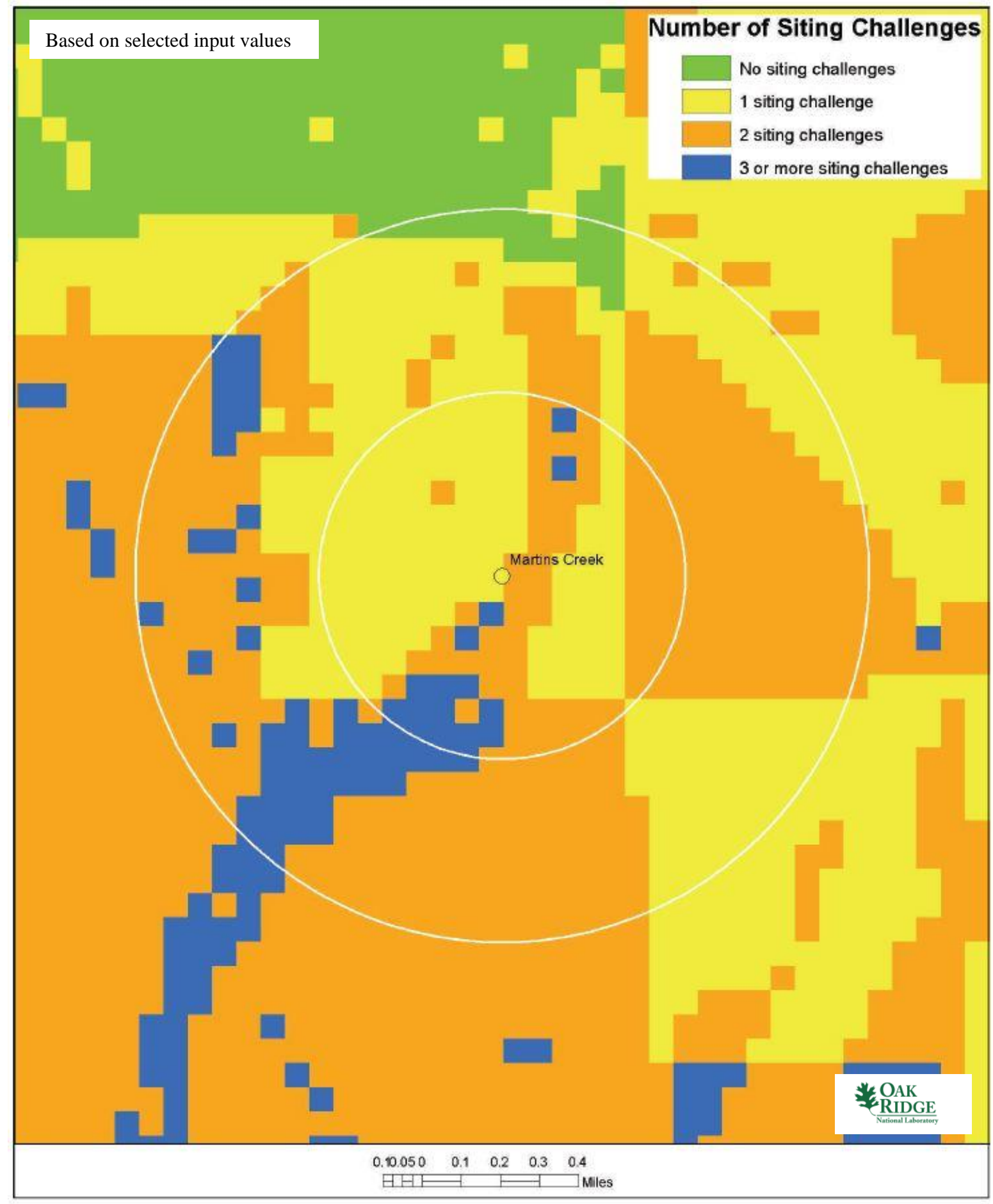

Fig. B.67. Martins Creek Power Plant composite map. 

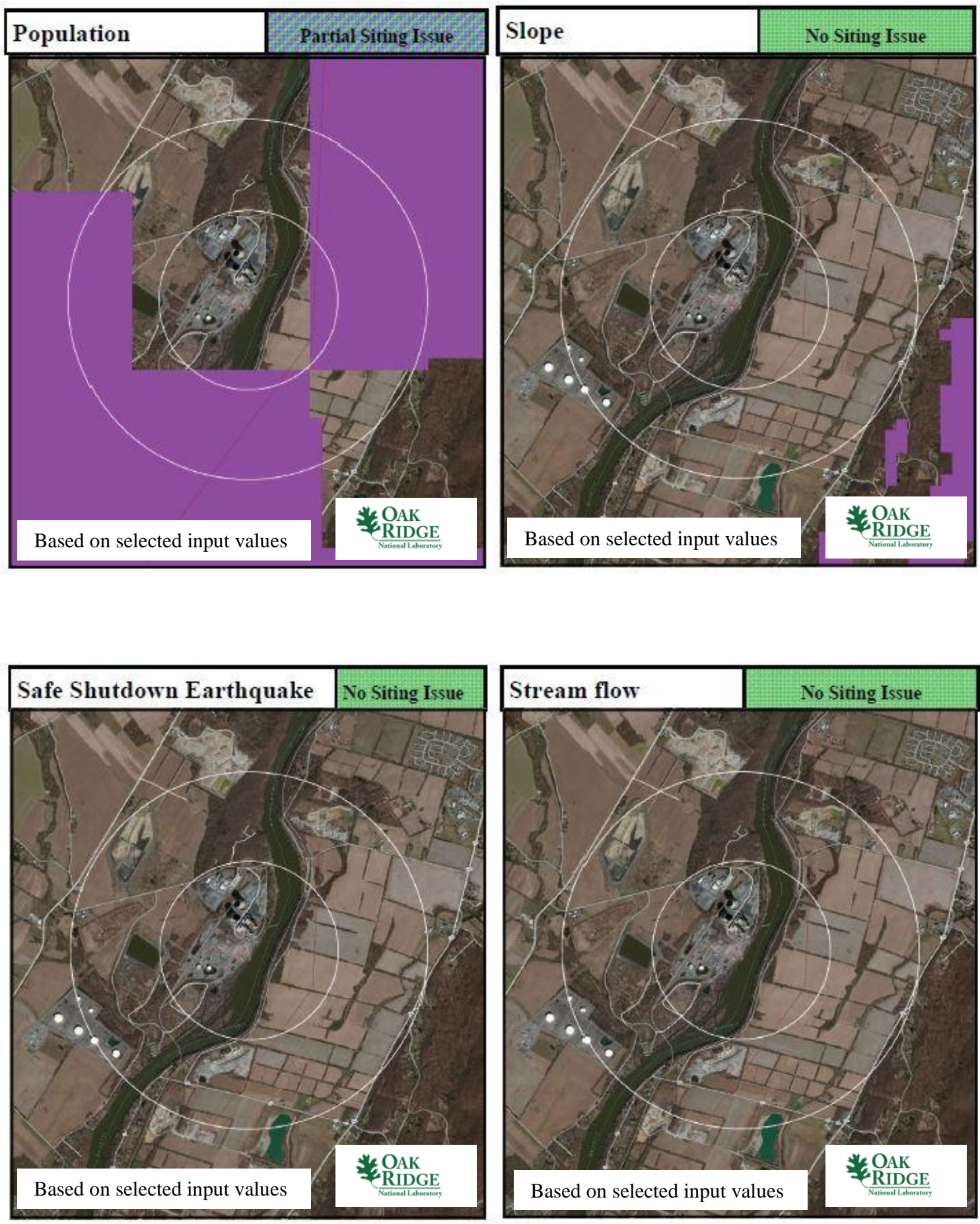

Martins Creek Power Plant 

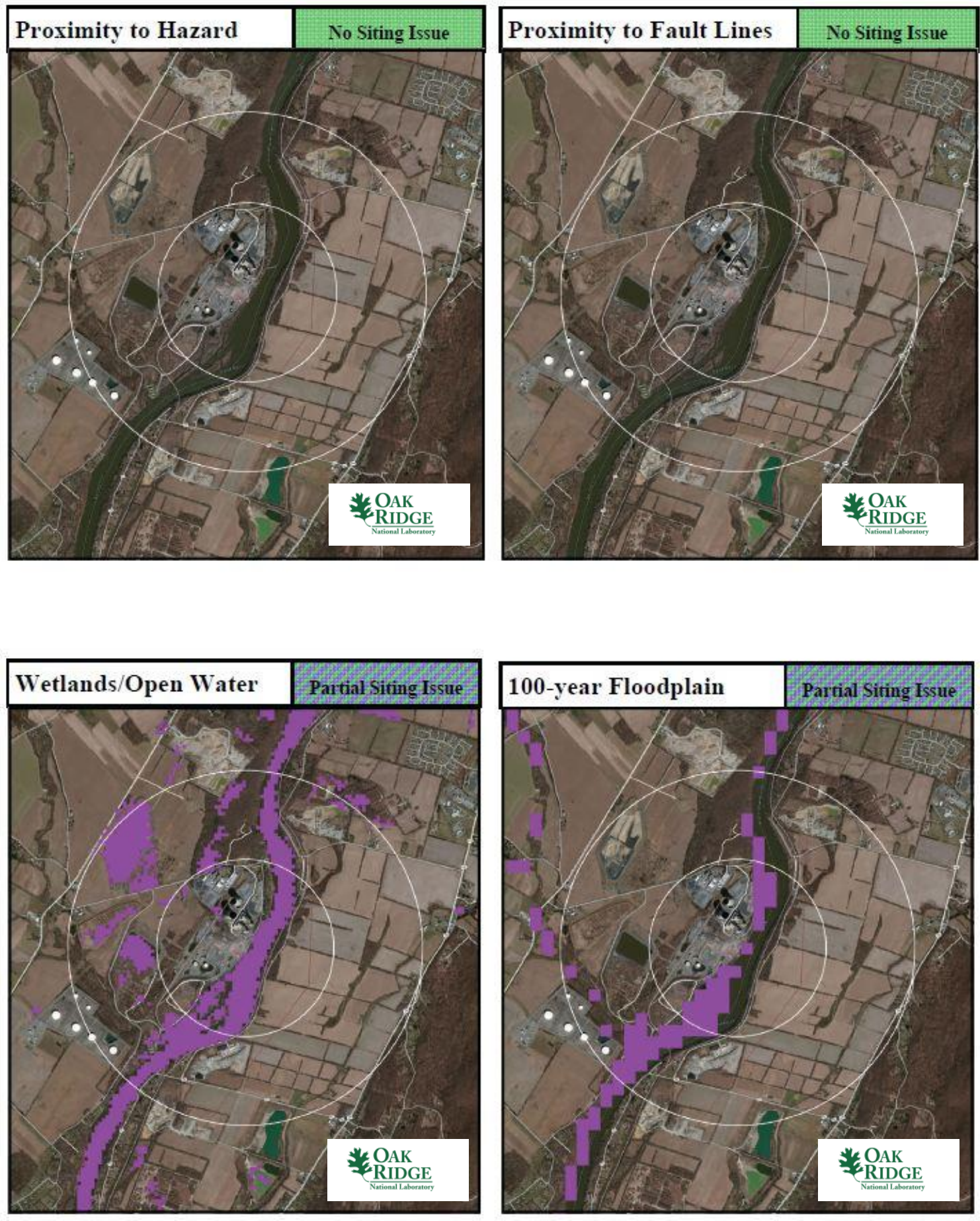

Martins Creek Power Plant 

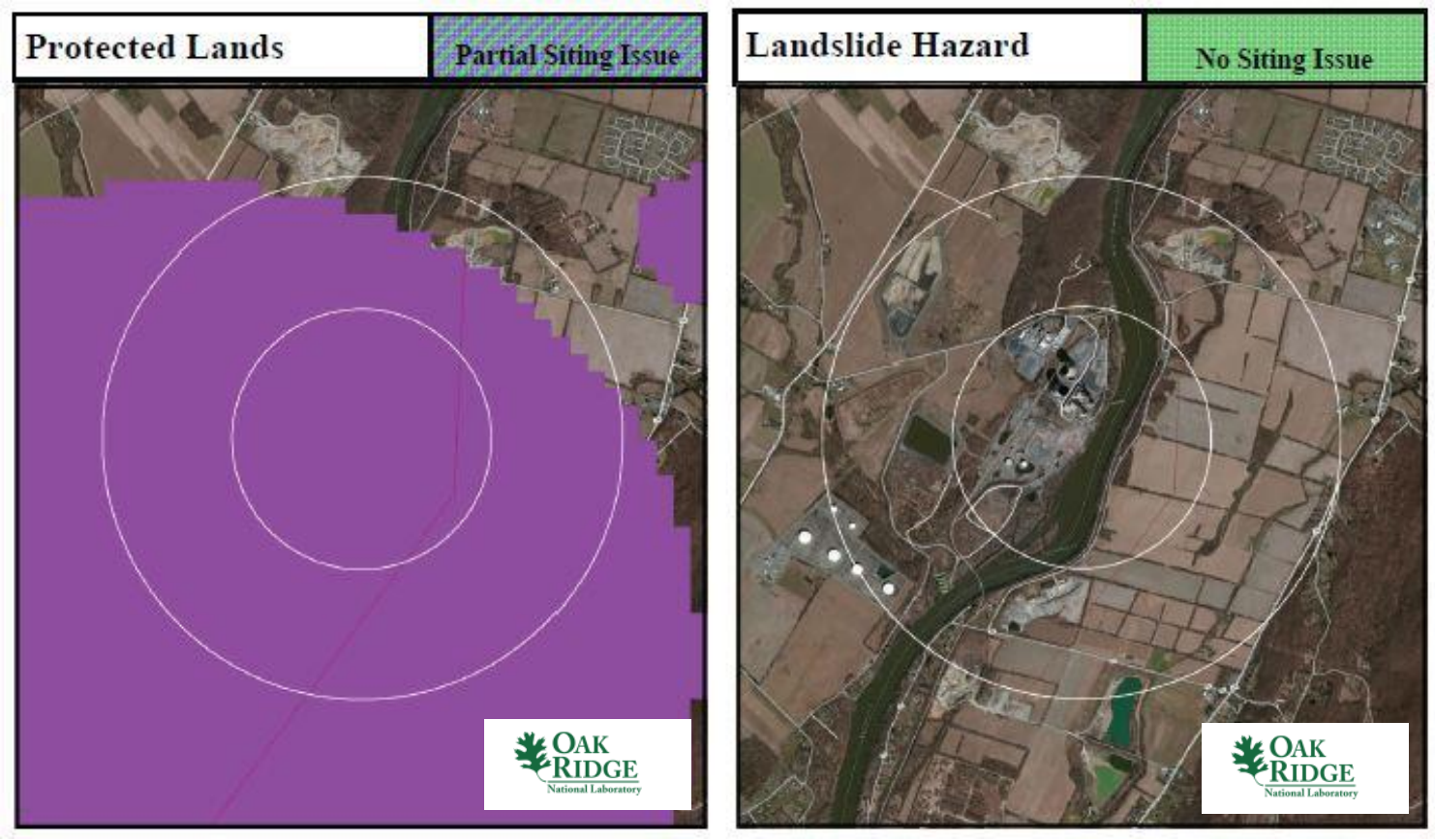

Martins Creek Power Plant

\section{B.4.6 Site Evaluation}

PPL Martins Creek does not own or operate any nuclear power plants in the United States. However, its parent company, PPL Corporation, via one of its subsidiaries, PPL Susquehanna, owns and operates two nuclear power plants near Berwick Pennsylvania (Susquehanna Steam Electric Station, Units 1 and 2). PPL has also applied for a COL for two nuclear plants to be located at the Susquehanna site. Therefore, PPL Corporation has the licensing experience to operate an SMR at the Martins Creek site. The site contains sufficient acreage to support siting an SMR.

From an environmental justice perspective, the community collectively appears to have achieved a reasonable level of education with median income levels typical of much of the United States. Therefore, siting an SMR at this location would not seem to be disenfranchising a less-educated or poverty-stricken community. Furthermore, the education level of the Martins Creek Steam Electric Station community would seem to support the higher-technology job opportunities provided by an SMR.

As shown in Sects. B. 0 and B.0, the Martins Creek Power Plant has a full site issue with protected lands. This appears to be due to numerous local parks that dot the area along the river in the vicinity of the plant. It does not appear that the plant is actually situated on protected land. Therefore, this SMR SSEC attribute should not affect the siting of an SMR at this location.

The Martins Creek Power Plant site also has partial SMR site screening issues with wetlands/open waters, 100-year floodplain, and population. The wetlands/open water and 100-year floodplain reflect the adjacent Delaware River and should not be an issue. The site also has a partial SMR site screening issue with population outside the 0.5 mile radius circle. This is primarily due to the larger towns northeast and southwest of the Martins Creek site. The plant site itself meets the SMR SSEC for population. However, population growth in these towns could negatively affect the population density regarding siting an SMR at this location in the future. The remaining SMR site screening criteria are met site-wide for the values established in the updated SMR siting report.1 
The aerial view of the site indicates a large tank farm a little more than 1 mile southwest of the plant site. Since the Martins Creek Power Plant has essentially converted to an oil-fired, natural gas power station, the tank farm likely serves as a storage facility for the crude oil used in the facility.

When future load demands indicate the need for expanded generation capacity in this region, the utility would need to work closely with local leaders and civic groups to make the case for siting an SMR at this location. The site meets current NRC RG 4.7 recommendations for population density with additional consideration for relaxed SMR population siting requirements based on reduced source term. The Martins Creek Power Plant site meets multiple conventional standards in the near term for consideration of siting an SMR at the coal station location, but there may be longer-term issues that could potentially preclude this site from further SMR siting consideration. The longer-term consideration includes population growth in the proximity of the plant. 
B-42 


\section{B.5 Meredosia Power Plant}

\section{B.5.1 Location Detail}

As shown in Fig. B.68, the Meredosia Power Plant is located in west central Illinois about 43 miles east of the Missouri border on the Mississippi River. More specifically, the plant is located off Illinois Highway 104, in Morgan County, Illinois. Illinois Highway 100 is accessible about 3 miles to the east of the site and Interstate 72 is accessible roughly 9 miles south of the site. Rail access is available onsite within 0.3 miles and barge access is available within 0.1 miles west from the adjacent Illinois River. The plant is located about 1 mile southwest of Meredosia, Illinois, with a population of approximately 1,041 people. The nearest city with a population in excess of 10,000 people is Jacksonville, Illinois, approximately 18 miles to the southeast of the Meredosia Power Plant.

- Plant: Meredosia Power Plant

- Utility: Ameren Illinois

- Coordinates: lat. $39.82328^{\circ} \mathrm{N}$, long. $90.56720^{\circ} \mathrm{W}$

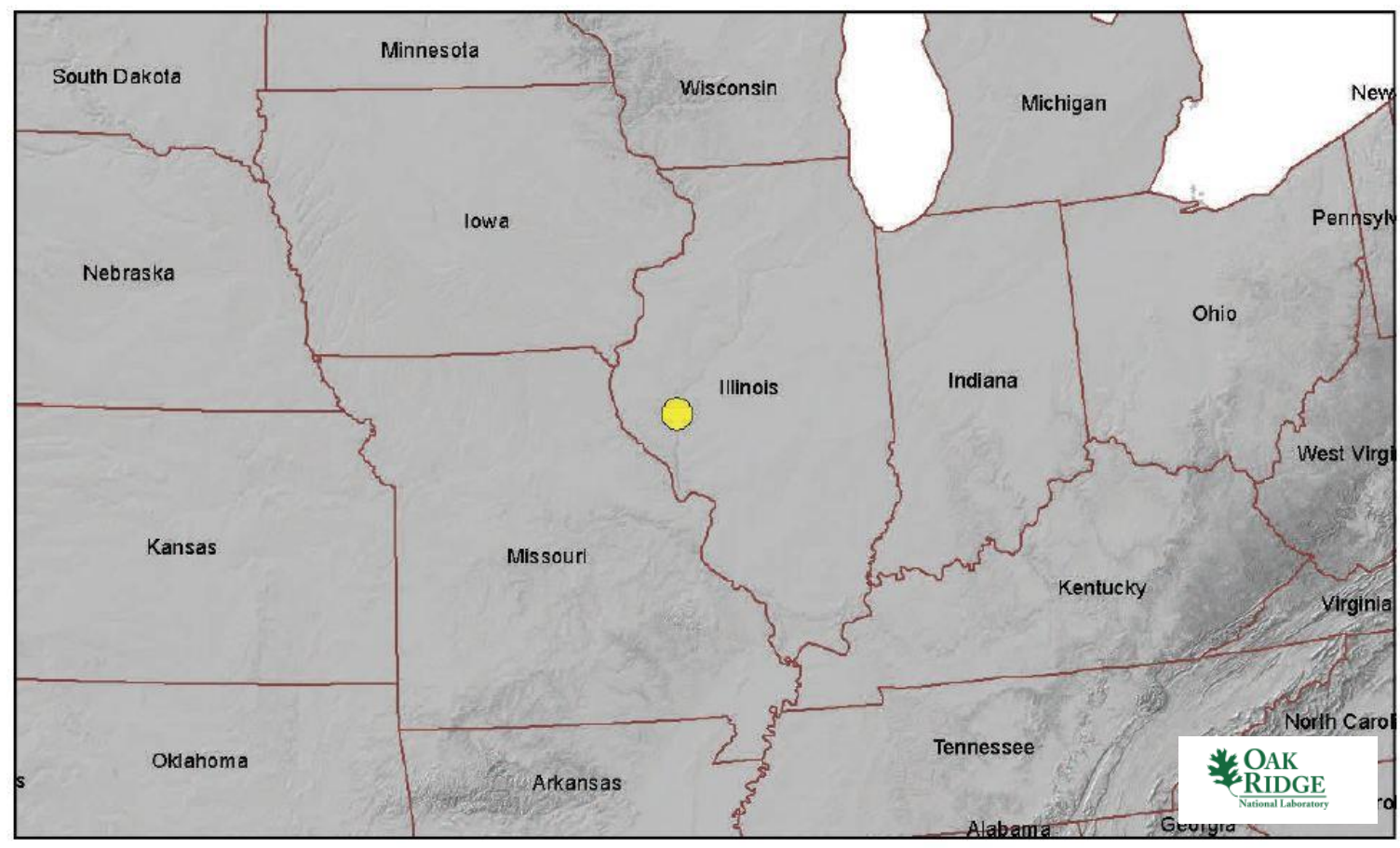

Fig. B.68. Meredosia Power Plant location map.

\section{B.5.2 Site Description and Status}

The Meredosia Power Plant is operated by Ameren Illinois, a subsidiary of the Ameren Corporation. The Meredosia Power Plant consists of three coal-fired units and one oil-fired unit. Unit 1, commissioned in 1948, was rated at 57.5 MW(e). Likewise, Unit 2, commissioned in 1949, was rated at 57.5 MW(e). Both these units were retired in March 2010, and the infrastructure remains intact. Unit 3, commissioned in 1960, is rated at $239 \mathrm{MW}(\mathrm{e})$ and is operated as a base load plant. Unit 3 has been selected to participate in the DOE clean coal power program to capture and store the carbon dioxide emissions. Unit 3 is cooled by once-through cooling from the adjacent Illinois River. The oil-fired $200 \mathrm{MW}(\mathrm{e})$ Unit 4 was commissioned in 1975. Unit 4 is cooled by mechanical draft cooling towers. The current Meredosia Power Plant capacity is $439 \mathrm{MW}(\mathrm{e})$. The addition of clean-coal technology could reduce the net plant capacity. 
The plant is situated on roughly 350 acres on the Illinois River approximately 92 miles northeast of the 1,228 MW(e) Callaway Nuclear Power Plant near Fulton, Missouri. Meredosia Power Plant is approximately 26 miles north of the $22 \mathrm{MW}(\mathrm{e})$ coal-fired Pearl plant and about 40 miles southwest of the 488 MW(e) coal-fired Havana plant. The site is about 58 miles southeast of the 135 MW(e) Keokuk Dam hydroelectric plant.

As noted in Table B.38, the nearest major fault line based on USGS data is about 511 miles southwest in Kansas. The maximum safe-shutdown earthquake for the site is below $0.3 \mathrm{~g}$ peak ground acceleration. More than 500,000 gpm of cooling water makeup is available from the adjacent Illinois River.

The permanent population within 1 mile of the plant is approximately 1,000 people, yielding a population density of approximately 318 people per square mile. The permanent population within 10 miles of the plant is approximately 17,500 people, yielding a population density of about slightly fewer than 56 people per square mile.

According to the US EPA Environmental Justice website, there are 2,533 occupied housing units within 10 miles of the plant site based on 2000 US Census data. Further, more than $80 \%$ of area adults over age 25 have a high school diploma or higher education. The median annual income for the area is between $\$ 25 \mathrm{~K}$ and $\$ 50 \mathrm{~K}$.

Table B.38. Meredosia Power Plant site statistics

\begin{tabular}{|c|c|c|c|}
\hline \multicolumn{2}{|l|}{$\begin{array}{l}\text { Population } \\
\text { Population Within }\end{array}$} & \multicolumn{2}{|l|}{$\begin{array}{l}\text { Utility } \\
\text { Distance to Grid Capacity }\end{array}$} \\
\hline $0.5 \mathrm{mi}$ & $<500$ & $>400 \mathrm{MWe}$ & $\sim 36 \mathrm{mi}$ \\
\hline $1 \mathrm{mi}$ & $\sim 1,000$ & $>800 \mathrm{MWe}$ & $\sim 58 \mathrm{mi}$ \\
\hline $5 \mathrm{mi}$ & $\sim 5,600$ & $>1600 \mathrm{MWe}$ & $\sim 111 \mathrm{mi}$ \\
\hline $10 \mathrm{mi}$ & $\sim 17,500$ & $>3200 \mathrm{MWe}$ & $\sim 148 \mathrm{mi}$ \\
\hline \multicolumn{2}{|c|}{ Nearest City with Population } & \multicolumn{2}{|c|}{ Distance to Cooling Water } \\
\hline$>10,000$ & Jacksonville, IL & $>50,000 \mathrm{gpm}$ & $\sim 0.1 \mathrm{mi}$ (Illinois River) \\
\hline$>50,000$ & O'Fallon, MO & $>100,000 \mathrm{gpm}$ & $\sim 0.1 \mathrm{mi}$ (Illinois River) \\
\hline$>100,000$ & Springfield, IL & $>200,000 \mathrm{gpm}$ & $\sim 0.1 \mathrm{mi}$ (Illinois River) \\
\hline$>500,000$ & Chicago, IL & $>500,000 \mathrm{gpm}$ & $\sim 0.1 \mathrm{mi}$ (Illinois River) \\
\hline \multicolumn{2}{|l|}{ Geotechnical } & \multicolumn{2}{|l|}{ Accessibility } \\
\hline Max Earthquake Acceleration & $<0.3 \mathrm{~g}$ & Distance to Major Roadway & $\sim 2.9 \mathrm{mi}(\mathrm{SR} 100)$ \\
\hline Max Slope & $\sim 4 \%$ & Distance to Water Transport & $\sim 0.1 \mathrm{mi}$ (Illinois River) \\
\hline Nearest Fault Line & $\sim 511 \mathrm{mi}$ (Kansas) & Distance to Rail Transport & $\sim 0.3 \mathrm{mi}(\mathrm{NS})$ \\
\hline Nearest Hazard Site & $\begin{array}{l}\sim 44 \mathrm{mi} \text { (Airport- } \\
\quad \text { Abraham Lincoln Capital) }\end{array}$ & Distance to Airport & $\begin{array}{c}44 \text { mi (Abraham Lincoln } \\
\text { Capital) }\end{array}$ \\
\hline
\end{tabular}




\section{B.5.3 Aerial Imagery}

The aerial imagery in Fig. B.69 indicates the Meredosia Power Plant site. Illinois Highway 104 is visible 0.5 miles of the Meredosia Power Plant site. Some housing units are visible within a 1 mile radius of the plant site.

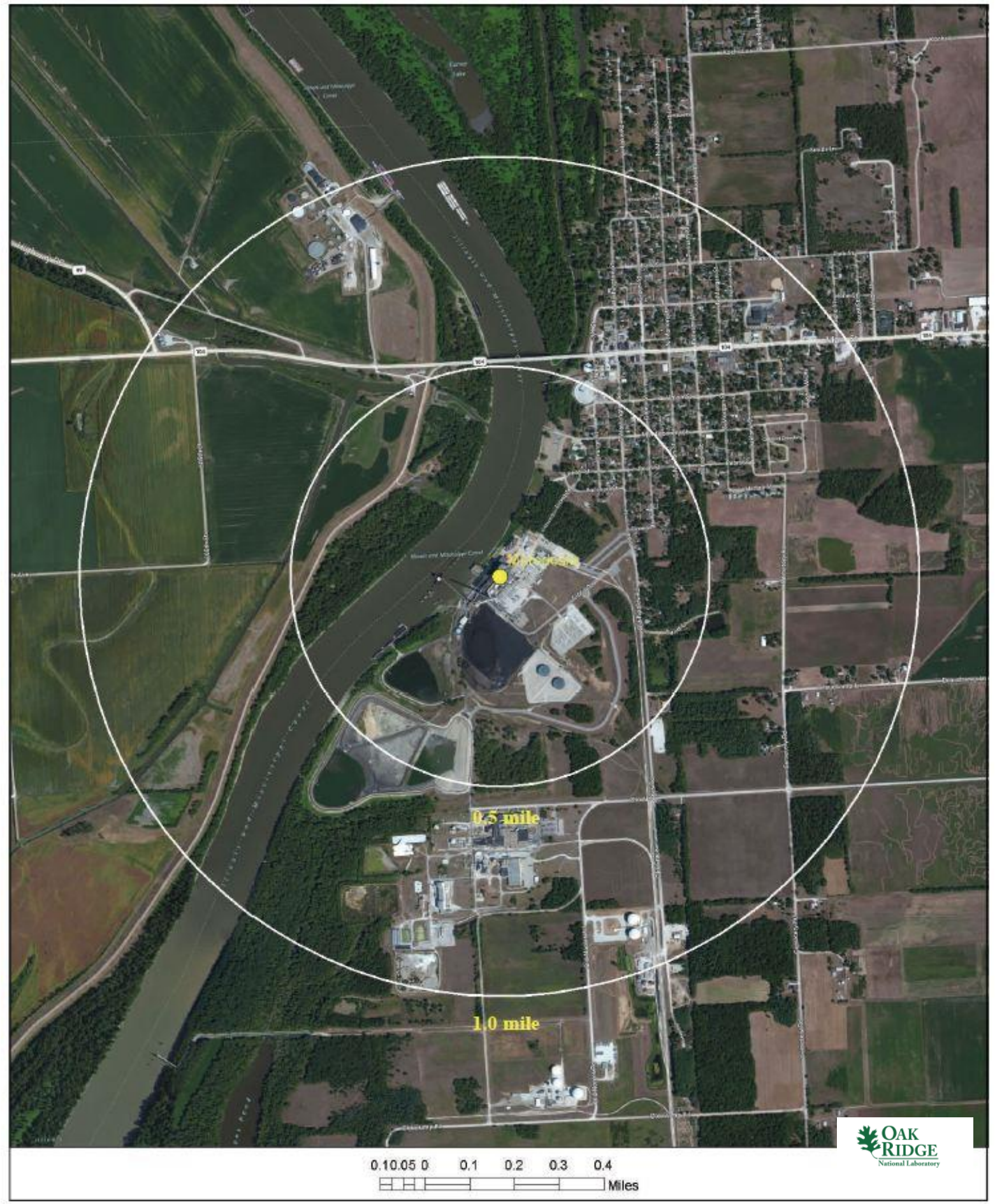

Fig. B.69. Satellite view of Meredosia Power Plant proximity 


\section{B.5.4 Screening Criteria Overview}

Table B.39. Meredosia Power Plant siting criteria summary

\begin{tabular}{|c|c|c|c|c|c|c|c|c|c|c|}
\hline \multicolumn{11}{|c|}{ Screening Criteria Summary Bar } \\
\hline & \multicolumn{2}{|c|}{ No Siting Issue } & & \begin{tabular}{|l|l|}
2 & Partial Siting Issue \\
\end{tabular} & \multicolumn{2}{|c|}{ Partial Siting Issue } & \multicolumn{4}{|c|}{ Full Siting Issue } \\
\hline \begin{tabular}{|l}
0.5 \\
Mile \\
Buffer
\end{tabular} & Population & Slope & SSE & $\begin{array}{l}\text { Stream } \\
\text { flow } \\
(65,000 \\
\mathrm{gpm}) \\
\end{array}$ & $\begin{array}{l}\text { Proximity } \\
\text { to } \\
\text { Hazard } \\
\text { Operations }\end{array}$ & $\begin{array}{l}\text { Proximity } \\
\text { to } \\
\text { Fault } \\
\text { Lines } \\
\end{array}$ & \begin{tabular}{|l|} 
Wetlands \\
Open \\
Water \\
\end{tabular} & \begin{tabular}{|l|}
100 -year \\
Flood- \\
plain
\end{tabular} & $\begin{array}{l}\text { Protected } \\
\text { Lands }\end{array}$ & $\begin{array}{l}\text { Land- } \\
\text { slide } \\
\text { Hazards }\end{array}$ \\
\hline $\begin{array}{l}1.0 \\
\text { Mile } \\
\text { Buffer }\end{array}$ & Population & Slope & SSE & $\begin{array}{l}\text { Stream } \\
\text { flow } \\
(65,000 \\
\text { gpm) }\end{array}$ & $\begin{array}{l}\text { Proximity } \\
\text { to } \\
\text { Hazard } \\
\text { Operations }\end{array}$ & \begin{tabular}{|l} 
Proximity \\
to \\
Fault \\
Lines
\end{tabular} & $\begin{array}{l}\text { Wetlands } \\
\text { Open } \\
\text { Water }\end{array}$ & $\begin{array}{l}\text { 100-year } \\
\text { Flood- } \\
\text { plain }\end{array}$ & $\begin{array}{l}\text { Protected } \\
\text { Lands }\end{array}$ & \begin{tabular}{|l} 
Land- \\
slide \\
Hazards
\end{tabular} \\
\hline & & & & & & & & & \multicolumn{2}{|c|}{ OAK } \\
\hline \multicolumn{11}{|c|}{ Site Selection and Evaluation Criteria Table } \\
\hline \multicolumn{6}{|c|}{ Criteria } & & \multicolumn{4}{|c|}{ Value } \\
\hline \multicolumn{7}{|c|}{ Population Density within 10 miles (people/square mile) } & \multicolumn{4}{|c|}{$>500$} \\
\hline \multicolumn{7}{|l|}{ Slope } & \multicolumn{4}{|c|}{$>18 \%$} \\
\hline \multicolumn{7}{|c|}{ Safe shutdown earthquake (ground acceleration) } & \multicolumn{4}{|c|}{$>0.5$} \\
\hline \multicolumn{7}{|c|}{ Streamflow/cooling water make-up (gpm) } & \multicolumn{4}{|c|}{$<65,000$} \\
\hline \multicolumn{7}{|c|}{ Proximity to hazardous operations - buffer (mile) } & \multicolumn{4}{|c|}{ Depends on hazardous operation ${ }^{1}$} \\
\hline \multicolumn{7}{|c|}{ Proximity to fault lines - buffer (mile) } & \multicolumn{4}{|c|}{ Depends on length of fault } \\
\hline \multicolumn{7}{|c|}{ Wetlands/Open Water } & \multicolumn{4}{|c|}{-} \\
\hline \multicolumn{7}{|c|}{ 100-year floodplain } & \multicolumn{4}{|c|}{-} \\
\hline \multicolumn{7}{|c|}{ Protected lands } & \multicolumn{4}{|c|}{ - } \\
\hline \multicolumn{7}{|c|}{ Landslide hazard (moderate and high) } & \multicolumn{4}{|c|}{ - } \\
\hline
\end{tabular}

${ }^{1}$ Hazardous facilities (airports- 5 miles and oil refineries- -1 mile) 


\section{B.5.5 Composite Map and Individual Siting Issue Maps}

A composite map of SMR siting challenges to the Meredosia Power Plant is shown in Fig. B.70. The physical plant structures are located on land with no siting challenges. Following this map are maps of the individual SMR siting criteria based on selected input values.

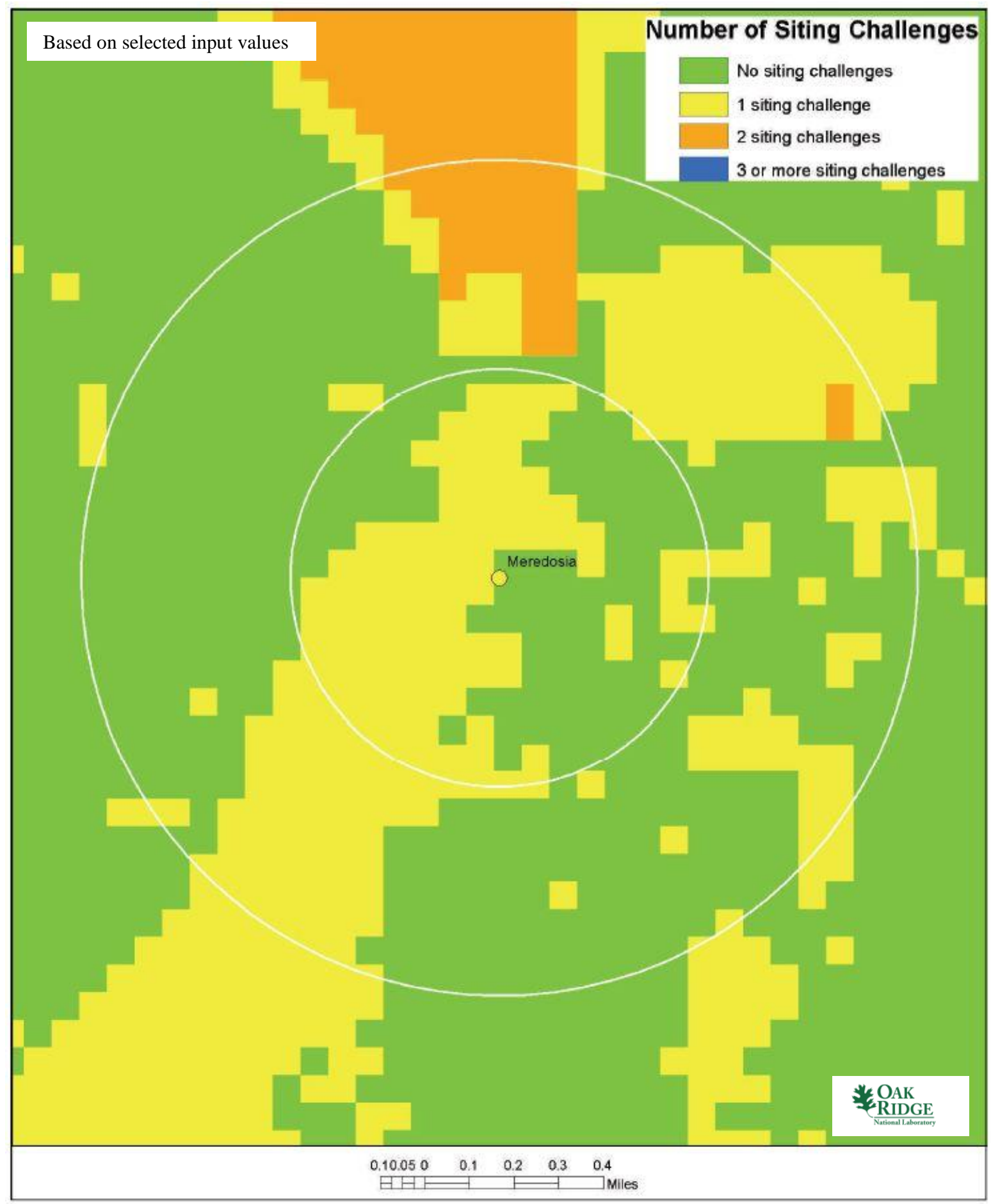

Fig. B.70. Meredosia Power Plant composite map. 

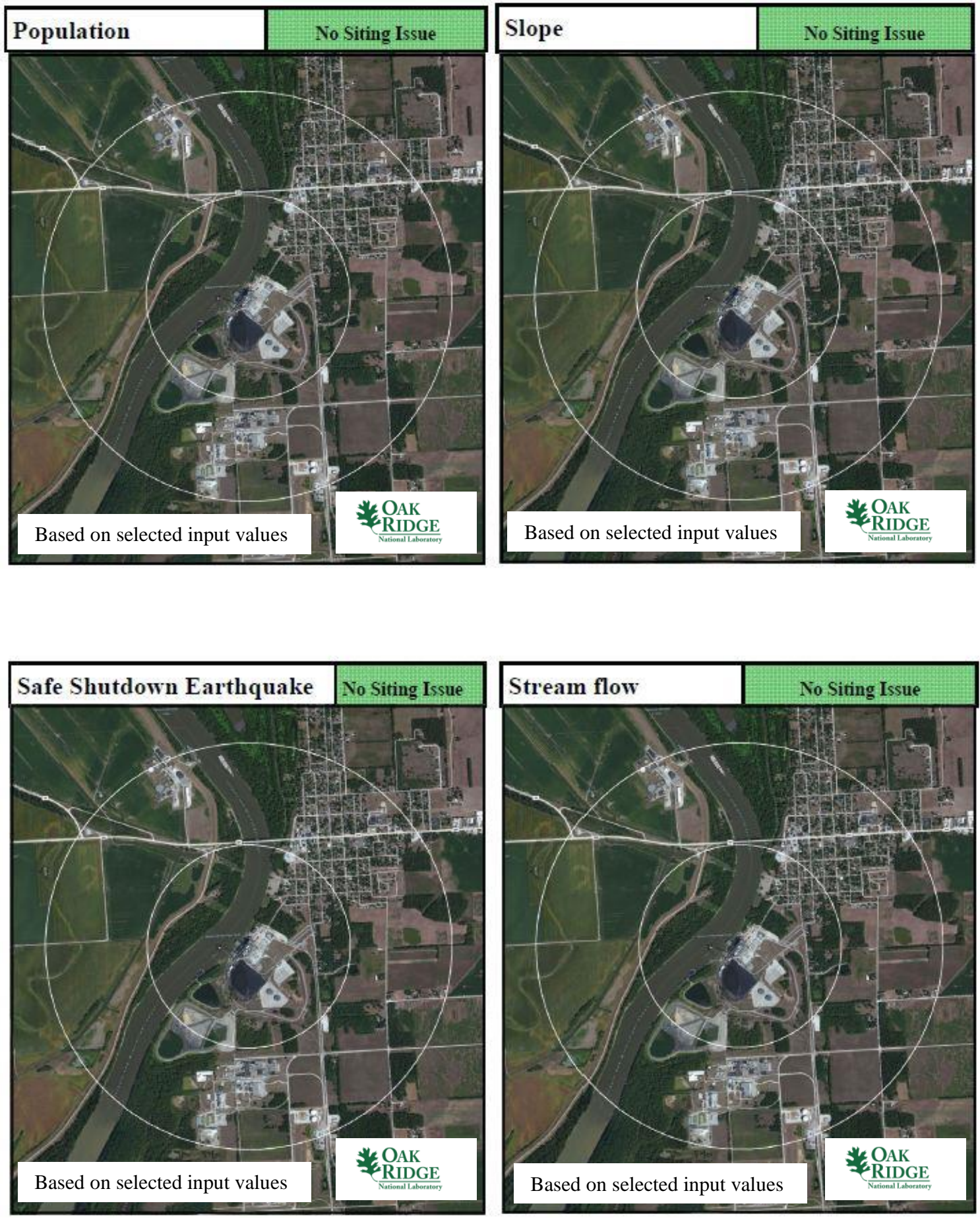

Meredosia Power Plant 

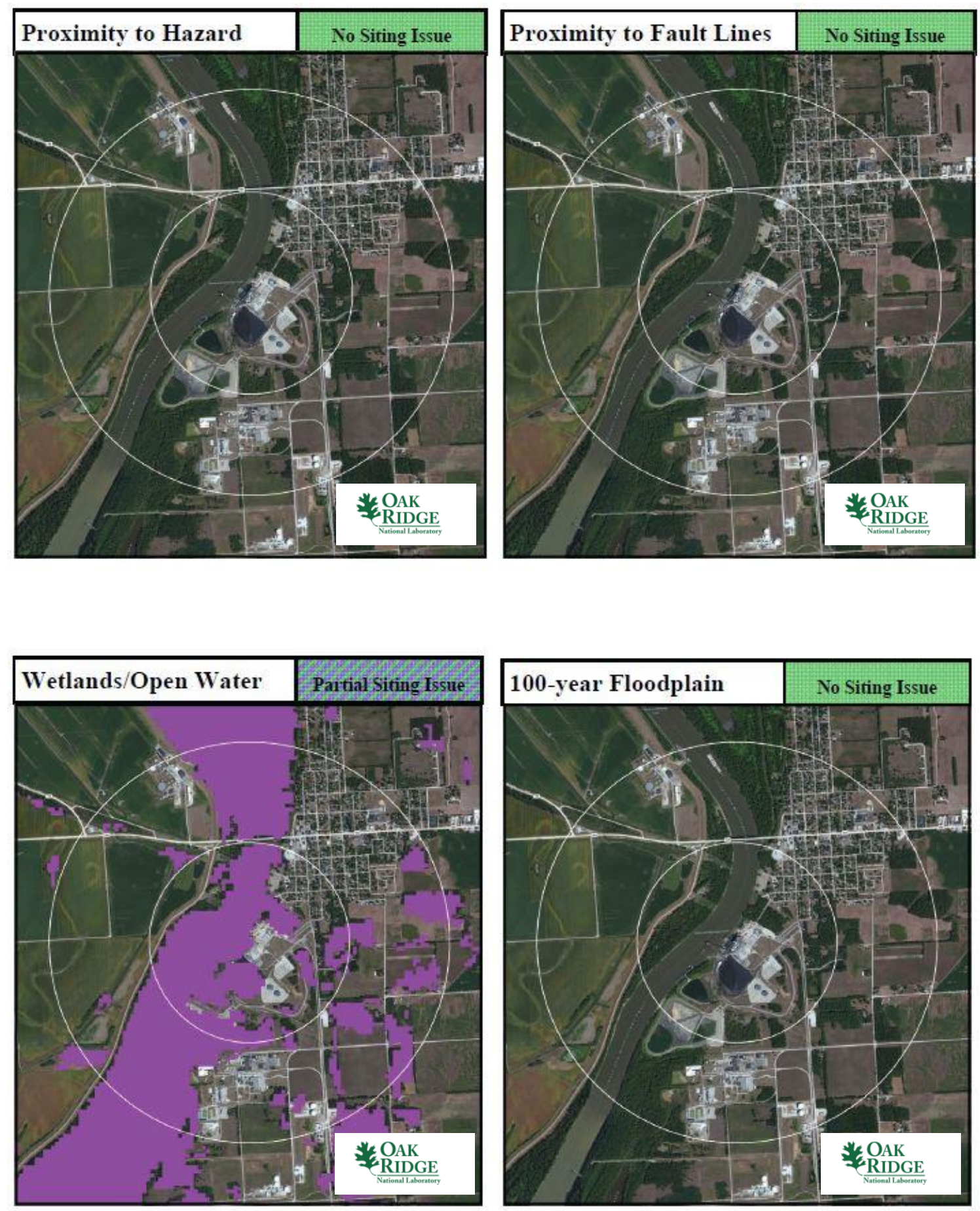

Meredosia Power Plant 

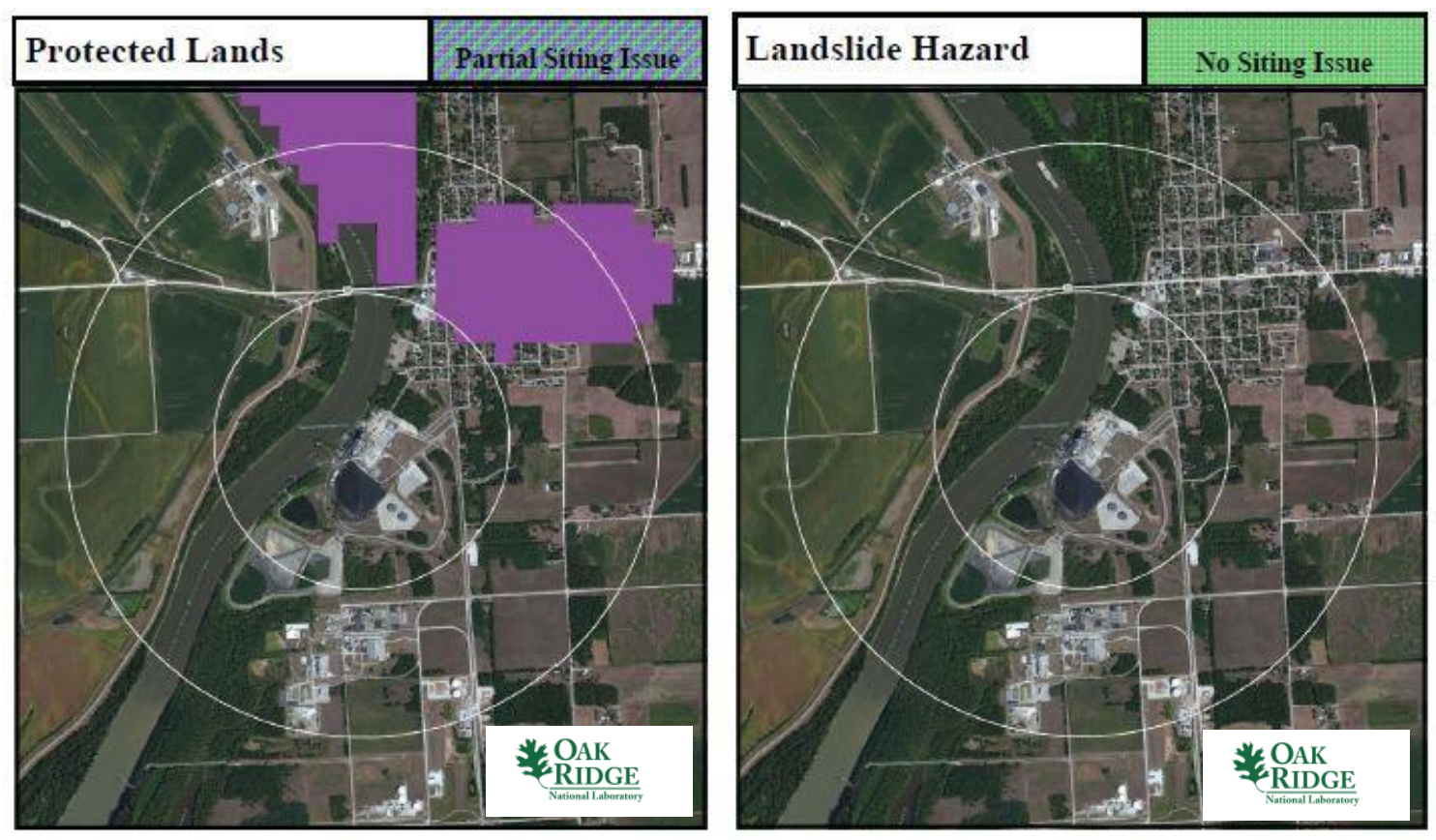

Meredosia Power Plant

\section{B.5.6 Site Evaluation}

Ameren Corporation, the parent company of Ameren Illinois, the owner and operator of the Meredosia Power plant, is the owner and operator via its subsidiary Ameren Missouri of the Callaway Nuclear Power Plant in Missouri. Ameren Missouri also has applied for a COL for a nuclear power plant to be located at the same site. In addition, Ameren Missouri, in association with Westinghouse Electric, submitted an application on May 18, 2012, for an SMR to be located at the same site. Therefore, Ameren has the licensing experience to operate an SMR at this site. The site contains sufficient acreage to support siting an SMR.

From an environmental justice perspective, the community collectively appears to have achieved a reasonable level of education with median income levels typical of much of the United States. Therefore, siting an SMR at this location would not seem to be disenfranchising a less-educated or poverty-stricken community. Furthermore, the education level of the Meredosia Power Plant community would seem to support the higher-technology job opportunities provided by an SMR.

As shown in Sects. B.0 and B.0, the Meredosia Power Plant site has partial SMR site screening issues with wetlands/open waters and protected lands. The wetlands/open waters issue reflects the adjacent Illinois River. Likewise, the protected land areas are primarily local parkland located to the north of the site. The remaining SMR site screening criteria are met site-wide for the values established in the updated SMR siting report.1

Illinois Highway 104 runs approximately 0.5 miles north of the site. This could be a factor in the ability of a nuclear licensee to control land access to areas very near the plant location. In addition, there is some housing within 1 mile of the site. This could be a contentious issue should Ameren decide to submit a COL application for an SMR at this site to meet any growing need for electrical capacity at this grid location.

When future load demands indicate the need for expanded generation capacity in this region, the utility would need to work closely with local leaders and civic groups to make the case for siting an SMR at this location. The site exceeds current NRC RG 4.7 recommendations for population density without 
additional consideration for relaxed SMR population siting requirements based on reduced source term. The Meredosia Power Plant site meets multiple conventional standards in the near term for consideration of siting an SMR at the coal station location, but there may be longer-term issues that could potentially preclude this site from further SMR siting consideration. The longer term considerations include population growth from the nearby town of Meredosia. 
B-52 


\section{B.6 Sutherland Generating Station}

\section{B.6.1 Location Detail}

As shown in Fig. B.71, the Sutherland Generating Station is located in the middle of Iowa, off Main Street Road in Marshall County. Iowa State Highway 14 is accessible approximately 2.3 miles to the west and Interstate 80 is accessible 25 miles to the south. Rail access is available within 0.6 miles and barge access is available via the Mississippi River about 97 miles to the east. The plant is located about 2.5 miles east of Marshalltown, Iowa, with a population of approximately 27,590.

- Plant: Sutherland Generating Station

- Utility: Interstate Power and Light Company

- Coordinates: lat. $42.04708^{\circ} \mathrm{N}$, long. $92.85973^{\circ} \mathrm{W}$

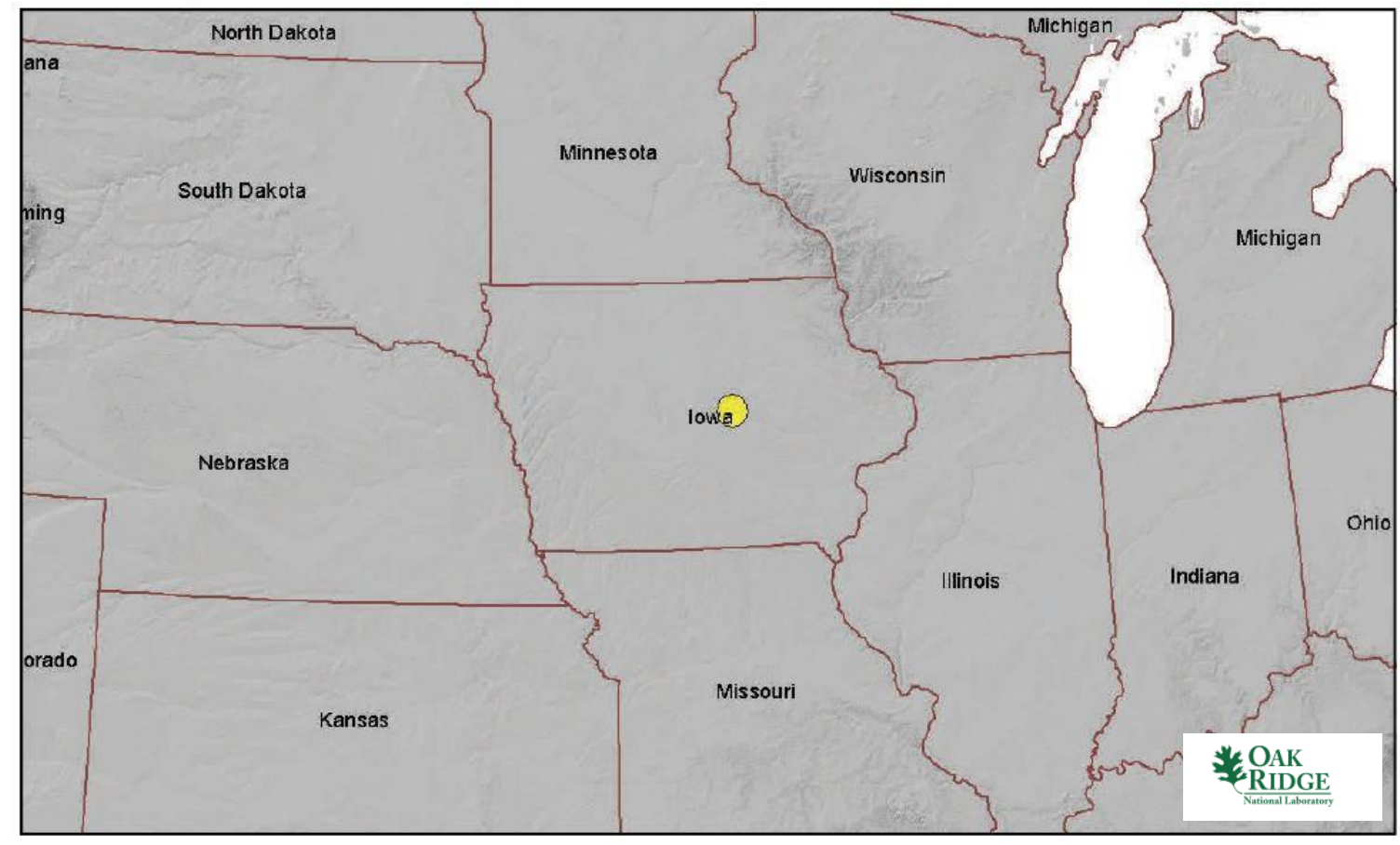

Fig. B.71. Sutherland Generating Station location map.

\section{B.6.2 Site Description and Status}

The Sutherland Generating Station is owned and operated by the Interstate Power and Light Company, a subsidiary of Alliant Energy Corporation. The 157 MW(e) Sutherland Generating Station consists of three coal-fired units. The plant is cooled by mechanical draft cooling towers and an onsite cooling pond. Units 1 and Unit 2 came online in 1955 and are each rated at 37.5 MW(e). Unit 3, commissioned in 1961, is rated at $82 \mathrm{MW}(\mathrm{e})$. The coal-fired units were converted to natural gas fuel in 2010 and are all scheduled to be permanently retired in December 2014. Alliant Energy has announced its intention to build a 600 MW(e) gas-fired plant in the vicinity of Marshalltown to be completed in 2017.

The plant is located on approximately 1,375 acres adjacent to the Iowa River approximately 55 miles west of the $615 \mathrm{MW}(\mathrm{e})$ Duane Arnold nuclear facility. The retired Maynard Power Station is 40 miles northeast of the Sutherland Generating Station. The coal-fired 98 MW(e) Ames Municipal Power Plant is 39 miles to the west. In addition, the $300 \mathrm{MW}(\mathrm{e})$ Story wind farm is 20 miles west of the Sutherland Generating Station and the $200 \mathrm{MW}$ (e) Century wind farm is 50 miles northwest of the site. 
As noted in Table B.40, the nearest major fault line based on USGS data is about 470 miles southwest in Kansas. The maximum safe-shutdown earthquake for the site is below $0.3 \mathrm{~g}$ peak ground acceleration.

More than 500,000 gpm of cooling water makeup is available from the Iowa River about 0.58 miles north of the plant site.

The permanent population within 1 mile of the plant is approximately 1,500 people, yielding a population density of a little more than 477 people per square mile. The permanent population within 10 miles of the plant is approximately 101,000 people, yielding a population density of about 321 people per square mile.

According to the US EPA Environmental Justice website, there are 13,046 occupied housing units within 10 miles of the plant site based on 2000 US Census data. Further, approximately $80 \%$ of area adults over age 25 have a high school diploma or higher education. The median annual income for the area is between $\$ 25 \mathrm{~K}$ and $\$ 50 \mathrm{~K}$.

Table B.40. Sutherland Generating Station site statistics

\begin{tabular}{|l|l|l|l|}
\hline $\begin{array}{l}\text { Population } \\
\text { Population Within }\end{array}$ & \multicolumn{2}{l|}{$\begin{array}{l}\text { Utility } \\
\text { Distance to Grid Capacity }\end{array}$} \\
\hline $0.5 \mathrm{mi}$ & $<500$ & $>400 \mathrm{MWe}$ & $\sim 33 \mathrm{mi}$ \\
\hline $1 \mathrm{mi}$ & $\sim 1,500$ & $>800 \mathrm{MWe}$ & $\sim 26 \mathrm{mi}$ \\
\hline $5 \mathrm{mi}$ & $\sim 65,000$ & $>1600 \mathrm{MWe}$ & $\sim 226 \mathrm{mi}$ \\
\hline $10 \mathrm{mi}$ & $\sim 101,000$ & $>3200 \mathrm{MWe}$ & $\sim 212 \mathrm{mi}$ \\
\hline Nearest City with Population & Distance to Cooling Water \\
\hline \multicolumn{2}{|l|}{} & & \\
\hline$>10,000$ & Marshalltown, IA & $>50,000 \mathrm{gpm}$ & $\sim 15 \mathrm{mi}$ (Iowa River) \\
\hline$>50,000$ & Ames, IA & $>100,000 \mathrm{gpm}$ & $\sim 15 \mathrm{mi}$ (Iowa River) \\
\hline$>100,000$ & Des Moines, IA & $>200,000 \mathrm{gpm}$ & $\sim 15 \mathrm{mi}$ (Iowa River) \\
\hline$>500,000$ & Milwaukee, WI & $>500,000$ gpm & $\sim 15 \mathrm{mi}$ (Iowa River) \\
\hline Geotechnical & \multicolumn{2}{|l|}{ Accessibility } \\
\hline Max Earthquake Acceleration & $<0.3 \mathrm{~g}$ & Distance to Major Roadway & $\sim 2.3 \mathrm{mi}$ (SR 14) \\
\hline Max Slope & $\sim 12 \%$ & Distance to Water Transport & $\sim 97 \mathrm{mi}$ (Mississippi River) \\
\hline Nearest Fault Line & $\sim 470$ mi (Kansas) & Distance to Rail Transport & $\sim 0.6 \mathrm{mi}$ (UP) \\
\hline Nearest Hazard Site & $\sim 51$ mi (Airport- & Distance to Airport & $\sim 51$ mi (Des Moines Int'l) \\
\hline
\end{tabular}




\section{B.6.3 Aerial Imagery}

The aerial imagery in Fig. B.72 indicates that the Sutherland Generating Station plant site is relatively isolated.

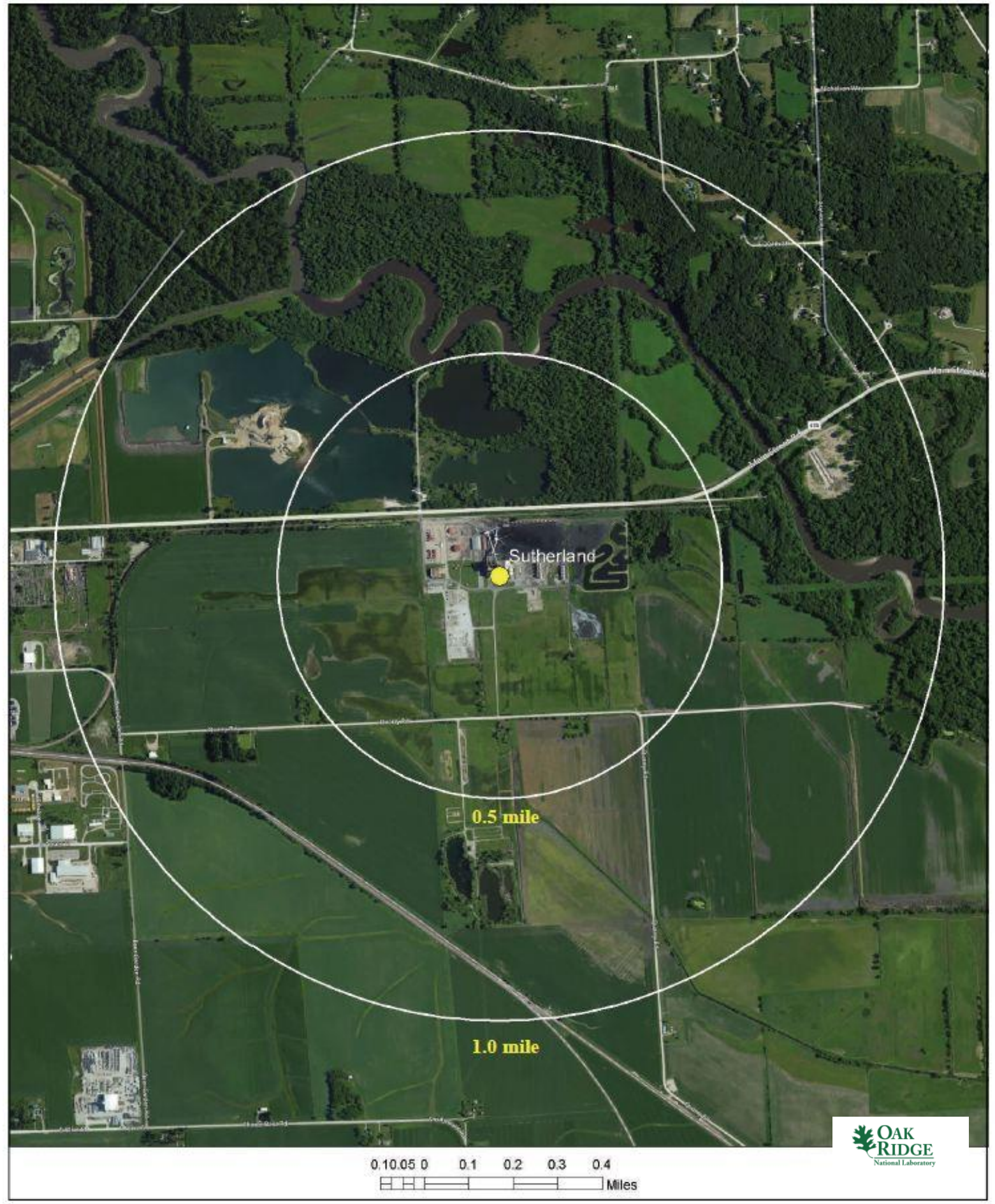

Fig. B.72. Satellite view of Sutherland Generating Station proximity. 


\section{B.6.4 Screening Criteria Overview}

Table B.41. Sutherland Generating Station siting criteria summary

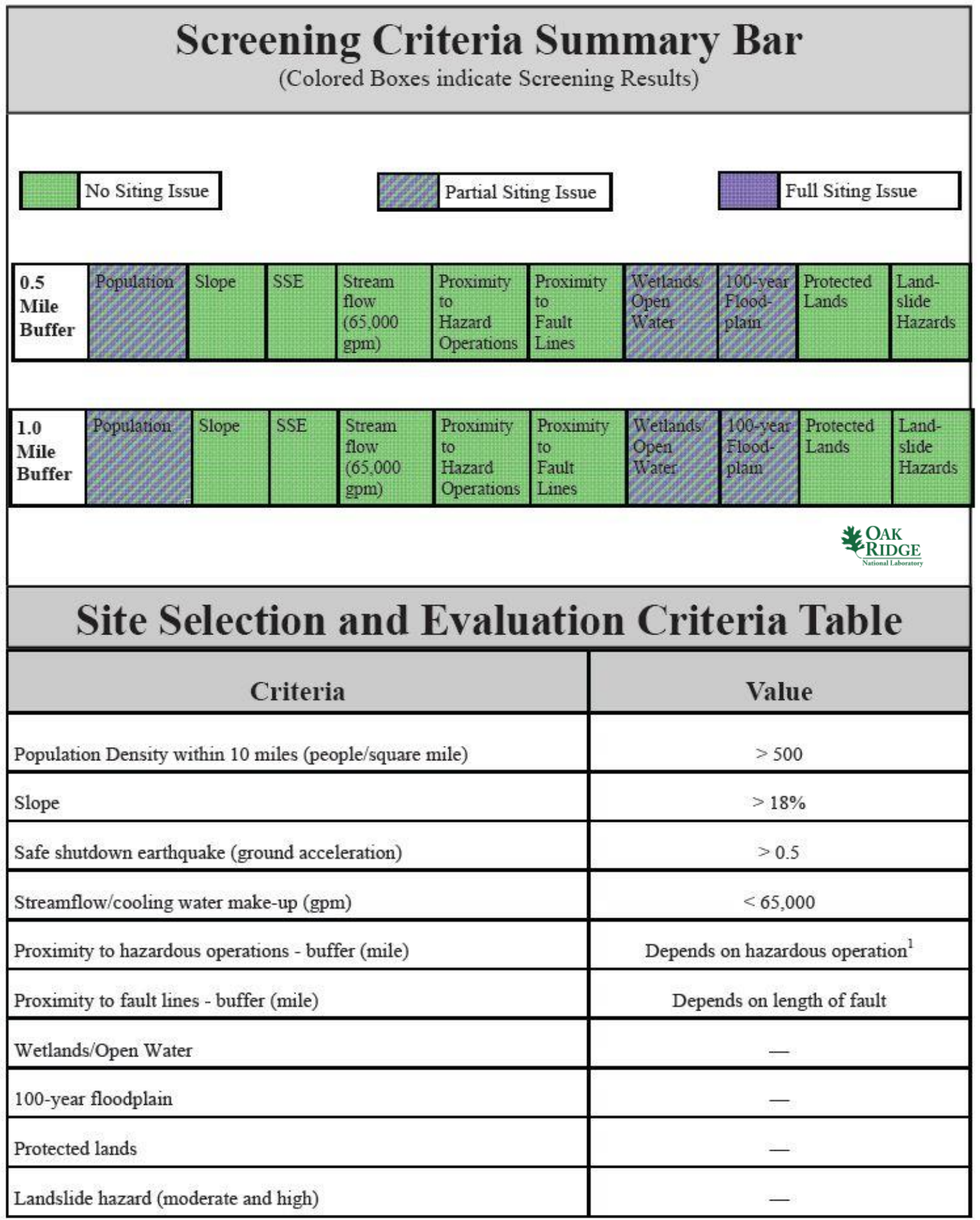

${ }^{1}$ Hazardous facilities (airports- 5 miles and oil refineries- 1 mile) 


\section{B.6.5 Composite Map and Individual Siting Issue Maps}

A composite map of SMR siting challenges to the Sutherland Generating Station is shown in Fig. B.73. The physical plant structures are located on land with no siting challenges. Following this map are maps of the individual SMR siting criteria based on selected input values.

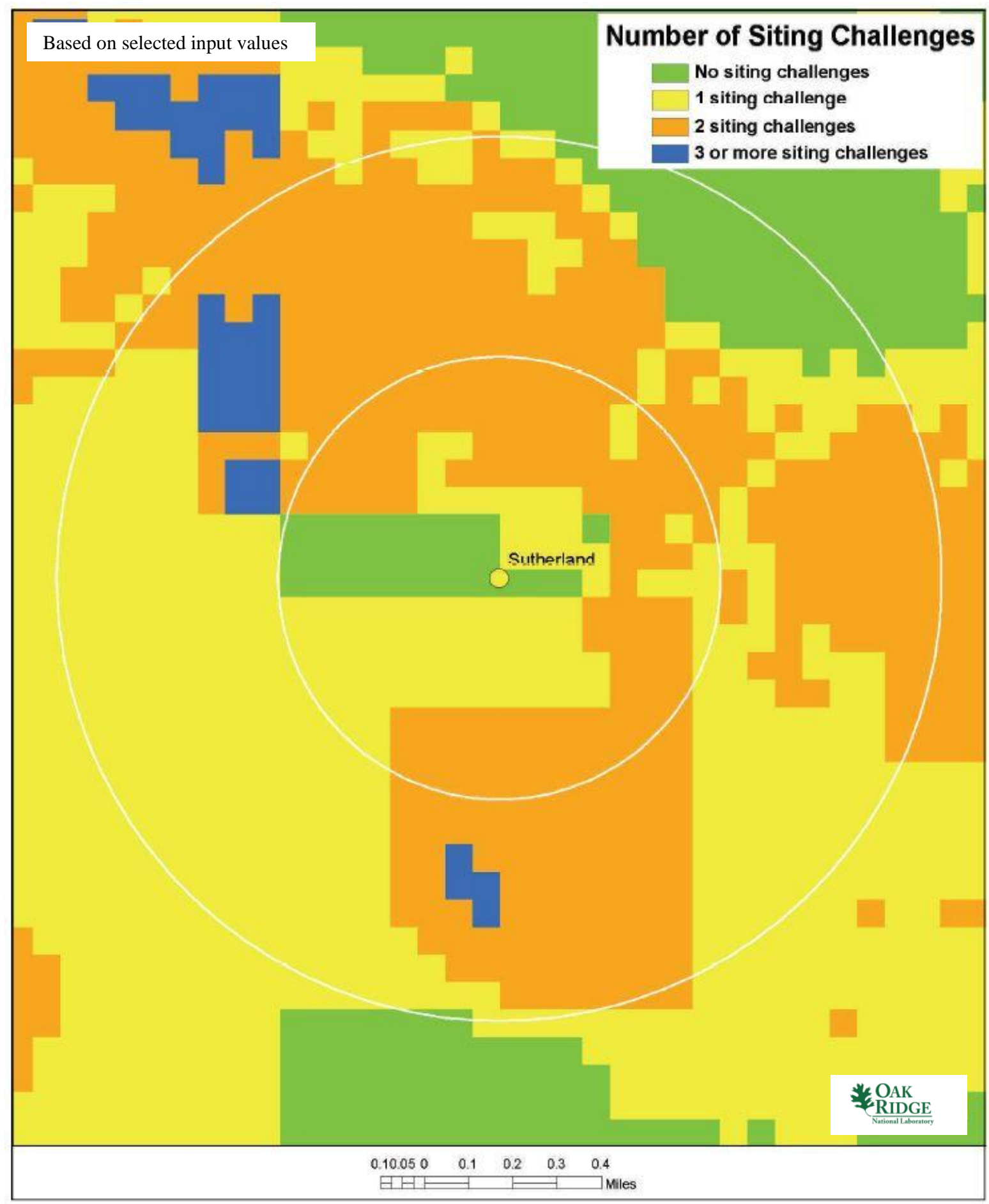

Fig. B.73. Sutherland Generating Station composite map. 

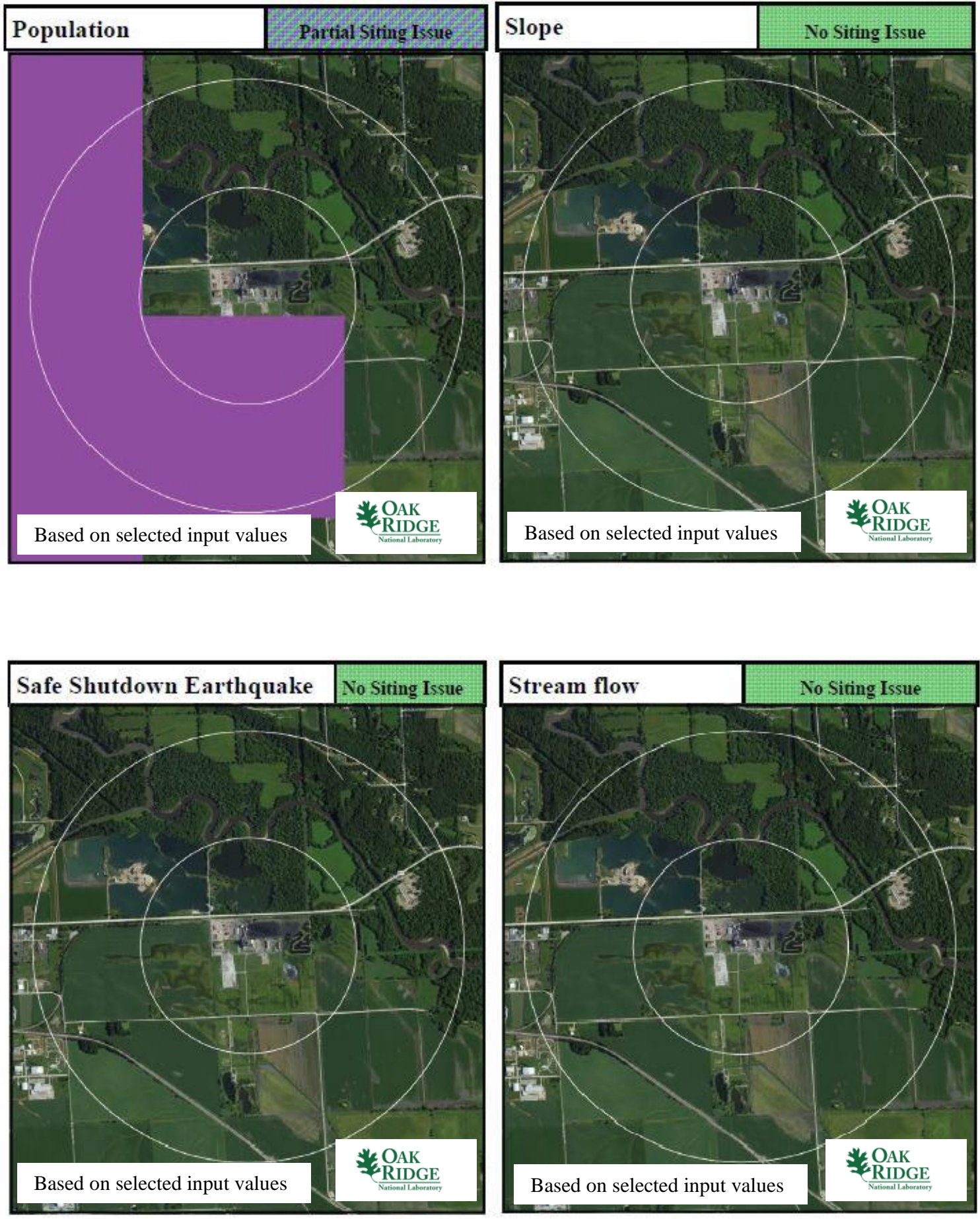

Sutherland Generating Station 

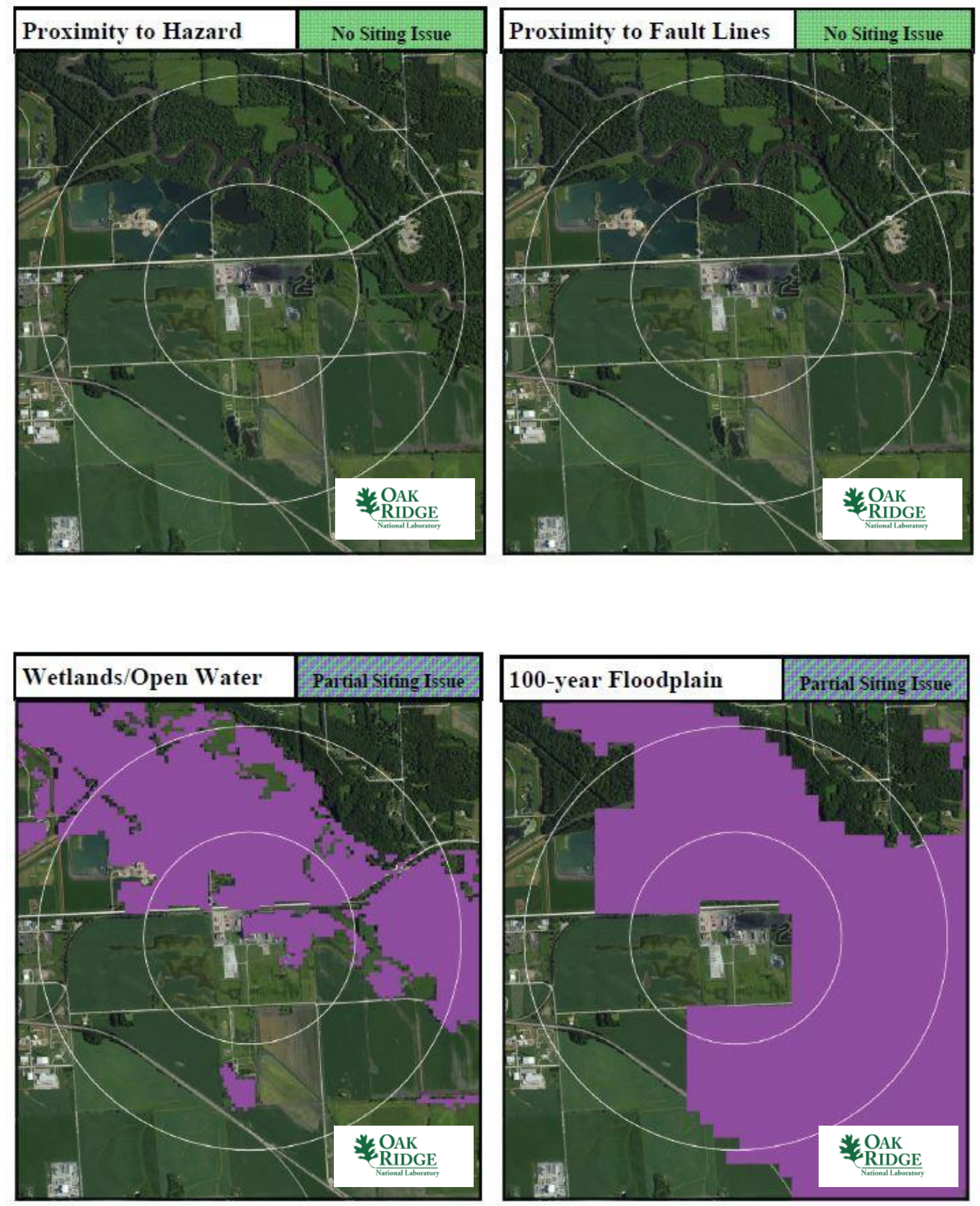

Sutherland Generating Station 

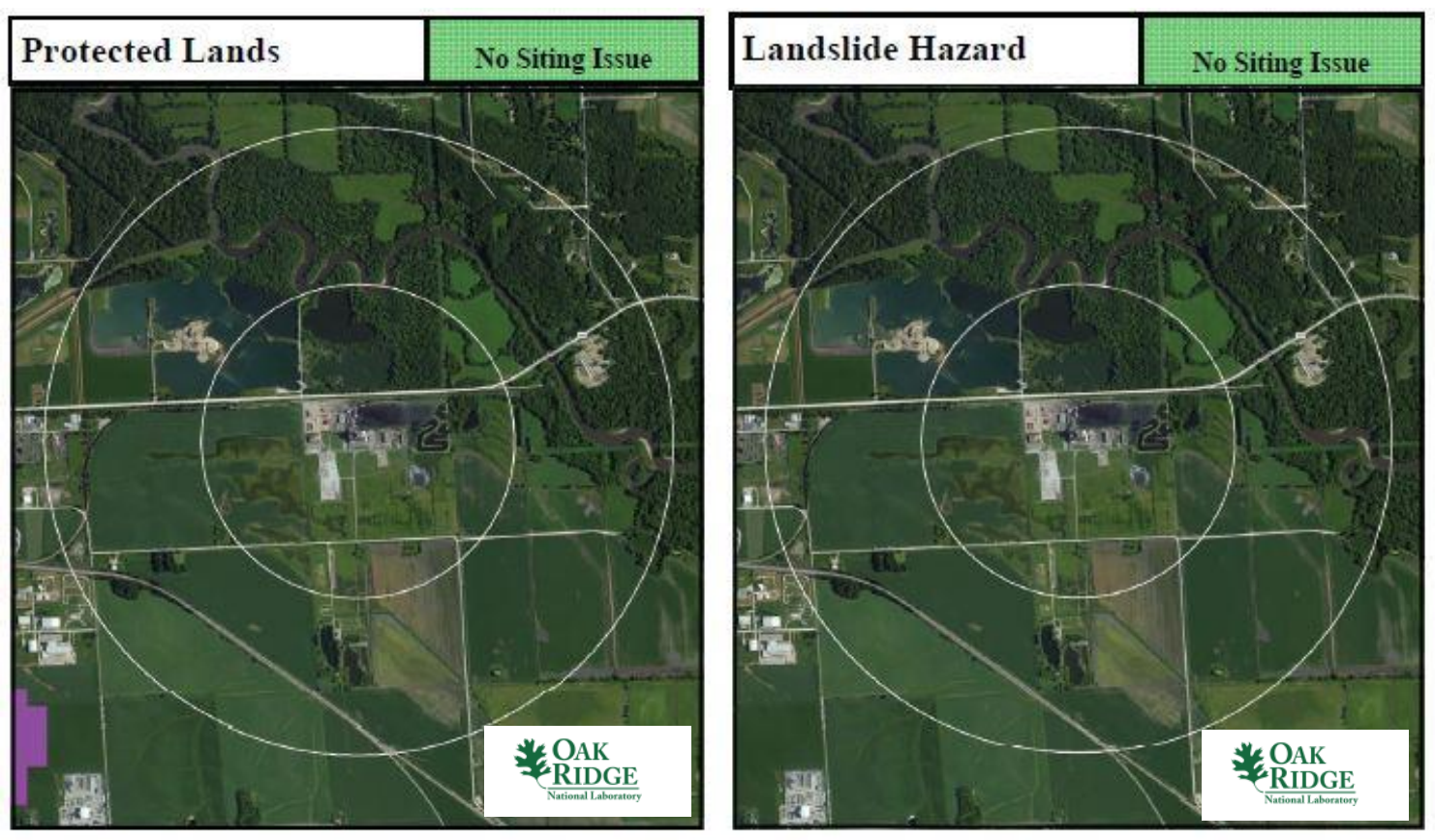

Sutherland Generating Station

\section{B.6.6 Site Evaluation}

Interstate Power and Light Company does not operate or own a share of any nuclear power plant in the United States. However, its parent company, Alliant Energy Corporation, announced in August 2012 that it was entering into a Purchase Power Agreement with NextEra Energy Duane Arnold, LLC, which owns and operates the Duane Arnold Energy Center nuclear power plant in Iowa. Therefore, NextEra Energy may be able to mentor Alliant Energy in the licensing process to operate an SMR at this site. The site contains sufficient acreage to support siting an SMR.

From an environmental justice perspective, the community collectively appears to have achieved a reasonable level of education with median income levels typical of much of the United States. Therefore, siting an SMR at this location would not seem to be disenfranchising a less-educated or poverty-stricken community. Furthermore, the education level of the Sutherland Generating Station community would seem to support the higher-technology job opportunities provided by an SMR.

As shown in Sects. B.0 and B.0, the Sutherland Generating Station site has partial SMR site screening issues with wetlands/open waters, 100-year floodplain, and population. The wetlands/open waters and 100-year floodplain issues reflect the adjacent Iowa River, but do not affect the immediate plant site. The population site screening issue affecting areas west of the plant site reflect the nearby town of Marshalltown, Iowa. The plant site is currently outside the area defined by the SMR SSEC population criteria. The remaining SMR site screening criteria are met site-wide for the values established in the updated SMR siting report.1

The site meets current NRC RG 4.7 recommendations for population density without additional consideration for relaxed SMR population siting requirements based on reduced source term. The Sutherland Generating Station site meets multiple conventional standards in the near term for consideration of siting an SMR at the coal station location, but there may be longer-term issues that could potentially preclude this site from further SMR siting consideration. The longer-term considerations include population growth from the nearby town of Marshalltown, Iowa. 


\section{APPENDIX C—COAL PLANT EVALUATIONS OF THIRD-TIER SITES}

The site meets conventional standards pending verification of parameters or an engineered solution to an issue. For example, a coal station site meets all SMR SSEC with the exception of having a moderate to high potential for landslide hazard. The existing coal plant has been at that location without a landslide incident since it was commissioned on some date before 1980. In this case, since the potential for landslide hazards is a wide-area probabilistic calculation, additional site-specific geological survey could validate the acceptance of the site for further SMR siting consideration.

Coal stations evaluated in this category are

- Armstrong Power Station

- Cameo Station

- Cooper Power Station

- Genoa Station

- Lansing Smith Power Station

- Powerton Generating Station

- Sibley Generating Station

- Willow Island Power Station 



\section{APPENDIX C—COAL PLANT EVALUATIONS OF THIRD-TIER SITES}

\section{C.1 ARMSTRONG POWER STATION}

\section{C.1.1 Location Detail}

As shown in Fig. C.74, the Armstrong Power Station is located in western Pennsylvania, off Reesedale Road in Armstrong County, Pennsylvania. State Highway 28 is available approximately 4 miles to the south, and Interstate 80 is accessible 17 miles to the north. Rail access is available within 0.1 miles and barge access is available within 0.2 miles. The closest town is Templeton, Pennsylvania, with a population of approximately 325 people. Templeton is approximately 1 mile south of the Armstrong Power Station. The nearest city with a population in excess of 10,000 people is Butler, Pennsylvania, approximately 23 miles to the southwest of the Armstrong Power Station.

- Plant: Armstrong Power Station

- Utility: FirstEnergy Corporation

- Coordinates: lat. $40.92937^{\circ} \mathrm{N}$, long. $79.46705^{\circ} \mathrm{W}$

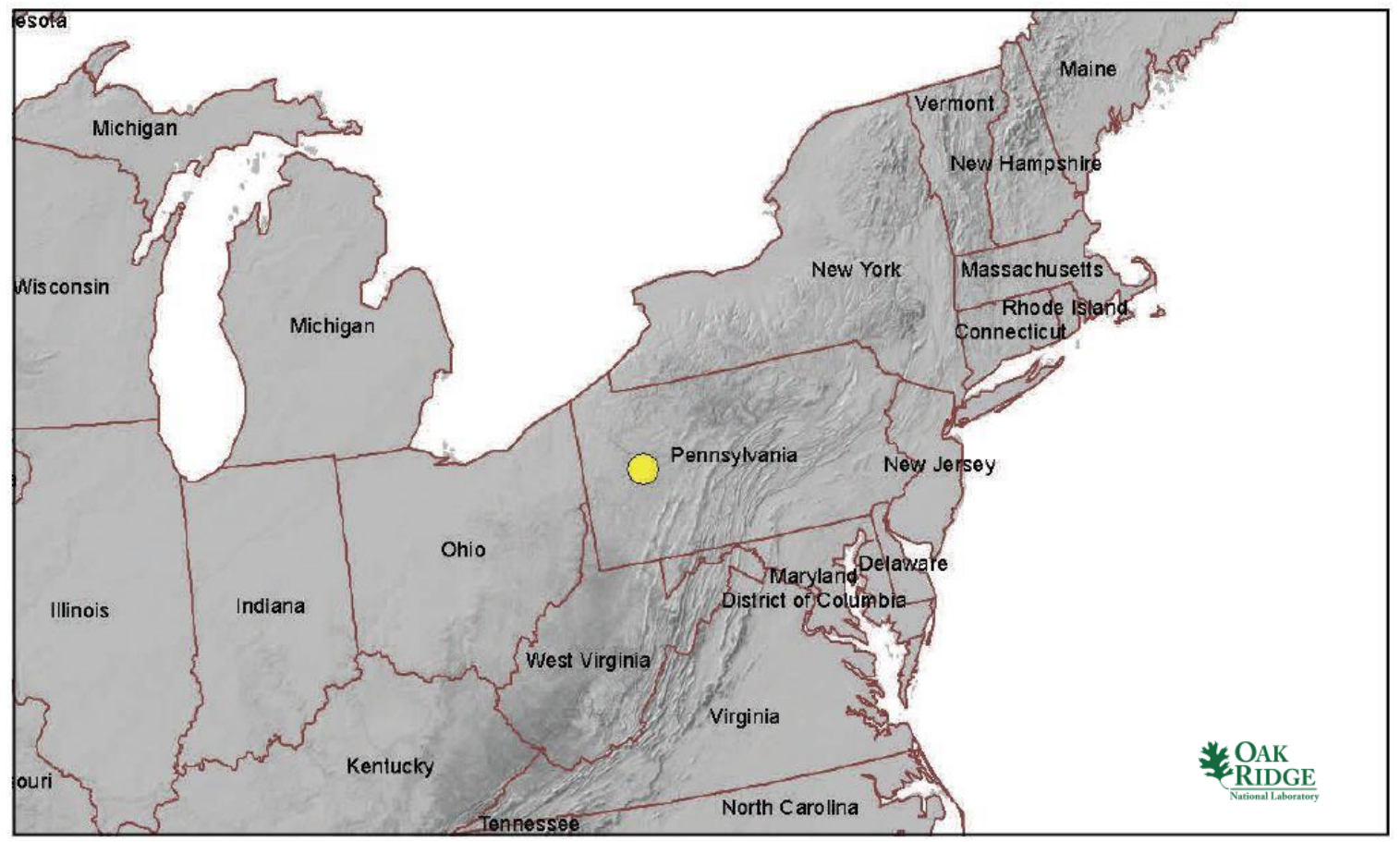

Fig. C.74. Armstrong Power Station location map.

\section{C.1.2 Site Description and Status}

The Armstrong Power Station is a two-unit coal station with both units recently shut down. The Armstrong Power Station is located on a 210 acre site adjacent to the Allegheny River. Both fossil units were rated at $163 \mathrm{MW}(\mathrm{e})$ for a total site capacity of $326 \mathrm{MW}(\mathrm{e})$. The units are operated by Allegheny Energy Supply Company, a subsidiary of Allegheny Energy. In 2005, Allegheny Energy derived over $80 \%$ of its power output from coal. FirstEnergy Corporation acquired Allegheny Power in 2011. The units 
were commissioned in 1958 and 1959. In 2012, FirstEnergy announced a plan to retire six coal plants, ${ }^{18}$ including the Armstrong Power Station, in the near future, citing the recently finalized EPA MATS. The units were shut down in September 2012. The two units had been used as peaking units. Cooling water was supplied by once-through cooling from the adjacent river.

The plant is located on roughly 60 acres on the Allegheny River approximately 55 miles northeast of the 1,890 MW(e) Beaver Valley nuclear facility. The Armstrong Power Station is 20 miles north of the coalfired 1,872 MW(e) Keystone Generating Station. The site is 10 miles west of the 6 MW(e) Mahoning Creek Dam hydroelectric facility.

As noted in Table C.42, the nearest major fault line based on USGS data is 1,047 miles west in Oklahoma. The maximum safe-shutdown earthquake for the site is below $0.3 \mathrm{~g}$ peak ground acceleration. More than 500,000 gpm of cooling water makeup is available from the adjacent Allegheny River.

The permanent population within 1 mile of the plant is fewer than 500 people, yielding a population density of fewer than 160 people per square mile. The permanent population within 10 miles of the plant is approximately 67,000 people, yielding a population density of approximately 215 people per square mile. According to the US EPA Environmental Justice website, there are 11,770 occupied housing units within 10 miles of the plant site based on 2000 US Census data. Further, over $75 \%$ of area adults over age 25 have a high school diploma or higher education. The median annual income for the area is between $\$ 25 \mathrm{~K}$ and $\$ 50 \mathrm{~K}$, although just over $20 \%$ of the area population has an annual income of less than $\$ 15 \mathrm{~K}$.

Table C.42. Armstrong Power Station site statistics

\begin{tabular}{|l|l|l|l|}
\hline $\begin{array}{l}\text { Population } \\
\text { Population Within }\end{array}$ & \multicolumn{2}{l|}{$\begin{array}{l}\text { Utility } \\
\text { Distance to Grid Capacity }\end{array}$} \\
\hline $0.5 \mathrm{mi}$ & $<500$ & $>400 \mathrm{MWe}$ & $\sim 1 \mathrm{mi}$ \\
\hline $1 \mathrm{mi}$ & $<500$ & $>800 \mathrm{MWe}$ & $\sim 19 \mathrm{mi}$ \\
\hline $5 \mathrm{mi}$ & $\sim 9,000$ & $>1600 \mathrm{MWe}$ & $\sim 14 \mathrm{mi}$ \\
\hline $10 \mathrm{mi}$ & $\sim 67,000$ & $>3200 \mathrm{MWe}$ & $\sim 98 \mathrm{mi}$ \\
\hline Nearest City with Population & Distance to Cooling Water \\
\hline \multicolumn{2}{|l|}{} & \multicolumn{2}{l|}{} \\
\hline$>10,000$ & Butler, PA & $>50,000$ gpm & $\sim 0.2 \mathrm{mi}$ (Allegheny River) \\
\hline$>50,000$ & Youngstown, OH & $>100,000$ gpm & $\sim 0.2 \mathrm{mi}$ (Allegheny River) \\
\hline$>100,000$ & Pittsburgh, PA & $>200,000$ gpm & $\sim 0.2 \mathrm{mi}$ (Allegheny River) \\
\hline$>500,000$ & Washington, DC & $>500,000$ gpm & $\sim 0.2 \mathrm{mi}$ (Allegheny River) \\
\hline Geotechnical & \multicolumn{3}{|l|}{ Accessibility } \\
\hline Max Earthquake Acceleration & $<0.3 \mathrm{~g}$ & Distance to Major Roadway & $\sim 4.3 \mathrm{mi}$ (SR 28) \\
\hline Max Slope & $\sim 66 \%$ & Distance to Water Transport & $\sim 0.2 \mathrm{mi}$ (Allegheny River) \\
\hline Nearest Fault Line & $\sim 1,047$ mi (Oklahoma) & Distance to Rail Transport & $\sim 0.1 \mathrm{mi}$ (BPRR) \\
\hline Nearest Hazard Site & $\sim 47$ mi (Airport- & Distance to Airport & $\sim 47$ mi (Pittsburgh Int'l) \\
\hline
\end{tabular}

\footnotetext{
${ }^{18}$ FirstEnergy News Release, "FirstEnergy, Citing Impact of Environmental Regulations, Will Retire Six Coal-Fired Power Plants," January 26, 2012.
} 


\section{C.1.3 Aerial Imagery}

The aerial imagery in Fig. C.75 indicates that a portion of the small town of Templeton is between 0.5 miles and 1 mile from the plant site. Otherwise, the immediate area is wooded and hilly.

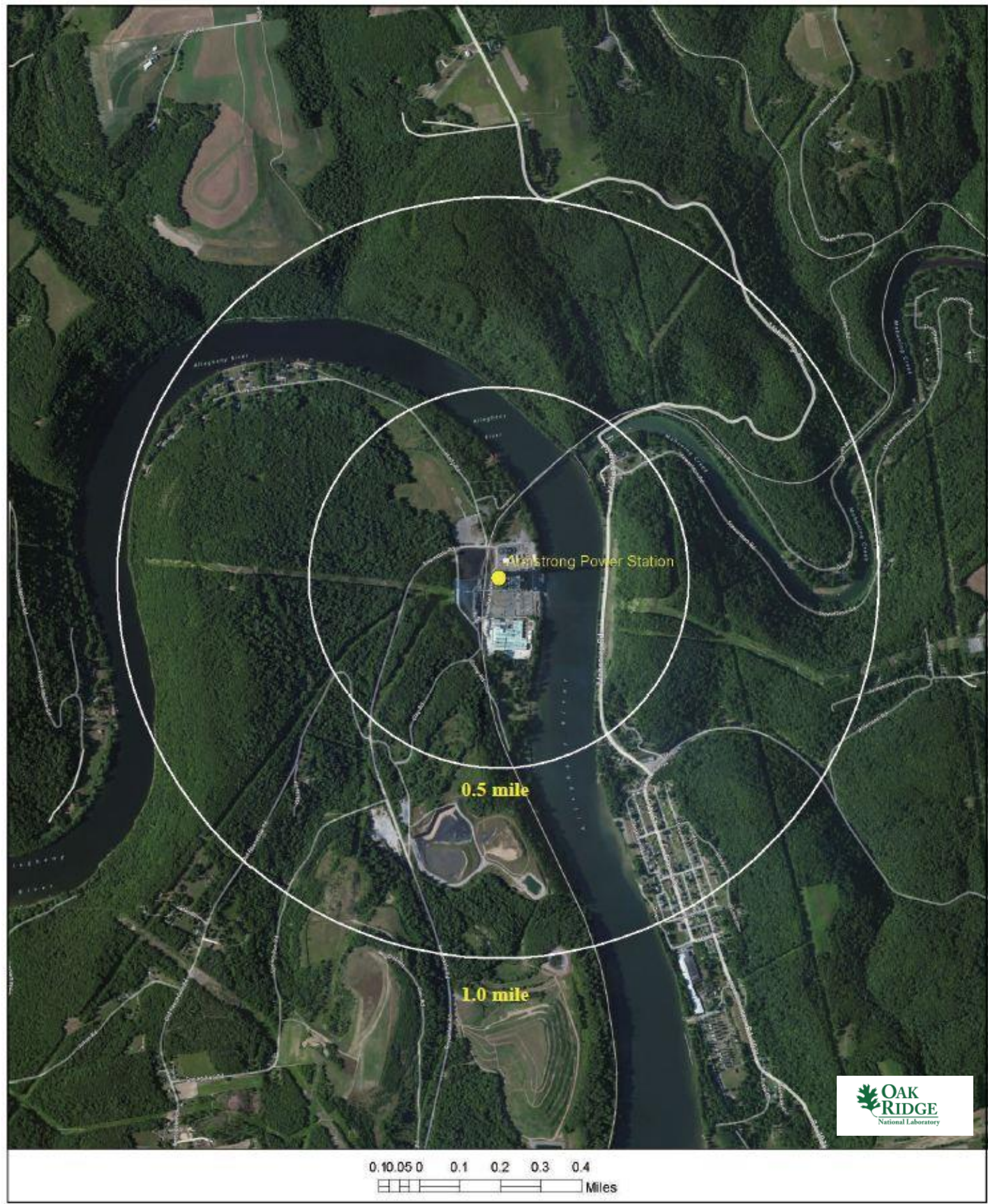

Fig. C.75. Satellite view of Armstrong Power Station proximity. 


\section{C.1.4 Screening Criteria Overview}

Table C.43. Armstrong Power Station siting criteria summary

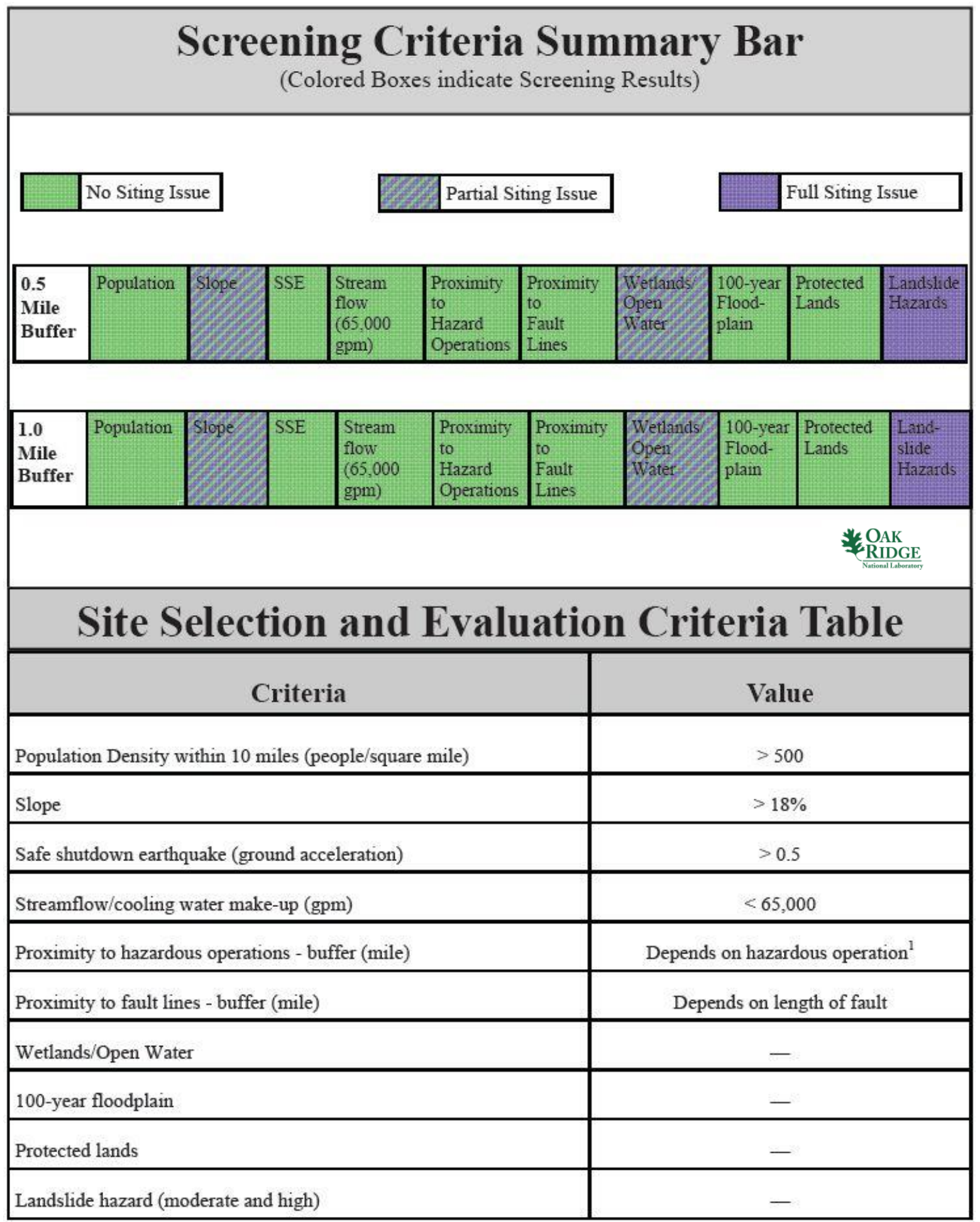

${ }^{1}$ Hazardous facilities (airports- 5 miles and oil refineries-1 mile) 


\section{C.1.5 Composite Map and Individual Siting Issue Maps}

A composite map of SMR siting challenges to the Armstrong Power Station is shown in Fig. C.76. The physical plant structures are located on land with a single siting issue. Following this map are maps of the individual SMR siting criteria based on selected input values.

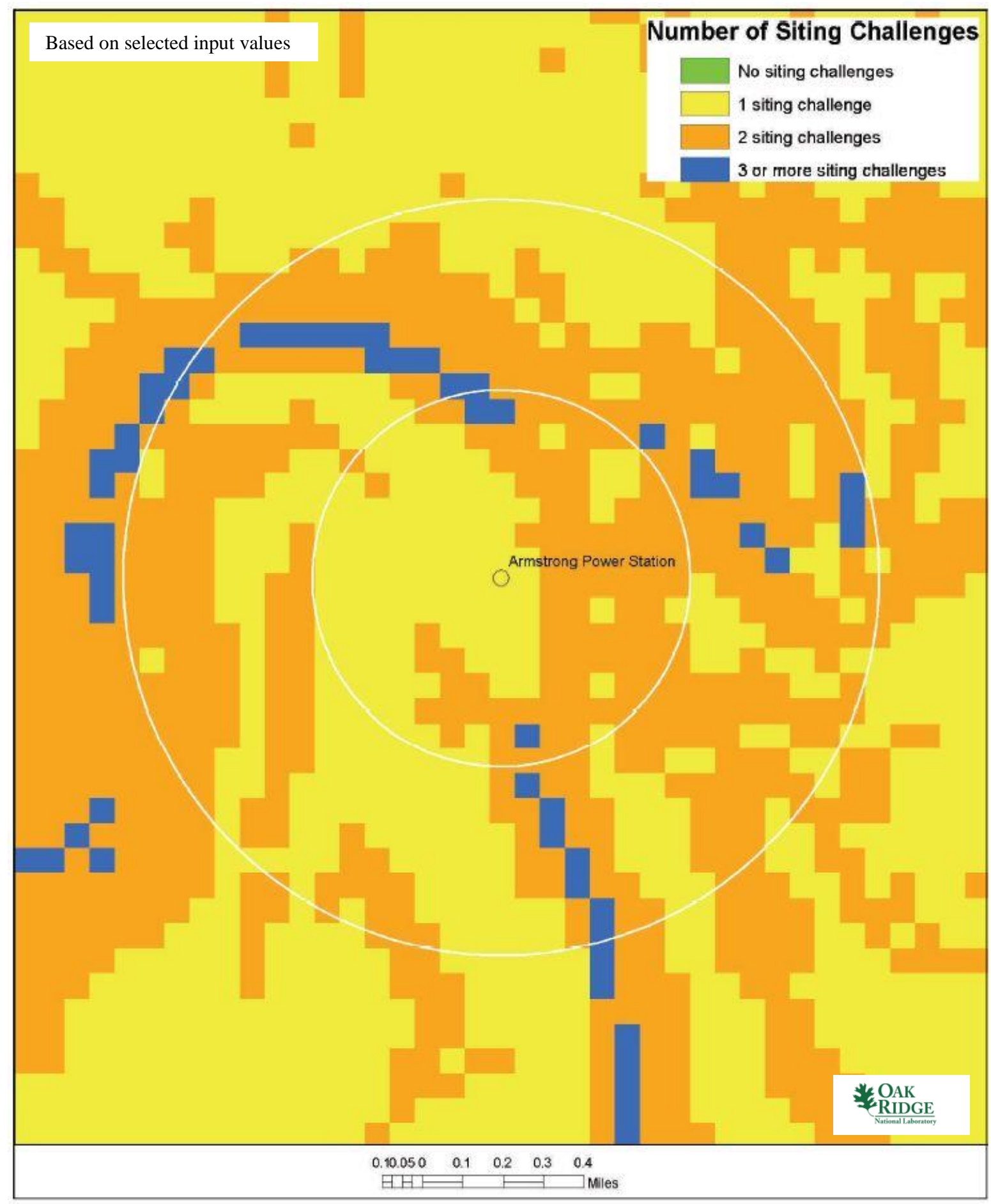

Fig. C.76. Armstrong Power Station composite map. 

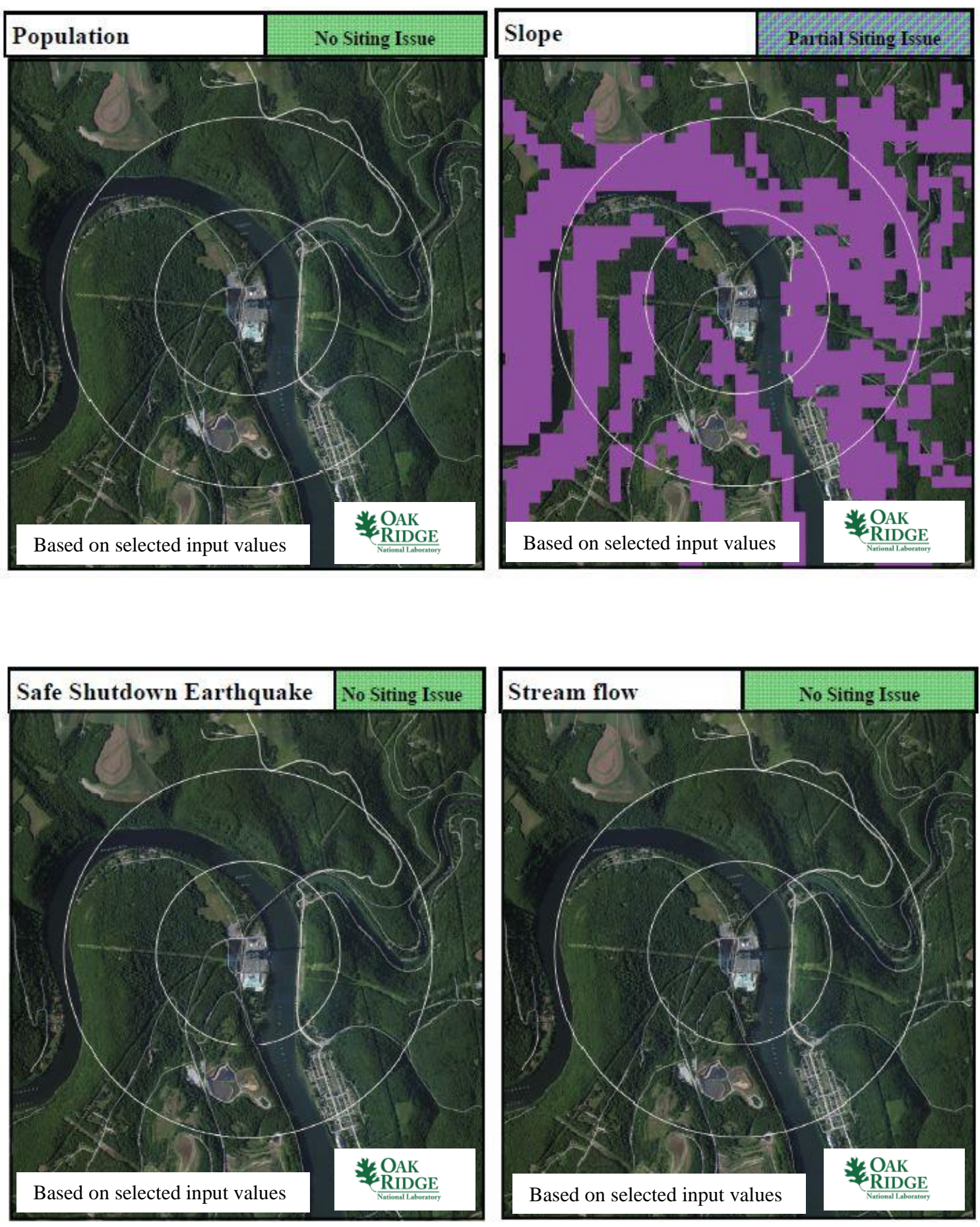

Armstrong Power Station 

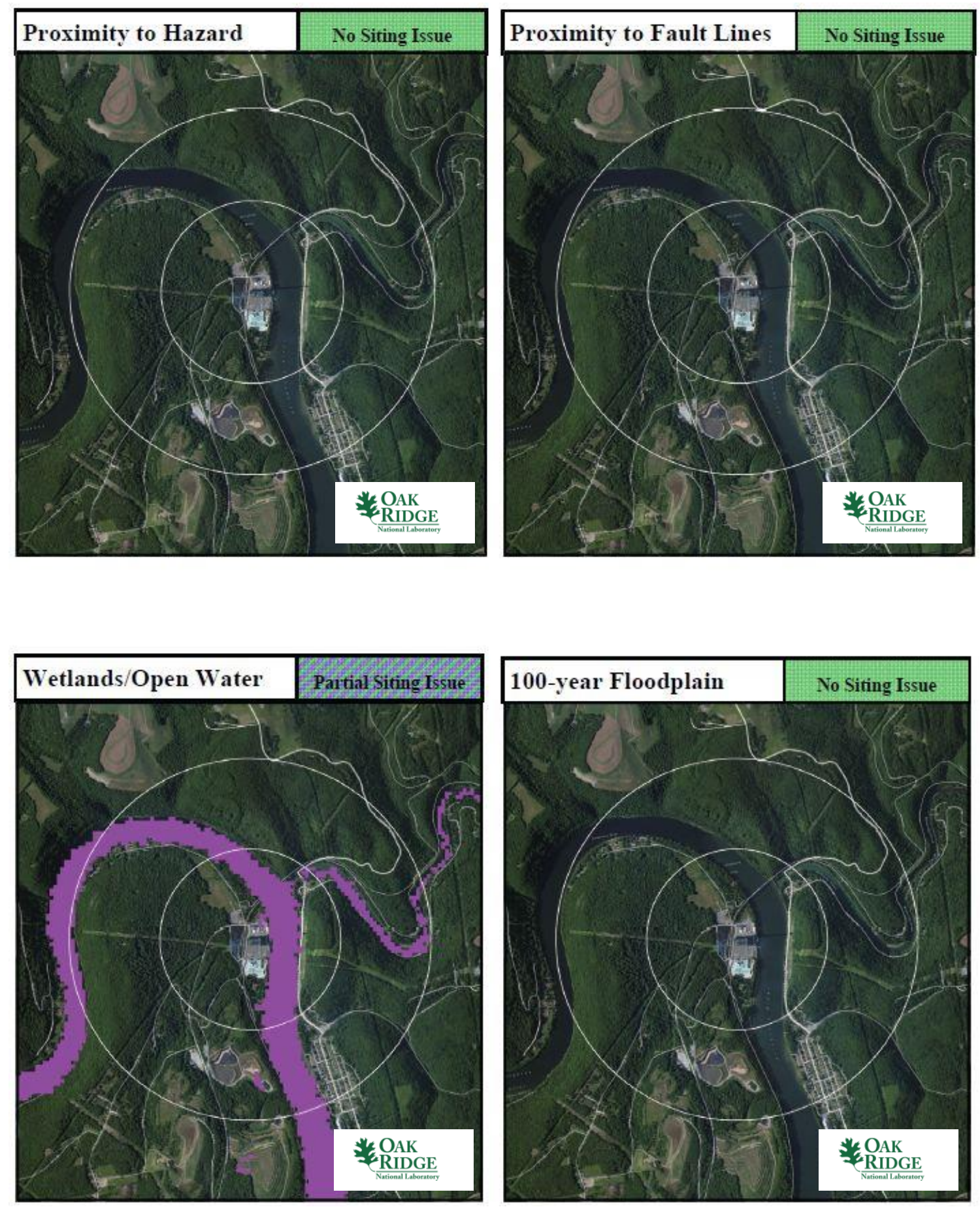

Armstrong Power Station 

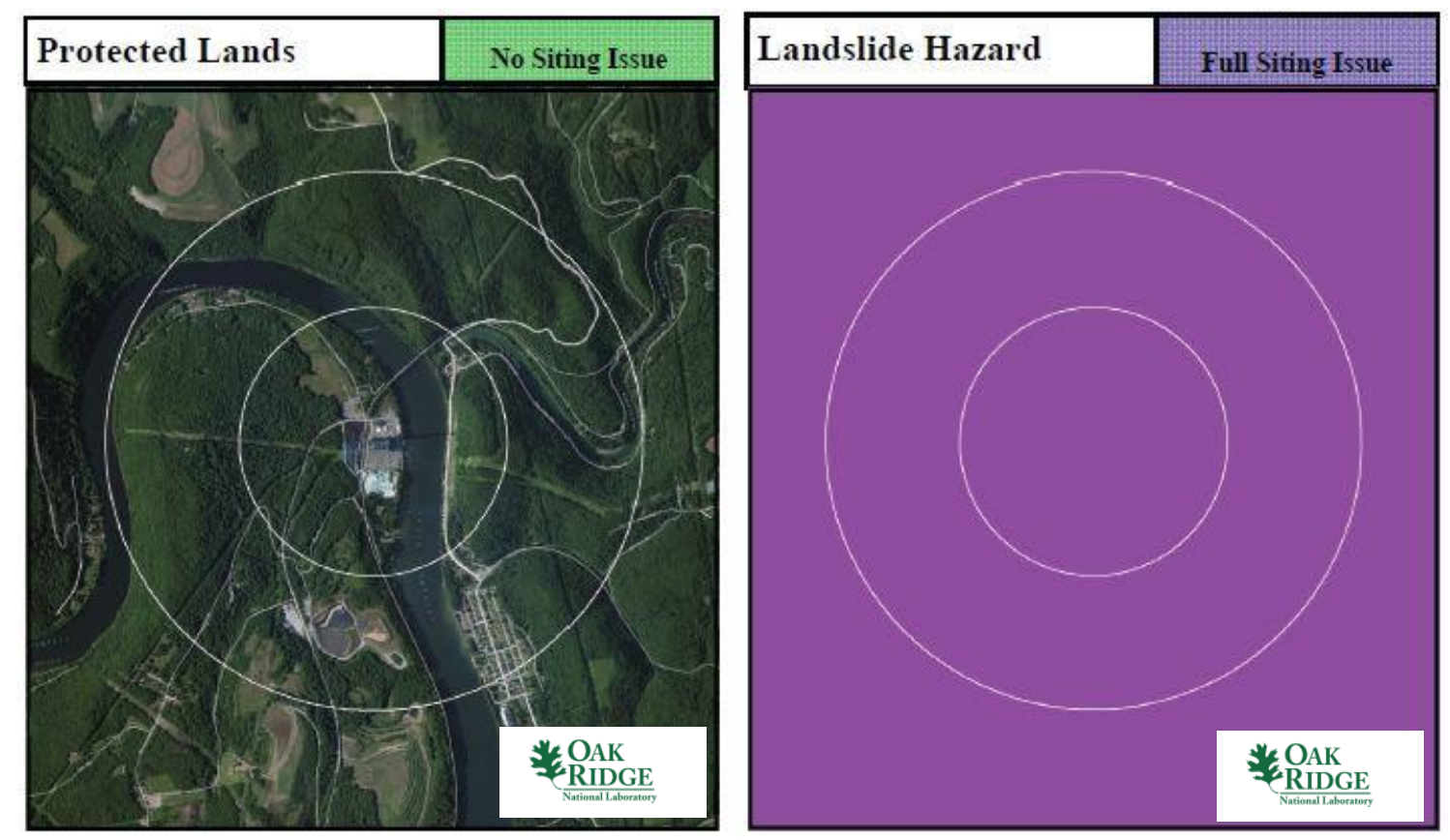

Armstrong Power Station

\section{C.1.6 Site Evaluation}

FirstEnergy operates several nuclear power plants, including Beaver Valley in Pennsylvania and DavisBesse and Perry in Ohio. Therefore, FirstEnergy Nuclear Operating Company (FENOC) has the licensing experience to operate an SMR at this site. The site contains sufficient acreage to support siting an SMR.

From an environmental justice perspective, the community collectively appears to have achieved a reasonable level of education with median income levels typical of much of the United States. Therefore, siting an SMR at this location would not seem to be disenfranchising a less-educated or poverty-stricken community. Furthermore, the education level of the Armstrong Power Station community would seem to support the higher-technology job opportunities provided by an SMR.

As shown in Sects. C.0 and C.0, the Armstrong Power Station site has widespread issues with the SMR site screening issue for landslide hazards. However, moderate and high landslide hazard risk is based on probabilistic analyses by the USGS. Therefore, more specific geological surveys would be required before eliminating the Armstrong Power Station site from SMR siting consideration. There has not been a landslide issue at the current site since its construction in 1958.

The Armstrong Power Station site has partial SMR site screening issues with wetlands/open waters and slope. The wetlands/open waters issue is related to the Allegheny River adjacent to the site. There is significant area around the site that exceeds the SMR slope criteria of $18 \%$. However, none of the land on the 210-acre plant site exceeds this value. A visual inspection of the aerial imagery indicates that neither issue should impact the siting of an SMR at this location. The remaining SMR site screening criteria are met site-wide for the values established in the updated SMR siting report.1

The Armstrong Power Station is 45 miles from Pittsburg and 63 miles from Youngstown, Ohio. Both these metropolitan areas are heavily industrialized and are forecast to grow in the next 25 years.

Therefore, as electrical demand increases with population growth, the Armstrong Power Station site may be acceptable for future consideration for SMR siting. However, even though population figures are not problematic within a 1 mile radius of the plant, part of the Templeton Township is within the 1 mile radius circle. This could be a contentious issue should FENOC decide to submit a COL application for an 
SMR at this site to meet any growing need for electrical capacity at this grid location, especially if the township grows in area and population. The utility would need to work closely with local leaders and civic groups to make the case for siting an SMR at this location. The site meets current NRC RG 4.7 recommendations for population density without additional consideration for relaxed SMR population siting requirements based on reduced source term. The Armstrong Power Station site meets conventional standards for SMR siting pending verification of no landslide limitations. 
C-12 


\section{C.2 Cameo Station}

\section{C.2.1 Location Detail}

As shown in Fig. C.77, Cameo Station is located in western Colorado about 45 miles from the Utah border on the Colorado River. More specifically, the plant is located off Interstate 70, in Mesa County, Colorado. Interstate 70 is accessible approximately 0.5 miles to the east. Rail access is available onsite within 0.1 miles, and barge access is unavailable. The plant is located about 4 miles northeast of Palisade, Colorado, with a population of approximately 2692 people. The nearest city with a population in excess of 10,000 people is Clifton, Colorado, approximately 8 miles to the southwest of the Cameo Station Power Plant.

- Plant: Cameo Station

- Utility: Public Service Company of Colorado

- Coordinates: lat. $39.14904^{\circ} \mathrm{N}$, long. $108.31794^{\circ} \mathrm{W}$

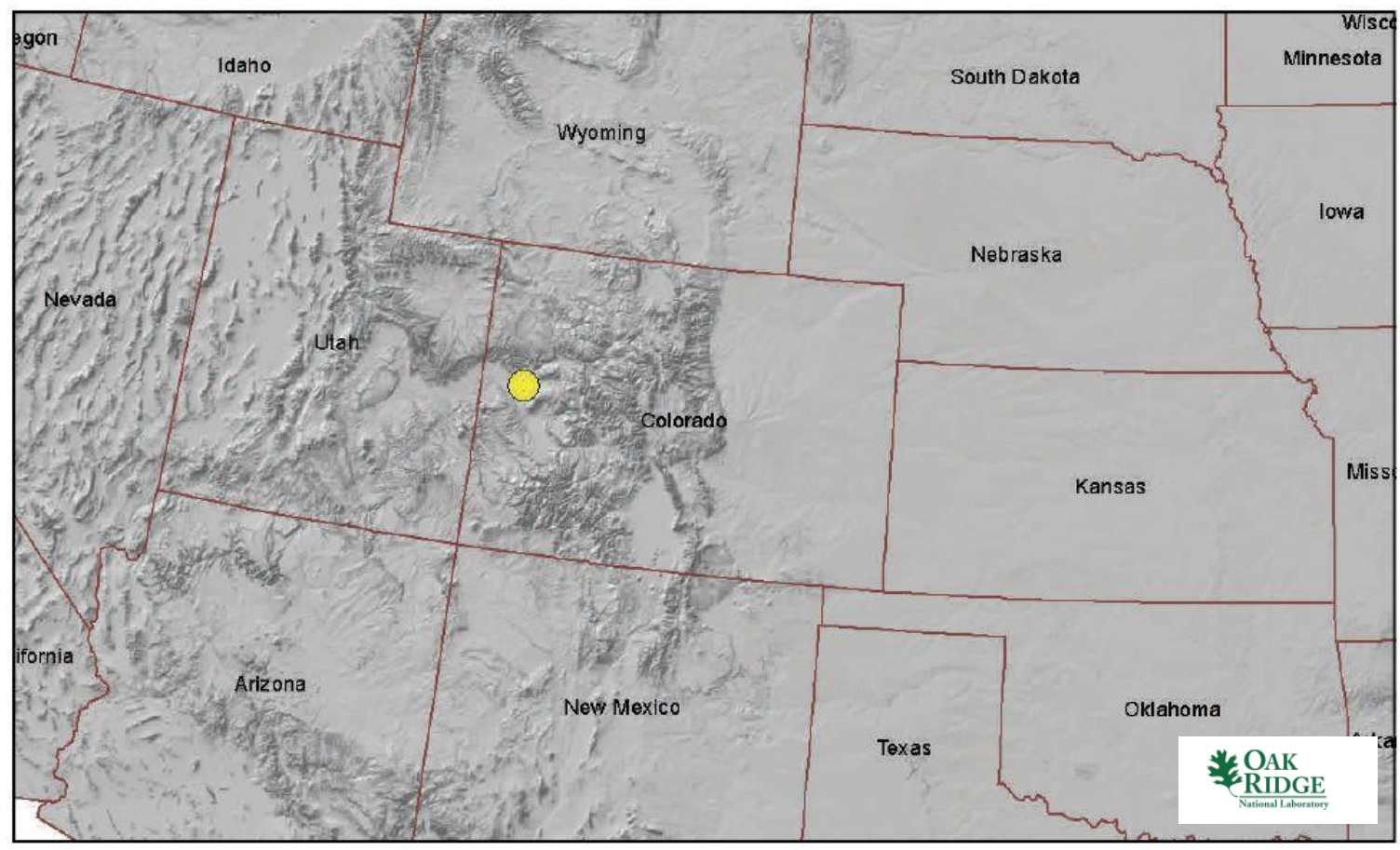

Fig. C.77. Cameo Station location map.

\section{C.2.2 Site Description and Status}

The Cameo Station Power Plant is operated by the Public Service Company of Colorado, a subsidiary of Xcel Energy. The Cameo Station Power Plant consists of two shutdown coal-fired units. Unit One came online in 1950 and produces $24 \mathrm{MW}(\mathrm{e})$. Unit Two came online in 1960 and produces $49 \mathrm{MW}(\mathrm{e})$. The station was cooled by once-through cooling from the adjacent Colorado River.

Xcel Energy remodeled the plant and began operating a first-of-its-kind hybrid solar-coal demonstration power plant using a solar thermal parabolic-trough technology. The demonstration project used solar 
thermal energy to supplement the steam cycle at Cameo Station Unit 2 and operated for about one year. The Cameo Station Power Plant ceased operations on December 29, 2010. ${ }^{19}$

The plant is situated on roughly 1,100 acres on the Colorado River approximately 471 miles north of the 3,810 MW(e) Palo Verde nuclear facility and 665 miles west of the 500 MW(e) Fort Calhoun nuclear facility. The plant is 62 miles north of the $115 \mathrm{MW}(\mathrm{e})$ coal-fired Nucla Plant and 98 miles south of the 1,338 MW(e) coal-fired Craig plant. The 31.5 MW(e) Crystal Dam hydroelectric project is 57 miles southeast of the Cameo Station Power Plant.

As noted in Table C.44, the nearest major fault line based on USGS data is about 14 miles west in Colorado. The maximum safe-shutdown earthquake for the site is below $0.3 \mathrm{~g}$ peak ground acceleration. More than 500,000 gpm of cooling water makeup is available from the adjacent Colorado River.

The permanent population within 1 mile of the plant is approximately 600 people, yielding a population density of approximately 191 people per square mile. The permanent population within 10 miles of the plant is approximately 86,500 people, yielding a population density of about 275 people per square mile. According to the US EPA Environmental Justice website, there are 9,628 occupied housing units within 10 miles of the plant site based on 2000 US Census data. Further, more than $80 \%$ of area adults over age 25 have a high school diploma or higher education. The median annual income for the area is between $\$ 25 \mathrm{~K}$ and $\$ 50 \mathrm{~K}$.

Table C.44. Cameo Station site statistics

\begin{tabular}{|l|l|l|l|}
\hline $\begin{array}{l}\text { Population } \\
\text { Population Within }\end{array}$ & \multicolumn{2}{l|}{$\begin{array}{l}\text { Utility } \\
\text { Distance to Grid Capacity }\end{array}$} \\
\hline $0.5 \mathrm{mi}$ & $<500$ & $>400 \mathrm{MWe}$ & $\sim 0.1 \mathrm{mi}$ \\
\hline $1 \mathrm{mi}$ & $\sim 600$ & $>800 \mathrm{MWe}$ & $\sim 32.0 \mathrm{mi}$ \\
\hline $5 \mathrm{mi}$ & $\sim 16,500$ & $>1600 \mathrm{MWe}$ & $\sim 181.0 \mathrm{mi}$ \\
\hline $10 \mathrm{mi}$ & $\sim 86,500$ & $>3200 \mathrm{MWe}$ & $\sim 484.0 \mathrm{mi}$ \\
\hline Nearest City with Population & Distance to Cooling Water \\
\hline \multicolumn{1}{|l|}{} & \multicolumn{2}{l|}{} \\
\hline$>10,000$ & Clifton, CO & $>50,000 \mathrm{gpm}$ & $\sim 0.1 \mathrm{mi}$ (Colorado River) \\
\hline$>100,000$ & Boulder, CO & $>100,000 \mathrm{gpm}$ & $\sim 0.1 \mathrm{mi}$ (Colorado River) \\
\hline$>500,000$ & Lakewood, CO & $>200,000$ gpm & $\sim 0.1 \mathrm{mi}$ (Colorado River) \\
\hline Geotechnical & Denver, CO & $>500,000$ gpm & $\sim 0.1 \mathrm{mi}$ (Colorado River) \\
\hline Max Earthquake Acceleration & $<0.3 \mathrm{~g}$ & Accessibility & \\
\hline Max Slope & $\sim 98 \%$ & Distance to Major Roadway & $\sim 0.2 \mathrm{mi}$ (Interstate 70) \\
\hline Nearest Fault Line & $\sim 14 \mathrm{mi}$ (Colorado) & Distance to Rail Transport & $\sim 0.1 \mathrm{mi}$ (UP) \\
\hline Nearest Hazard Site & $\sim 11$ mi (Airport- & Distance to Airport & $\sim 11.0 \mathrm{mi}$ (Grand Regional) \\
\hline
\end{tabular}

\footnotetext{
${ }^{19}$ Public Service Company of Colorado (Xcel Energy) report, "Final Report, Innovative Clean Technology - The Colorado
} Integrated Solar Project," Docket No. 09A-015E, March 2, 2011. 


\section{C.2.3 Aerial Imagery}

The aerial imagery in Fig. C.78 indicates that Interstate 70 runs within 0.5 miles of the Cameo Station Power Plant site.

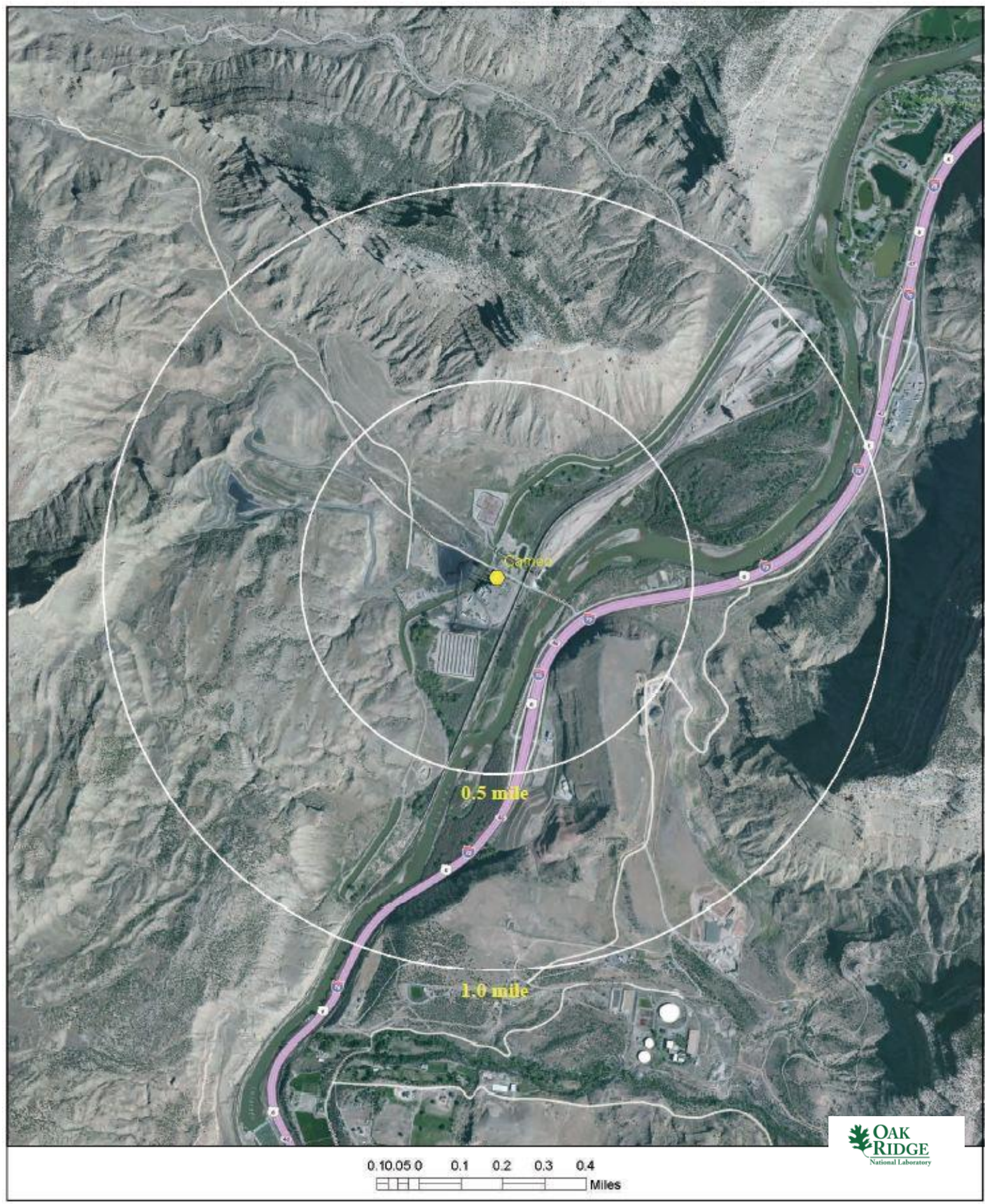

Fig. C.78. Satellite view of Cameo Station proximity. 


\section{C.2.4 Screening Criteria Overview}

Table C.45. Cameo Station siting criteria summary

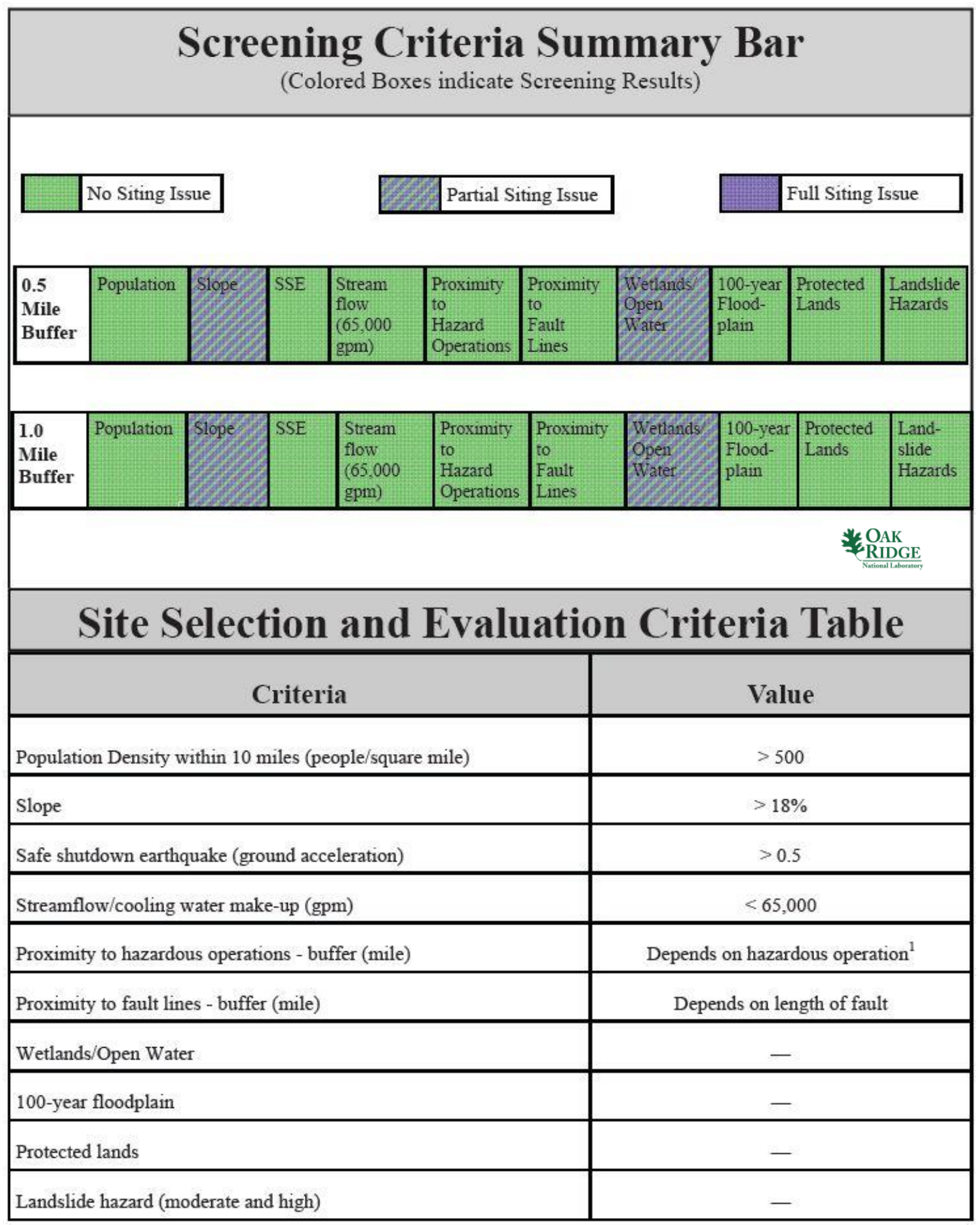

${ }^{1}$ Hazardous facilities (airports-5 miles and oil refineries-1 mile) 


\section{C.2.5 Composite Map and Individual Siting Issue Maps}

A composite map of SMR siting challenges to the Cameo Station Power Plant is shown in Fig. C.79. The physical plant structures are located on land with a single siting challenge. Following this map are maps of the individual SMR siting criteria based on selected input values.

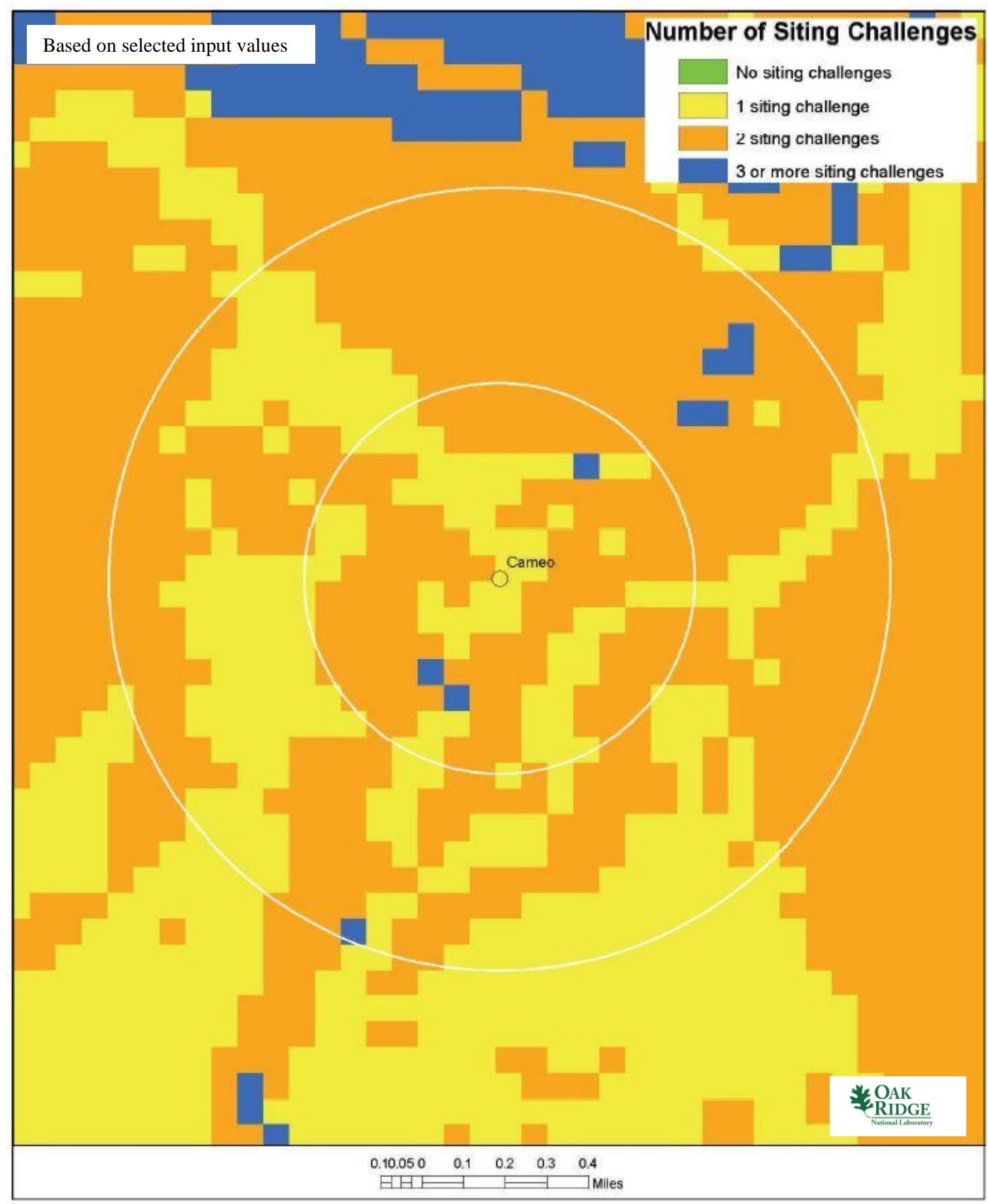

Fig. C.79. Cameo Station composite map. 

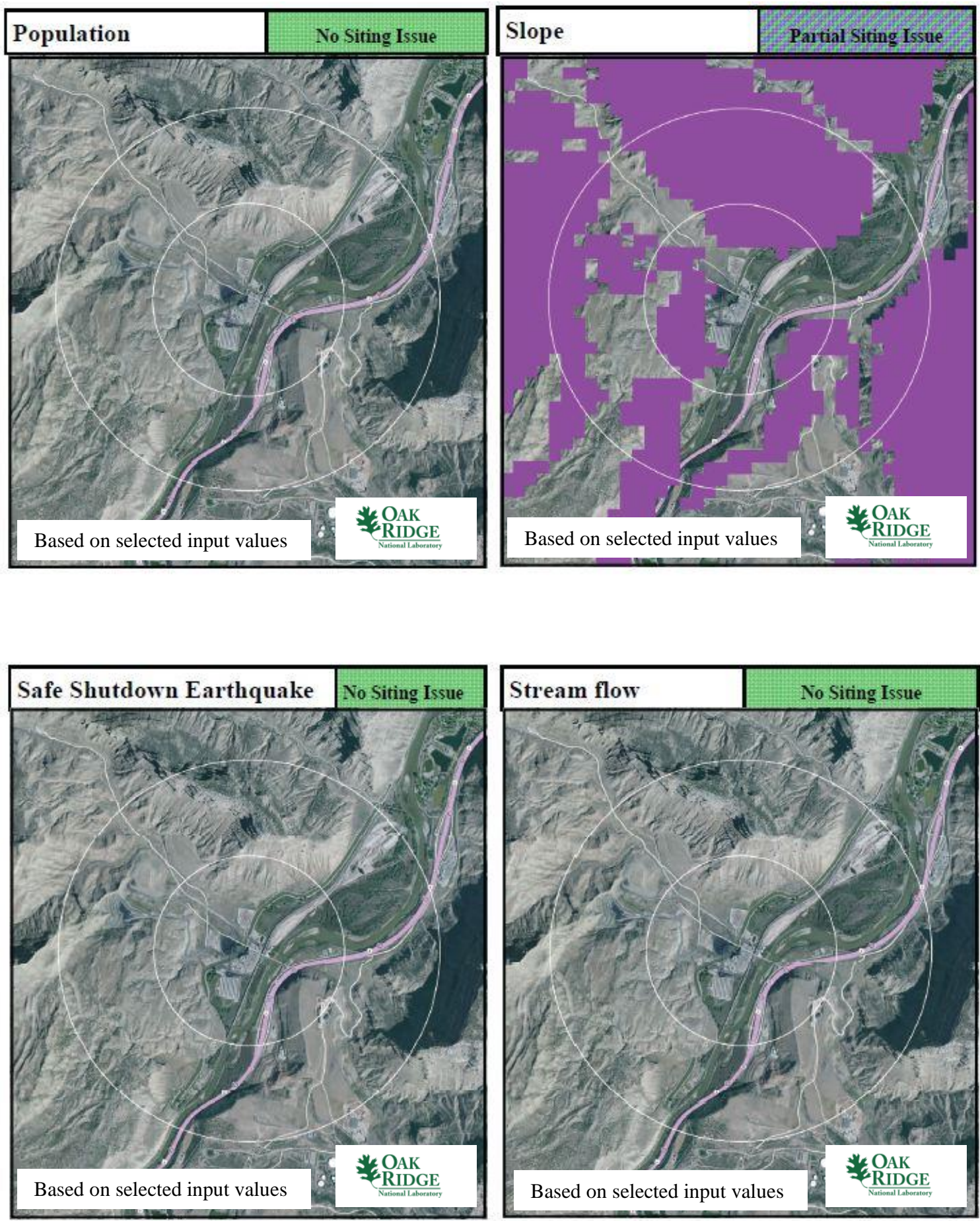

Cameo Station 

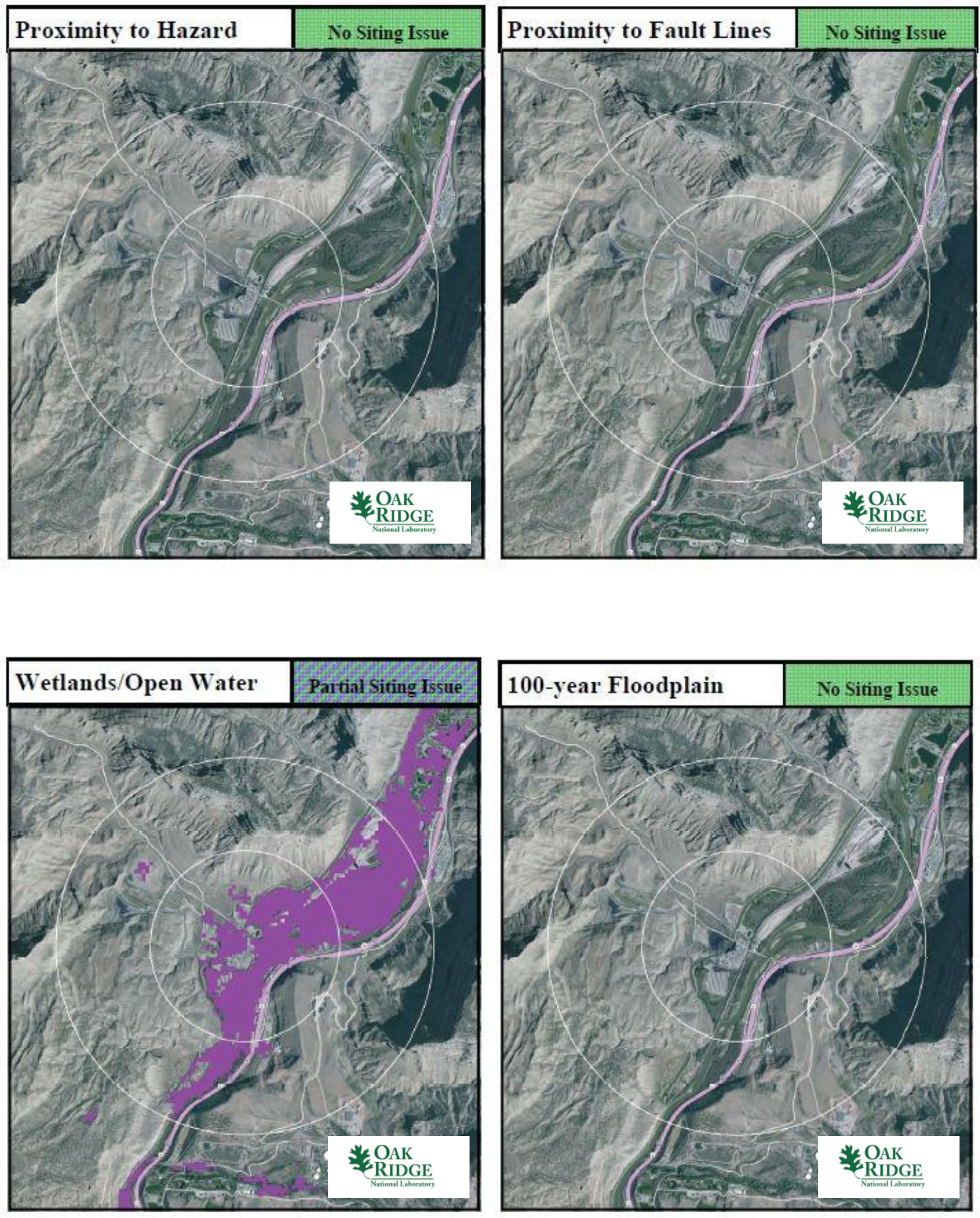

Cameo Station 

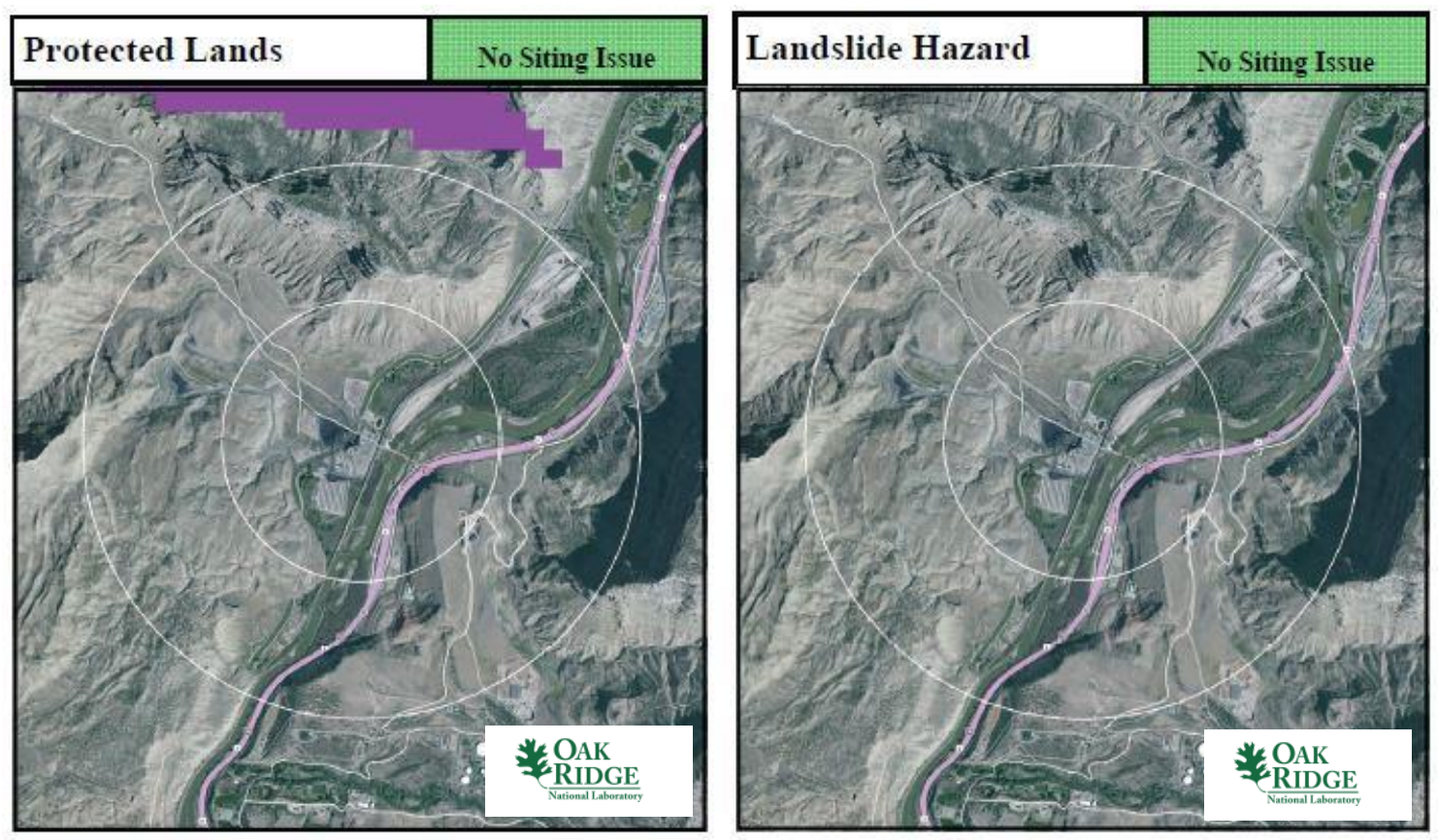

Cameo Station

\section{C.2.6 Site Evaluation}

Xcel Energy operates three nuclear power plants in Minnesota though its subsidiary, Northern States Power Company. The Monticello Nuclear Generating Plant, Unit 1, is located about 30 miles northwest of Minneapolis, Minnesota. The Prairie Island Nuclear generating Plant, Units 1 and 2 are located about 28 miles southeast of Minneapolis, Minnesota. Therefore, Xcel Energy has the licensing experience to operate an SMR at this site. The site contains sufficient acreage to support siting an SMR.

From an environmental justice perspective, the community collectively appears to have achieved a reasonable level of education with median income levels typical of much of the United States. Therefore, siting an SMR at this location would not seem to be disenfranchising a less-educated or poverty stricken community. Furthermore, the education level of the Cameo Station Power Plant community would seem to support the higher-technology job opportunities provided by an SMR.

As shown in Sects. C.0 and C.0, the Cameo Station Power Plant site has partial SMR site screening issues with wetlands/open waters and slope. The slope issue is related to land on all sides of the plant site. However, the plant structures are on land that meets the slope criteria. Likewise, the wetlands/open waters issue affects area on all sides of the plant site, including the Colorado River and a cooling water canal for once-through cooling. This could be a problematic issue for siting an SMR at this location in light of recent industry focus on flooding. However, the cooling water canal may be isolable. The remaining SMR site screening criteria are met site-wide for the values established in the updated SMR siting report.1

Interstate 70 runs immediately adjacent to the site, which could make it difficult for a nuclear licensee to control land access to areas very near the plant location. It should be noted that the interstate is across the Colorado River, and access is limited to a single bridge.

The site meets current NRC RG 4.7 recommendations for population density without additional consideration for relaxed SMR population siting requirements based on reduced source term. The Cameo Station Power Plant site meets conventional standards for SMR siting pending verification of any open water or wetlands restrictions. 


\section{C.3 John Sherman Cooper Power Station}

\section{C.3.1 Location Detail}

As shown in Fig. C.80, the Cooper Power Station is located in southeastern Kentucky, just north of the Tennessee border. More specifically, the plant is located 0.8 miles off Highway 27, in Pulaski County, Kentucky. Interstate 75 is accessible 24 miles to the east. Rail access is available within 0.6 miles and barge access is available within 0.3 miles from the adjacent Cumberland River. The closest town is Burnside, Kentucky, with a population of approximately 611 people. Burnside is less than 1 mile southwest of the Cooper Power Station. The nearest city with a population in excess of 10,000 people is Somerset, Kentucky, approximately 6.5 miles to the north of the Cooper Power Station.

- Plant: Cooper Power Station

- Utility: East Kentucky Power Cooperative

- Coordinates: lat. $36.99649^{\circ} \mathrm{N}$, long. $84.58527^{\circ} \mathrm{W}$

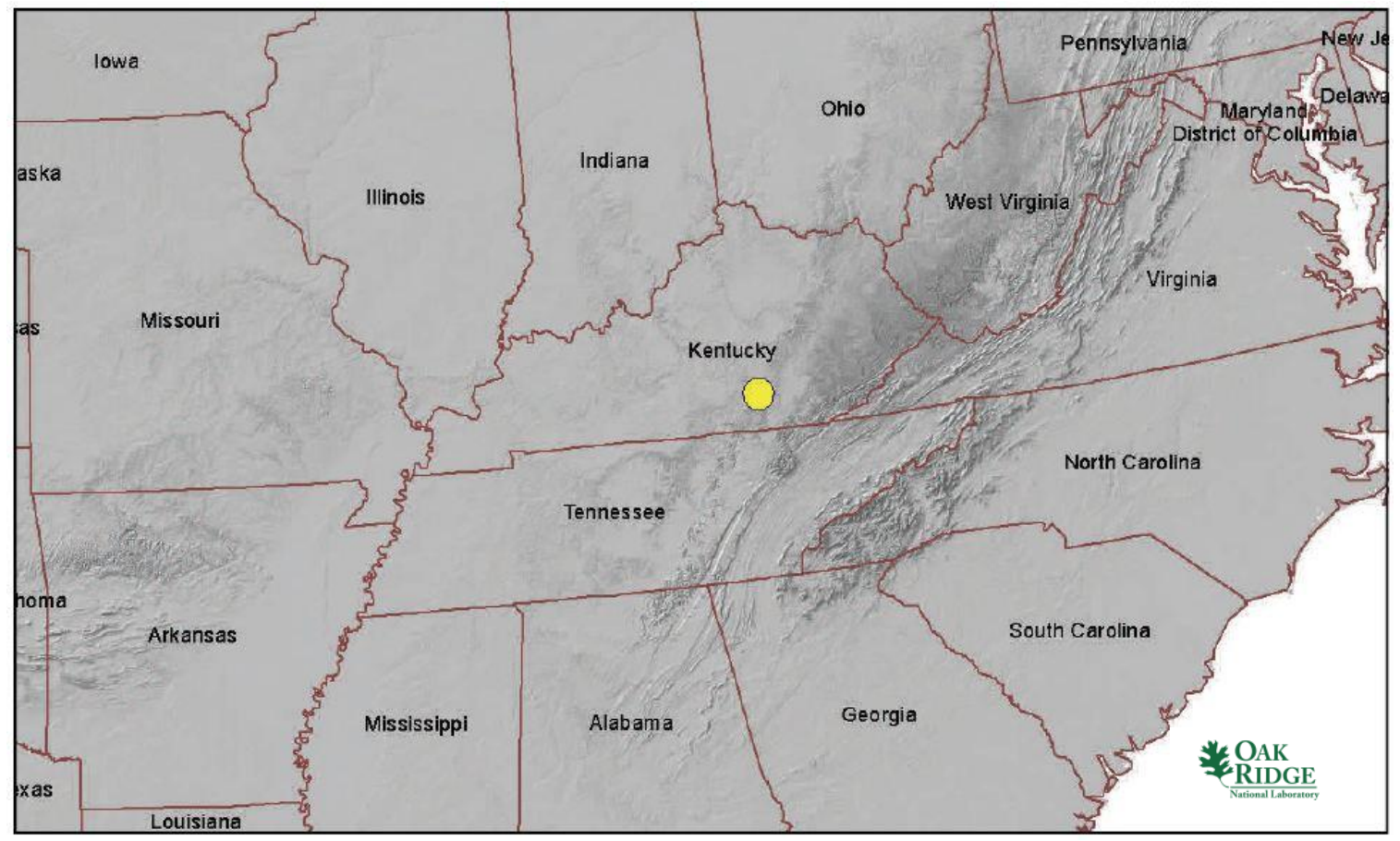

Fig. C.80. Cooper Power Station location map.

\section{C.3.2 Site Description and Status}

The Cooper Power Station is a two-unit coal station with both units currently operating as base load plants. Cooper Power Station is owned and operated by the East Kentucky Power Cooperative. Unit 1, commissioned in 1965, is rated at $114 \mathrm{MW}$ (e) and unit 2, commissioned in 1969, is rated at $230 \mathrm{MW}(\mathrm{e})$. The total site capacity is $344 \mathrm{MW}(\mathrm{e})$. Unit 2 is currently undergoing a $\$ 270 \mathrm{M}$ upgrade to install added emission controls. No decision on adding similar controls to unit 1 has been made. The site is cooled by mechanical draft cooling towers.

The plant is situated on approximately 200 acres on the Cumberland River approximately 98 miles north of the 1,100 MW(e) Watts Bar nuclear facility. The Cooper Power Station is 55 miles south of the operational 739 MW(e) E.W. Brown Coal Plant. In addition, the 70 MW(e) Laurel River Dam 
hydroelectric plant is 18 miles east of the Cooper Power Station and the 270 MW(e) Wolf Creek Dam hydroelectric plant is 32 miles to the west.

As noted in Table C.46, the nearest major fault line based on USGS data is 740 miles west in Oklahoma. The maximum safe-shutdown earthquake for the site is below $0.3 \mathrm{~g}$ peak ground acceleration. More than $500,000 \mathrm{gpm}$ of cooling water makeup is available from the adjacent Cumberland River.

The permanent population within 1 mile of the plant is fewer than 500 people, yielding a population density of fewer than 160 people per square mile. The permanent population within 10 miles of the plant is approximately 101,500 people, yielding a population density of approximately 325 people per square mile. According to the US EPA Environmental Justice website, there are 14,470 occupied housing units within 10 miles of the plant site based on 2000 US Census data. Further, roughly $64 \%$ of area adults over age 25 have a high school diploma or higher education. The median annual income for the area is between $\$ 25 \mathrm{~K}$ and $\$ 50 \mathrm{~K}$.

Table C.46. Cooper Power Station site statistics

\begin{tabular}{|c|c|c|c|}
\hline \multicolumn{2}{|l|}{$\begin{array}{l}\text { Population } \\
\text { Population Within }\end{array}$} & \multicolumn{2}{|l|}{$\begin{array}{l}\text { Utility } \\
\text { Distance to Grid Capacity }\end{array}$} \\
\hline $0.5 \mathrm{mi}$ & $<500$ & $>400 \mathrm{MWe}$ & $\sim 4 \mathrm{mi}$ \\
\hline $1 \mathrm{mi}$ & $\sim 1,600$ & $>800 \mathrm{MWe}$ & $\sim 27 \mathrm{mi}$ \\
\hline $5 \mathrm{mi}$ & $\sim 36,500$ & $>1600 \mathrm{MWe}$ & $\sim 70 \mathrm{mi}$ \\
\hline $10 \mathrm{mi}$ & $\sim 101,500$ & $>3200 \mathrm{MWe}$ & $\sim 138 \mathrm{mi}$ \\
\hline \multicolumn{2}{|c|}{ Nearest City with Population } & \multicolumn{2}{|c|}{ Distance to Cooling Water } \\
\hline$>10,000$ & Somerset, KY & $>50,000 \mathrm{gpm}$ & $\sim 0.3 \mathrm{mi}$ (Cumberland River) \\
\hline$>50,000$ & Bowling Green, KY & $>100,000 \mathrm{gpm}$ & $\sim 0.3 \mathrm{mi}$ (Cumberland River) \\
\hline$>100,000$ & Lexington-Fayette, KY & $>200,000 \mathrm{gpm}$ & $\sim 0.3 \mathrm{mi}$ (Cumberland River) \\
\hline$>500,000$ & Nashville, TN & $>500,000 \mathrm{gpm}$ & $\sim 0.3 \mathrm{mi}$ (Cumberland River) \\
\hline \multicolumn{2}{|l|}{ Geotechnical } & \multicolumn{2}{|l|}{ Accessibility } \\
\hline Max Earthquake Acceleration & $<0.3 \mathrm{~g}$ & Distance to Major Roadway & $\sim 0.8 \mathrm{mi}($ US 27$)$ \\
\hline Max Slope & $\sim 59 \%$ & Distance to Water Transport & $\sim 0.3 \mathrm{mi}$ (Cumberland River) \\
\hline Nearest Fault Line & $\sim 740 \mathrm{mi}$ (Oklahoma) & Distance to Rail Transport & $\sim 0.6 \mathrm{mi}$ (NS) \\
\hline Nearest Hazard Site & $\begin{array}{l}\sim 5 \text { mi (Refinery- } \\
\quad \text { Somerset Refinery Inc.) }\end{array}$ & Distance to Airport & $\sim 68 \mathrm{mi}$ (Blue Grass) \\
\hline
\end{tabular}




\section{C.3.3 Aerial Imagery}

The aerial imagery in Fig. C.81 shows the town of Burnside approximately 0.5 miles south of the plant across the Cumberland River. Also visible is a subdivision within 1.0 mile east of the site.

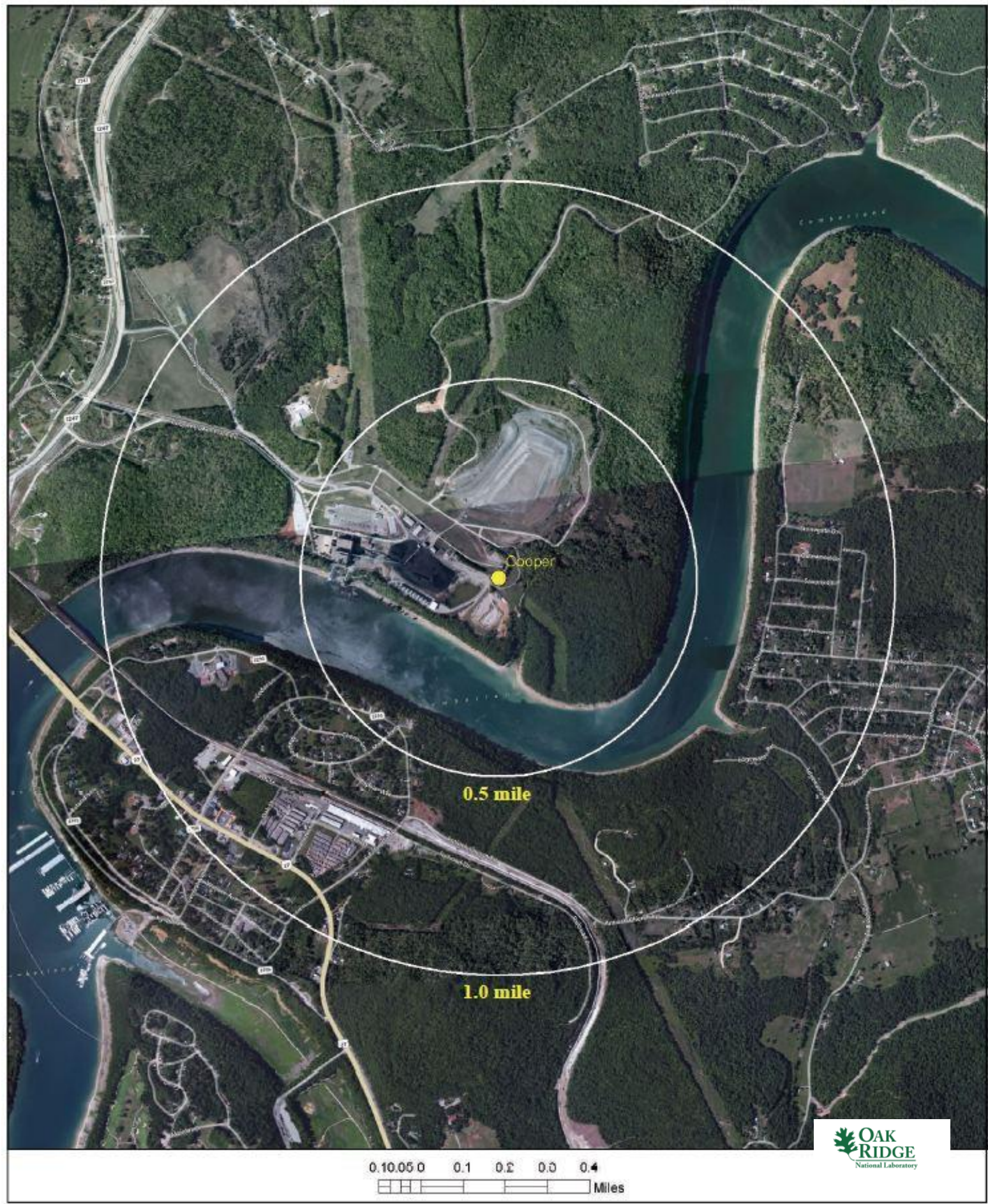

Fig. C.81. Satellite view of Cooper Power Station proximity. 


\section{C.3.4 Screening Criteria Overview}

Table C.47. Cooper Power Station siting criteria summary

\begin{tabular}{|c|c|c|c|c|c|c|c|c|c|c|}
\hline \multicolumn{11}{|c|}{$\underset{\text { (Colored Boxes indicate Screening Results) }}{\text { Screening Criteria Summar }}$} \\
\hline \multicolumn{3}{|c|}{ No Siting Issue } & \multicolumn{2}{|c|}{\begin{tabular}{|l|l|} 
& Partial Siting Issue \\
\end{tabular}} & \multicolumn{2}{|c|}{ Partial Siting Issue } & \multicolumn{4}{|c|}{ Full Siting Issue } \\
\hline \begin{tabular}{|l}
0.5 \\
Mile \\
Buffer
\end{tabular} & Population & Slope & SSE & $\begin{array}{l}\text { Stream } \\
\text { flow } \\
(65,000 \\
\text { gpm) }\end{array}$ & \begin{tabular}{|l|} 
Proximity \\
to \\
Hazard \\
Operations \\
\end{tabular} & $\begin{array}{l}\text { Proximity } \\
\text { to } \\
\text { Fault } \\
\text { Lines }\end{array}$ & \begin{tabular}{|l|} 
Wetlands/ \\
Open \\
Water \\
\end{tabular} & \begin{tabular}{|l|}
100 -year \\
Flood- \\
plain
\end{tabular} & $\begin{array}{l}\text { Protected } \\
\text { Lands }\end{array}$ & $\begin{array}{l}\text { Landsirde } \\
\text { Hazards }\end{array}$ \\
\hline $\begin{array}{l}1.0 \\
\text { Mile } \\
\text { Buffer }\end{array}$ & Population & & SSE & $\begin{array}{l}\text { Stream } \\
\text { flow } \\
(65,000 \\
\mathrm{gpm})\end{array}$ & $\begin{array}{l}\text { Proximity } \\
\text { to } \\
\text { Hazard } \\
\text { Operations }\end{array}$ & \begin{tabular}{|l} 
Proximity \\
to \\
Fault \\
Lines
\end{tabular} & $\begin{array}{l}\text { Wetlands: } \\
\text { Open } \\
\text { Water }\end{array}$ & \begin{tabular}{|l|}
100 -year \\
Flood- \\
plain
\end{tabular} & $\begin{array}{l}\text { Protected } \\
\text { Lands }\end{array}$ & \begin{tabular}{|l} 
Land- \\
slide \\
Hazards
\end{tabular} \\
\hline \multicolumn{11}{|c|}{ 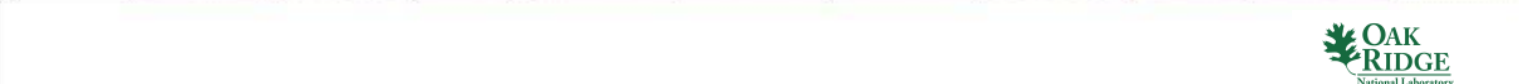 } \\
\hline \multicolumn{11}{|c|}{ Site Selection and Evaluation Criteria Table } \\
\hline \multicolumn{7}{|c|}{ Criteria } & \multicolumn{4}{|c|}{ Value } \\
\hline \multicolumn{7}{|c|}{ Population Density within 10 miles (people/square mile) } & \multicolumn{4}{|c|}{$>500$} \\
\hline \multicolumn{7}{|l|}{ Slope } & \multicolumn{4}{|c|}{$>18 \%$} \\
\hline \multicolumn{7}{|c|}{ Safe shutdown earthquake (ground acceleration) } & \multicolumn{4}{|c|}{$>0.5$} \\
\hline \multicolumn{7}{|c|}{ Streamflow/cooling water make-up (gpm) } & \multicolumn{4}{|c|}{$<65,000$} \\
\hline \multicolumn{7}{|c|}{ Proximity to hazardous operations - buffer (mile) } & \multicolumn{4}{|c|}{ Depends on hazardous operation ${ }^{1}$} \\
\hline \multicolumn{7}{|c|}{ Proximity to fault lines - buffer (mile) } & \multicolumn{4}{|c|}{ Depends on length of fault } \\
\hline \multicolumn{7}{|c|}{ Wetlands/Open Water } & \multicolumn{4}{|c|}{-} \\
\hline \multicolumn{7}{|c|}{ 100-year floodplain } & \multicolumn{4}{|c|}{-} \\
\hline \multicolumn{7}{|c|}{ Protected lands } & \multicolumn{4}{|c|}{ - } \\
\hline \multicolumn{7}{|c|}{ Landslide hazard (moderate and high) } & \multicolumn{4}{|c|}{-} \\
\hline
\end{tabular}

${ }^{1}$ Hazardous facilities (airports-5 miles and oil refineries-1 mile) 


\section{C.3.5 Composite Map and Individual Siting Issue Maps}

A composite map of SMR siting challenges to the Cooper Power Station is shown in Fig. C.82. The physical plant structures are located on land with one siting issue. Following this map are maps of the individual SMR siting criteria based on selected input values.

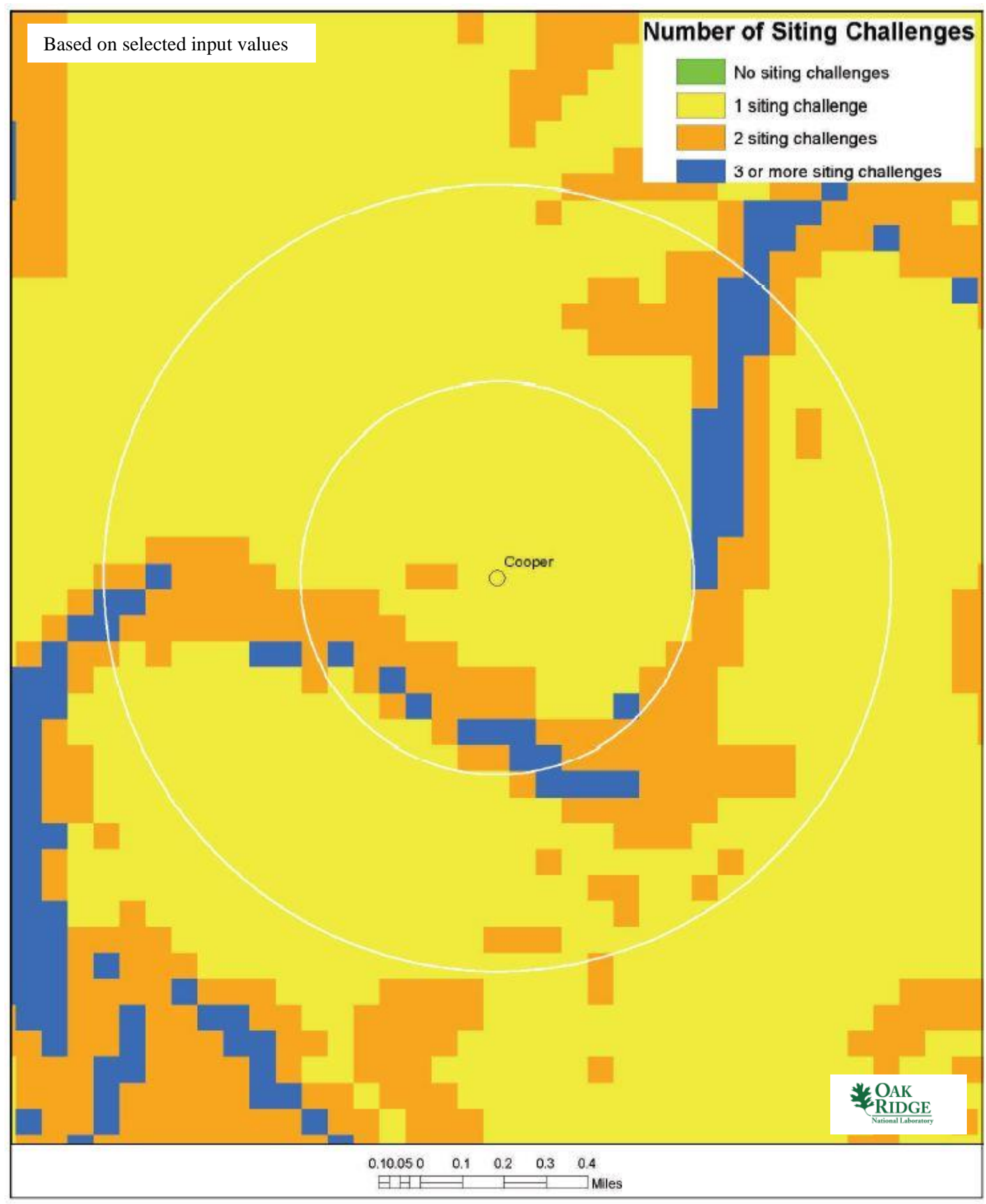

Fig. C.82. Cooper Power Station composite map. 

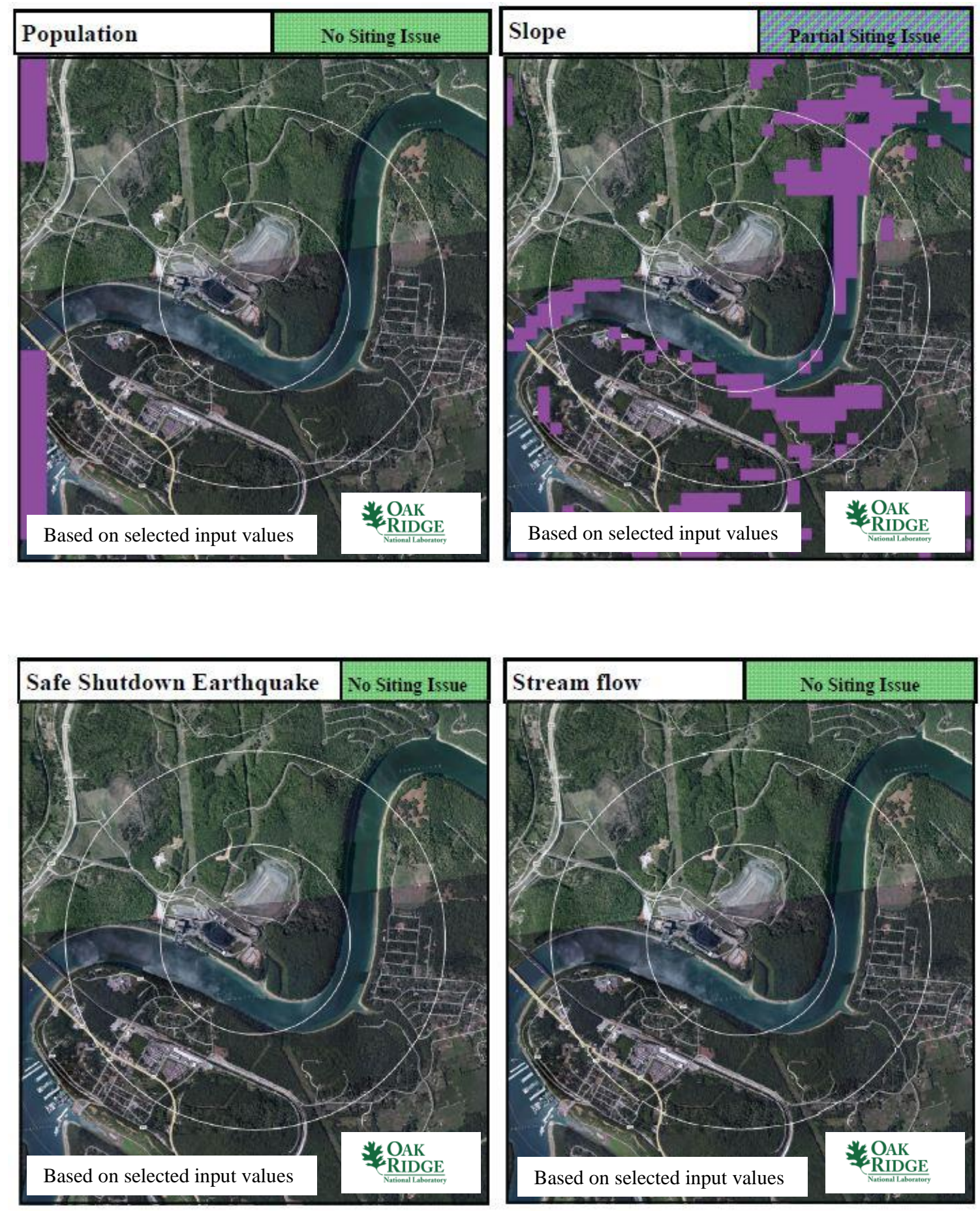

Cooper Power Station 

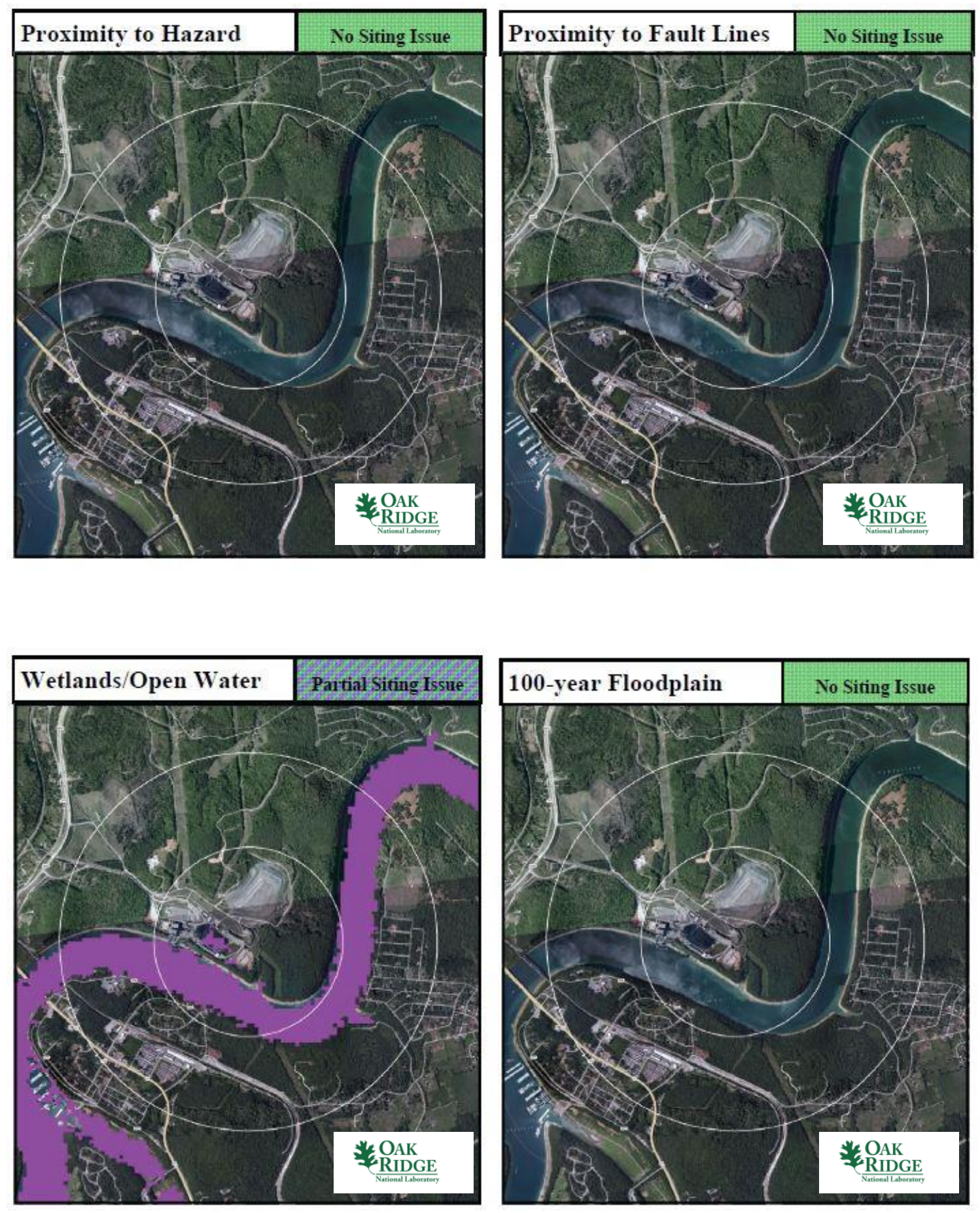

Cooper Power Station 

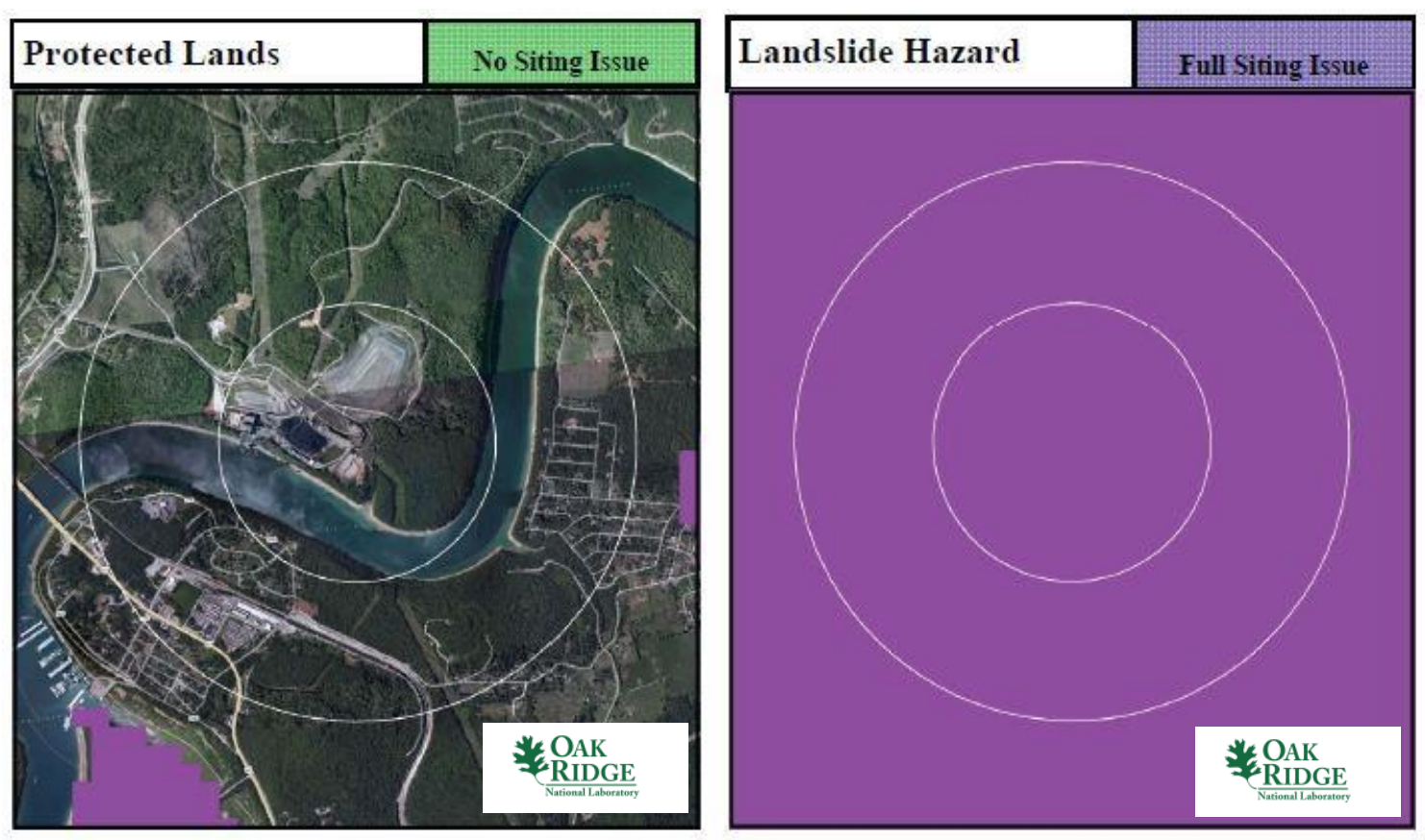

Cooper Power Station

\section{C.3.6 Site Evaluation}

The East Kentucky Power Cooperative operates three base load coal plants and numerous gas- and oilfired combustion turbines for power peaking, as well as six landfill methane power units. The East Kentucky Power Cooperative does not operate or own a share of any nuclear power plants in the United States. Therefore, the utility would need to be mentored through the licensing process to build and operate an SMR. Additionally, there are numerous other electric power generation facilities within 100 miles of the Cooper Power Station to subsidize area power requirements. Furthermore, the East Kentucky Power Cooperative previously made the decision to backfit unit 2 at this site with better emissions control equipment to continue to meet area electrical load demands in the near term.

From an environmental justice perspective, the community collectively appears to have achieved a reasonable level of education with median income levels typical of much of the United States. Therefore, siting an SMR at this location would not seem to be disenfranchising a less-educated or poverty-stricken community. Furthermore, the education level of the Cooper Power Station community would seem to support the higher-technology job opportunities provided by an SMR.

As shown in Sects. C.0 and C.0, the Cooper Power Station site has a widespread issue with landslide hazards. Moderate and high landslide hazard risk is based on probabilistic analyses by the USGS. Therefore, more specific geological surveys would be required before eliminating the Cooper Power Station site from SMR siting consideration. There has not been a landslide issue at the current site since its construction in 1965.

The Cooper Power Station site has partial SMR site screening issues with slope and wetlands/open waters. The slope issue is related to land in multiple directions around the plant, but greater than 0.5 miles from the center of the plant site. The wetlands/open waters issue reflects the adjacent Cumberland River. There are no 100-year floodplain affects indicated for the site, so flooding is not expected to be a concern. The plant is situated just upstream of Lake Cumberland formed by the Wolf Creek Dam, 32 miles to the west. Further visual inspection of the aerial imagery indicates that neither of these issues should directly 
impact the siting of an SMR at this location. The remaining SMR site screening criteria are met site-wide for the values established in the updated SMR siting report.1

Though population figures are not problematic within a 1 mile radius of the plant, one subdivision area and the small town of Burnside are visually apparent in an aerial view of the site between the 0.5 mile radius circle and the 1 mile radius circle. This could be a contentious issue should the East Kentucky Power Cooperative decide to submit a COL application for an SMR at this site to meet any growing need for electrical capacity at this grid location.

When future load demands indicate the need for expanded generation capacity in this region, the utility would need to work closely with local leaders and civic groups to make the case for siting an SMR at this location. The site meets current NRC RG 4.7 recommendations for population density without additional consideration for relaxed SMR population siting requirements based on reduced source term. The Cooper Power Station site meets conventional standards for siting an SMR pending verification of no landslide limitations. In addition, there is a longer-term consideration for population growth in the proximity of the town of Burnside. 
C-30 


\section{C.4 Genoa Station}

\section{C.4.1 Location Detail}

As shown in Fig. C.83, Genoa Station is located in Southwestern Wisconsin just east of the Minnesota border. More specifically, the plant is along Wisconsin Highway 35, also known as Great River Road, in Vernon County, Wisconsin. The Great River Road runs adjacent to the plant's east side. Interstate 90 is 20 miles to the north. Rail access is available onsite within 0.1 miles and barge access is available within 0.2 miles from the adjacent Mississippi River. The closest town is Genoa, Wisconsin, with a population of about 266 people. The nearest city with a population in excess of 10,000 people is Onalaska, Wisconsin, which is on the north side of La Crosse, Wisconsin, with a population of 51,230 approximately 18 miles to the north Genoa Station.

- Plant: Genoa Station

- Utility: Dairyland Power Cooperative

- Coordinates: lat. $43.55906^{\circ} \mathrm{N}$, long. $91.23037^{\circ} \mathrm{W}$

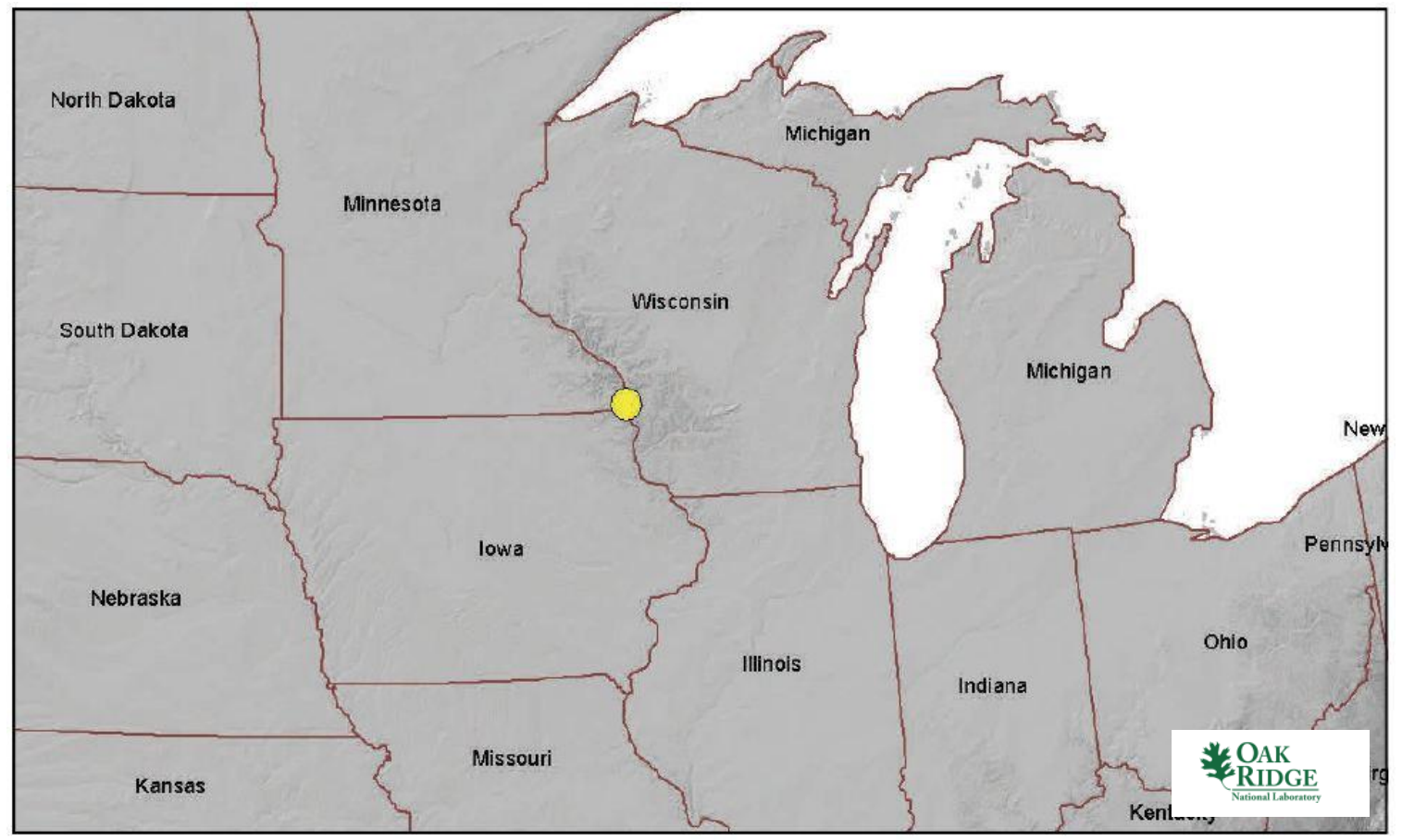

Fig. C.83. Genoa Station location map.

\section{C.4.2 Site Description and Status}

Genoa Station is owned and operated by the Dairyland Power Cooperative. A single coal-fired unit, commissioned in 1969, is operating on the site. The 345.6 MW(e) unit is identified as Genoa Station \#3. The unit is cooled by once-through cooling from the adjacent river. Genoa Station \# 1, a previous 14 MW(e) coal-fired facility at the site, was retired in 1985 and has been dismantled. Additionally, the La Crosse Boiling Water Reactor was operated at this site and is currently defueled. The 50 MW(e) reactor was commissioned in 1969 and shut down in 1987 for economic reasons.

The plant is situated on approximately 100 acres along the Mississippi River approximately 102 miles southeast of the 1,100 MW(e) Prairie Island nuclear facility and 105 miles north of the $615 \mathrm{MW}(\mathrm{e})$ Duane 
Arnold nuclear facility. Genoa Station is 16 miles upriver of the 339 MW(e) coal-fired Lansing Station in Iowa. Numerous small hydroelectric projects exist in the region.

As noted in Table C.48, the nearest major fault line based on USGS data is 591 miles southwest in Kansas. The maximum safe-shutdown earthquake for the site is below $0.3 \mathrm{~g}$ peak ground acceleration. More than 500,000 gpm of cooling water makeup is available from the adjacent Mississippi River.

The permanent population within 1 mile of the plant is fewer than 500 people, yielding a population density of fewer than 160 people per square mile. The permanent population within 10 miles of the plant is approximately 26,100 people, yielding a population density of approximately 83 people per square mile. According to the US EPA Environmental Justice website, there are 2,638 occupied housing units within 10 miles of the plant site based on 2000 US Census data. Further, over $80 \%$ of area adults over age 25 have a high school diploma or higher education. The median annual income for the area is between $\$ 25 \mathrm{~K}$ and $\$ 50 \mathrm{~K}$.

Table C.48. Genoa Station site statistics

\begin{tabular}{|l|l|l|l|}
\hline $\begin{array}{l}\text { Population } \\
\text { Population Within }\end{array}$ & \multicolumn{2}{l|}{$\begin{array}{l}\text { Utility } \\
\text { Distance to Grid Capacity }\end{array}$} \\
\hline $0.5 \mathrm{mi}$ & $<500$ & $>400 \mathrm{MWe}$ & $\sim 71 \mathrm{mi}$ \\
\hline $1 \mathrm{mi}$ & $<500$ & $>800 \mathrm{MWe}$ & $\sim 61 \mathrm{mi}$ \\
\hline $5 \mathrm{mi}$ & $\sim 6,500$ & $>1600 \mathrm{MWe}$ & $\sim 155 \mathrm{mi}$ \\
\hline $10 \mathrm{mi}$ & $\sim 26,100$ & $>3200 \mathrm{MWe}$ & $\sim 179 \mathrm{mi}$ \\
\hline Nearest City with Population & Distance to Cooling Water \\
\hline \multicolumn{2}{|l|}{} & \multicolumn{2}{l|}{} \\
\hline$>10,000$ & Onalaska, WI & $>50,000$ gpm & $\sim 0.2 \mathrm{mi}$ (Mississippi River) \\
\hline$>50,000$ & La Crosse, WI & $>100,000 \mathrm{gpm}$ & $\sim 0.2 \mathrm{mi}$ (Mississippi River) \\
\hline$>100,000$ & Cedar Rapids, IA & $>200,000$ gpm & $\sim 0.2 \mathrm{mi}$ (Mississippi River) \\
\hline$>500,000$ & Milwaukee, WI & $>500,000$ gpm & $\sim 0.2 \mathrm{mi}$ (Mississippi River) \\
\hline Geotechnical & \multicolumn{3}{|l|}{ Accessibility } \\
\hline Max Earthquake Acceleration & $<0.3 \mathrm{~g}$ & Distance to Major Roadway & $\sim 0.1 \mathrm{mi}$ (SR 35) \\
\hline Max Slope & $\sim 64 \%$ & Distance to Water Transport & $\sim 0.2 \mathrm{mi}$ (Mississippi River) \\
\hline Nearest Fault Line & $\sim 591$ mi (Kansas) & Distance to Rail Transport & $\sim 0.1 \mathrm{mi}$ (BNSF) \\
\hline Nearest Hazard Site & $\sim 21$ mi (Airport- & Distance to Airport & $\sim 21$ mi (La Crosse Munici- \\
\hline
\end{tabular}




\section{C.4.3 Aerial Imagery}

The aerial imagery in Fig. C.84 indicates the Genoa Station site. What appears to be a small trailer-park community is across the road to the east of the plant site within 0.5 miles.

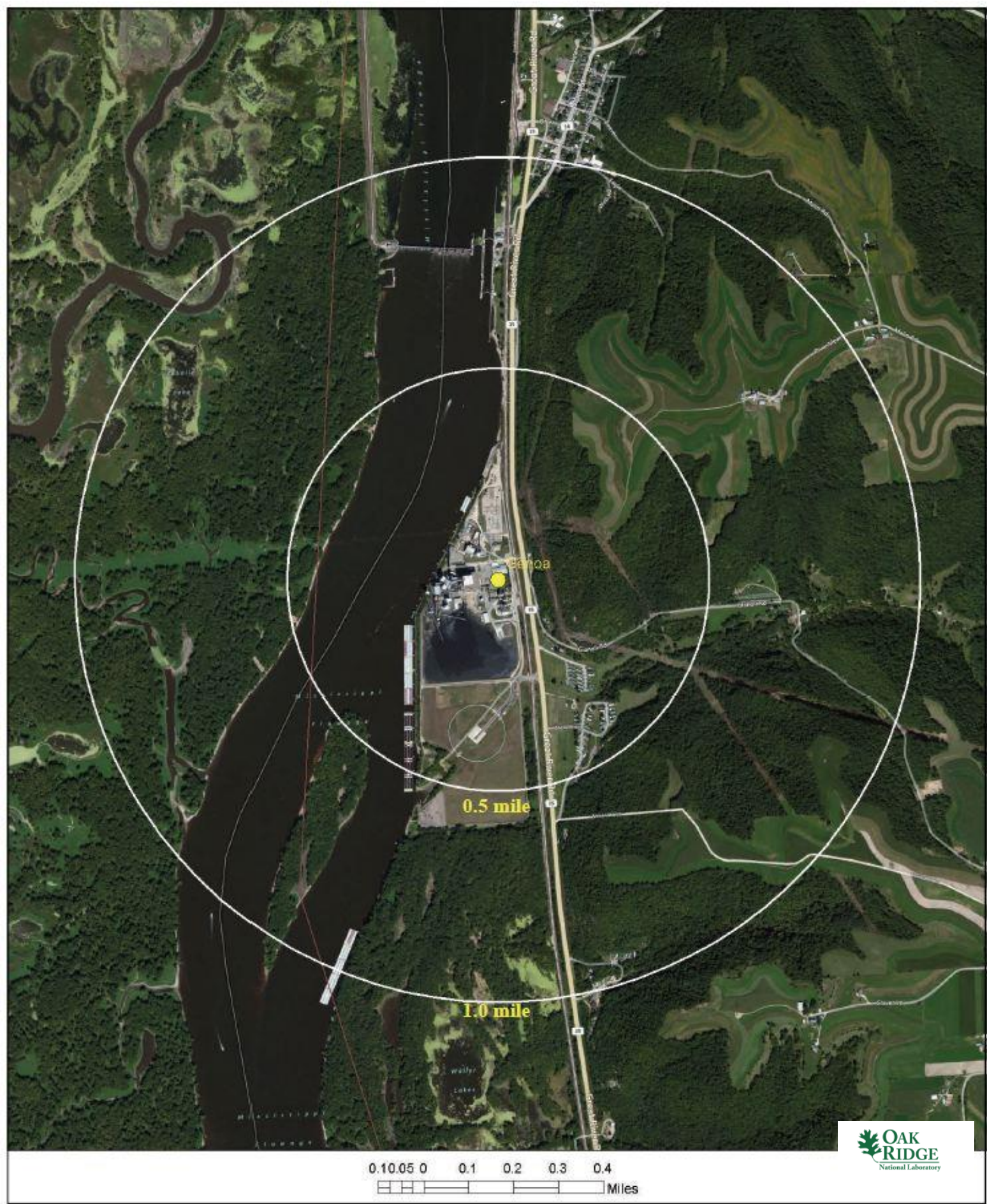

Fig. C.84. Satellite view of Genoa Station proximity. 


\section{C.4.4 Screening Criteria Overview}

Table C.49. Genoa Station siting criteria summary

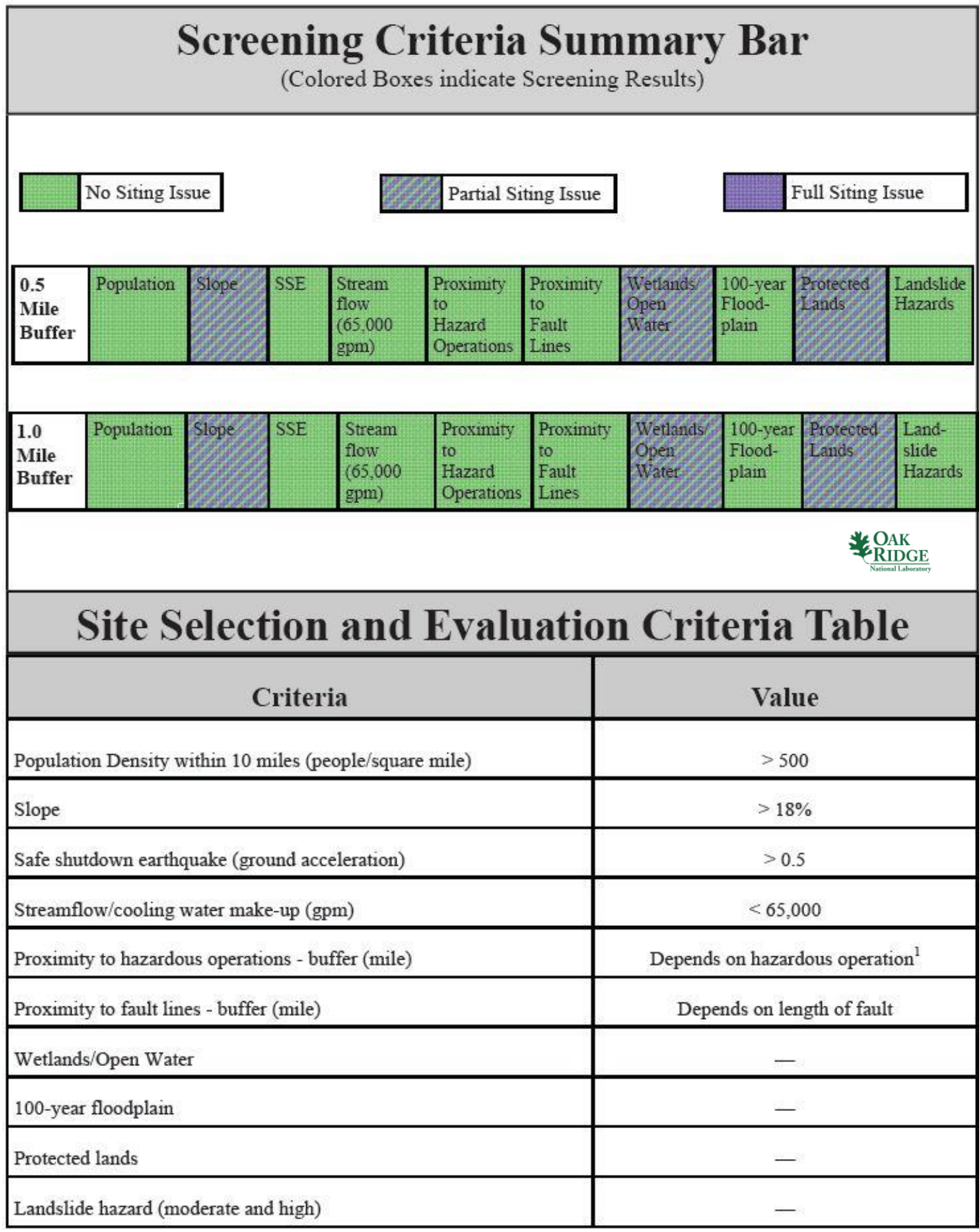

${ }^{1}$ Hazardous facilities (airports-5 miles and oil refineries-1 mile) 


\section{C.4.5 Composite Map and Individual Siting Issue Maps}

A composite map of SMR siting challenges to the Genoa Station is shown in Fig. C.85. The physical plant structures are located on land with no siting issues. Following this map are maps of the individual SMR siting criteria based on selected input values.

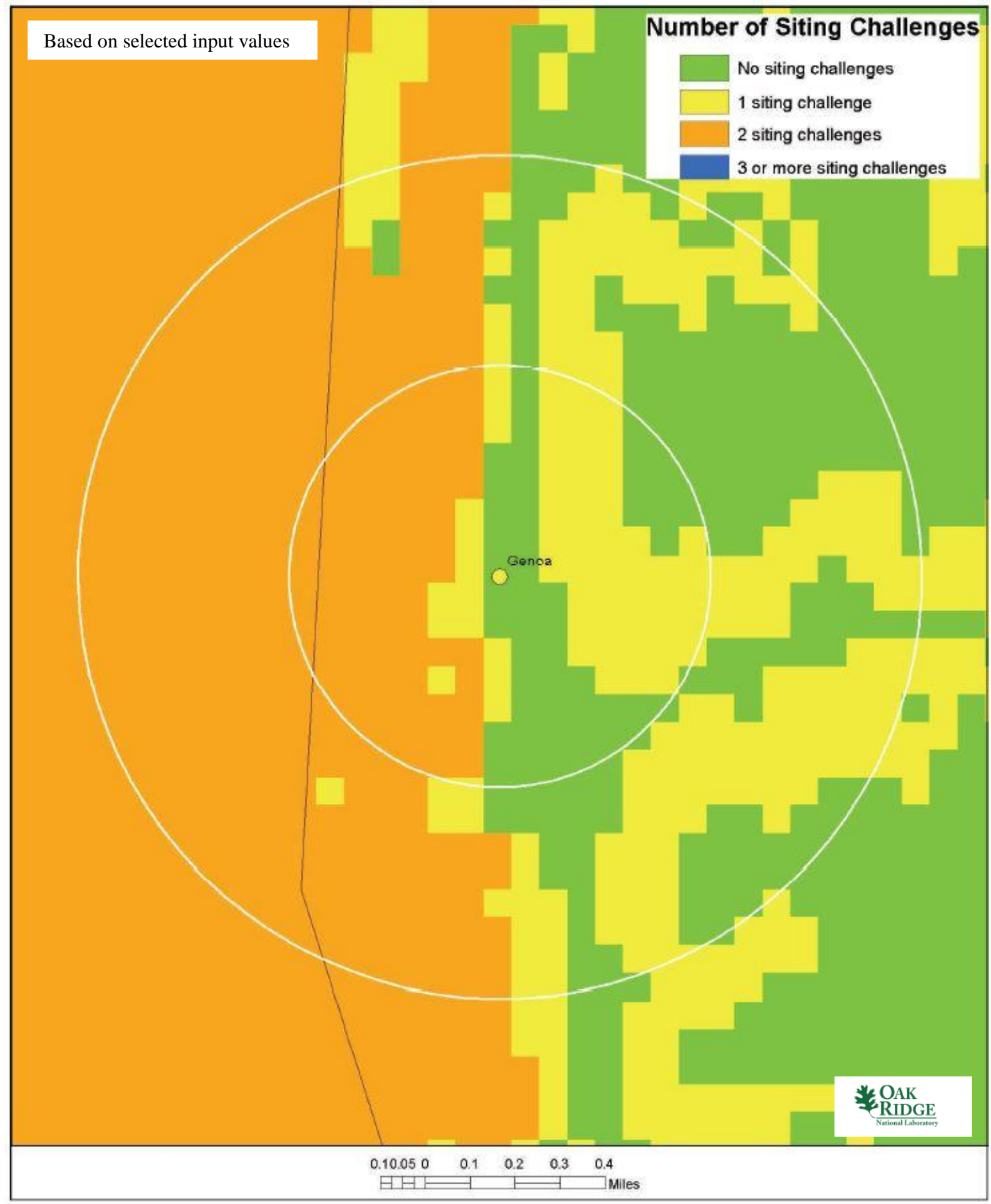

Fig. C.85. Genoa Station composite map. 

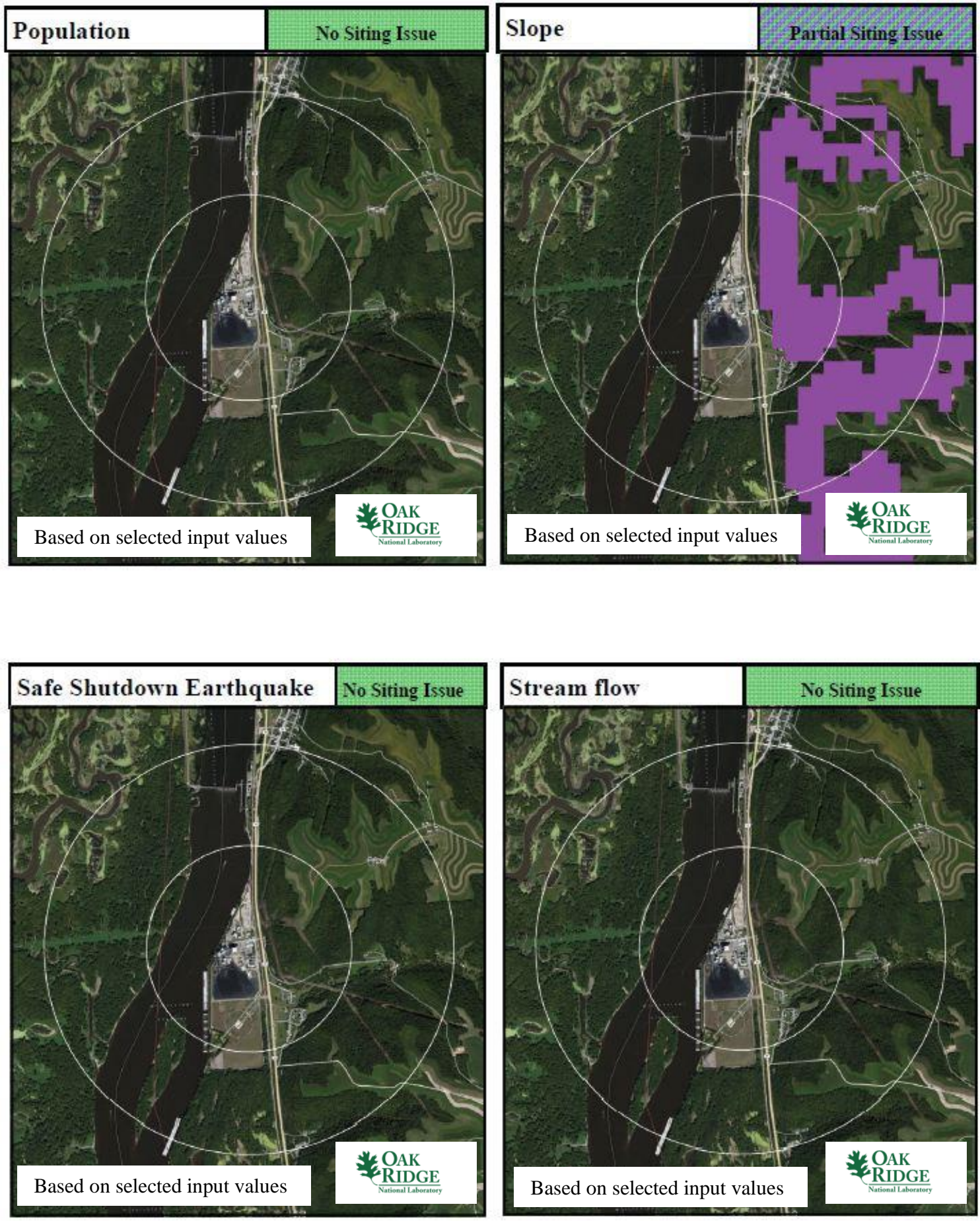

Genoa Station 

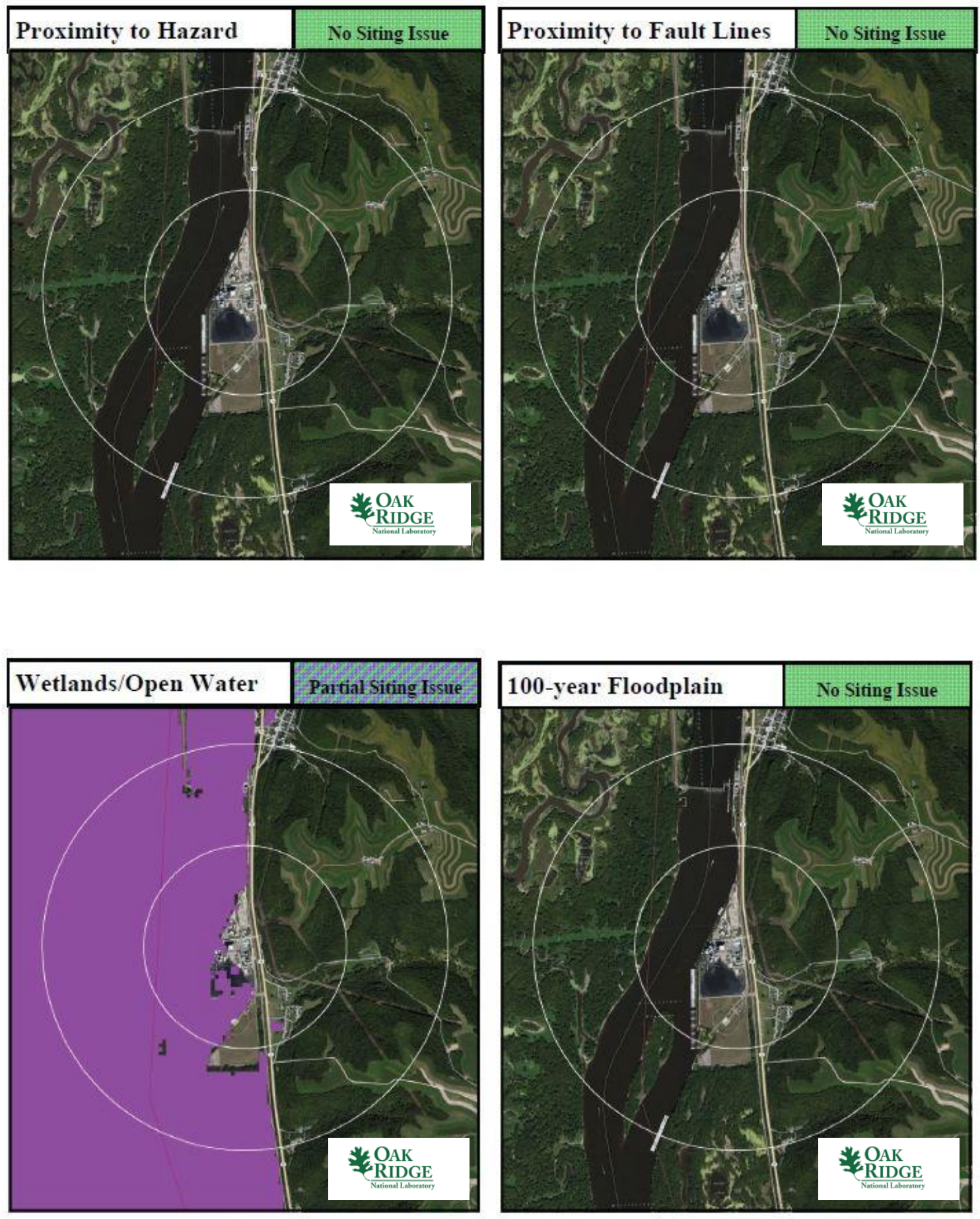

Genoa Station 

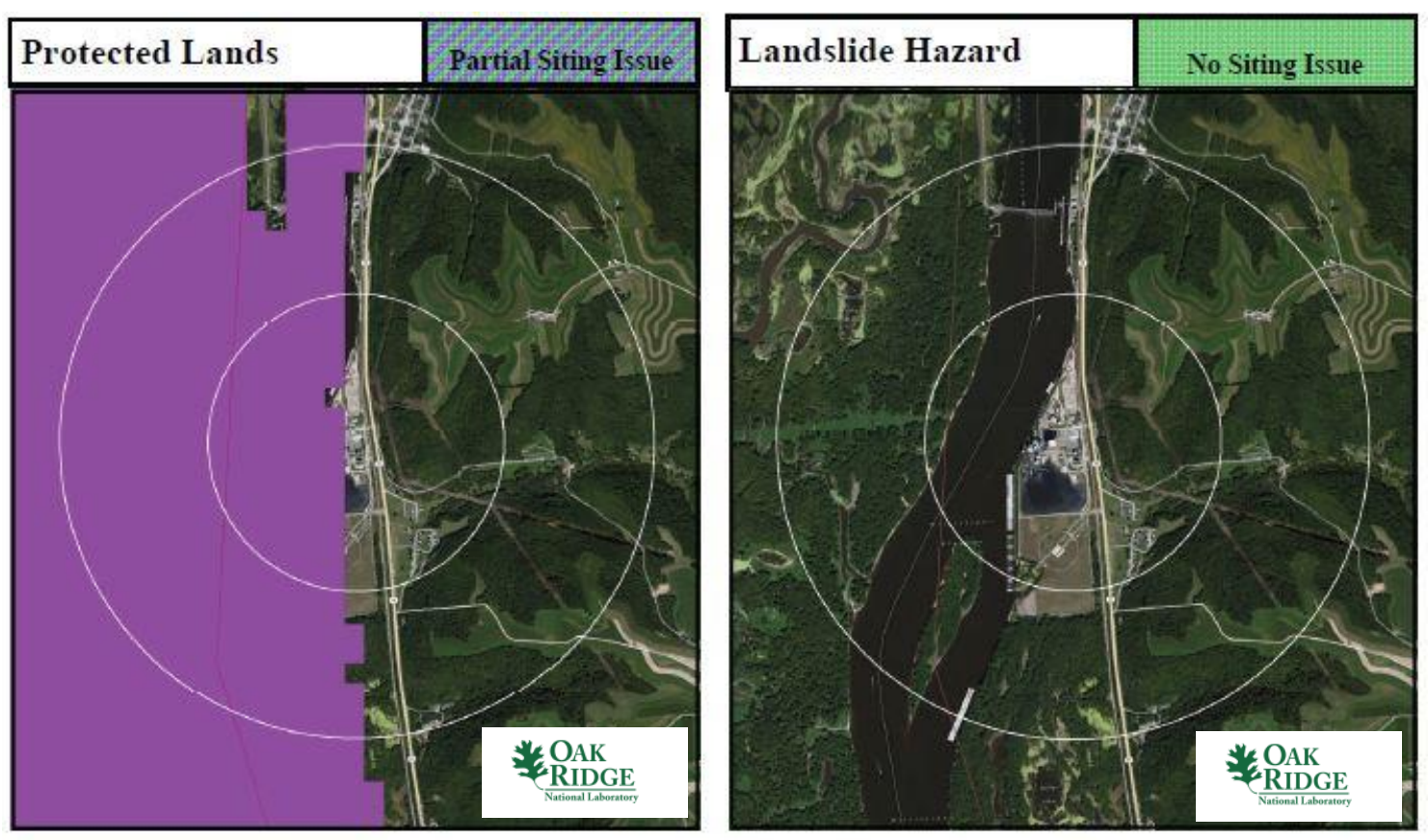

Genoa Station

\section{C.4.6 Site Evaluation}

Dairyland Power Cooperative owned and operated the La Crosse Boiling water reactor, which was permanently shut down in 1987. The fuel was removed from the reactor and is currently stored in the reactor containment building. Therefore, Dairyland Power Cooperative has the licensing experience to operate an SMR at this site. Also, the site would have an environmental pedigree for siting future nuclear power units at the site.

From an environmental justice perspective, the community collectively appears to have achieved a reasonable level of education with median income levels typical of much of the United States. Therefore, siting an SMR at this location would not seem to be disenfranchising a less-educated or poverty-stricken community. Furthermore, the education level of the Genoa Station community would seem to support the higher-technology job opportunities provided by an SMR.

As shown in Sects. C.0 and C.0, the Genoa Station site has partial SMR site screening issues with slope, wetlands/open waters, and protected land. The slope issue is related to hills to the east of the site across Wisconsin Highway 35. The wetlands/open waters issue reflects the adjacent Mississippi River. The protected lands issue reflects a series of islands across the main Mississippi River channel west of the plant site. Further visual inspection of the aerial imagery indicates that these three issues would not directly impact the siting of an SMR at this location. The remaining SMR site screening criteria are met site-wide for the values established in the updated SMR siting report.1

The site is somewhat landlocked because it is bordered on the west side by the Mississippi River and relatively steep-grade hills on the east side adjacent to Wisconsin Highway 35. The aerial view indicates that the north end of the site is almost completely occupied with existing structures. In addition, Genoa Station is just 1 mile downstream from Mississippi River Lock and Dam \# 8, which introduces a beyonddesign-basis site external flooding concern, which could be problematic in the post-Fukushima licensing era. Also, a small trailer community appears to exist directly across the highway from the plant site. This could be a contentious issue should Dairyland Power decide to submit a COL application for an SMR at this site to meet any growing need for electrical capacity at this grid location. 
When future load demands indicate the need for expanded generation capacity in this region, the utility would need to work closely with local leaders and civic groups to make the case for siting an SMR at this location. The site meets current NRC RG 4.7 recommendations for population density without additional consideration for relaxed SMR population siting requirements based on reduced source term. The Genoa Station site meets conventional standards for SMR siting pending verification of flooding parameters associated with the nearby upstream dam. 
C-40 


\section{C.5 Lansing Smith Power Station}

\section{C.5.1 Location Detail}

As shown in Fig. C.86, the Lansing Smith Power Station is located along the coast of the Gulf of Mexico in Florida's Panhandle, off Florida Highway 77, in Bay County. Florida Highway 368 is accessible approximately 5.2 miles to the south. Interstate 10 is accessible approximately 32 miles to the north. Rail access is available within 5.4 miles and barge access is available from the North Bay within 1.2 miles of the site. The plant is located about 3.6 miles northwest of Lynn Haven, Florida, with a population of approximately 18,542 people.

- Plant: Lansing Smith Power Station

- Utility: Gulf Power

- Coordinates: lat. $30.26862^{\circ} \mathrm{N}$, long. $85.70051^{\circ} \mathrm{W}$

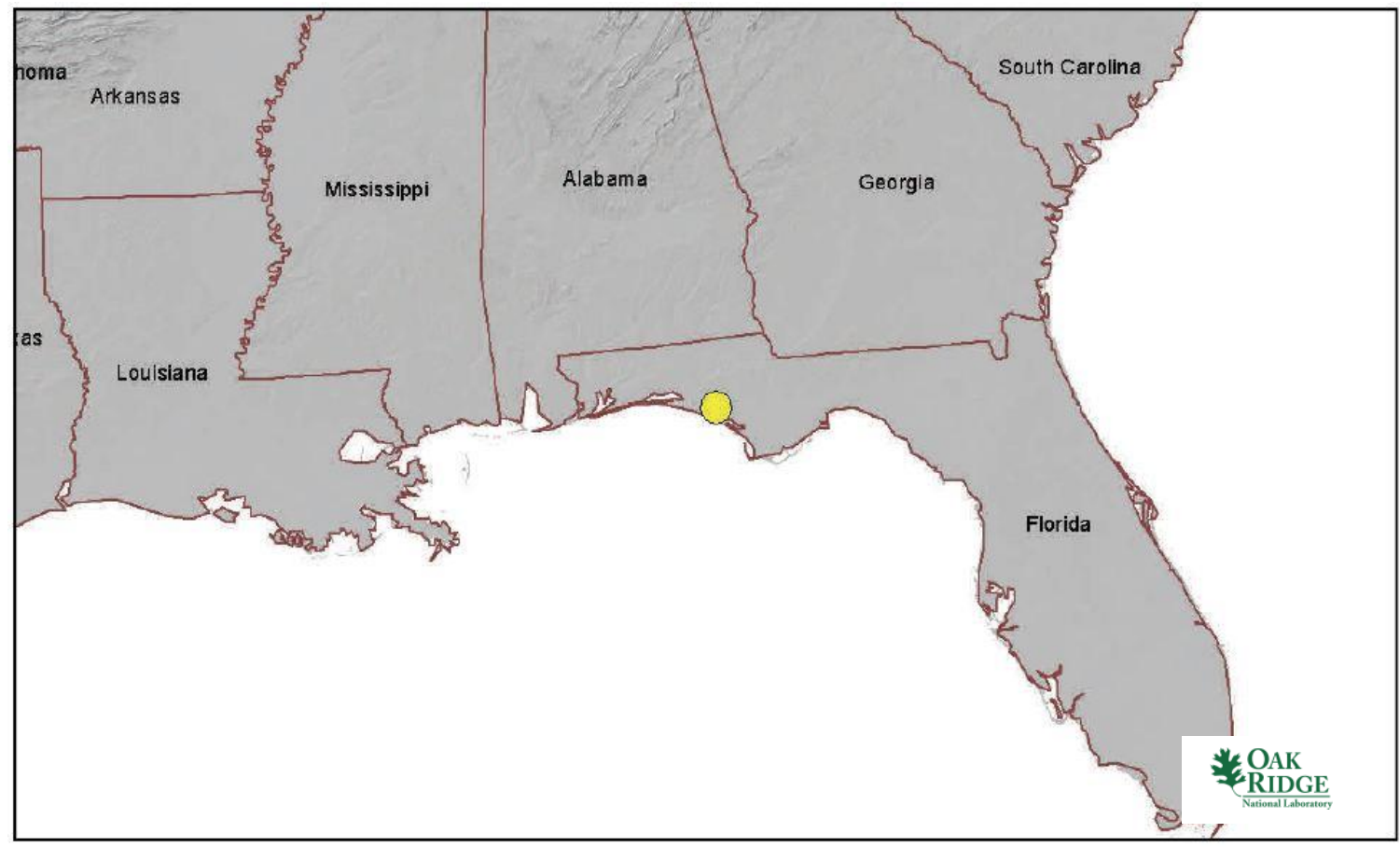

Fig. C.86. Lansing Smith Power Station location map.

\section{C.5.2 Site Description and Status}

The Lansing Smith Power Station is owned and operated by Gulf Power, a subsidiary of Southern Company. The Lansing Smith Power Station is a two-unit coal-fired plant. Unit 1, commissioned in 1965, is rated at $150 \mathrm{MW}(\mathrm{e})$ and Unit 2, commissioned in 1967, is rated at $190 \mathrm{MW}(\mathrm{e})$ for a total station base load capacity of $340 \mathrm{MW}(\mathrm{e})$. The coal-fired units are cooled by once-through cooling via a canal system connected to the North Bay. In addition, a 3-unit combustion turbine, commissioned in 2002 has a combined peaking capacity of $620 \mathrm{MW}(\mathrm{e})$. These units are cooled by mechanical draft cooling towers. Finally, the site includes a $42 \mathrm{MW}$ (e) gas turbine, commissioned in 1971. Therefore, the site currently has a total fossil fuel capacity of $1002 \mathrm{MW}(\mathrm{e})$. All units are currently operable.

The plant is situated on roughly 1300 acres on the North Bay approximately 75 miles southwest of the 1,776 MW(e) Farley nuclear facility. Lansing Smith Power Station is approximately 55 miles southwest of the $98 \mathrm{MW}$ (e) Scholz coal-fired plant and approximately 93 miles east of the 1,135 MW(e) Crist coal- 
fired plant. A 35 MW(e) hydroelectric project is under development about 1 mile southwest of the Willow Island Power Station.

As noted in Table C.50, the nearest major fault line based on USGS data is about 755 miles northwest in Oklahoma. The maximum safe-shutdown earthquake for the site is below $0.3 \mathrm{~g}$ peak ground acceleration. More than 500,000 gpm of cooling water makeup is available from the Choctawhatchee River about 16.2 miles away. In addition, the adjacent North Bay provides a source of cooling water.

The permanent population within 1 mile of the plant is approximately 800 people, yielding a population density of approximately 255 people per square mile. The permanent population within 10 miles of the plant is approximately 247,000 people, yielding a population density of about 786 people per square mile.

According to the US EPA Environmental Justice website, there are 40,992 occupied housing units within 10 miles of the plant site based on 2000 US Census data. Further, more than $80 \%$ of area adults over age 25 have a high school diploma or higher education. The median annual income for the area is between $\$ 25 \mathrm{~K}$ and $\$ 50 \mathrm{~K}$.

Table C.50. Lansing Smith Power Station site statistics

\begin{tabular}{|l|l|l|l|}
\hline $\begin{array}{l}\text { Population } \\
\text { Population Within }\end{array}$ & \multicolumn{2}{l|}{$\begin{array}{l}\text { Utility } \\
\text { Distance to Grid Capacity }\end{array}$} \\
\hline $0.5 \mathrm{mi}$ & $<500$ & $>400 \mathrm{MWe}$ & $\sim 0.3 \mathrm{mi}$ \\
\hline $1 \mathrm{mi}$ & $\sim 800$ & $>800 \mathrm{MWe}$ & $\sim 131 \mathrm{mi}$ \\
\hline $5 \mathrm{mi}$ & $\sim 54,500$ & $>1600 \mathrm{MWe}$ & $\sim 71 \mathrm{mi}$ \\
\hline $10 \mathrm{mi}$ & $\sim 247,000$ & $>3200 \mathrm{MWe}$ & $\sim 206 \mathrm{mi}$ \\
\hline Nearest City with Population & Distance to Cooling Water \\
\hline$>10,000$ & Lynn Haven, FL & $>50,000 \mathrm{gpm}$ & $\sim 5.4 \mathrm{mi}$ (Burnt Mill Creek) \\
\hline$>50,000$ & Dothan, AL & $>100,000$ gpm & $\sim 7.3 \mathrm{mi}$ (Ecofina Creek) \\
\hline$>100,000$ & Tallahassee, FL & $>200,000$ gpm & $\sim 7.3 \mathrm{mi}$ (Ecofina Creek) \\
\hline$>500,000$ & Jacksonville, FL & $>500,000$ gpm & $\sim 16.2 \mathrm{mi}$ (Choctawhatchee \\
\hline Geotechnical & \multicolumn{3}{l}{ River) } \\
\hline Max Earthquake Acceleration & $<0.3 \mathrm{~g}$ & Accessibility & \\
\hline Max Slope & $\sim 2 \%$ & Distance to Major Roadway & $\sim 5.2 \mathrm{mi}$ (SR 368) \\
\hline Nearest Fault Line & $\sim 755$ mi (Oklahoma) & Distance to Rail Transport & $\sim 5.4$ mi (BAYL) \\
\hline Nearest Hazard Site & $\sim 4$ mi (Airport- \\
\hline
\end{tabular}




\section{C.5.3 Aerial Imagery}

The aerial imagery in Fig. C.87 indicates that Company Road 230 runs within 1.0 mile of the Lansing Smith Power Station. The Lansing Smith site appears to be relatively isolated.

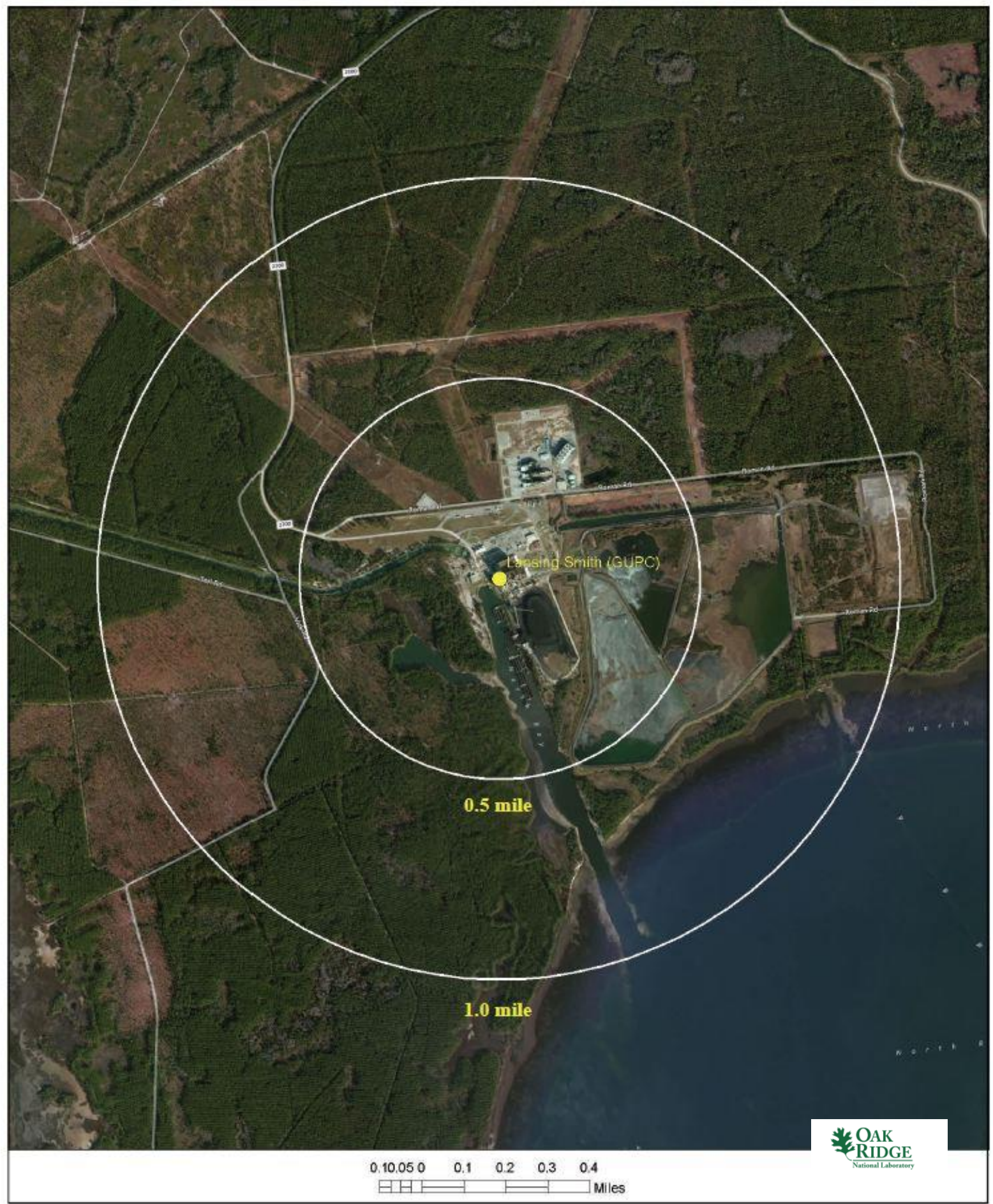

Fig. C.87. Satellite view of Lansing Smith Power Station proximity. 


\section{C.5.4 Screening Criteria Overview}

Table C.51. Lansing Smith Power Station siting criteria summary

\begin{tabular}{|c|c|c|c|c|c|c|c|c|c|}
\hline & & '̌r & & $\lg C$ & $\begin{array}{l}\text { iteria } \\
\text { indicate }\end{array}$ & $\begin{array}{l}\text { Sun } \\
\text { Screenin }\end{array}$ & $\underset{\text { Results) }}{\operatorname{mary} \text { Bar }}$ & & \\
\hline & No Siting Is: & & & & Partial Si & iting Issue & & Full Siting & ssue \\
\hline \begin{tabular}{|l|}
0.5 \\
Mile \\
Buffer
\end{tabular} & Population & Slope & SSE & $\begin{array}{l}\text { Stream } \\
\text { flow } \\
(65,000 \\
\text { gpm) } \\
\end{array}$ & $\begin{array}{l}\text { Proximity } \\
\text { to } \\
\text { Hazard } \\
\text { Operations }\end{array}$ & $\begin{array}{l}\text { Proximity } \\
\text { to } \\
\text { Fault } \\
\text { Lines }\end{array}$ & \begin{tabular}{|l|l|} 
Wetlandsy & $\begin{array}{l}\text { 100-year } \\
\text { Open } \\
\text { Wlood- } \\
\text { plain }\end{array}$ \\
\end{tabular} & $\begin{array}{l}\text { Protected } \\
\text { Lands }\end{array}$ & $\begin{array}{l}\text { Landslide } \\
\text { Hazards }\end{array}$ \\
\hline \begin{tabular}{|l|}
1.0 \\
Mile \\
Buffer
\end{tabular} & Population & Slope & SSE & $\begin{array}{l}\text { Stream } \\
\text { flow } \\
(65,000 \\
\mathrm{gpm}) \\
\end{array}$ & $\begin{array}{l}\text { Proximity } \\
\text { to } \\
\text { Hazard } \\
\text { Operations }\end{array}$ & \begin{tabular}{|l} 
Proximity \\
to \\
Fault \\
Lines
\end{tabular} & \begin{tabular}{|l|l|} 
Wetlands & $\begin{array}{l}100-y e a r \\
\text { Open }\end{array}$ \\
Flood- \\
plain
\end{tabular} & $\begin{array}{l}\text { Protected } \\
\text { Lands }\end{array}$ & \begin{tabular}{|l} 
Land- \\
slide \\
Hazards
\end{tabular} \\
\hline & & & & & & & & & $\begin{array}{l}\text { AK } \\
\text { IDGE }\end{array}$ \\
\hline & ite S & er & & anc & Vall & io & riteria & Tah & \\
\hline & & & rite & & & & Valu & & \\
\hline Populat & on Density w & ithin 1 & ailes ( & ople/squa & mile) & & $>50$ & & \\
\hline Slope & & & & & & & $>18^{\circ}$ & & \\
\hline Safe shu & tdown earthq & uake ( & und a & eleration) & & & $>0.5$ & & \\
\hline Streamf & ow/cooling $\mathrm{n}$ & rater $\mathrm{m}$ & e-up ( & & & & $<65,0$ & & \\
\hline Proximi & $y$ to hazardor & is oper & ons - 1 & ffer (mile) & & & Depends on hazard & dous operat & ion $^{1}$ \\
\hline Proximi & $\mathrm{y}$ to fault line & s - buf & (mile & & & & Depends on len & ngth of faul & \\
\hline Wetland & s/Open Wate & & & & & & - & & \\
\hline 100 -yea & floodplain & & & & & & - & & \\
\hline Protecte & lands & & & & & & - & & \\
\hline Landslic & e hazard (mo & derate & high & & & & - & & \\
\hline
\end{tabular}

${ }^{1}$ Hazardous facilities (airports- 5 miles and oil refineries -1 mile) 


\section{C.5.5 Composite Map and Individual Siting Issue Maps}

A composite map of SMR siting challenges to the Lansing Smith Power Station is shown in Fig. C.88. The physical plant structures are located on land with a single siting challenge. Following this map are maps of the individual SMR siting criteria based on selected input values.

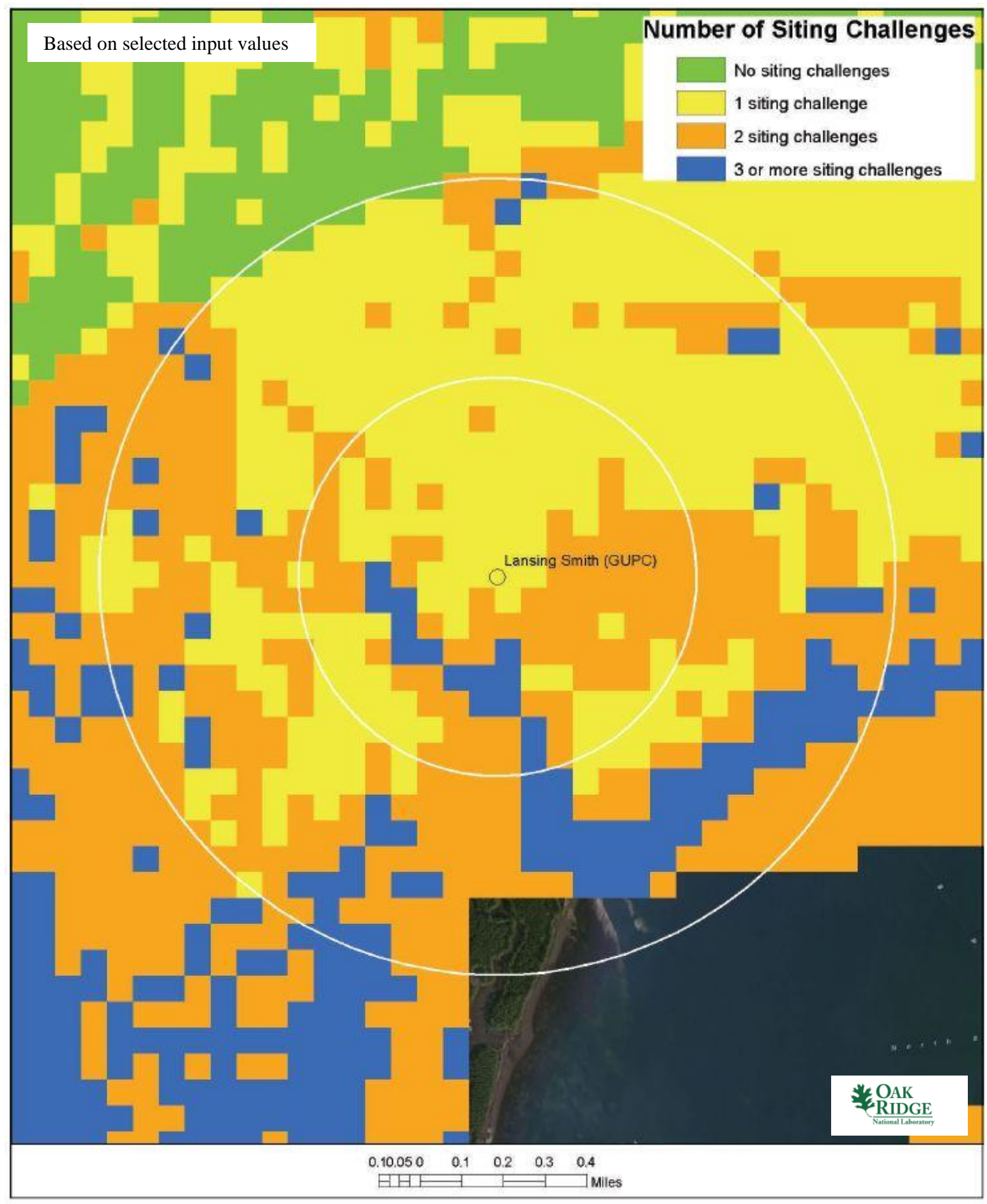

Fig. C.88. Lansing Smith Power Station composite map. 

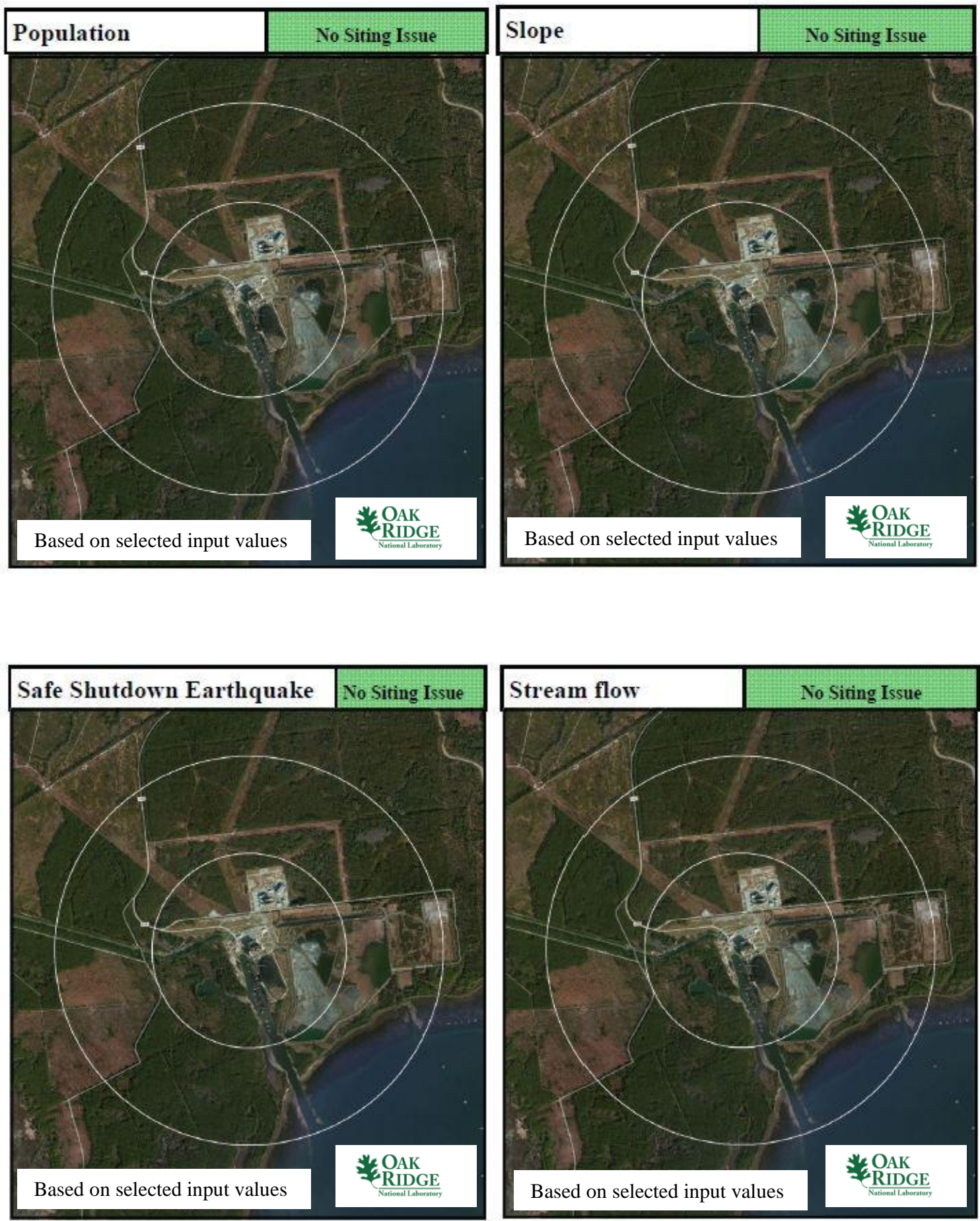

Lansing Smith Power Station 

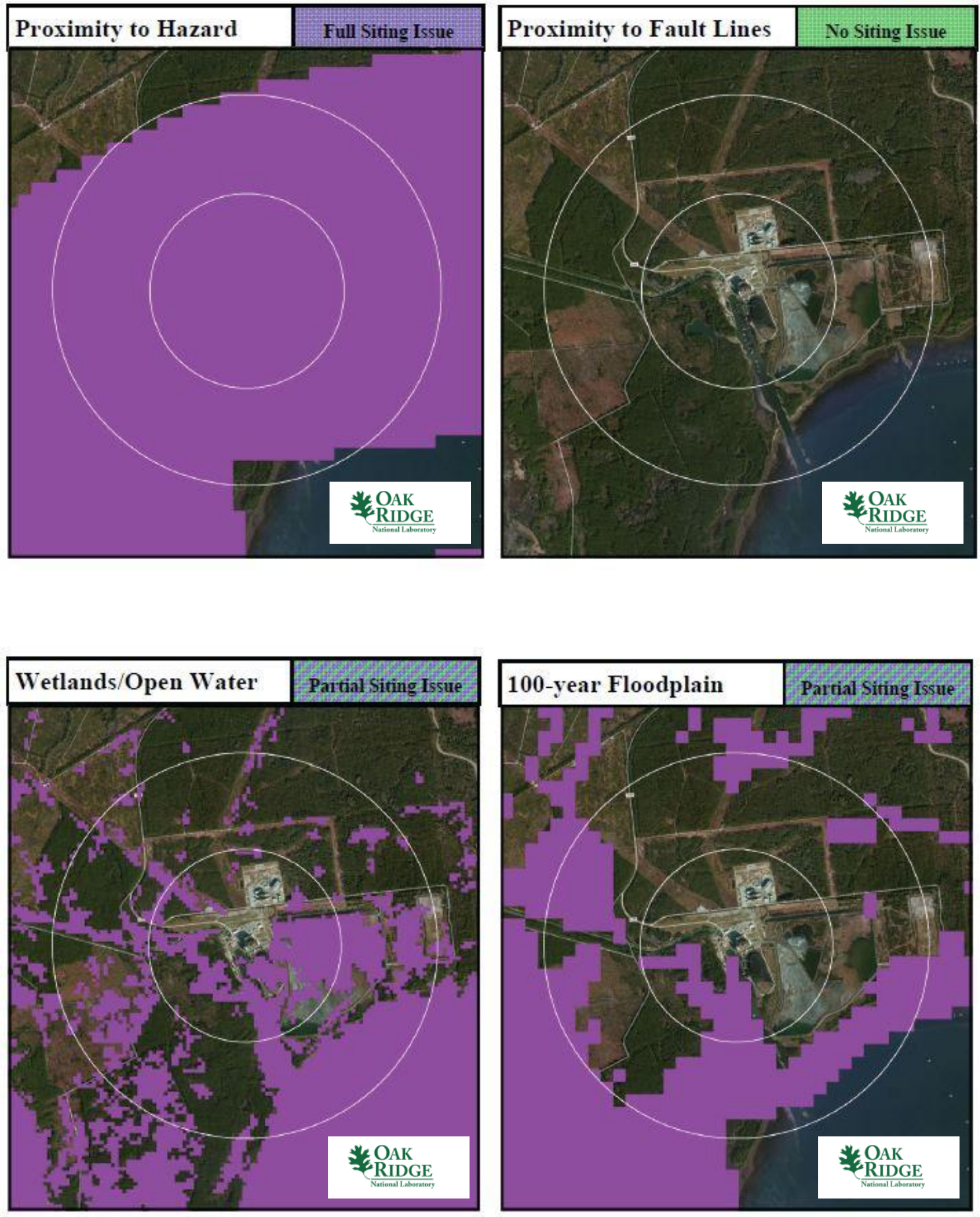

Lansing Smith Power Station 

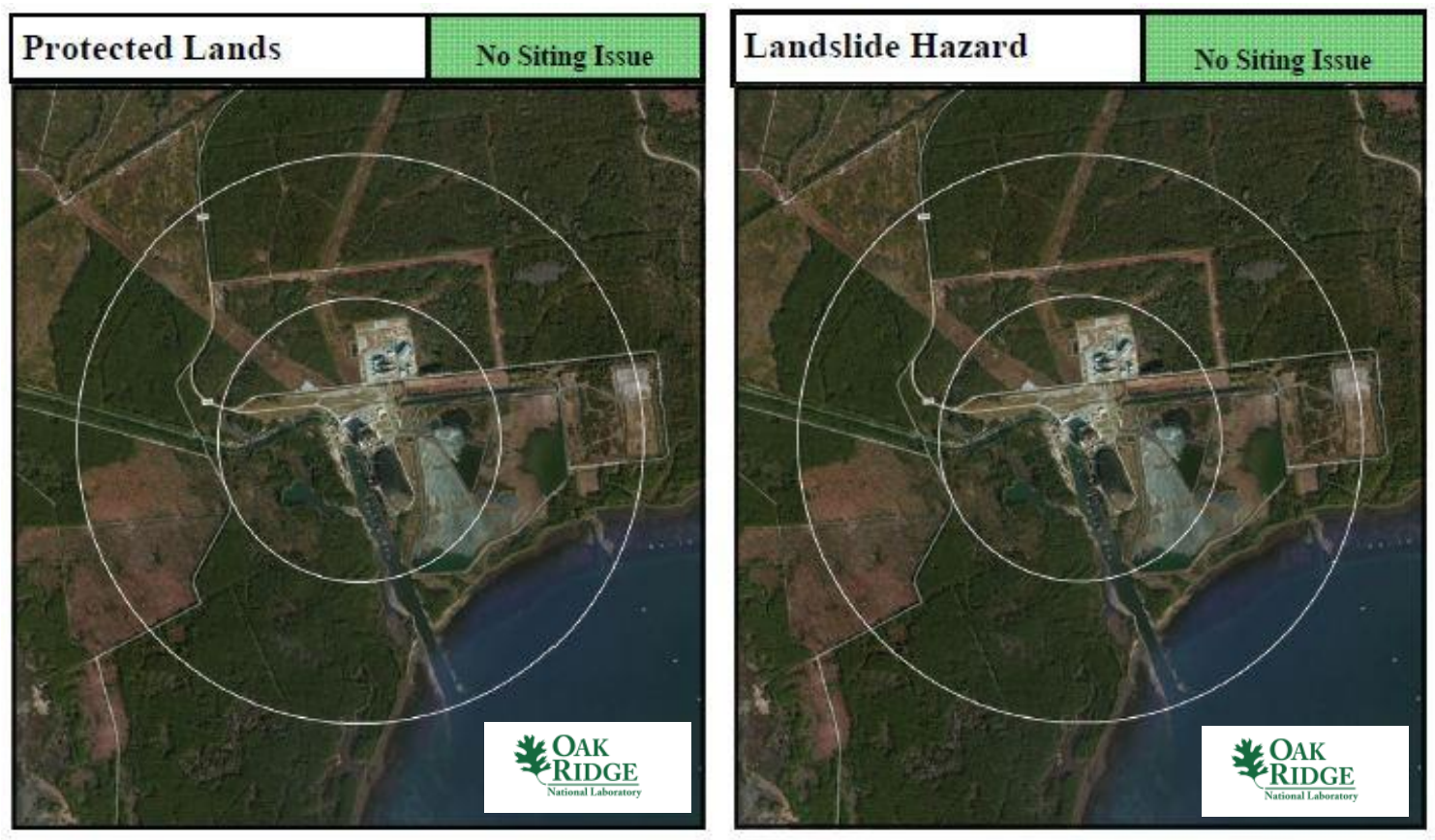

Lansing Smith Power Station

\section{C.5.6 Site Evaluation}

Gulf Power does not operate any nuclear power plants in the United States. However, its parent company, Southern Company, operates six nuclear power facilities, four in Georgia and two in Alabama. Southern Company has also applied for a COL for two nuclear plants at the Vogtle Plant site in Georgia. Therefore, Southern Company has the licensing experience to operate an SMR at this site. The site contains sufficient acreage to support siting an SMR.

From an environmental justice perspective, the community collectively appears to have achieved a reasonable level of education with median income levels typical of much of the United States. Therefore, siting an SMR at this location would not seem to be disenfranchising a less-educated or poverty-stricken community. Furthermore, the education level of the Lansing Smith Power Station community would seem to support the higher-technology job opportunities provided by an SMR.

As shown in Sects. C.0 and C.0, the Lansing Smith Power Station has a full site issue with proximity to hazards. The Panama City--Bay County International Airport is across the North Bay about 4.1 miles southeast of the plant site. The proximity-to-hazards SMR SSEC notes airports within 5 miles. The runways are not directly in line with the power plant site, and the plans for underground siting would probably eliminate the airport location as a safety concern. Furthermore, proximity to an airport is an avoidance issue, as opposed to a hard exclusion.

The Lansing Smith Power Station site also has partial SMR site screening issues with wetlands/open waters and 100-year floodplain. The wetlands/open waters and 100-year floodplain issues affect the area on the south side of the plant site, which reflects the adjacent North Bay that connects to the Gulf of Mexico. The 100-year floodplain could be a problematic issue for siting an SMR at this location in light of recent industry focus on flooding. The remaining SMR site screening criteria are met site-wide for the values established in the updated SMR siting report.1

The GIS population algorithm did not cite the plant location as a population density concern based on the SMR SSEC criteria. The aerial view of the plant supports this result. However, the nearby city of Lynn 
Haven, Florida, and the attractiveness of living near the gulf could negatively affect the population density regarding siting an SMR at this location in the future.

When future load demands indicate the need for expanded generation capacity in this region, the utility would need to work closely with local leaders and civic groups to make the case for siting an SMR at this location. An SMR at this location would make the Lansing Smith plant site a diversified energy park. The site meets current NRC RG 4.7 recommendations for population density with additional consideration for relaxed SMR population siting requirements based on reduced source term. The Lansing Smith Power Station site meets multiple conventional standards in the near-term for consideration of siting an SMR at the coal station location pending verification that the Panama City-Bay County International Airport does not pose a safety issue for the site. In addition, there is a longer-term consideration for population growth in the proximity of the city of Lynn Haven, Florida. 
C-50 


\section{C.6 Powerton Generating Station}

\section{C.6.1 Location Detail}

As shown in Fig. C.89, the Powerton Generating Station is located in central Illinois about 12 miles south of Peoria, off County Road 1500, in Tazewell County. Illinois State Road 29 is accessible within 1 mile and Interstate 474 is accessible approximately 7 miles to the north. Rail access is available onsite and barge access is available within 1 mile via the Illinois River. The plant is located about 3 miles southwest of Pekin, Illinois, with a population of approximately 34,000 people.

- Plant: Powerton Generating Station

- Utility: Midwest Generation

- Coordinates: lat. $40.54066^{\circ} \mathrm{N}$, long. $89.67858^{\circ} \mathrm{W}$

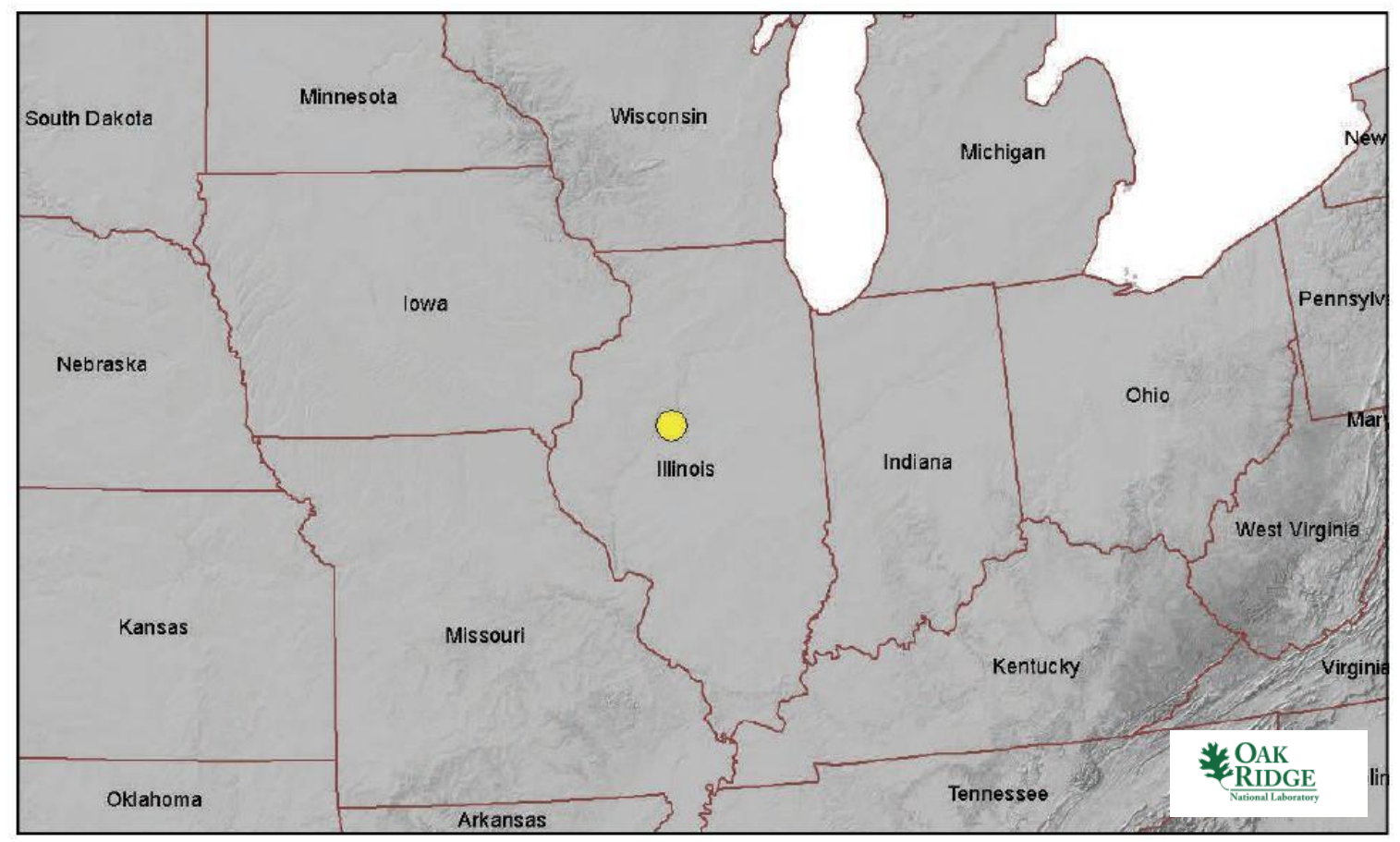

Fig. C.89. Powerton Generating Station Location Map

\section{C.6.2 Site Description and Status}

The Powerton Generating Station is owned and operated by Midwest Generation, a subsidiary of Edison International. The Powerton Generating Station was a four-unit coal-fired facility. Units 1 and 2, commissioned in 1928 and 1929, were both rated at $55 \mathrm{MW}(\mathrm{e})$. Units 3 and 4, commissioned in 1930 and 1940, were both rated at $105 \mathrm{MW}(\mathrm{e})$. All four original units were retired in 1974. The original four units, with a total capacity of $320 \mathrm{MW}(\mathrm{e})$, are recognized in the Platt's database and were used to qualify this site for selection as a sample plant. However, two additional coal-fired units, unrecognized by the Platt's database, were commissioned in 1972 and 1975 and are both rated at 893 MW(e) for a current site capacity of 1,786 MW(e). Therefore, based on the high station capacity, this site should not have been selected as a sample site. However, since the location data have been generated, the site will be evaluated. Units 5 and 6 are cooled by an onsite cooling pond. The operating units are cooled by an onsite cooling pond. The Powerton Generating Station has been backfit with updated emission control equipment to 
meet stricter upcoming EPA regulations. The site employs 190 people and generates $\$ 850 \mathrm{~K}$ in property taxes annually to the local government.

Including the large cooling pond, the Powerton site encompasses approximately 2000 acres. The site is approximately 51 miles northwest of the 1,065 MW(e) Clinton nuclear facility and 71 miles southwest of the 2,288 MW(e) LaSalle nuclear facility. The plant is 4 miles downstream of the $780 \mathrm{MW}$ (e) coal-fired Edwards Plant and 17 miles upstream of the $441 \mathrm{MW}(\mathrm{e})$ coal-fired Duck Creek plant. In addition, the 488 MW(e) coal-fired Havana Generating Station is 28 miles southwest of the site. The 135 MW(e) Keokuk Dam hydroelectric project is 90 miles west of the Powerton Generating Station.

As noted in Table C.52, the nearest major fault line based on USGS data is about 566 miles southwest in Kansas. The maximum safe-shutdown earthquake for the site is below $0.3 \mathrm{~g}$ peak ground acceleration. More than 500,000 gpm of cooling water makeup is available from the adjacent Illinois River.

The permanent population within 1 mile of the plant is approximately 2300 people, yielding a population density of approximately 730 people per square mile. The permanent population within 10 miles of the plant is approximately 210,000 people, yielding a population density of about 670 people per square mile.

According to the US EPA Environmental Justice website, there are 35,270 occupied housing units within 10 miles of the plant site based on 2000 US Census data. Further, just under $80 \%$ of area adults over age 25 have a high school diploma or higher education. The median annual income for the area is between $\$ 25 \mathrm{~K}$ and $\$ 50 \mathrm{~K}$.

Table C.52. Powerton Generating Station site statistics

\begin{tabular}{|c|c|c|c|}
\hline \multicolumn{2}{|l|}{$\begin{array}{l}\text { Population } \\
\text { Population Within }\end{array}$} & \multicolumn{2}{|l|}{$\begin{array}{l}\text { Utility } \\
\text { Distance to Grid Capacity }\end{array}$} \\
\hline $0.5 \mathrm{mi}$ & $\sim 1,000$ & $>400 \mathrm{MWe}$ & $\sim 0.2 \mathrm{mi}$ \\
\hline $1 \mathrm{mi}$ & $\sim 2,300$ & $>800 \mathrm{MWe}$ & $\sim 0.1 \mathrm{mi}$ \\
\hline $5 \mathrm{mi}$ & $\sim 81,000$ & $>1600 \mathrm{MWe}$ & $\sim 138 \mathrm{mi}$ \\
\hline $10 \mathrm{mi}$ & $\sim 210,000$ & $>3200 \mathrm{MWe}$ & $\sim 84 \mathrm{mi}$ \\
\hline \multicolumn{2}{|c|}{ Nearest City with Population } & \multicolumn{2}{|c|}{ Distance to Cooling Water } \\
\hline$>10,000$ & Pekin, IL & $>50,000 \mathrm{gpm}$ & $\sim 0.8 \mathrm{mi}$ (Illinois River) \\
\hline$>50,000$ & Bloomington, IL & $>100,000 \mathrm{gpm}$ & $\sim 0.8 \mathrm{mi}$ (Illinois River) \\
\hline$>100,000$ & Peoria, IL & $>200,000 \mathrm{gpm}$ & $\sim 0.8 \mathrm{mi}$ (Illinois River) \\
\hline$>500,000$ & Chicago, IL & $>500,000 \mathrm{gpm}$ & $\sim 0.8 \mathrm{mi}$ (Illinois River) \\
\hline \multicolumn{2}{|l|}{ Geotechnical } & \multicolumn{2}{|l|}{ Accessibility } \\
\hline Max Earthquake Acceleration & $<0.3 \mathrm{~g}$ & Distance to Major Roadway & $\sim 0.7 \mathrm{mi}(\mathrm{SR} 29)$ \\
\hline Max Slope & $\sim 5 \%$ & Distance to Water Transport & $\sim 0.8 \mathrm{mi}$ (Illinois River) \\
\hline Nearest Fault Line & $\sim 566 \mathrm{mi}$ (Kansas) & Distance to Rail Transport & $\sim 0.1 \mathrm{mi}$ (IMRR) \\
\hline Nearest Hazard Site & $\begin{array}{l}8 \text { mi (Airport- } \\
\text { Greater Peoria Regional) }\end{array}$ & Distance to Airport & $\begin{array}{c}\sim 8 \text { mi (Greater Peoria } \\
\text { Regional) }\end{array}$ \\
\hline
\end{tabular}




\section{C.6.3 Aerial Imagery}

The aerial imagery in Fig. C.90 indicates the large industrial area that makes up the Powerton site. Housing can be identified to the northeast within 1 mile of the site. This is the southern end of Pekin, Illinois.

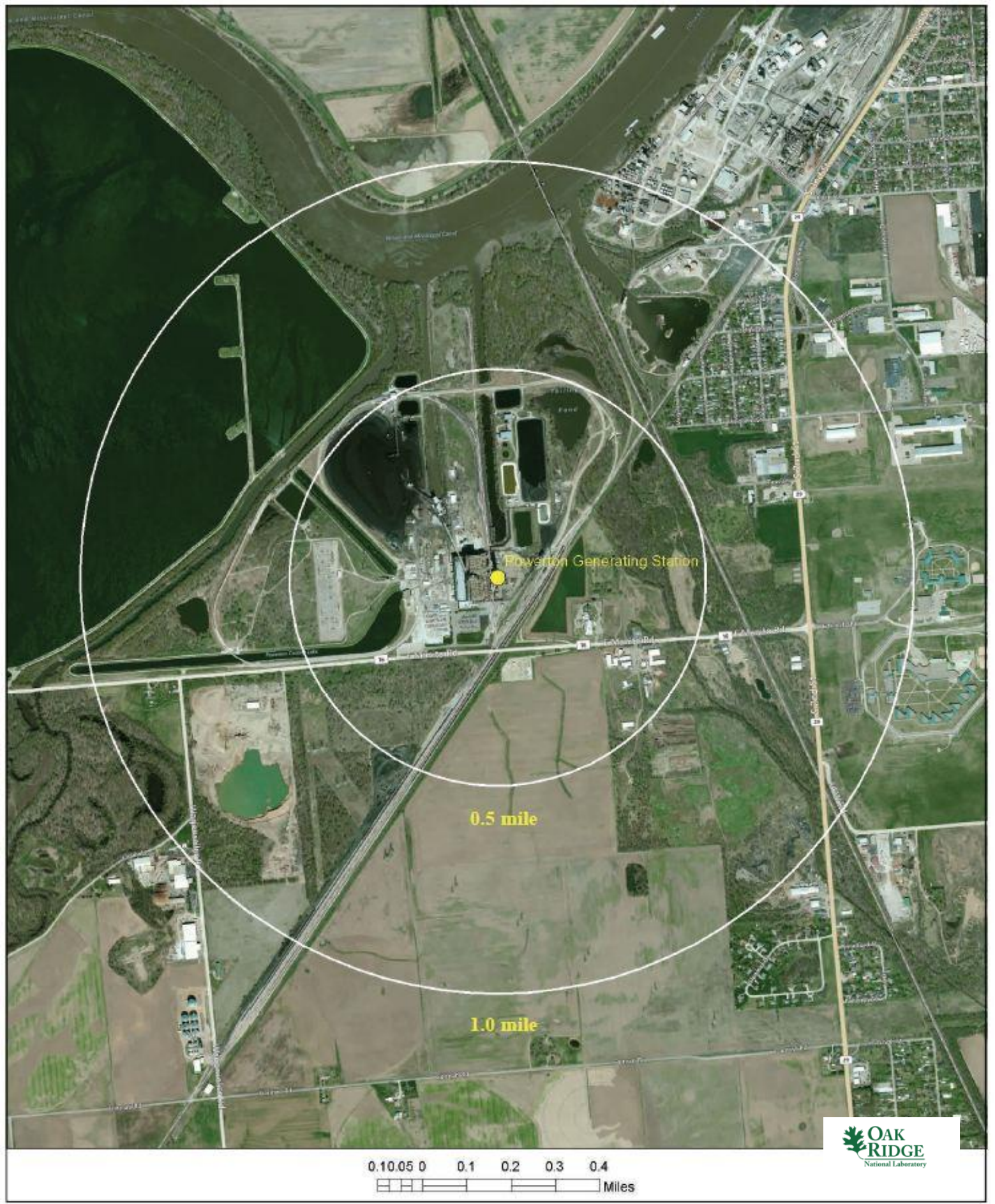

Fig. C.90. Satellite view of Powerton Generating Station proximity. 


\section{C.6.4 Screening Criteria Overview}

Table C.53. Powerton Generating Station siting criteria summary

\begin{tabular}{|c|c|c|c|c|c|c|c|c|c|}
\hline \multicolumn{10}{|c|}{$\underset{\text { Sclored Boxes indicate } S_{\text {Screening Results })}}{\text { Screening Criteria Summar }}$} \\
\hline \multicolumn{2}{|c|}{ No Siting Issue } & & \begin{tabular}{|l|l|} 
& Partial Siting Issue \\
\end{tabular} & \multicolumn{2}{|c|}{ Partial Siting Issue } & \multicolumn{4}{|c|}{ Full Siting Issue } \\
\hline \begin{tabular}{|l|}
0.5 \\
Mile \\
Buffer
\end{tabular} & Slope & SSE & $\begin{array}{l}\text { Stream } \\
\text { flow } \\
(65,000 \\
\mathrm{gpm})\end{array}$ & $\begin{array}{l}\text { Proximity } \\
\text { to } \\
\text { Hazard } \\
\text { Operations }\end{array}$ & $\begin{array}{l}\text { Proximity } \\
\text { to } \\
\text { Fault } \\
\text { Lines }\end{array}$ & \begin{tabular}{|l|} 
Wetlanis \\
Open \\
Water
\end{tabular} & $\begin{array}{l}\text { 100-year } \\
\text { Flood- } \\
\text { plain }\end{array}$ & $\begin{array}{l}\text { Protected } \\
\text { Lands }\end{array}$ & $\begin{array}{l}\text { Land- } \\
\text { slide } \\
\text { Hazards }\end{array}$ \\
\hline \begin{tabular}{|l|}
1.0 \\
Mile \\
Buffer
\end{tabular} & Slope & SSE & $\begin{array}{l}\text { Stream } \\
\text { flow } \\
(65,000 \\
\mathrm{gpm})\end{array}$ & $\begin{array}{l}\text { Proximity } \\
\text { to } \\
\text { Hazard } \\
\text { Operations }\end{array}$ & $\begin{array}{l}\text { Proximit } \\
\text { to } \\
\text { Fault } \\
\text { Lines } \\
\end{array}$ & $\begin{array}{l}\text { Wetlands? } \\
\text { Open } \\
\text { Water? }\end{array}$ & $\begin{array}{l}100 \text {-year } \\
\begin{array}{l}\text { Flood- } \\
\text { plain }\end{array}\end{array}$ & $\begin{array}{l}\text { Prorected } \\
\text { Lands }\end{array}$ & $\begin{array}{l}\text { Land- } \\
\text { slide } \\
\text { Hazard's }\end{array}$ \\
\hline & & & & & & & & \multicolumn{2}{|c|}{ OAK } \\
\hline \multicolumn{10}{|c|}{ Site Selection and Evaluation Criteria Table } \\
\hline \multicolumn{6}{|c|}{ Criteria } & \multicolumn{4}{|c|}{ Value } \\
\hline \multicolumn{6}{|c|}{ Population Density within 10 miles (people/square mile) } & \multicolumn{4}{|c|}{$>500$} \\
\hline \multicolumn{6}{|l|}{ Slope } & \multicolumn{4}{|c|}{$>18 \%$} \\
\hline \multicolumn{6}{|c|}{ Safe shutdown earthquake (ground acceleration) } & \multicolumn{4}{|c|}{$>0.5$} \\
\hline \multicolumn{6}{|c|}{ Streamflow/cooling water make-up (gpm) } & \multicolumn{4}{|c|}{$<65,000$} \\
\hline \multicolumn{6}{|c|}{ Proximity to hazardous operations - buffer (mile) } & \multicolumn{4}{|c|}{ Depends on hazardous operation ${ }^{1}$} \\
\hline \multicolumn{6}{|c|}{ Proximity to fault lines - buffer (mile) } & \multicolumn{4}{|c|}{ Depends on length of fault } \\
\hline \multicolumn{6}{|c|}{ Wetlands/Open Water } & \multicolumn{4}{|c|}{-} \\
\hline \multicolumn{6}{|c|}{ 100-year floodplain } & \multicolumn{4}{|c|}{-} \\
\hline \multicolumn{6}{|c|}{ Protected lands } & \multicolumn{4}{|c|}{-} \\
\hline \multicolumn{6}{|c|}{ Landslide hazard (moderate and high) } & \multicolumn{4}{|c|}{-} \\
\hline
\end{tabular}

${ }^{1}$ Hazardous facilities (airports- 5 miles and oil refineries-1 mile) 


\section{C.6.5 Composite Map and Individual Siting Issue Maps}

A composite map of SMR siting challenges to the Powerton Generating Station is shown in Fig. C.91. The physical plant structures are located on land with multiple siting challenges. Following this map are maps of the individual SMR siting criteria based on selected input values.

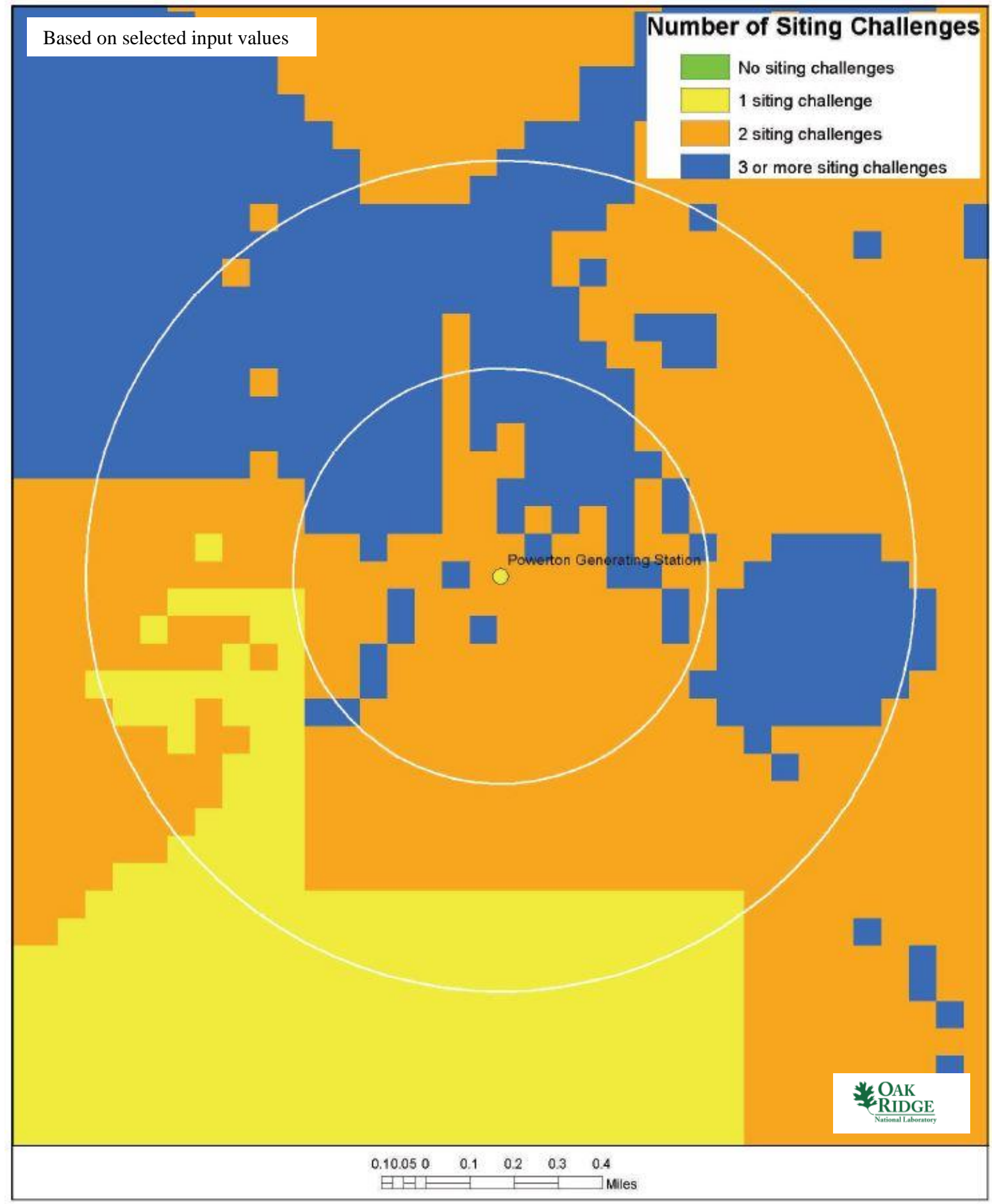

Fig. C.91. Powerton Generating Station composite map. 

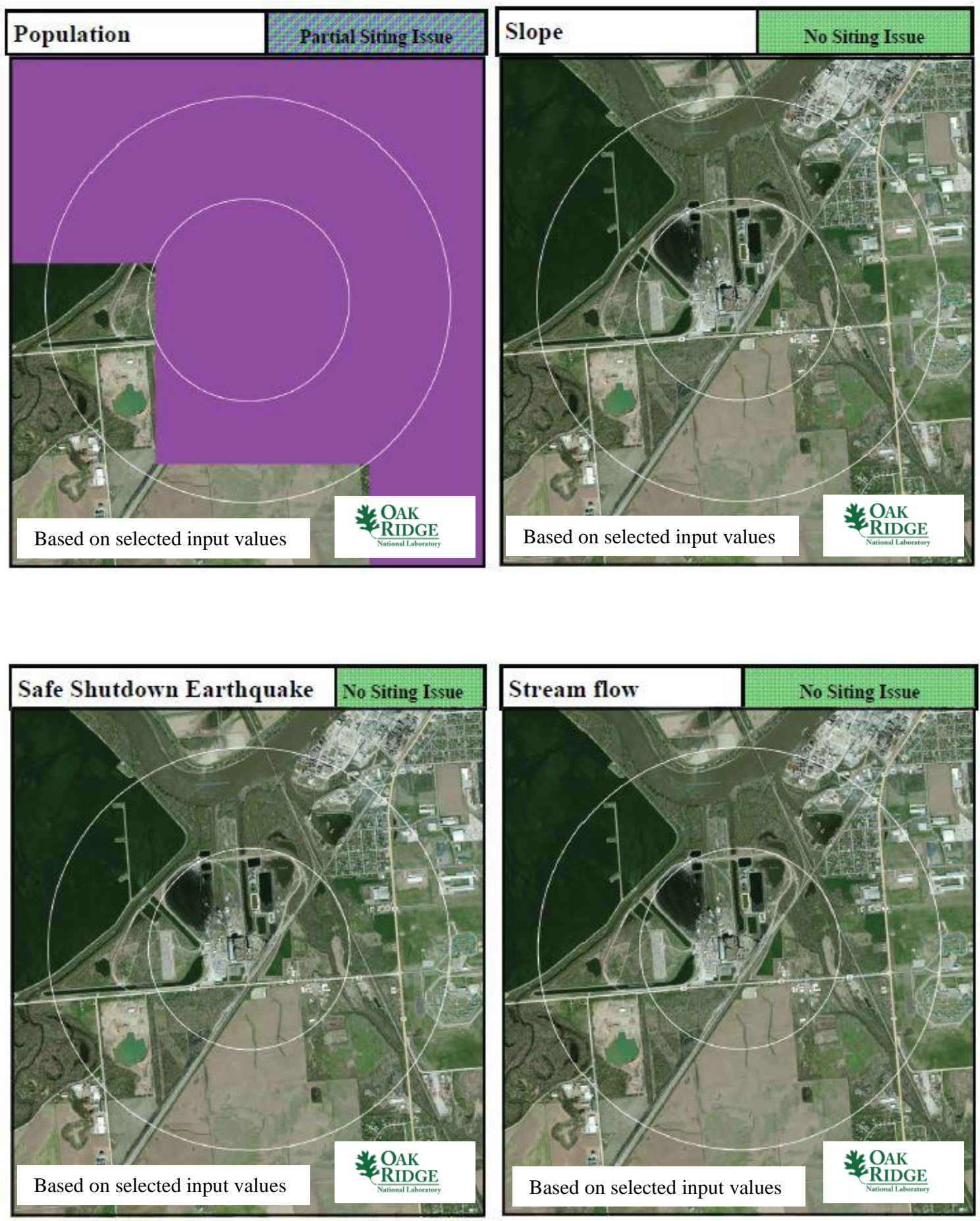

Powerton Generating Station 

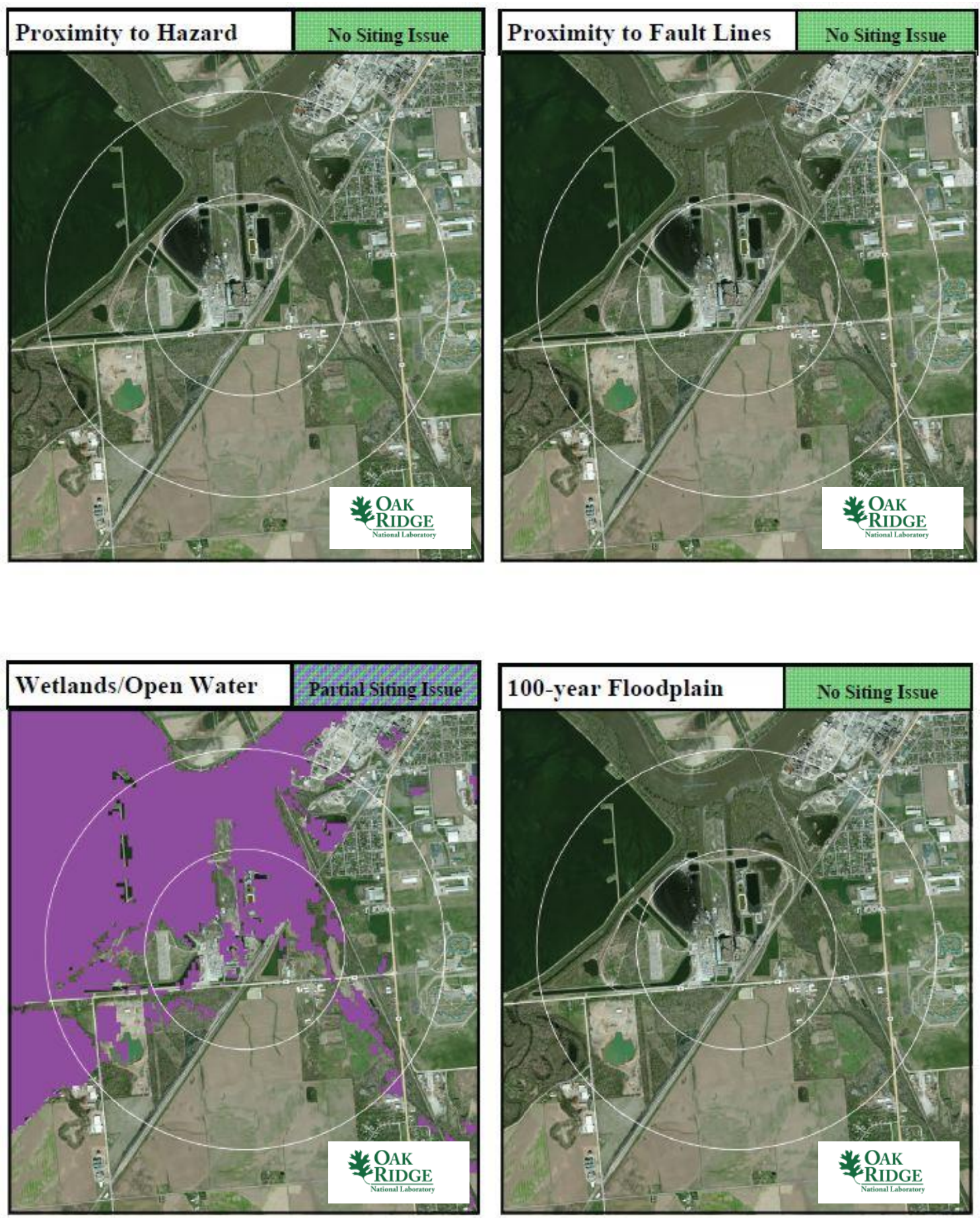

Powerton Generating Station 

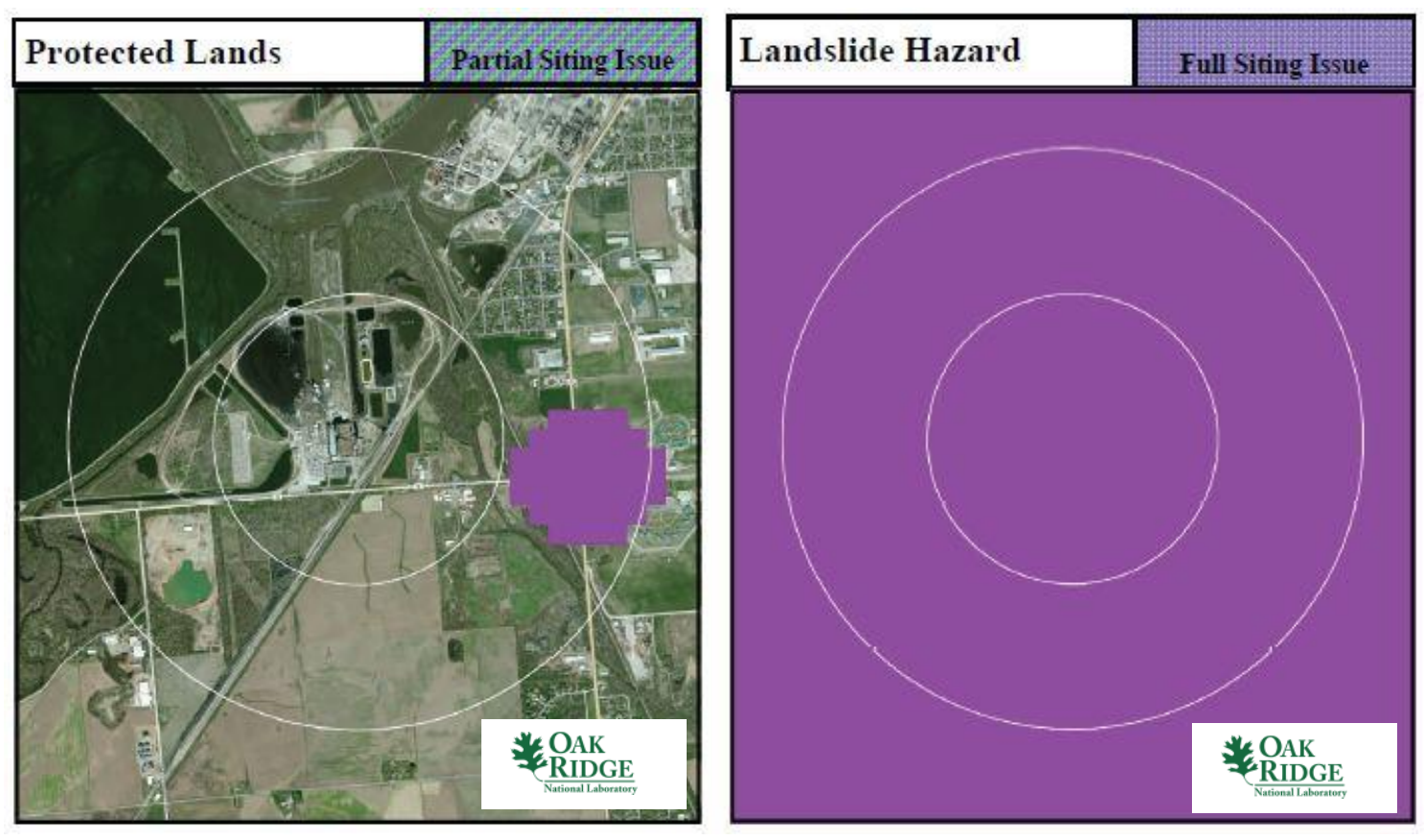

Powerton Generating Station

\section{C.6.6 Site Evaluation}

Edison International operates two nuclear power plant through its subsidiary, Southern California Edison. Therefore, Midwest Generation has the licensing experience through its parent company to license and operate an SMR at this site. The site contains sufficient acreage to support siting an SMR.

From an environmental justice perspective, the community collectively appears to have achieved a reasonable level of education with median income levels typical of much of the United States. Therefore, siting an SMR at this location would not seem to be disenfranchising a less-educated or poverty-stricken community. Furthermore, the education level of the Powerton Generating Station community would seem to support the higher-technology job opportunities provided by an SMR.

As shown in Sects. C.0 and C.0, the Powerton Generating Station site has full SMR site screening issues with population and landslide hazard. The population concern engulfs the main portion of the site and reflects the population centers of Pekin and Peoria, Illinois, to the northeast. Some utility land and adjacent farmland to the southwest meet the SMR population criteria. Moderate and high landslide hazard risk is based on probabilistic analyses by the USGS. Therefore, more specific geological surveys would be required before eliminating the Powerton Generating Station site from SMR siting consideration. There has not been a landslide issue at the current site since its construction in 1928 .

The Powerton Generating Station site has partial SMR site screening issues with wetlands/open waters and protected land. The wetlands/open waters concern is primarily related to the onsite cooling pond, which does not affect the site structures. The wetlands/open waters concern also reflects the nearby Illinois River north of the site. The protected land concern is outside the 0.5 mile radius and reflects a prison to the east of the site. The remaining SMR site screening criteria are met site-wide for the values established in the updated SMR siting report.1

So, there are significant pros and cons for siting an SMR at this location. Therefore, when future load demands indicate the need for expanded generation capacity in this region, the utility would need to work closely with local leaders and civic groups to make the case for siting an SMR at this location. The site meets current NRC RG 4.7 recommendations for population density without additional consideration for 
relaxed SMR population siting requirements based on reduced source term. Because of the flooding concern, this site should be classified as acceptable with reservations.

The central site area does not meets current NRC RG 4.7 recommendations for population density with additional consideration for relaxed SMR population siting requirements based on reduced source term. Utility land and open farmland to the immediate southwest of the site is outside of the population avoidance area. Therefore, if grid demands at this location warrant continued power generation, the general site area meets conventional standards for SMR siting pending acquisition of adjacent land and geological verification that there is not a landslide concern. However, the central Powerton Generating Station site is not a likely candidate for consideration of siting an SMR based on the population concern. Continued population growth could make future SMR siting adjacent to the plant difficult. 
C-60 


\section{C.7 Sibley Generating Station}

\section{C.7.1 Location Detail}

As shown in Fig. C.92, the Sibley Generating Station is located in northwest Missouri on the South Bank of the adjacent Missouri River. More specifically, the plant is located off Johnson Street in Jackson County, Missouri. Highway 24 is accessible approximately 2.7 miles to the south and Interstate 70 is accessible 10 miles to the south. Rail access is available onsite and barge access is available via the adjacent Missouri River. The plant is located about 0.5 miles east of Sibley, Missouri, with a population of approximately 358 people. The nearest city with a population in excess of 10,000 people is Excelsior, Missouri, approximately 11.2 miles to the north of the Sibley Generating Station.

- Plant: Sibley Generating Station

- Utility: Kansas City Power and Light Greater Missouri Operations Company

- Coordinates: lat. $39.17870^{\circ} \mathrm{N}$, long. $94.18423^{\circ} \mathrm{W}$

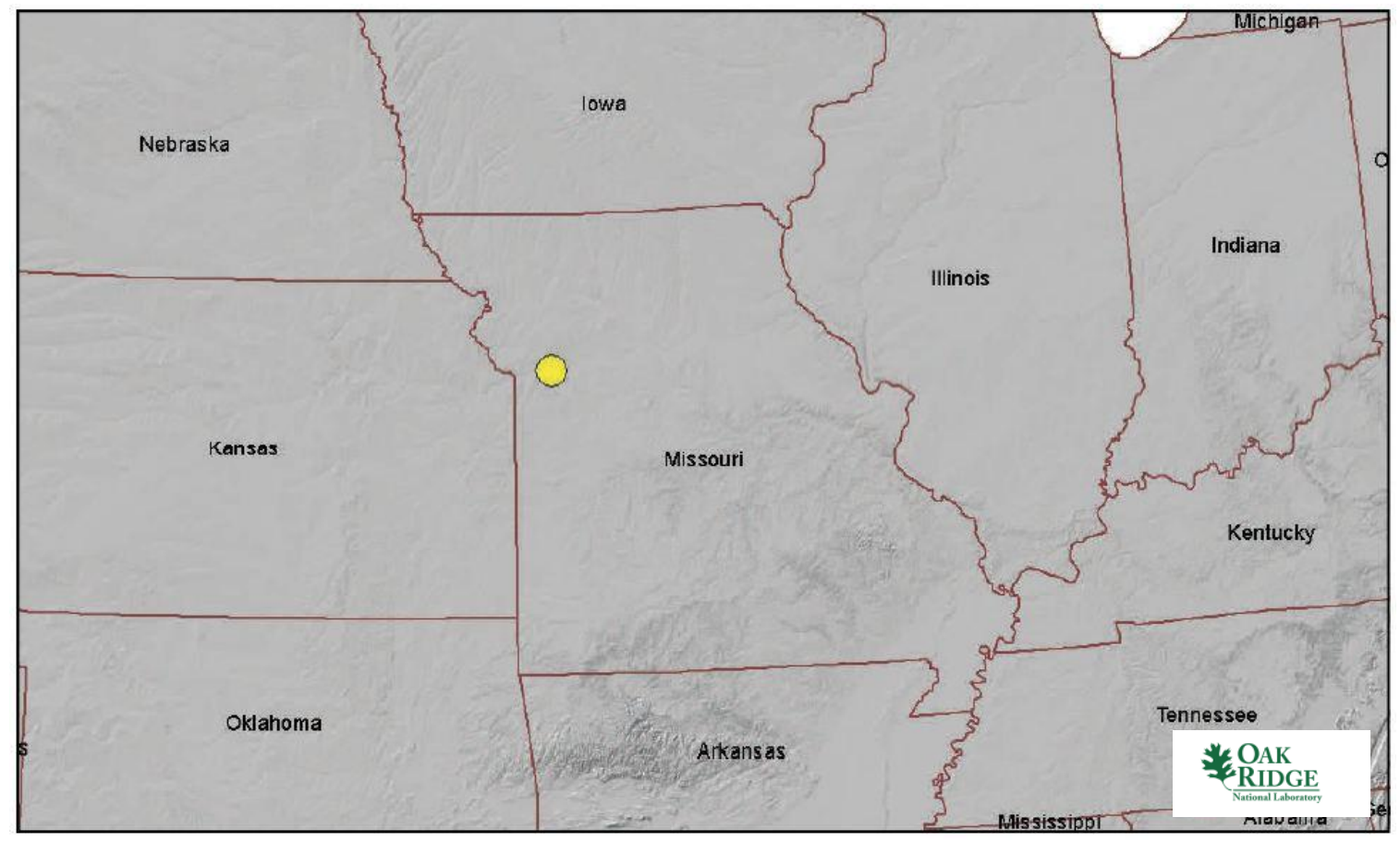

Fig. C.92. Sibley Generating Station location map.

\section{C.7.2 Site Description and Status}

The Sibley Generating Station is owned and operated by the Kansas City Power and Light Greater Missouri Operations Company, a subsidiary of Great Plains Energy Incorporated. The 524 MW(e) Sibley Generating Station consists of three coal-fired units. Unit 1, commissioned in 1960, is rated at 55 MW(e). Unit 2, commissioned in 1962, is rated at $50 \mathrm{MW}(\mathrm{e})$. Unit 3, commissioned in 1969, is rated at 419 MW(e). Selective catalytic reduction equipment was added to 419 MW(e) unit in 2012. The plant is cooled by once-through cooling from the adjacent Missouri River.

The Quindaro Power Station is located on roughly 70 acres about 104 miles northeast of the 1,170 MW(e) Wolf Creek Generating Station nuclear power plant near Burlington, Kansas. Numerous coal-fired facilities are nearby, including the $46 \mathrm{MW}$ (e) Missouri City Power Plant 8 miles to the northwest, the 
115 MW(e) Blue Valley plant 10 miles to the southwest, and the 594 MW(e) Hawthorn Station 16 miles to the west.

As noted in Table C.54, the nearest major fault line based on USGS data is about 324 miles west in Kansas. The maximum safe-shutdown earthquake for the site is below $0.3 \mathrm{~g}$ peak ground acceleration. More than 500,000 gpm of cooling water makeup is available from the adjacent Missouri River.

The permanent population within 1 mile of the plant is approximately 1,100 people, yielding a population density of approximately 350 people per square mile. The permanent population within 10 miles of the plant is approximately 131,500 people, yielding a population density of a little more than 418 people per square mile.

According to the US EPA Environmental Justice website, there are 12,054 occupied housing units within 10 miles of the plant site based on 2000 US Census data. Further, more than $85 \%$ of area adults over age 25 have a high school diploma or higher education. The median annual income for the area is between $\$ 25 \mathrm{~K}$ and $\$ 50 \mathrm{~K}$.

Table C.54. Sibley Generating Station site statistics

\begin{tabular}{|c|c|c|c|}
\hline \multicolumn{2}{|l|}{$\begin{array}{l}\text { Population } \\
\text { Population Within }\end{array}$} & \multicolumn{2}{|l|}{$\begin{array}{l}\text { Utility } \\
\text { Distance to Grid Capacity }\end{array}$} \\
\hline $0.5 \mathrm{mi}$ & $<500$ & $>400 \mathrm{MWe}$ & $\sim 0.8 \mathrm{mi}$ \\
\hline $1 \mathrm{mi}$ & $\sim 1,100$ & $>800 \mathrm{MWe}$ & $\sim 1.2 \mathrm{mi}$ \\
\hline $5 \mathrm{mi}$ & $\sim 31,500$ & $>1600 \mathrm{MWe}$ & $\sim 206 \mathrm{mi}$ \\
\hline $10 \mathrm{mi}$ & $\sim 131,500$ & $>3200 \mathrm{MWe}$ & $\sim 322 \mathrm{mi}$ \\
\hline \multicolumn{2}{|c|}{ Nearest City with Population } & \multicolumn{2}{|c|}{ Distance to Cooling Water } \\
\hline$>10,000$ & Excelsior Springs, MO & $>50,000 \mathrm{gpm}$ & $\sim 0.1 \mathrm{mi}$ (Missouri River) \\
\hline$>50,000$ & Lees Summit, MO & $>100,000 \mathrm{gpm}$ & $\sim 0.1 \mathrm{mi}$ (Missouri River) \\
\hline$>100,000$ & Independence, $\mathrm{MO}$ & $>200,000 \mathrm{gpm}$ & $\sim 0.1 \mathrm{mi}$ (Missouri River) \\
\hline$>500,000$ & Oklahoma City, OK & $>500,000 \mathrm{gpm}$ & $\sim 0.1 \mathrm{mi}$ (Missouri River) \\
\hline \multicolumn{2}{|l|}{ Geotechnical } & \multicolumn{2}{|l|}{ Accessibility } \\
\hline Max Earthquake Acceleration & $<0.3 \mathrm{~g}$ & Distance to Major Roadway & $\sim 2.7 \mathrm{mi}($ US 24$)$ \\
\hline Max Slope & $\sim 15 \%$ & Distance to Water Transport & $\sim 0.1 \mathrm{mi}$ (Missouri River) \\
\hline Nearest Fault Line & $\sim 324 \mathrm{mi}$ (Kansas) & Distance to Rail Transport & $\sim 0.1 \mathrm{mi}(\mathrm{PVTX})$ \\
\hline Nearest Hazard Site & $\begin{array}{l}28 \mathrm{mi} \text { (Airport- } \\
\text { Kansas City Int'1) }\end{array}$ & Distance to Airport & $\sim 28 \mathrm{mi}$ (Kansas City Int'l) \\
\hline
\end{tabular}




\section{C.7.3 Aerial Imagery}

The aerial imagery in Fig. C.93 indicates a limited amount of housing within 1.0 mile of the Sibley Generating Station site.

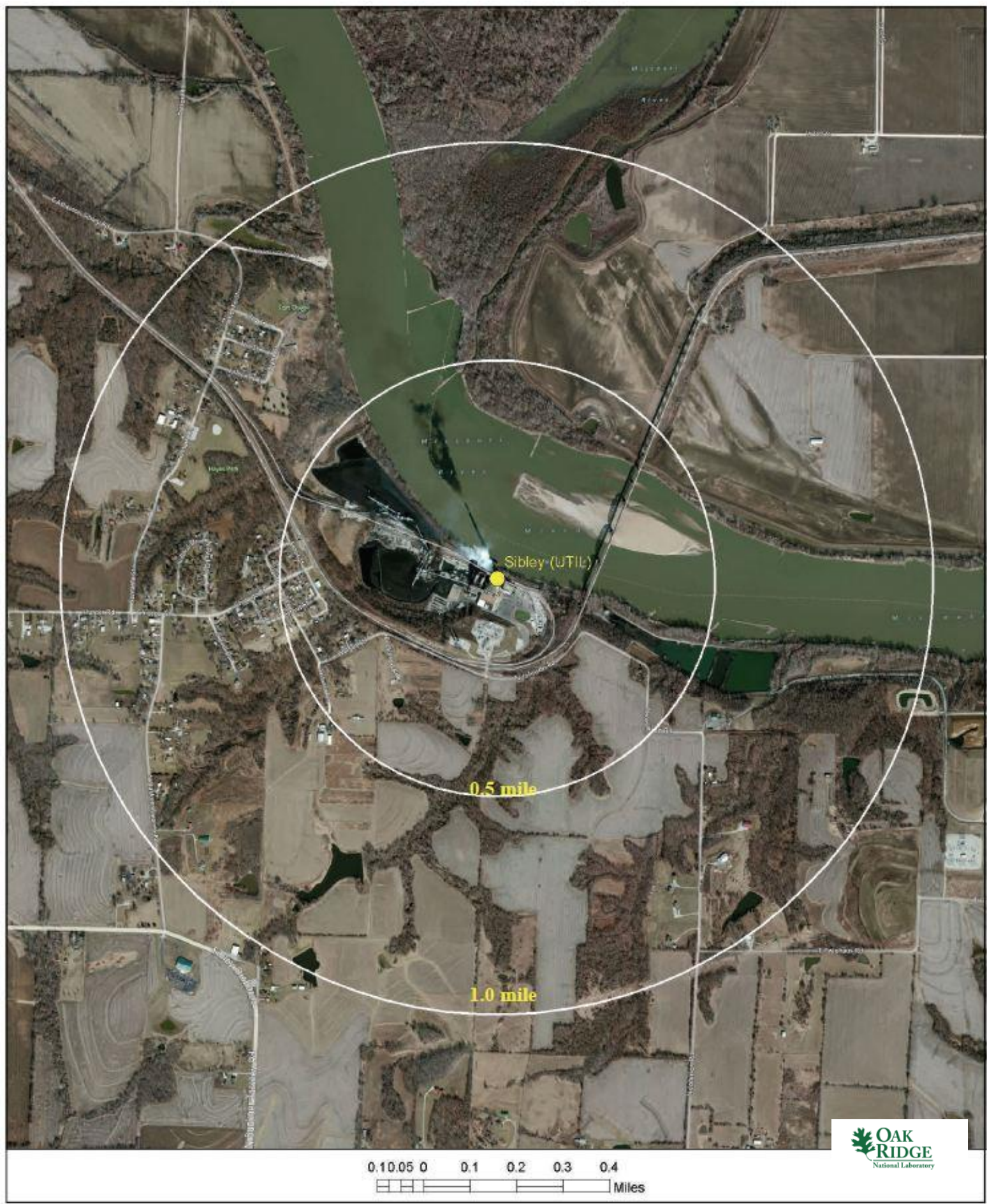

Fig. C.93. Satellite view of Sibley Generating Station proximity. 


\section{C.7.4 Screening Criteria Overview}

Table C.55. Sibley Generating Station siting criteria summary

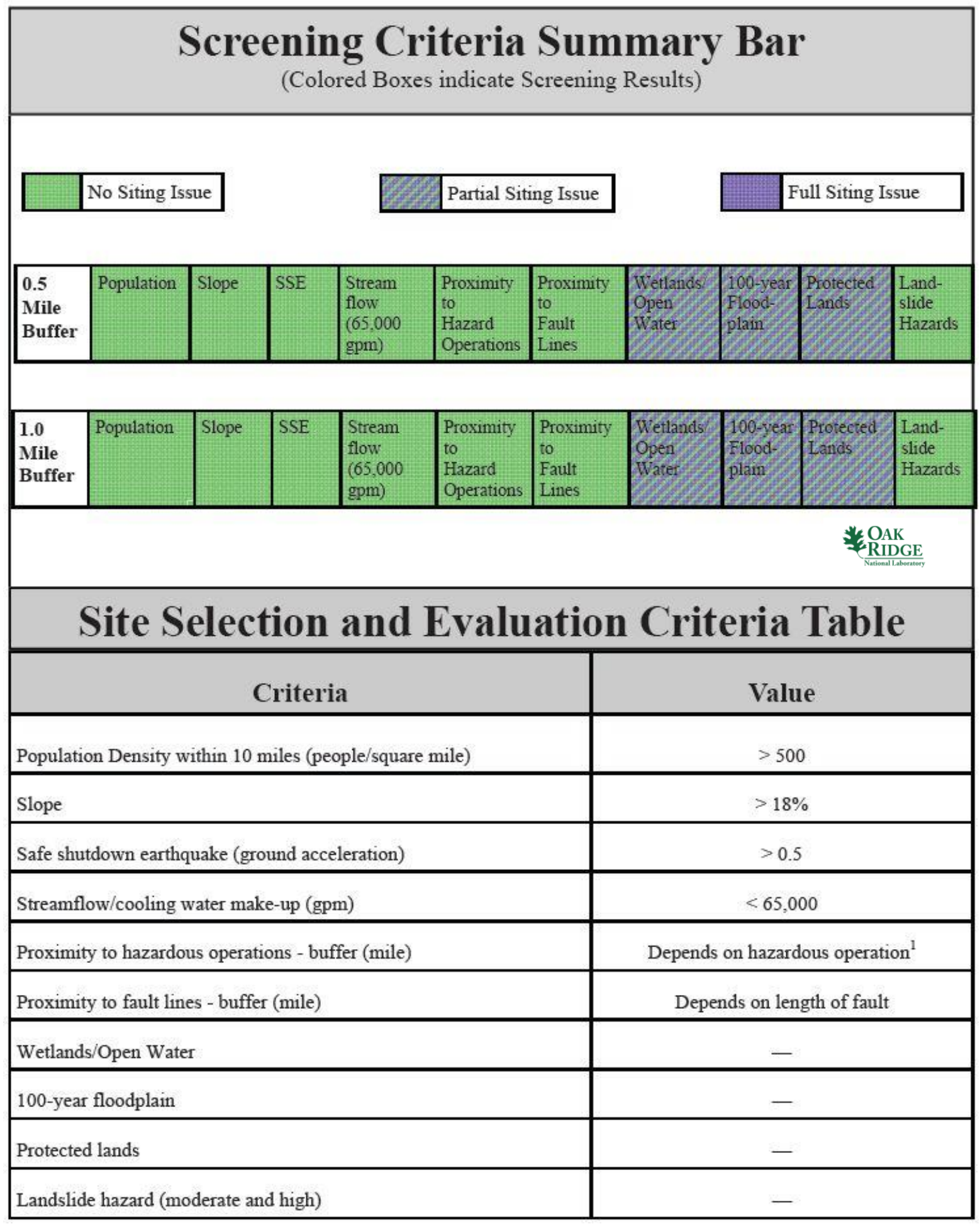

${ }^{1}$ Hazardous facilities (airports- 5 miles and oil refineries- 1 mile) 


\section{C.7.5 Composite Map and Individual Siting Issue Maps}

A composite map of SMR siting challenges to the Sibley Generating Station is shown in Fig. C.94. The physical plant structures are located on land with multiple siting challenges. Following this map are maps of the individual SMR siting criteria based on selected input values.

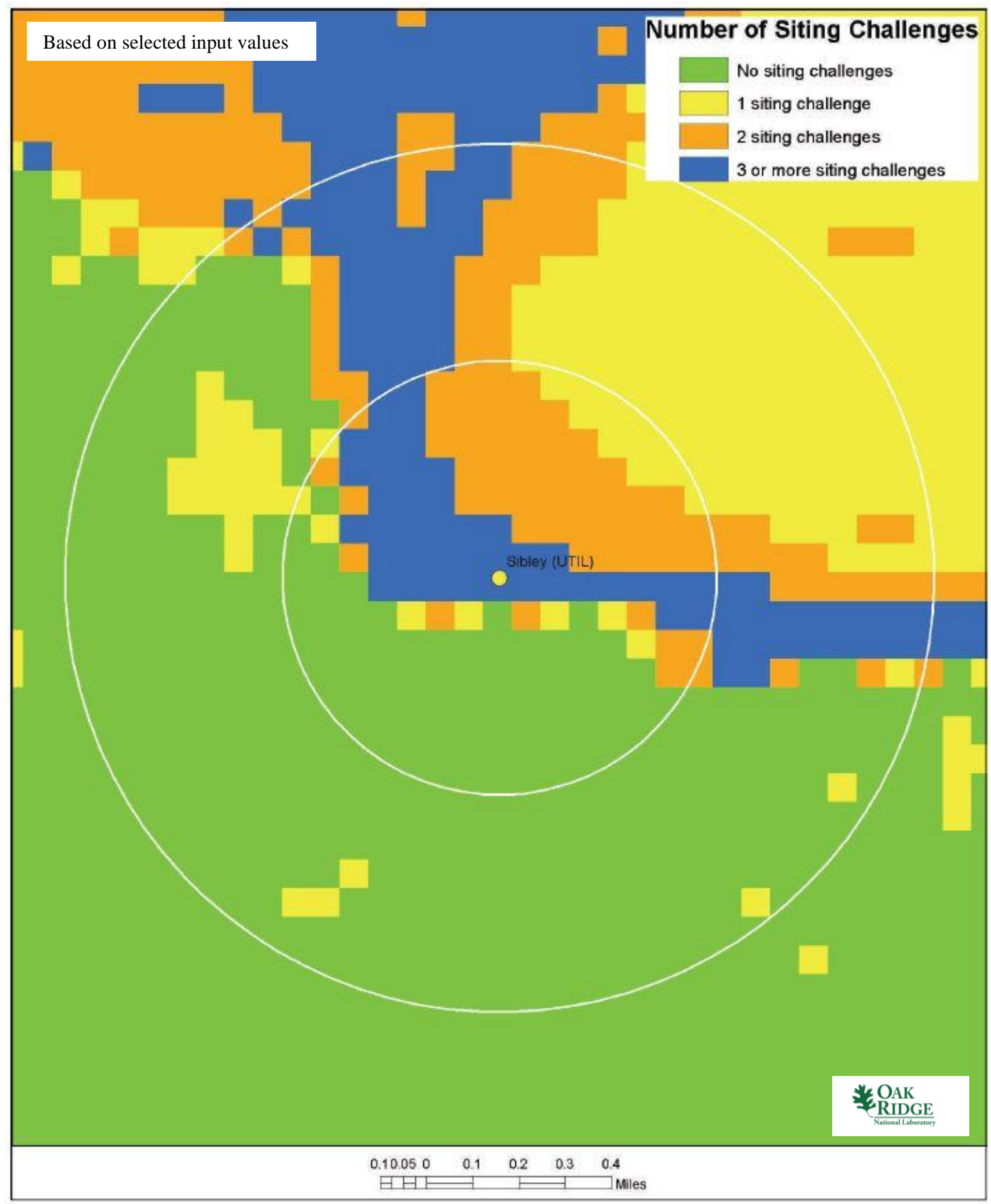

Fig. C.94. Sibley Generating Station composite map. 

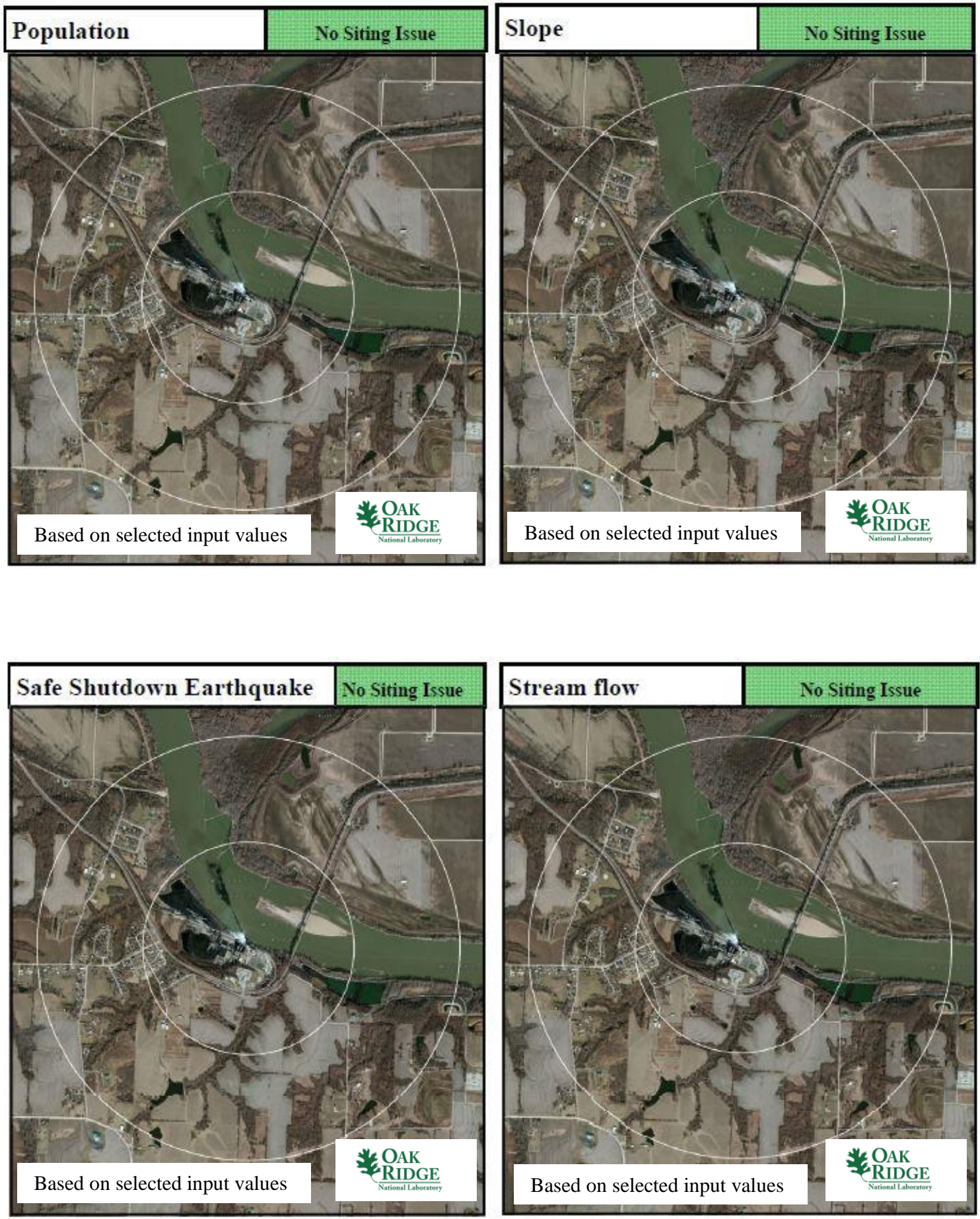

Sibley Generating Station 

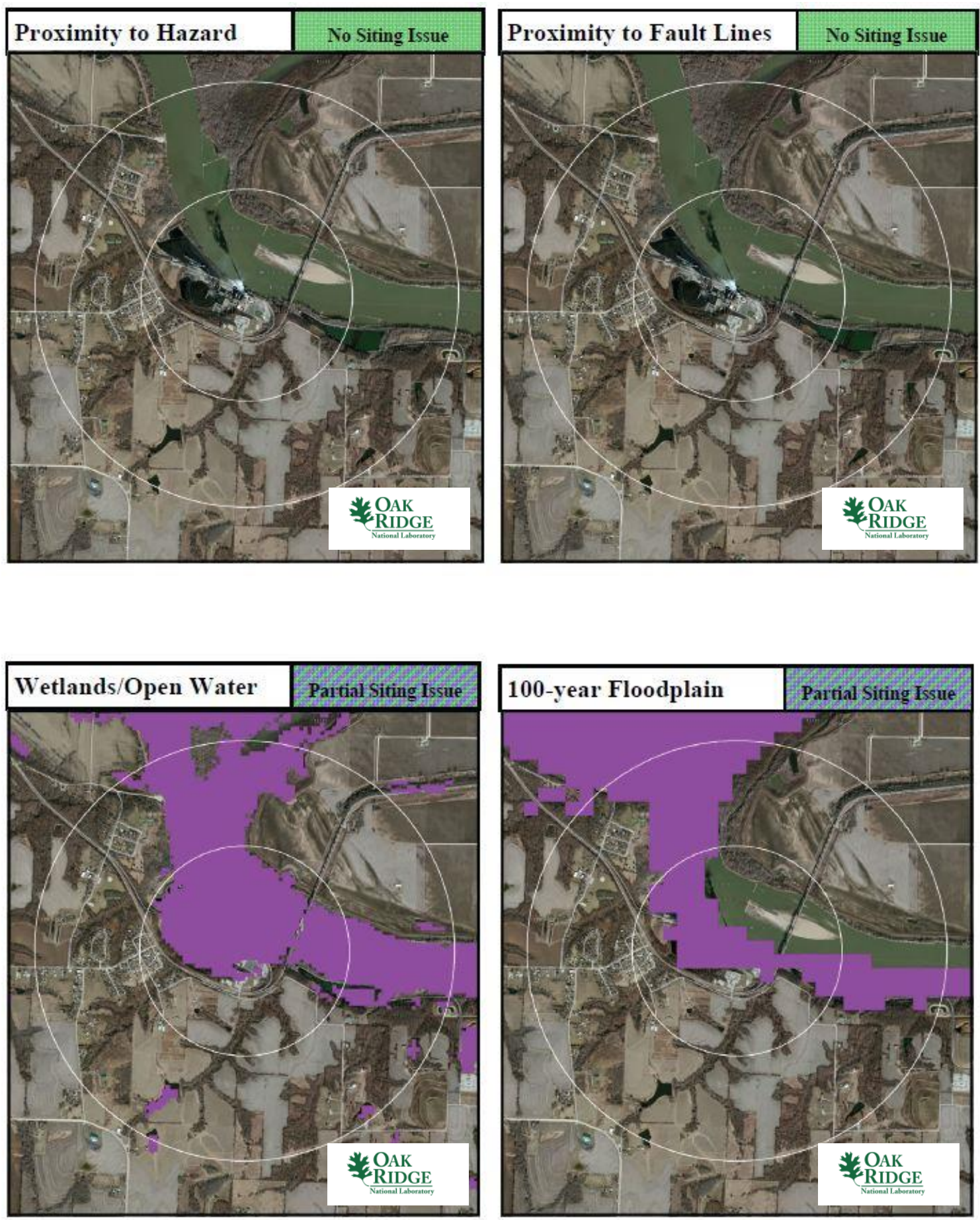

Sibley Generating Station 

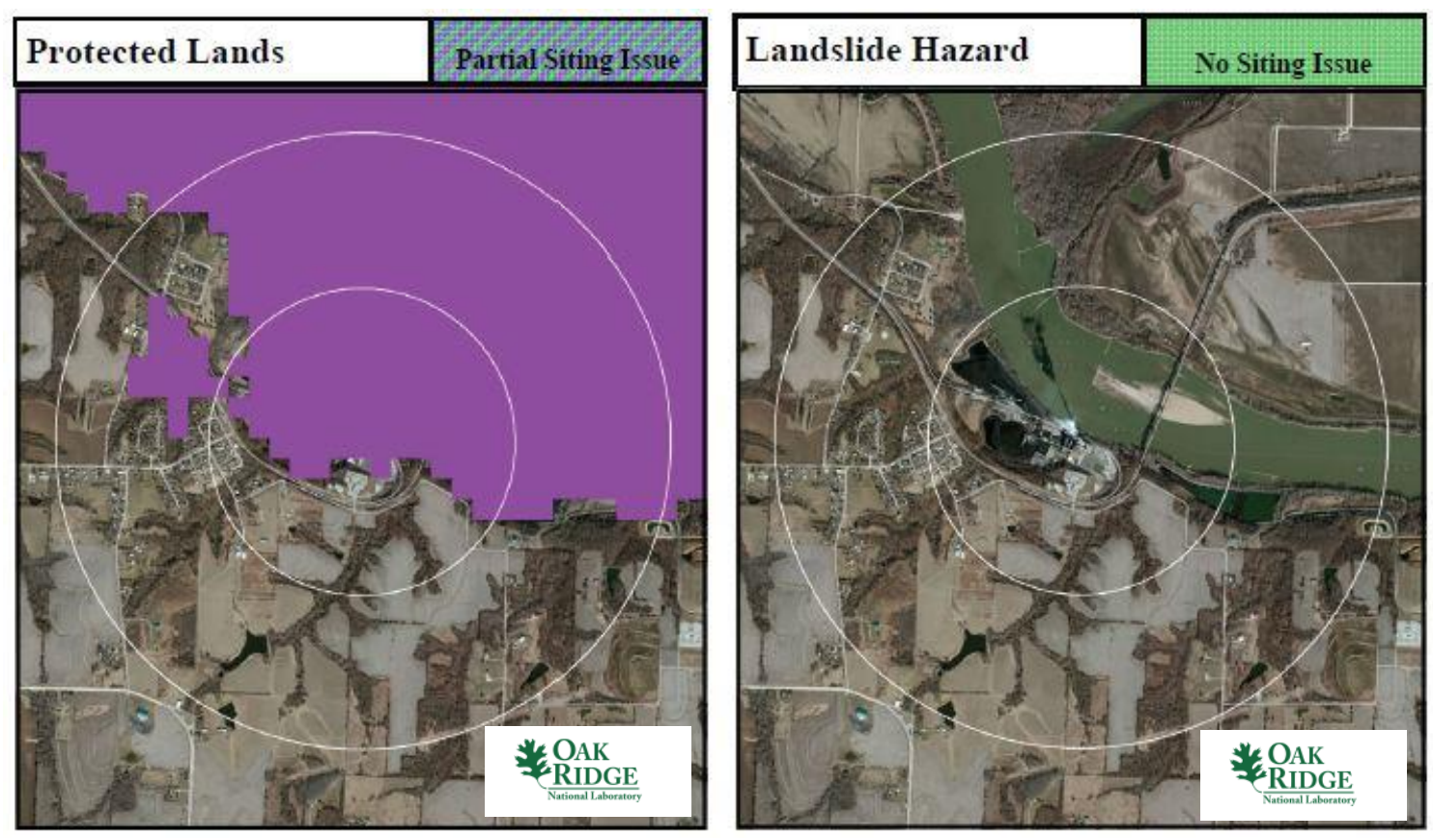

Sibley Generating Station

\section{C.7.6 Site Evaluation}

Kansas City Power and Light and the Greater Missouri Operations Company do not own or operate any nuclear power plants in the United States. Therefore, the utility would need to be mentored through the licensing process to build and operate an SMR at this site. The site contains sufficient acreage to support siting an SMR.

From an environmental justice perspective, the community collectively appears to have achieved a reasonable level of education with median income levels typical of much of the United States. Therefore, siting an SMR at this location would not seem to be disenfranchising a less-educated or poverty-stricken community. Furthermore, the education level of the Sibley Generating Station community would seem to support the higher-technology job opportunities provided by an SMR.

As shown in Sects. C.0 and C.0, the Sibley Generating Station site has partial SMR site screening issues with wetlands/open waters, 100-year floodplain, and protected lands. The wetlands/open waters and 100year floodplain reflect the adjacent Missouri River and the onsite ponds. The open waters concern is not a major factor. However, most of the plant structures, except the switchyard, are in the designated 100-year floodplain. Nearby local fairgrounds and the historic Fort Osage put the plant site in close proximity to protected lands. These could be problematic issues for siting an SMR at this location, especially in light of the recent industry focus on flooding. The remaining SMR site screening criteria are met site-wide for the values established in the updated SMR siting report.1

The site meets current NRC RG 4.7 recommendations for population density without additional consideration for relaxed SMR population siting requirements based on reduced source term. Open farmland to the immediate southeast of the site is outside of both the 100-year floodplain and the protected lands. Therefore, if grid demands at this location warrant continued power generation, the general site area meets conventional standards for SMR siting pending acquisition of adjacent land. The actual Sibley Generating Station site is not a likely candidate for consideration of siting an SMR based on the stated concerns. 


\section{C.8 Willow Island Power Station}

\section{C.8.1 Location Detail}

As shown in Fig. C.95, the Willow Island Power Station is located in West Virginia just east of the Ohio border. More specifically, the plant is located off West Virginia Route 2, in Pleasants County, West Virginia. Interstate 77 is accessible approximately 7 miles to the west. Rail access is available onsite within 0.1 miles and barge access is available within 0.2 miles from the adjacent Ohio River. The closest town is Belmont, West Virginia, with a population of approximately 905 people. Belmont is approximately 2.5 miles northeast of the Willow Island Power Station. The nearest city with a population in excess of 10,000 people is Marietta, Ohio, approximately 9 miles to the northwest of the Willow Island Power Station.

- Plant: Willow Island Power Station

- Utility: Monongahela Power

- Coordinates: lat. $39.36692^{\circ} \mathrm{N}$, long. $81.29968^{\circ} \mathrm{W}$

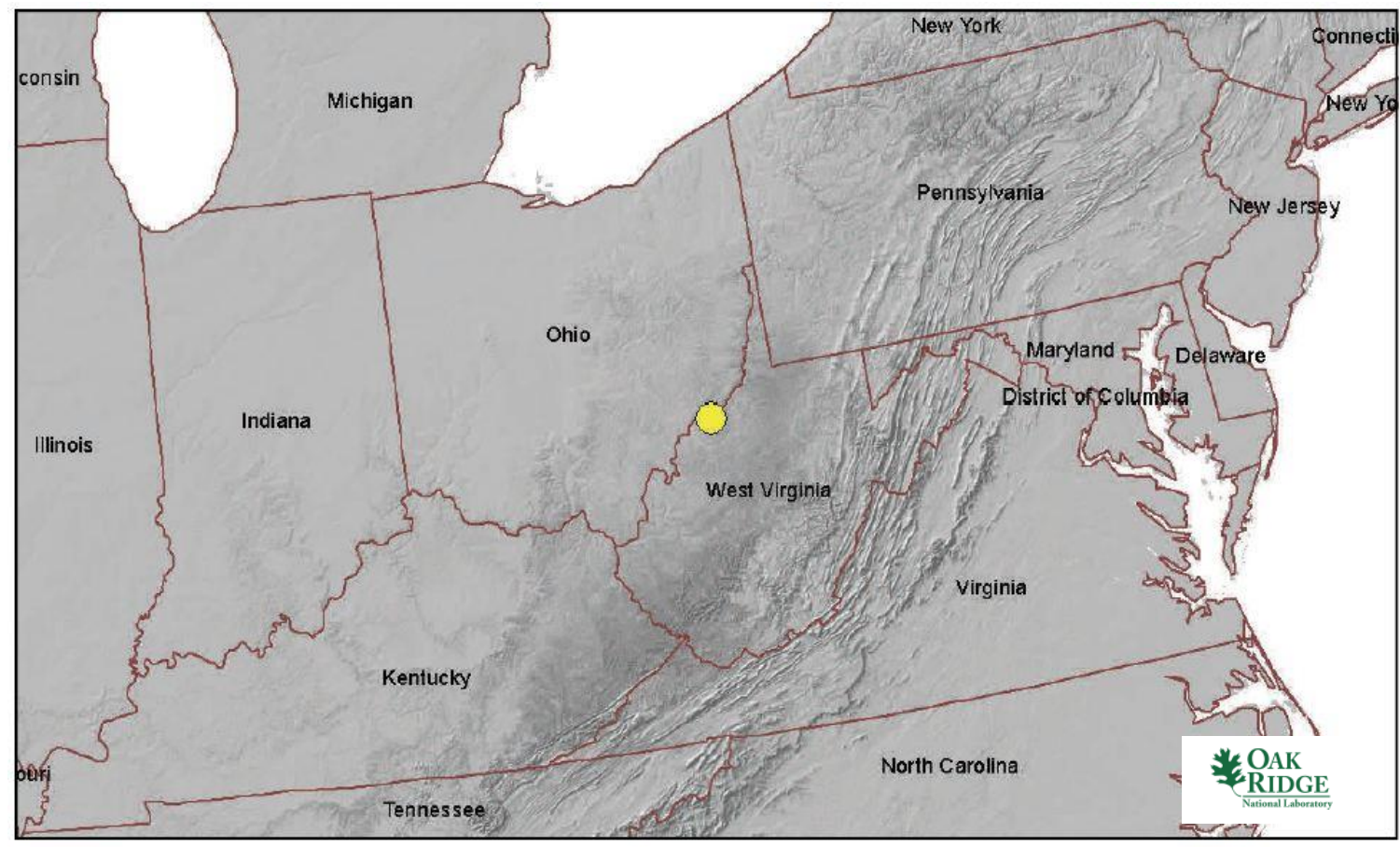

Fig. C.95. Willow Island Power Station location map.

\section{C.8.2 Site Description and Status}

The Willow Island Power Station is operated by Monongahela Power, a subsidiary of FirstEnergy Corporation. The two-unit coal station was planned for shutdown in late 2012 because of the high cost to implement new EPA MATS. The shutdown has been delayed pending further review by the Public Service Commission, but it is unlikely that the units will remain operational much longer. One of the fossil units, commissioned in 1949, was rated at $50 \mathrm{MW}(\mathrm{e})$ and the second unit, commissioned in 1960, was rated at $163 \mathrm{MW}(\mathrm{e})$ for a total site capacity of $213 \mathrm{MW}(\mathrm{e})$. The two units are used as peaking units. The units are cooled by once-through cooling from the adjacent river. The two-unit 1368 MW(e) Pleasants Power Station located next to the Willow Island site remains in operation. The Pleasants Power 
Station units, rated at $684 \mathrm{MW}(\mathrm{e})$ each, were commissioned in 1979 and 1980. The Pleasants Power Station is cooled by natural draft cooling towers.

The plant is situated on roughly 50 acres on the Ohio River approximately 98 miles southwest of the 1,890 MW(e) Beaver Valley nuclear facility. A $35 \mathrm{MW}$ (e) hydroelectric project is under development about 1 mile southwest of the Willow Island Power Station. The hydroelectric project is slated for completion in 2014.

As noted in Table C.56, the nearest major fault line based on USGS data is 933 miles west in Oklahoma. The maximum safe-shutdown earthquake for the site is below $0.3 \mathrm{~g}$ peak ground acceleration. More than $500,000 \mathrm{gpm}$ of cooling water makeup is available from the adjacent Ohio River.

The permanent population within 1 mile of the plant is fewer than 500 people, yielding a population density of fewer than 160 people per square mile. The permanent population within 10 miles of the plant is approximately 95,000 people, yielding a population density of approximately 300 people per square mile. According to the US EPA Environmental Justice website, there are 15,827 occupied housing units within 10 miles of the plant site based on 2010 US Census data. Further, over $80 \%$ of area adults over age 25 have a high school diploma or higher education. The median annual income for the area is between $\$ 25 \mathrm{~K}$ and $\$ 50 \mathrm{~K}$.

Table C.56. Willow Island Power station site statistics

\begin{tabular}{|c|c|c|c|}
\hline \multicolumn{2}{|l|}{$\begin{array}{l}\text { Population } \\
\text { Population Within }\end{array}$} & \multicolumn{2}{|l|}{$\begin{array}{l}\text { Utility } \\
\text { Distance to Grid Capacity }\end{array}$} \\
\hline $0.5 \mathrm{mi}$ & $<500$ & $>400 \mathrm{MWe}$ & $\sim 24 \mathrm{mi}$ \\
\hline $1 \mathrm{mi}$ & $\sim 700$ & $>800 \mathrm{MWe}$ & $\sim 21 \mathrm{mi}$ \\
\hline $5 \mathrm{mi}$ & $\sim 16,000$ & $>1600 \mathrm{MWe}$ & $\sim 1 \mathrm{mi}$ \\
\hline $10 \mathrm{mi}$ & $\sim 95,000$ & $>3200 \mathrm{MWe}$ & $\sim 36 \mathrm{mi}$ \\
\hline \multicolumn{2}{|c|}{ Nearest City with Population } & \multicolumn{2}{|c|}{ Distance to Cooling Water } \\
\hline$>10,000$ & Marietta, $\mathrm{OH}$ & $>50,000 \mathrm{gpm}$ & $\sim 0.2 \mathrm{mi}$ (Ohio River) \\
\hline$>50,000$ & Charleston, WV & $>100,000 \mathrm{gpm}$ & $\sim 0.2 \mathrm{mi}$ (Ohio River) \\
\hline$>100,000$ & Pittsburgh, PA & $>200,000 \mathrm{gpm}$ & $\sim 0.2 \mathrm{mi}$ (Ohio River) \\
\hline$>500,000$ & Columbus, $\mathrm{OH}$ & $>500,000 \mathrm{gpm}$ & $\sim 0.2 \mathrm{mi}$ (Ohio River) \\
\hline \multicolumn{2}{|l|}{ Geotechnical } & \multicolumn{2}{|l|}{ Accessibility } \\
\hline Max Earthquake Acceleration & $<0.3 \mathrm{~g}$ & Distance to Major Roadway & $\sim 0.3 \mathrm{mi}(\mathrm{SR} 2)$ \\
\hline Max Slope & $\sim 36 \%$ & Distance to Water Transport & $\sim 0.2 \mathrm{mi}$ (Ohio River) \\
\hline Nearest Fault Line & $\sim 933 \mathrm{mi}$ (Oklahoma) & Distance to Rail Transport & $\sim 0.1 \mathrm{mi}(\mathrm{CSXT})$ \\
\hline Nearest Hazard Site & $\begin{array}{c}\sim 66 \text { mi (Airport- } \\
\text { Yeager) }\end{array}$ & Distance to Airport & $\sim 66 \mathrm{mi}$ (Yeager) \\
\hline
\end{tabular}




\section{C.8.3 Aerial Imagery}

The aerial imagery in Fig. C.96 indicates the hydroelectric project and an industrial area in the lower left. The Pleasants Generating Plant is to the right of the Willow Island facility by the cooling towers. No housing is visible within a 1 mile radius of the plant site.

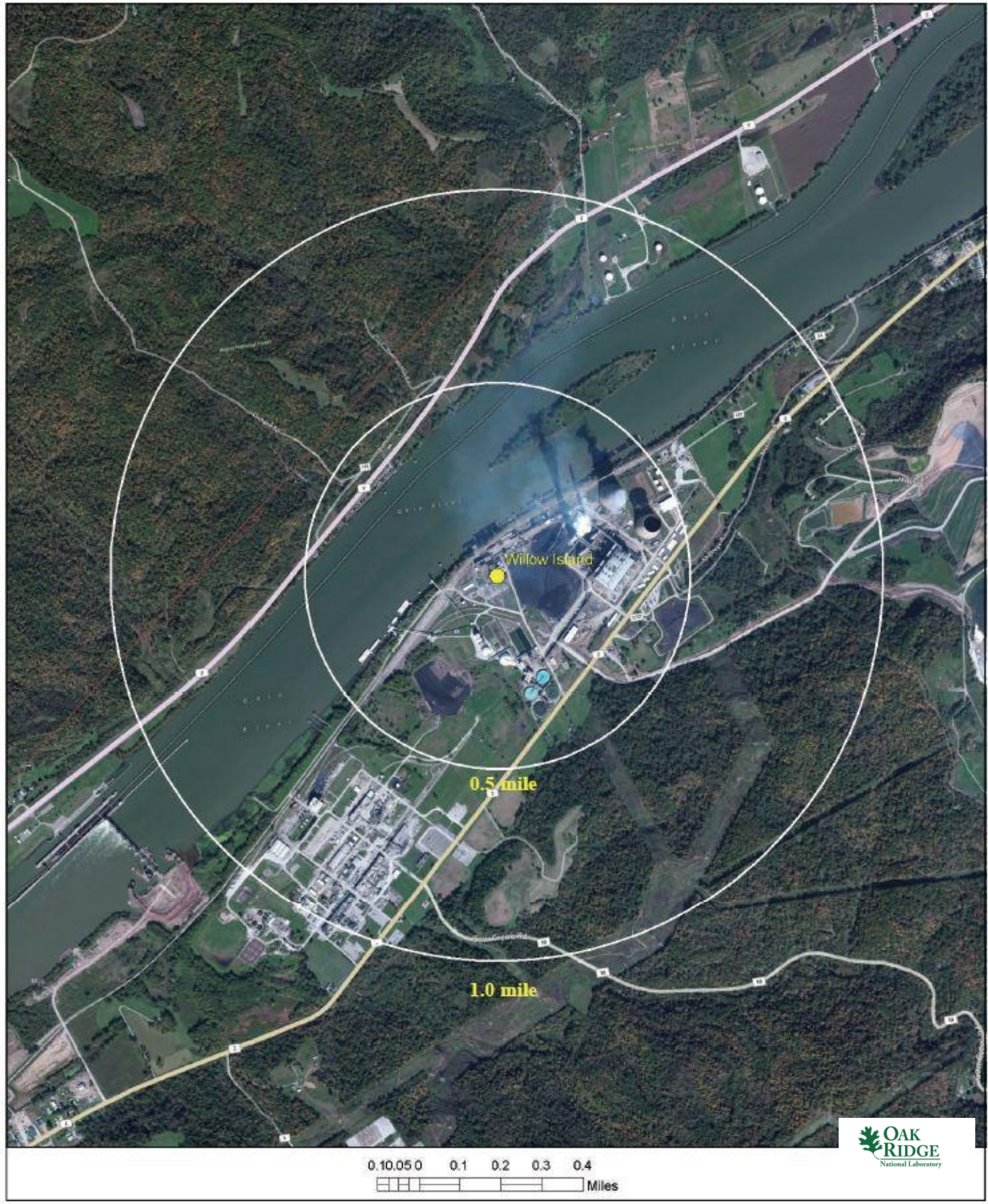

Fig. C.96. Satellite view of Willow Island Power Station proximity. 


\section{C.8.4 Screening Criteria Overview}

Table C.57. Willow Island Power Station siting criteria summary

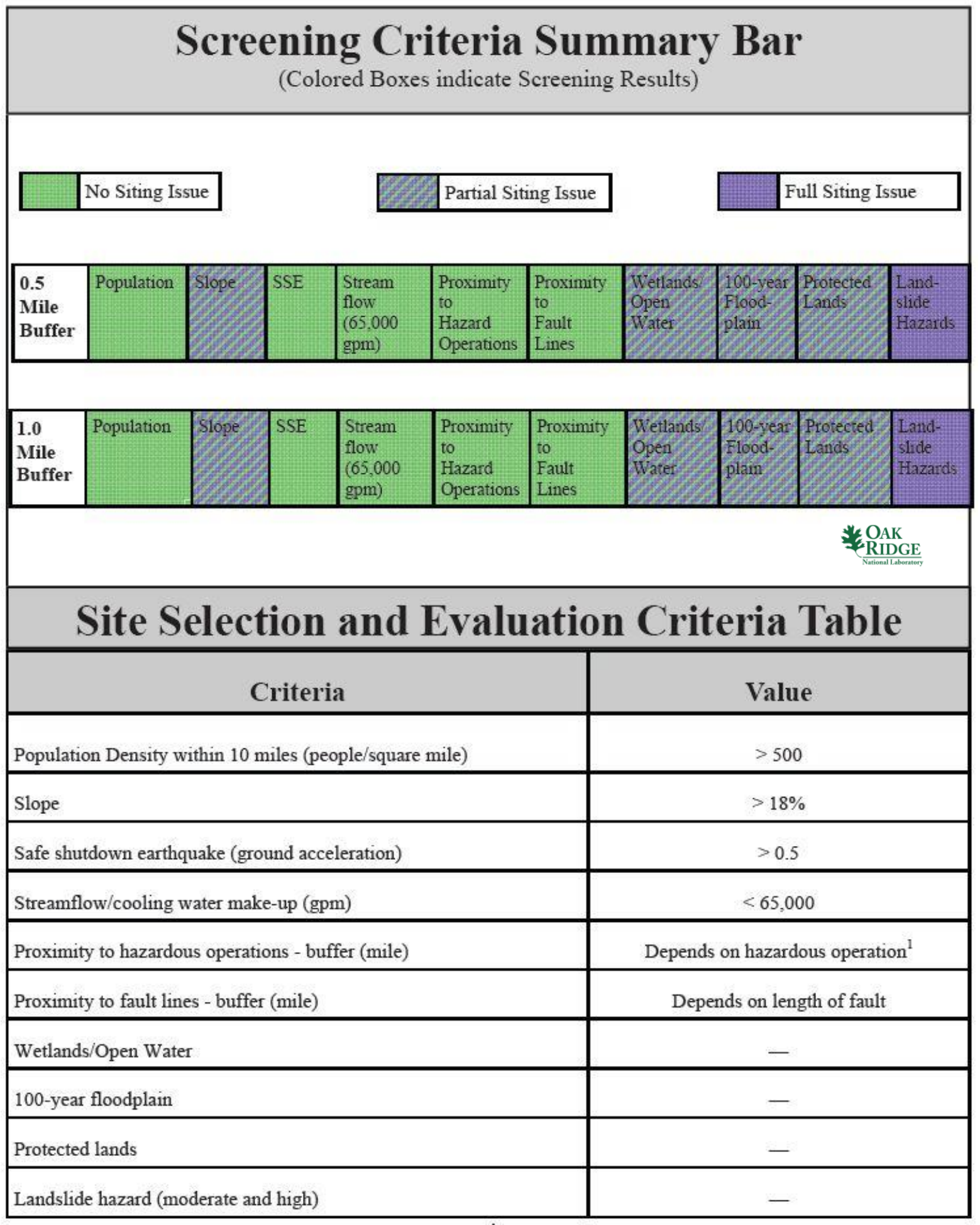

${ }^{1}$ Hazardous facilities (airports-5 miles and oil refineries- 1 mile) 


\section{C.8.5 Composite Map and Individual Siting Issue Maps}

A composite map of SMR siting challenges to the Willow Island Power Station is shown in Fig. C.97. The physical plant structures are located on land with a single siting issue. Following this map are maps of the individual SMR siting criteria based on selected input values.

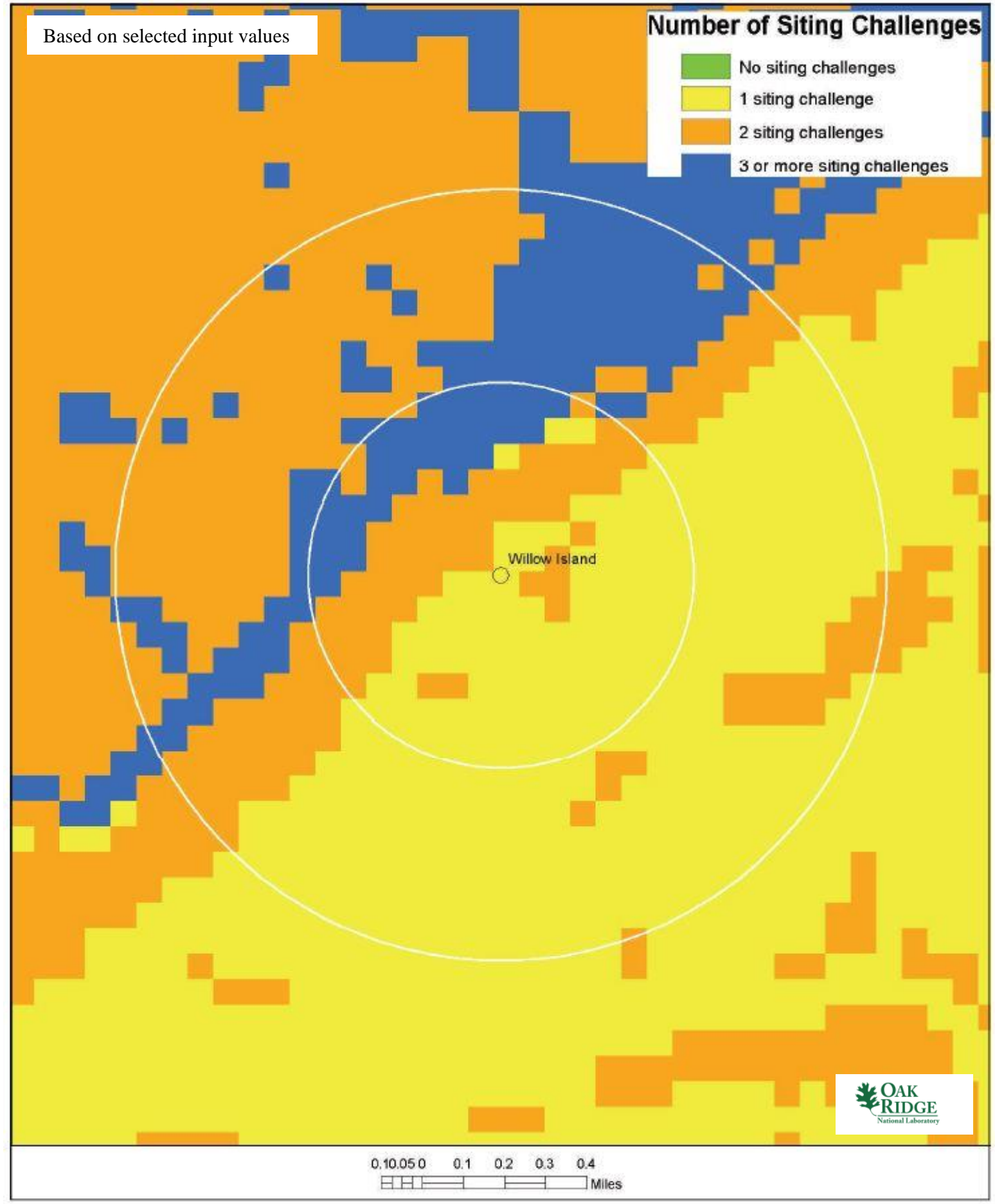

Fig. C.97. Willow Island Power Station composite map. 

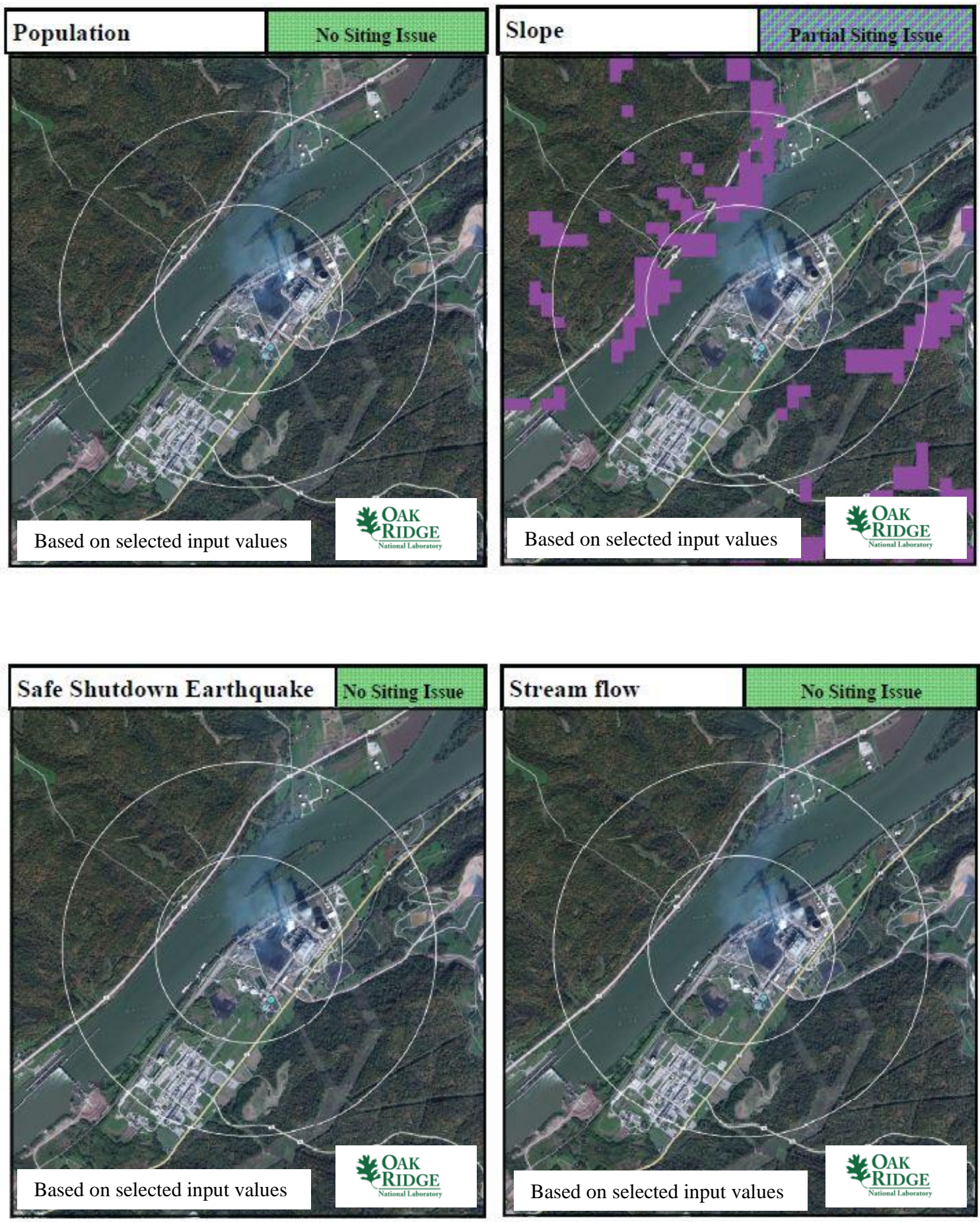

Willow Island Power Station 

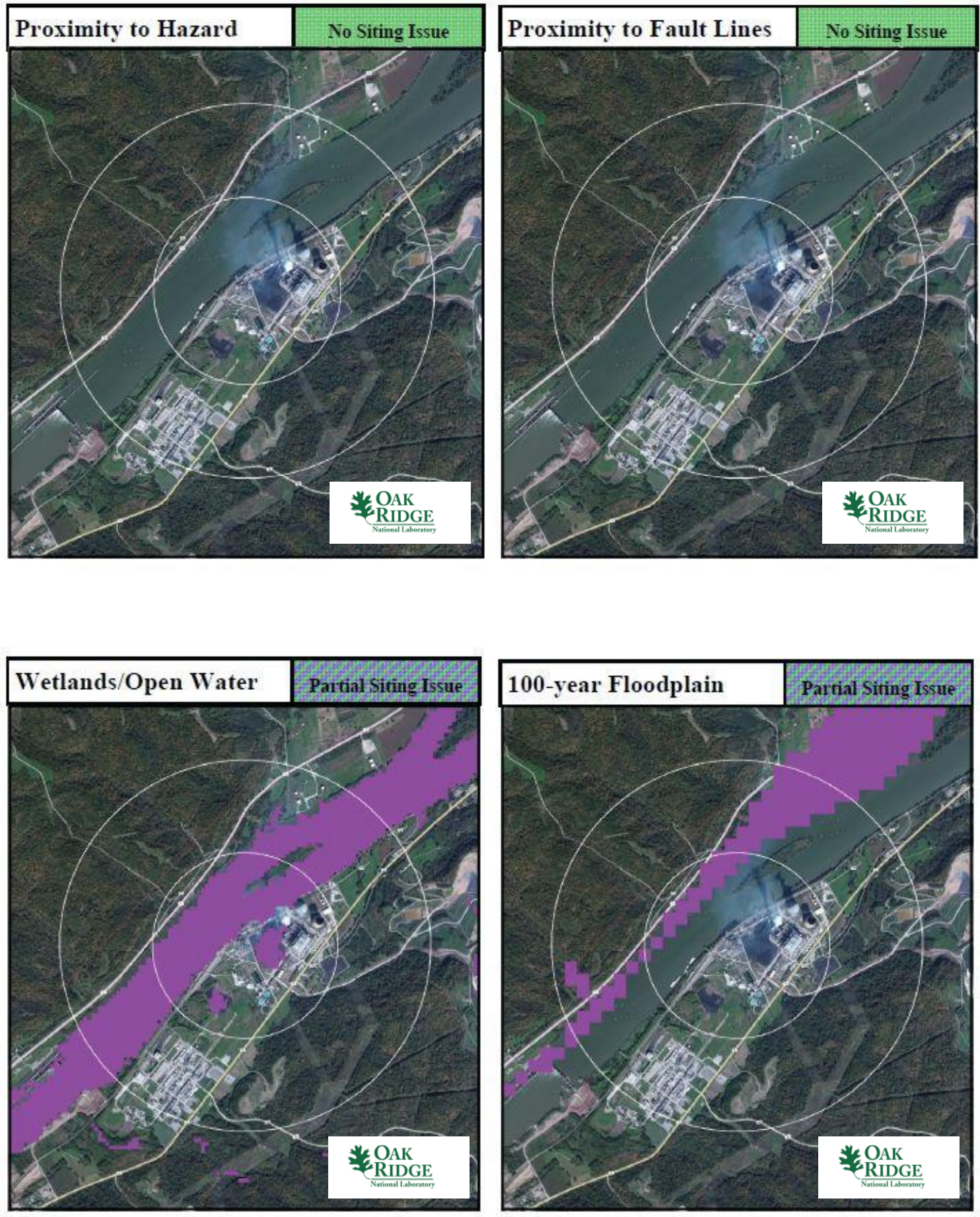

Willow Island Power Station 

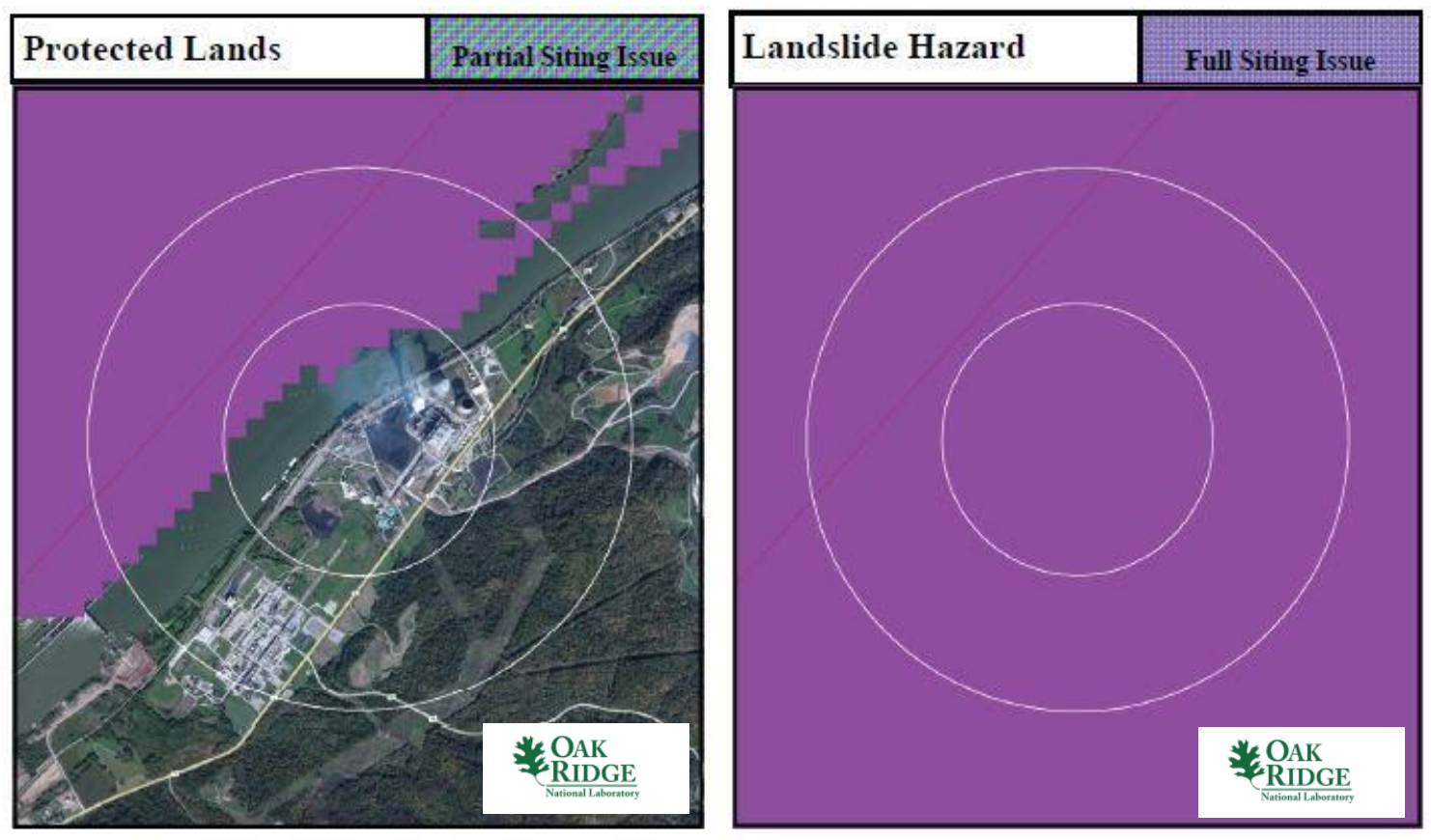

Willow Island Power Station

\section{C.8.6 Site Evaluation}

Monongahela Power does not operate or own a share of any nuclear power plants in the United States. However, its parent company, FirstEnergy Corporation, does operate numerous nuclear power facilities, including Beaver Valley in Pennsylvania, and Davis-Besse and Perry in Ohio. Therefore, FirstEnergy Nuclear Operating Company has the licensing experience to operate an SMR at this site. The site contains sufficient acreage to support siting an SMR.

From an environmental justice perspective, the community collectively appears to have achieved a reasonable level of education with median income levels typical of much of the United States. Therefore, siting an SMR at this location would not seem to be disenfranchising a less-educated or poverty-stricken community. Furthermore, the education level of the Willow Island Power Station community would seem to support the higher-technology job opportunities provided by an SMR.

As shown in Sects. C.0 and C.0, the Willow Island Power Station site has a widespread issue with landslide hazards. Moderate and high landslide hazard risk is based on probabilistic analyses by the USGS. Therefore, more specific geological surveys would be required before eliminating the Willow Island Power Station site from SMR siting consideration. There has not been a landslide issue at the current site since its construction in 1949.

The Willow Island Power Station site has partial SMR site screening issues with slope, wetlands/open waters, 100-year floodplain, and protected land. The slope issue is related to land to the north of the site on the opposite side of the Ohio River from the coal plant and land outside the half-mile circle in the wooded area south of the site. The wetlands/open waters issue reflects the adjacent Ohio River. The 100year floodplain affects land north of the site on the opposite side of the Ohio River. Likewise, a partial site screening issue for protected land appears due to the 240,000 acre Wayne National Forest on the opposite side of the Ohio River in the state of Ohio. Further visual inspection of the aerial imagery indicates that none of these four issues should directly impact the siting of an SMR at this location. The remaining SMR site screening criteria are met site-wide for the values established in the updated SMR siting report. 1 
The Willow Island Power Station is next to an operating, large coal plant and within a mile of a future hydroelectric facility. If future energy demand requires additional generation capacity at this grid location, an SMR would make this site a multi-faceted energy park. The site meets current NRC RG 4.7 recommendations for population density without additional consideration for relaxed SMR population siting requirements based on reduced source term. The Willow Island Power Station site meets multiple conventional standards for consideration of siting an SMR pending verification of no landslide limitations. 
C-78 


\section{APPENDIX D—COAL PLANT EVALUATIONS OF FOURTH-TIER SITES}

The site is not a likely candidate for consideration of siting an SMR. Numerous SSEC are not met that could make it difficult for a utility to consider replacing the coal-fired power produced at an existing coal station with an SMR.

Coal stations evaluated in this category are

- Ashtabula Power Plant

- Gadsden Electric Generating Plant

- Kramer Power Plant

- Marysville Power Plant

- Maynard Power Station

- Merrimack Station

- Quindaro Power Station

- R. Paul Smith Power Station 



\section{APPENDIX D—COAL PLANT EVALUATIONS OF FOURTH-TIER SITES}

\section{D.1 ASHTABULA POWER PLANT}

\section{D.1.1 Location Detail}

As shown in Fig. D.98, the Ashtabula Power Plant is located on Lake Erie in northeastern Ohio just west of the Pennsylvania border. More specifically, the plant is located off Lake Road, in Ashtabula County, Ohio. Highway 20 is accessible approximately 2 miles to the south. Limited access local highway 11 is within 1 mile. Highway 11 connects with Interstate 905 miles to the south. Rail access is available within 1.4 miles and barge access is available at the site via the Lake Erie. The closest city is Ashtabula, Ohio, with a population of approximately 19,000 people. The city of Ashtabula is approximately 2 miles southwest of the Ashtabula Power Plant.

- Plant: Ashtabula Power Plant

- Utility: FirstEnergy Corporation

- Coordinates: lat. $41.90923^{\circ} \mathrm{N}$, long. $80.76978^{\circ} \mathrm{W}$

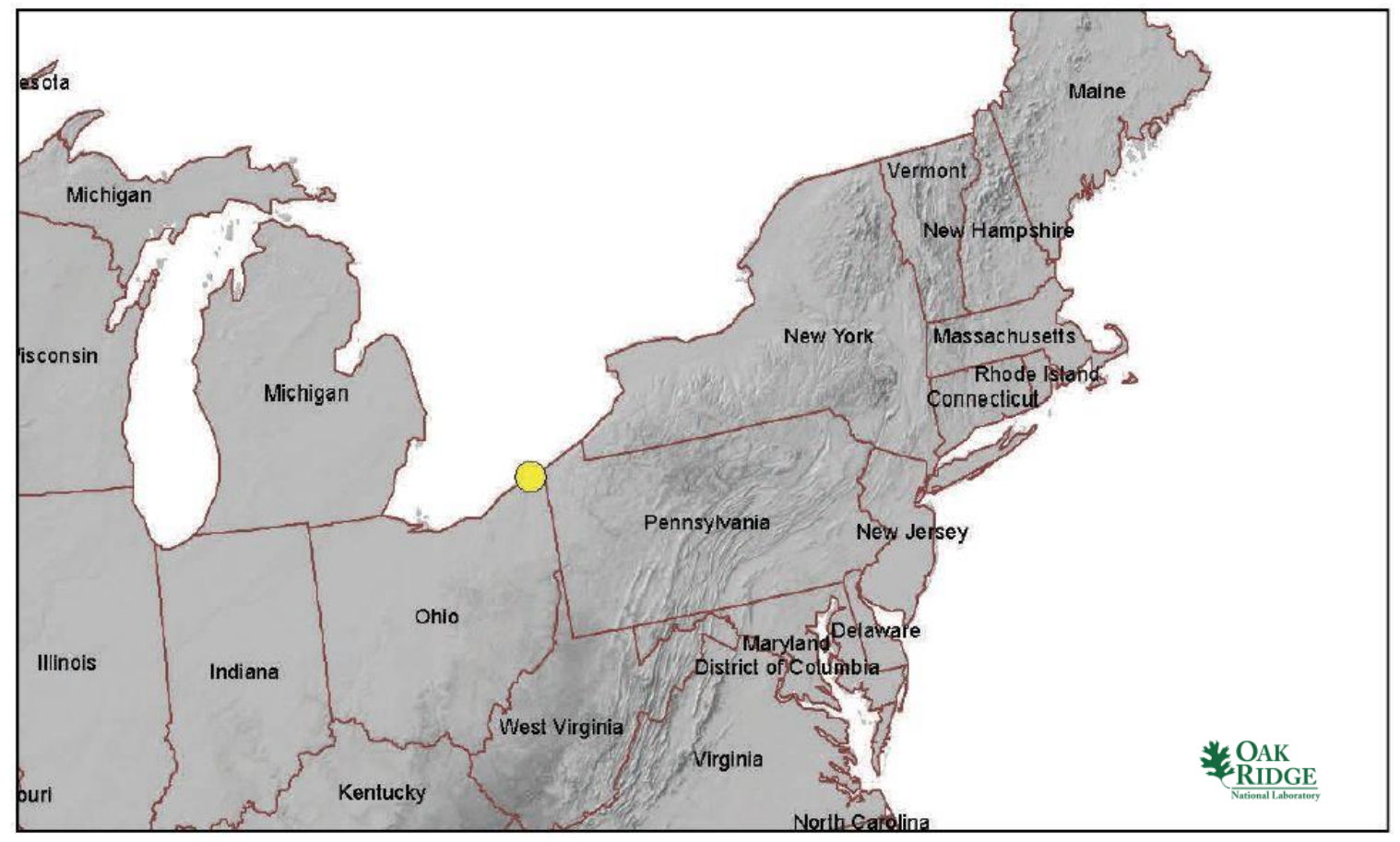

Fig. D.98. Ashtabula Power Plant location map.

\section{D.1.2 Site Description and Status}

The Ashtabula Power Plant is a single unit 256 MW(e) coal station commissioned in 1958. The unit is operated by FirstEnergy Corporation. In January of 2012, FirstEnergy announced its intention to shut down the Ashtabula plant by September 2012 rather than backfit scrubbing equipment to allow continued operation under more stringent EPA rules. However, the plant shutdown is delayed until 2015 to allow transmission line upgrades to avoid state-wide transmission problems during peak energy demand. The Ashtabula Power Plant is operated as a peaking power unit. The site is cooled by once-through cooling from the adjacent Lake Erie. 
The plant is situated on approximately 100 acres on Lake Erie just east of the point where the Ashtabula River flows into the lake. The plant is approximately 20 miles northeast of the 1,260 MW(e) Perry nuclear facility and approximately 90 miles north of the 1,890 MW(e) Beaver Valley nuclear facility. The Ashtabula Power Plant is 38 miles northeast of the 1,257 MW(e) FirstEnergy Eastlake Coal-fired Power Plant, also scheduled for shutdown in 2015, and 51 miles north of the 266 MW(e) Niles Coal Plant.

As noted in Table D.58, the nearest major fault line based on USGS data is 1,000 miles west in Oklahoma. The maximum safe-shutdown earthquake for the site is below $0.3 \mathrm{~g}$ peak ground acceleration. More than 500,000 gpm of cooling water makeup is available from the adjacent Lake Erie.

Using Landscan data, the ambient population within 1 mile of the plant is approximately 2,700 people, yielding a population density of approximately than 860 people per square mile. The US EPA Environmental Justice website notes a permanent population density within 1 mile of the plant to be 180 people per square mile. The latter number appears to be visually consistent with the small residential neighborhood within the 1 mile target circle shown in Fig. A.21. The permanent population within 10 miles of the plant is approximately 120,000 people, yielding a population density of approximately 380 people per square mile. According to the US EPA Environmental Justice website, there are 19,134 occupied housing units within 10 miles of the plant site based on 2000 US Census data. Further, slightly less than $80 \%$ of area adults over age 25 have a high school diploma or higher education. The median annual income for the area is between $\$ 25 \mathrm{~K}$ and $\$ 50 \mathrm{~K}$.

Table D.58. Ashtabula Power Plant site statistics

\begin{tabular}{|l|l|l|l|}
\hline $\begin{array}{l}\text { Population } \\
\text { Population Within }\end{array}$ & \multicolumn{2}{l|}{$\begin{array}{l}\text { Utility } \\
\text { Distance to Grid Capacity }\end{array}$} \\
\hline $0.5 \mathrm{mi}$ & $\sim 1,000$ & $>400 \mathrm{MWe}$ & $\sim 20 \mathrm{mi}$ \\
\hline $1 \mathrm{mi}$ & $\sim 2,700$ & $>800 \mathrm{MWe}$ & $\sim 0.1 \mathrm{mi}$ \\
\hline $5 \mathrm{mi}$ & $\sim 65,300$ & $>1600 \mathrm{MWe}$ & $\sim 60 \mathrm{mi}$ \\
\hline $10 \mathrm{mi}$ & $\sim 120,000$ & $>3200 \mathrm{MWe}$ & $\sim 74 \mathrm{mi}$ \\
\hline Nearest City with Population & Distance to Cooling Water \\
\hline \multicolumn{1}{|l|}{} & \multicolumn{2}{l|}{} \\
\hline$>10,000$ & Ashtabula, OH & $>50,000 \mathrm{gpm}$ & $\sim 1.2 \mathrm{mi}$ (Lake Erie) \\
\hline$>100,000$ & Mentor, OH & $>100,000$ gpm & $\sim 1.2 \mathrm{mi}$ (Lake Erie) \\
\hline$>500,000$ & Erie, PA & $>200,000$ gpm & $\sim 1.2 \mathrm{mi}$ (Lake Erie) \\
\hline Geotechnical & Detroit, MI & $>500,000$ gpm & $\sim 1.2 \mathrm{mi}$ (Lake Erie) \\
\hline Max Earthquake Acceleration & $<0.3 \mathrm{~g}$ & Accessibility & \\
\hline Max Slope & $\sim 9 \%$ & Distance to Major Roadway & $\sim 2.2 \mathrm{mi}$ (US 20) \\
\hline Nearest Fault Line & $\sim 1,008$ mi (Oklahoma) & Distance to Rail Transport & $\sim 1.4$ mi (CSXT) \\
\hline Nearest Hazard Site & $\sim 31$ mi (Airport- & Distance to Airport & $\sim 31$ mi (Erie Int'l) \\
\hline
\end{tabular}




\section{D.1.3 Aerial Imagery}

The aerial imagery in Fig. D.99 indicates a small residential neighborhood within 1 mile of the Ashtabula Power Plant. Also visible are several industrial facilities, including a coal export dock.

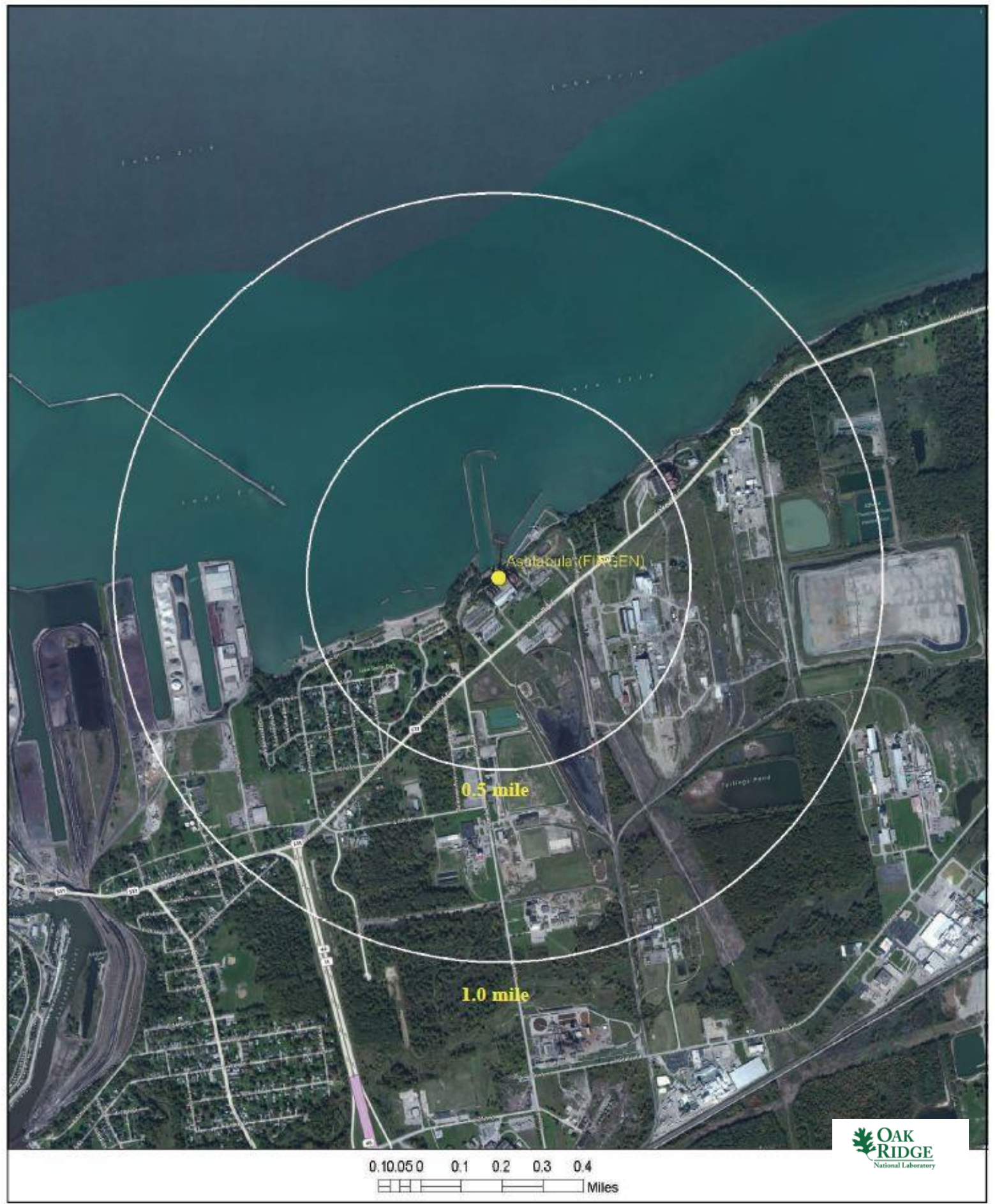

Fig. D.99. Satellite view of Ashtabula Power Plant proximity. 


\section{D.1.4 Screening Criteria Overview}

Table D.59. Ashtabula Power Plant siting criteria summary

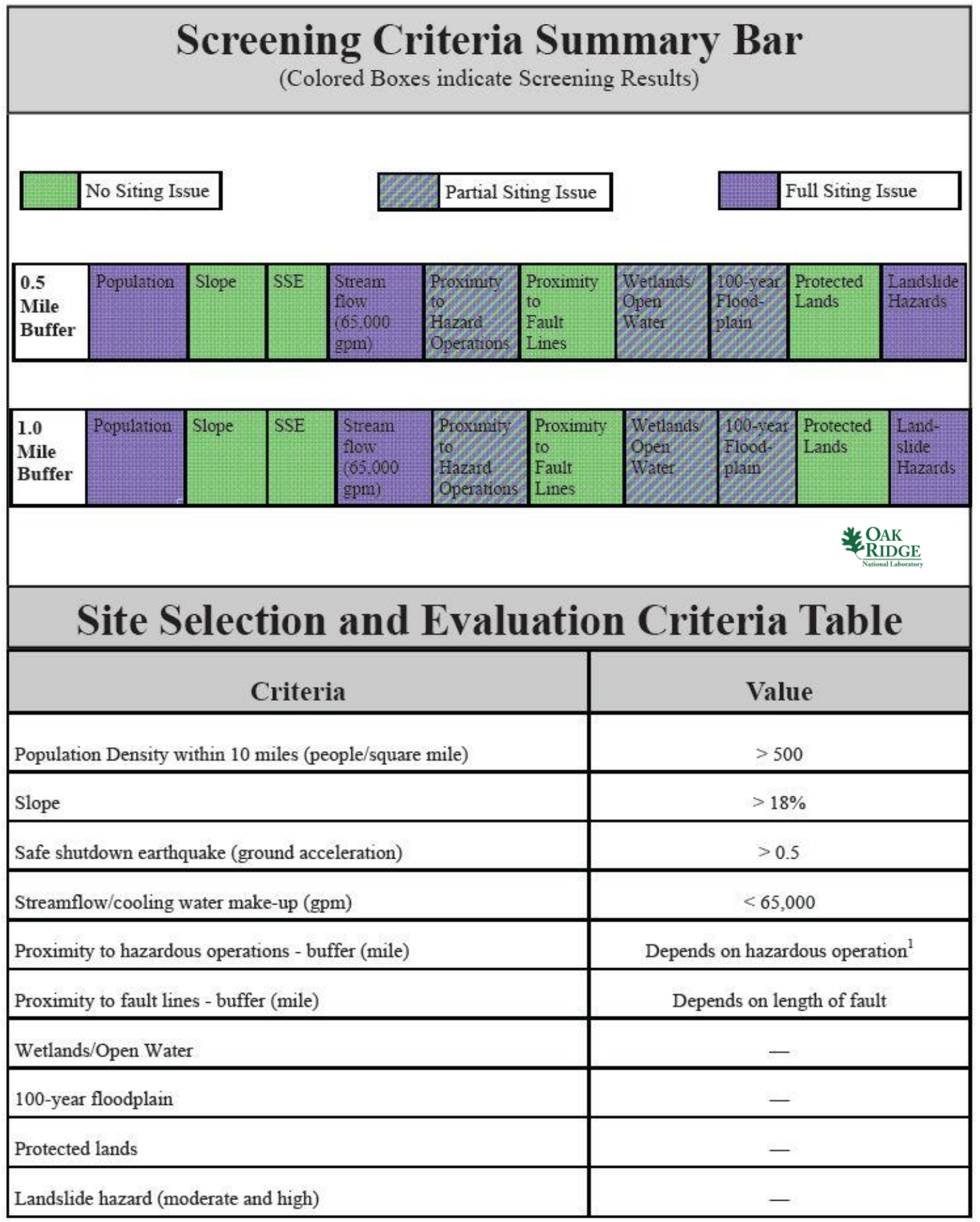

${ }^{1}$ Hazardous facilities (airports- 5 miles and oil refineries- -1 mile) 


\section{D.1.5 Composite Map and Individual Siting Issue Maps}

A composite map of SMR siting challenges to the Ashtabula Power Plant is shown in Fig. D.100. The physical plant structures are located on land with multiple siting issues. Following this map are maps of the individual SMR siting criteria based on selected input values.

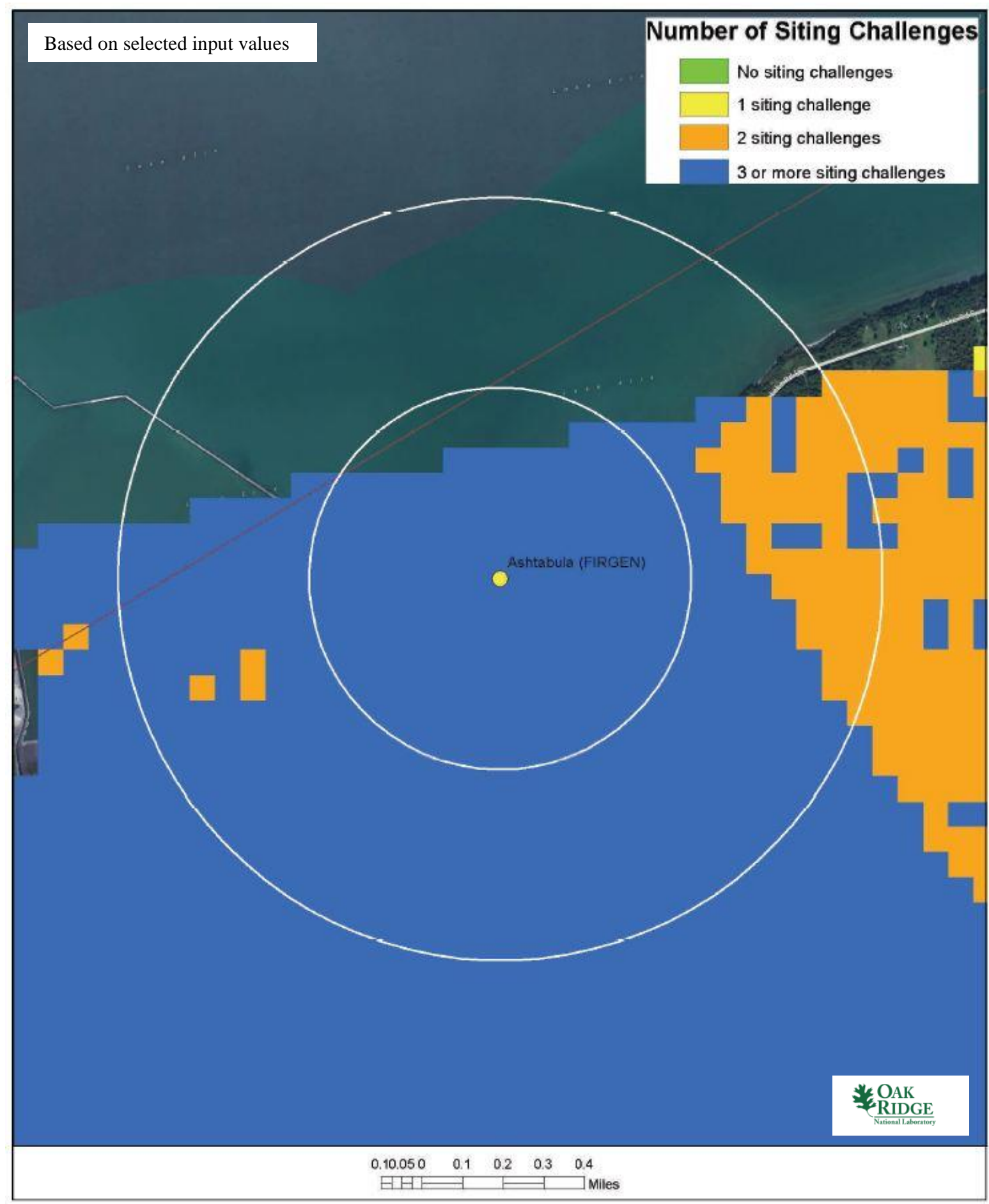

Fig. D.100. Ashtabula Power Plant composite map. 

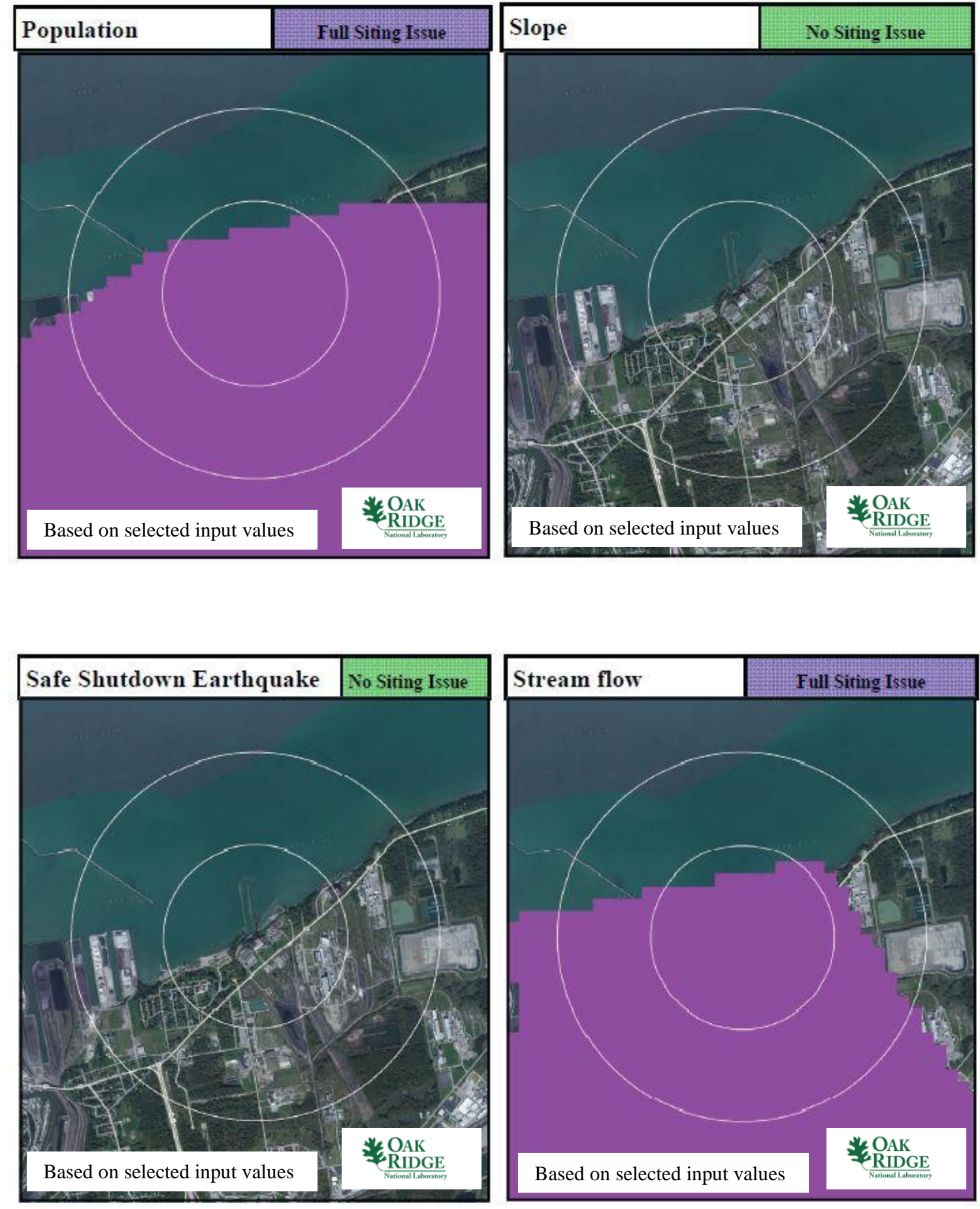

Ashtabula Power Plant 

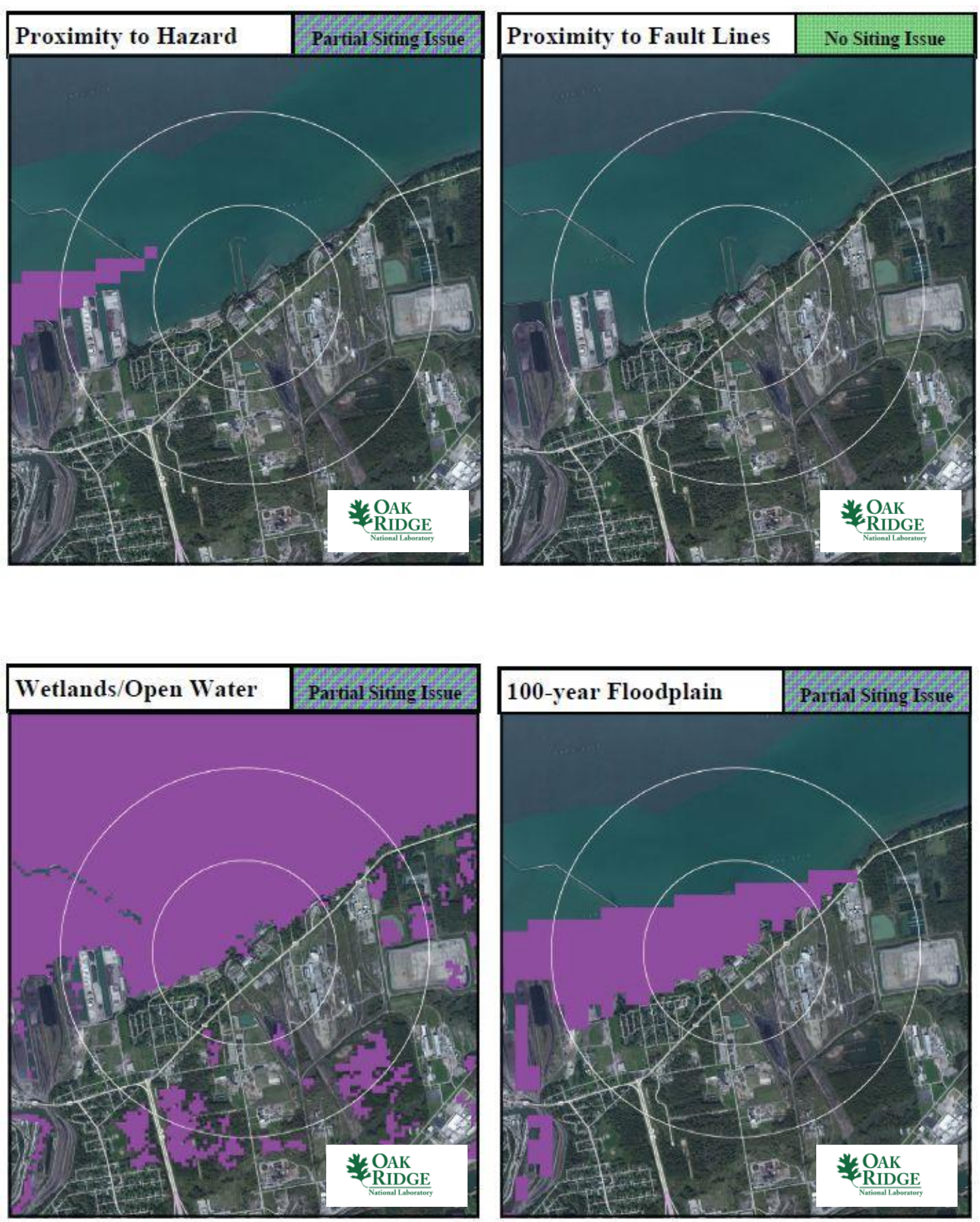

Ashtabula Power Plant 

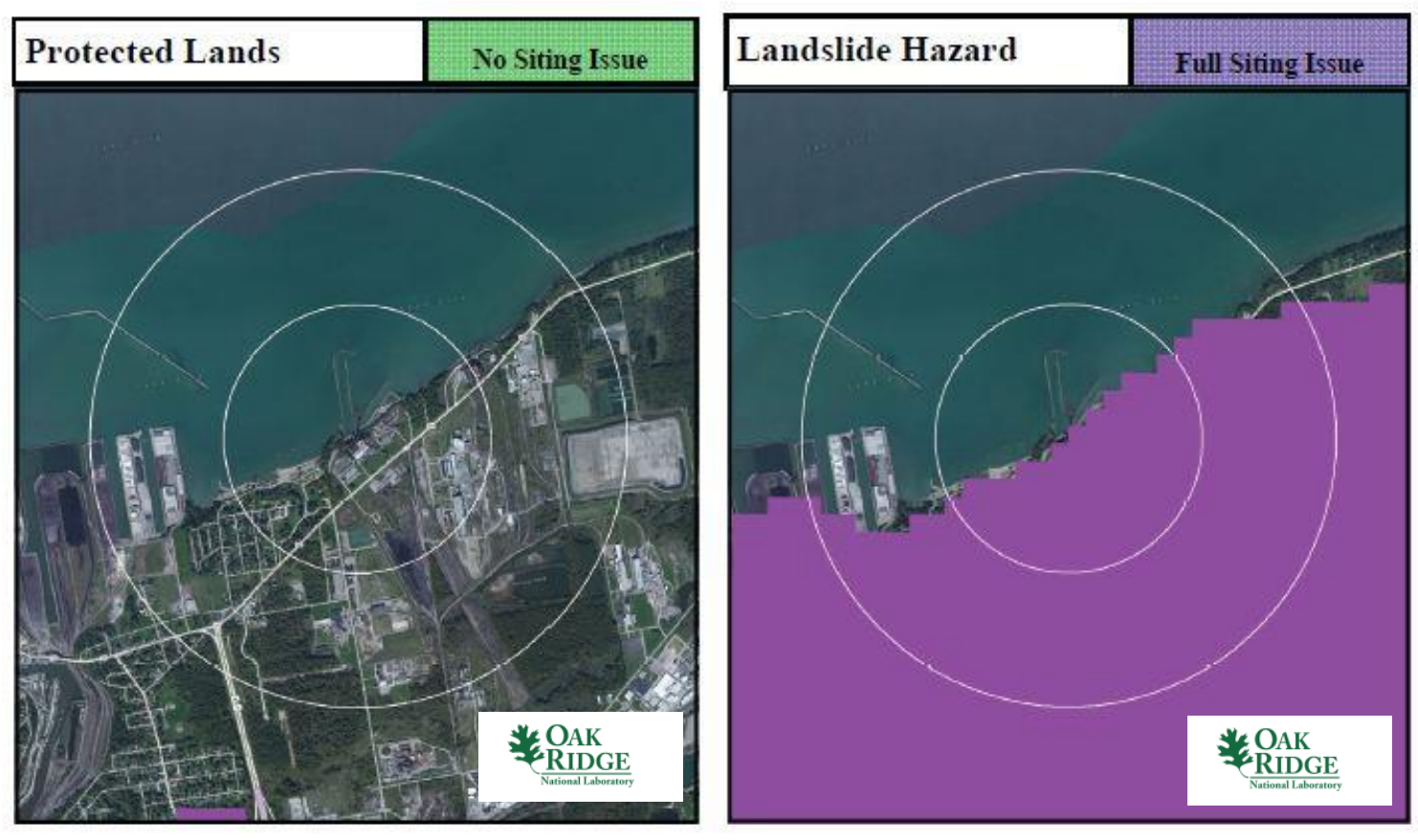

Ashtabula Power Plant

\section{D.1.6 Site Evaluation}

FirstEnergy Corporation operates several nuclear power plants, including Beaver Valley in Pennsylvania and Davis-Besse and Perry in Ohio. Therefore, it has the licensing experience to operate an SMR at this site. The site contains sufficient acreage to support siting an SMR.

From an environmental justice perspective, the community collectively appears to have achieved a reasonable level of education with median income levels typical of much of the United States. Therefore, siting an SMR at this location would not seem to be disenfranchising a less-educated or poverty-stricken community. Furthermore, the education level of the Ashtabula Power Plant community would seem to support the higher-technology job opportunities provided by an SMR.

As shown in Sects. D.0 and D.0, the Ashtabula Power Plant site has widespread issues with the SMR site screening issue for population, adequate SMR stream flow, and landslide hazards. The population in the city of Ashtabula greatly exceeds the SMR siting criteria of fewer than 500 people per square mile within 10 miles of the plant site. This would appear to prohibit siting an SMR at this location, though the population density within 1 mile of the plant site is reasonably small. Adequate stream flow for cooling water makeup water is not available from the Ashtabula River. However, the plant site sits adjacent to Lake Erie and would pull its cooling water makeup from the lake. So inadequate stream flow is not an issue for this site. Finally, moderate and high landslide hazard risk is based on probabilistic analyses by the USGS. Therefore, more specific geological surveys would be required before eliminating the Ashtabula Power Plant site from SMR siting consideration. There has not been a landslide issue at the current site since its construction in 1958.

The Ashtabula Power Plant site has partial SMR site screening issues with wetlands/open waters and 100year flood plain. The wetlands/open waters issue and the 100-year flood plain issue reflect Lake Erie on the north boundary of the plant site. Neither criterion is an issue for the site. The remaining SMR site screening criteria are met site-wide for the values established in the updated SMR siting report.1

Though population figures may not be problematic within a 1 mile radius of the plant industrial area, a subdivision is visually apparent in an aerial view of the site between the 0.5 mile radius circle and the 
1 mile radius circle. The overall population density in the area greatly exceeds current NRC RG 4.7 recommendations for population density. In addition, geological surveys would be required to verify that there are no landslide hazards at this site. As a result, the Ashtabula Power Plant site is not a likely candidate for consideration of siting an SMR. 
D-12 


\section{D.2 Gadsden Electric Generating Plant}

\section{D.2.1 Location Detail}

As shown in Fig. D.101, the Gadsden Electric Generating Plant is located in Northeastern Alabama, off Goodyear Road in Etowah County. Highway 278 is accessible approximately 0.4 miles to the west. Rail access is available onsite within 1.0 mile and barge access is available within 28 miles northwest of the site from the Tennessee River. The closest town is Gadsden, Alabama, with a population of approximately 36,813 people. Gadsden is also the county seat. Gadsden is approximately 1.86 miles west of the Gadsden Electric Generating Plant.

- Plant: Gadsden Electric Generating Plant

- Utility: Alabama Power Company

- Coordinates: lat. $34.01273^{\circ} \mathrm{N}$, long. $85.97027^{\circ} \mathrm{W}$

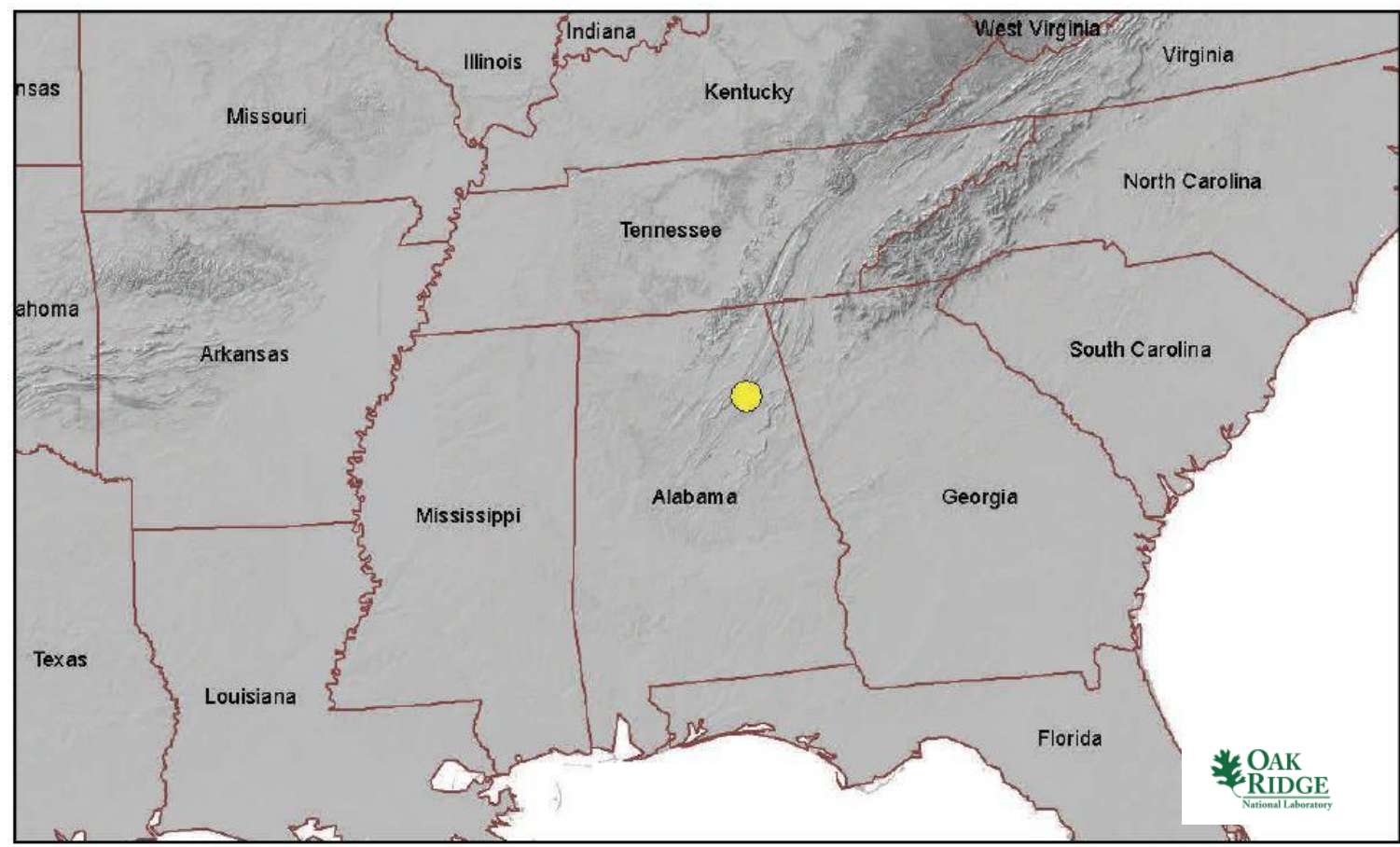

Fig. D.101. Gadsden Electric Generating Plant location map

\section{D.2.2 Site Description and Status}

The Gadsden Electric Generating Plant is operated by Alabama Power Company, a subsidiary of Southern Company. The two-unit station uses either coal or natural gas. Both units were commissioned in 1949 and are rated at $69 \mathrm{MW}(\mathrm{e})$ each for a station nameplate of $138 \mathrm{MW}(\mathrm{e})$. The site is cooled by an onsite cooling pond. A principal customer of the plant is the virtually collocated Goodyear Tire \& Rubber Plant.

The plant is situated on roughly 40 acres on the Coosa River approximately 81 miles southeast of the 3,300 MW(e) Brown's Ferry nuclear facility. The plant is 61 miles south of the 1,969 MW(e) coal-fired Widows Creek Plant and 68 miles northeast of the 2,822 MW(e) coal-fired Miller Steam Plant. In 
addition, the plant is 13 miles southwest of the $73 \mathrm{MW}(\mathrm{e})$ Weiss hydroelectric plant and 16 miles north of the Henry hydroelectric plant.

As noted in Table D.60, the nearest major fault line based on USGS data is 667 miles west in Oklahoma. The maximum safe-shutdown earthquake for the site is below $0.3 \mathrm{~g}$ peak ground acceleration. More than $500,000 \mathrm{gpm}$ of cooling water makeup is available from the adjacent Coosa River.

The permanent population within 1 mile of the plant is approximately 7,000 people, yielding a population density of about 2,228 people per square mile. The permanent population within 10 miles of the plant is approximately 172,000 people, yielding a population density of approximately 547 people per square mile. According to the US EPA Environmental Justice website, there are 33,587 occupied housing units within 10 miles of the plant site based on 2000 US Census data. Further, $73 \%$ of area adults over age 25 have a high school diploma or higher education. The median annual income for the area is between $\$ 25 \mathrm{~K}$ and $\$ 50 \mathrm{~K}$.

Table D.60. Gadsden Electric Generating Plant site statistics

\begin{tabular}{|c|c|c|c|}
\hline \multicolumn{2}{|l|}{$\begin{array}{l}\text { Population } \\
\text { Population Within }\end{array}$} & \multicolumn{2}{|l|}{$\begin{array}{l}\text { Utility } \\
\text { Distance to Grid Capacity }\end{array}$} \\
\hline $0.5 \mathrm{mi}$ & $\sim 2,000$ & $>400 \mathrm{MWe}$ & $\sim 15 \mathrm{mi}$ \\
\hline $1 \mathrm{mi}$ & $\sim 7,000$ & $>800 \mathrm{MWe}$ & $\sim 40 \mathrm{mi}$ \\
\hline $5 \mathrm{mi}$ & $\sim 92,000$ & $>1600 \mathrm{MWe}$ & $\sim 37 \mathrm{mi}$ \\
\hline $10 \mathrm{mi}$ & $\sim 172,000$ & $>3200 \mathrm{MWe}$ & $\sim 65 \mathrm{mi}$ \\
\hline \multicolumn{2}{|c|}{ Nearest City with Population } & \multicolumn{2}{|c|}{ Distance to Cooling Water } \\
\hline$>10,000$ & Gadsden, AL & $>50,000 \mathrm{gpm}$ & $\sim 0.1 \mathrm{mi}$ (Coosa River) \\
\hline$>50,000$ & Hoover, AL & $>100,000 \mathrm{gpm}$ & $\sim 0.1 \mathrm{mi}$ (Coosa River) \\
\hline$>100,000$ & Huntsville, AL & $>200,000 \mathrm{gpm}$ & $\sim 0.1 \mathrm{mi}$ (Coosa River) \\
\hline$>500,000$ & Nashville, TN & $>500,000 \mathrm{gpm}$ & $\sim 0.1 \mathrm{mi}$ (Coosa River) \\
\hline \multicolumn{2}{|l|}{ Geotechnical } & \multicolumn{2}{|l|}{ Accessibility } \\
\hline Max Earthquake Acceleration & $<0.3 \mathrm{~g}$ & Distance to Major Roadway & $\sim 0.4 \mathrm{mi}($ US 278) \\
\hline Max Slope & $\sim 6 \%$ & Distance to Water Transport & $\sim 28.2 \mathrm{mi}$ (Tennessee River) \\
\hline Nearest Fault Line & $667 \mathrm{mi}$ (Oklahoma) & Distance to Rail Transport & $\sim 1.0 \mathrm{mi}(\mathrm{ATN})$ \\
\hline Nearest Hazard Site & $\begin{array}{l}\sim 52 \text { mi (Airport- } \\
\text { Birmingham Int'1) }\end{array}$ & Distance to Airport & $\sim 52.0 \mathrm{mi}$ (Birmingham Int' 1$)$ \\
\hline
\end{tabular}




\section{D.2.3 Aerial Imagery}

The aerial imagery in Fig. D.102 indicates that housing is visible within a 1 mile radius of the plant site.

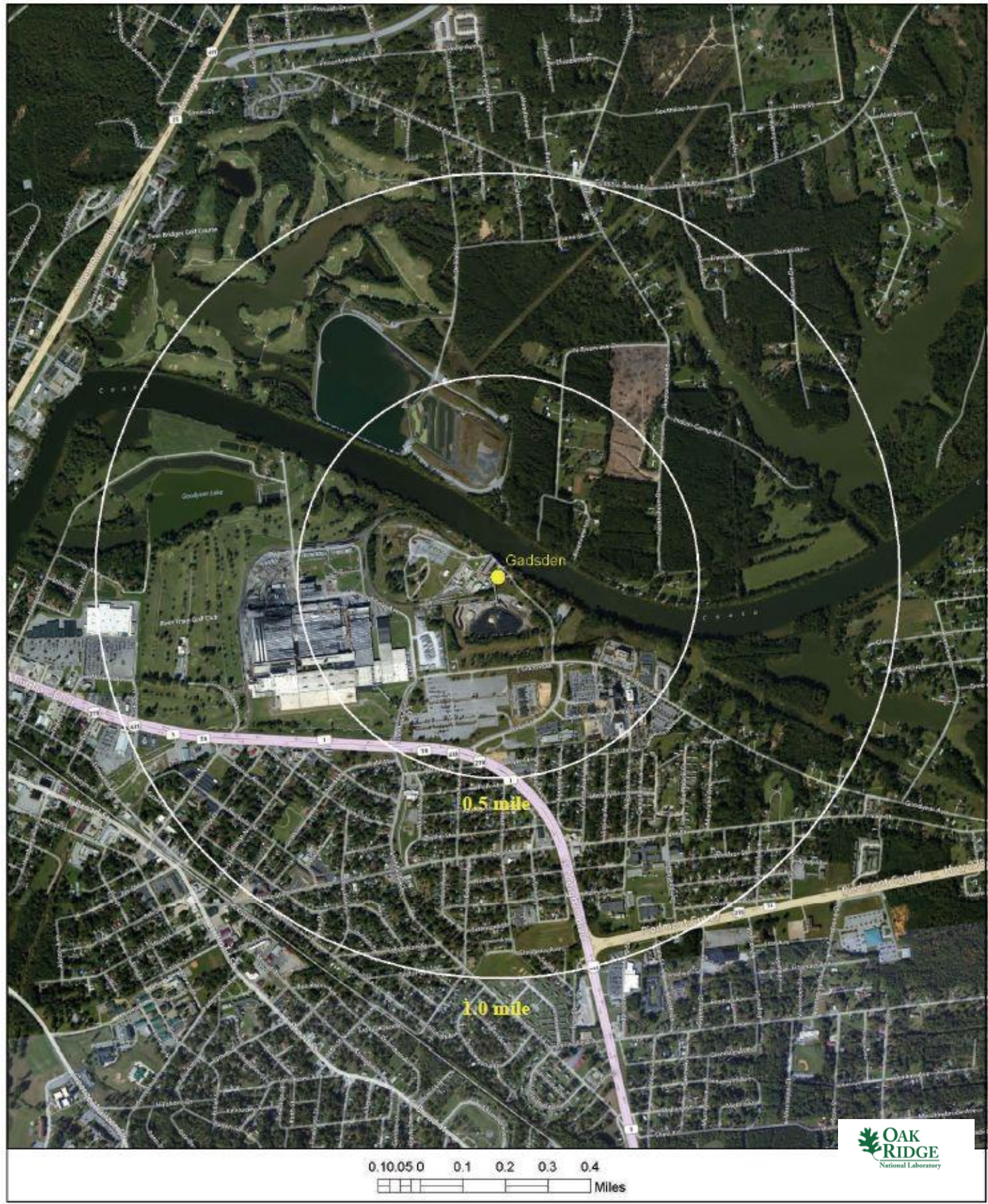

Fig. D.102. Satellite view of Gadsden Electric Generating Plant proximity. 


\section{D.2.4 Screening Criteria Overview}

Table D.61. Gadsden Electric Generating Plant siting criteria summary

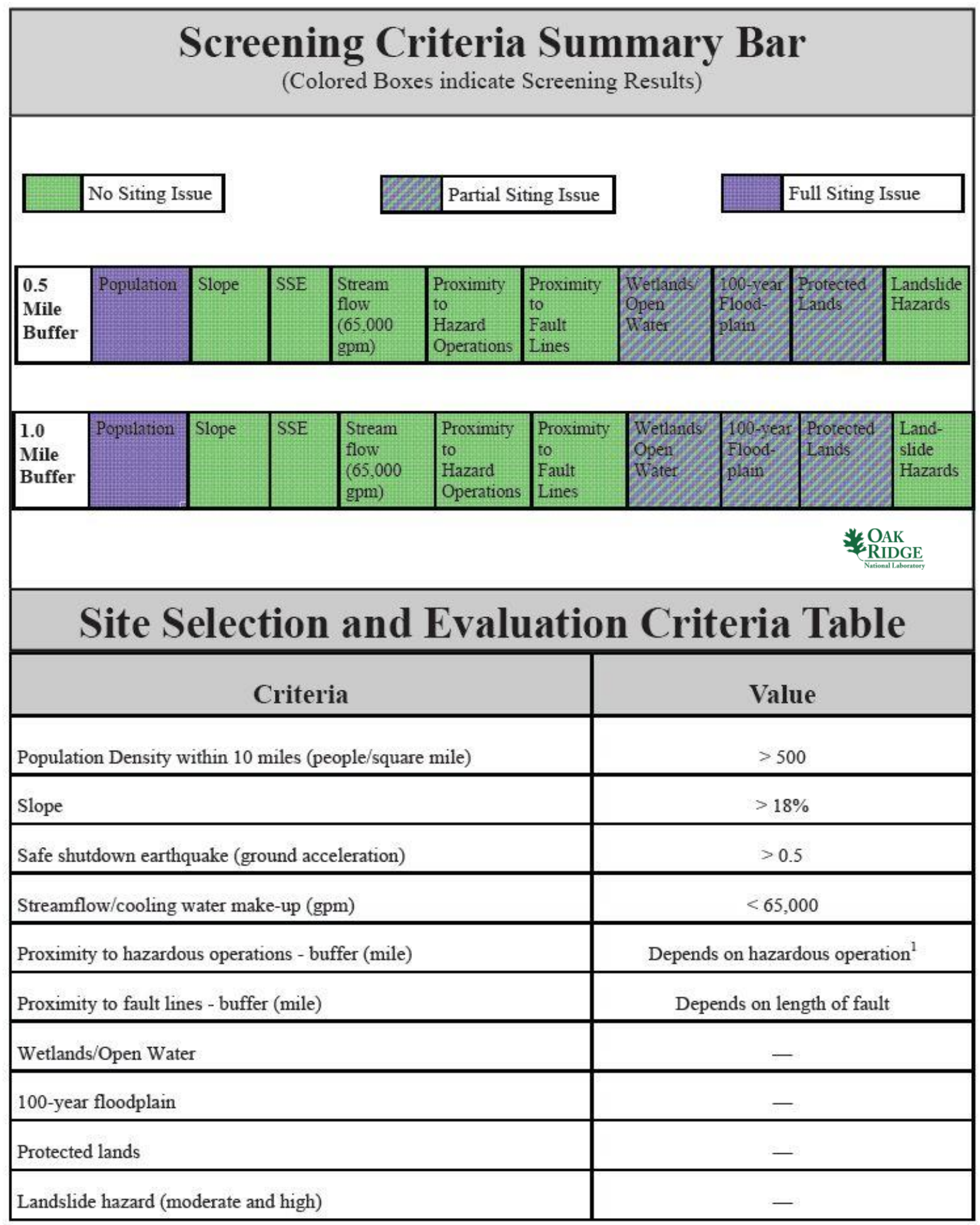

${ }^{1}$ Hazardous facilities (airports-5 miles and oil refineries-1 mile) 


\section{D.2.5 Composite Map and Individual Siting Issue Maps}

A composite map of SMR siting challenges to the Gadsden Electric Generating Plant is shown in Fig. D.103. The physical plant structures are located on land with a single siting issue. Following this map are maps of the individual SMR siting criteria based on selected input values.

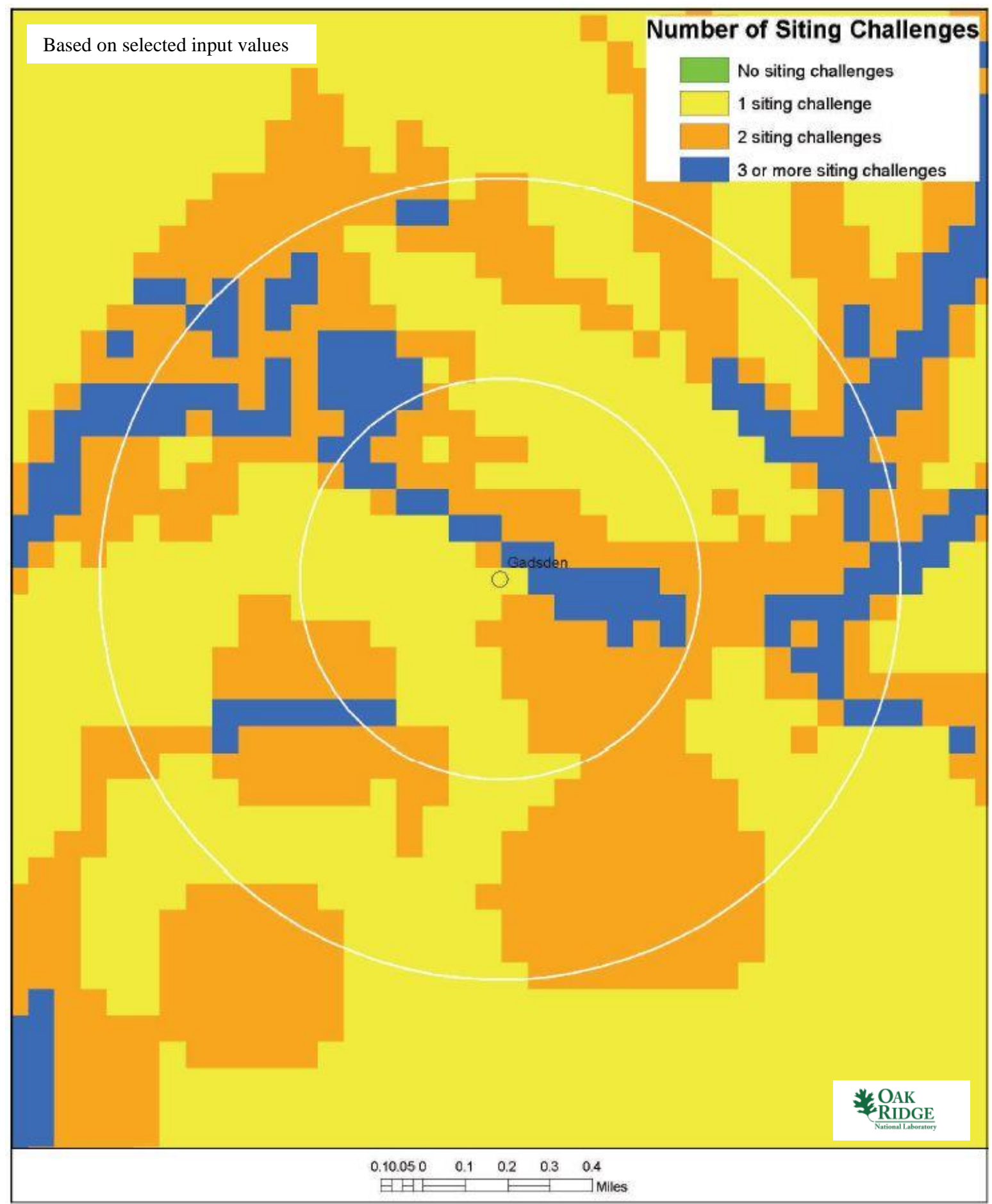

Fig. D.103. Gadsden Electric Generating Plant composite map. 

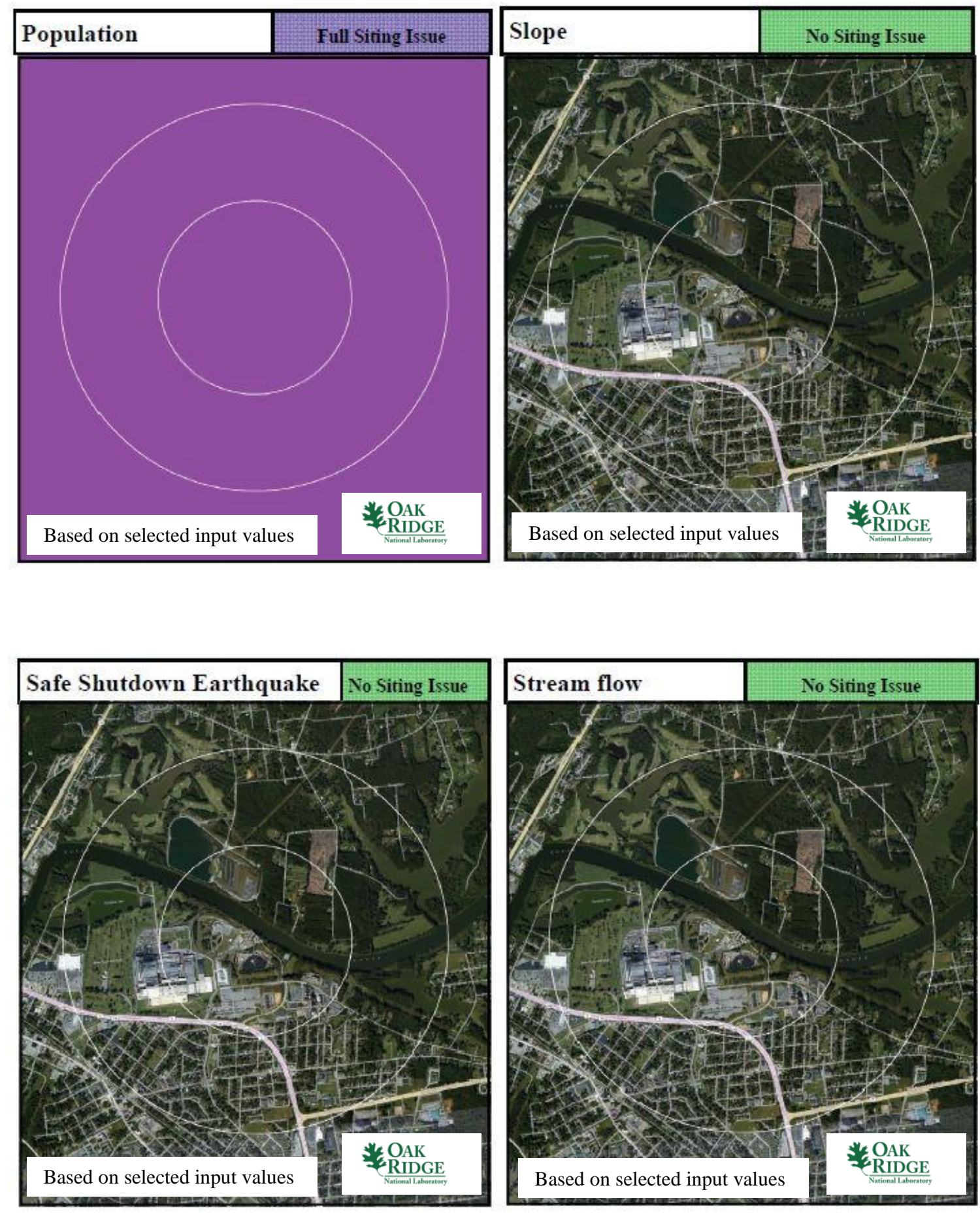

Gadsden Electric Generating Plant 

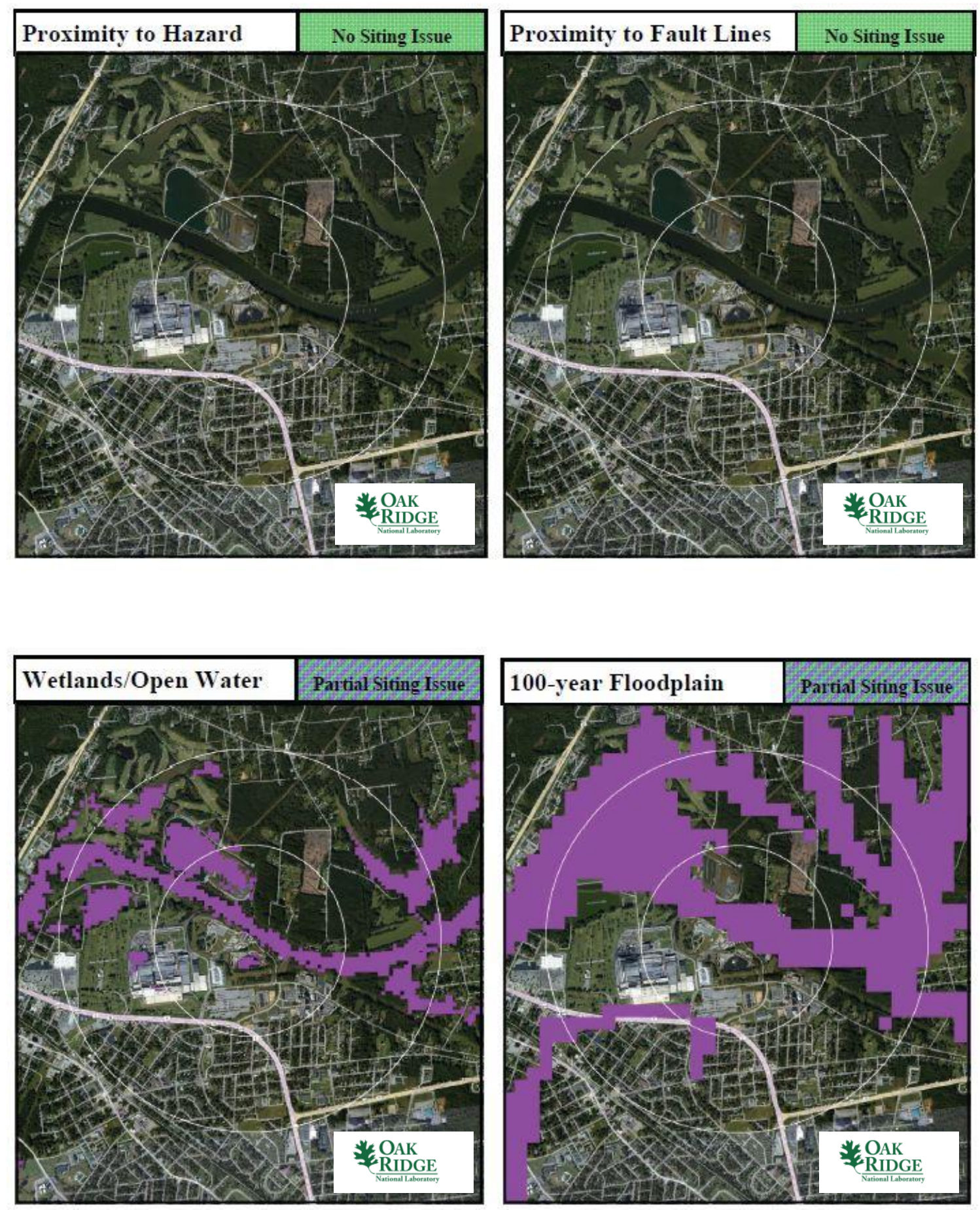

Gadsden Electric Generating Plant 

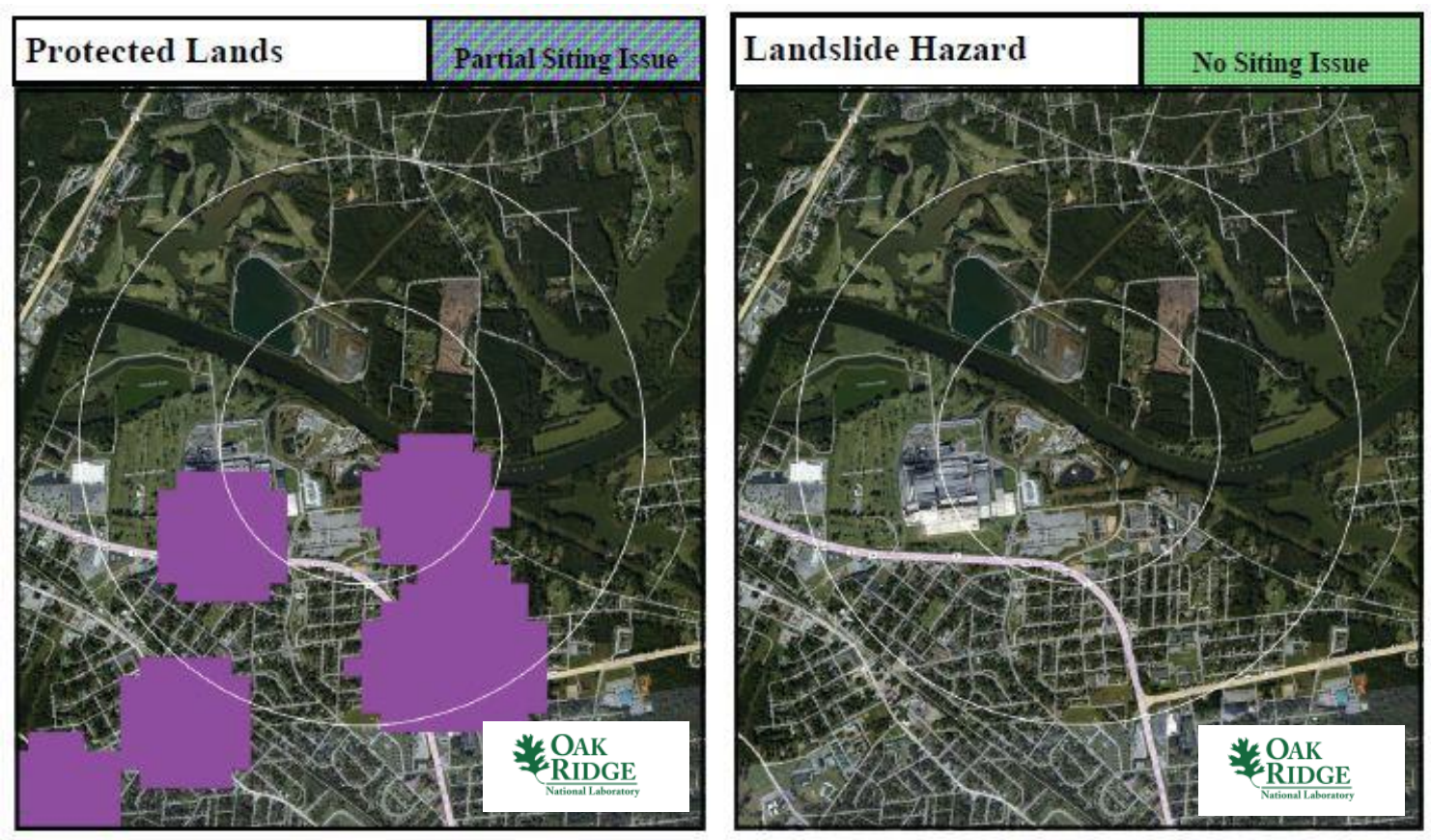

Gadsden Electric Generating Plant

\section{D.2.6 Site Evaluation}

Alabama Power Company does not operate any nuclear power plants in the United States. However, its parent company, Southern Company, does operate six nuclear power facilities, four in Georgia and two in Alabama. Southern Company has also applied for a COL for two nuclear plants at the Vogtle Plant site in Georgia. Therefore, Southern Company has the licensing experience to operate an SMR at this site. The site contains sufficient acreage to support siting an SMR.

From an environmental justice perspective, the community collectively appears to have achieved a reasonable level of education with median income levels typical of much of the United States. Therefore, siting an SMR at this location would not seem to be disenfranchising a less-educated or poverty-stricken community. Furthermore, the education level of the Gadsden Electric Generating Plant community would seem to support the higher-technology job opportunities provided by an SMR.

As shown in Sects. D.0 and D.0, the Gadsden Electric Generating Plant site has a full site issue with population. Housing and numerous subdivisions are within 2 miles of the plant. East Gadsden is less than 1 mile from the plant site and the population density is in excess of 2000 people per square mile within a mile of the plant.

The Gadsden Electric Generating Plant site has partial SMR site screening issues with wetland/open water, 100 year floodplain, and protected land. The wetlands/open waters issue reflects the adjacent Coosa River. The 100-year floodplain affects land north of the site on the opposite side of the Coosa River. A partial site screening issue for protected land is noticeable on the east, west, and south sides of the plant, which reflects local area parkland. The remaining SMR site screening criteria are met site-wide for the values established in the updated SMR siting report.1

The Gadsden Electric Generating Plant is adjacent to the Goodyear Tire \& Rubber Company Gadsden Plant. If future energy demand requires additional generation capacity at this grid location, an SMR would make this site a multi-faceted energy park. However, the nearby population density within 1 mile greatly exceeds current NRC RG 4.7 recommendations for population density. As a result, the Gadsden Electric Generating Plant site is not a likely candidate for consideration of siting an SMR. 


\section{D.3 Kramer Power Plant}

\section{D.3.1 Location Detail}

As shown in Fig. D.104, the former Kramer Power Plant is located in Nebraska on the West Bank of the Missouri River along the western border of Iowa. More specifically, the plant was located off Nebraska Highway 370 in Sarpy County, Nebraska. Interstate 29 is accessible approximately 3.2 miles to the east. Rail access is available onsite within 0.1 miles and barge access is available within 0.1 miles from the adjacent Missouri River. The closest town is Bellevue, Nebraska, with a population of a little more than 50,000 people. Bellevue borders the site of the former Kramer Power Plant.

- Plant: Kramer Power Plant

- Utility: Nebraska Public Power District

- Coordinates: lat. $41.14304^{\circ} \mathrm{N}$, long. $95.88411^{\circ} \mathrm{W}$

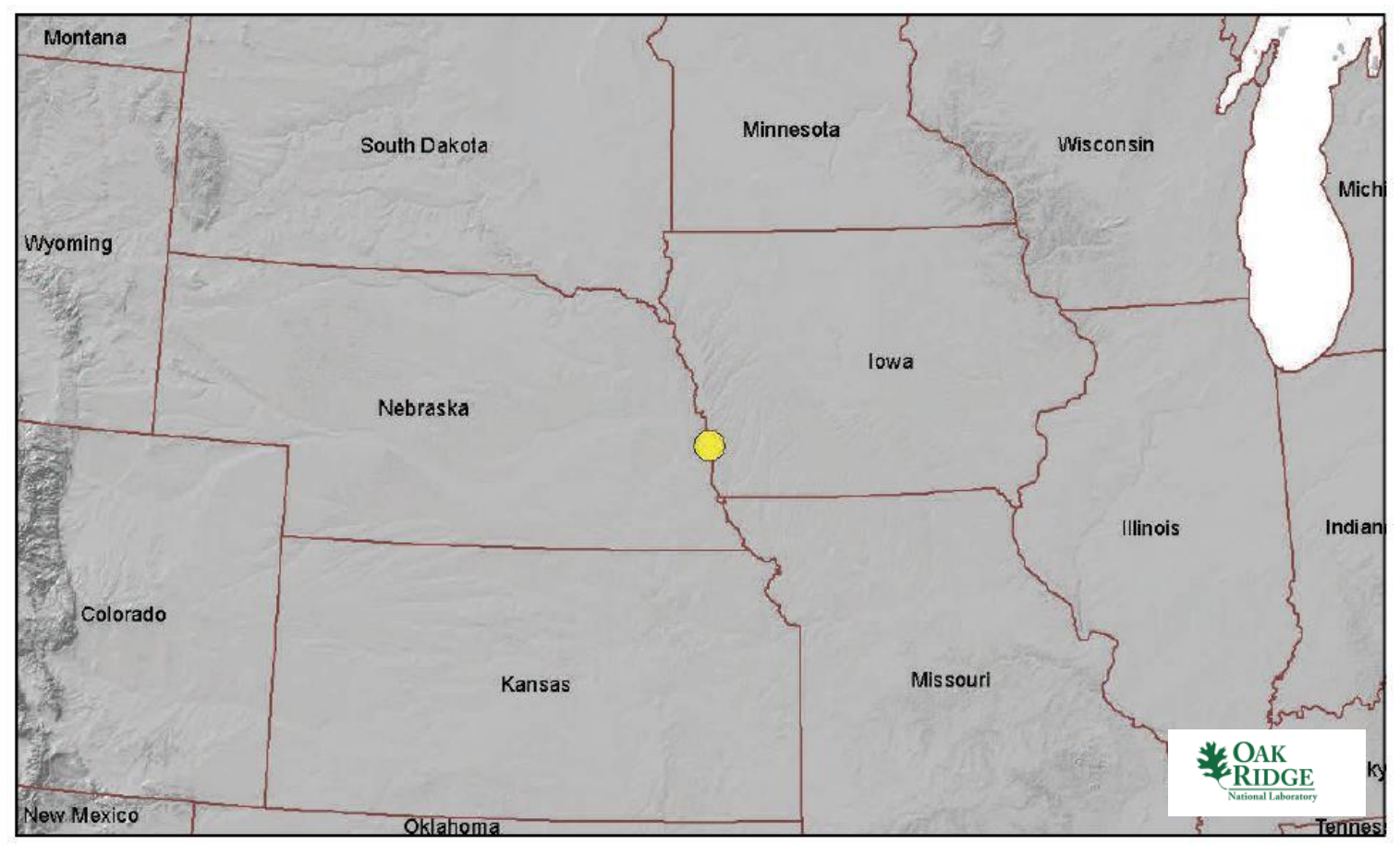

Fig. D.104. Kramer Power Plant location map.

\section{D.3.2 Site Description and Status}

The Kramer Power Plant was owned and operated by the Nebraska Public Power District (NPPD). The single-unit coal station was retired in 1987 because of the high cost to implement new EPA MATS. The plant was formerly cooled by once-through cooling from the adjacent river. The plant was situated on roughly 100 acres on the Missouri River.

As noted in Table D.62, the nearest major fault line based on USGS data is 320 miles south in Kansas. The maximum safe-shutdown earthquake for the site is below $0.3 \mathrm{~g}$ peak ground acceleration. More than 500,000 gpm of cooling water makeup is available from the adjacent Missouri River.

The permanent population within 1 mile of the plant is fewer than 7,600 people, yielding a population density of approximately 2,419 people per square mile. The permanent population within 10 miles of the plant is approximately 762,000 people, yielding a population density of approximately 2,426 people per 
square mile. According to the US EPA Environmental Justice website, there are 122,352 occupied housing units within 10 miles of the plant site based on 2000 US Census data. Further, more than $80 \%$ of area adults over age 25 have a high school diploma or higher education. The median annual income for the area is between $\$ 25 \mathrm{~K}$ and $\$ 50 \mathrm{~K}$.

\section{Table D.62. Kramer Power Plant site statistics}

\begin{tabular}{|l|l|l|l|}
\hline $\begin{array}{l}\text { Population } \\
\text { Population Within }\end{array}$ & \multicolumn{2}{l|}{$\begin{array}{l}\text { Utility } \\
\text { Distance to Grid Capacity }\end{array}$} \\
\hline $0.5 \mathrm{mi}$ & $\sim 2,500$ & $>400 \mathrm{MWe}$ & $\sim 2 \mathrm{mi}$ \\
\hline $1 \mathrm{mi}$ & $\sim 7,600$ & $>800 \mathrm{MWe}$ & $\sim 3 \mathrm{mi}$ \\
\hline $5 \mathrm{mi}$ & $\sim 166,000$ & $>1600 \mathrm{MWe}$ & $\sim 313 \mathrm{mi}$ \\
\hline $10 \mathrm{mi}$ & $\sim 762,000$ & $>3200 \mathrm{MWe}$ & $\sim 361 \mathrm{mi}$ \\
\hline Nearest City with Population & Distance to Cooling Water \\
\hline \multicolumn{1}{|l|}{} & \multicolumn{2}{l|}{} \\
\hline$>10,000$ & Bellevue, NE & $>50,000 \mathrm{gpm}$ & $\sim 0.1 \mathrm{mi}$ (Missouri River) \\
\hline$>50,000$ & Council Bluffs, IA & $>100,000 \mathrm{gpm}$ & $\sim 0.1 \mathrm{mi}$ (Missouri River) \\
\hline$>100,000$ & Omaha, NE & $>200,000$ gpm & $\sim 0.1 \mathrm{mi}$ (Missouri River) \\
\hline$>500,000$ & Oklahoma City, OK & $>500,000$ gpm & $\sim 0.1 \mathrm{mi}$ (Missouri River) \\
\hline Geotechnical & \multicolumn{3}{|l|}{ Accessibility } \\
\hline Max Earthquake Acceleration & $<0.3 \mathrm{~g}$ & Distance to Major Roadway & $\sim 0.4 \mathrm{mi}$ (SR 370) \\
\hline Max Slope & $\sim 16 \%$ & Distance to Water Transport & $\sim 0.1 \mathrm{mi}$ (Missouri River) \\
\hline Nearest Fault Line & $\sim 320$ mi (Kansas) & Distance to Rail Transport & $\sim 0.1 \mathrm{mi}$ (BNSF) \\
\hline Nearest Hazard Site & $\sim 10$ mi (Airport-Eppley & Distance to Airport & $\sim 10 \mathrm{mi}$ (Eppley Airfield) \\
\hline
\end{tabular}




\section{D.3.3 Aerial Imagery}

The aerial imagery in Fig. D.105 indicates the site of the former Kramer Power Plant. Many housing units and business structures are visible within a 1 mile radius of the plant site.

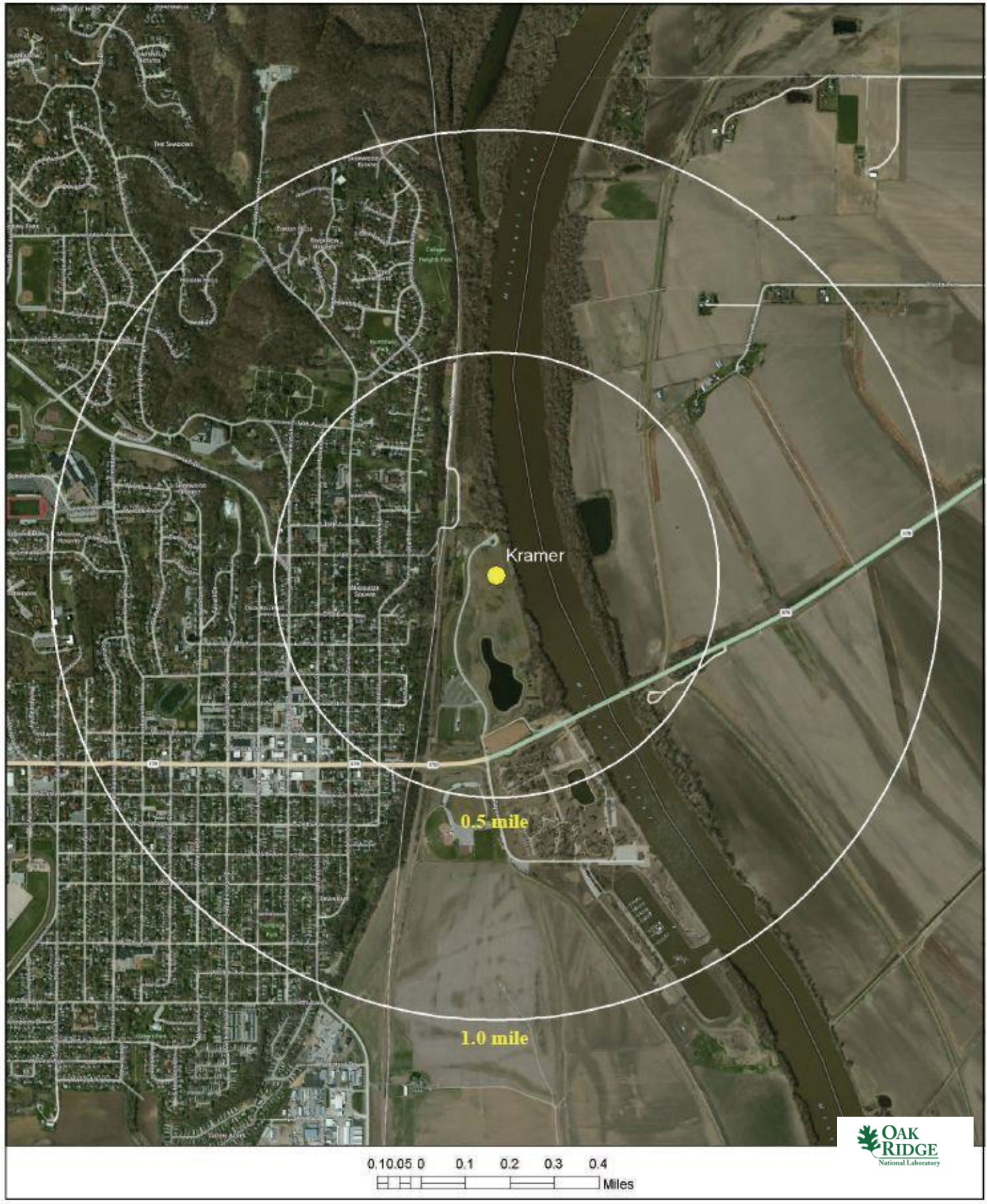

Fig. D.105. Satellite view of Kramer Power Plant proximity. 


\section{D.3.4 Screening Criteria Overview}

Table D.63. Kramer Power Plant siting criteria summary

\begin{tabular}{|c|c|c|c|c|c|c|c|c|}
\hline \multicolumn{9}{|c|}{$\underset{\text { (Colored Boxes indicate Screening Results) }}{\text { Screening Criteria Sum Bar }}$} \\
\hline \multicolumn{2}{|c|}{ No Siting Issue } & \multicolumn{2}{|c|}{\begin{tabular}{|l|l|} 
& Partial Siting Issue \\
\end{tabular}} & \multicolumn{2}{|c|}{ Partial Siting Issue } & \multicolumn{3}{|c|}{ Full Siting Issue } \\
\hline \begin{tabular}{|l}
0.5 \\
Mile \\
Buffer
\end{tabular} & Slope & SSE & $\begin{array}{l}\text { Stream } \\
\text { flow } \\
(65,000 \\
\text { gpm) }\end{array}$ & \begin{tabular}{|l|} 
Proximity \\
to \\
Hazard \\
Operations
\end{tabular} & $\begin{array}{l}\text { Proximity } \\
\text { to } \\
\text { Fault } \\
\text { Lines }\end{array}$ & \begin{tabular}{|l|l|} 
Wetlands) & 100 -year \\
Open & Flood \\
Water & plain \\
\end{tabular} & \begin{tabular}{|l|l} 
Protected \\
Lands
\end{tabular} & $\begin{array}{l}\text { Landslide } \\
\text { Hazards }\end{array}$ \\
\hline $\begin{array}{l}1.0 \\
\text { Mile } \\
\text { Buffer }\end{array}$ & Slope & SSE & $\begin{array}{l}\text { Stream } \\
\text { flow } \\
(65,000 \\
\mathrm{gpm})\end{array}$ & \begin{tabular}{|l} 
Proximity \\
to \\
Hazard \\
Operations
\end{tabular} & \begin{tabular}{|l} 
Proximity \\
to \\
Fault \\
Lines \\
\end{tabular} & \begin{tabular}{|l|l|} 
Wetlands & 100 -year \\
Open & Flood- \\
Water & plain \\
\end{tabular} & \begin{tabular}{|l|} 
Protected \\
Lands \\
\end{tabular} & $\begin{array}{l}\text { Land- } \\
\text { slide } \\
\text { Hazards }\end{array}$ \\
\hline & & & & & & & 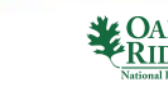 & $\begin{array}{l}\text { AK } \\
\text { IDGE }\end{array}$ \\
\hline \multicolumn{9}{|c|}{ Site Selection and Evaluation Criteria Table } \\
\hline \multicolumn{6}{|c|}{ Criteria } & \multicolumn{3}{|c|}{ Value } \\
\hline \multicolumn{6}{|c|}{ Population Density within 10 miles (people/square mile) } & \multicolumn{3}{|c|}{$>500$} \\
\hline \multicolumn{6}{|l|}{ Slope } & \multicolumn{3}{|c|}{$>18 \%$} \\
\hline \multicolumn{6}{|c|}{ Safe shutdown earthquake (ground acceleration) } & \multicolumn{3}{|c|}{$>0.5$} \\
\hline \multicolumn{6}{|c|}{ Streamflow/cooling water make-up (gpm) } & \multicolumn{3}{|c|}{$<65,000$} \\
\hline \multicolumn{6}{|c|}{ Proximity to hazardous operations - buffer (mile) } & \multicolumn{3}{|c|}{ Depends on hazardous operation ${ }^{1}$} \\
\hline \multicolumn{6}{|c|}{ Proximity to fault lines - buffer (mile) } & \multicolumn{3}{|c|}{ Depends on length of fault } \\
\hline \multicolumn{6}{|c|}{ Wetlands/Open Water } & \multicolumn{3}{|l|}{ - } \\
\hline \multicolumn{6}{|c|}{ 100-year floodplain } & \multicolumn{3}{|l|}{-} \\
\hline \multicolumn{6}{|c|}{ Protected lands } & \multicolumn{3}{|l|}{-} \\
\hline \multicolumn{6}{|c|}{ Landslide hazard (moderate and high) } & \multicolumn{3}{|l|}{-} \\
\hline
\end{tabular}

${ }^{1}$ Hazardous facilities (airports- 5 miles and oil refineries- -1 mile) 


\section{D.3.5 Composite Map and Individual Siting Issue Maps}

A composite map of SMR siting challenges to the Kramer Power Plant is shown in Fig. D.106. The physical plant structures are located on land with multiple siting issues. Following this map are maps of the individual SMR siting criteria based on selected input values.

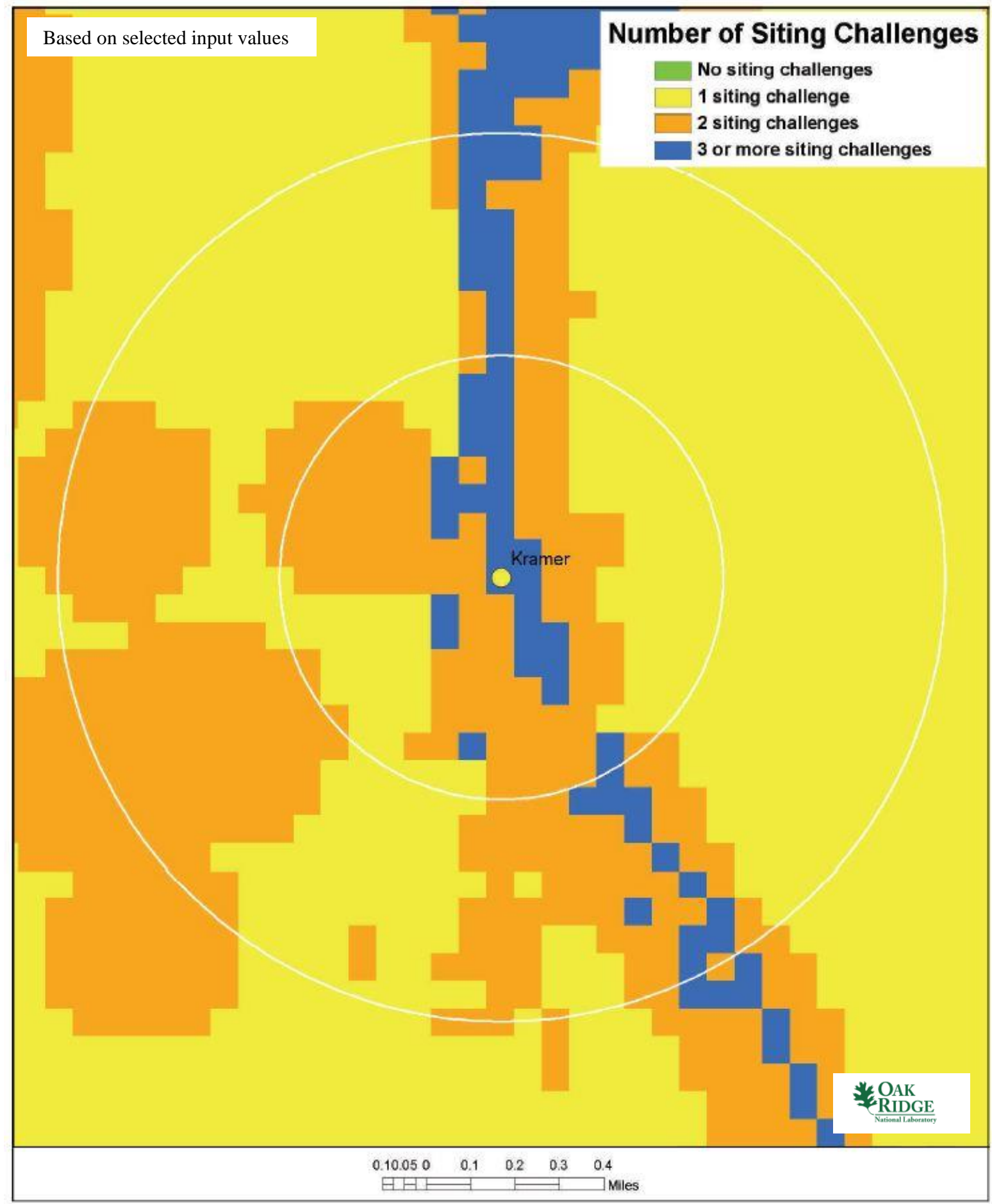

Fig. D.106. Kramer Power Plant composite map. 

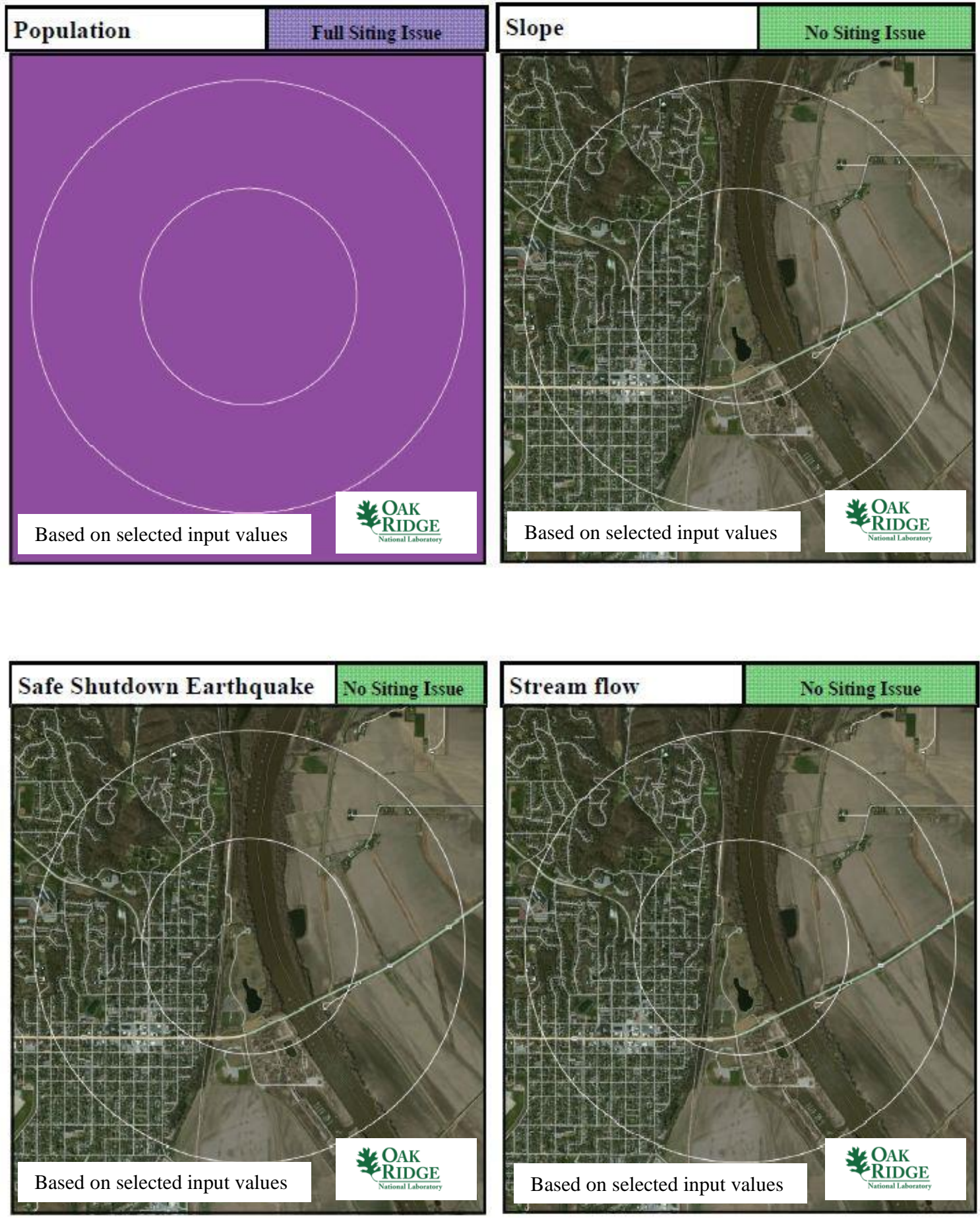

Kramer Power Plant 

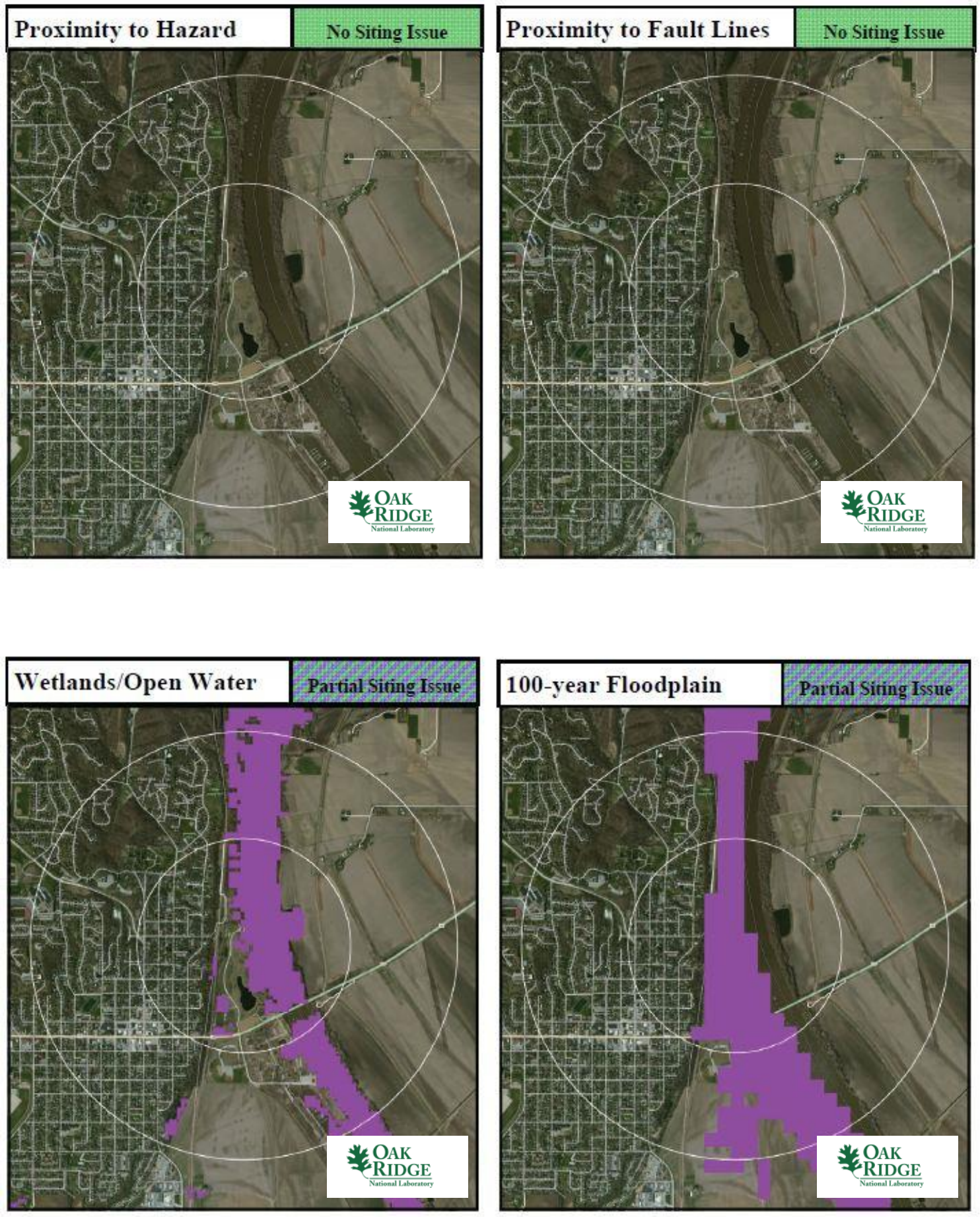

Kramer Power Plant 

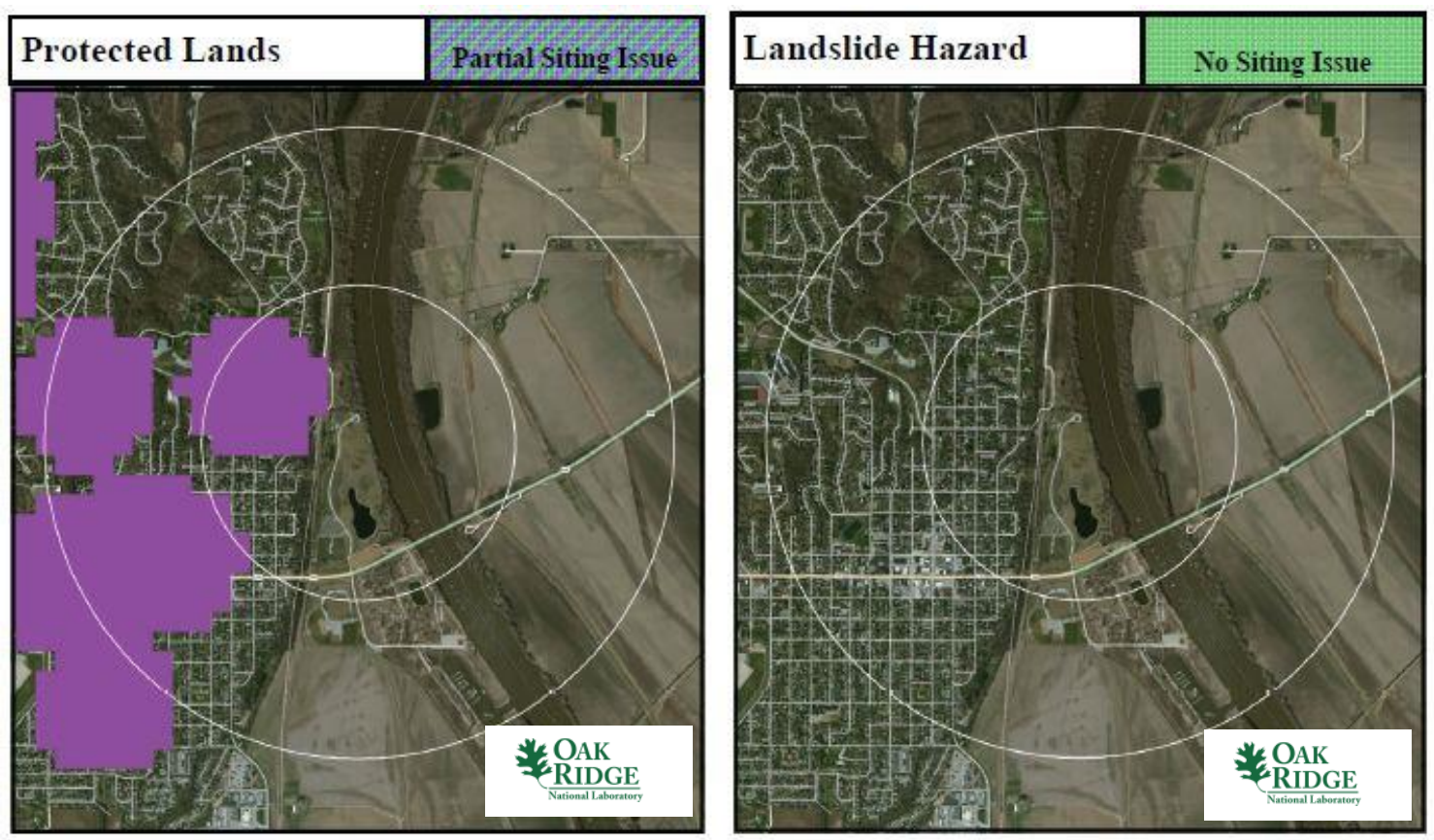

Kramer Power Plant

\section{D.3.6 Site Evaluation}

The NPPD owns and operates the Cooper Nuclear Station near Brownville, Nebraska. Therefore, NPPD has the licensing experience to operate an SMR at this site. The site contains minimal, yet sufficient, acreage to support siting an SMR.

From an environmental justice perspective, the community collectively appears to have achieved a reasonable level of education with median income levels typical of much of the United States. Therefore, siting an SMR at this location would not seem to be disenfranchising a less-educated or poverty-stricken community. Furthermore, the education level of the Kramer Power Plant community would seem to support the higher-technology job opportunities provided by an SMR.

As shown in Sects. D.0 and D.0, the Kramer Power Plant site has a full site issue with population density. Housing and numerous subdivisions are within 1 mile of the plant site. Bellevue is less than 1 mile from the plant site.

The Kramer Power Plant site has partial SMR site screening issues with wetlands/open waters, 100-year floodplain, and protected land. The wetlands/open waters concern reflects the adjacent Missouri River. However, the 100-year floodplain issue appears to engulf the site. The partial site screening issue for protected land appears to be due to local parks in the town of Bellevue adjacent to the site. The plant site was deeded to the city of Bellevue in 2003 and the plant was demolished in 2004. The site was renamed Kramer Park and is part of the larger Haworth Park. The park has flooded out, more than 8 feet above flood stage, nearly every year since the plant was removed. The park is currently closed until further notice. The remaining SMR site screening criteria are met site-wide for the values established in the updated SMR siting report.1

The population and floodplain concerns would impact siting an SMR at this location. The site does not meet current NRC RG 4.7 recommendations for population density without additional consideration for relaxed SMR population siting requirements based on reduced source term. As a result, the Kramer Power Plant site is not a likely candidate for consideration of siting an SMR. 


\section{D.4 Marysville Power Plant}

\section{D.4.1 Location Detail}

As shown in Fig. D.107, the Marysville Power Plant site is located in eastern Michigan a little more than 5 miles from the southern tip of Lake Huron. More specifically, the plant site is located off Interstate 94, in St. Clair County, Michigan. Interstate 94 is accessible approximately 0.1 miles to the west. Rail access is available onsite within 0.1 miles and barge access is available within 0.2 miles on the adjacent St. Clair River. The plant is located about 1.6 miles northeast of Marysville, Michigan, with a population of approximately 10,000 people.

- Plant: Marysville Power Plant

- Utility: Detroit Edison

- Coordinates: lat. $42.92568^{\circ} \mathrm{N}$, long. $82.46072^{\circ} \mathrm{W}$

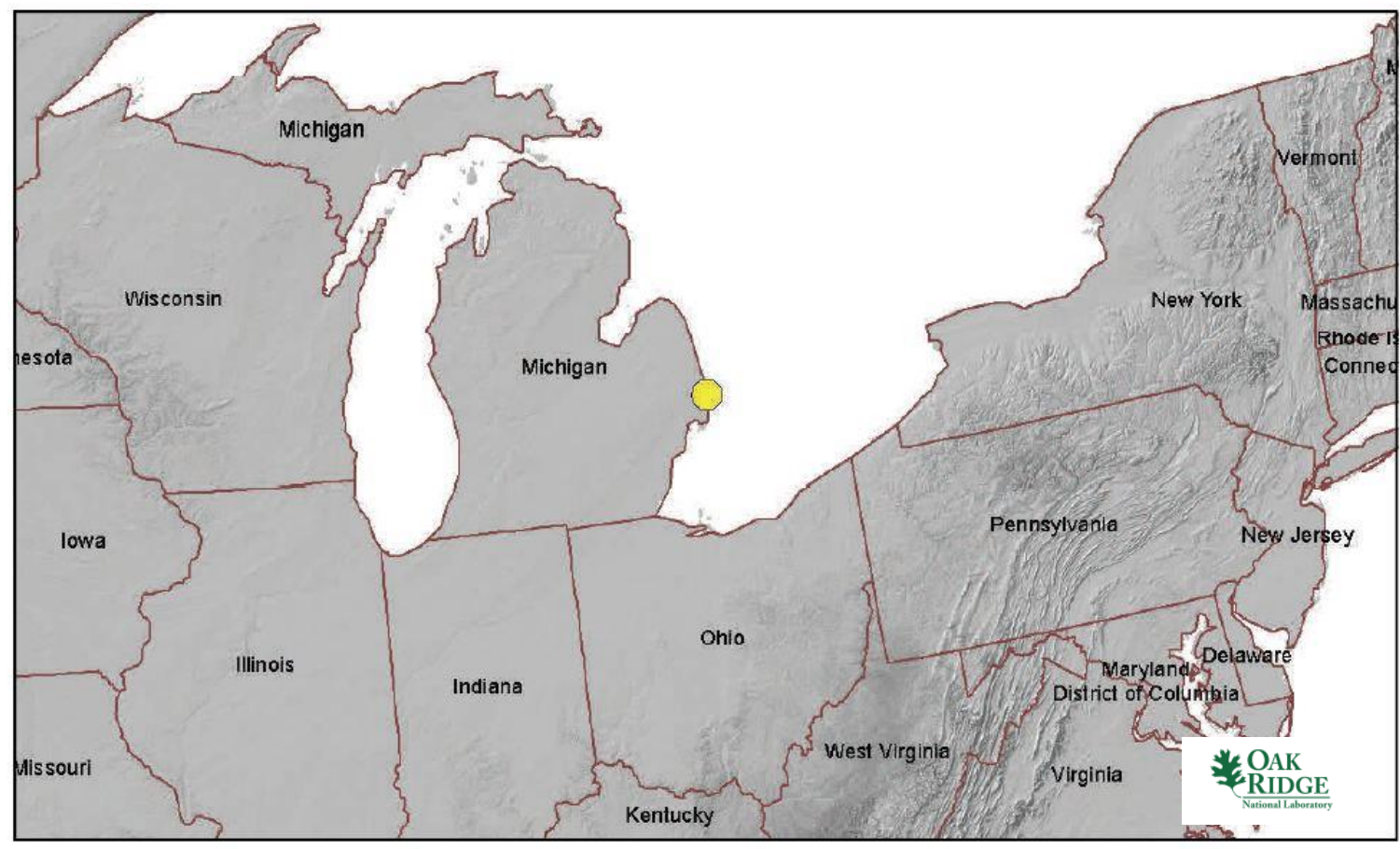

Fig. D.107. Marysville Power Plant location map.

\section{D.4.2 Site Description and Status}

The Marysville Power Plant was owned and operated by Detroit Edison, a subsidiary of DTE Energy. The Marysville Power Plant was a multi-unit coal-fired power plant. The initial plant began operation in 1900. The last two units operating were commissioned in 1943 and 1947, respectively, and had a combined capacity of $150 \mathrm{MW}(\mathrm{e})$. The plants were permanently shut down in 2001 and they were decommissioned in 2011. The plant structures are still standing. The plant was cooled by once-through cooling from Lake Huron.

The 30-acre plant site is still owned by DTE Energy on the St. Clair River, approximately 85 miles north of the 1,150 MW(e) Enrico Fermi, Unit 2 nuclear power plant in Monroe, Michigan. The 1,547 MW(e) coal-fired DTE Energy St. Clair power plant is 11 miles to the south. 
As noted in Table D.64, the nearest major fault line based on USGS data is about 946 miles southwest in Kansas. The maximum safe-shutdown earthquake for the site is below $0.3 \mathrm{~g}$ peak ground acceleration. More than 500,000 gpm of cooling water makeup is available from Lake Huron about 5.4 miles north and slightly east of the plant site.

The permanent population within 1 mile of the plant is approximately 6,500 people, yielding a population density of slightly more than 2,000 people per square mile. The permanent population within 10 miles of the plant is approximately 372,000 people, yielding a population density of about 1,184 people per square mile.

According to the US EPA Environmental Justice website, there are 34,006 occupied housing units within 10 miles of the plant site based on 2000 US Census data. Further, more than $80 \%$ of area adults over age 25 have a high school diploma or higher education. The median annual income for the area is between $\$ 25 \mathrm{~K}$ and $\$ 50 \mathrm{~K}$.

Table D.64. Marysville Power Plant site statistics

\begin{tabular}{|c|c|c|c|}
\hline \multicolumn{2}{|l|}{$\begin{array}{l}\text { Population } \\
\text { Population Within }\end{array}$} & \multicolumn{2}{|l|}{$\begin{array}{l}\text { Utility } \\
\text { Distance to Grid Capacity }\end{array}$} \\
\hline $0.5 \mathrm{mi}$ & $\sim 2,300$ & $>400 \mathrm{MWe}$ & $\sim 3 \mathrm{mi}$ \\
\hline $1 \mathrm{mi}$ & $\sim 6,500$ & $>800 \mathrm{MWe}$ & $\sim 6 \mathrm{mi}$ \\
\hline $5 \mathrm{mi}$ & $\sim 160,000$ & $>1600 \mathrm{MWe}$ & $\sim 41 \mathrm{mi}$ \\
\hline $10 \mathrm{mi}$ & $\sim 372,000$ & $>3200 \mathrm{MWe}$ & $\sim 41 \mathrm{mi}$ \\
\hline \multicolumn{2}{|c|}{ Nearest City with Population } & \multicolumn{2}{|c|}{ Distance to Cooling Water } \\
\hline$>10,000$ & Marysville, MI & $>50,000 \mathrm{gpm}$ & $\sim 10 \mathrm{mi}$ (Lake Huron) \\
\hline$>50,000$ & Saint Clair Shores, MI & $>100,000 \mathrm{gpm}$ & $\sim 10 \mathrm{mi}$ (Lake Huron) \\
\hline$>100,000$ & Sterling Heights, MI & $>200,000 \mathrm{gpm}$ & $\sim 10 \mathrm{mi}$ (Lake Huron) \\
\hline$>500,000$ & Detroit, MI & $>500,000 \mathrm{gpm}$ & $\sim 10 \mathrm{mi}$ (Lake Huron) \\
\hline \multicolumn{2}{|l|}{ Geotechnical } & \multicolumn{2}{|l|}{ Accessibility } \\
\hline Max Earthquake Acceleration & $<0.3 \mathrm{~g}$ & Distance to Major Roadway & $\sim 0.1 \mathrm{mi}$ (Interstate $94 \mathrm{BL}$ ) \\
\hline Max Slope & $\sim 4 \%$ & Distance to Water Transport & $\sim 0.2 \mathrm{mi}$ (St. Clair River) \\
\hline Nearest Fault Line & $\sim 946 \mathrm{mi}$ (Kansas) & Distance to Rail Transport & $\sim 0.1 \mathrm{mi}(\mathrm{CSXT})$ \\
\hline Nearest Hazard Site & $\begin{array}{l}53 \text { mi (Refinery- } \\
\quad \text { Marathon Petroleum Co) }\end{array}$ & Distance to Airport & $\begin{array}{r}\sim 62 \mathrm{mi} \text { (Detroit Metropoli } \\
\text { tan Wayne County) }\end{array}$ \\
\hline
\end{tabular}




\section{D.4.3 Aerial Imagery}

The aerial imagery in Fig. D.108 indicates the site of the Marysville Power Plant. Interstate 94 runs within 0.5 miles of the site and many housing units are visible within a 1 mile radius of the plant site.

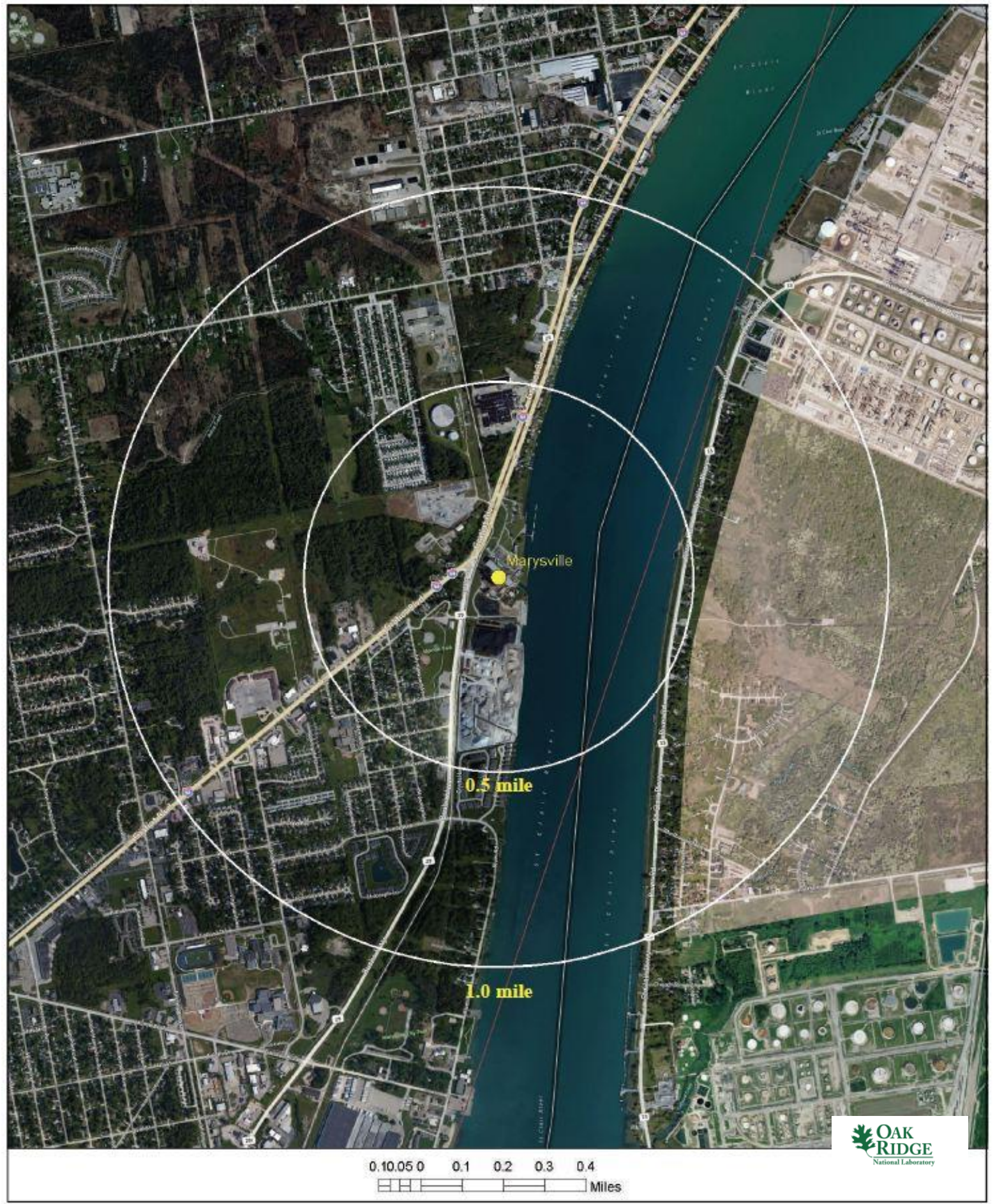

Fig. D.108. Satellite view of Marysville Power Plant proximity. 


\section{D.4.4 Screening Criteria Overview}

Table D.65. Marysville Power Plant siting criteria summary

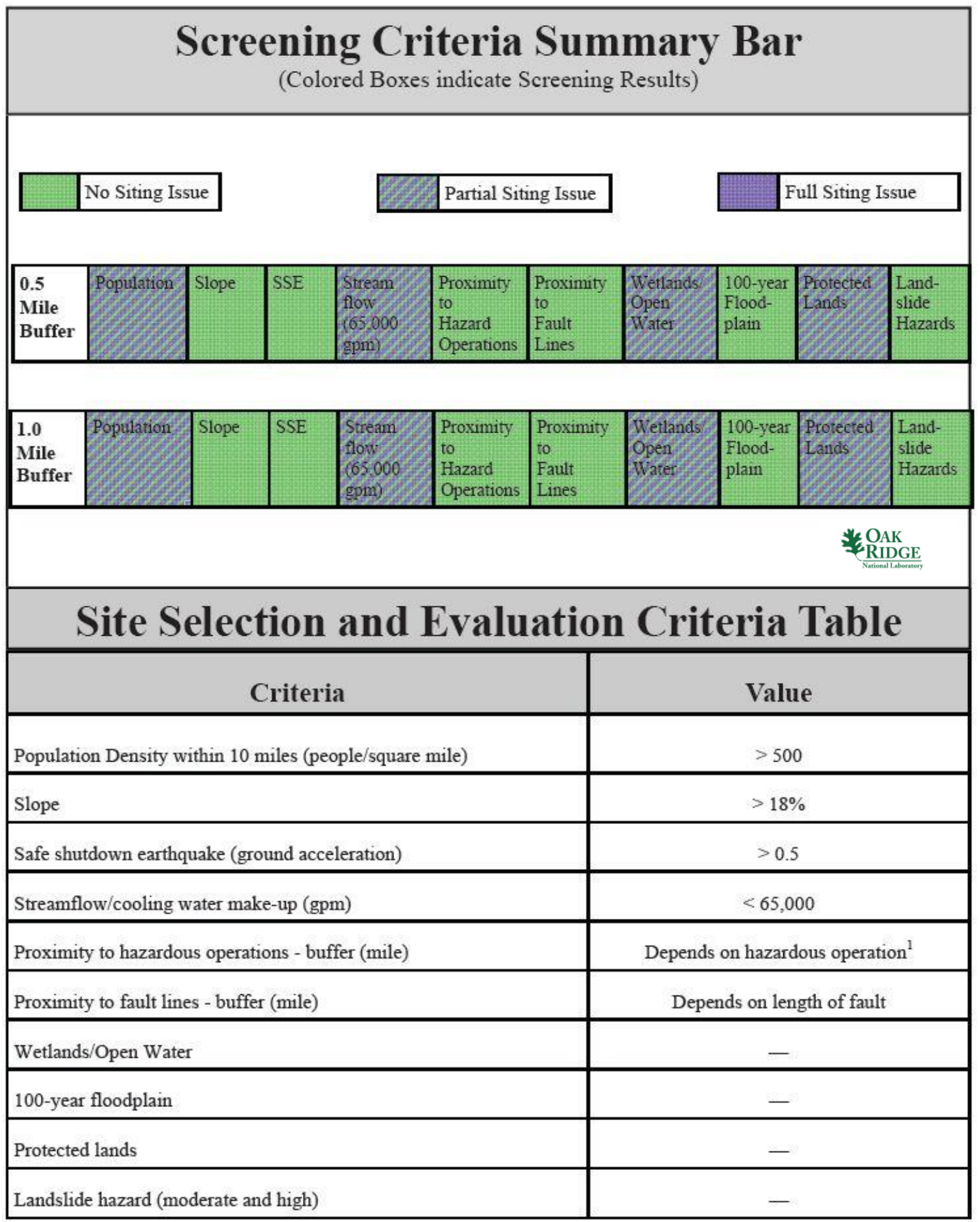

${ }^{1}$ Hazardous facilities (airports- 5 miles and oil refineries- -1 mile) 


\section{D.4.5 Composite Map and Individual Siting Issue Maps}

A composite map of SMR siting challenges to the Marysville Power Plant is shown in Fig. D.109. The physical plant structures are located on land with two siting challenges. Following this map are maps of the individual SMR siting criteria based on selected input values.

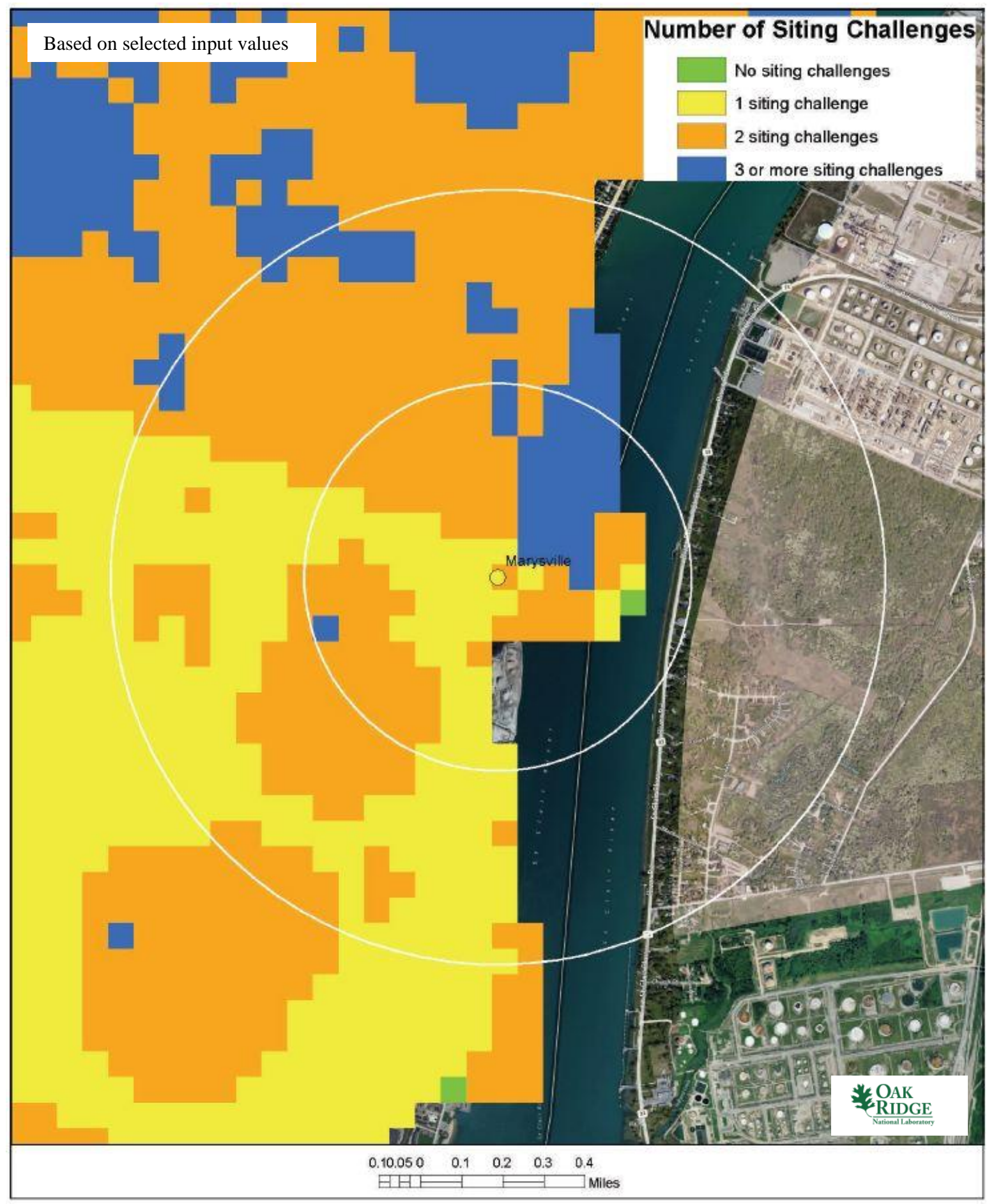

Fig. D.109. Marysville Power Plant composite map. 

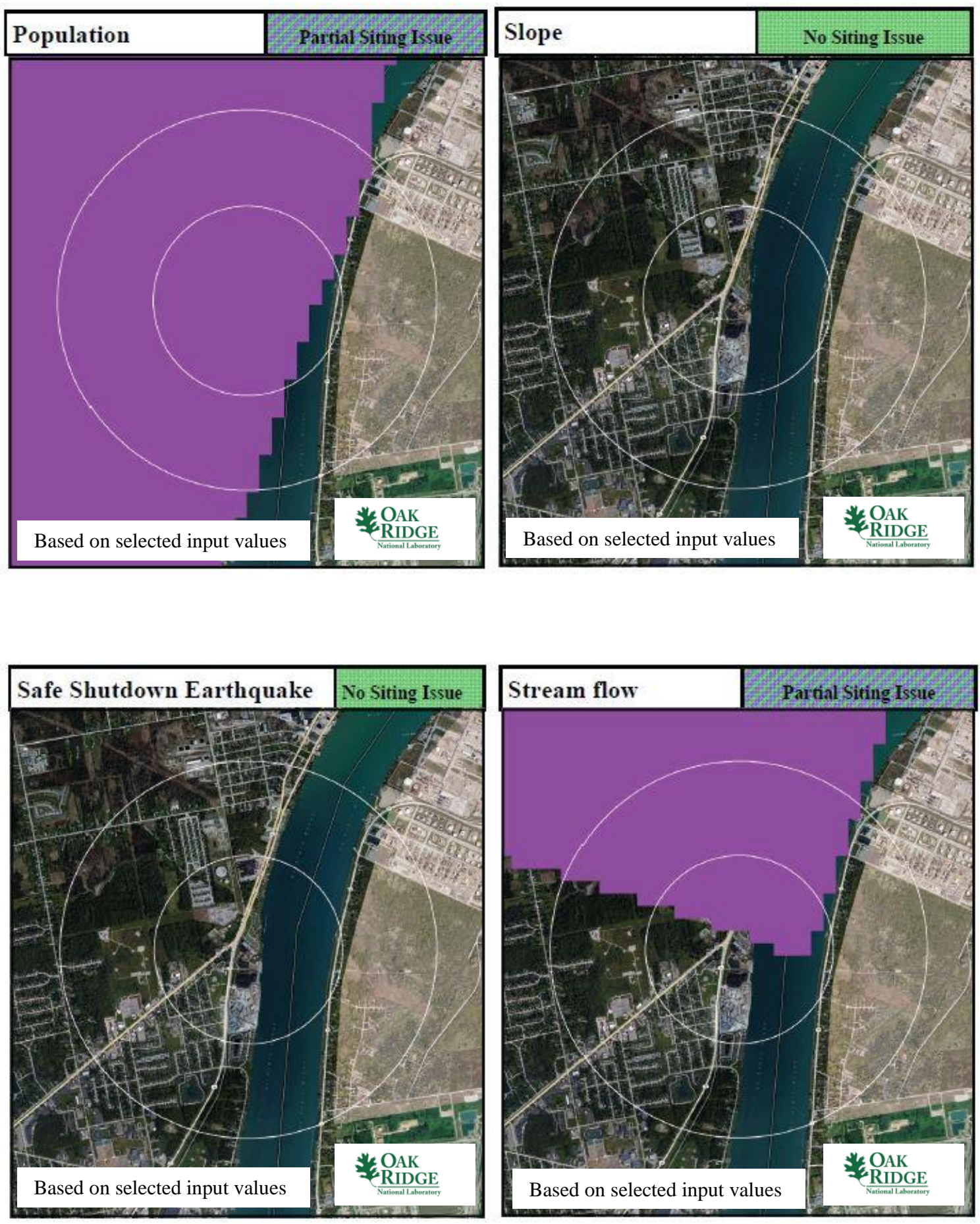

Marysville Power Plant 

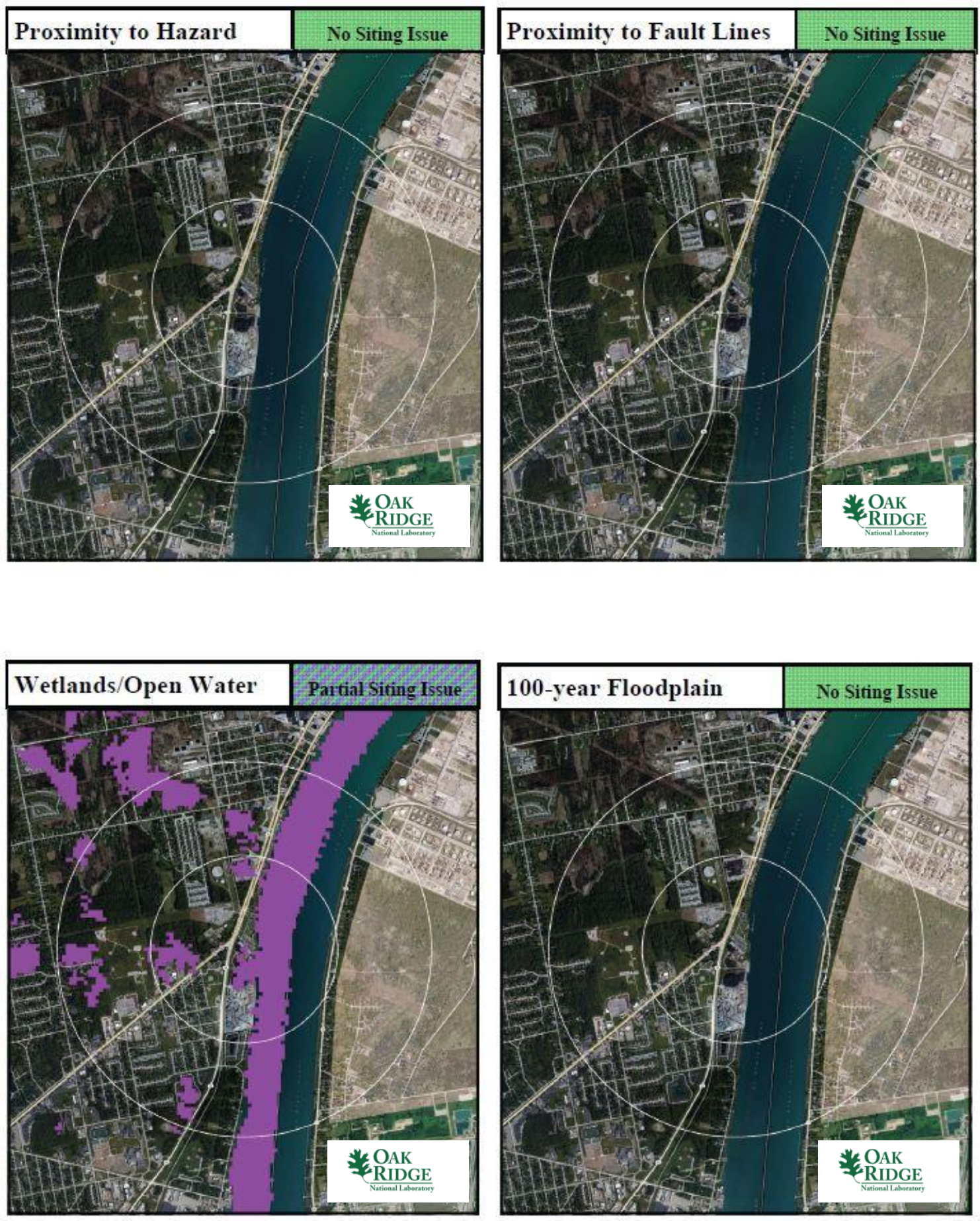

Marysville Power Plant 

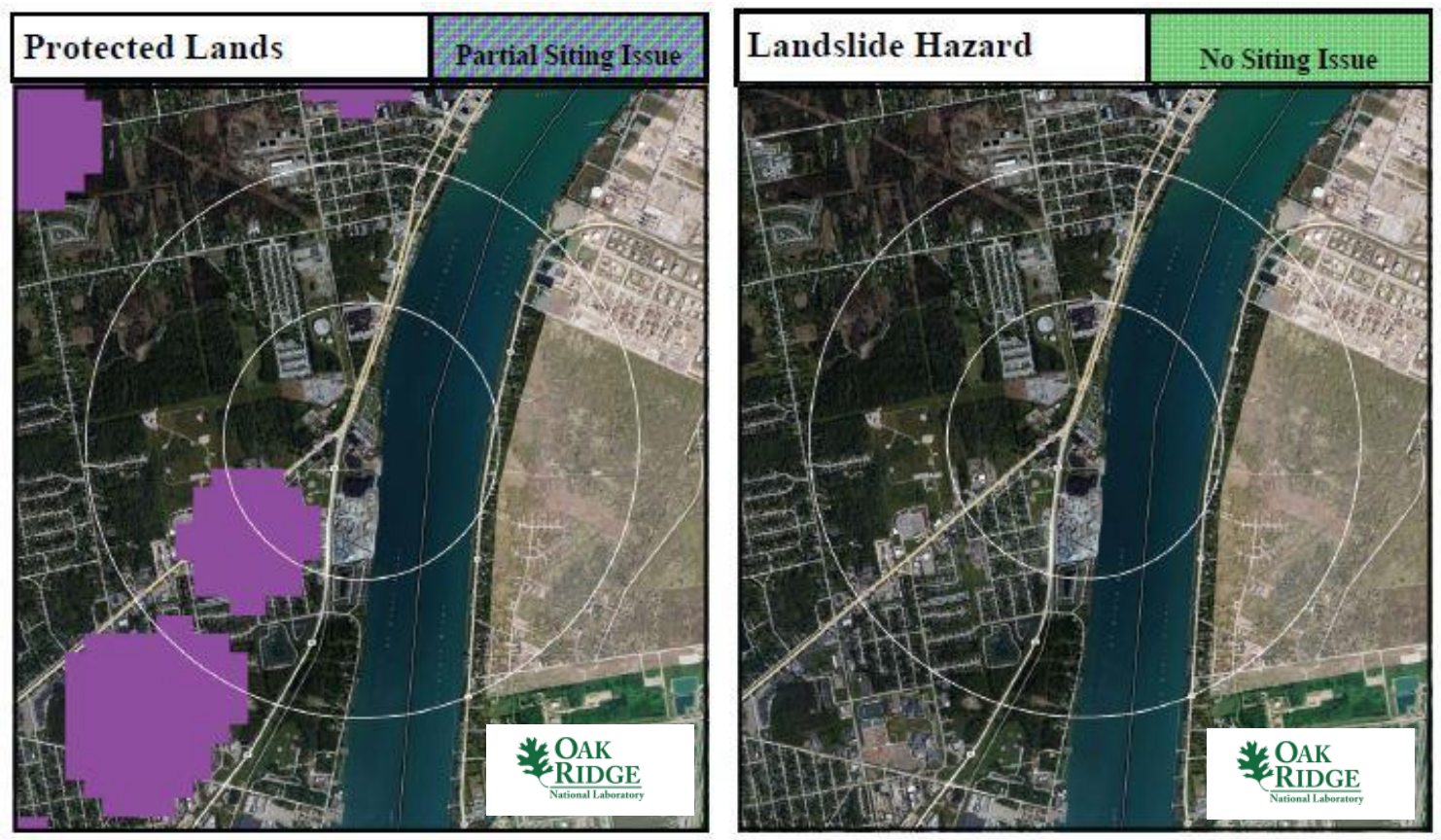

Marysville Power Plant

\section{D.4.6 Site Evaluation}

DTE Energy owns and operates the Enrico Fermi, Unit 2 nuclear power plant in Monroe, Michigan, which is also the site of a permanently shut down nuclear power plant, Enrico Fermi, Unit 1. In addition, DTE Energy has applied for a COL for a nuclear power plant to be located at the same site. Therefore, DTE Energy has the licensing experience to operate an SMR at the Marysville site. However, the site contains insufficient acreage to support siting an SMR.

From an environmental justice perspective, the community collectively appears to have achieved a reasonable level of education with median income levels typical of much of the United States. Therefore, siting an SMR at this location would not seem to be disenfranchising a less-educated or poverty-stricken community. Furthermore, the education level of the Marysville Power Plant community would seem to support the higher-technology job opportunities provided by an SMR.

As shown in Sects. D.0 and D.0, the Marysville Power Plant site has a full siting issue with population. Also, Interstate 94 intersects Michigan Highway 29, also known as the Busha Highway, just north of the site, which would make it difficult for a nuclear licensee to control land access to areas very near the plant location. These problems would make it difficult to consider siting an SMR at this location.

The Marysville Power Plant site also has partial SMR site screening issues with stream flow, wetlands/open waters, and protected lands. The stream flow issue is a false cooling water makeup concern given the proximity of Lake Huron. The wetlands/open waters reflect the adjacent St. Clair River. The protected lands reflect parks in the adjacent city. The remaining SMR site screening criteria are met sitewide for the values established in the updated SMR siting report.1

The site does not meet the current NRC RG 4.7 recommendations for population density and fails the SMR SSEC for population. In addition, there is insufficient acreage to fit a current iPWR design. As a result, the Marysville Power Plant site is not a likely candidate for consideration of siting an SMR. 


\section{D.5 Maynard Power Station}

\section{D.5.1 Location Detail}

As shown in Fig. D.110, the Maynard Power Station site is located in northeastern Iowa along the West Fork of the Cedar River, off Iowa Highway 63, in Black Hawk County. Iowa Highway 63 is accessible approximately 0.2 miles to the east. Interstate 35 is accessible 55 miles to the west. Rail access is available onsite within 0.6 miles and barge access is available 62 miles away via the Mississippi River. The plant site is located within the metropolitan area of Cedar Falls-Waterloo, Iowa, with populations of approximately 39,260 and 68,462, respectively. Waterloo is just across the river about 0.7 miles south and slightly east of the site, and Cedar Falls is upriver about 5 miles north and slightly west of the site.

- Plant: Maynard Power Station

- Utility: Iowa Public Service

- Coordinates: lat. $42.50424^{\circ} \mathrm{N}$, long. $92.34487^{\circ} \mathrm{W}$

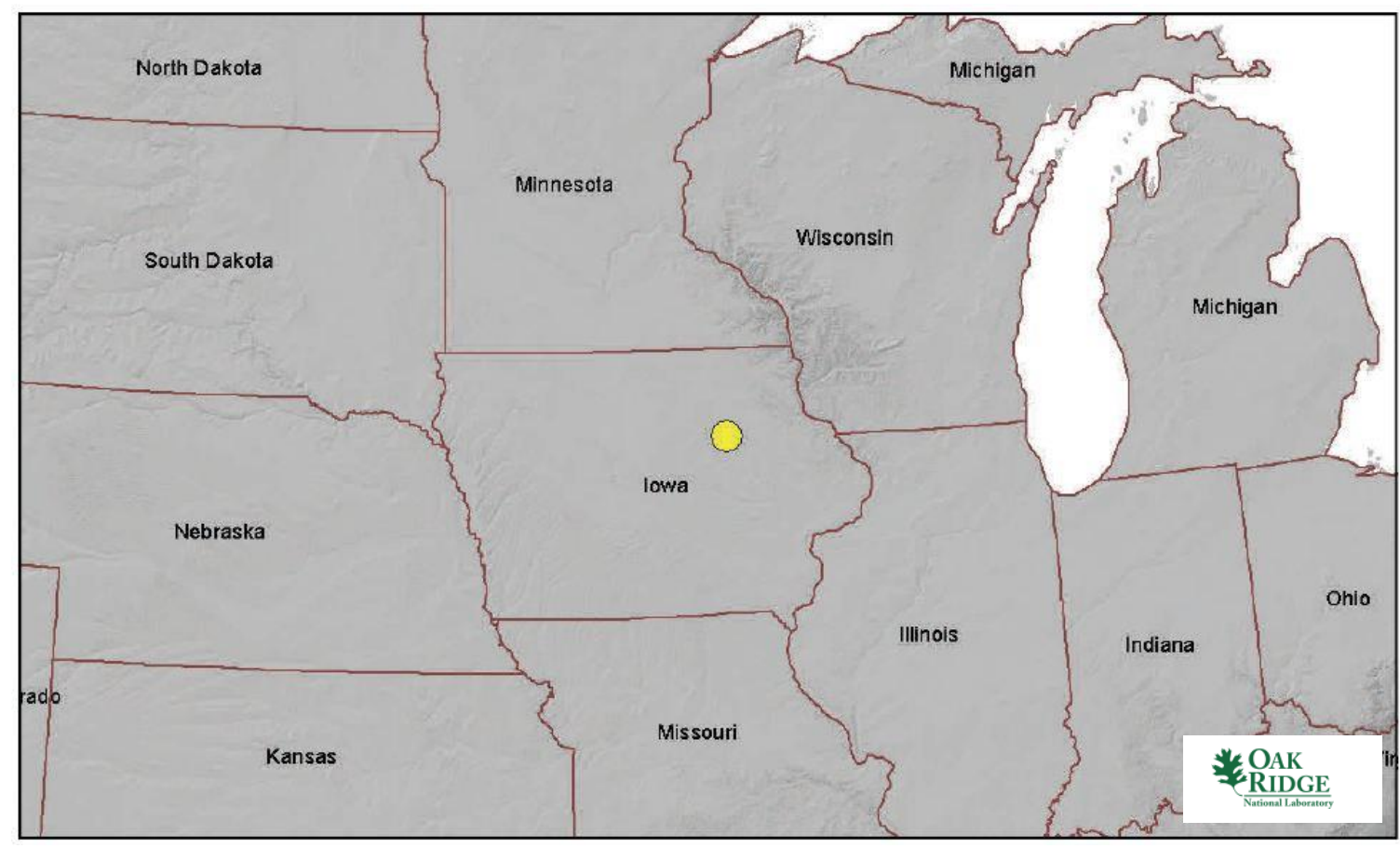

Fig. D.110. Maynard Power Station location map.

\section{D.5.2 Site Description and Status}

The Maynard Power Station was owned and operated by Iowa Public Service Company, which merged with Iowa Power Company, Inc., in 1992 to form Midwest Power Systems. The single-unit station had a coal-fired generating capacity of $54 \mathrm{MW}(\mathrm{e})$. The unit was retired in 1988 and has been razed. The intake area and some switchyard structure remains. The plant was formerly cooled by once-through cooling from the adjacent river. The Lundquist Station peaking facility is adjacent to these structures.

The plant is situated on less than 20 acres on the Cedar River approximately 40 miles northwest of the 615 MW(e) Duane Arnold nuclear facility. Maynard Power Station is 40 miles northeast of the operational 158 MW(e) Sutherland Generating Station and 20 miles downstream of the operational 141 MW(e) Riverside Coal Plant. In addition, the 135 MW(e) Keokuk Dam hydroelectric plant is 150 miles south of Maynard Power Station. 
As noted in Table D.66, the nearest major fault line based on USGS data is about 507 miles southwest in Kansas. The maximum safe-shutdown earthquake for the site is below $0.3 \mathrm{~g}$ peak ground acceleration. More than 500,000 gpm of cooling water makeup is available from the adjacent West Fork of the Cedar River.

The permanent population within 1 mile of the plant site is approximately 14,500 people, yielding a population density of approximately 4,616 people per square mile. The permanent population within 10 miles of the plant is approximately 279,000 people, yielding a population density of about 888 people per square mile.

According to the US EPA Environmental Justice website, there are 46,484 occupied housing units within 10 miles of the plant site based on 2000 US Census data. Further, more than $85 \%$ of area adults over age 25 have a high school diploma or higher education. The median annual income for the area is between $\$ 25 \mathrm{~K}$ and $\$ 50 \mathrm{~K}$.

Table D.66. Maynard Power Station site statistics

\begin{tabular}{|c|c|c|c|}
\hline \multicolumn{2}{|l|}{$\begin{array}{l}\text { Population } \\
\text { Population Within }\end{array}$} & \multicolumn{2}{|l|}{$\begin{array}{l}\text { Utility } \\
\text { Distance to Grid Capacity }\end{array}$} \\
\hline $0.5 \mathrm{mi}$ & $\sim 5,750$ & $>400 \mathrm{MWe}$ & $\sim 22 \mathrm{mi}$ \\
\hline $1 \mathrm{mi}$ & $\sim 14,500$ & $>800 \mathrm{MWe}$ & $\sim 21 \mathrm{mi}$ \\
\hline $5 \mathrm{mi}$ & $\sim 162,000$ & $>1600 \mathrm{MWe}$ & $\sim 199 \mathrm{mi}$ \\
\hline $10 \mathrm{mi}$ & $\sim 279,000$ & $>3200 \mathrm{MWe}$ & $\sim 193 \mathrm{mi}$ \\
\hline \multicolumn{2}{|c|}{ Nearest City with Population } & \multicolumn{2}{|c|}{ Distance to Cooling Water } \\
\hline$>10,000$ & Cedar Falls, IA & $>50,000 \mathrm{gpm}$ & $\sim 0.1 \mathrm{mi}$ (WestFork Cedar $\mathrm{R}$ ) \\
\hline$>50,000$ & Waterloo, IA & $>100,000 \mathrm{gpm}$ & $\sim 0.1 \mathrm{mi}$ (WestFork Cedar $\mathrm{R}$ ) \\
\hline$>100,000$ & Cedar Rapids, IA & $>200,000 \mathrm{gpm}$ & $\sim 0.1 \mathrm{mi}$ (WestFork Cedar $\mathrm{R}$ ) \\
\hline$>500,000$ & Milwaukee, WI & $>500,000 \mathrm{gpm}$ & $\sim 0.1 \mathrm{mi}$ (WestFork Cedar $\mathrm{R})$ \\
\hline \multicolumn{2}{|l|}{ Geotechnical } & \multicolumn{2}{|l|}{ Accessibility } \\
\hline Max Earthquake Acceleration & $<0.3 \mathrm{~g}$ & Distance to Major Roadway & $\sim 0.2 \mathrm{mi}($ US 63 ) \\
\hline Max Slope & $\sim 4 \%$ & Distance to Water Transport & $\sim 62 \mathrm{mi}$ (Mississippi River) \\
\hline Nearest Fault Line & $\sim 507$ mi (Kansas) & Distance to Rail Transport & $\sim 0.6 \mathrm{mi}(\mathrm{CN})$ \\
\hline Nearest Hazard Site & $\begin{array}{c}50 \mathrm{mi} \text { (Airport- } \\
\text { The Eastern Iowa) }\end{array}$ & Distance to Airport & $\sim 50 \mathrm{mi}$ (The Eastern Iowa) \\
\hline
\end{tabular}




\section{D.5.3 Aerial Imagery}

The aerial imagery in Fig. D.111 indicates the site of the Maynard Power Station. Iowa Highway 63 runs within 0.5 miles of the site and many housing units are visible within a 1 mile radius of the plant site.

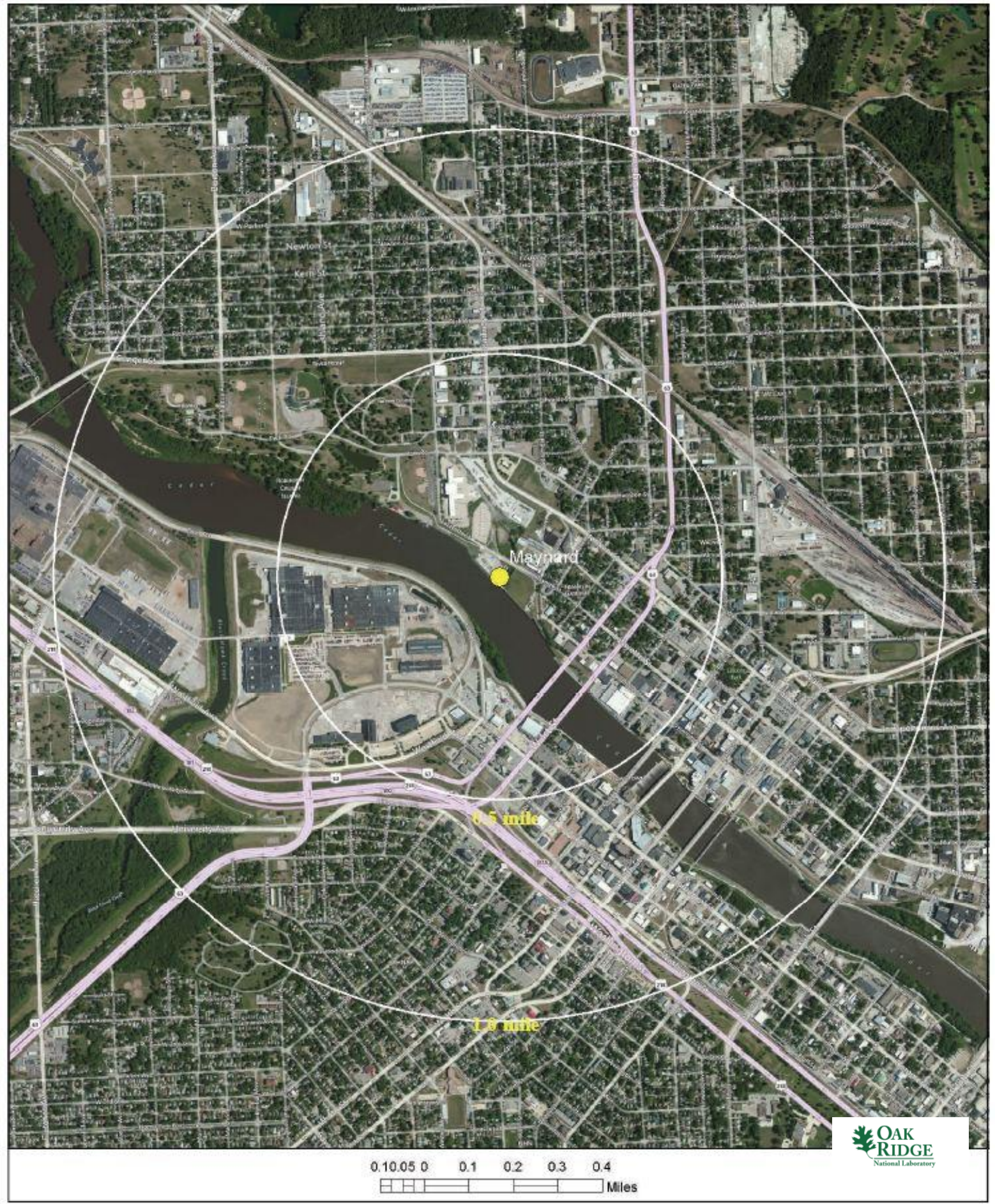

Fig. D.111. Satellite view of Maynard Power Station proximity. 


\section{D.5.4 Screening Criteria Overview}

Table D.67. Maynard Power Station siting criteria summary

\begin{tabular}{|c|c|c|c|c|c|c|c|c|c|}
\hline \multicolumn{10}{|c|}{$\underset{\text { (Colored Boxes indicate } \text { Screening Results) }}{\text { Screening Criteria Summar }}$} \\
\hline \multicolumn{2}{|c|}{ No Siting Issue } & \multicolumn{2}{|c|}{\begin{tabular}{|l|l|} 
& Partial Siting Issue \\
\end{tabular}} & \multicolumn{2}{|c|}{ Partial Siting Issue } & \multicolumn{4}{|c|}{ Full Siting Issue } \\
\hline \begin{tabular}{|l|}
0.5 \\
Mile \\
Buffer
\end{tabular} & Slope & SSE & $\begin{array}{l}\text { Stream } \\
\text { flow } \\
(65,000 \\
\mathrm{gpm}) \\
\end{array}$ & $\begin{array}{l}\text { Proximity } \\
\text { to } \\
\text { Hazard } \\
\text { Operations }\end{array}$ & \begin{tabular}{|l} 
Proximity \\
to \\
Fault \\
Lines \\
\end{tabular} & \begin{tabular}{|l|} 
Wetlands \\
Open \\
Waten \\
\end{tabular} & $\begin{array}{l}100 \text {-year } \\
\text { Flood- } \\
\text { plain }\end{array}$ & \begin{tabular}{|l|} 
Protected \\
Lands \\
\end{tabular} & $\begin{array}{l}\text { Land- } \\
\text { slide } \\
\text { Hazards }\end{array}$ \\
\hline $\begin{array}{l}1.0 \\
\text { Mile } \\
\text { Buffer }\end{array}$ & Slope & SSE & $\begin{array}{l}\text { Stream } \\
\text { flow } \\
(65,000 \\
\mathrm{gpm})\end{array}$ & $\begin{array}{l}\text { Proximity } \\
\text { to } \\
\text { Hazard } \\
\text { Operations }\end{array}$ & \begin{tabular}{|l} 
Proximitt \\
to \\
Fault \\
Lines \\
\end{tabular} & $\begin{array}{l}\text { Wetlands } \\
\text { Open } \\
\text { Water } \\
\end{array}$ & $\begin{array}{l}100 \text {-year } \\
\text { Flood- } \\
\text { plain }\end{array}$ & \begin{tabular}{|l|} 
Protected \\
Lands
\end{tabular} & $\begin{array}{l}\text { Land- } \\
\text { slide } \\
\text { Hazards }\end{array}$ \\
\hline & & & & & & & & 期 & \\
\hline & er & & ind & valu & in & $\Gamma$ & ria & Table & \\
\hline & & rite & & & & & Valu & & \\
\hline Populat & ithin 10 & iiles & ple/squas & nile) & & & $>50$ & & \\
\hline Slope & & & & & & & $>18^{\circ}$ & & \\
\hline Safe shy & uake $(g$ & and a & leration) & & & & $>0.5$ & & \\
\hline Streamf & rater $\mathrm{m}$ & -up & & & & & $<65,0$ & & \\
\hline Proximi & is oper: & ons - & fer (mile) & & & Depends & on hazard & dous operatio & \\
\hline Proximi & s- buf & (mil & & & & Depen & nds on len & ggth of fault & \\
\hline Wetland & & & & & & & - & & \\
\hline 100-yea & & & & & & & - & & \\
\hline Protecte & & & & & & & - & & \\
\hline Landslic & derate & high & & & & & - & & \\
\hline
\end{tabular}

${ }^{1}$ Hazardous facilities (airports- 5 miles and oil refineries- -1 mile) 


\section{D.5.5 Composite Map and Individual Siting Issue Maps}

A composite map of SMR siting challenges to the Maynard Power Station site is shown in Fig. D.112. The site indicates a single siting challenge. Following this map are maps of the individual SMR siting criteria based on selected input values.

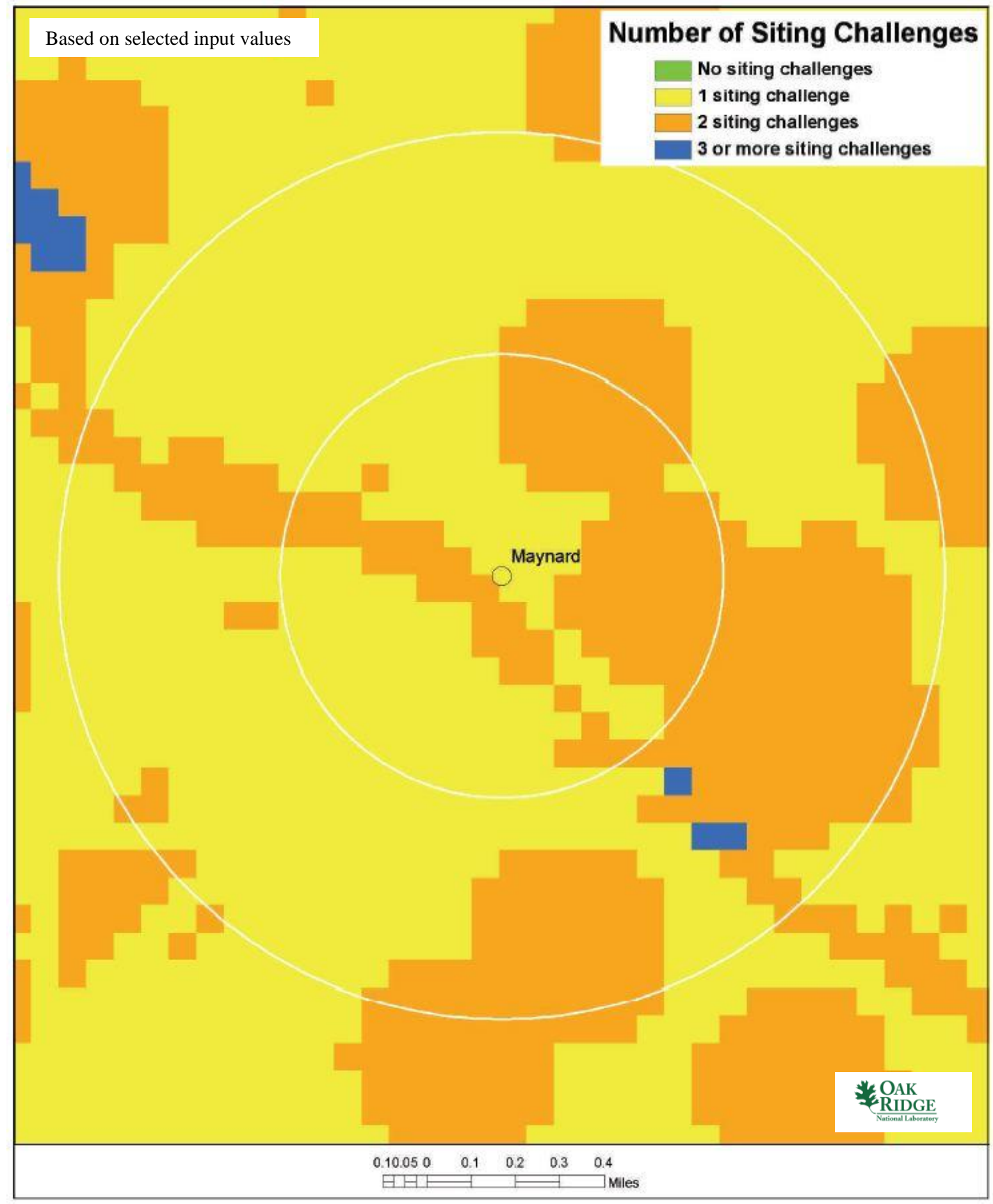

Fig. D.112. Maynard Power Station composite map. 

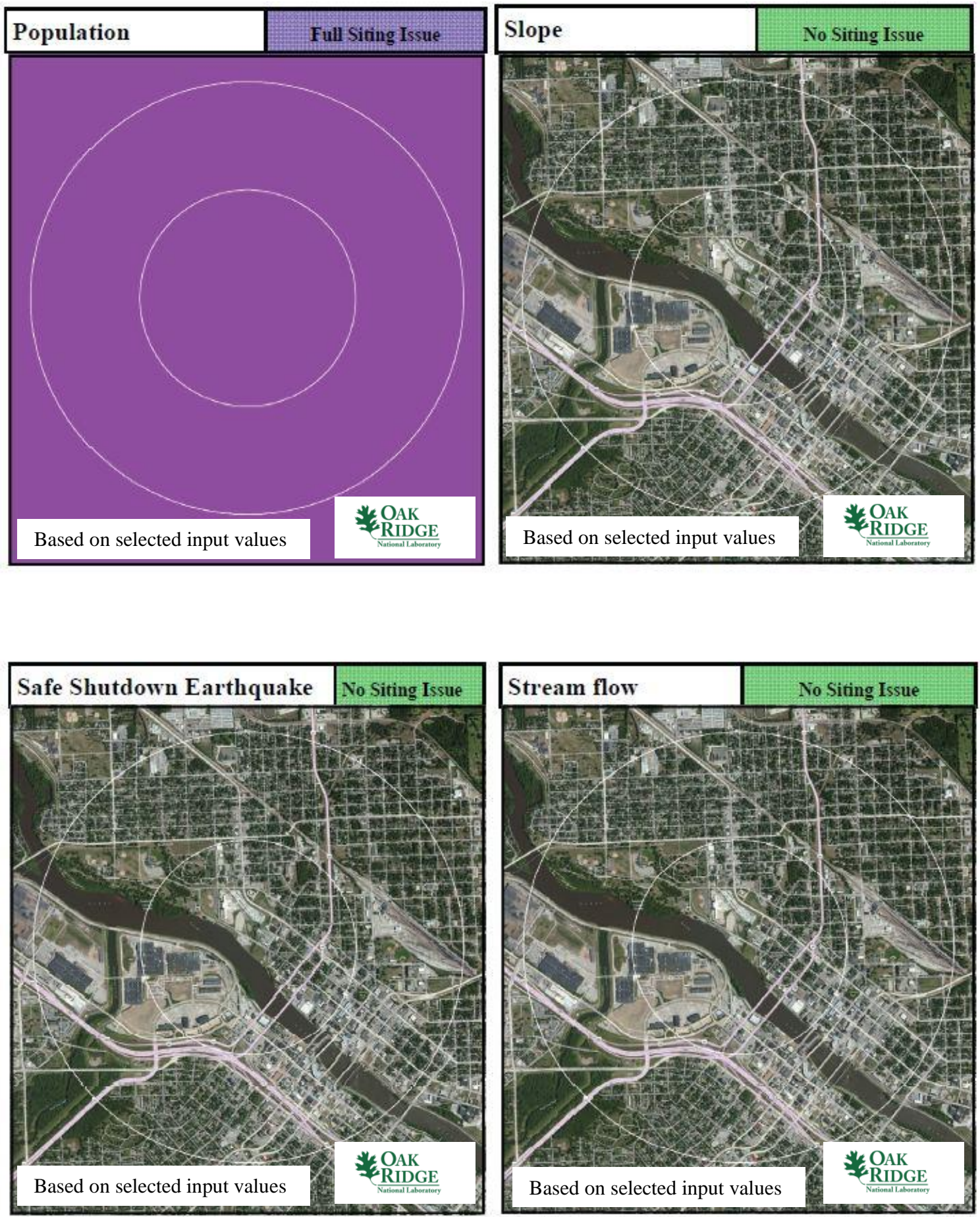

Maynard Power Station 

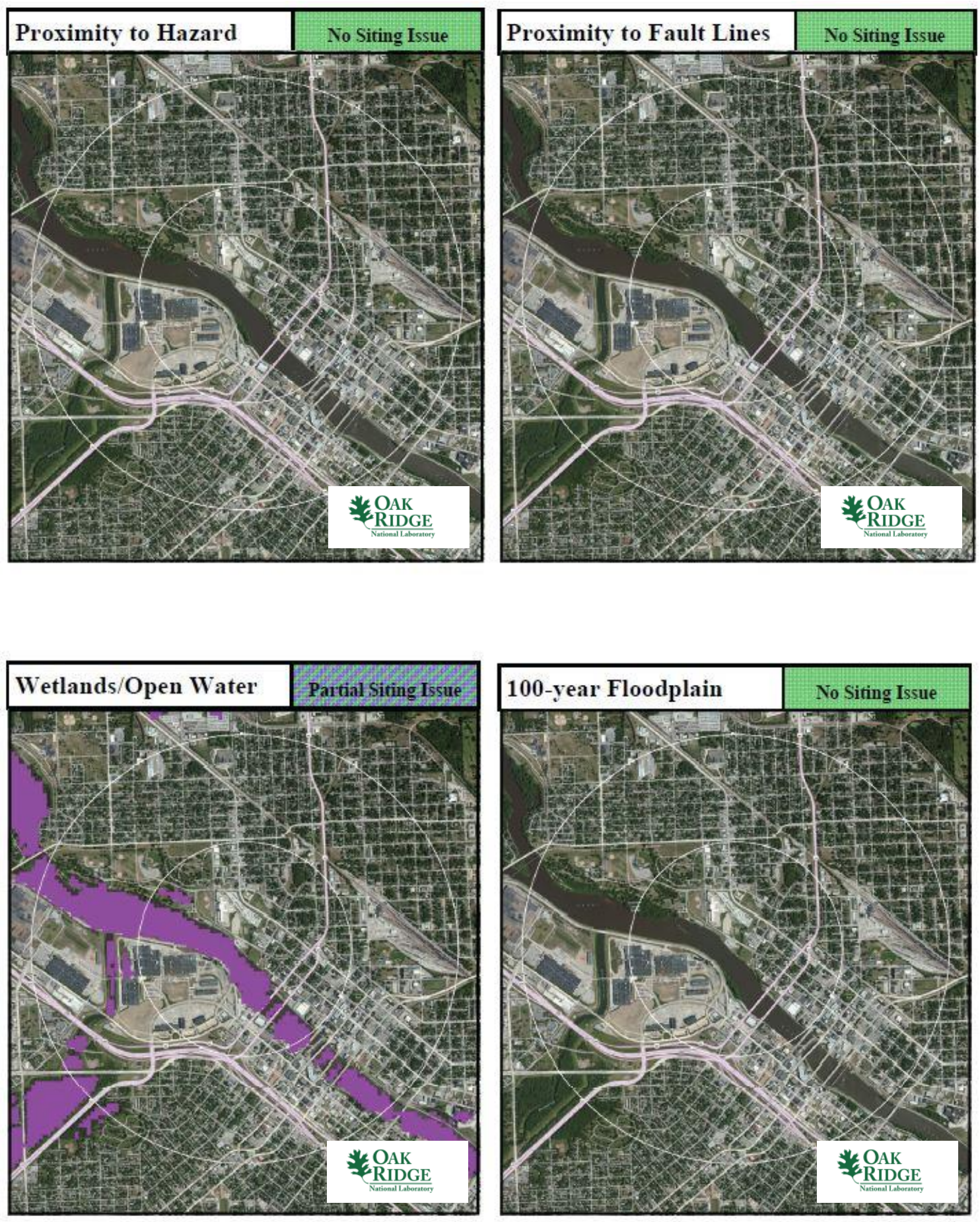

Maynard Power Station 

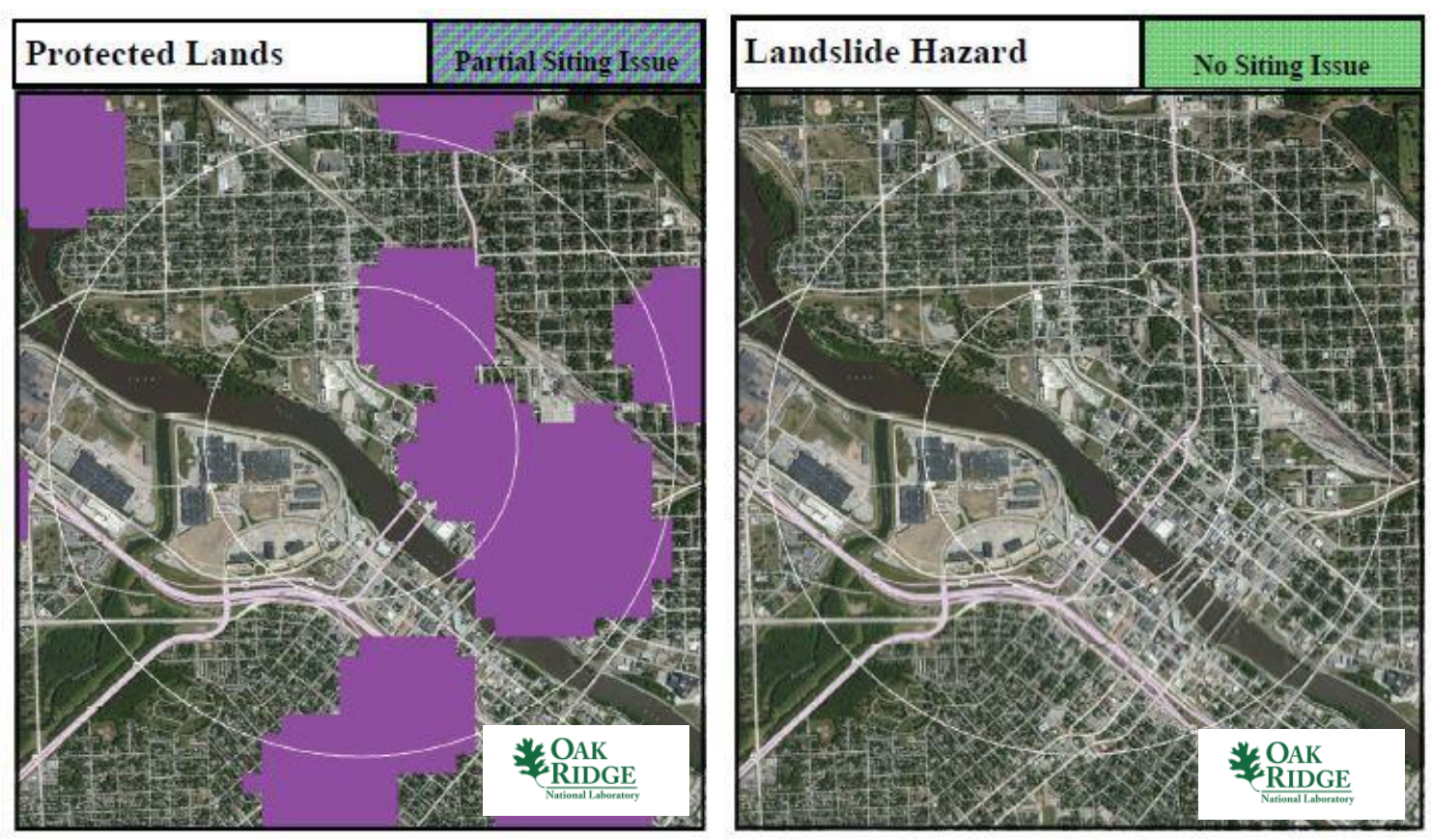

Maynard Power Station

\section{D.5.6 Site Evaluation}

The companies Iowa Public Service Company, Iowa Power Company, Inc., and Midwest Power System do not own or operate a nuclear power plant in the United States. Therefore, the utility would need to be mentored through the licensing process to build and operate an SMR. The Maynard Power Station has been shut down for decades, so the direct need for power at this location is unknown. However, there is a large John Deere factory directly across the river from the site. Unfortunately, the acreage available at the site is likely insufficient to support an SMR.

From an environmental justice perspective, the community collectively appears to have achieved a reasonable level of education with median income levels typical of much of the United States. Therefore, siting an SMR at this location would not seem to be disenfranchising a less-educated or poverty-stricken community. Furthermore, the education level of the Maynard Power Station plant site community would seem to support the higher-technology job opportunities provided by an SMR.

As shown in Sects. D.0 and D.0, the Maynard Power Station site has a full SMR site screening issue with population. This reflects the fact that more than 100,000 people live within a few miles of the plant site by virtue of the site's downtown location. In addition, Iowa Highway 63 runs within 0.5 miles of the site, which would make it difficult for a nuclear licensee to control land access to areas very near the plant location.

Maynard Power Station site also has partial SMR site screening issues with wetlands/open waters and protected lands. The wetlands/open waters issue reflects the adjacent West Fork of the Cedar River. Likewise, the protected land areas are primarily local parkland located to the east and south of the site. Neither of these issues would impact siting an SMR at this location. The remaining SMR site screening criteria are met site-wide for the values established in the updated SMR siting report.1

The site does not meet current NRC RG 4.7 recommendations for population density without significant additional consideration for relaxed SMR population siting requirements based on reduced source term. In addition, the site is too small to accommodate a near-term SMR design without acquiring additional land 
in the downtown area. As a result, the Maynard Power Station site is not a likely candidate for consideration of siting an SMR. 
D-46 


\section{D.6 Merrimack Station}

\section{D.6.1 Location Detail}

As shown in Fig. D.113, the Merrimack Station is located in southeastern New Hampshire on the West Bank of the Merrimack River. More specifically, the plant is located off River Road, in Merrimack County, New Hampshire. Interstate 93 is accessible approximately 1.3 miles to the southwest. Rail access is available onsite within 0.1 miles and barge access is 26 miles east on the Lamprey River. The plant is located about 0.4 miles southwest and just across the Merrimack River from Pembroke, New Hampshire, with a population of approximately 7,344 people. The nearest city with a population in excess of 10,000 people is Concord, New Hampshire, a little less than 6 miles to the northwest of the Merrimack Station.

- Plant: Merrimack Station

- Utility: Public Service Company of New Hampshire

- Coordinates: lat. $43.14058^{\circ} \mathrm{N}$, long. $71.47019^{\circ} \mathrm{W}$

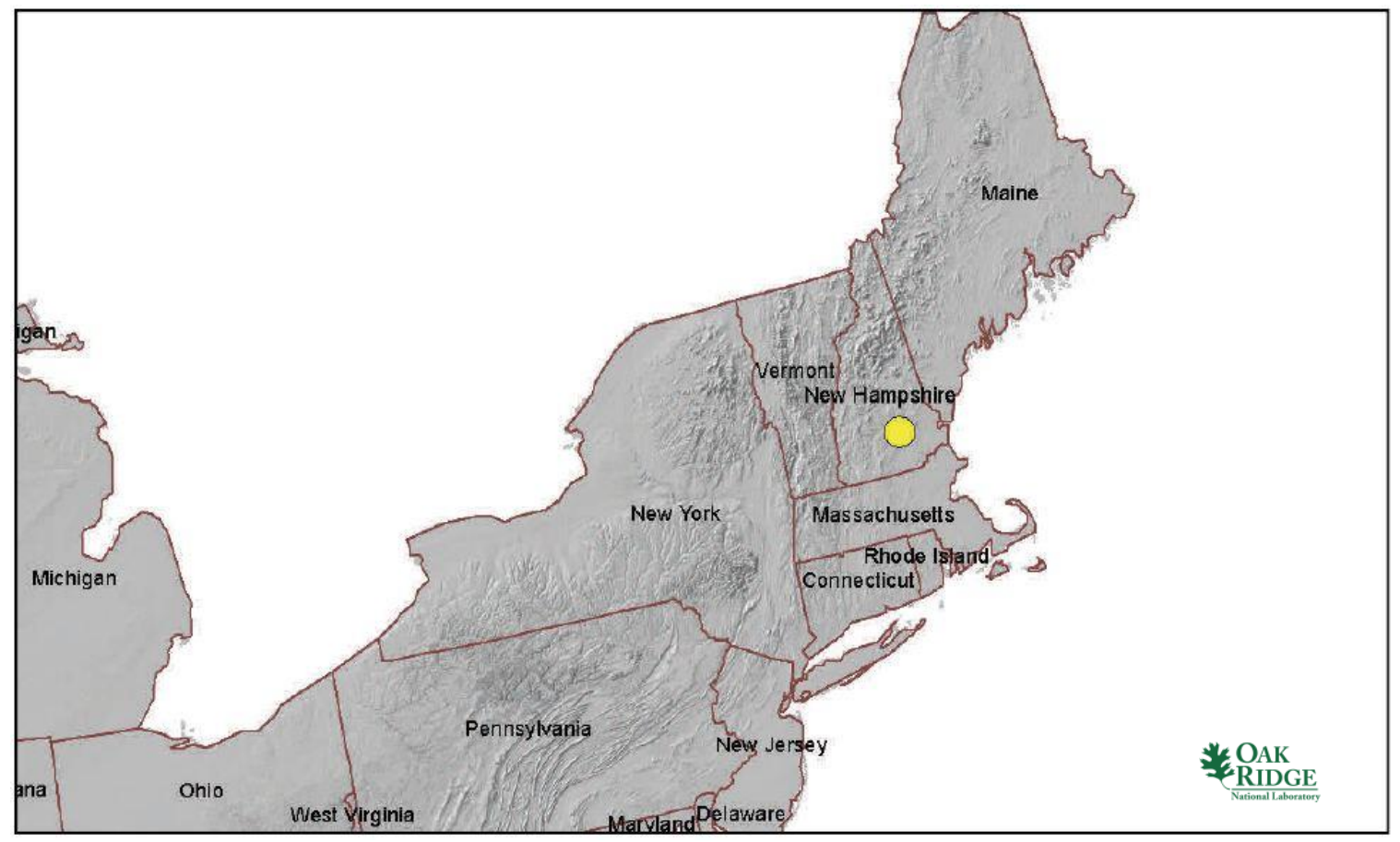

Fig. D.113. Merrimack Station location map

\section{D.6.2 Site Description and Status}

The Merrimack Station is operated by the Public Service Company of New Hampshire (PSNH), a subsidiary of Northeast Utilities Company. The Merrimack Station consists of two coal-fired units. Unit 1, commissioned in 1960, is rated at $114 \mathrm{MW}(\mathrm{e})$. Unit 2, commissioned in 1968, is rated at $346 \mathrm{MW}(\mathrm{e})$. The Merrimack Station produces 459.2 MW(e). The plant had been used as a base load plant. However, as gas prices have decreased, the utility has found it cheaper to purchase power during low demand months and only operates the station as a base load plant during heavier demand periods in the summer and winter. The plant is cooled by once-through cooling and sprays from the adjacent river.

The plant is located on roughly 100 acres on the Merrimack River approximately 36 miles northwest of the 1,248 MW(e) Seabrook 1 nuclear power plant near Portsmouth, New Hampshire. Merrimack Station is 35 miles west of the coal-fired 150 MW(e) Schiller Station. The 14 MW(e) Garvins Falls Dam and its 
associated hydroelectric station are 2.7 miles upstream from the Merrimack Station. Similarly, the 1.6 MW(e) Hooksett Dam and its associated hydroelectric station is 3 miles downstream from the Merrimack Station.

As noted in Table D.68, the nearest major fault line based on USGS data is about 1,457 miles southwest in Oklahoma. The maximum safe-shutdown earthquake for the site is below $0.3 \mathrm{~g}$ peak ground acceleration. More than 500,000 gpm of cooling water makeup is available from the adjacent Merrimack River.

The permanent population within 1 mile of the plant is approximately 3,100 people, yielding a population density of approximately 987 people per square mile. The permanent population within 10 miles of the plant is approximately 302,000 people, yielding a population density of about 961 people per square mile.

According to the US EPA Environmental Justice website, there are 45,368 occupied housing units within 10 miles of the plant site based on 2000 US Census data. Further, more than $85 \%$ of area adults over age 25 have a high school diploma or higher education. The median annual income for the area is between $\$ 25 \mathrm{~K}$ and $\$ 50 \mathrm{~K}$.

Table D.68. Merrimack Station Site statistics

\begin{tabular}{|c|c|c|c|}
\hline \multicolumn{2}{|l|}{$\begin{array}{l}\text { Population } \\
\text { Population Within }\end{array}$} & \multicolumn{2}{|l|}{$\begin{array}{l}\text { Utility } \\
\text { Distance to Grid Capacity }\end{array}$} \\
\hline $0.5 \mathrm{mi}$ & $\sim 1,700$ & $>400 \mathrm{MWe}$ & $\sim 13 \mathrm{mi}$ \\
\hline $1 \mathrm{mi}$ & $\sim 3,100$ & $>800 \mathrm{MWe}$ & $\sim 14 \mathrm{mi}$ \\
\hline $5 \mathrm{mi}$ & $\sim 64,000$ & $>1600 \mathrm{MWe}$ & $\sim 63 \mathrm{mi}$ \\
\hline $10 \mathrm{mi}$ & $\sim 302,000$ & $>3200 \mathrm{MWe}$ & $\sim 160 \mathrm{mi}$ \\
\hline \multicolumn{2}{|c|}{ Nearest City with Population } & \multicolumn{2}{|c|}{ Distance to Cooling Water } \\
\hline$>10,000$ & Concord, $\mathrm{NH}$ & $>50,000 \mathrm{gpm}$ & $\sim 0.2 \mathrm{mi}$ (Merrimack River) \\
\hline$>50,000$ & Nashua, $\mathrm{NH}$ & $>100,000 \mathrm{gpm}$ & $\sim 0.2 \mathrm{mi}$ (Merrimack River) \\
\hline$>100,000$ & Manchester, NH & $>200,000 \mathrm{gpm}$ & $\sim 0.2 \mathrm{mi}$ (Merrimack River) \\
\hline$>500,000$ & Boston, MA & $>500,000 \mathrm{gpm}$ & $\sim 0.2 \mathrm{mi}$ (Merrimack River) \\
\hline \multicolumn{2}{|l|}{ Geotechnical } & \multicolumn{2}{|l|}{ Accessibility } \\
\hline Max Earthquake Acceleration & $<0.3 \mathrm{~g}$ & Distance to Major Roadway & $\sim 1.1 \mathrm{mi}$ (Interstate 93 ) \\
\hline Max Slope & $\sim 23 \%$ & Distance to Water Transport & $\sim 26$ mi (Lamprey River) \\
\hline Nearest Fault Line & $\sim 1457$ mi (Oklahoma) & Distance to Rail Transport & $\sim 0.1 \mathrm{mi}(\mathrm{PVTX})$ \\
\hline Nearest Hazard Site & $\begin{array}{c}14 \text { mi (Airport- } \\
\text { Manchester) }\end{array}$ & Distance to Airport & $\sim 14 \mathrm{mi}$ (Manchester) \\
\hline
\end{tabular}




\section{D.6.3 Aerial Imagery}

The aerial imagery in Fig. D.114 indicates the Merrimack Station site. New Hampshire Highways 3 and $3 \mathrm{~A}$ run within 1.0 mile of the Merrimack Station plant site. Numerous housing units are visible within a 1 mile radius of the plant site.

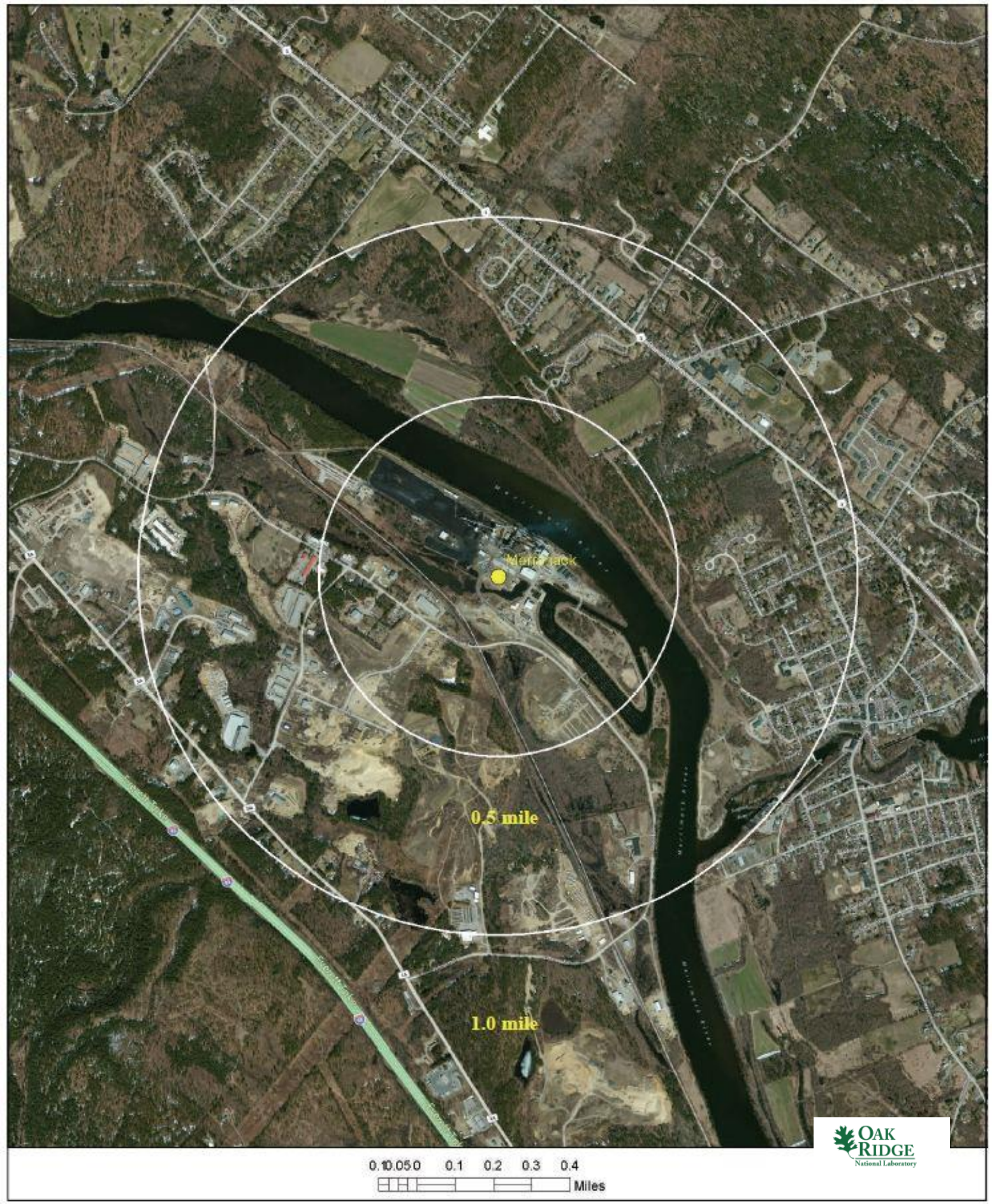

Fig. D.114. Satellite view of Merrimack Station proximity. 


\section{D.6.4 Screening Criteria Overview}

Table D.69. Merrimack Station siting criteria summary

\begin{tabular}{|c|c|c|c|c|c|c|c|c|c|}
\hline \multicolumn{10}{|c|}{$\underset{\text { (Colored Boxes indicate Screening Results) }}{\text { Screening Criteria Summary }}$} \\
\hline \multicolumn{2}{|c|}{ No Siting Issue } & & \begin{tabular}{|l|l|} 
& Partial Siting Issue \\
\end{tabular} & \multicolumn{2}{|c|}{ Partial Siting Issue } & \multicolumn{4}{|c|}{ Full Siting Issue } \\
\hline \begin{tabular}{|l|}
0.5 \\
Mile \\
Buffer
\end{tabular} & Slope & SSE & $\begin{array}{l}\text { Stream } \\
\text { flow } \\
(65,000 \\
\text { gpm) }\end{array}$ & $\begin{array}{l}\text { Proximity } \\
\text { to } \\
\text { Hazard } \\
\text { Operations } \\
\end{array}$ & $\begin{array}{l}\text { Proximity } \\
\text { to } \\
\text { Fault } \\
\text { Lines } \\
\end{array}$ & \begin{tabular}{|l|} 
Wetlands \\
Open \\
Water \\
\end{tabular} & $\begin{array}{l}\text { 100-year } \\
\text { Flood- } \\
\text { plain }\end{array}$ & $\begin{array}{l}\text { Protected } \\
\text { Lands }\end{array}$ & $\begin{array}{l}\text { Land- } \\
\text { slide } \\
\text { Hazards }\end{array}$ \\
\hline \begin{tabular}{|l|}
1.0 \\
Mile \\
Buffer
\end{tabular} & Slope & SSE & $\begin{array}{l}\text { Stream } \\
\text { flow } \\
(65,000 \\
\text { gpm })\end{array}$ & $\begin{array}{l}\text { Proximity } \\
\text { to } \\
\text { Hazard } \\
\text { Operations }\end{array}$ & $\begin{array}{l}\text { Proximity } \\
\text { to } \\
\text { Fault } \\
\text { Lines } \\
\end{array}$ & $\begin{array}{l}\text { Wetlands } \\
\text { Open } \\
\text { Water }\end{array}$ & $\begin{array}{l}100 \text {-year } \\
\text { Flood- } \\
\text { plain }\end{array}$ & $\begin{array}{l}\text { Protected } \\
\text { Lands }\end{array}$ & \begin{tabular}{|l} 
Land- \\
slide \\
Hazards
\end{tabular} \\
\hline & & & & & & & & 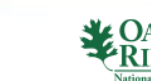 & DGE \\
\hline \multicolumn{10}{|c|}{ Site Selection and Evaluation Criteria Table } \\
\hline \multicolumn{6}{|c|}{ Criteria } & \multicolumn{4}{|c|}{ Value } \\
\hline \multicolumn{6}{|c|}{ Population Density within 10 miles (people/square mile) } & \multicolumn{4}{|c|}{$>500$} \\
\hline \multicolumn{6}{|l|}{ Slope } & \multicolumn{4}{|c|}{$>18 \%$} \\
\hline \multicolumn{6}{|c|}{ Safe shutdown earthquake (ground acceleration) } & \multicolumn{4}{|c|}{$>0.5$} \\
\hline \multicolumn{6}{|c|}{ Streamflow/cooling water make-up (gpm) } & \multicolumn{4}{|c|}{$<65,000$} \\
\hline \multicolumn{6}{|c|}{ Proximity to hazardous operations - buffer (mile) } & \multicolumn{4}{|c|}{ Depends on hazardous operation ${ }^{1}$} \\
\hline \multicolumn{6}{|c|}{ Proximity to fault lines - buffer (mile) } & \multicolumn{4}{|c|}{ Depends on length of fault } \\
\hline \multicolumn{6}{|c|}{ Wetlands/Open Water } & \multicolumn{4}{|c|}{-} \\
\hline \multicolumn{6}{|c|}{ 100-year floodplain } & \multicolumn{4}{|c|}{-} \\
\hline \multicolumn{6}{|c|}{ Protected lands } & \multicolumn{4}{|c|}{-} \\
\hline \multicolumn{6}{|c|}{ Landslide hazard (moderate and high) } & \multicolumn{4}{|c|}{-} \\
\hline
\end{tabular}

${ }^{1}$ Hazardous facilities (airports- 5 miles and oil refineries- -1 mile) 


\section{D.6.5 Composite Map and Individual Siting Issue Maps}

A composite map of SMR siting challenges to the Merrimack Station is shown in Fig. D.115. The physical plant structures are located on land with a single siting challenge. Following this map are maps of the individual SMR siting criteria based on selected input values.

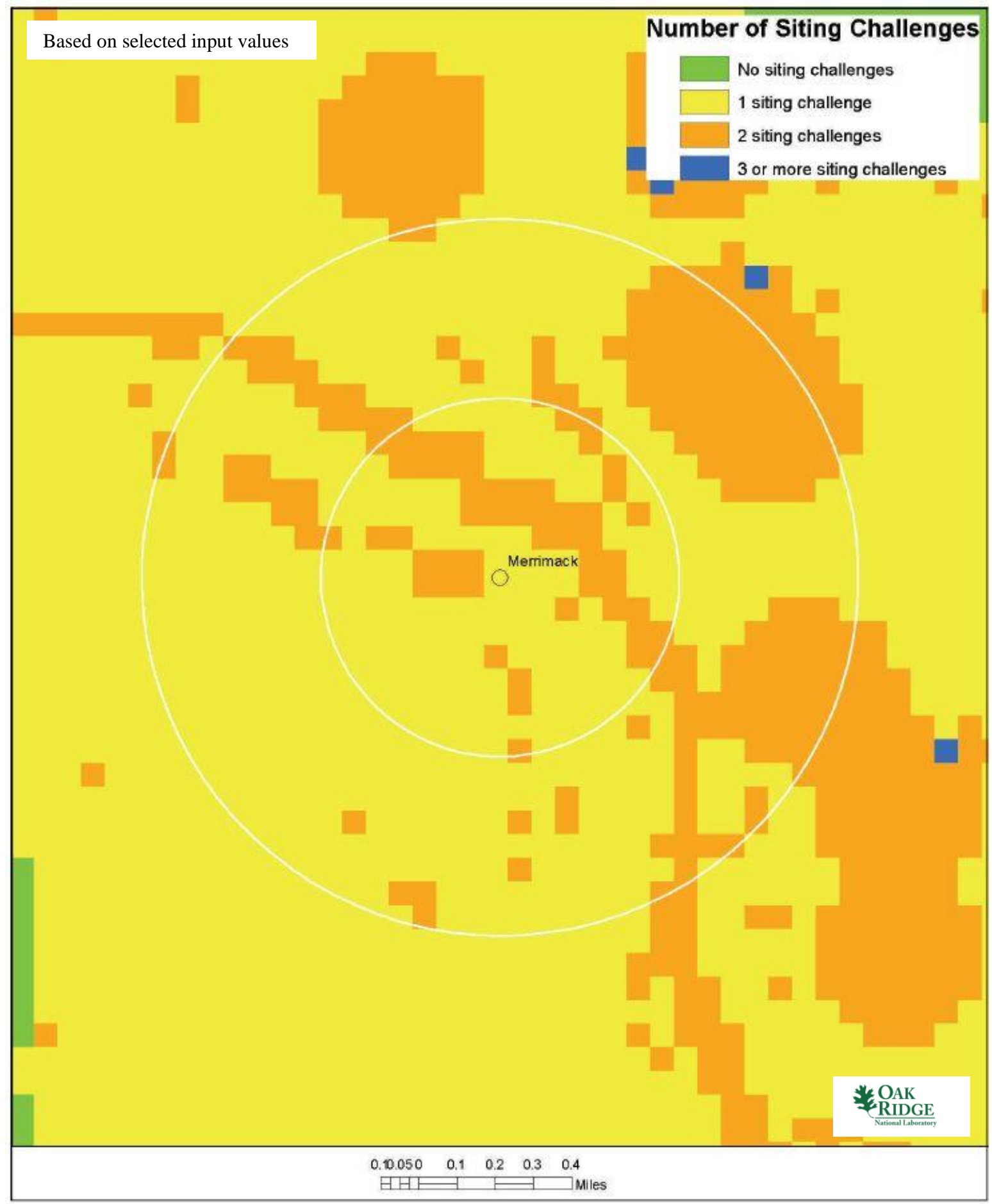

Fig. D.115. Merrimack Station composite map. 

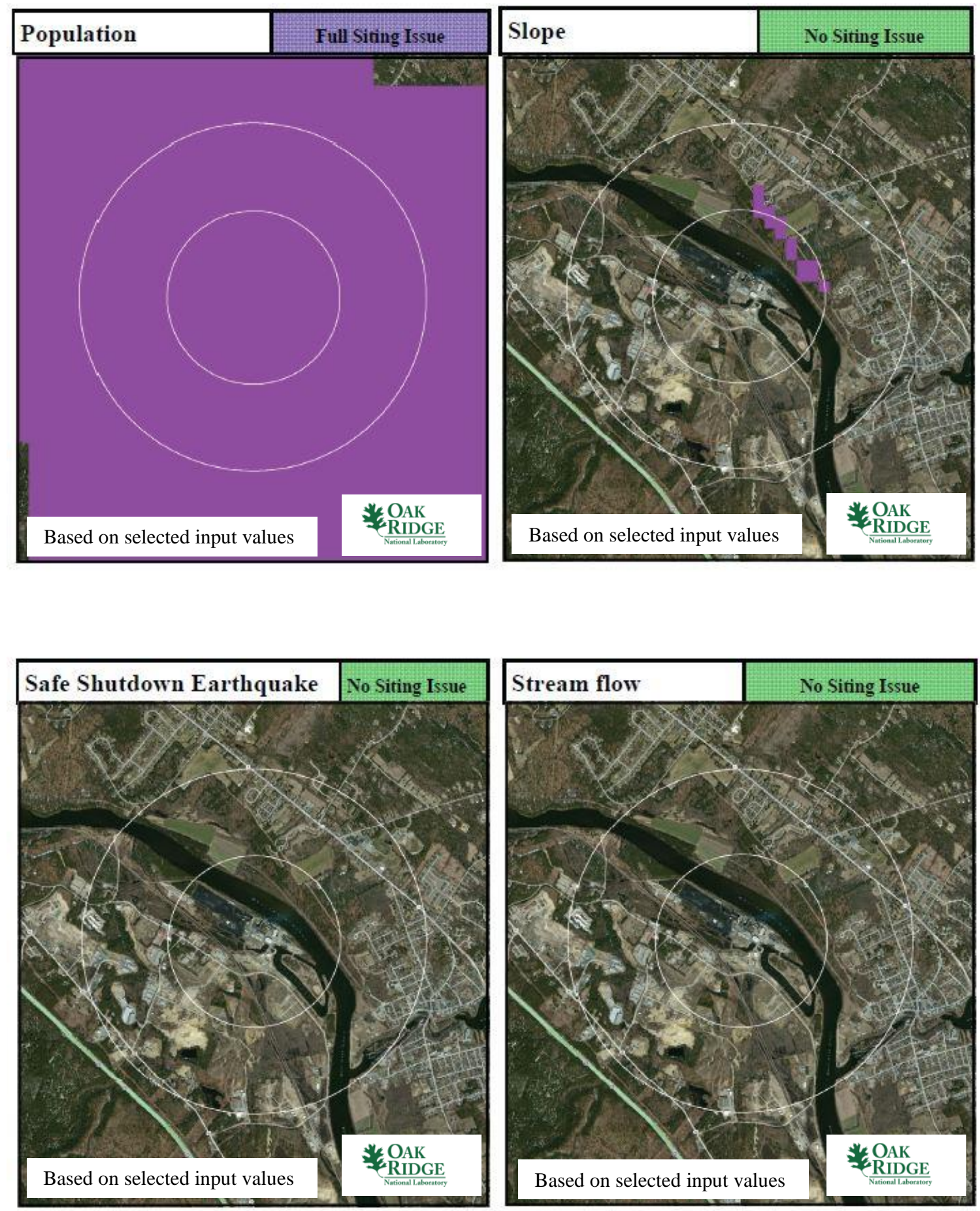

Merrimack Station 

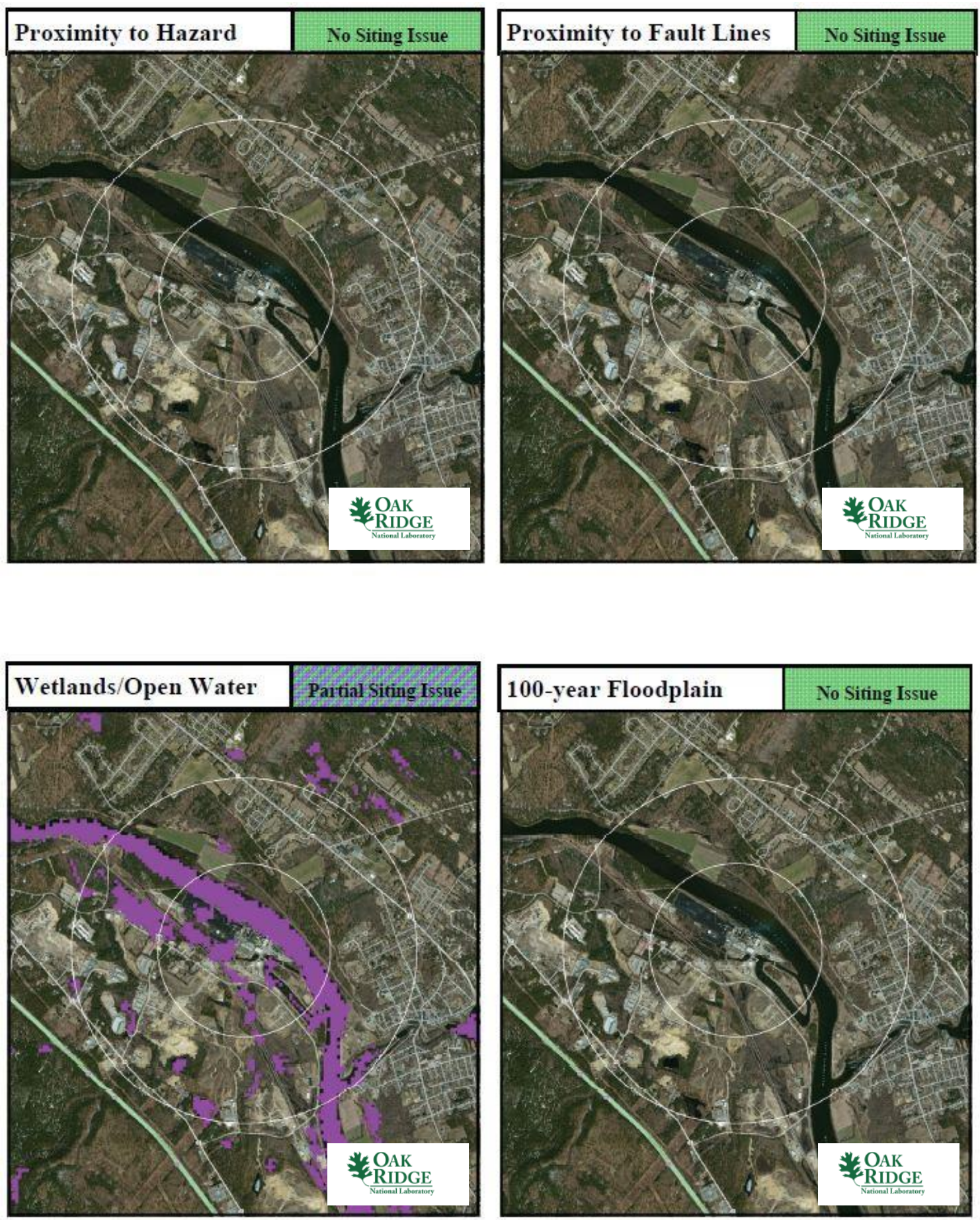

Merrimack Station 

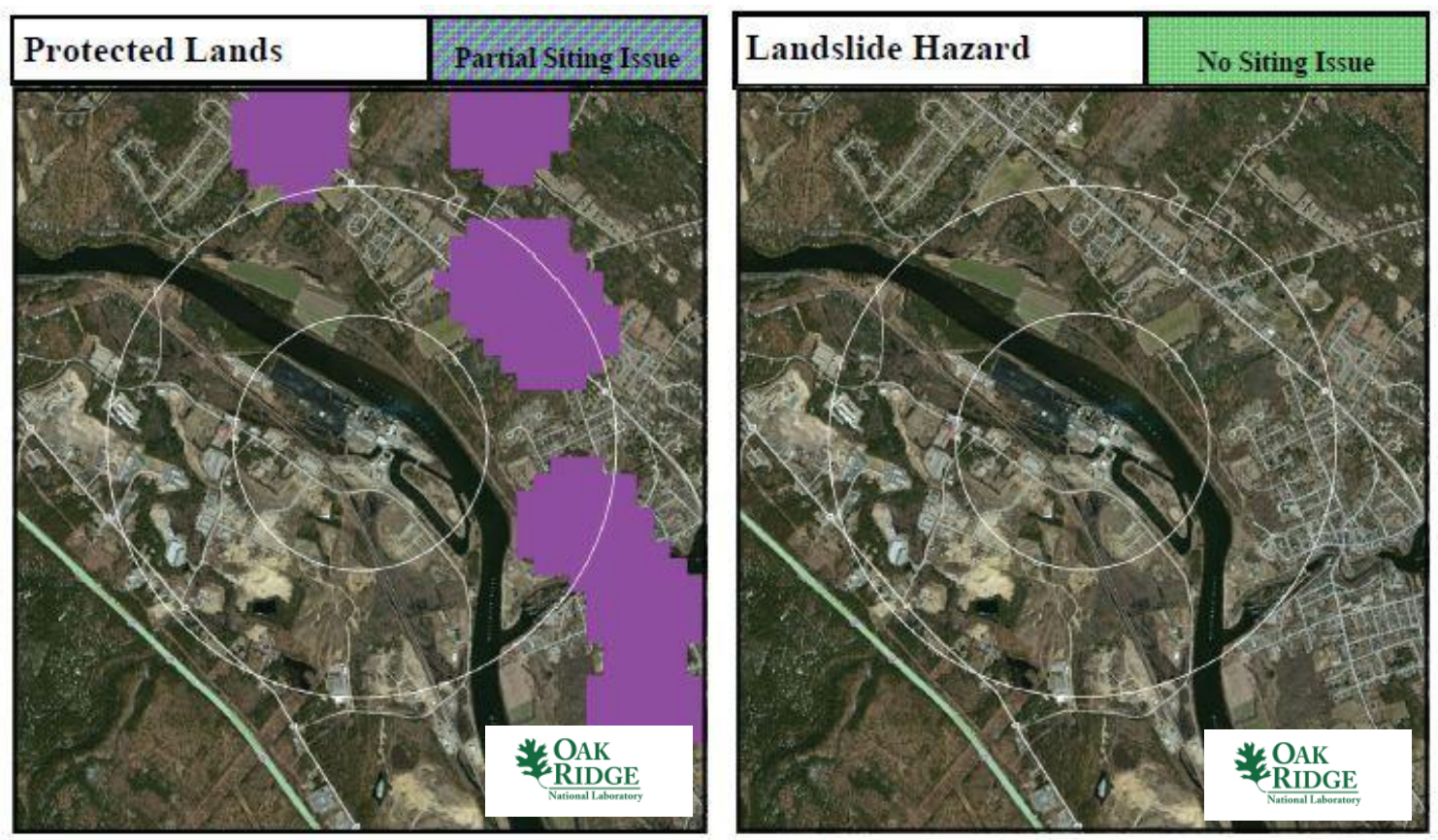

Merrimack Station

\section{D.6.6 Site Evaluation}

Northeast Utilities Company and its subsidiary, PSNH, do not own or operate any nuclear power plants in the United States. Therefore, the utility would need to be mentored through the licensing process to build and operate an SMR. The site contains sufficient acreage to support siting an SMR.

From an environmental justice perspective, the community collectively appears to have achieved a reasonable level of education with median income levels typical of much of the United States. Therefore, siting an SMR at this location would not seem to be disenfranchising a less-educated or poverty-stricken community. Furthermore, the education level of the Merrimack Station community would seem to support the higher-technology job opportunities provided by an SMR.

As shown in Sects. D.0 and D.0, the Merrimack Station site has a full SMR site screening issue with population. This reflects the fact that more than 300,000 people live within a 10 miles of the plant site. Future population growth will only compound this siting concern.

The Merrimack Station site also has partial SMR site screening issues with wetlands/open waters and protected lands. The wetlands/open waters issue reflects the adjacent Merrimack River. Likewise, the protected land areas are primarily local parkland located to the north and east of the site. Neither of these issues would impact siting an SMR at this location. The remaining SMR site screening criteria are met site-wide for the values established in the updated SMR siting report.1

The site does not meet current NRC RG 4.7 recommendations for population density without additional consideration for relaxed SMR population siting requirements based on reduced source term. The utility has already decided that it is cheaper to purchase power than to generate power from coal at the site. In addition, the attitude toward nuclear power in this part of the northeast is generally negative. As a result, the Merrimack Station site is not a likely candidate for consideration of siting an SMR. 


\section{D.7 Quindaro Power Station}

\section{D.7.1 Location Detail}

As shown in Fig. D.116, the Quindaro Power Station is located in northeastern Kansas on the South Bank of the Missouri River, which forms the border between Kansas and Missouri. The river also separates Kansas City, Kansas, from Kansas City, Missouri. More specifically, the plant is located off Interstate 635 (The Harry Darby Memorial Highway) and Kansas Highway 69, in Wyandotte County, Kansas. Interstate 635 is accessible approximately 0.76 miles to the west. Rail access is available onsite within 0.2 miles and barge access is within 0.2 miles on the Missouri River. The plant is located in Kansas City, Kansas, with a population of approximately 146,070 people.

- Plant: Quindaro Power Station

- Utility: Kansas City Kansas Board of Public Utilities

- Coordinates: lat. $39.15092^{\circ} \mathrm{N}$, long. $94.63655^{\circ} \mathrm{W}$

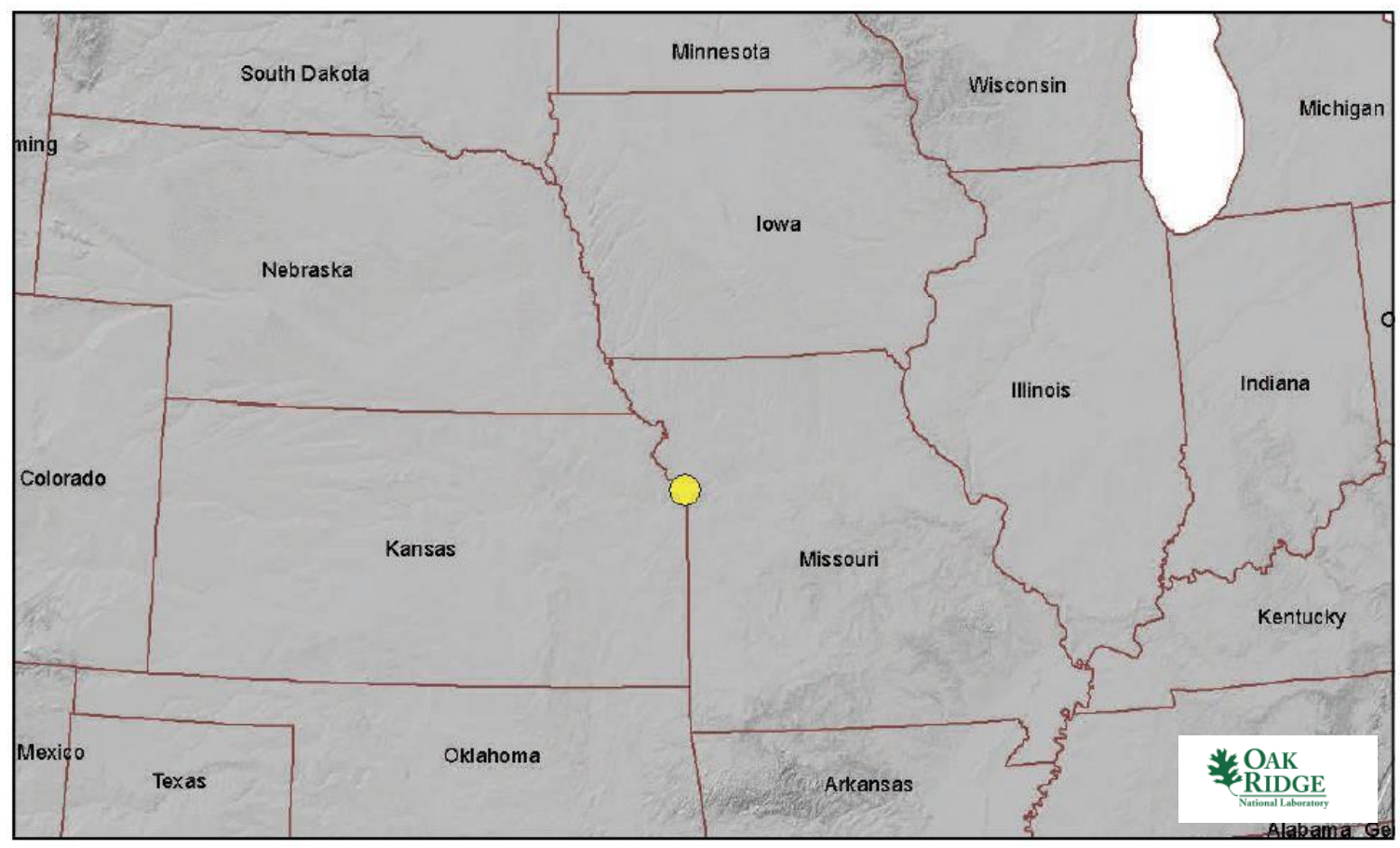

Fig. D.116. Quindaro Power Station location map

\section{D.7.2 Site Description and Status}

The Quindaro Power Station is owned and operated by the Kansas City, Kansas, Board of Public Utilities. The Quindaro Power Station consists of two coal-fired or natural gas-fired units. Unit 1, commissioned in 1965, is rated at $82 \mathrm{MW}(\mathrm{e})$. Unit 2, commissioned in 1971, is rated at $158 \mathrm{MW}(\mathrm{e})$. The plant is cooled by once-through cooling from the adjacent river.

The Quindaro Power Station is located on roughly 90 acres about 75 miles northeast of the 1,170 MW(e) Wolf Creek Generating Station nuclear power plant near Burlington, Kansas. The site is 3.5 miles southeast of the $261 \mathrm{MW}(\mathrm{e})$ coal-fired Nearman Creek plant and 35 miles northeast of the $566 \mathrm{MW}(\mathrm{e})$ coal-fired Lawrence Energy Center. 
As noted in Table D.70, the nearest major fault line based on USGS data is about 302 miles west in Kansas. The maximum safe-shutdown earthquake for the site is below $0.3 \mathrm{~g}$ peak ground acceleration. More than 500,000 gpm of cooling water makeup is available from the adjacent Missouri River.

The permanent population within 1 mile of the plant is approximately 9,400 people, yielding a population density of slightly fewer than 300 people per square mile. The permanent population within 10 miles of the plant is approximately $1,100,000$ people, yielding a population density of about 3,500 people per square mile.

According to the US EPA Environmental Justice website, there are 217,883 occupied housing units within 10 miles of the plant site based on 2000 US Census data. Further, just under $80 \%$ of area adults over age 25 have a high school diploma or higher education. The median annual income for the area is between $\$ 25 \mathrm{~K}$ and $\$ 50 \mathrm{~K}$.

Table D.70. Quindaro Power Station site statistics

\begin{tabular}{|l|l|l|l|}
\hline $\begin{array}{l}\text { Population } \\
\text { Population Within }\end{array}$ & \multicolumn{2}{l|}{$\begin{array}{l}\text { Utility } \\
\text { Distance to Grid Capacity }\end{array}$} \\
\hline $0.5 \mathrm{mi}$ & $<500$ & $>400 \mathrm{MWe}$ & $\sim 7 \mathrm{mi}$ \\
\hline $1 \mathrm{mi}$ & $\sim 9,400$ & $>800 \mathrm{MWe}$ & $\sim 24 \mathrm{mi}$ \\
\hline $5 \mathrm{mi}$ & $\sim 295,000$ & $>1600 \mathrm{MWe}$ & $\sim 227 \mathrm{mi}$ \\
\hline $10 \mathrm{mi}$ & $\sim 1,100,000$ & $>3200 \mathrm{MWe}$ & $\sim 343 \mathrm{mi}$ \\
\hline Nearest City with Population & Distance to Cooling Water \\
\hline \multicolumn{2}{|l|}{} & \multicolumn{2}{l|}{} \\
\hline$>50,000$ & Gladstone, MO & $>50,000$ gpm & $\sim 0.2 \mathrm{mi}$ (Missouri River) \\
\hline$>100,000$ & Shawnee, KS & $>100,000$ gpm & $\sim 0.2 \mathrm{mi}$ (Missouri River) \\
\hline$>500,000$ & Kansas City, KS & $>200,000$ gpm & $\sim 0.2 \mathrm{mi}$ (Missouri River) \\
\hline Geotechnical & Oklahoma City, OK & $>500,000$ gpm & $\sim 0.2 \mathrm{mi}$ (Missouri River) \\
\hline Max Earthquake Acceleration & $<0.3 \mathrm{~g}$ & Accessibility & \\
\hline Max Slope & $\sim 21 \%$ & Distance to Major Roadway & $\sim 0.5 \mathrm{mi}$ (SR 5) \\
\hline Nearest Fault Line & $\sim 302$ mi (Kansas) & Distance to Rail Transport & $\sim 0.2$ mi (UP) \\
\hline Nearest Hazard Site & $\sim 10$ mi (Airport- \\
\hline
\end{tabular}




\section{D.7.3 Aerial Imagery}

The aerial imagery in Fig. D.117 indicates that Interstate 635 and Kansas Highways 5 and 69 all run within 1.0 mile of the Quindaro Power Station site. Many residential and industrial units are visible within a 1 mile radius of the plant site.

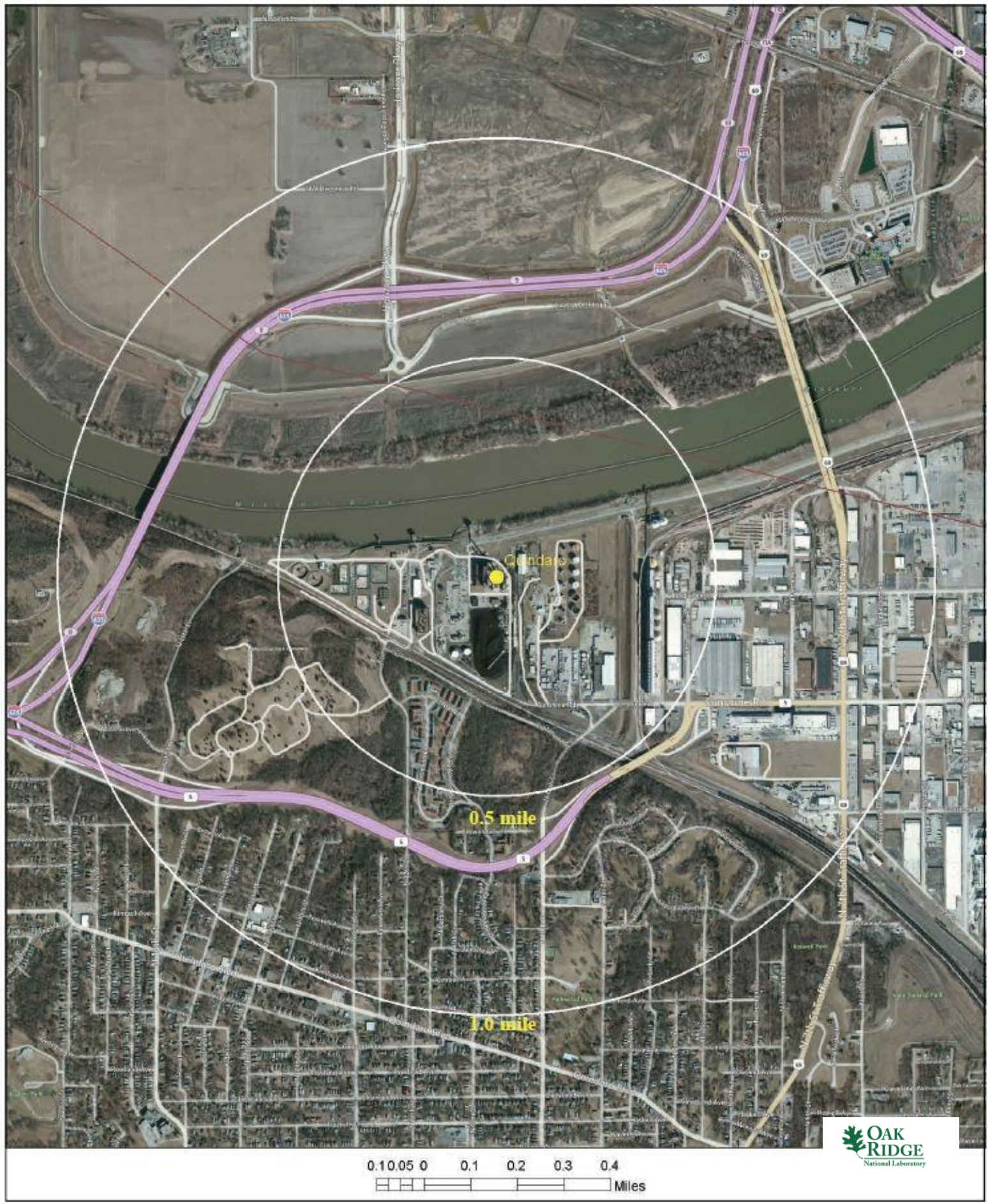

Fig. D.117. Satellite view of Quindaro Power station proximity. 


\section{D.7.4 Screening Criteria Overview}

Table D.71. Quindaro Power Station siting criteria summary

\begin{tabular}{|c|c|c|c|c|c|c|c|c|c|}
\hline \multicolumn{10}{|c|}{$\underset{\text { (Colored Boxes indicate Screening Results) }}{\text { Screening Criteria Summary }}$} \\
\hline \multicolumn{2}{|c|}{ No Siting Issue } & \multicolumn{2}{|c|}{\begin{tabular}{|l|l|} 
& Partial Siting Issue \\
\end{tabular}} & \multicolumn{2}{|c|}{ Partial Siting Issue } & \multicolumn{4}{|c|}{ Full Siting Issue } \\
\hline $\begin{array}{l}0.5 \\
\text { Mile } \\
\text { Buffer }\end{array}$ & Slope & SSE & \begin{tabular}{|l|} 
Stream \\
flow \\
$(65,000$ \\
$\mathrm{gpm})$ \\
\end{tabular} & $\begin{array}{l}\text { Proximity } \\
\text { to } \\
\text { Hazard } \\
\text { Operations } \\
\end{array}$ & \begin{tabular}{|l} 
Proximity \\
to \\
Fault \\
Lines \\
\end{tabular} & \begin{tabular}{|l|} 
Wetlands \\
Open \\
Water \\
\end{tabular} & \begin{tabular}{|l|}
$\begin{array}{l}100 \text {-year } \\
\text { Flood- } \\
\text { plain }\end{array}$ \\
\end{tabular} & $\begin{array}{l}\text { Protected } \\
\text { Lands }\end{array}$ & $\begin{array}{l}\text { Land- } \\
\text { slide } \\
\text { Hazards }\end{array}$ \\
\hline $\begin{array}{l}1.0 \\
\text { Mile } \\
\text { Buffer }\end{array}$ & Slope & SSE & $\begin{array}{l}\text { Stream } \\
\text { flow } \\
(65,000 \\
\text { gpm) }\end{array}$ & \begin{tabular}{|l|} 
Proximity \\
to \\
Hazard \\
Operations
\end{tabular} & $\begin{array}{l}\text { Proximity } \\
\text { to } \\
\text { Fault } \\
\text { Lines } \\
\end{array}$ & $\begin{array}{l}\text { Wetlands } \\
\text { Open } \\
\text { Water }\end{array}$ & $\begin{array}{l}\text { 100-year } \\
\text { Flood- } \\
\text { plain }\end{array}$ & $\begin{array}{l}\text { Protected } \\
\text { Lands }\end{array}$ & \begin{tabular}{|l} 
Land- \\
slide \\
Hazards
\end{tabular} \\
\hline \multicolumn{10}{|c|}{ 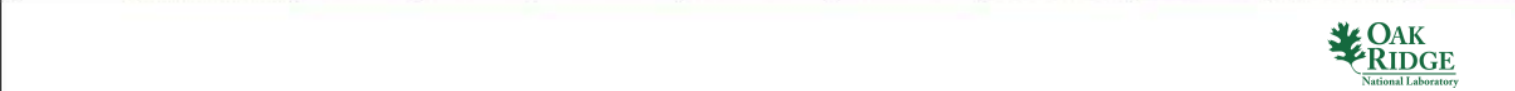 } \\
\hline \multicolumn{10}{|c|}{ Site Selection and Evaluation Criteria Table } \\
\hline \multicolumn{6}{|c|}{ Criteria } & \multicolumn{4}{|c|}{ Value } \\
\hline \multicolumn{6}{|c|}{ Population Density within 10 miles (people/square mile) } & \multicolumn{4}{|c|}{$>500$} \\
\hline \multicolumn{6}{|l|}{ Slope } & \multicolumn{4}{|c|}{$>18 \%$} \\
\hline \multicolumn{6}{|c|}{ Safe shutdown earthquake (ground acceleration) } & \multicolumn{4}{|c|}{$>0.5$} \\
\hline \multicolumn{6}{|c|}{ Streamflow/cooling water make-up (gpm) } & \multicolumn{4}{|c|}{$<65,000$} \\
\hline \multicolumn{6}{|c|}{ Proximity to hazardous operations - buffer (mile) } & \multicolumn{4}{|c|}{ Depends on hazardous operation ${ }^{1}$} \\
\hline \multicolumn{6}{|c|}{ Proximity to fault lines - buffer (mile) } & \multicolumn{4}{|c|}{ Depends on length of fault } \\
\hline \multicolumn{6}{|c|}{ Wetlands/Open Water } & \multicolumn{4}{|c|}{-} \\
\hline \multicolumn{6}{|c|}{ 100-year floodplain } & \multicolumn{4}{|c|}{-} \\
\hline Protecte & & & & & & & - & & \\
\hline Landslic & derate & d high & & & & & - & & \\
\hline
\end{tabular}

${ }^{1}$ Hazardous facilities (airports-5 miles and oil refineries- -1 mile) 


\section{D.7.5 Composite Map and Individual Siting Issue Maps}

A composite map of SMR siting challenges to the Quindaro Power Station is shown in Fig. D.118. The physical plant structures are located on land with a single siting challenge. Following this map are maps of the individual SMR siting criteria based on selected input values.

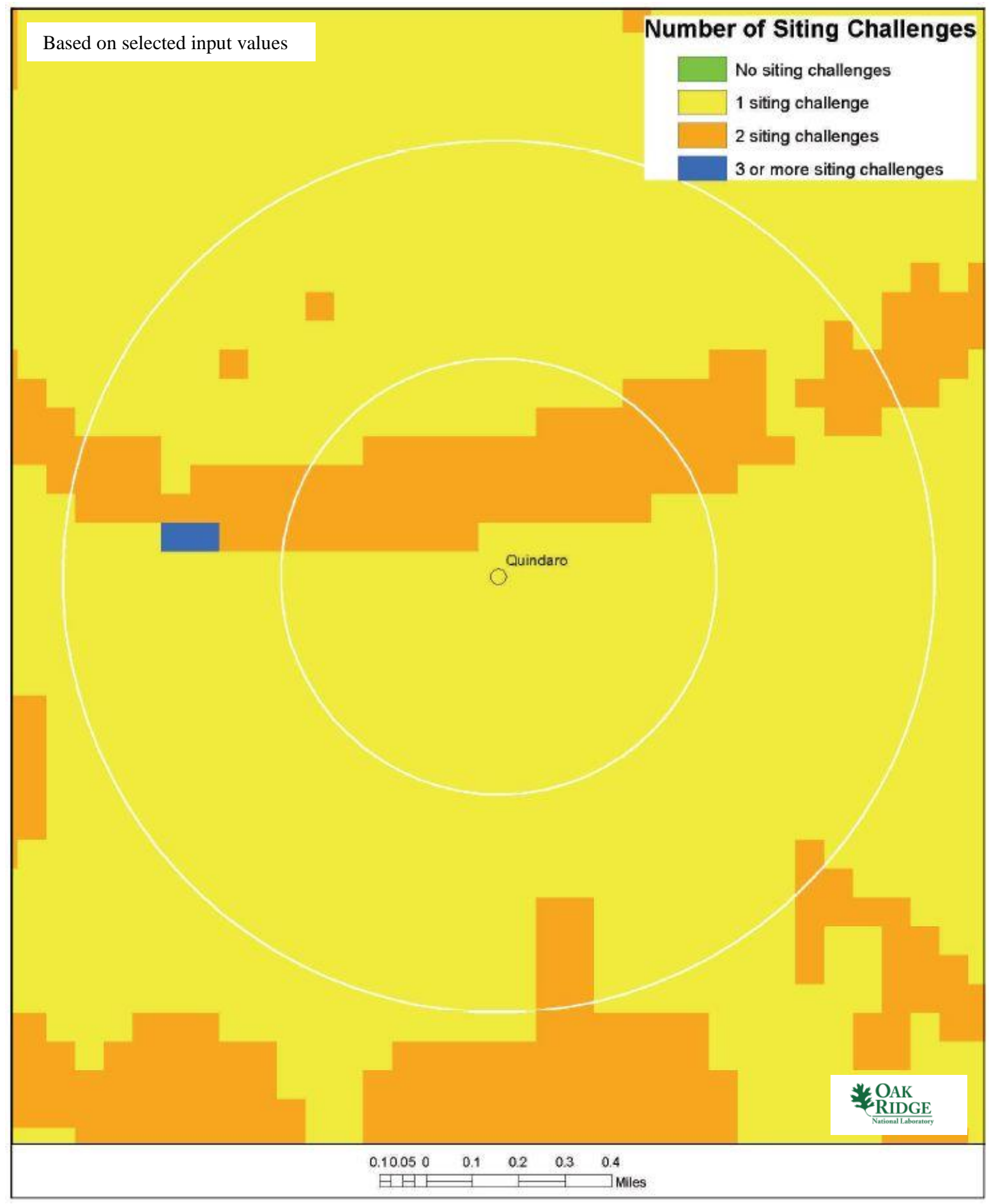

Fig. D.118. Quindaro Power Station composite map. 

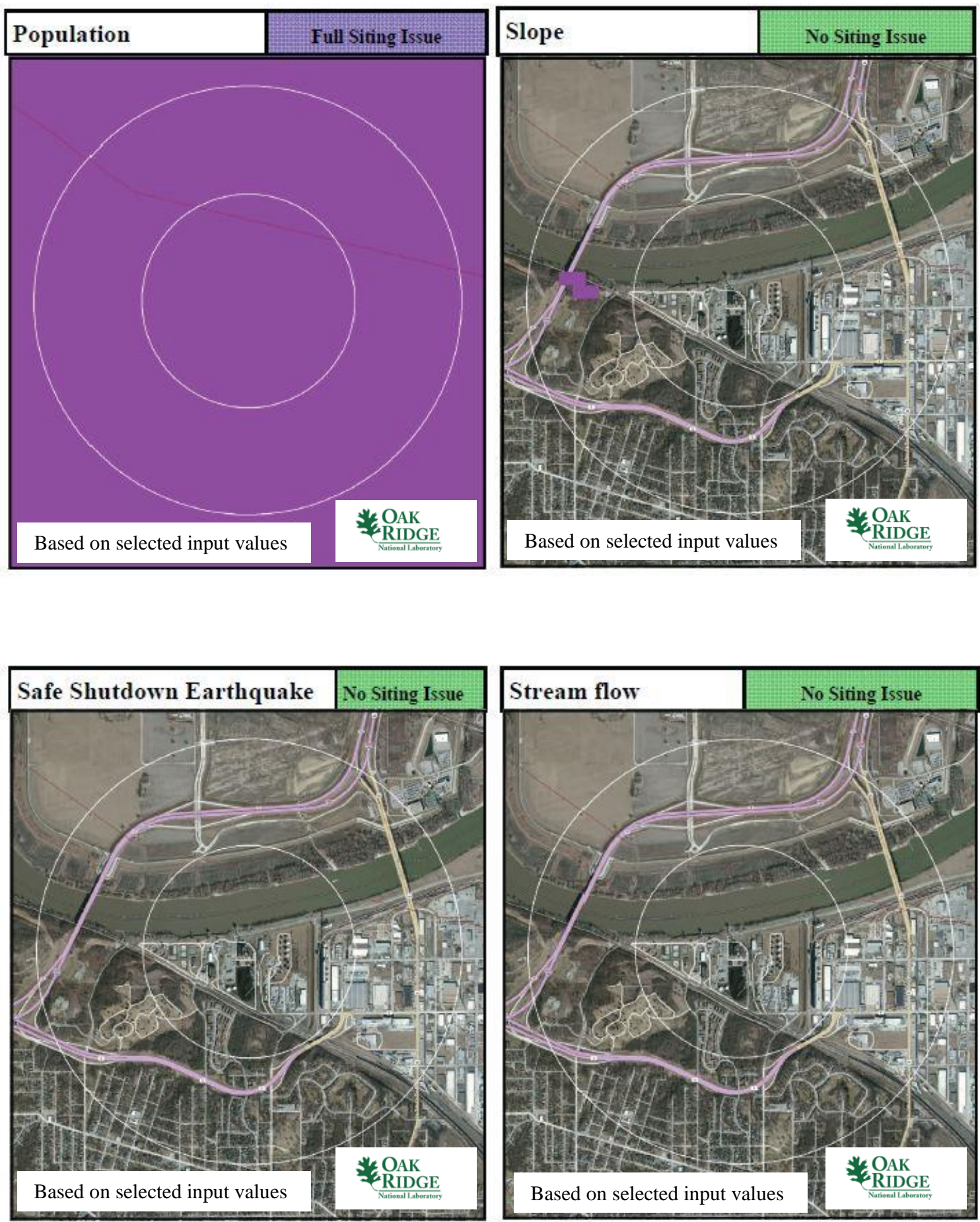

Quindaro Power Station 

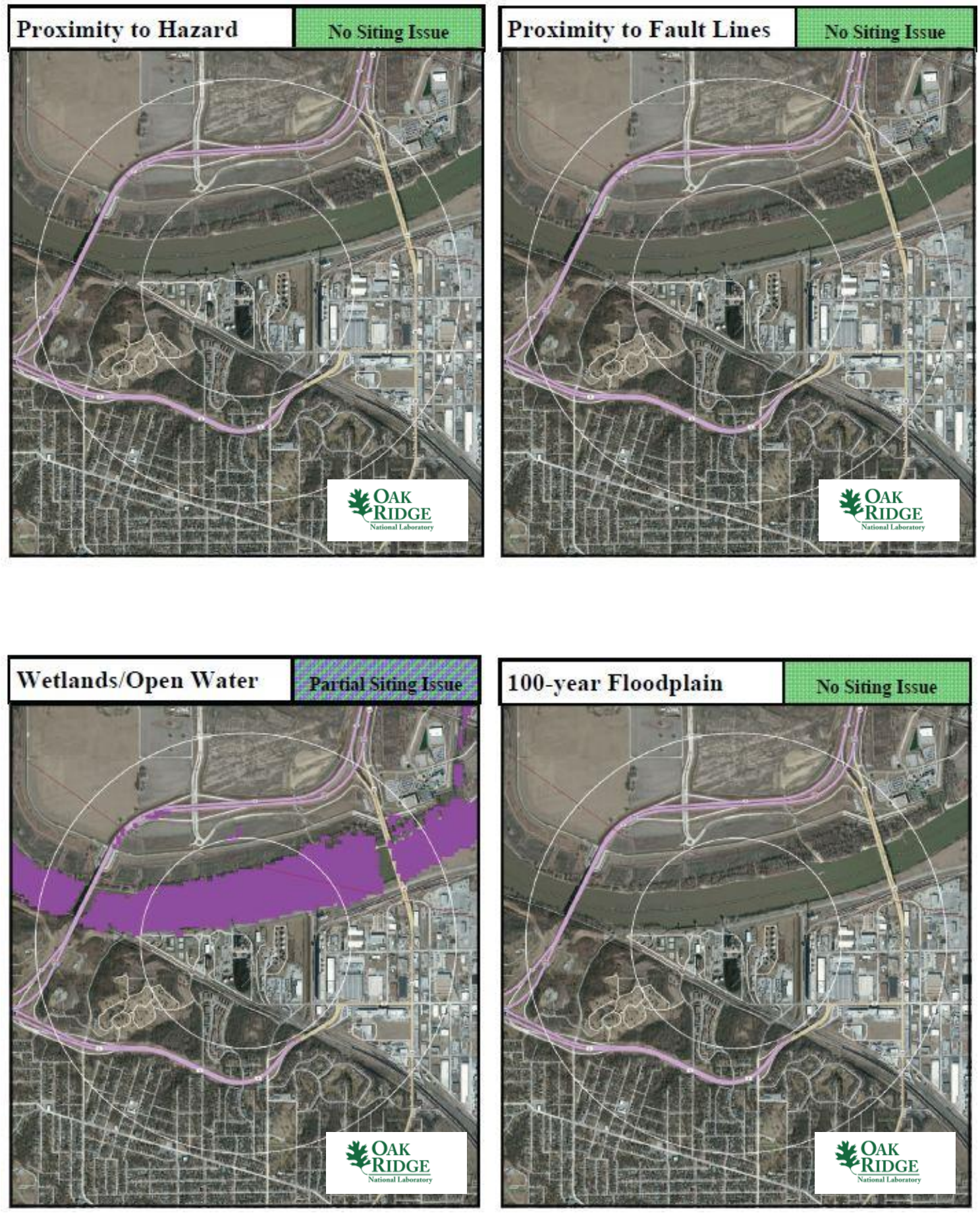

Quindaro Power Station 

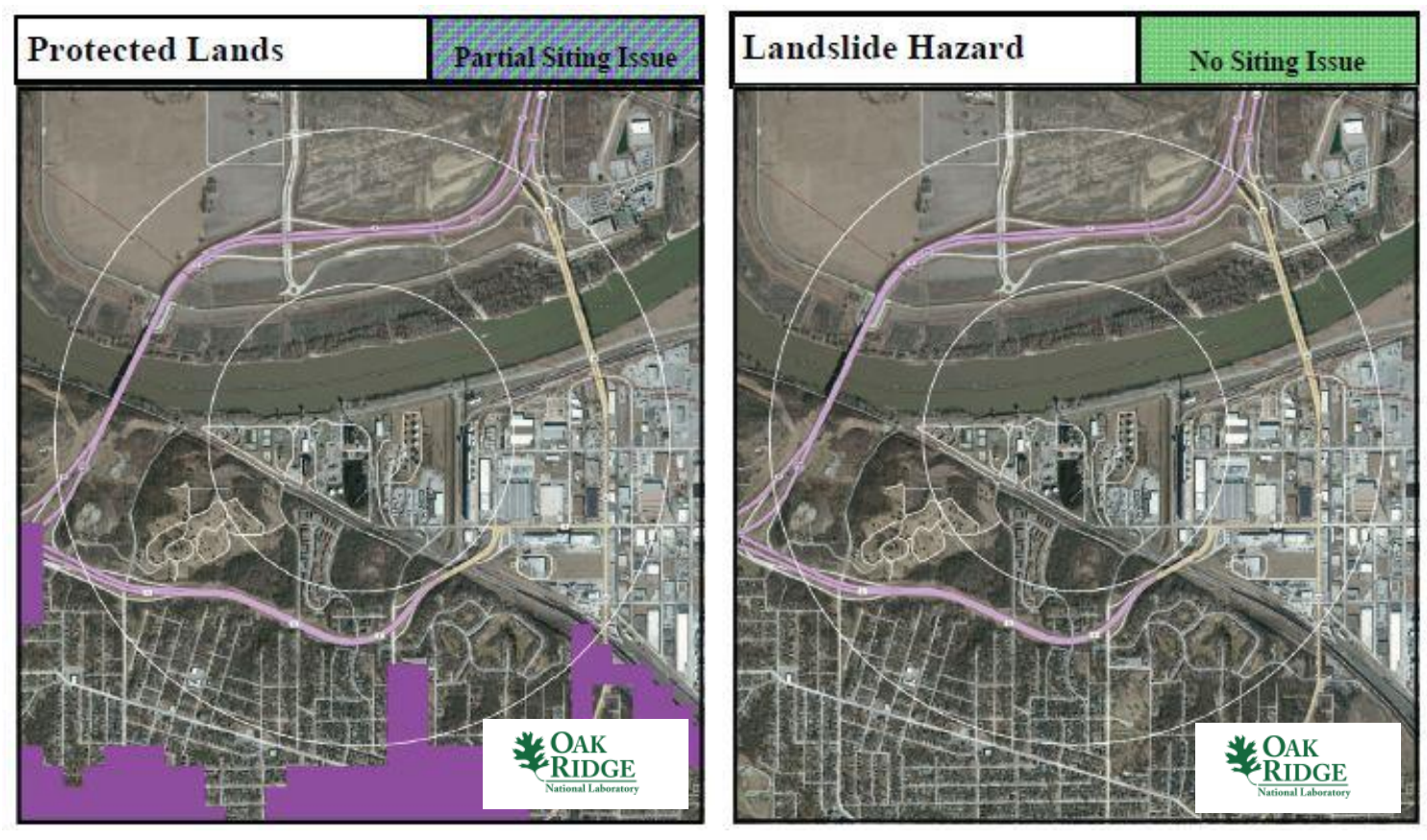

Quindaro Power Station

\section{D.7.6 Site Evaluation}

Kansas City, Kansas, Board of Public Utilities does not own or operate and nuclear power plants in the United States. Therefore, Kansas City, Kansas, Board of Public Utilities would need to be mentored through the licensing process to build and operate an SMR at this site. The site contains sufficient acreage to support siting an SMR.

From an environmental justice perspective, the community collectively appears to have achieved a reasonable level of education with median income levels typical of much of the United States. Therefore, siting an SMR at this location would not seem to be disenfranchising a less-educated or poverty-stricken community. Furthermore, the education level of the Quindaro Power Station community would seem to support the higher-technology job opportunities provided by an SMR.

As shown in Sects. D.0 and D.0, the Quindaro Power Station site has a full siting issue with population. This is due to the fact that the plant is situated on the Missouri River within Kansas City, Kansas, with a population of 146,070 and just across the river from Kansas City, Missouri, with a population of 460,724. In addition, Interstate 635 runs within 1 mile of the site, which could make it difficult for a nuclear licensee to control land access to areas very near the plant location.

The site also has partial SMR site screening issues with wetlands/open waters and protected lands. The wetlands/open waters concern reflects the adjacent Missouri River. The protected lands concern reflects local park land to the south of the site. Neither of these issues would impact siting an SMR at this location. The remaining SMR site screening criteria are met site-wide for the values established in the updated SMR siting report.1

The site does not meet current NRC RG 4.7 recommendations for population density without significant additional consideration for relaxed SMR population siting requirements based on reduced source term. As a result, the Quindaro Power Station site is not a likely candidate for consideration of siting an SMR. Numerous power plant sites further outside of the Kansas City limits, such as the Lawrence Energy Center, might provide SMR siting opportunities with less difficulty. 


\section{D.8 R. Paul Smith Power Station}

\section{D.8.1 Location Detail}

As shown in Fig. D.119, the R. Paul Smith Power Station is located in northwestern Maryland across the Potomac River from West Virginia. More specifically, the plant is located off West Salisbury Street in Washington County, Maryland. Interstate 81 is accessible approximately 0.7 miles to the east. Rail access is available onsite and barge access is available from the adjacent Potomac River. The plant is located less than 0.5 miles southwest of Williamsport, Maryland, with a population of approximately 2,139 people. The nearest city with a population in excess of 10,000 people is Halfway, Maryland, approximately 4 miles to the northeast of the R. Paul Smith Power Station.

- Plant: R. Paul Smith Power Station

- Utility: Allegheny Energy

- Coordinates: lat. $39.59503^{\circ} \mathrm{N}$, long. $77.82632^{\circ} \mathrm{W}$

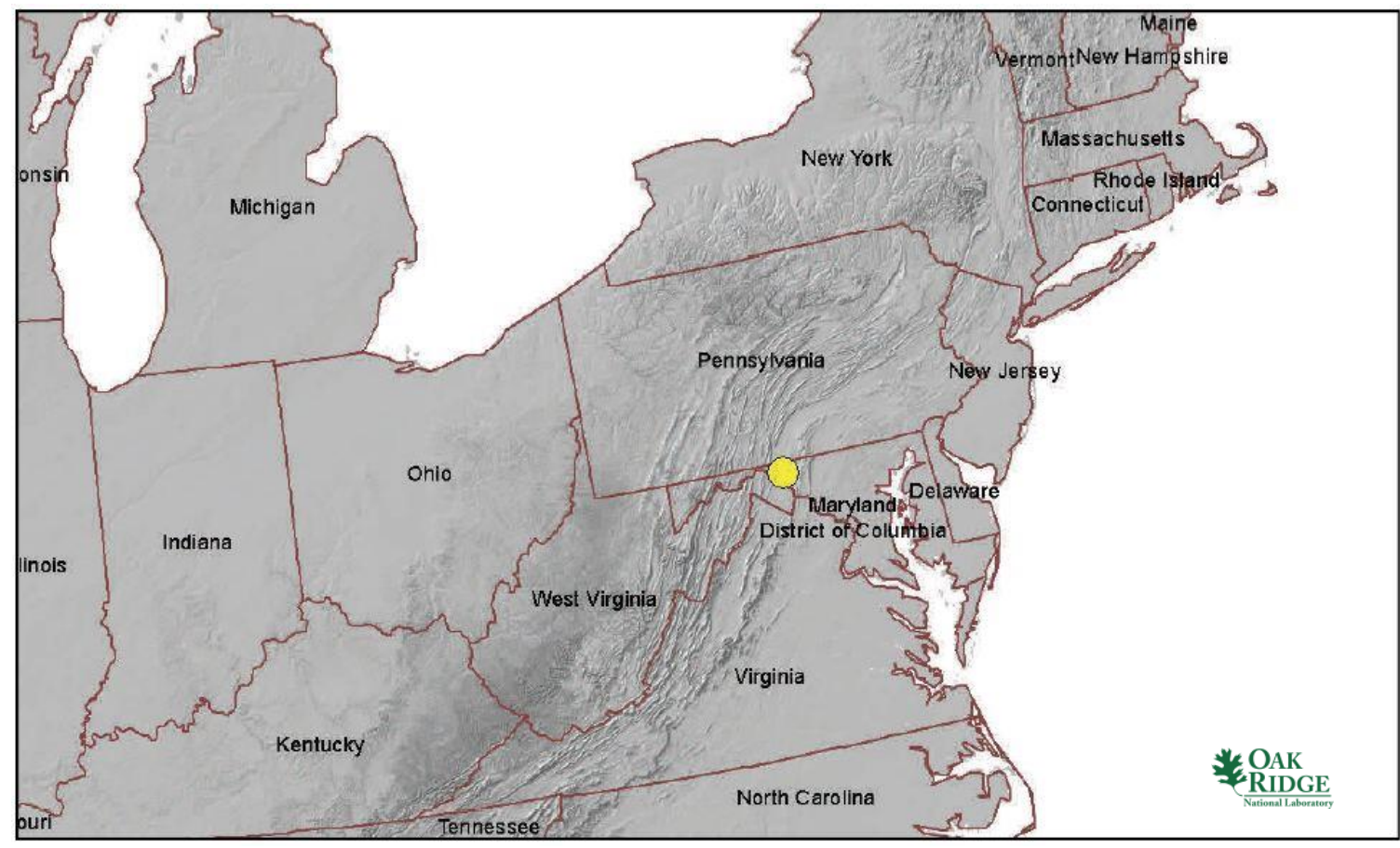

Fig. D.119. R. Paul Smith Power Station location map.

\section{D.8.2 Site Description and Status}

The R. Paul Smith Power Station is owned and operated by Allegheny Energy, a subsidiary of the FirstEnergy Corporation. The $110 \mathrm{MW}(\mathrm{e})$ station consists of two coal-fired units that can also run on oil. The units are cooled by once-through cooling from the Potomac River. Unit 1, commissioned in 1947, is rated at $35 \mathrm{MW}(\mathrm{e})$ and Unit 2, commissioned in 1958, is rated at $75 \mathrm{MW}(\mathrm{e})$. The utility opted to retire the coal-fired plant in September 2012, citing the high cost of complying with stricter EPA MATS regulations set to go into effect in $2015 .^{20}$

\footnotetext{
${ }^{20}$ Williamsport Herald-Mail, "FirstEnergy to Close Power Station in Williamsport," January 26, 2012.
} 
The R. Paul Smith Power Station is located on roughly 30 acres about 83 miles west of the 2,280 MW(e) Peach Bottom nuclear power plant. The site is 33 miles northwest of the $588 \mathrm{MW}(\mathrm{e})$ coal-fired Dickerson plant, 50 miles east of the $229 \mathrm{MW}(\mathrm{e})$ coal-fired AES Warrior Run plant, and 82 miles northeast of the 1,662 MW(e) coal-fired Mount Storm plant. Numerous hydroelectric facilities are also within 100 miles of the site.

As noted in Table D.72, the nearest major fault line based on USGS data is about 1,107 miles southwest in Oklahoma. The maximum safe-shutdown earthquake for the site is below $0.3 \mathrm{~g}$ peak ground acceleration. More than 500,000 gpm of cooling water makeup is available from the adjacent Potomac River.

The permanent population within 1 mile of the plant is approximately 4,500 people, yielding a population density of approximately 1,432 people per square mile. The permanent population within 10 miles of the plant is approximately 286,000 people, yielding a population density of about 910 people per square mile.

According to the US EPA Environmental Justice website, there are 46,818 occupied housing units within 10 miles of the plant site based on 2000 US Census data. Further, more than $75 \%$ of area adults over age 25 have a high school diploma or higher education. The median annual income for the area is between $\$ 25 \mathrm{~K}$ and $\$ 50 \mathrm{~K}$.

Table D.72. R. Paul Smith Power station site statistics

\begin{tabular}{|l|l|l|l|}
\hline $\begin{array}{l}\text { Population } \\
\text { Population Within }\end{array}$ & \multicolumn{2}{l|}{$\begin{array}{l}\text { Utility } \\
\text { Distance to Grid Capacity }\end{array}$} \\
\hline $0.5 \mathrm{mi}$ & $\sim 1,900$ & $>400 \mathrm{MWe}$ & $\sim 12 \mathrm{mi}$ \\
\hline $1 \mathrm{mi}$ & $\sim 4,500$ & $>800 \mathrm{MWe}$ & $\sim 7 \mathrm{mi}$ \\
\hline $5 \mathrm{mi}$ & $\sim 72,500$ & $>1600 \mathrm{MWe}$ & $\sim 7 \mathrm{mi}$ \\
\hline $10 \mathrm{mi}$ & $\sim 286,000$ & $>3200 \mathrm{MWe}$ & $\sim 151 \mathrm{mi}$ \\
\hline Nearest City with Population & Distance to Cooling Water \\
\hline & & \multicolumn{2}{l|}{} \\
\hline$>10,000$ & Halfway, MD & $>50,000$ gpm & $\sim 0.2 \mathrm{mi}$ (Potomac River) \\
\hline$>50,000$ & Frederick, MD & $>100,000$ gpm & $\sim 0.2$ mi (Potomac River) \\
\hline$>100,000$ & Arlington, VA & $>200,000$ gpm & $\sim 0.2$ mi (Potomac River) \\
\hline$>500,000$ & Washington, DC & $>500,000$ gpm & $\sim 0.2$ mi (Potomac River) \\
\hline Geotechnical & & Accessibility & \\
\hline Max Earthquake Acceleration & $<0.3 \mathrm{~g}$ & Distance to Major Roadway & $\sim 0.7$ mi (Interstate 81 ) \\
\hline Max Slope & $\sim 16 \%$ & Distance to Water Transport & $\sim 0.2$ mi (Potomac River) \\
\hline Nearest Fault Line & $\sim 1107$ mi (Oklahoma) & Distance to Rail Transport & $\sim 0.8$ mi (CSXT) \\
\hline Nearest Hazard Site & $\sim 46$ mi (Airport- & Distance to Airport & $\sim 46$ mi (Washington Dulles \\
\hline
\end{tabular}




\section{D.8.3 Aerial Imagery}

The aerial imagery in Fig. D.120 indicates nearby housing and business structures. Interstate 81 runs within 1.0 mile of the R. Paul Smith Power Station site.

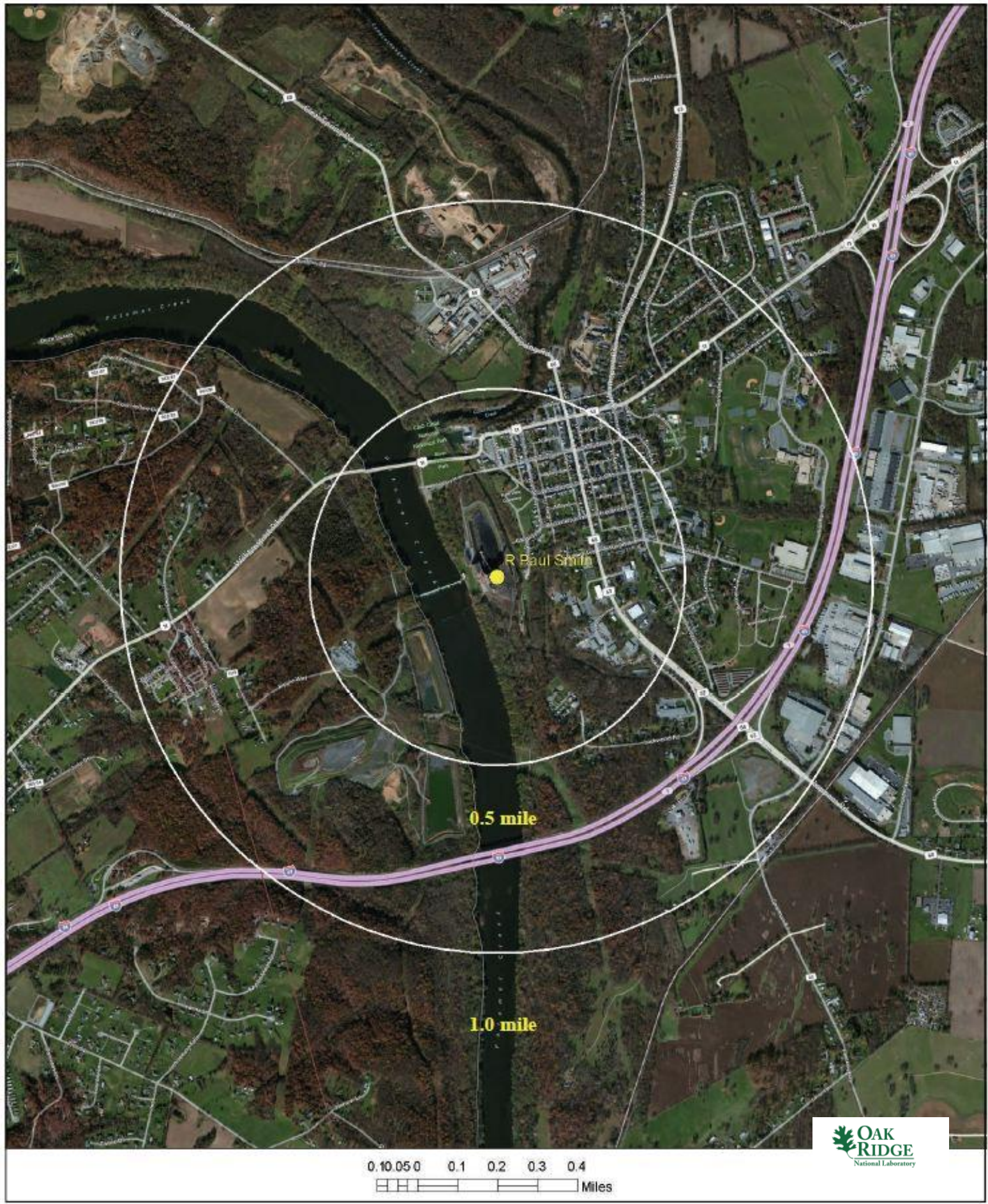

Fig. D.120. Satellite view of R. Paul Smith Power Station proximity. 


\section{D.8.4 Screening Criteria Overview}

Table D.73. R. Paul Smith Power Station siting criteria summary

\begin{tabular}{|c|c|c|c|c|c|c|c|c|c|}
\hline \multicolumn{10}{|c|}{$\underset{\text { (Colored Boxes indicate } S_{\text {Screening Results })}}{\text { Screening Criteria Summar }}$} \\
\hline \multicolumn{2}{|c|}{ No Siting Issue } & & \begin{tabular}{|l|l|} 
& Partial Siting Issue \\
\end{tabular} & \multicolumn{2}{|c|}{ Partial Siting Issue } & \multicolumn{4}{|c|}{ Full Siting Issue } \\
\hline $\begin{array}{l}0.5 \\
\text { Mile } \\
\text { Buffer }\end{array}$ & Slope & SSE & \begin{tabular}{|l} 
Stream \\
flow \\
$(65,000$ \\
gpm) \\
\end{tabular} & \begin{tabular}{|l} 
Proximity \\
to \\
Hazard \\
Operations
\end{tabular} & $\begin{array}{l}\text { Proximit } \\
\text { to } \\
\text { Fault } \\
\text { Lines } \\
\end{array}$ & \begin{tabular}{|l} 
Wetlands \\
Open \\
Water
\end{tabular} & $\begin{array}{l}\text { 100-year } \\
\text { Flood- } \\
\text { plain }\end{array}$ & \multicolumn{2}{|c|}{\begin{tabular}{|l|l}
$\begin{array}{l}\text { Protected } \\
\text { Lands }\end{array}$ & $\begin{array}{l}\text { Land- } \\
\text { slide } \\
\text { Hazards }\end{array}$ \\
\end{tabular}} \\
\hline $\begin{array}{l}1.0 \\
\text { Mile } \\
\text { Buffer }\end{array}$ & Slope & SSE & \begin{tabular}{|l|} 
Stream \\
flow \\
$(65,000$ \\
$\mathrm{gpm})$ \\
\end{tabular} & \begin{tabular}{|l} 
Proximity \\
to \\
Hazard \\
Operations
\end{tabular} & \begin{tabular}{|l} 
Proximit \\
to \\
Fault \\
Lines \\
\end{tabular} & $\begin{array}{l}\text { Wetlands } \\
\text { Open } \\
\text { Water }\end{array}$ & $\begin{array}{l}\text { 100-year } \\
\text { Flood- } \\
\text { plain }\end{array}$ & \begin{tabular}{|l|} 
Protected \\
\end{tabular} & $\begin{array}{l}\text { Land- } \\
\text { slide } \\
\text { Hazards }\end{array}$ \\
\hline \multicolumn{10}{|c|}{ OAK } \\
\hline \multicolumn{10}{|c|}{ Site Selection and Evaluation Criteria Table } \\
\hline \multicolumn{6}{|c|}{ Criteria } & \multicolumn{4}{|c|}{ Value } \\
\hline \multicolumn{6}{|c|}{ Population Density within 10 miles (people/square mile) } & \multicolumn{4}{|c|}{$>500$} \\
\hline \multicolumn{6}{|l|}{ Slope } & \multicolumn{4}{|c|}{$>18 \%$} \\
\hline \multicolumn{6}{|c|}{ Safe shutdown earthquake (ground acceleration) } & \multicolumn{4}{|c|}{$>0.5$} \\
\hline \multicolumn{6}{|c|}{ Streamflow/cooling water make-up (gpm) } & \multicolumn{4}{|c|}{$<65,000$} \\
\hline \multicolumn{6}{|c|}{ Proximity to hazardous operations - buffer (mile) } & \multicolumn{4}{|c|}{ Depends on hazardous operation ${ }^{1}$} \\
\hline \multicolumn{6}{|c|}{ Proximity to fault lines - buffer (mile) } & \multicolumn{4}{|c|}{ Depends on length of fault } \\
\hline \multicolumn{6}{|c|}{ Wetlands/Open Water } & \multicolumn{4}{|c|}{ - } \\
\hline \multicolumn{6}{|c|}{ 100-year floodplain } & \multicolumn{4}{|c|}{-} \\
\hline \multicolumn{6}{|c|}{ Protected lands } & \multicolumn{4}{|c|}{ - } \\
\hline \multicolumn{6}{|c|}{ Landslide hazard (moderate and high) } & \multicolumn{4}{|c|}{-} \\
\hline
\end{tabular}

${ }^{1}$ Hazardous facilities (airports- 5 miles and oil refineries- -1 mile) 


\section{D.8.5 Composite Map and Individual Siting Issue Maps}

A composite map of SMR siting challenges to the R. Paul Smith Power Station is shown in Fig. D.121. The physical plant structures are located on land with two siting challenges. Following this map are maps of the individual SMR siting criteria based on selected input values.

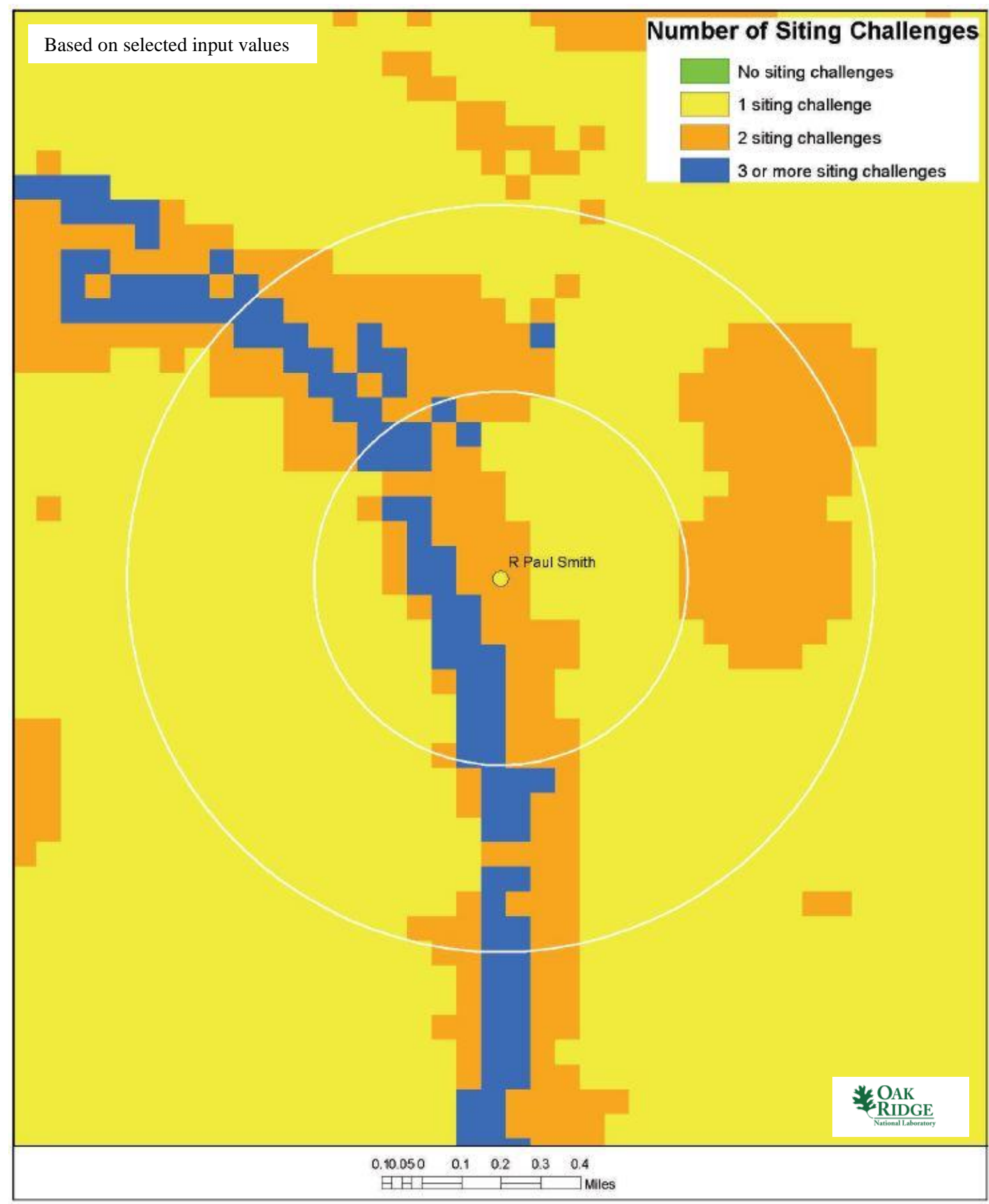

Fig. D.121. R. Paul Smith Power Station composite map. 

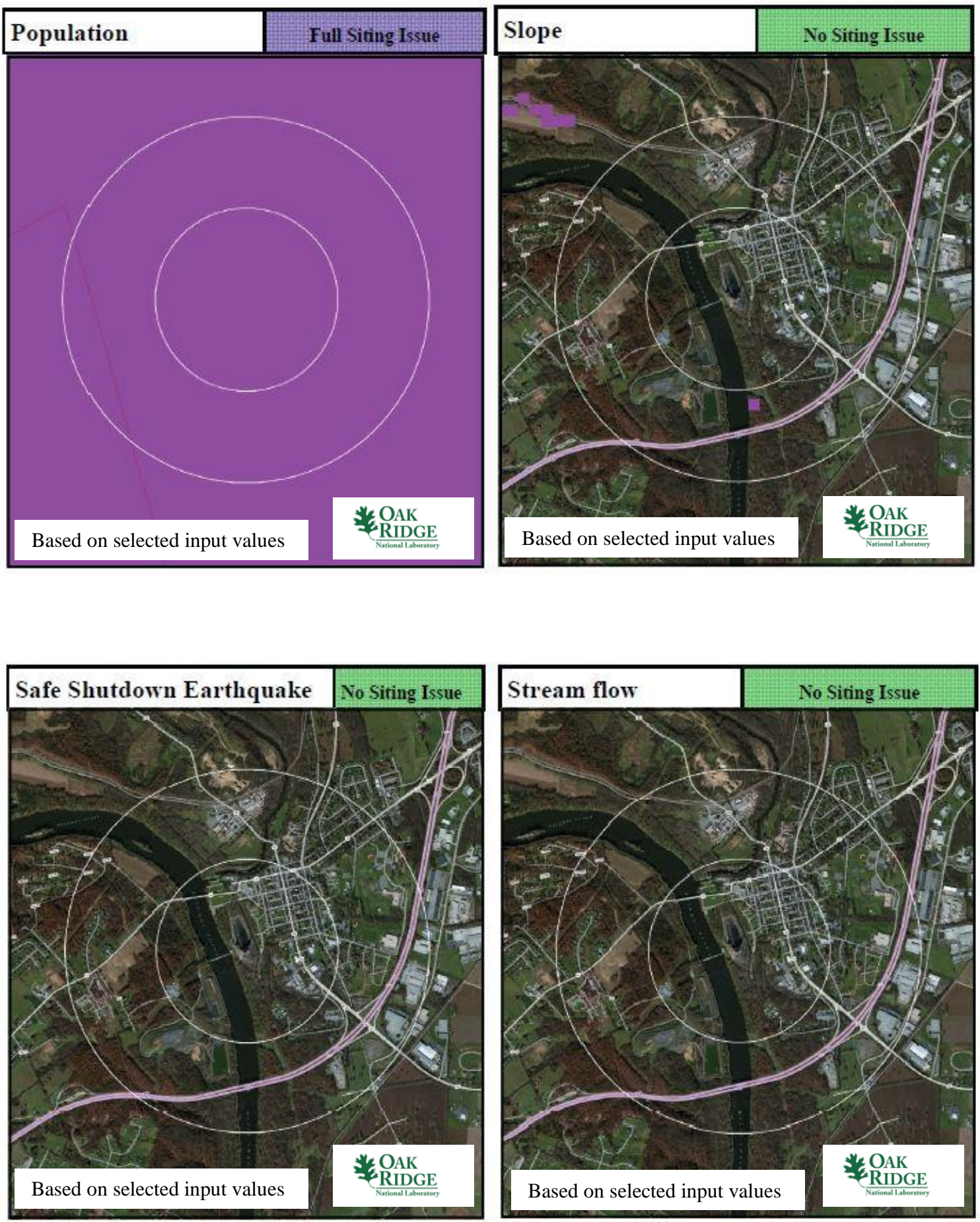

R. Paul Smith Power Station 

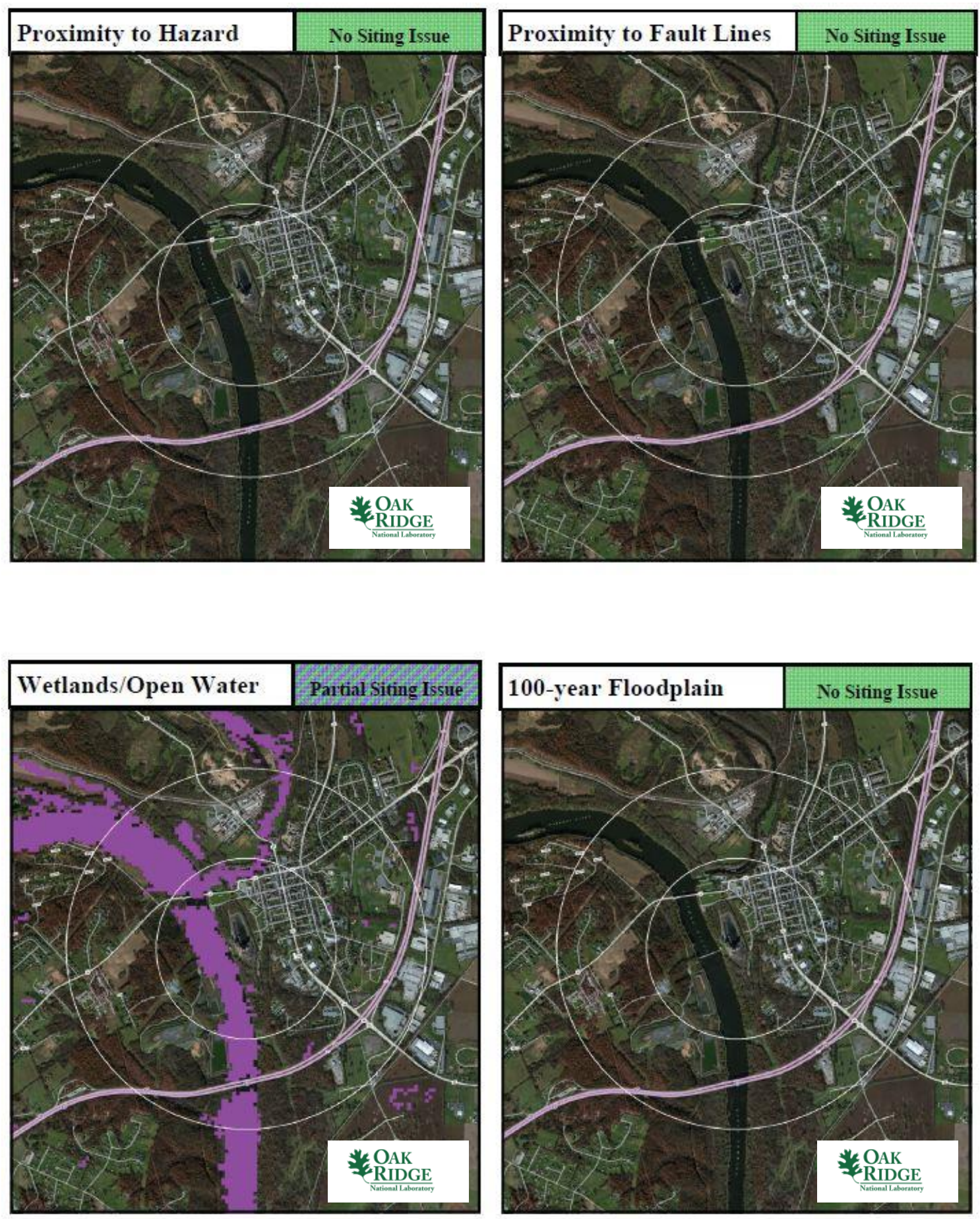

R. Paul Smith Power Station 

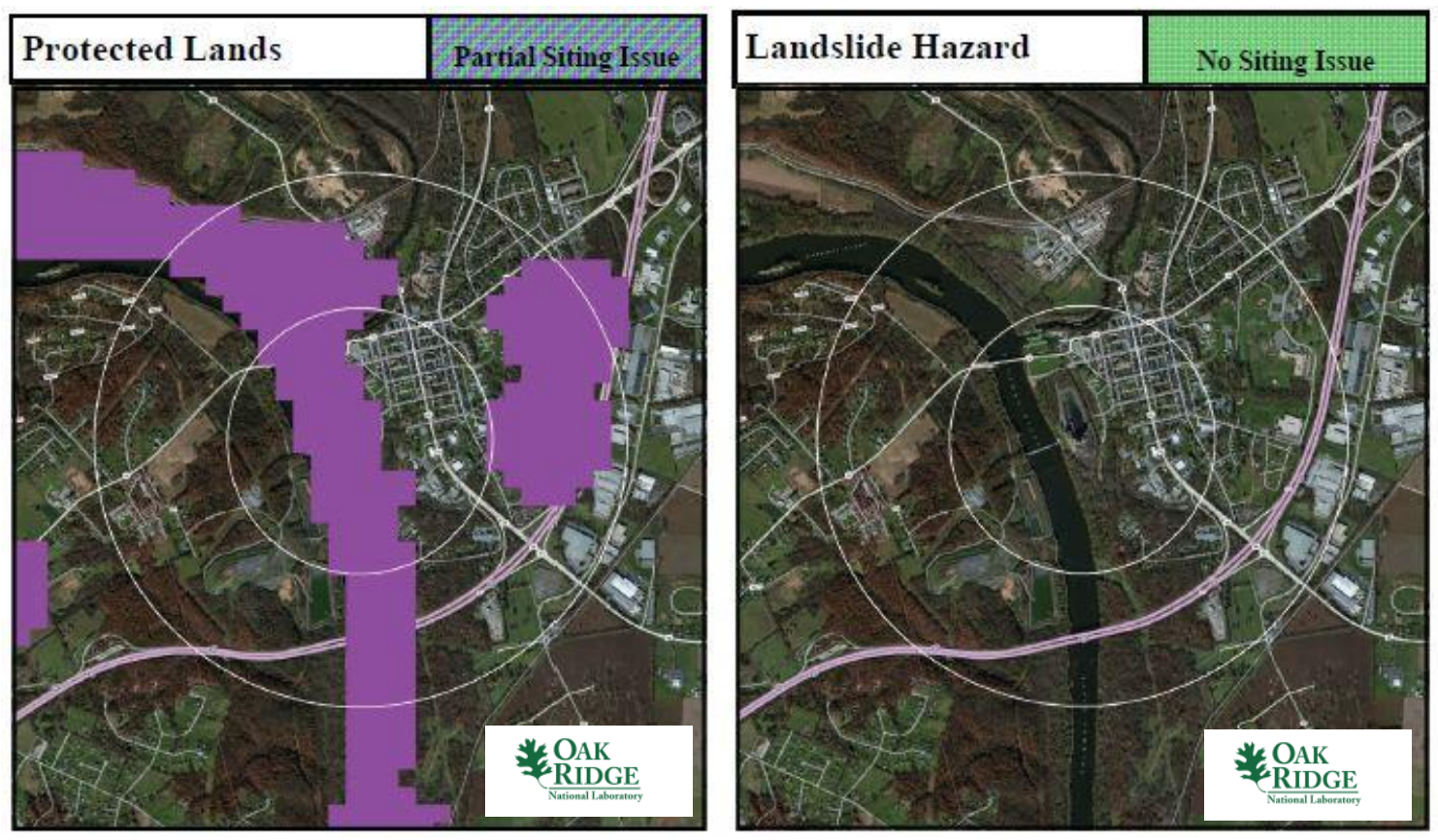

R. Paul Smith Power Station

\section{D.8.6 Site Evaluation}

FirstEnergy Corporation owns and operates four nuclear power plants in two states: Beaver Valley Power Station, Units 1 and 2 near Shippingport, Pennsylvania; Davis-Besse Nuclear Power Station near Oak Harbor, Ohio; and Perry Nuclear Power Plant near Perry, Ohio. Therefore, FirstEnergy has the licensing experience to operate an SMR at this site. The site does not include sufficient acreage to support siting an SMR.

From an environmental justice perspective, the community collectively appears to have achieved a reasonable level of education with median income levels typical of much of the United States. Therefore, siting an SMR at this location would not seem to be disenfranchising a less-educated or poverty-stricken community. Furthermore, the education level of the R. Paul Smith Power Station community would seem to support the higher-technology job opportunities provided by an SMR.

As shown in Sects. D.0 and D.8.5, the R. Paul Smith Power Station site has a full site screening issue with population. This is due to the vicinity of the site to Williamsport, Maryland, with a population of 2,150 people and Hagerstown, Maryland, with a population of approximately 40,000 people. In addition, Interstate 81 and Maryland Highway 11 run within 1.0 mile of the site, which could make it difficult for a nuclear licensee to control land access to areas very near the plant location.

The site also has partial SMR site screening issues with wetlands/open waters and protected lands. The wetlands/open waters concern reflects the adjacent Potomac River. The protected lands issues reflects the abandoned C\&O Canal and its associated railroad lift bridge, which were established as a National Monument in 1961 and a National Historical Park in 1971. Building an SMR on protected lands would be an added difficulty. The remaining SMR site screening criteria are met site-wide for the values established in the updated SMR siting report.1

The site does not meet current NRC RG 4.7 recommendations for population density without significant additional consideration for relaxed SMR population siting requirements based on reduced source term. In addition, there is insufficient acreage to fit a current iPWR design, and the surrounding area is designated as a National Monument and Historical Park. As a result, the R. Paul Smith Power Station site is not a likely candidate for consideration of siting an SMR. 